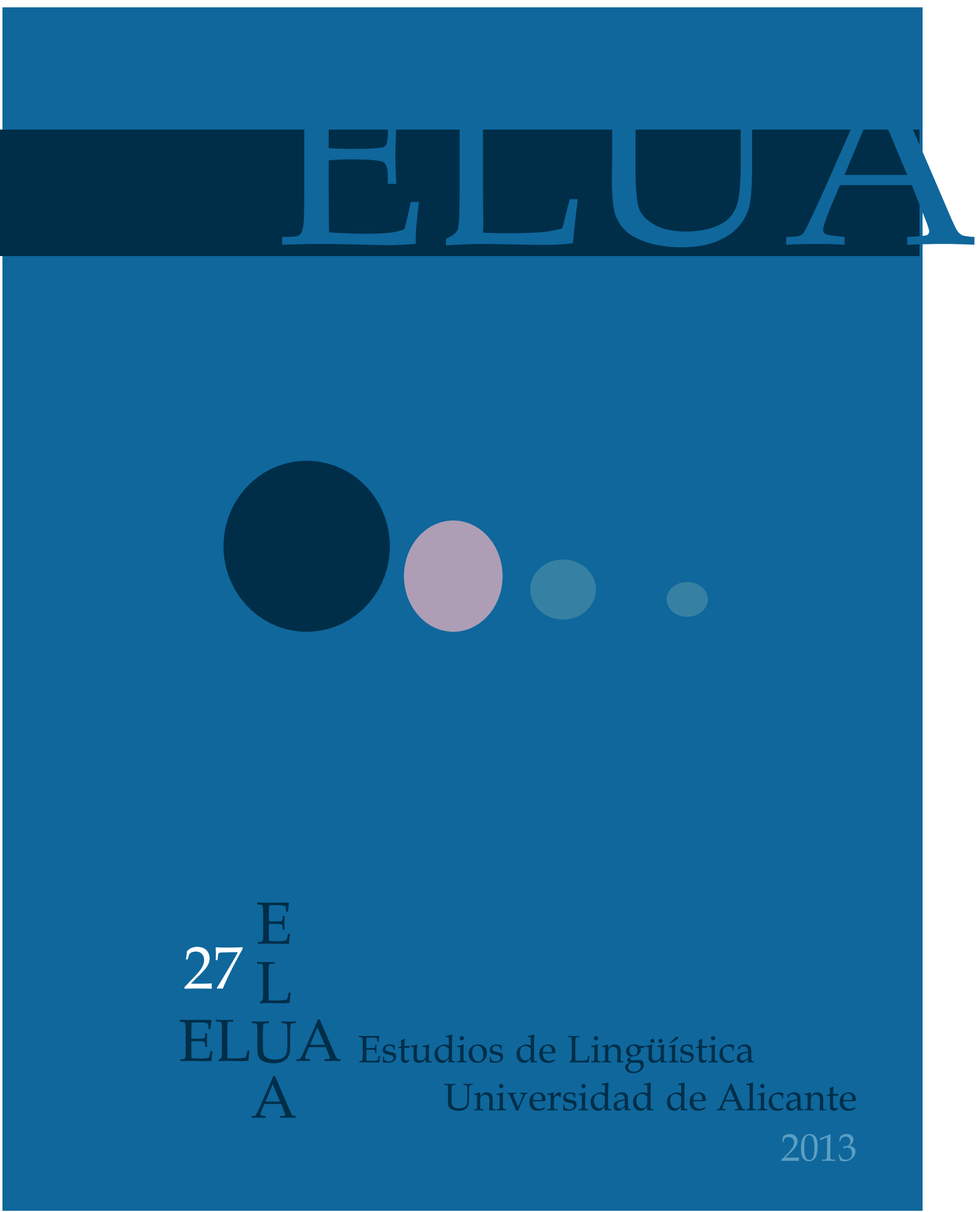




\title{
ESTUDIOS DE LINGÜÍSTICA
}

UNIVERSIDAD DE ALICANTE

(ELUA)

2013

NúMERO 27

REVISTA DE LENGUA ESPAÑOLA

Y LINGÜÍSTICA GENERAL

\author{
Aniversitat d'Alacant \\ Universidad de Alicante
}




\title{
DIRECTOR
}

José Luis Cifuentes Honrubia

\section{SECRETARIA}

Susana Rodríguez Rosique

\section{COORDINADORAS}

Elisa Barrajón López

Herminia Provencio Garrigós

\section{CONSEJO DE REDACCIÓN}

$\mathrm{M}^{\mathrm{a}}$ Belén Alvarado Ortega (U. Alicante)

$M^{a}$ Cruz Amorós Céspedes (U. Alicante)

Dolores Azorín Fernández (U. Alicante)

Elisa Barrajón López (U. Alicante)

José Antonio Candalija Reina (U. Alicante)

José Luis Cifuentes Honrubia (U. Alicante)

Pilar Díez de Revenga Torres (U. Murcia)

Dmitrij O. Dobrovol'skij (Academia Ciencias Rusia)

Jorge Fernández Jaén (U. Alicante)

Catalina Fuentes (U. Sevilla)

M. ${ }^{a}$ Mar Galindo Merino (U. Alicante)

Francisco Gimeno Menéndez (U. Alicante)

Juan Luis Jiménez Ruiz (U. Alicante)

Johannes Kabatek (U. Zürich)

Ruth Lavale Ortiz (U. Alicante)

Óscar Loureda (U. Heidelberg)

Carmen Marimón Llorca (U. Alicante)

José Joaquín Martínez Egido (U. Alicante)

\author{
M. ${ }^{a}$ Antonia Martínez Linares (U. Alicante) \\ Francisco Matte Bon (U. Luspio) \\ Elena de Miguel (U. Autónoma Madrid) \\ Irma Muñoz Baell (U. Alicante) \\ Ana Isabel Navarro Carrasco (U. Alicante) \\ Xose Padilla García (U. Alicante) \\ Susana Pastor Cesteros (U. Alicante) \\ Inmaculada Penadés (U. Alcalá) \\ Herminia Provencio Garrigós (U. Alicante) \\ Susana Rodríguez Rosique (U. Alicante) \\ Joaquín Rodrigo López (U. Alicante) \\ Leonor Ruiz Gurillo (U. Alicante) \\ Ventura Salazar (U. Jaén) \\ Isabel Santamaría Pérez (U. Alicante) \\ Augusto Soares da Silva (U. Católica Portuguesa) \\ Larissa Timofeeva (U. Alicante) \\ Alexandre Veiga Rodríguez (U. Santiago de \\ Compostela)
}

\section{CONSEJO ASESOR}

Manuel Alvar Ezquerra (U. Complutense Madrid) Ignacio Bosque (U. Complutense Madrid y RAE)

Antonio Briz Gómez (U. Valencia)

María Antonia Martín Zorraquino (U. Zaragoza) Lourdes Ortega (U. Hawai en Manoa) $M^{a}$ Teresa Placencia (U. Londres)

Nicole Delbecque (U. Católica Lovaina)

Estanislao Ramón Trives (U. Murcia)

Milagros Fernández Pérez (U. Santiago de Compostela) Emilio Ridruejo Alonso (U. Valladolid)

Salvador Gutiérrez Ordóñez (U. León y RAE)

Günther Haensch (U. Ausburgo)

Ángel López García (U. València)

Humberto López Morales (Real Academia Española)

Agustín Vera Luján (UNED)

Juan Andrés Villena Ponsoda (U. Málaga)

Gerd Wotjak (U. Leipzig)

ISSN: 0212-7636

Depósito legal: A-15-1985

Diseño de la cubierta: Xose. A. Padilla García

Publicada gracias a las ayudas para la publicación de revistas científicas de la Facultad de Filosofía y Letras y del Vicerrectorado de Investigación, Desarrollo e Innovación de la Universidad de Alicante. Fotocomposición e impresión: Compobell, S.L.

Normas para envío, evaluación y edición de contribuciones:

http://www.ua.es/dpto/dfelg/publicaciones/estudios-linguistica/ 


\section{ÍNDICE}

\section{ARTíCUlOS}

Análisis semántico-cognitivo del discurso humorístico en el texto multimodal de las viñetas de Forges

Marta Agüero Guerra

Fenómenos de transferencia entre lenguas: evidencialidad en el español en contacto con el guaraní y el quechua

Alicia Avellana

El uso de entonces/así que en contexto narrativo sobre datos del PRESEEA-

Buenos Aires

Claudia Borzi

Los actos silenciosos en la conversación de los jóvenes españoles: ¿(des)cortesía o "anticortesía”?

Laura Camargo Fernández y Beatriz Méndez Guerrero

Reconsidering syllabic minimality in Spanish truncation.

Antonio Grau Sempere

La (autoantonimia) al- ̣dad en las lenguas, según la teoría 'el esquema básico de la referencia'

Abeer Hussein Abid

Las etiquetas discursivas: del mantenimiento a la construcción del referente

$$
\text { Anna López Samaniego }
$$

Redes polisémicas y niveles de interpretación. Representación semántica de unidades lingüísticas complejas: el caso de vamos

Fernando Polanco Martínez 
Parody as evaluation: about a television sketch in Spanish 251

Leonor Ruiz Gurillo

De la cognición al discurso: el efecto de la prominencia cognitiva y la informatividad textual en el estudio de la variación de los sujetos pronominales..

María José Serrano

Especificación semántica versus neutralización entre español y portugués. Su

formalización en los diccionarios bilingües

Ignacio Vázquez Diéguez

\section{NoTAS}

Sobre la forma muncho

Enrique Pato

\section{RESEÑAS}

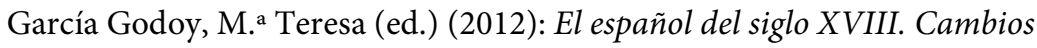
diacrónicos en el primer español moderno. Berna: Peter Lang (David Prieto García-Seco)

Kiesling, Scott F. (2011): Linguistic variation and change. Edinburgh: Edinburgh University Press (Cristina Bleortu y Alba García Rodríguez).

Litosseliti, Lia (2010): Research methods in linguistics. Londres: Continuum International Publishing Group (Camilo Enrique Díaz Romero)

Placencia, María Elena y García, Carmen (eds.) (2012): Pragmática y comunicación intercultural en el mundo hispanohablante. Amsterdam y Nueva York: Rodopi B.V. (Marta Pilar Montañez Mesas).

Grümpel, Claudia (2009): La adquisición del alemán en un contexto universitario por adultos hispanohablantes. Granada: Editorial Comares (Nuria Mechán Aravid) 


\section{INDEX}

\section{ARTICLES}

Humor in Forges' editorial cartoons: A cognitive-semantic analysis of multi-

modal texts.

Marta Agüero Guerra

Language transfer: evidentiality in Spanish in contact with Guarani and

Quechua

Alicia Avellana

The use of entonces/asi que in narrative context on data from PRESEEA-

Buenos Aires

Claudia Borzi

Silent acts in young Spanish speakers' conversations: impoliteness or anti politeness?

Laura Camargo Fernández y Beatriz Méndez Guerrero

Reconsidering syllabic minimality in Spanish truncation.

Antonio Grau Sempere

The "autantonym" al-ddad in languages, according to the theory 'the basic scheme of reference'

Abeer Hussein Abid

Discourse labels: from continuity to construction of reference

Anna López Samaniego

Representation of complex linguistic units: the case of Spanish conversational

marker vamos

Fernando Polanco Martínez 
Parody as evaluation: about a television sketch in Spanish

Leonor Ruiz Gurillo

From cognition to discourse: applying cognitive saliente and textual informativeness in pronominal subject variations analysis.....

María José Serrano

Semantic specification versus neutralization between Spanish and Portuguese.

Formalization in bilingual dictionaries.

Ignacio Vázquez Diéguez

\section{NoTes}

On the form muncho

\section{Enrique Pato}

\section{BOOK REVIEWS}

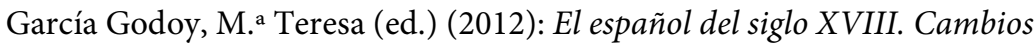
diacrónicos en el primer español moderno. Bern: Peter Lang (David Prieto García-Seco)

Kiesling, Scott F. (2011): Linguistic variation and change. Edinburgh: Edinburgh University Press (Cristina Bleortu y Alba García Rodríguez).

Litosseliti, Lia (2010): Research methods in linguistics. London: Continuum International Publishing Group (Camilo Enrique Díaz Romero)

Placencia, María Elena y García, Carmen (eds.) (2012): Pragmática y comunicación intercultural en el mundo hispanohablante. Amsterdam and New York: Rodopi B.V. (Marta Pilar Montañez Mesas).

Grümpel, Claudia (2009): La adquisición del alemán en un contexto universitario por adultos hispanohablantes. Granada: Editorial Comares (Nuria Mechán Aravid) 


\title{
ANÁLISIS SEMÁNTICO-COGNITIVO DEL DISCURSO HUMORÍSTICO EN EL TEXTO MULTIMODAL DE LAS VIÑETAS DE FORGES
}

\author{
MARTA AgÜERo GUERRA \\ Universidad de Salamanca - The University of Iowa \\ marta-agueroguerra@uiowa.edu
}

Resumen

Partiendo de la semántica y la lingüística cognitiva, la Teoría General del Humor Verbal (Attardo y Raskin, 1991; Attardo, 1991, 2001 y 2006), deudora de la teoría de la incongruencia (Kant, 1790; Schopenhauer, 1891[1818]), sostiene que los mecanismos de comprensión del humor están basados en la resolución, parcial o total, de una incongruencia producida por la alternancia de marcos cognitivos (scripts) incompatibles. En este estudio se demuestra que la TGHV es perfectamente aplicable al humor gráfico contemporáneo como género multimodal y sirve de base para el análisis de un corpus representativo de viñetas de Forges, clasificadas según el modelo 3 WD de apreciación del humor (Ruch, 1992; Hempelmann y Ruch, 2005). El análisis evidencia que Forges emplea, junto a la ironía y la metáfora, diversos mecanismos complementarios en viñetas donde palabra e imagen convergen en una identidad de lectura recíproca para criticar la realidad social y política actual.

PALABRAS CLAVE: Humor gráfico, Teoría General del Humor Verbal, Test 3 WD, Lingüística cognitiva.

\begin{abstract}
Taking Semantics and Cognitive Linguistics as a point of departure, the General Theory of Verbal Humor (Attardo and Raskin, 1991; Attardo, 1991, 2001 and 2006), heir to the incongruity theory (Kant, 1790; Schopenhauer, 1891[1818]), states that humor comprehension mechanisms are based on the partial or complete resolution of an incongruity produced by the opposition of incompatible scripts. This article demonstrates that the GTVH can be perfectly applied to contemporary graphic humor as a multimodal genre and serves as the basis for the analysis of a representative corpus of cartoons by Forges that has been classified according to the 3 WD test of humor appreciation (Ruch, 1992; Hempelmann and Ruch, 2005). The analysis shows that, together with irony and metaphor, Forges uses a variety of complementary mechanisms in cartoons containing visual and verbal elements that work together and encourage an implicit evaluation of the social and political contemporary reality.
\end{abstract}

KEY WORDS: Graphic humour, General Theory of Verbal Humour, 3 WD Test, Cognitive Linguistics.

\section{Introducción}

El humor es un fenómeno cuyo estudio se aborda, en la actualidad, desde una perspectiva multidisciplinar, en campos científicos tan diversos como la antropología, la 
sociología, la medicina o la lingüística. Es un concepto elusivo, difícil de definir, si se tienen en cuenta los diversos factores que entran en juego en la producción y comprensión de un texto humorístico.

En este artículo se analizará exclusivamente el humor gráfico en la viñeta de prensa actual, concebida como una unidad narrativa espacio-temporal que codifica el discurso humorístico (verbal y/o visual) de un determinado autor. Su estudio se abordará partiendo de un amplio corpus de 372 viñetas, creadas por Antonio Fraguas ${ }^{1}$, Forges ${ }^{2}$ y publicadas en las páginas de opinión del diario El País entre el 1 de febrero de 2010 y el 28 de febrero de 2011. La poética del cómic en la prensa permite distinguir tres formatos bien definidos en los que el autor refleja su visión crítica de la realidad: la viñeta única (caricatura o cartoon), la tira cómica y la historieta seriada.

La viñeta editorial se publica en las páginas de opinión de los periódicos con una clara función ideológica. Su propósito es cuestionar con lucidez las actitudes sociales y evaluar, de forma implícita (irónica), una única visión de la realidad (El Refaie, 2005).

\footnotetext{
${ }^{1}$ Quiero expresar mi agradecimiento a Antonio Fraguas (Forges) por su generosidad al autorizar la reproducción de las viñetas incluidas en este artículo. Mi trabajo es un humilde tributo a la obra de un excepcional creador de la viñeta de opinión, cuya visión irónica de la realidad es un inapreciable testimonio diario que contribuye a cuestionar las actitudes y comportamientos de nuestra sociedad con una inteligencia analítica que cautiva al lector por su ingenio y su humor mordaz.

${ }^{2}$ Antonio Fraguas de Pablo, conocido como Forges, su apellido en catalán, nace en Madrid en 1942. Después de trabajar durante años en televisión, publica su primer dibujo en 1964 en el diario Pueblo. Ha trabajado como viñetista en diferentes revistas de humor como Hermano Lobo, Por Favor o El Jueves y en periódicos como Diario 16 o El Mundo. Además, ha ilustrado diferentes libros, ha escrito una novela, Doce de Babilonia, y ha publicado libros sobre la historia de España en forma de cómic, Historia Forgesporánea o Los Forrenta Años. Desde 1995 colabora a diario en El País. Es un creador de personajes de repertorio caricaturizados (i.e. funcionarios antipáticos, becarios explotados, matrimonios aburridos o mujeres familiares y trabajadoras) que comparten unos rasgos comunes (grandes narices y ojos, escasez de pelo, cuerpos flexibles...). Su ingenio consiste en condensar en el pequeño espacio de sus viñetas dibujos sencillos que representan escenas cotidianas con mensajes lingüísticos marcados por un gusto desmesurado por los neologismos (Galán Rodríguez, 1994). Forges es un creador lingüístico que juega con el lenguaje popular y los sonidos, como se aprecia en sus conocidos forgendros (gensanta, chasgracias, parejólogo, aeropuerting...). El humor de Forges es un humor inteligente, de su tiempo, "comprometido con la sonrisa de los seres humanos a través de poner en solfa la injusticia, la insolidaridad y la estupidez del poder" (entrevista al autor en El Diario Montañés, 16 de julio de 2006, disponible en <http://www.eldiariomontanes.es/prensa/20060716/sociedad/antoniofraguas-forges-dibujante_200607160034.html>). De ahí que sus técnicas más frecuentes sean la ironía, la paradoja y la hipérbole. No se trata de un humor cruel, sino comprensivo, realizado con ternura, pero que no deja de ofrecer una crítica mordaz e irónica de la realidad social y política actual. Sus viñetas son el escaparate en el que ofrece a los demás su manera de ver la vida $(<\mathrm{http} / / /$ www.forges.com $>/$ $<$ http://www.elpais.com/vineta/>).
} 
Algunos humoristas gráficos prefieren un formato de viñeta exclusivamente visual, mientras que otros prefieren un formato escripto-icónico, que combina narración visual (i.e. aplica los recursos de composición gráfica, como son el encuadre, los ángulos de visión, el color, el estilo del trazo o el gestuario de los personajes) y narración verbal (diálogo, onomatopeya, globos o cartelas).

En las viñetas exclusivamente visuales, el mensaje humorístico suele coincidir con una metáfora visual que, por sí misma, evoca múltiples significados (Fig. 1). La Teoría de la Metáfora Conceptual (Conceptual Metaphor Theory), iniciada por Lakoff y Johnson, explica este tipo de metáforas como representaciones visuales de un pensamiento metafórico (Lakoff y Johnson, 1980). En este tipo de viñetas, el dominio origen (source domain) y el dominio destino (target domain) de la metáfora se encuentran en la misma modalidad (Ortiz Díaz-Guerra, 2010). Es tarea del lector identificar por medio del contexto pictográfico cuál es el segundo término al que alude la metáfora. No obstante, es fundamental que el lector conozca el contexto informativo en el que se publica la viñeta para comprender su significado: "it would be important to study the meaning of cartoons in relation to a whole page or even a complete issue of a newspaper" (El Refaie, 2003: 92). La metáfora visual de la Figura 1 es de difícil comprensión si no se conoce el co-texto verbal que acompañaba a la viñeta en el diario El Pais en febrero de 2011. En aquel momento, los ciudadanos de los países del norte de África habían iniciado una revolución exigiendo mayor democracia y mejores condiciones de vida. La publicación de esta viñeta coincidió con una oleada de protestas en Egipto que reclamaba el final de la era Mubarack y la dimisión en bloque de la cúpula de su partido.

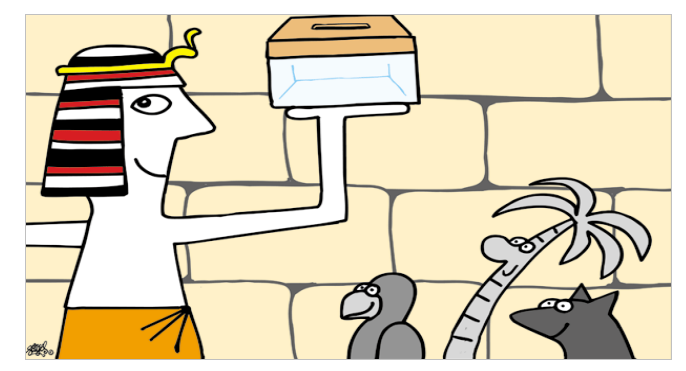

Fig.1. El País, 5 febrero 2011. Reproducción autorizada por Forges

En el segundo tipo de viñetas multimodales se produce una fusión o interacción entre imagen y palabra. El término multimodalidad ha sido acuñado recientemente en el ámbito de la comunicación audiovisual y de la narratología para referirse a formas textuales en las que existe más de un código semiótico, ya sea texto, imagen, gesto o sonido 
(Kress y van Leuween, 2006 [1996]). En el proceso de interpretación, el lector debe primero asumir la presunción óptima de relevancia, con el fin de restringir el número de inferencias posibles y así poder captar el mensaje humorístico de la viñeta (Sperber y Wilson, 1986). No basta, sin embargo, con la comprensión del código lingüístico sino que es preciso descifrar el mensaje codificado que resulta de la interacción entre elementos simbólicos (palabras) y elementos icónicos (imágenes).

Barthes (1977) analizó la relación entre imagen y palabra y estudió el papel que ambos recursos semióticos desempeñaban en la transmisión del mensaje. Distinguía dos formas de representación del lenguaje: función de relevo y función de anclaje. Cuando en una viñeta existe una función de relevo, es la imagen la que ayuda a interpretar el mensaje lingüístico (Fig. 2). Los elementos lingüísticos y analógicos están en relación complementaria, en muchos casos contradictoria, cuando se les atribuye significado irónico. Por el contrario, en la función de anclaje, es el mensaje lingüístico el que da sentido al contenido de la imagen, subrayando asimismo su marcado valor irónico (Fig. 3). En la Figura 2 es necesario analizar el dibujo para poder comprender el chiste, ya que las palabras emprendedor e ilusionado no se corresponden con la expresión facial y la actitud despreocupada del personaje de la viñeta. Por el contrario, en la Figura 3, el cartucho Tesoro Público en la puerta confiere sentido a la gestualidad del personaje y a su deseo de conseguir la llave en el interior de la urna (tesoro privado).

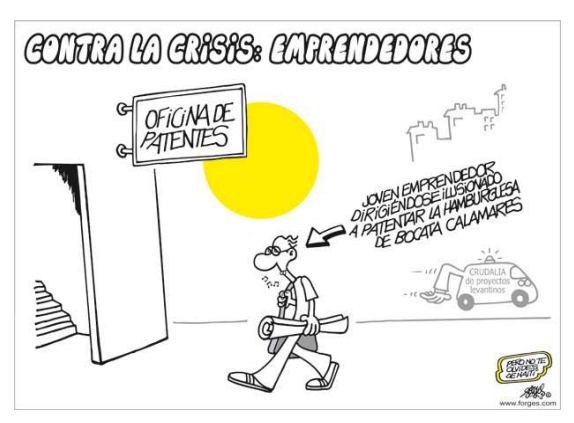

Fig. 2. El País, 15 octubre 2010. Reproducción autorizada por Forges

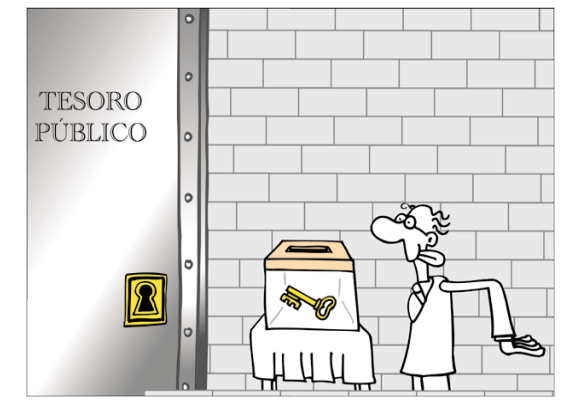

Fig. 3. El País, 7 febrero 2011. Reproducción autorizada por Forges

Son numerosas las investigaciones que abordan en la actualidad el análisis del texto multimodal. Desde que Halliday sentara las bases de la Lingüística Sistémico-Funcional (1985), el interés de los lingüistas por explorar la interacción del lenguaje con otros recursos semióticos ha crecido considerablemente (O’Halloran, 2011). Los estudios más novedosos en este terreno han partido de la semiótica social (Kress y van Leeuwen, 2001 
y 2006 [1996]), desde donde se postula la necesidad de desarrollar una gramática visual que ayude a interpretar los patrones de significado expresados en las imágenes. Otros estudios han abordado la multimodalidad en los libros ilustrados (picture books) vinculada a un tema de creciente interés: la alfabetización visual (Moya Guijarro y Pinar Sanz, 2009). Elizabeth El Refaie (2003, 2009a, 2010) ha analizado los distintos factores que entran en juego en la comprensión de textos humorísticos multimodales (i.e. el conocimiento del género, el contexto, la edad o el propio formato de presentación de las viñetas) $)^{3}$.

El objetivo de este artículo consistirá en describir los recursos que Forges emplea en sus viñetas de opinión (editorial cartoons) para conseguir un efecto cómico partiendo de un análisis semántico-cognitivo. Se analizará el mensaje lingüístico de sus viñetas a partir de la Teoría General del Humor Verbal (TGHV) (Attardo y Raskin, 1991; Attardo, 1991, 2001 y 2006) y el modelo 3 WD (3 Witz Dimensionen) de apreciación del humor (Ruch, 1992; Hempelmann y Ruch, 2005). Una vez delimitado el campo de estudio a la viñeta humorística de prensa, o viñeta editorial, en sus dos formatos (monomodal y multimodal), se identificará, a continuación, el marco teórico en el que se inscribe este análisis junto a una breve referencia a las teorías filosóficas del humor, precursoras de los enfoques actuales. Por último, se procederá a analizar las viñetas seleccionadas y los resultados que arroje esta investigación con el fin de comprender los mecanismos que utiliza Forges para transmitir su crítica irónica de la realidad política y social.

\section{Marco teórico: Teorías del humor}

Han sido numerosas las teorías que han tratado de explicar desde diversas disciplinas qué mecanismos desencadenan la risa. Las primeras teorías del humor se formularon en el campo de la filosofía. La más antigua es la Teoría de la Superioridad (Hobbes, 1994 [1668]; Bergson, 1911 [1899]), que afirma que nos reímos de los demás cuando los vemos en una situación de desventaja, i.e. cuando detectamos algún defecto ajeno, alguien comete algún error o sufre algún contratiempo. Freud (1991 [1905]) y Spencer (1911) parten de la noción de risa como correctivo social que pone en tela de juicio las

\footnotetext{
${ }^{3}$ Forceville y Urios Aparisi (2009) continúan investigando los procesos cognitivos que entran en juego en la interpretación de las metáforas multimodales y proponen un enfoque que aúne lingüística cognitiva y semiótica. María Jesús Ortiz (2010: 122) aboga, en cambio, por una teoría integrada de la metáfora visual, dado que la metáfora es "un proceso cognitivo que puede manifestarse tanto de modo verbal como de modo no verbal".
} 
normas impuestas por la sociedad para desarrollar la Teoría de la Liberación de Tensión. La risa es el resultado del sentimiento de alivio que nos produce superar una situación de restricción, dando lugar a un incremento de la energía nerviosa que se manifiesta en forma de risa, como ocurre, por ejemplo, cuando oímos algo que no es políticamente correcto. Por último, la tercera teoría filosófica, la Teoría de la Incongruencia, es en la que se basan la mayoría de las investigaciones que se están realizando en la actualidad y, por lo tanto, es sobre la que se asientan las teorías utilizadas para llevar a cabo el análisis en este trabajo. Esta teoría, articulada en los siglos XVIII y XIX, y cuyos máximos exponentes fueron Kant (1790) y Schopenhauer (1891[1818]), defiende que la risa se produce como resultado de una disonancia entre lo que es esperable en una determinada situación y lo que realmente ocurre. Como se explicará más adelante, esta idea de disonancia es clave para la percepción del humor.

Tomando como punto de partida la teoría de la incongruencia, los estudios del humor en español se han afianzado notablemente en los últimos años gracias a interesantes contribuciones que lo han abordado desde una perspectiva lingüística. Buen ejemplo de ello son las publicaciones de Leonor Ruiz Gurillo (2012), Ana María Vigara Tauste (2004) o las investigaciones que se impulsan desde el grupo GRIALE en la Universidad de Alicante. La pragmática ha estudiado también este fenómeno, entendiéndolo como una forma de metacomunicación:

Humor is an implicit form of communication, which deliberately leaves something implied and requires a greater level of cooperation on the part of the viewer/reader than the processing of a piece of ordinary information. Because of this, any theory of humor must also explore the pragmatics of humor appreciation (El Refaie, 2009b: $82)$.

Los estudios pragmáticos se han centrado en las teorías que se desarrollaron durante los años setenta y ochenta del siglo XX para explicar el proceso comunicativo: el Principio de Cooperación de Grice (1975), el Principio de Cortesía de Leech (1983) y la Teoría de la Relevancia de Sperber y Wilson (1986). Esta última considera que la clave del discurso humorístico reside en la búsqueda de relevancia óptima que realiza el destinatario del mensaje en cualquier intercambio comunicativo. A pesar de que no se trata de una teoría diseñada específicamente para el análisis del humor, lingüistas como Francisco Yus (2003), entre otros, defienden su utilización para interpretar las manifestaciones humorísticas y su aplicabilidad a los textos verbo-icónicos (Yus, 1995). Yus señala que la búsqueda de relevancia no se produce exclusivamente por parte del receptor, sino también por parte del emisor. El humorista construye sus chistes prediciendo el tipo de presuposición que va a escoger su interlocutor y asumiendo que los interpretará en dos fases: primero seleccionará una interpretación accesible por medio del principio de 
relevancia y más tarde la invalidará, sustituyéndola por una más adecuada. De este modo, Yus enlaza la Teoría de la Relevancia con estudios teóricos posteriores y propone el análisis de los procesos cognitivos que realizan los emisores para codificar el mensaje humorístico.

La pragmática no ha sido la única disciplina lingüística que ha investigado el concepto de humor; también desde la semántica y desde la lingüística cognitiva se han aportado interesantes teorías sobre este tema, como la que se ha tomado para este análisis, que se encuentra a medio camino entre estas dos áreas: la Teoría General del Humor Verbal (Attardo y Raskin, 1991; Attardo, 1991, 2001 y 2006). Esta elección se ve justificada si partimos de la idea de que no se puede concebir la percepción y producción del humor sin atender al significado de los enunciados o a los procesos cognitivos que se producen en diferentes partes de nuestro cerebro a la hora de descifrar el mensaje humorístico.

Las teorías cognitivas sostienen que la percepción de una incongruencia es la base de la mayor parte de nuestras experiencias humorísticas. Entre los teóricos que han investigado el humor desde un punto de vista cognitivo merecen especial atención Schank y Abelson (1977), a quienes debemos el concepto de marco cognitivo o script que posteriormente sentó las bases de las teorías que han fundamentado mi investigación. Estos autores apoyan la tesis de Lakoff (1987) sobre la organización de nuestro conocimiento mediante estructuras llamadas "modelos cognitivos idealizados". Los marcos cognitivos (scripts), en términos de representación psíquica, son entidades de organización de la memoria episódica, construidos alrededor de experiencias reales; es decir, un script es una estructura cognitiva interiorizada que nos proporciona información sobre cómo está estructurada una entidad determinada (palabra, situación, etc.), cuáles son sus partes y qué relaciones tienen con otras entidades.

Partiendo de este concepto de marco cognitivo (script) y de la Teoría de la Incongruencia, Raskin desarrolla la Teoría Semántica de Esquemas, que postula que cualquier texto humorístico debe contener dos marcos cognitivos (scripts) que se oponen entre sí en tres tipos generales de relaciones: (1) real / irreal, (2) normal / no normal, (3) posible / imposible (Raskin, 1985). Estas, a su vez, pueden dividirse en subcategorías binarias más concretas, como vemos en este ejemplo, donde se oponen los marcos cognitivos (scripts) doctor / amante y sexo / no sexo:

(1)

- “'Está el doctor en casa?’ pregunta el paciente con un hilo de voz provocado por el catarro.

- 'No', responde la joven y bella esposa del doctor. 'Pasa'” (Raskin, 1985: 32). 
A pesar de la importante contribución que supuso la Teoría Semántica de Esquemas para comprender el texto humorístico, algunas investigaciones posteriores la han refutado, puesto que no se trata de una teoría aplicable al humor en general, sino solo al humor verbal y, en concreto, al chiste. Sin embargo, esta teoría es precursora de la Teoría General del Humor Verbal (Attardo y Raskin, 1991; Attardo, 1991, 2001 y 2006), en la que se ha basado el presente análisis.

La Teoría General del Humor Verbal (en adelante, TGHV) integra la Teoría Semántica de Esquemas (Raskin, 1985) con los cinco niveles de representación del humor verbal de Attardo, creando un modelo jerárquico dividido en seis parámetros que ayudan a resolver la incongruencia y comprender los textos humorísticos: (1) la oposición de los marcos cognitivos, (2) la situación desencadenante del chiste, (3) el mecanismo lógico que crea la oposición, (4) el objetivo o blanco del texto, (5) la estrategia narrativa y (6) el lenguaje utilizado:

1. La oposición de marcos cognitivos (scripts) (Script Opposition o SO): el parámetro heredado de la Teoría Semántica de Esquemas y requisito indispensable para la producción y comprensión del humor.

2. El mecanismo lógico (Logical Mechanism o LM): la manera en que dos marcos cognitivos (scripts) se relacionan (ambigüedad, analogía, contradicción, exageración, yuxtaposición, etc.)

3. La situación (Situation o SI): el contexto del chiste; incluye los personajes, las actividades, objetos, instrumentos que rodean al blanco del chiste

4. El blanco (Target o TA): el objetivo del chiste, que suele coincidir con personajes estereotipados social o políticamente.

5. La estrategia narrativa (Narrative Strategy o NS): la organización narrativa del chiste (i.e. su género).

6. El lenguaje (Language o $L A$ ): la información necesaria para la verbalización de un texto como, por ejemplo, las elecciones fonéticas, fonológicas, morfológicas, léxicas, semánticas y pragmáticas que realiza el emisor.

Algunos defensores de la TGHV han añadido posteriormente detalles a estos parámetros para ampliar su aplicabilidad a todo tipo de textos humorísticos. Leonor Ruiz Gurillo (2012: 41), en su interesante estudio de la lingüística del humor en español, completa la TGHV y amplía algunos parámetros. Añade relaciones sintagmáticas o razonamientos a los mecanismos lógicos de Attardo y Raskin y explicita el parámetro de la estrategia narrativa para que incluya el análisis del registro y del género textual.

A diferencia de la Teoría Semántica de Esquemas, que solo era aplicable al chiste, la Teoría General del Humor Verbal abarca todos los tipos de humor verbal, ya que la 
introducción de estos cinco nuevos parámetros es fundamental para distinguir entre los distintos tipos de textos humorísticos. Además, los parámetros establecidos en esta teoría son perfectamente aplicables al análisis del humor gráfico como género multimodal que integra elementos verbales e icónicos (Forceville, 2006):

(2)

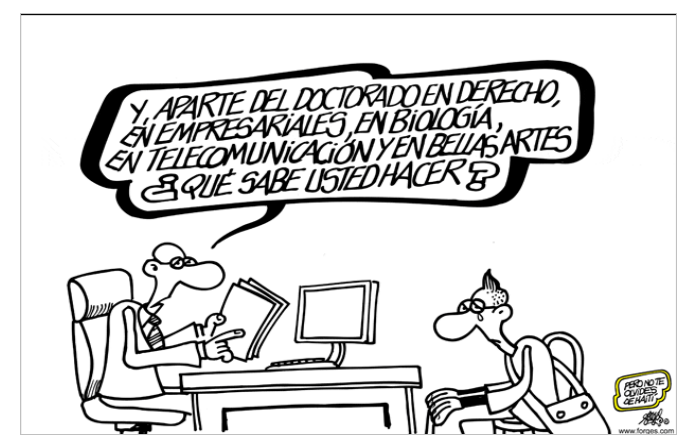

Fig. 4. El País, 2 noviembre 2010. Reproducción autorizada por Forges

1. Oposición de marcos cognitivos (SO): Formación / no formación: tener un buen nivel educativo es una ventaja para encontrar trabajo / tener diferentes doctorados equivale a no saber hacer nada.

2. Mecanismo lógico (LM): Exageración (de la poca importancia que se le dan a los doctorados) y contradicción (cuantos más méritos se tiene, más difícil es conseguir un trabajo).

3. Situación (SI): Un joven con cinco doctorados en una entrevista de trabajo.

4. Blanco (TA): Empresas/doctores cualificados.

5. Estrategia narrativa (NS): Viñeta con una escena y globo.

6. Lenguaje (LA): Lenguaje hiperbólico (amplificación por repetición) en contradicción con la imagen.

El mensaje humorístico de las viñetas multimodales se encuentra codificado en la interacción de imagen y palabra. Se trata de una relación semántica (i.e.: ambos elementos construyen el significado en una relación complementaria), dado que la comprensión del texto no sería completa sin uno de los dos recursos semióticos. Por esta razón, la TGHV es perfectamente aplicable al estudio y comprensión de los dos códigos semióticos. "Although Attardo and Raskin's GTVH was developed to explain verbal jokes, there is no reason why it cannot be applied to cartoon humor as well" (El Refaie, 2009b: 81). En efecto, al aplicar teorías lingüísticas al estudio de textos multimodales, hay que 
tener en cuenta que cada género tiene sus propios modos de construcción de significado. En el caso de las viñetas multimodales, las relaciones plásticas y semánticas que se establecen en el marco de la viñeta son relevantes para un estudio de estas características (Kress y van Leeuwen, 2001). En la Figura 4, la mayoría de las interpretaciones proporcionadas en el análisis de los distintos parámetros no serían apreciables sin el componente visual.

Algunos estudios posteriores a la Teoría General del Humor Verbal han investigado, además, el nivel de resolución de la incongruencia necesario para comprender un texto humorístico. Hempelmann y Ruch (Ruch, 1992; Hempelmann y Ruch, 2005) proponen una taxonomía a partir del Test 3 WD (3 Witz Dimensionen), un modelo para la apreciación del humor que distingue tres categorías relacionadas con el nivel de incongruencia: (1) humor que resuelve la incongruencia (INC-RES), (2) humor absurdo o sin sentido que apenas resuelve la incongruencia (NON) y (3) humor de contenido sexual (SEX). Partiendo de un análisis empírico de un corpus de chistes, Hempelmann y Ruch (2005) llegan a la conclusión de que la incongruencia que se produce en los textos humorísticos siempre se resuelve de una manera parcial, por lo que INC-RES y NON son dos extremos de un continuo de procesos cognitivos. INC-RES es el extremo más cercano a la resolución completa, mientras que NON es el extremo más cercano a una falta de resolución. En el corpus que ha servido de base para la elaboración de este artículo, se han identificado aquellas viñetas de Forges que resuelven casi por completo la incongruencia (Fig. 5.) y las que apenas la resuelven (Fig. 6.). No se han identificado, en el corpus seleccionado, viñetas de contenido sexual.

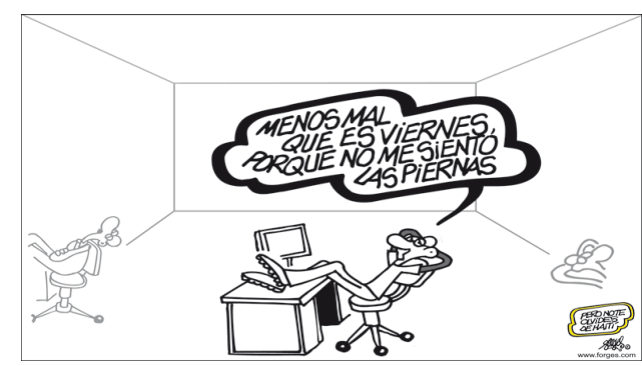

Fig. 5. El País, 19 noviembre 2010. Reproducción autorizada por Forges

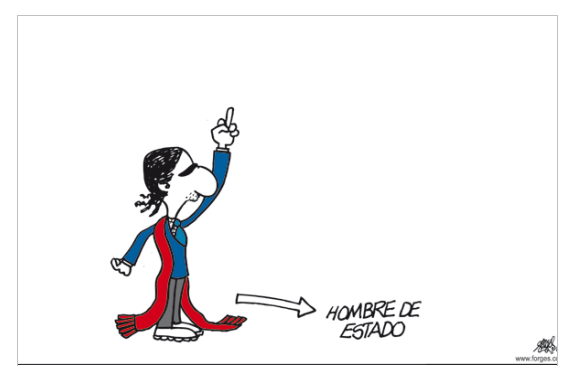

Fig. 6. El País, 19 febrero 2010. Reproducción autorizada por Forges

Además de la TGHV y del Test 3 WD se han tenido en cuenta aportaciones posteriores que han sido precursoras en la investigación del humor gráfico. John C. Paolillo (1998) aplica la Teoría General del Humor Verbal al análisis de un corpus de ochocien- 
tas viñetas de la serie Far Side Cartoons de Gary Larson para identificar características comunes. Paolillo crea una primera lista de quince mecanismos lógicos (o maneras en las que se relacionan dos marcos cognitivos) aplicables al análisis de viñetas. Posteriormente, Attardo, Hempelmann y Di Maio (2002: 9) la amplían y crean una taxonomía de mecanismos lógicos (LMs), que se ha utilizado para analizar las viñetas editoriales de Forges. Hempelmann y Ruch (2005) llegan a la conclusión de que, de los seis parámetros de la TGHV, solamente cuatro son relevantes para el análisis de viñetas: (1) la oposición de marcos cognitivos (scripts) (SO), (2) los mecanismos lógicos (LMs), (3) la estrategia narrativa (NS) y (4) el blanco (TA). No consideran relevantes el análisis del lenguaje (LA) y de la situación (SI), ya que es difícil encontrar elementos en común entre estos parámetros. Por último, la investigación más reciente, que ha servido de base para realizar una primera división del corpus seleccionado de viñetas de Forges, es la de Samson (2008). En su estudio, Samson relaciona el proceso de resolución de la incongruencia con diferentes regiones del cerebro y ofrece una distinción entre tres tipos de humor gráfico que difieren en base a sus mecanismos lógicos:

1. Viñetas visuales (PUNs): un elemento visual activa por sí solo dos marcos cognitivos (scripts) que son incongruentes entre sí (Fig. 7).

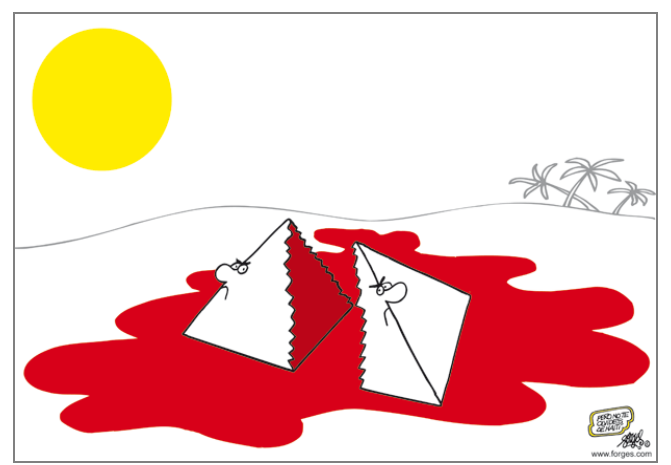

Fig. 7. El País, 4 febrero 2011. Reproducción autorizada por Forges

2. Viñetas semánticas (SEMs): la incongruencia es el resultado de la oposición de dos marcos cognitivos (scripts) basados en aspectos semánticos (Fig. 8). 


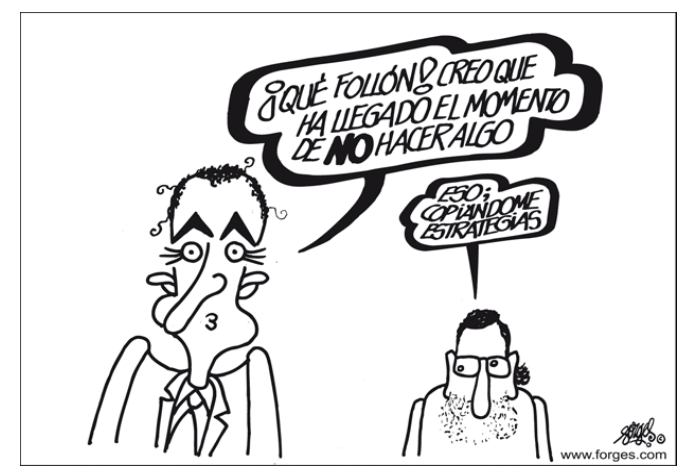

Fig. 8. El País, 6 febrero 2010. Reproducción autorizada por Forges

3. Viñetas de falsa ambigüedad (TOMs: Theory of Mind): requieren la atribución de estados mentales falsos a los personajes para entender el chiste. En ellas un personaje no se da cuenta de algo que es obvio en la viñeta (Fig. 9).

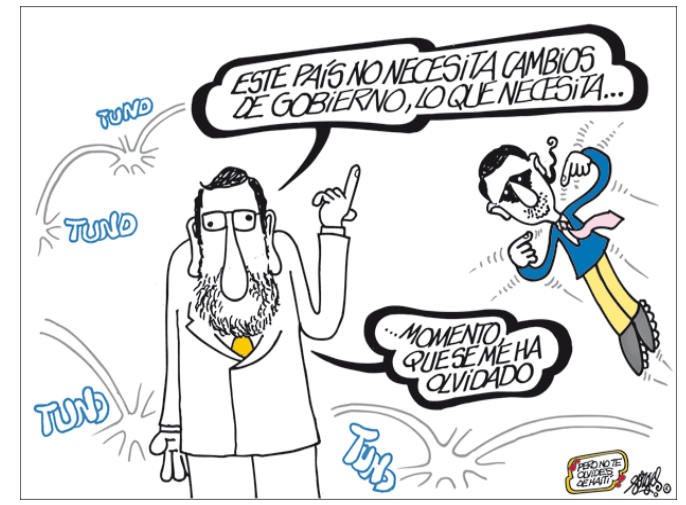

Fig. 9. El País, 21 octubre 2010. Reproducción autorizada por Forges

\section{Método}

En este artículo se ha aplicado la Teoría General del Humor Verbal y el Test 3 WD a un corpus de 372 viñetas de Forges publicadas en el periódico El País entre el 1 de febrero de 2010 y el 28 de febrero de 2011. El corpus seleccionado está compuesto por 89 viñetas de contenido político y 283 viñetas de contenido social. Su análisis está basado en las investigaciones recientes sobre humor gráfico: (1) la clasificación de viñetas realizada por Samson (PUN, SEM y TOM), (2) los parámetros que Hempelmann y Ruch distinguen como relevantes (SO, LM, NS y TA), (3) los mecanismos lógicos generales 
descubiertos por Hempelmann, Attardo y Di Maio, y (4) la división de las relaciones entre marcos cognitivos (scripts) en subcategorías binarias.

El procedimiento que se ha seguido para el análisis de las viñetas de Forges se ha desarrollado en tres fases: (1) división de las viñetas en función de su contenido político y contenido social, (2) análisis pormenorizado de cada grupo de viñetas, y (3) análisis individual de cada viñeta según los cuatro parámetros de la TGHV que son relevantes (SO, LM, NS y TA), en orden jerarquizado, subdividiendo las viñetas en INC-RES y NON y en subapartados cuando ha sido necesario, como en el caso de los mecanismos lógicos, donde era oportuno distinguir entre PUNs, SEMs y TOMs:

(3)

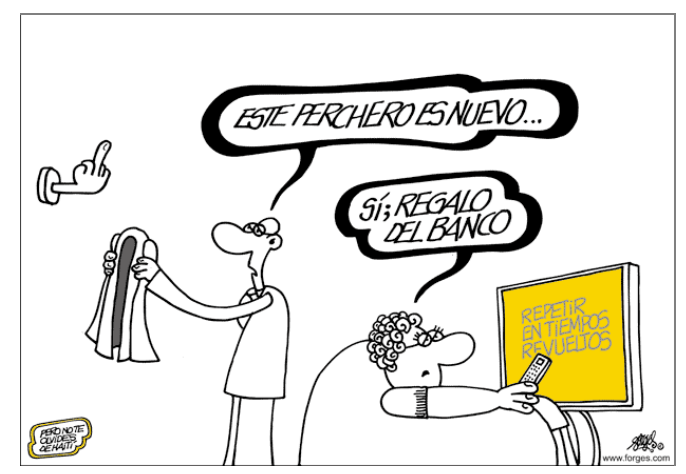

Fig. 10. El País, 3 noviembre 2010. Reproducción autorizada por Forges

1. Contenido social o político: viñeta de contenido social que aborda un tema de interés general: estrategias de captación de clientes con el reclamo de regalos de escasa utilidad.

2. INC-RES o NON: viñeta INC-RES; el remate del chiste ayuda al lector a resolver la incongruencia gracias a la analogía del perchero con el gesto provocador de la peineta (dedo corazón levantado).

3. PUN, SEM, o TOM: viñeta semántica; la incongruencia es el resultado de la oposición de dos marcos cognitivos basados en aspectos semánticos: el banco concede préstamos / el banco no ofrece nada (engaña a los ahorradores); el banco capta el dinero de sus clientes / el banco se queda con su dinero (prácticas fraudulentas).

4. Oposición de marcos cognitivos: la oposición presentada es dinero / no dinero.

5. Mecanismos lógicos: se utiliza la analogía para asociar el perchero, el regalo del banco, con el gesto provocador de la peineta, que revela la actitud de menosprecio de las propias entidades bancarias hacia sus ahorradores. 
6. Estrategia narrativa: Se trata de una viñeta de una sola escena con globos de diálogo y una apoyatura (pantalla de televisión).

7. Blancos u objetivos: crítica a las entidades bancarias.

\section{Análisis y resultados}

\subsection{Viñetas de contenido político}

\subsubsection{Oposición de marcos cognitivos}

Entre las viñetas que resuelven casi por completo la incongruencia (INC-RES), los tipos de oposiciones que más se repiten son: verdad / mentira (4), dinero / no dinero (4), poder / no poder (4), esfuerzo / no esfuerzo (4) (Fig. 11) y voto / no voto (3). En las viñetas políticas que apenas resuelven la incongruencia (NON), este parámetro no es relevante (no se repite).

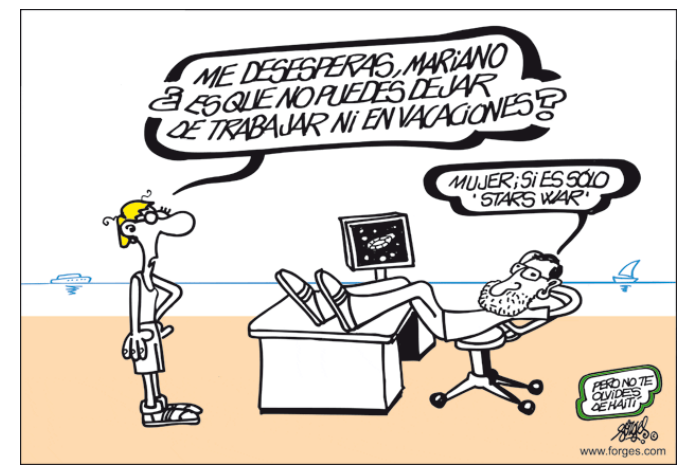

Fig. 11. El País, 17 agosto 2010. Reproducción autorizada por Forges

\subsubsection{Mecanismos lógicos}

Como se aprecia en la tabla que se presenta a continuación (Fig. 12), no se ha encontrado en este corpus de viñetas de contenido político ninguna viñeta visual (PUN) y solo se han identificado dos viñetas de falsa ambigüedad (TOM) en el grupo de las que resuelven casi completamente la incongruencia (INC-RES) (Fig. 9). 


\begin{tabular}{|c|c|c|c|c|c|c|}
\hline \multicolumn{4}{|l|}{ INC-RES } & \multicolumn{3}{|c|}{ NON } \\
\hline LMs & PUN & SEM & TOM & PUN & SEM & TOM \\
\hline Ambigüedad & & 9 & & & & \\
\hline Analogía & & 25 & & & 2 & \\
\hline Contradicción & & 18 & & & 2 & \\
\hline Exageración & & 15 & & & 1 & \\
\hline Cambio de roles & & 1 & & & & \\
\hline Juego de palabras & & 2 & & & & \\
\hline Yuxtaposición & & 8 & & & & \\
\hline Razonamiento desde premisa falta & & 1 & & & & \\
\hline Roles paralelos & & 1 & & & & \\
\hline Error obvio & & & 2 & & & \\
\hline Sin LMs & & & & & 4 & \\
\hline
\end{tabular}

Fig. 12. Tabla de mecanismos lógicos en viñetas de contenido político

Las demás viñetas son semánticas (SEM) y los mecanismos lógicos más utilizados por Forges son analogía (25), contradicción (18) y exageración (15) en las viñetas que resuelven casi completamente la incongruencia (INC-RES). En la Figura 13, Forges establece una clara analogía entre dos políticos europeos y la relación imposible que mantienen los personajes (Don Juan Tenorio y doña Inés) en el drama romántico de José Zorrilla.

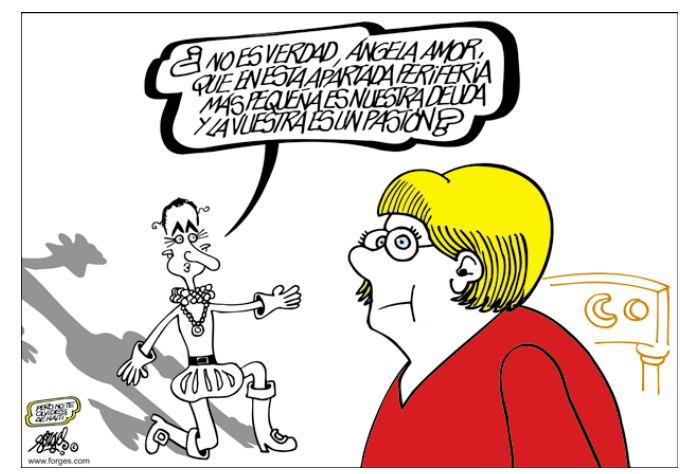

Fig. 13. El País, 3 febrero 2011. Reproducción autorizada por Forges

Sin embargo, en las viñetas que apenas resuelven la incongruencia (NON), la mayoría contiene mecanismos lógicos no definibles. Se trata de viñetas en las que la imagen no es relevante y el mensaje es transmitido exclusivamente por el texto, como se aprecia en la Figura 14. 


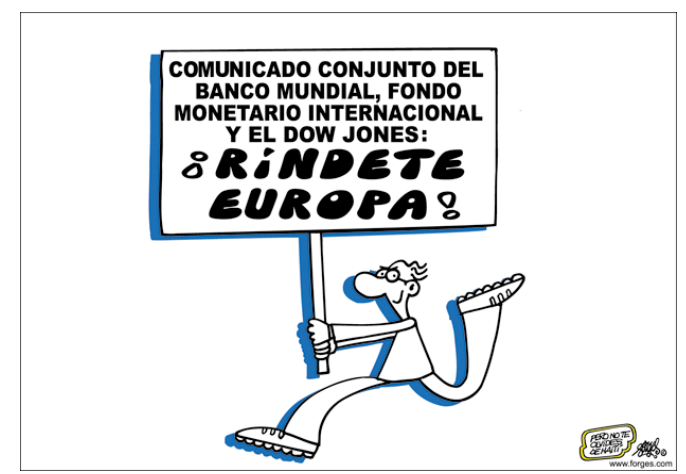

Fig. 14. El País, 27 octubre 2010. Reproducción autorizada por Forges

\subsubsection{Estrategias narrativas}

Como se observa en la tabla (Fig. 15), en las viñetas que resuelven la incongruencia (INC-RES), la estrategia narrativa más utilizada es la de viñetas de una escena con globos $(55)^{4}$, mientras que en las viñetas que apenas la resuelven $(\mathrm{NON})$, la estrategia narrativa más utilizada es la de viñetas de una escena con apoyaturas verbales $(6)^{5}$ (Fig. 14).

\begin{tabular}{|l|c|c|}
\hline \multicolumn{2}{|c|}{ ESTRATEGIAS NARRATIVAS } \\
\hline & INC-RES & NON \\
\hline 1 escena con globlos & 55 & 2 \\
\hline 1 escena con apoyaturas & 4 & 6 \\
\hline 1 escena con globos más apoyaturas & & 1 \\
\hline 1 escena con título & 8 & \\
\hline 1 escena con título más globos & 6 & \\
\hline 1 escena con título más apoyaturas & 5 & \\
\hline 2 escenas con globos & 1 & \\
\hline 2 escenas más títulos & 1 & \\
\hline
\end{tabular}

Fig. 15. Tabla de estrategias narrativas en viñetas de contenido político

\footnotetext{
${ }^{4}$ Forma gráfica que introduce el diálogo o los pensamientos de los personajes y que consiste en un cuerpo circular u ovalado con un delta o vértice que apunta al emisor.

${ }^{5}$ Forma gráfica que introduce el discurso del narrador y que tiene una función explicativa.
} 


\subsubsection{Blancos u objetivos}

Los blancos que más se repiten en las viñetas políticas de Forges con resolución de la incongruencia son José Luis Rodríguez Zapatero (18) (Figs. 8 y 13), Mariano Rajoy (17) (Figs. 8, 9 y 11), José María Aznar (8), viñetas que no tienen un blanco definido (7), la trama Gürtel (6), los políticos en general (5), los mercados (3) y el PSOE (3). Por otro lado, en las viñetas que apenas resuelven la incongruencia, los blancos que más se repiten son la trama Gürtel de nuevo (2) y aquellas viñetas que no tienen un blanco definido (2).

\subsection{Viñetas de contenido social}

\subsubsection{Oposición de marcos cognitivos}

En las viñetas que resuelven casi completamente la incongruencia (INC-RES), los tipos de oposiciones que más se repiten son del tipo binario: dinero / no dinero (12) (Fig. 16), real / no real (11), mundial / no mundial (11), actualidad / no actualidad (8), sano / enfermo (8), toros / no toros (7), crisis / no crisis (6), caro / barato (6), fútbol / no fútbol (5), trabajo / no trabajo (5) y rico / pobre (4). En las viñetas de contenido social que apenas resuelven la incongruencia (NON), los tipos de oposiciones no son relevantes ya que ninguno se repite.

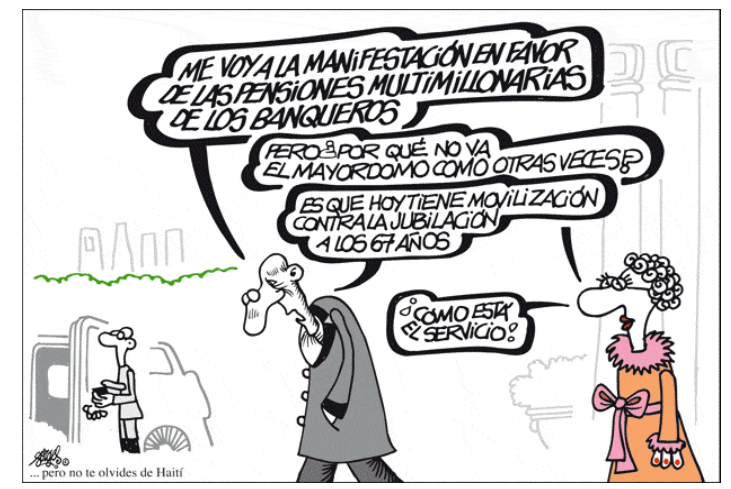

Fig. 16. El País, 23 febrero 2010. Reproducción autorizada por Forges

\subsubsection{Mecanismos lógicos}

Como se observa en la tabla (Fig. 17), en las viñetas que resuelven casi completamente la incongruencia (INC-RES), esta vez aparecen dos viñetas exclusivamente visua- 
les (PUN) (Figs. 1 y 7). Sin embargo, en todo el corpus de viñetas de contenido social no hay ninguna de falsa ambigüedad (TOM).

\begin{tabular}{|c|c|c|c|c|c|c|}
\hline \multicolumn{3}{|c|}{ INC-RES } & \multicolumn{3}{c|}{ NON } \\
\hline LMs & PUN & SEM & TOM & PUN & SEM & TOM \\
\hline Ambigüedad & & 8 & & & 2 & \\
\hline Analogía & 1 & 71 & & & 7 & \\
\hline Contradicción & & 44 & & & 4 & \\
\hline Exageración & & 84 & & & 8 & \\
\hline Cambio de roles & & 2 & & & & \\
\hline Juego de palabras & & 16 & & & 2 & \\
\hline Yuxtaposición & & 9 & & & & \\
\hline Sin LMs & 1 & 14 & & & 10 & \\
\hline
\end{tabular}

Fig. 17. Tabla de mecanismos lógicos en viñetas de contenido social

La mayoría de las viñetas es de tipo semántico y los mecanismos más utilizados son analogía (71), contradicción (44) y exageración (84) en las viñetas INC-RES, y analogía (7), exageración (8) y mecanismos lógicos no definidos (10) (Fig. 19) en las viñetas NON. La Figura 18 muestra la contradicción entre lo que expresa el locugrama y la expresión facial de los personajes dibujados. En la Figura 19, sin embargo, no existe mecanismo lógico definible ni se resuelve ninguna incongruencia.

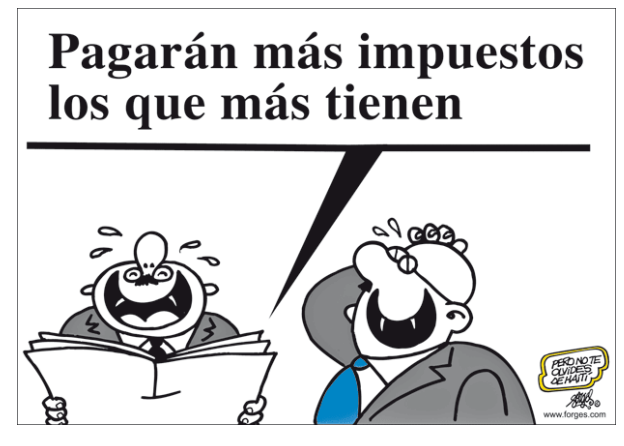

Fig. 18. El País, 21 mayo 2010. Reproducción autorizada por Forges

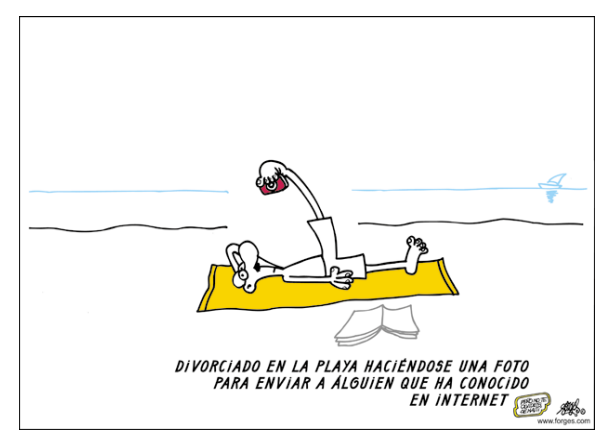

Fig. 19. El País, 6 agosto 2010. Reproducción autorizada por Forges

\subsubsection{Estrategias narrativas}

Como se aprecia en la tabla (Fig. 20), en las viñetas que resuelven la incongruencia predominan aquellas compuestas por una escena y globo (144) y, de nuevo, en las viñe- 
tas que apenas resuelven la incongruencia, la diferencia entre estas (14) y las que tienen una sola escena con apoyatura (11) es menor.

\begin{tabular}{|l|c|c|}
\hline \multicolumn{3}{|c|}{ ESTRATEGIAS NARRATIVAS } \\
\hline 1 escena con globlos & INC-RES & NON \\
\hline 1 escena con apoyaturas & 144 & 14 \\
\hline 1 escena con globos más apoyaturas & 21 & 11 \\
\hline 1 escena con título & 8 & 4 \\
\hline 1 escena con título más globos & 18 & 3 \\
\hline 1 escena con título más apoyaturas & 14 & 1 \\
\hline 1 escena con título más globos más apoyaturas & 2 & \\
\hline 1 escena sin palabras & 4 & \\
\hline 2 escenas con globos & 1 & \\
\hline 2 escenas con apoyaturas & 1 & \\
\hline 2 escenas más globos más apoyaturas & 1 & \\
\hline
\end{tabular}

Fig. 20. Tabla de estrategias narrativas en viñetas de contenido social

\subsubsection{Blancos u objetivos}

Los blancos que más se repiten en las viñetas de contenido social que resuelven casi completamente la incongruencia (INC-RES) son viñetas sin blanco definido (83) (Figs. 5,10 y 19), aficionados al fútbol (15) (Fig. 21), especuladores (11), bancos (9), aficionados a los toros (6), becarios (5), funcionarios (4), el Fondo Monetario Internacional (3) y los meteorólogos (3). Por otro lado, en las viñetas que apenas resuelven la incongruencia, la mayoría de los blancos no son definidos (17); Haití es también un foco de interés recurrente (3).

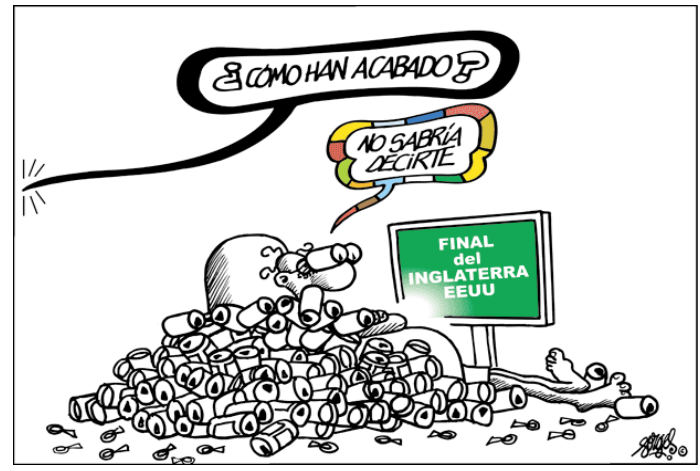

Fig. 21. El País, 13 junio 2010. Reproducción autorizada por Forges 


\section{Conclusiones}

El estudio realizado demuestra que los parámetros establecidos en la Teoría General del Humor Verbal son aplicables al humor gráfico. De los resultados del análisis del corpus seleccionado se pueden extraer conclusiones acerca de los mecanismos que emplea Forges para realizar su crítica o aportar su punto de vista dentro del panorama político y social actual. Antonio Fraguas es un autor comprometido con la realidad social y política actual, como revela la repetición de las oposiciones de marcos cognitivos y blancos relacionados con sucesos ocurridos entre los años 2010 y 2011. Sin embargo, predomina en su obra la viñeta de crítica social sobre la de carácter político. Son también mayoritarias las viñetas que resuelven casi por completo la incongruencia (332) sobre las que apenas la resuelven (42). Del mismo modo, las viñetas semánticas (368) priman sobre las visuales (2) y las de falsa ambigüedad (2).

Los mecanismos lógicos más utilizados por Forges para conseguir el efecto cómico en sus viñetas son la analogía, la contradicción y la exageración, aunque en las viñetas que apenas resuelven la incongruencia (NON) es recurrente el uso de mecanismos lógicos no definidos (en particular, en aquellas en las que un personaje sostiene un cartel con un mensaje reivindicativo). En cuanto a las estrategias narrativas utilizadas, predominan las viñetas con una escena o recuadro complementados por globos que integran gráficamente el texto de los diálogos o el pensamiento de los personajes en la estructura icónica de la viñeta. Sin embargo, en las viñetas de contenido político que apenas resuelven la incongruencia (NON) son más comunes las viñetas que integran apoyaturas explicativas.

A pesar de que la TGHV fue propuesta en principio para el análisis del humor verbal, en este artículo se ha demostrado que es perfectamente aplicable al análisis de las viñetas visuales y verbo-icónicas. En una viñeta multimodal es necesario identificar las distintas estrategias que el autor utiliza cuando se funden imagen y palabra en ese marco espacial. En las viñetas multimodales (escripto-icónicas), el efecto humorístico se produce cuando el receptor percibe la disonancia entre los elementos visuales y verbales del texto. En la mayoría de los pictogramas de Forges, existe una función de relevo o de interreferencia (Barthes, 1977); es decir, la imagen ayuda a interpretar el mensaje lingüístico. En ellas, los elementos lingüísticos y analógicos están en relación complementaria a la hora de transmitir un mensaje irónico. En las viñetas que solo contienen una pequeña apoyatura verbal (Fig. 6), esta cumple una función de anclaje con un claro valor irónico (Barthes, 1977); es decir, es el mensaje lingüístico el que da sentido al contenido de la imagen. Por último, las viñetas basadas exclusivamente en la imagen, sin elementos verbales, contienen siempre metáforas visuales (Figs. 1 y 7 ). 
Las viñetas que aparecen en las páginas editoriales de los periódicos permiten a los autores expresar su ideología, utilizando la ironía y la metáfora como estrategias subversivas para concienciar a los lectores de sucesos que podrían pasarles inadvertidos (El Refaie, 2005). A pesar de su aparente sencillez, como se ha demostrado en este artículo, la producción y percepción del discurso humorístico en las viñetas de prensa no es tarea fácil. Los humoristas gráficos emplean viñetas monomodales y viñetas multimodales para transmitir al lector su particular visión de la realidad política o social. En ambas se utiliza la imagen como recurso semiótico para producir un efecto cómico. Sin embargo, en el caso de las viñetas multimodales, el éxito del mensaje depende no solo del contenido pictográfico, sino también de la relación de dependencia que dicho contenido guarda con un elemento lingüístico, con una clara función de relevo o de anclaje.

Numerosos estudios han abordado la relación entre las viñetas de humor político y la lingüística cognitiva (Bergen, 2003): La Teoría de la Integración Conceptual (Conceptual Blending) (Faucconier y Turner, 2002), la Teoría de la Metáfora Conceptual (Lakoff y Johnson, 1980) y la Teoría de los Modelos Culturales (Holland y Quinn, 1987). Las investigaciones de Forceville (1996, 2006 y 2009) o de Juana Marín Arrese (2008) han analizado el papel que desempeñan mecanismos cognitivos como la metáfora y la metonimia en la creación e interpretación del humor en las viñetas de opinión.

La multimodalidad es, por tanto, un campo de estudio de creciente interés investigador. Aunque la TGHV es aplicable al estudio de las viñetas escripto-icónicas, queda un largo camino por recorrer en la comprensión del humor de textos intersemióticos. Quizá sea necesario, como proponen Kress y van Leeuwen (2006 [1996]), diseñar gramáticas dentro de los recursos semióticos multimodales, ya sean lingüísticos, visuales o sonoros. Un mayor conocimiento de las características del medio permitiría comprender mejor las relaciones de significado entre ambos códigos. Asimismo, sería interesante analizar la resemiotización de los fenómenos multimodales dependiendo de las prácticas sociales (O’Halloran, 2011), i.e., cómo cambia el significado a medida que el discurso alterna con distintos recursos semióticos. Tampoco debe olvidarse que las viñetas políticas son efímeras y que, por tanto, su comprensión puede ser parcial si se las escinde de su contexto original. Sobre la importancia del contexto, El Refaie (2009b) apuesta por un análisis de la viñeta política ubicada en la página de opinión en que aparece publicada en el periódico. 


\section{Referencias bibliográficas}

Attardo, S. (1991): Linguistic theories of humor. Berlín, Mouton de Gruyter.

Attardo, S. (2001): Humorous texts: A semantic and pragmatic analysis. Berlín/Nueva York, Mouton de Gruyter.

Attardo, S. (2006): “Cognitive linguistics and humor”, Humor: International Journal of Humor Research, 19 (3), págs. 341-362.

Attardo, S. y Raskin, V. (1991): "Script theory revis(it)ed: joke similarity and joke representation model”, Humor: International Journal of Humor Research, 4 (3-4), págs. 293-347.

Attardo, S., Hempelmann, C. F. y DiMaio, S. (2002): "Script oppositions and logical mechanisms: modeling incongruities and their resolutions", Humor: International Journal of Humor Research, 15, págs. 3-46.

Barthes, R. (1977): Image, music and text. Londres, Fontana.

Bergen, B. (2003): "To awaken a sleeping giant. Cognition and culture in September 11 political cartoons", Language, Culture, and Mind, págs. 23-35.

Bergson, H. (1911 [1899]): Laughter: An essay on the meaning of the comic. Nueva York, Macmillan.

El Refaie, E. (2003): "Understanding visual metaphor: The example of newspaper cartoons”, Visual Communication, 2 (1), págs. 75-96.

El Refaie, E. (2005): "Our purebred ethnic compatriots: irony in newspaper journalism", Journal of Pragmatics, 37, págs. 781-797.

El Refaie, E. (2009a): "Multiliteracies: How readers interpret political cartoons", Revista Visual Comunication, 2 (8), págs. 181-205.

El Refaie, E. (2009b): "What makes us laugh? Verbo-visual humour in newspaper cartoons". En Ventola, E. y Moya Guijarro, A. J. (eds.): The world told and the world shown: Multisemiotic issues. Hampshire, Palgrave Mcmillan, págs. 75-90.

El Refaie, E. y Hörschelmann, K. (2010): "Young people's readings of a political cartoon and the concept of multimodal literacy", Revista Discourse: Studies in the Cultural Politics of Education, 2 (31), págs. 195-207.

Fauconnier, G, y Turner, M. (2002): The way we think: Conceptual blending and the mind's hidden complexities. New York, Basic Books.

Forceville, G. (1996): Pictorial metaphor in advertising. Londres/Nueva York, Routledge.

Forceville, C. (2006): "Non-verbal and multimodal metaphor in a cognitivist framework: agendas for research". En Kristiansen, G., Achard, M., Dirven, R. y Ruiz de Mendoza, F. (eds.): Cognitive linguistics: Current applications and future perspectives. Berlín/Nueva York, Mouton de Gruyter, págs. 379-402. 
Forceville, C. y Urios-Aparisi, E. (2009): Multimodal metaphor. Berlín y Nueva York, Mouton de Gruyter.

Freud, S. (1991 [1905]): Jokes and their relation to the unconscious. Harmondsworth, Penguin.

Galán Rodríguez, M. (1994): "La creatividad léxica: los neologismos en A. Fraguas de Pablo (Forges)". Disponible en: http://dialnet.unirioja.es/servlet/articulo?codigo =58814. (Acceso: 29.03.2013).

Grice, H. P. (1975): "Logic and conversation". En Cole, P. y Morgan, J. (eds.): Syntax and semantics, vol. 3. Nueva York, Academic Press, págs. 41-58.

Halliday, M. (1985): An introduction to functional grammar. Londres, Edward Arnold.

Hempelmann, C. y Ruch, W. (2005): "3 WD meets GTVH: breaking the ground for interdisciplinary humor research", Humor: International Journal of Humor Research, 18 (4), págs. 353-387.

Hobbes, T. (1994 [1668]): Leviathan. Indianápolis, Hackett.

Holland, D y Quinn, N., (eds) (1987): Cultural models in language and thought. Cambridge, Cambridge University Press

Kant, I. (1790): Critique of judgement. Guyer, P. (trans.) Cambridge, Cambridge University Press, 2000.

Kress, G. y Van Leeuwen, T. (2001): Multimodal discourse - The modes and media of contemporary communication. Londres, Edward Arnold.

Kress, G. y Van Leeuwen, T. (2006 [1996]): Reading images: The grammar of visual design. Londres, Routledge.

Lakoff, G. y Johnson, M. (1980): Metaphors we live by. Chicago, The University of Chicago Press.

Lakoff, G. (1987): Women, fire and dangerous things: What categories reveal about the mind. Chicago y Londres, University of Chicago Press.

Leech, G. (1983): Principles of Pragmatics. Londres, Longman.

Marín Arrese, J. I. (2008): "Cognition and culture in political cartoons", Intercultural Pragmatics, 1 (5), págs. 1-18.

Moya Guijarro, A. J. y Pinar Sanz, M. J. (2009): “On interaction of image and verbal text in a picture book. A multimodal and systemic fuctional study". En Ventola, E. y Moya Guijarro, A. J. (eds.): The world told and the world shown: Multisemiotic issues. Hampshire, Palgrave Mcmillan, págs. 107-124.

O'Halloran, K. (2011): "Multimodal discourse analysis". En Hyland, K. Paltridge, B. (eds): Companion to discourse, Londres y Nueva York, Continuum, págs. 120-137.

Ortiz Díaz-Guerra, M.J. (2010): “Teoría integrada de la metáfora visual”, Comunicación y Sociedad, XXIII, 2, págs. 97-125. 
Paolillo, J. (1998): “Gary Larson's Far Side: nonsense? nonsense!”, Humor: International Journal of Humor Research, 11, págs. 261-290.

Raskin, V. (1985): Semantic mechanisms of humor. Dordrecht, D. Reidel.

Ruch, W. (1992): "Assessment of appreciation of humor: studies with the 3 WD humor test". En Butcher, J. N. y Spielberger, C. D. (eds.): Advances in personality assessment, vol. 9. Hillsdale, NJ, Erlbaum, págs. 27-75.

Ruiz Gurillo, L. (2012): La lingüística del humor en español. Madrid, Arco/Libros.

Samson, A. (2008): Cognitive and neural humor processing: The influence of structural stimulus properties and theory of mind. Tesis doctoral inédita. Universidad de Friburgo (Suiza).

Schank, R. y Abelson, R. (1977): Scripts, plans, goals and understanding. Nueva York, Wiley.

Schopenhauer, A. (1891 [1818]): "On the theory of the ludicrous". En Schopenhauer, A. (ed.): The world as will and idea, vol. 2. Londres, Kegan Paul, Trench, Trübner and Co, págs. 270-284.

Spencer, H. (1911): “On the physiology of laughter", Essays on Education, Etc., Londres, Dent, págs. 298-309.

Sperber, D. y Wilson, D. (1986): Relevance: Communication and cognition. Oxford, Blackwell.

Vigara Tauste, A. M. (2004): "Podréis quitarme todo, menos el miedo... El humor y su(s) sentido(s) en el acto de la comunicación”, Exit: Imagen y Cultura, 13, págs. 94-108.

Yus, F. (1995): "La significación social de las máximas de Grice: el caso del cómic alternativo ingles", Revista Canaria de Estudios Ingleses, 30-31, págs. 109-128.

Yus, F. (2003): "Humor and the search for relevance", Journal of Pragmatics, 35, págs. $1295-1331$. 


\title{
FENÓMENOS DE TRANSFERENCIA ENTRE LENGUAS: EVIDENCIALIDAD EN EL ESPAÑOL EN CONTACTO CON EL GUARANÍ Y EL QUECHUA ${ }^{1}$
}

\author{
Alicia Avellana \\ Universidad de Buenos Aires, Comisión Nacional de Investigaciones Cienfíticas y Técnicas \\ alliciaavellana@yahoo.com.ar
}

Resumen

El presente trabajo describe, compara y analiza distintos valores evidenciales que adopta el pretérito pluscuamperfecto en dos variedades de contacto en la Argentina y Paraguay: el español en contacto con el que-chua y con el guaraní.

A partir de una descripción detallada de las gramáticas involucradas en el contacto determinamos, por un lado, si las construcciones consideradas se deben a procesos de transferencia. Por otro lado, especificamos el tipo de elemento gramatical transferido, dentro del marco teórico de la Gramática Generativa (Chomsky, 1981 y trabajos posteriores) y, especialmente, desde la propuesta de la Morfología Distribuida (Halle y Marantz, 1993, 1994, entre otros). Finalmente, evaluamos el alcance de este análisis para la sistematización de la variación lingüística dentro del modelo considerado.

PALABRAS CLAVE: contacto de lenguas; español-guaraní; español-quechua; evidencialidad; pretérito pluscuamperfecto.

\begin{abstract}
This paper describes, compares and analyses different evidential values conveyed by the Spanish pluperfect in two contact varieties in Argentina and Paraguay: Spanish in contact with Quechua and Guarani.

On basis on a detailed description of the grammars involved in each contact situation we examine, on the one hand, wether the constructions are due to tranference processes and, on the other hand, we determine the type of the grammatical element transferred, according to the framework of the Generative Grammar (Chomsky, 1981 and subsequent work) and, especially, the Distributed Morphology approach (Halle \& Marantz, 1993, 1994, among others). Finally, we evaluate the implications of this analysis for the sistematization of the interlinguistic variation within the generative framework.
\end{abstract}

KEY WORDS: language contact; SpanishGuarani; Spanish-Quechua; evidentiality; pluperfect.

\section{Introducción}

El presente trabajo describe, compara y analiza distintos valores modales que adopta el pretérito pluscuamperfecto en dos variedades del español en contacto con lenguas

\footnotetext{
${ }^{1}$ Quisierea agradecer la lectura y los valiosos comentarios de Laura Kornfeld.
} 
indígenas, dentro del marco teórico de la Gramática Generativa (Chomsky, 1981 y trabajos posteriores) y, en especial, desde la propuesta de la Morfología Distribuida (Halle y Marantz, 1993, 1994, entre otros).

Específicamente, trabajamos con datos del contacto con quechua en el noroeste de la Argentina y del contacto con guaraní en el nordeste de dicho país y en Paraguay. En particular, mostramos cómo una forma verbal similar en ambas variedades - y existente también en el español general- (i.e. el pretérito pluscuamperfecto) puede adoptar características sintáctico-semánticas y morfológicas propias de la lengua con la que está en contacto.

Así, a lo largo de este trabajo analizamos cómo el pretérito pluscuamperfecto manifiesta un valor evidencial, es decir, expresa distintos aspectos vinculados con la fuente mediante la cual se ha obtenido la información. Por un lado, en el contacto con el guaraní, codifica la sorpresa del hablante frente a un hecho no percibido previamente, como se ejemplifica en (1):

(1) a. Mirá vos, había sido que la pistola de Robocop sí existe [W1]. ('Resultó (ser) que la pistola de Robocop existe [pero yo no lo sabía hasta ahora].')

b. Se mudaron había sido... [W2] ('Resultó (ser) que se mudaron [pero yo no lo sabía hasta este momento].')

Por otro lado, en el contacto con el quechua adopta un tipo de valor evidencial diferente, que expresa que el hablante no ha experimentado personalmente los hechos que relata (2):

(2) a. Mi finado fue una vez a cazar a una laguna y ahí había estado ['estaba'], en un palo, la madre del agua, peinándose con un costillar de pescado. (...) Se había llegado ['llegó'] cerquita y vido que muy rubia había sido ['era']. [V:417, VIII] ('Mi finado fue una vez a cazar a una laguna y ahí estaba, en un palo, la madre del agua, peinándose con un costillar de pescado. (...) Se llegó cerquita y vio que era muy rubia [pero no tengo evidencia directa de ello].')

b. Le pegó otra vez. Lo agarra de la cabeza y va, lo mete en la pileta con agua. Lo baña bien.(...) Gritando había estado, el loro. [V:511, III] ('El loro estaba gritando [lo cual no me consta personalmente].')

A partir del análisis de datos como los de (1) y (2), en este trabajo nos proponemos, en primer lugar, determinar si puede hablarse efectivamente de transferencia por contacto, comparando en detalle las propiedades sintáctico-semánticas y morfológicas de estas estructuras con las de las lenguas indígenas correspondientes. En segundo lugar, examinamos el tipo de elementos que se traslada de una lengua a otra, con el objetivo de precisar qué aspectos gramaticales pueden resultar transferidos en el contacto. Finalmente, evaluamos el alcance que este análisis presenta para el estudio de la variación 
lingüística dentro del modelo generativo y, en especial, para la especificación de la noción de parámetro dentro de la propuesta de la Morfología Distribuida (Halle y Marantz, 1993, 1994, entre otros).

El trabajo se organiza de la siguiente manera: en el primer apartado, exponemos algunos aspectos vinculados con el marco teórico que resultarán útiles para el análisis posterior. El segundo y el tercer apartado están dedicados a la descripción y análisis de los datos del español en contacto con el guaraní y con el quechua respectivamente. En el cuarto apartado recapitulamos los distintos fenómenos de contacto y sistematizamos el tipo de modificación que producen sobre la gramática del español. Finalmente, en el último apartado, recogemos las conclusiones y examinamos sus consecuencias para la noción de variación dentro del marco teórico considerado.

\section{El marco teórico}

Este trabajo se inscribe dentro del marco teórico de la Gramática Generativa, un modelo formal en el que el estudio de la variación lingüística recibió un interés particular a partir de los años 80 con el modelo de Principios y Parámetros (Chomsky, 1981 y trabajos posteriores). Allí se propuso la noción de gramática universal para referirse a un componente gramatical innato conformado por un conjunto de principios universales, comunes a todas las lenguas. Estos principios, a su vez, se vinculan con una serie de parámetros, que son los que dan cuenta de la variación entre las lenguas dentro de los límites impuestos por la gramática universal.

La noción de parámetro, es decir, el elemento que permite formalizar la variación entre las lenguas, ha recibido distintas formulaciones desde su propuesta original. Así, en un comienzo se concebía como un conjunto de propiedades sintácticas abstractas que afectaba la aplicación de los principios universales en las lenguas particulares (como, por ejemplo, las propiedades vinculadas al parámetro del sujeto nulo en relación con el principio de proyección extendida). Sin embargo, en las propuestas más actuales los parámetros ya no se vinculan al componente sintáctico sino que afectan a las categorías funcionales presentes en cada lengua y, más específicamente, a los rasgos funcionales.

En esta investigación trabajamos en particular desde la propuesta de la Morfología Distribuida (Halle y Marantz, 1993, 1994, entre otros). Desde esta perspectiva, las gramáticas de las lenguas varían, en primer lugar, en cuanto a los rasgos que seleccionan dentro de un conjunto universal, que se denomina inventario universal de rasgos [Universal Feature Inventory]. Así, por ejemplo, existen lenguas que seleccionan un rasgo [dual], mientras que otras no lo hacen. En segundo lugar, las lenguas pueden variar en 
relación con distintas características que operan en el componente morfológico. Dicho componente - que constituye una de las propuestas innovadoras de la Morfología Distribuida - se ubica luego de la sintaxis y consiste en un conjunto de operaciones que son particulares a las lenguas (y que son puramente formales, es decir, que no reciben interpretación semántica). Por ejemplo, se aplica allí la operación de concordancia, que multiplica los mismos rasgos en distintas posiciones de la oración, o la operación de fusión, que une rasgos que luego serán expresados mediante un único morfema (como sucede en español, por ejemplo, con los rasgos de tiempo y aspecto en la morfología de pasado). Además de las operaciones mencionadas, en el componente morfológico se relacionan los rasgos abstractos con los exponentes fonológicos que los expresan en cada lengua (por ejemplo, se vincula el rasgo [plural] con sus realizaciones en español $s$, -es o $\varnothing$, o bien el rasgo [progresivo] con el exponente fonológico - $n d o$ correspondiente al gerundio). Los elementos que dan cuenta de la unión entre los rasgos abstractos y los exponentes fonológicos se conocen como ítemes de vocabulario ${ }^{2}$.

En suma, no se concibe un léxico inicial único que almacena toda la información paramétrica (como en los modelos generativos minimalistas) sino que esta se encuentra distribuida fundamentalmente entre la selección de rasgos del inventario universal y los distintos aspectos involucrados en el componente morfológico. A partir de esta propuesta teórica, en este trabajo indagamos sobre la posibilidad de que en el contacto de lenguas se transfieran distintas propiedades de la lengua fuente; en especial, discutimos si, a causa del contacto, puede modificarse, por un lado, la selección de rasgos sintáctico-semánticos y, por el otro, las distintas características morfológicas involucradas en el pretérito pluscuamperfecto. Específicamente, partimos de la hipótesis de que las transferencias pueden provocar transformaciones profundas en la gramática de una lengua. De este modo, defenderemos un análisis según el cual no solo las formas morfológicas superficiales pueden verse afectadas por el contacto sino también el conjunto de rasgos sintáctico-semánticos de una lengua.

\footnotetext{
${ }^{2}$ Técnicamente, los ítemes de vocabulario se formalizan de la siguiente manera: [progresivo] $\leftrightarrow /-$ ndo/. En este caso, el ítem ilustra para el gerundio la relación entre el rasgo [progresivo], que es resultado de las operaciones sintácticas y morfológicas previas, y el exponente fonológico -ndo que lo realiza en español.
} 


\section{El contacto con el guaraní}

Los datos con los que trabajamos en este apartado corresponden a hablantes bilingües español-guaraní y hablantes monolingües del español del nordeste de la Argentina (fundamentalmente de las provincias de Corrientes y Misiones) y de Paraguay ${ }^{3}$.

A continuación, nos abocamos al análisis del pretérito pluscuamperfecto de esta zona. En la primera sección describimos el fenómeno; en la segunda, contrastamos su funcionamiento con la construcción guaraní correspondiente. Finalmente, analizamos la forma verbal resultante del contacto en términos del marco teórico en el que se inscribe este trabajo.

\subsection{Descripción del fenómeno}

En toda el área en donde se habla guaraní se observa un uso muy productivo del pretérito pluscuamperfecto con valor modal ${ }^{4}$, bajo la forma había sido (que). El significado que expresa puede parafrasearse, aproximadamente, mediante la estructura resultó (ser) que del español general, y se encuentra en distintos tipos de hablantes y de registros en toda la zona del nordeste de la Argentina (3) y en Paraguay (4):

(3) a. Había sido que esa canción está cantado a un desaparecido5.

b. Mirá vos, había sido que la pistola de Robocop sí existe. [W1]

c. Había sido que Anabela Askar es de las bizarras cultas. [W3]

d. Había sido que me re copé escribiendo. [W4]

(4) a. Había sido que el pelado fue castigado. [W5]

b. Había sido que todavía no almorcé ...I love my job! [W6]

\footnotetext{
${ }^{3}$ A lo largo del trabajo incluimos, por un lado, datos propios, obtenidos en viajes de campo (a las provincias argentinas de Santiago del Estero y Corrientes y a Paraguay), mediante la observación participante y entrevistas semipautadas. Por otro lado, utilizamos también datos tomados de otros autores que han trabajado en la zona y de búsquedas en sitios web (cuyas referencias se indican entre corchetes al lado de cada ejemplo). Cuando no se indica la fuente, se trata de datos propios. La estructura que analizamos aquí está extendida en el español de esta área, no solo en hablantes bilingües sino también en monolingües de español, debido a que se trata de una zona de contacto prolongado con el guaraní en la que muchas transferencias se han integrado por completo en el español actual.

${ }^{4}$ Utilizamos en este trabajo el término modal en un sentido general que abarca distintos valores tales como la evidencialidad y la miratividad (como se usa, por ejemplo, en Cinque (1999)). Volveremos sobre estos conceptos con mayor detalle en $\$ 2.2$.

${ }^{5}$ Como se observa en este ejemplo, en esta variedad de contacto es frecuente la neutralización del género.
} 


\section{c. Había sido que Wang Chan Kein se murió ahorcado. [W7] \\ d. Pero no, ¡había sido que era ella!! [W8]}

Semánticamente, en (3) y (4) el pretérito pluscuamperfecto pierde el valor de anterioridad en el pasado que posee en el español general (cfr. Cuando yo llegué Mariana ya se había ido). Aquí, esta forma verbal expresa sorpresa frente un evento que sucedió y del cual el hablante no tuvo registro durante su ocurrencia sino que, por el contrario, lo percibe posteriormente. Así, (3a) debe interpretarse como 'Esa canción es sobre un desaparecido [pero yo no lo sabía hasta ahora]'. Este valor no se manifiesta en el español general de manera gramaticalizada sino léxicamente mediante estructuras como la ya mencionada resultó (ser) que (...) o al final (...), o bien con el uso del pretérito imperfecto acompañado por expresiones de asombro o de alguna entonación particular (Mirá vos/Ah, era sobre un desaparecido.).

En cuanto a su posición, la estructura había sido (que) se ubica al comienzo de la oración cuando lleva el complementante que (cfr. 3-4). Sin embargo, en el español de Paraguay ocurre más frecuentemente sin que, lo cual le otorga una mayor libertad posicional. En ese caso suele ubicarse al final de la oración, como se observa en (5), aunque puede ocurrir también al comienzo (6):

(5) a. Hay una máquina para estirar el alambre había sido.

b. Eras vos había sido.

c. Teníamos orden de captura había sido. [W9]

d. ¡No era simulación había sido!! [W10]

(6) a. Había sido tenía una novia bien guardadita. [W5]

b. Había sido todo sigue igual que cuando me fui. [W11]

c. ¡Había sido hay algunas linditas en el equipo! [W12]

d. Había sido era olimpero luego el tipo. [W13]

Asimismo, la estructura sin complementante puede posponerse a algún elemento dentro de la oración, como en (7), pudiendo incluso interrumpir la adyacencia entre el verbo y sus complementos (cfr. 7b):

(7) a. El trabajador del volante había sido estuvo laburando toda la noche y camino ya a su casa, le dio el patatús letal. [Pa:291]

b. Por errores del sistema no se pudo cargar había sido el número gratis. [W14]

c. Ganó un sueldazo había sido ahí.

d. A todos nos pasa había sido esto. [W14] 
En términos sintácticos, esta estructura modifica una oración completa, que puede llevar flexión de tiempo presente (8) o pasado (9), cualquiera sea la posición que ocupe en la oración:

(8) Presente

a. Había sido que de la costa oeste del Paraná también hay locos sueltos. [W1]

b. Había sido que los nuevos vecinos son coreanos. [GT]

c. Franko pio ${ }^{6}$ es holandés había sido. [W15]

(9) Pasado

Pretérito imperfecto

a. Había sido que era anoréxica.

b. Había sido que Guido Süller tenía sus novias. [W16]

c. Era su cumpleaños había sido. [An]

Pretérito perfecto simple

d. Hotmail no es "correo caliente". Había sido que Jack Smith eligió algunas letras de HTML [W17]

e. Había sido que se tomaron todo el vino.

f. Se mudaron había sido. [W2]

La diferencia entre el uso de la morfología de presente y de pasado, sin embargo, no siempre conlleva una distinción temporal. En particular, el pretérito imperfecto puede extenderse también hasta el presente (dado que no codifica perfectividad) y funcionar solo como un refuerzo del valor sorpresivo, como ocurre en el español general. Así, (9a) puede interpretarse con alcance sobre el momento de habla: 'Resultó ser que es anoréxica'. Esto contrasta con el pretérito perfecto simple, que codifica efectivamente un valor perfectivo, sin alcance sobre el presente.

Finalmente, otra característica de interés es que esta estructura funciona como una unidad indivisible y fosilizada: se construye siempre con el participio del verbo ser y no es productiva con otras clases léxicas ni flexiona en otros rasgos de número y persona.

Teniendo en cuenta lo anterior, los usos descriptos hasta aquí deben ser diferenciados de una estructura muy similar que se registra de manera extendida en el habla rural de varios países hispanoparlantes. Así, Kany (1969)7 documenta la estructura había sido,

\footnotetext{
${ }^{6}$ Variante de piko, préstamo del morfema guaraní que se utiliza en cierto tipo de interrogaciones.

${ }^{7}$ Kany (1969) propone que esta estructura podría deberse a una analogía con la forma ha de ser. Si ha de ser en muchas regiones significa 'será' (es decir, la forma presente de haber señala futuro) es posible que el imperfecto había se reinterprete como presente.
} 
con valores semánticos similares a los mencionados, tanto en la Argentina (10a) como en otros países (10b-f) y la atribuye al "habla gauchesca":

(10) a. ¡Cha que había sido salame! [Argentina] [Ka:206]

b. iPucha qui habían sido flojo los nacione! [Uruguay] [Ka:207]

c. Brava había sido Ud. ¿no? [Ecuador] [Ka:208]

d. Tu hijo había sido un mañudo. [Bolivia] [Ka:207]

e. ¡Qué mal pensado había sido usted, Don Juan Francisco! [Perú] [Ka:207]

f. Había sido una mujer. [Colombia] [Ka:208]

Las estructuras descriptas por Kany se encuentran también con cierta frecuencia en el español rural de la Argentina, incluso en zona de influencia guaraní:

(11) a. ¡Qué interesada había sido la virgen!! [V:186, VIII]

b. Encontró un guazuncho. Y habian sido dos. [V:760, IX]

c. Este viejito mendigo había sido Dios. [V:800, VII]

d. Ha visto que había sido mentira que era dura la cabeza de mi hermanito. $[\mathrm{V}: 643, \mathrm{VII}]$

Sin embargo, si comparamos en detalle la estructura descrita por Kany, que representamos en (12a), con la que analizamos aquí (12b) veremos que existen diferencias no triviales entre ambas; así, mientras que las estructuras del tipo de (12a) responden siempre al esquema había sido + sustantivo/adjetivo, las de (12b) poseen una forma invariable había sido (que) + oración:

(12) a. Había sido usted.

b. Había sido que era usted / Era usted había sido.

La diferencia esencial es que en (12a) el pretérito pluscuamperfecto constituye el verbo principal de la oración, de modo que concuerda con un sujeto referencial (cfr. Habían sido ustedes) mientras que en (12b), por el contrario, la forma invariable había sido (que) no es el verbo principal sino un modificador de la oración y, en consecuencia, no establece concordancia con el sujeto (cfr. Había sido que era usted / Había sido que eran ustedes).

El hecho de que la estructura había sido de (12b) posee un alcance oracional se ve reforzado por la posibilidad de que aparezca junto con que, imposible en (12a). Estas diferencias se explican a partir de una distinta estructura según la cual - como veremos en las próximas secciones- había sido (que) en (12b) no se comporta como un verbo pleno sino como un elemento funcional, una marca modal que gramaticaliza un rasgo evidencial. 
En suma, la expresión había sido (que) en la zona de contacto con el guaraní pierde el valor de anterioridad en el pasado ${ }^{8}$ adopta un significado modal. Asimismo, se ubica dentro de la oración en posiciones que resultan anómalas para el español general y, morfológicamente, se gramaticaliza de modo tal que deja de ser productivo junto a otras clases léxicas verbales y otros rasgos flexivos de número y persona.

En el próximo apartado analizaremos la relación de esta estructura con la gramática del guaraní para luego volver sobre su análisis teórico.

\subsection{Vinculación con el guaraní}

La estructura que hemos descripto en el apartado anterior es de frecuencia muy alta en toda el área de influencia del guaraní y parece, incluso, privativa de ella, al menos con las características que hemos delimitado.

A la frecuencia de aparición se suma la existencia de una construcción guaraní paralela a la descripta, lo cual favorece un análisis en términos de transferencia lingüística. En efecto, en guaraní existe un morfema ( $\left.r a^{\prime} e\right)$ que expresa un valor modal y normalmente junto con otros morfemas como niko/ningo o nipo/nimbo, que acompañan exclamaciones- adopta cierto matiz sorpresivo, como ilustran los siguientes ejemplos:

$\begin{array}{llllll}\text { (13) a. Lo } \quad \text { rico } & \text { r-a'y } & \text { nimbo } & \text { o-tĩ } & \text { avei } & \text { ra'e } \\ \text { Los rico } & \text { REL-hijo } & \text { NIPO } & \text { 3-avergonzarse } & \text { también } & \text { RA'E } \\ \text { 'Había sido que los hijos de los ricos también tienen vergüenza.' } & \\ \text { b. E'a, } & \text { ma'ẽ } & \text { Aniceto re-ju } & \text { nipo } & \text { ra'e } \\ \text { INTERJ } & \text { mirar } & \text { Aniceto 2sg-venir } & \text { NIPO } & \text { RA'E }^{\prime}\end{array}$

'Ea, mira Aniceto viniste pues (había sido)'. （Melià et al., 1997: 70)

${ }^{8}$ Conviene observar que, para indicar anterioridad en el pasado, en esta zona el pretérito pluscuamperfecto tiende a ser reemplazado por el pretérito perfecto simple (reforzado por la presencia del adverbio $y a$ ), como ocurre también en otras variedades:

(i) a. Eran tres hermanos; dos ya se fueron ['habían ido'] a rodar el mundo. [V:762, IX]

b. Y en ese fueron a visitarle a la madre que no le conoció porque creyó que ya murió ['había muerto'] con la torta envenenada. [V:764, IX]

c. Cuando vino la tormenta yo ya salí. ['había salido']. [GT]

${ }^{9}$ Las abreviaturas utilizadas en las glosas son las siguientes: 1, 2, 3: primera, segunda y tercera persona; BEN: benefactivo; CONT: continuativo; DIM: diminutivo; DUR: durativo; FUT: futuro; INTERJ: interjección; LIM: limitativo; LOC: locativo; NMZ: nominalizador; PAS.E: pasado experimentado; PAS.NE: pasado no experimentado; REL: relacionante; TOP: tópico. 
Según Krivoshein y Acosta (2007: 101), este morfema "indica el conocimiento que adquiere el hablante o su sorpresa al enterarse en un momento dado de la realización de una acción", es decir, se comporta de manera general como un morfema modal. Específicamente, asumiremos — siguiendo a Velázquez Castillo (2010) - que ra'e codifica un valor de evidencia inferida con extensiones mirativas, como precisaremos a continuación.

La evidencialidad es la categoría mediante la cual el hablante explicita la fuente de información (Aikhenvald, 2003), es decir, manifiesta si el hablante vio lo que relata (y, en consecuencia, tiene evidencia directa de ello) o si lo infirió o escuchó (y, en ese caso, posee evidencia indirecta). Existen lenguas para las cuales la naturaleza de la evidencia en la que se basa una afirmación debe ser especificada gramaticalmente en cada emisión mientras que otras, como el español, pueden expresarla solo léxicamente. Las lenguas varían en los sistemas de evidencialidad que presentan: algunas distinguen dos términos (visto $v s$. no visto o reportado $v s$. no reportado), mientras que otras pueden manifestar muchos valores más.

El morfema ra'e y, en especial, su correlato español habia sido (que) responde de manera ajustada a lo que se ha denominado "percepción demorada" [deferred realization] (Reuse, 2003). Este es un valor semántico de ciertos evidenciales que expresa que la información completa se obtuvo y se interpretó plenamente post-factum, sin que sea determinante el hecho de que el hablante haya efectivamente visto o no su ocurrencia (Aikhenvald, 2004). Por ejemplo, en (13b) el hablante posee evidencia directa para su afirmación; sin embargo, lo que está en juego es que dicha evidencia es utilizada para inferir un estado de cosas anterior no percibido en el momento de su ocurrencia.

En los ejemplos dados se observa, además, un valor de sorpresa sobre la percepción demorada, que indica que esta resulta inusual o inesperada para el hablante. Si se privilegia esta característica, ra'e cae también dentro de lo que se conoce como miratividad. Este valor ha sido recientemente descripto y codifica la "mente no preparada" [unprepared mind], es decir, lo que se percibe como información nueva no esperada y la sorpresa concomitante (Aikhenvald, 2004). La miratividad ha sido analizada como un valor diferenciado de la evidencialidad (cfr. DeLancey, 1997). Si bien la estructura había sido (que) podría ser considerada de este modo, creemos que la sorpresa se aplica aquí siempre sobre la percepción demorada y no de manera independiente. De este modo, una frase como Viniste había sido no manifiesta sorpresa solamente frente al hecho afirmado sino más bien frente a la percepción demorada del mismo. Aquí la miratividad (entendida en términos de codificación de la sorpresa) constituye un matiz semántico derivado, reforzado por la entonación y los elementos exclamativos, de la misma manera que en guaraní es la presencia del morfema exclamativo niko/nipo que aparece junto a 
ra'e lo que contribuye con dicho matiz (cfr. 13). Por todo esto, consideramos al rasgo codificado por el morfema ra'e un evidencial de "percepción demorada" con extensiones mirativas.

Por otra parte, si bien algunos autores (Liuzzi y Kirtchuk, 2010; Dietrich, 2010, entre otros) clasifican al morfema ra'e como una marca de pasado, siguiendo a VelázquezCastillo (2010) asumimos que la interpretación temporal surge solo como una extensión natural de su valor modal. De hecho, este puede referirse al presente (cuando el hecho se extiende hasta el momento de su percepción), como en (13a), o aparecer en un contexto de futuro como en (14), por lo que el tiempo deíctico no parece una limitación para su aparición:

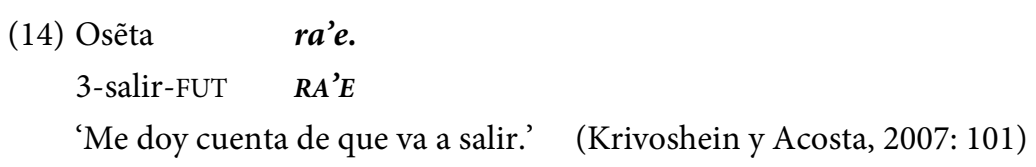

A partir de esto, la equivalencia entre ra'e y había sido (que) resulta evidente. Así, Palacios Alcaine (2008:291) afirma que "en la variedad coloquial paraguaya ra'e se traduce por había sido, forma que en esta variedad acentúa el carácter sorpresivo del hablante al transmitir una información que desconocía". Esto es consistente con la sistematicidad con la que los hablantes e investigadores de guaraní traducen una forma por otra (cfr. 13).

De modo similar, en el español de Paraguay se incorpora el morfema $r a^{\prime} e$ como préstamo en construcciones equivalentes a las que hemos ejemplificado con había sido $(q u e)^{10}$ :

(15)a. jLa nueva Miss Mundo quería ser monja ra'e! [W18]

b. Winnie the Pooh es ladrón ra'e. [W5]

c. 28 años es la edad perfecta de la mujer ra'e. [W5]

d. Su amada esposa ra'e tenía otro marido. [W5]

Asimismo, es posible encontrar ambas formas ( $r a$ 'e/había sido (que)) en el español de Paraguay en coexistencia dentro de la misma oración, de manera adyacente (16a-b) o no (16c-d), para expresar el mismo valor. Esta duplicación de las estructuras que son paralelas en las dos lenguas es muy frecuente en las situaciones de contacto:

${ }^{10}$ De manera inversa, lo mismo sucede en guaraní, que incopora como préstamo la forma del español: (i) Había sido la che dúo iñakã raku peteĩ morocha porãre oikóvo ra'e (Había sido que mi amigo se enamoró perdidamente de una bella morena) [W59] (La traducción corresponde al mismo hablante.). 
(16)a. El origen de las hortalizas era rapailandia, había sido ra'e.[W20]

b. Y había sido ra'e cuando hacés dieta tu cuerpo debe acostumbrarse a ella para abandonarla o, si no, subís el doble. [W5]

c. Había sido que a un ganadero francés lo "suicidaron" ra'e... [W5]

d. Había sido Aquiles era el problema ra'e. [W15]

En consecuencia, la similitud entre ra'e y había sido (que) ocurre, por un lado, en el nivel sintáctico-semántico, dado que ambos codifican percepción demorada con un matiz mirativo según el cual el hablante expresa sorpresa frente a un hecho no percibido previamente. Por otro lado, la forma había sido (que) funciona como un único morfema gramaticalizado, que modifica a la oración en su conjunto, tal como ocurre con ra'e. Asimismo, estas formas se asemejan en cuanto a la posición que ocupan: la estructura española calca normalmente la posición final (o pospuesta a algún constituyente) del morfema $r a^{\prime} e$, lo cual resulta inusual para el español general. De este modo, si bien las estructuras son superficialmente muy distintas en cada una de las lenguas (un morfema libre en guaraní frente a una perífrasis verbal en español), la equivalencia semántica que se establece entre estas conlleva también transferencias de tipo más superficial.

En suma, a pesar de que algunos autores como Granda (1988) -basándose en la existencia de las estructuras descritas por Kany (1969) (cfr. 10-11) - proponen que no es correcto postular una relación con el guaraní para este fenómeno, creemos que hay suficiente evidencia como para considerarlo un proceso de transferencia. La construcción que analizamos aquí se ha visto sin dudas favorecida y gramaticalizada por la presencia del guaraní y ha adoptado en esta área de influencia características particulares que la diferencian de los usos existentes en otras variedades.

En el próximo apartado nos detendremos en el análisis teórico de la estructura sintáctica y de los aspectos morfológicos vinculados con esta construcción.

\subsection{Estructura sintáctica y morfológica de la construcción de contacto}

Teniendo en cuenta la descripción provista en los apartados anteriores, adoptamos un análisis según el cual la expresión había sido (que) se ha gramaticalizado en esta zona; en particular, ha dejado de funcionar como un núcleo verbal para convertirse en un elemento funcional con valor modal. Esta construcción presenta diferencias respecto del pretérito pluscuamperfecto del español general, que pueden ubicarse tanto en el nivel de los rasgos sintáctico-semánticos como en la morfología que los realiza, como detallaremos a continuación. 
En el nivel abstracto, la construcción introduce un nuevo rasgo en el español, que denominaremos [percepción demorada]. De esta manera, esta variedad de español amplía su conjunto de rasgos activos a causa del contacto con la lengua indígena.

El rasgo mencionado se incorpora en la sintaxis sobre una proyección modal. En particular, desde la propuesta de Cinque (1999) — quien identifica las distintas proyecciones que se ubican por encima del Sintagma de Tiempo- este corresponde a una de las categorías más altas, es decir, aquellas que se refieren a la opinión o actitud del hablante respecto de la proposición:

(17) Modo (acto de habla)(M1) $>$ Modo (evaluativo)(M2) $>$ Modo $_{(\text {evidencial)(M3) }}>$ Modo (epistémico)(M4)

Específicamente, el rasgo [percepción demorada] debería vincularse con la proyección de Modo (evidencial), que indica el tipo de evidencia que tiene el hablante sobre lo expresado en la proposición. En otras palabras, proponemos que la expresión había sido (que) codifica un rasgo [percepción demorada] que se aloja en el núcleo de una proyección modal evidencial. De esta manera, esta estructura no constituye una proyección verbal sino un núcleo funcional más alto, con alcance sobre el resto de la oración. De esto se desprende, en consecuencia, que todos los ejemplos que hemos presentado en los apartados anteriores deben ser analizados como oraciones simples, con un único verbo pleno y en los que la estructura había sido (que) es una marca modal en el dominio de esa proyección verbal. La gran movilidad que presenta esta forma en la variedad de contacto es la habitual en las expresiones de este tipo, que se ubican en las proyecciones más altas de la oración.

En el nivel morfológico, por su parte, la incorporación del rasgo [percepción demorada] provoca una reorganización de los ítemes de vocabulario del español general (cfr. $\$ 1$ ). Para su expresión, como hemos observado, se toma en ocasiones el morfema ra'e como préstamo de la lengua indígena (cfr. 16). Sin embargo, lo más frecuente es que se resignifique una forma ya existente en español como lo es el pretérito pluscuamperfecto. Así, la estructura había sido (que) sufre un proceso de gramaticalización y se fosiliza como un único exponente fonológico, ligado a un nuevo rasgo. En otras palabras, la variedad de español en contacto con el guaraní incorpora un nuevo ítem de vocabulario, inexistente en el español general, que vincula el rasgo [percepción demorada] con el exponente fonológico había sido (que). En este sentido, el pretérito pluscuamperfecto del español general solo se asemeja superficialmente a la estructura que analizamos aquí, dado que codifica rasgos que había sido (que) no manifiesta (como, por ejemplo, rasgos aspectuales y de anterioridad). 
Es interesante notar que la equivalencia entre el guaraní y el español de contacto se establece en el nivel sintáctico-semántico y no en el de los exponentes fonológicos, que resultan muy distintos en cada lengua: en español general se trata de una forma perifrástica, compuesta por un conjunto de morfemas frente a un único morfema libre en guaraní. Las diferencias superficiales no impiden, sin embargo, la transferencia de rasgos, como observa Sánchez (2004) en el español en contacto con el quechua. Por otra parte, una vez seleccionada la expresión fonológica del español que expresará el nuevo rasgo $^{11}$, esta puede calcar ciertas características de la lengua indígena como, por ejemplo, la posición pospuesta.

En suma, el análisis de la estructura había sido (que) muestra que la gramática del español en contacto con el guaraní se ha modificado en los dos niveles analizados. Por un lado, en el nivel de los rasgos abstractos, ha ampliado su inventario al incorporar un nuevo rasgo: [percepción demorada]. Esto confirma —en contra de lo que sostienen muchos autores- que el contacto de lenguas no provoca solamente simplificaciones sobre las gramáticas de contacto sino que los sistemas pueden verse enriquecidos con rasgos gramaticales innovadores. Asimismo, apoya el hecho de que las transferencias entre lenguas no son meramente superficiales sino que pueden producir cambios gramaticales profundos en las variedades de contacto. Por otro lado, en el nivel de la morfología superficial, hemos verificado también ciertas transferencias, que provocan reestructuraciones sobre el conjunto de los ítemes de vocabulario del español. A partir de esto, podemos concluir que la estructura había sido (que) ha adoptado características peculiares en ambos niveles analizados, que son resultado de la presencia de la lengua indígena y de su interacción con las propiedades del español, generándose así una nueva gramática de contacto.

\footnotetext{
${ }^{11}$ Es posible que la elección de la forma del pret. pluscuamperfecto para dar cuenta de este nuevo rasgo no sea totalmente azarosa. Este tiempo verbal en español indica anterioridad en relación con un momento de referencia, de modo similar a ra'e, que manifiesta la percepción posterior de algo normalmente ya sucedido. De todos modos, no es la mayor similitud lo determinante en dicha elección. Así, no se explica por qué se prefiere la gramaticalización de dicha forma verbal frente a, por ejemplo, el uso del pretérito imperfecto, que ya expresa valores similares en el español general (acompañado de otros elementos que refuerzan dichos valores pragmáticos; cfr. jAh, eras vos!).
} 


\section{El contacto con el quechua}

En cuanto a la situación de contacto con el quechua, trabajamos con datos de hablantes bilingües español-quechua y monolingües de español correspondientes al noroeste de la Argentina (principalmente a la provincia de Santiago del Estero) ${ }^{12}$.

\subsection{Descripción del fenómeno}

Herminia Martín (1976) inicia su artículo "Un caso de interferencia en el español paceño" con el siguiente ejemplo, que ilustra en el español boliviano ${ }^{13}$ el uso del pretérito pluscuamperfecto al que nos dedicaremos en este apartado:

(18) A: - Sapir fue un gran lingüista.

B: - ¿Cómo lo sabes?

A: - Los libros lo dicen.

B: - Entonces no puedes hablar así; debes decir: Sapir había sido un gran lingüista.

(Herminia Martín, 1976: 119)

En la Argentina, el valor del pretérito pluscuamperfecto ejemplificado en (18) aparece fundamentalmente en zonas rurales que están y/o han estado en contacto con el quechua. Mediante esta forma verbal se indica que el hablante no presenció los hechos que relata, como se ejemplifica en las siguientes oraciones correspondientes al español rural de Santiago del Estero y de otras provincias del noroeste argentino:

(19) a. Se había llegado ['llegó'] cerquita y vido que muy rubia había sido ['era']. [V:417, VIII]

b. Gritando había estado ['estaba'], el loro. [V:511, III]

c. $Y$ entonces advierte él que andaba arriba un cuervo y dice:

- ¿Sabe que me voy a hacer el muerto?

\footnotetext{
${ }^{12}$ Cabe remarcar que, si bien hay hablantes bilingües en esta zona, la estructura que analizamos se debe fundamentalmente a una situación de sustrato; en otras palabras, la presencia del quechua a lo largo de los siglos ha dejado huellas sobre el español de la zona que son prácticamente independientes de su vitalidad actual. No obstante, estos usos se reservan, en el español de la Argentina, a contextos rurales y no poseen un uso extendido en la variedad regional, a diferencia de lo señalado para el contacto con el guaraní.

${ }^{13}$ Este ejemplo corresponde al contacto con el aymara. No obstante, el fenómeno que analizamos aquí es idéntico a lo que ocurre en esta lengua indígena ( $y$ en el español en contacto con ella).
} 
Y así había hecho ['hizo']. Se había tirado ['tiró'] en el campito y había dado ['dio'] vuelta al sieso. [V:391, III]

d. Y por ahí había encontrado ['encontró'] una higuera. [V:26, VI]

Los verbos remarcados en (19) corresponden a formas de pasado simples en español general, como se indica entre corchetes. Semánticamente, el pretérito pluscuamperfecto pierde aquí también el valor de anterioridad en el pasado para utilizarse como un pasado narrativo no experimentado, es decir, una forma que agrupa pasado y evidenciali$\operatorname{dad}^{14}$. De esta manera, aunque abandona el rasgo temporal anafórico, mantiene un rasgo de tiempo deíctico, que codifica pasado respecto del momento de la enunciación.

Específicamente, este tiempo verbal expresa evidencia indirecta, es decir, manifiesta que el hablante no ha experimentado los hechos que relata. Así, por ejemplo, (19a) debe interpretarse como 'Llegó cerquita y vio que era muy rubia [pero no tengo evidencia directa de ello]' o (19b) como 'El loro estaba gritando [lo cual no me consta personalmente]'.

Dado que se trata aquí de un pasado narrativo, su uso no se reduce a oraciones aisladas en contextos discursivos acotados (como sucede con había sido (que) en el contacto con el guaraní, que se utiliza en contextos exclamativos) sino que aparece de manera reiterada a lo largo de una narración. Asimismo, el pretérito pluscuamperfecto se utiliza en esta zona de manera productiva con distintas raíces verbales y no se limita al verbo ser. Estas dos características aparecen ejemplificadas en el siguiente fragmento narrativo. Allí se observa la repetición de las formas del pluscuamperfecto utilizado como tiempo de la narración y su productividad con distintas raíces verbales:

(20) Mi finado fue una vez a cazar a una laguna y ahí había estado, en un palo, la madre del agua, peinándose con un costillar de pescado. Y ahí la ha hallado. Se había llegado cerquita y vido que muy rubia había sido. Dice que había tenido la cara delgadita, como una criatura chica y muy bonita había sido. Pero las trenzas decía que las tenía, po, muy largas, que habían estado topando el agua, y ella había tendido casi todo el cuerpo afuera, y desnudo que había estado. Y decía que después de un rato que se había volcau al agua, y que el agua había quedado batiéndose. [V:417, VIII]

\footnotetext{
${ }^{14}$ En otras variedades del español andino algunos autores señalan que es el pretérito perfecto compuesto el que manifiesta valores evidenciales. Según Kany (1969) este tiempo verbal funciona en Ecuador como un evidencial de presente y el pretérito pluscuamperfecto como un evidencial de pasado: Bastantes muebles ha tenido ['tiene'] / Habían sido ['eran'] los hijos de unos señores de las haciendas de Machachi [Kany, 1969:208].
} 
Asimismo, se desprende de los ejemplos que los verbos flexionados en pretérito pluscuamperfecto se comportan aquí como verbos plenos, es decir, son los elementos que determinan la estructura argumental de cada oración y portan los morfemas de concordancia con el sujeto.

Otra de las características que puede resaltarse del pretérito pluscuamperfecto en el contacto con el quechua es que bajo esta forma se neutraliza la oposición aspectual perfectivo/imperfectivo propia del tiempo pasado en el español general. En efecto, esta construcción verbal cubre los valores correspondientes tanto al aspecto perfectivo (21) como al aspecto imperfectivo (22), como se observa en los siguientes ejemplos:

(21) a. Y por ahí había encontrado ['encontró'] una higuera. [V:26, VI]

b. Y diz que el tigre nada había dicho ['dijo'] [V:278, I]

c. Habían salido ['salieron'] corriendo carrera. [V:418, II]

d. Se había llegado ['llegó'] cerquita (...) [V:417, VIII]

(22) a. Gritando había estado ['estaba'] el loro. [V:511, III]

b. Había habido ['había'] una laguna cerca. [V:461, II]

c. Y por ahí habían estado ['estaban'] cantando las chuñas. [V:608, III]

d. Había estado ['estaba'] Pedro, embolsado sobre un río. [V:204, VIII]

Asimismo, como se observa en (21b), estos usos evidenciales del pretérito pluscuamperfecto coexisten frecuentemente con las formas diz que/dice que/que, que especifican que la información que tiene el hablante proviene de algo que este ha oído, como en los siguientes ejemplos:

(23) a. Diz que habían sido ['eran'] dos hermanos. [V:679, VII]

b. Que era como pa partirla con la uña, diz que había sido ['era']. [V:278, I]

Por otra parte, esta forma verbal puede adoptar un valor mirativo en algunos contextos ${ }^{15}$, en los que se utiliza también de manera productiva con distintas raíces verbales $(24 \mathrm{a}-\mathrm{c})$, incluyendo la cópula ser (24d-f):

(24) a. ¡Qué muchos niñitos y tan lindos que había tenido, señora! [V:213, I]

b. Los difuntos habían estado muy caros. [V:223, VIII]

c. Lo había metido mal. [V:293, VIII]

d. ¡Bah! No había sido médico. [V:547, III]

\footnotetext{
${ }^{15}$ En el español de Ecuador, en donde el pretérito perfecto compuesto puede adoptar un valor evidencial, este puede codificar también un valor mirativo: Mire, compró estos, los probé y ¡han sido peras! (Olbertz, 2009: 70).
} 
e. El hueso había sido de león. [V:430, VII]

f. Había sido la casa de los ladrones. [V:44, VIII]

Cuando expresa un valor mirativo como en (24), el pretérito pluscuamperfecto puede extenderse hasta el presente, al igual que sucede en el contacto con el guaraní. Así, (24a) debe entenderse como ‘¿Cuántos y qué lindos niñitos que tiene, señora!', con alcance sobre el momento de enunciación.

La utilización del pretérito pluscuamperfecto como pasado no experimentado conlleva, a su vez, una reorganización de todo el sistema verbal. Así, este tiempo se opone al del pretérito perfecto compuesto ${ }^{16}$, que se vuelve la forma no marcada respecto de la evidencialidad.

Finalmente, de manera similar a lo que sucede en el contacto con el guaraní (cfr. nota al pie (7)), el pretérito pluscuamperfecto tiende a ser reemplazado por el pretérito perfecto simple/compuesto - acompañado de la forma ya- para expresar anterioridad en el pasado:

(25)a. Y, claro, ya si ha dado ['había dado'] cuenta de las intenciones del compadre. $[\mathrm{V}: 212, \mathrm{I}]$

b. Pero ha pasado de alto una parte, ella ya lo alcanzó a ver ['había alcanzado a ver'] también. [V:390, VIII]

c. Y ya se dio cuenta ['había dado cuenta'] que venía el sapo. [V:497, II]

Por lo demás, el pretérito pluscuamperfecto con valor evidencial no presenta más restricciones relevantes que las observadas. Lo descrito hasta aquí, sin embargo, resulta suficiente para distinguir las estructuras del contacto con el quechua de las resultantes del contacto con el guaraní, por un lado, y de los "usos gauchescos" presentes de manera más extendida en otras regiones de la Argentina (cfr. 10-11), por el otro, como argumentaremos a continuación.

Una de las diferencias esenciales entre la estructura de contacto con el quechua y la de contacto con el guaraní se da en el nivel sintáctico-semántico. El valor evidencial que

\footnotetext{
${ }^{16}$ En esta zona existe una tendencia a neutralizar (aunque no de modo absoluto) la oposición entre el pretérito perfecto simple y el compuesto en favor de este último, de modo exactamente opuesto a lo que ocurre en la mayor parte de la Argentina. Así, el pretérito perfecto compuesto se convierte en la forma no marcada del pasado y puede, en consecuencia, señalar hechos ya concluidos, sean estos cercanos o no al momento de habla:

(i) Y ha seguido el tigre persiguiéndolo al zorro. Y se le disparaba siempre, hasta que ha resuelto hacerse el muerto. Y se ha hecho el muerto. Y la tigra ha llamado a todos los animales. Y lo han llamado al zorro (...). [V:292, I]
} 
codifica cada una de estas estructuras es distinto y esto explica las asimetrías en los contextos discursivos en los que aparece cada una: mientras que en el guaraní su aparición está acotada a contextos exclamativos, que indican sopresa, en el contacto con el quechua se reitera a lo largo de una secuencia narrativa. Asimismo, otra diferencia en este nivel es que, si bien en ambas situaciones el pretérito pluscuamperfecto pierde su valor de anterioridad en el pasado, en el contacto con el quechua mantiene un rasgo temporal de pasado deíctico.

Por otra parte, en relación con las propiedades morfológicas, en el contacto con el guaraní constituye una estructura fosilizada que se expresa de manera separada del verbo principal, es decir, funciona como un morfema aislado, portador de un único rasgo modal. En el quechua, por el contrario, el rasgo evidencial se fusiona con la morfología temporal y constituye el verbo principal de la oración, aquel que aporta la estructura argumental. En consecuencia, no se limita a la construcción con el verbo ser sino que es productivo con distintas raíces verbales. Estas diferencias repercuten, a su vez, en la posición que ocupa la estructura en cada caso. En el contacto con el guaraní, al tratarse de un morfema libre, correspondiente a un valor modal, posee una libertad mucho mayor, que calca usualmente la posición pospuesta del morfema guaraní. En el contacto con el quechua, por el contrario, presenta las restricciones posicionales propias del verbo principal de la oración.

En cuanto a los "usos gauchescos" (cfr. 10-11), por su parte, encontramos dos diferencias sustanciales: en relación con los rasgos sintáctico-semánticos, los usos descritos por Kany (1969) se limitan a valores mirativos ${ }^{17}$, mientras que los que se hallan en zona de contacto con el quechua funcionan como un pasado narrativo; en segundo lugar y en relación con lo anterior, en el contacto con el quechua la forma es productiva con distintas raíces verbales y no se limita a la construcción con ser como sucede con los otros.

En el próximo apartado examinamos el valor que posee la estructura correspondiente en quechua y establecemos las similitudes y diferencias existentes con el español, con el objetivo de determinar su posible vinculación.

\subsection{Vinculación con el quechua}

La estructura que hemos descrito en el apartado anterior se registra en toda el área del español andino, tanto con su valor de pasado no experimentado como cuando pre-

\footnotetext{
${ }^{17}$ Olbertz (2005) señala algo similar para el español de Ecuador, en donde solo los usos mirativos puros se han extendido al español estándar regional.
} 
senta extensiones mirativas. En la bibliografía, numerosos autores (Schumacher de Peña, 1975; Hardman de Bautista, 1982; Granda, 1988; Klee y Ocampo, 1995; Cerrón Palomino, 2003; Sánchez, 2004; Merma Molina, 2007, entre muchos otros) vinculan estos usos del pretérito pluscuamperfecto con el morfema evidencial quechua -sqa (o, en algunas zonas, con el morfema paralelo en aymara).

En líneas generales, el morfema -sqa manifiesta que el hablante no posee evidencia directa para aquello que afirma (26), en oposición a su contraparte -rqa (27):

(26) Para-sha-sqa

llover-DUR-PAS.NE

'Estaba lloviendo.' (el hablante escuchó/infirió que estaba lloviendo.)

(27) Para-sha-rqa-n

llover-DUR-PAS.E-3

'Estuvo lloviendo.' (el hablante vio que estuvo lloviendo.) (Faller, 2004: 46)

En efecto, en (26) -sqa expresa que el hablante no posee evidencia directa de que ha llovido sino que conoce esta información porque se la han dicho o porque la ha inferido a partir del resultado de la lluvia; por el contrario, en (27) -rqa señala que el hablante posee evidencia directa para su afirmación. De este modo, asumimos aquí que -sqa codifica un "pasado no experimentado", es decir, manifiesta que el hablante no ha experimentado personalmente los hechos que relata, sin especificar si estos han sido reportados o inferidos ${ }^{18}$.

En relación con lo anterior, en quechua es posible especificar que el hablante ha obtenido la información a partir del relato de otros hablantes. Para esto, se utiliza el enclítico reportativo si/s, que indica que el hablante adquirió la información porque la escuchó. Las formas -sqa y si coexisten con frecuencia, como se observa en el siguiente ejemplo:

(28) wawa-cha

ka-sha-qti-lla-y-raq-si

tiyu-y-qa

bebé-DIM

ser-DUR-NMZ-LIM-1-CONT-REP

tío-1-TOP

\footnotetext{
${ }^{18}$ No todos los autores analizan este morfema de igual modo. Así, este ha recibido distintas denominaciones que privilegian algún matiz de significado, entre las que se encuentran "pasado reportativo" (Cusihuamán, 1976), y “tiempo de descubrimiento repentino" [sudden discovery tense] (Adelaar, 1977; Lefebvre y Muysken, 1988), además de "pasado no experimentado" (Cerrón Palomino, 1994), que adoptamos aquí. Por su parte, Faller (2004) propone que se trata de un elemento deíctico, que ubica la situación fuera del campo perceptual del hablante; en consecuencia, el valor evidencial que posee es, para la autora, solo una interpretación derivada del valor espacial.
} 
wañu-pu-sqa

morir-BEN-PAS.NE

'Mi tío murió cuando yo era todavía un bebé'.

(Faller, 2004: 52)

El valor reportativo de si exige, cuando el relato está en pasado, el morfema -sqa. Este reportativo, como indican Albarracín et al. (2002: 152) se traduce normalmente en español por dicen que/diz que/se dice que.

Por otra parte, el morfema -sqa puede aportar también un valor mirativo, lo cual ha dado lugar al término "pasado de descubrimiento repentino" [sudden discovery tense] (Adelaar, 1977; Lefebvre y Muysken, 1988) (cfr. nota 17), como en los siguientes ejemplos:

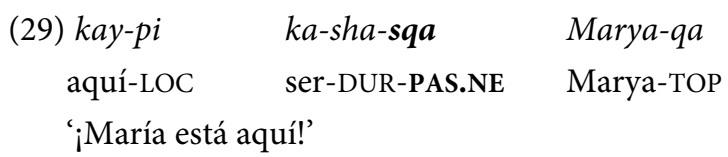

(Faller, 2004: 53)

De esta manera, como un pasado narrativo puro, el morfema -sqa señala una acción que el hablante no ha experimentado de manera directa o bien sobre la cual no ha tenido control (durante un sueño, por ejemplo); cuando posee una extensión mirativa, expresa sorpresa sobre la percepción del hecho que se relata. En este último caso, el hablante puede hacer referencia a una situación que se extiende hasta el presente.

Por último, -sqa fusiona los valores de pasado y evidencialidad en un único afijo que, morfológicamente, se sufija a cualquier base verbal, como se observa en los siguientes ejemplos:

(30)a. Tapusqa ['él había preguntado'].

b. Nipusqa ['él le había dicho'].

c. Sorqosqa ['él había sacado'].

d. Tarisqa ['él había encontrado’]. (Albarracín et al., 2002: 106)

De lo expuesto hasta aquí se desprende un comportamiento paralelo entre el morfema -sqa y el pretérito pluscuamperfecto del español de contacto: por un lado, se asemejan semánticamente, en tanto ambas formas codifican un pasado deíctico con evidencia indirecta que puede, en algunos contextos, poseer extensiones mirativas. Por otro lado, este morfema en quechua se aplica de manera productiva sobre distintas raíces verbales, al igual que sucede con el tiempo del español, para conformar el verbo principal de la oración. Asimismo, el morfema quechua aparece en el contexto del clítico reportativo $s i$, tal como ocurre con las distintas formas de decir en la variedad que analizamos. De modo paralelo al comportamiento de los morfemas -sqa y si en quechua, la diferencia fundamental entre el uso del pretérito pluscuamperfecto y el del 
verbo decir reside en que el primero codifica que la información no le consta al hablante, mientras que el segundo explicita que el conocimiento ha sido adquirido de oídas. De esta manera, siguiendo a Hardman de Bautista (1982), las diferencias modales que pueden establecerse en las variedades andinas como la que analizamos aquí son las siguientes:

(31)a. Ella ha comprado la casa

b. Ella había comprado la casa

c. Ella había comprado la casa dice
'Ella compró la casa [lo cual me consta].'

'Ella compró la casa [lo cual no me consta].'

(Adaptado de Hardman de Bautista, 1982)

De esto se desprende que el uso del pretérito pluscuamperfecto para señalar evidencia indirecta supone una oposición modal respecto del pretérito perfecto compuesto. Así, no es solo la incorporación de un nuevo rasgo lo que está en juego aquí sino la gramaticalización de todo un sistema evidencial que establece nuevas oposiciones entre las formas ya existentes.

En el próximo apartado precisaremos en términos teóricos cuál es la estructura gramatical resultante del contacto.

\subsection{Estructura sintáctica y morfológica de la construcción de contacto}

En este caso, al igual que en el contacto con el guaraní, el quechua provoca modificaciones tanto en el nivel de los rasgos sintáctico-semánticos como en el de la morfología del español.

Por un lado, en cuanto a la selección de rasgos abstractos, el pretérito pluscuamperfecto codifica en esta zona un nuevo rasgo, que denominaremos [evidencia indirecta], que expresa que el hablante no experimentó la situación que relata. De este modo, la presencia de la lengua indígena genera una ampliación de la lista de rasgos activos en esta variedad del español. Este nuevo rasgo se incorpora en la sintaxis sobre un sintagma modal, que siguiendo la propuesta de Cinque (1999), correspondería también a la proyección de Modo (evidencial) ${ }^{19}$ (cfr. 17).

Por otra parte, además de sumar un valor modal, hemos observado que este uso del pretérito pluscuamperfecto presenta diferencias temporales respecto del español gene-

\footnotetext{
${ }^{19}$ En cuanto a los valores mirativos, asumiremos aquí (siguiendo a Faller, 2007) que estos son una extensión pragmática del valor evidencial inherente de -sqa, de modo similar a lo que ocurre con este significado en el pretérito imperfecto del español general.
} 
ral, dado que no codifica un tiempo anafórico de anterioridad sino solamente un pasado deíctico. Así, en español general, se propone que este tiempo verbal implica dos proyecciones temporales: la correspondiente al tiempo deíctico, o $\mathrm{T}_{1}$ (que aloja el rasgo [pasado]) y la correspondiente a $\mathrm{T}_{2}$, que codifica el tiempo anafórico (con el rasgo [anterior]) (cfr. Giorgi y Pianesi, 1997; Kornfeld, 2004). En el contacto con el quechua, por el contrario, no se proyectan dos nodos temporales sino que se despliega únicamente el nodo deíctico $\left(\mathrm{T}_{1}\right)$ (con el rasgo [pasado]), sumado al nodo evidencial (con el rasgo [evidencia indirecta]).

Asimismo, la sintaxis del pretérito pluscuamperfecto en el español de contacto es neutral en cuanto a la oposición perfectivo/imperfectivo dado que, como hemos observado, puede ser equivalente tanto al pretérito perfecto simple como al pretérito imperfecto del español general (cfr. 21-22).

En suma, el contacto provoca las siguientes modificaciones en el dominio sintáctico de esta variedad ${ }^{20}$ : (i) introducción de una proyección de Modo (evidencial), que aloja el rasgo [evidencia indirecta]; (ii) presencia de un único nodo temporal $\left(\mathrm{T}_{1}\right)$, que da cuenta del rasgo deíctico [pasado]; (iii) ausencia de especificación aspectual.

A su vez, estas modificaciones sobre el conjunto de rasgos sintáctico-semánticos provocan reorganizaciones en los elementos morfológicos superficiales que los expresan. Los nuevos rasgos no se manifiestan mediante un préstamo de la lengua indígena - como ocurre, por ejemplo, en el contacto con el guaraní con el morfema ra'e- sino únicamente mediante la resignificación de los ítemes de vocabulario correspondientes a las formas del pretérito pluscuamperfecto ${ }^{21}$. Así, mientras que en español general este tiempo verbal se asocia con rasgos aspectuales, de tiempo deíctico y de tiempo anafórico, en el español de contacto se vincula solamente con un rasgo modal ([evidencia indirecta]) y un rasgo de tiempo deíctico ([pasado]).

A diferencia de lo que hemos propuesto para el contacto con el guaraní, en este caso la forma verbal no se comporta como una unidad, de manera fosilizada, sino que es productiva sobre distintas raíces verbales. De este modo, no se corresponde con un único ítem de vocabulario sino con un conjunto de ellos. Así, proponemos que la mor-

\footnotetext{
${ }^{20}$ Sánchez (2004) analiza este uso del pretérito pluscuamperfecto como un caso de convergencia funcional: las formas del quechua y del español coinciden parcialmente en los rasgos que expresan, lo cual facilita la transferencia del rasgo evidencial al español.

${ }^{21}$ La selección del pret. pluscuamperfecto puede deberse a que este reproduce, en el discurso indirecto del español general, los verbos en pretérito perfecto simple (cfr. Vino $\rightarrow$ Dijo que había venido). Si se considera que los verbos analizados aquí están enmarcados por el verbo decir con valor reportativo, no resulta completamente azarosa su selección.
} 
fología flexiva presente en el auxiliar había codifica el rasgo [evidencia indirecta] mientras que el participio codifica un rasgo de [pasado]. El hecho de que el participio sea el que aporta este valor es paralelo a lo que ocurre con el pretérito perfecto compuesto en esta zona, que se comporta como el pretérito perfecto simple del resto del país (cfr. nota 15). De este modo, los auxiliares había y ha se oponen aquí en términos de evidencialidad, mientras que el participio es el que codifica el valor de pasado deíctico ${ }^{22}$.

A partir de este análisis resulta interesante resaltar que los ítemes de vocabulario correspondientes al pretérito pluscuamperfecto se alejan de las características morfológicas del morfema -sqa paralelo en la lengua indígena. En quechua, el rasgo de tiempo pasado y el de evidencialidad indirecta sufren una operación de fusión a partir de la cual ambos se codifican bajo un mismo sufijo, es decir, mediante un único ítem de vocabulario. En el español de contacto, por el contrario, la fusión no se aplica y los rasgos involucrados se reorganizan en ítemes de vocabulario separados, lo que da como resultado una forma perifrástica. Esto constituye evidencia a favor de la propuesta de Sánchez (2004) de que la transferencia entre lenguas ocurre fundamentalmente en el nivel de los rasgos abstractos, es decir, es independiente de las formas superficiales que los manifiestan en cada una de las lenguas de contacto.

\section{Los fenómenos de contacto}

El análisis de los datos nos ha permitido concluir que el contacto provoca reorganizaciones en al menos dos niveles fundamentales de una gramática: el de los rasgos sintáctico-semánticos y el morfológico. Así, dos formas a primera vista equivalentes, como son el pretérito pluscuamperfecto en ambas variedades de contacto, presentan diferencias respecto del español general que pueden ubicarse en los dos niveles analizados.

En relación con el nivel de los rasgos sintáctico-semánticos, se incorporan en el español de contacto nuevos rasgos ([percepción demorada] y [evidencia indirecta]) en cada una de las variedades. Dichas incorporaciones generan una reorganización de todo el sistema, que se hace evidente, por ejemplo, en el hecho de que en el contacto con el

${ }^{22}$ Nótese al respecto que en el pretérito perfecto compuesto, al igual que sucede con el pretérito pluscuamperfecto, se neutraliza también la oposición aspectual, pudiendo utilizarse incluso en contextos imperfectivos:

(ii) a. Diz que ahí, cuando ya ha estado carniando ['estaba carniando'] y sacando las achuras, que le dice (...). [V:276, I]

b. En eso que ha estado ['estaba'] ahí el zorro, que se han juntado muchas moscas, y diz que el zorro despacito los ha ido echando en la vejiga. [V:276, I] 
quechua la aparición del rasgo [evidencia indirecta] supone una oposición modal del pretérito pluscuamperfecto respecto del pretérito perfecto compuesto. En este sentido, no es solo la selección de un nuevo rasgo lo que está en juego aquí sino la gramaticalización de todo un sistema evidencial que establece nuevas oposiciones entre las formas existentes.

En consecuencia, podemos concluir que la presencia de la lengua indígena puede modificar el inventario de rasgos que operan en el español. En los ejemplos analizados el contacto supone la ampliación de dicho inventario. Sin embargo, esto no siempre es así sino que es posible, también, que este se vea reducido. Esto es frecuente, por ejemplo, en variedades del español en contacto con lenguas que no seleccionan género (como ocurre en las dos variedades de contacto analizadas aquí, véase nota al pie 4) o que no codifican rasgos temporales (como sucede en el contacto con el toba (qom) en el nordeste de la Argentina (cfr. Avellana, 2012). En suma, lo que en una lengua se manifiesta de manera léxica puede pasar a codificarse de manera gramatical a causa de la incorporación de un rasgo que no poseía previamente, o viceversa.

A su vez, las incorporaciones en el nivel de los rasgos sintáctico-semánticos repercuten en la morfología. En particular, observamos que en ambas situaciones de contacto el pretérito pluscuamperfecto - ya existente en el español general - se resignifica para dar cuenta de los nuevos rasgos. La resignificación de una forma existente es solo una de las tantas posibilidades que habilita el contacto de lenguas, entre las cuales se encuentran también la incorporación directa de un préstamo de la lengua indígena (como sucede con ra'e; cfr. 15), la retención de una forma propia de otro estadio del español (como ocurre con diz que; cfr. 23) o la mayor frecuencia de uso de una forma propia del español general, con igual significado.

Asimismo, las peculiaridades morfológicas que posee el pretérito pluscuamperfecto en ambas situaciones de contacto encuentran cierto correlato en las propiedades de las lenguas indígenas: mientras que en guaraní el morfema ra'e se comporta como un morfema no ligado, que codifica un único rasgo y se ubica normalmente pospuesto a algún constituyente de la oración, el morfema quechua -sqa es un sufijo que expresa más de un rasgo y que se encuentra unido morfológicamente a las raíces verbales. Esto explica la libertad posicional de había sido (que) en el contacto con el guaraní, un morfema 
libre que señala un único rasgo ${ }^{23}$, frente al uso flexivo de la morfología del pret. pluscuamperfecto en zona de contacto con el quechua.

De esta manera, en el nivel morfológico existen, por un lado, reorganizaciones sobre los ítemes de vocabulario que se producen como una consecuencia derivada de lo que ocurre en el nivel sintáctico-semántico (i.e. los rasgos abstractos que se incorporan deben recibir una expresión fonológica y los ítemes de vocabulario se resignifican para dar cuenta de ellos). Por otro lado, con menor frecuencia, también se incorporan de manera directa propiedades puramente morfológicas de la lengua indígena (como, por ejemplo, se calca la ubicación de los morfemas de la lengua indígena). Más allá de estas similitudes, creemos junto con Sánchez (2004) que la existencia de diferencias morfológicas superficiales entre las lenguas en contacto no es un impedimento para la transferencia de rasgos. Más bien el camino es el inverso: la equivalencia se establece en primera instancia en el nivel de los rasgos sintáctico-semánticos y lo que ocurre en el componente morfológico es dependiente de dicha equivalencia.

\section{Conclusiones}

Con este trabajo esperamos haber contribuido, por un lado, con el estudio del español americano en contacto con lenguas indígenas, a partir de la descripción y delimitación de un conjunto de estructuras gramaticales.

Por otro lado, la comparación de dichas estructuras con las gramáticas de las lenguas indígenas con las que están en contacto nos ha permitido corroborar ciertos procesos de transferencia. En este sentido, hemos justificado mediante herramientas gramaticales la existencia de dichos procesos y, al mismo tiempo, hemos profundizado en el conocimiento de las estructuras de contacto por medio del trabajo contrastivo. A partir de esto, podemos concluir que el pretérito pluscuamperfecto en ambas variedades adopta características particulares, transferidas de las lenguas indígenas respectivas.

Asimismo, hemos ahondado en el análisis teórico de los procesos de transferencia identificados y hemos concluido que estos ocurren tanto en el nivel de los rasgos abstractos como en las características propias del componente morfológico. En este sentido, corroboramos que el contacto de lenguas puede llevar a la modificación del inventario de rasgos activos de cada lengua y que los fenómenos de transferencia no son me-

\footnotetext{
${ }^{23}$ No obstante, es necesario remarcar que la tendencia a que las transferencias se manifiesten mediante morfemas libres es algo frecuente en las situaciones de contacto y no siempre guarda relación con las propiedades morfológicas (aislantes, aglutinantes o fusionales) de las lenguas involucradas.
} 
ramente superficiales sino que pueden transformar aspectos sustanciales de la gramática de una lengua. De igual forma, determinamos que las propiedades transferidas en cada uno de los dos niveles considerados son independientes y pueden (y deben) ser analizadas de ese modo.

Finalmente, hemos argumentado que los aspectos sujetos a transferencia coinciden, precisamente, con aquellos lugares en los que, desde la propuesta de la Morfología Distribuida, puede sistematizarse la variación interlingüística. Por esto, consideramos que el estudio del contacto de lenguas aporta un conjunto de datos relevantes para la discusión sobre los aspectos universales y particulares de las lenguas, dado que todas aquellas propiedades que pueden ser transferidas son, a su vez, las que están sujetas a variación.

En líneas generales, esperamos haber provisto un análisis gramatical detallado que confirma que los hechos de transferencia no son fenómenos aislados ni caóticos. Por el contrario, dichos fenómenos se vinculan con propiedades gramaticales concretas, que pueden formalizarse dentro de un sistema en el cual una modificación en un aspecto de la gramática puede conllevar cambios en otros aspectos del sistema. Asimismo, la coexistencia con otra lengua no genera solo simplificaciones sobre la gramática de contacto sino que, por el contrario, provoca complejas interrelaciones entre lo que se expresa por medio de elementos gramaticales o léxicos en cada lengua. En suma, las propiedades de una lengua pueden incorporarse en otra, generando una nueva gramática con características que resultan innovadoras para el español general pero que son tan gramaticales como las de cualquier otra lengua natural.

Recibido: 22-VII-2012

Aceptado: 20-II-2013

\section{Referencias bibliográficas}

Adelaar, Willem (1977): Tarma Quechua: Grammar, Texts, Dictionary. Lisse, Peter de Ridder Press.

Aikhenvald, Alexandra (2003): "Mechanisms of Change in Areal Diffusion: New Morphology and Language Contact”, Linguistics, 39, págs. 1-29.

Aikhenvald, Alexandra (2004): Evidentiality. Oxford, Oxford University Press.

Albarracín, Lelia, Mario Tebes y Jorge Alderetes (2002): Introducción al Quichua Santiagueño por Ricardo Nardi. Buenos Aires, Dunken.

Angulo, Stella Maris, Emilene Núñez Campos y Andrea Chaves (2011): "República del Paraguay" (ms.). Disponible en: http://www.slideshare.net/hadita10/paraguay9257927.

Avellana, Alicia (2012): Las categorías funcionales en el español en contacto con lenguas 
indígenas en la Argentina: tiempo, aspecto y modo. Tesis de doctorado, Universidad de Buenos Aires.

Cerrón Palomino, Rodolfo (1994): Quechumara; Estructuras paralelas de las lenguas Quechua y Aimara. La Paz, CIC.

Cerrón Palomino, Rodolfo (2003): Castellano andino. Aspectos sociolingüísticos, pedagógicos y gramaticales. Lima, Pontificia Universidad Católica del Perú.

Cinque, Guglielmo (1999): Adverbs and functional heads: A cross-linguistic perspective. Oxford, Oxford University Press.

Chomsky, Noam (1981): Lectures on Government and Binding. Dordrecht, Foris.

Chomsky, Noam (1986): Knowledge of Language, its Nature, Origin and Use. New York, Praeger.

Chomsky, Noam (1993): “A Minimalist Program for Linguistic Theory”. En Hale, K. y S. Keyser (eds.): The View from Building 20: Essays in Linguistics in Honor of Sylvain Bromberger. Cambridge, MIT Press, págs. 1-52.

Chomsky, Noam (1995): El Programa Minimalista. Madrid, Alianza.

Cusihuamán, Antonio (1976): Gramática quechua. Cuzco-Collao. Lima, Instituto de Estudios Peruanos.

DeLancey, S. (1997) "Mirativiy: The grammatical marking of unexpected information". Linguistic Typology, 1, págs. 33-52.

Dietrich, Wolf (2010): “Tiempo, aspecto y evidencialidad en guaraní”, Liames, 10, págs. 67-83.

Faller, Martina (2004): "The Deictic Core of 'Non-Experienced Past' in Cuzco Quechua", Journal of Semantics, 21, págs. 45-85.

Faller, Martina (2007): "The Cusco Quechua Reportative Evidential and Rhetorical Relations" (ms.). Disponible en: http://personalpages.manchester.ac.uk/staff/ martina.t.faller.

Giorgi, Alessandra y Fabio Pianesi (1997): Tense and Aspect: From Semantics to Morphosyntax. Oxford, Oxford University Press.

González Torres, Dionisio (1992): Cómo nos expresamos particularmente en nuestro español y en jopará. Disponible en: http://www.portalguarani.com/obras_autores_ detalles.php?id_obras=14916.

Granda, Germán de (1998): "De nuevo sobre quechua y español en el noroeste argentino. Reexamen de algunos temas". Lexis, XXII, 1, págs. 1-10.

Halle, Morris y Alec Marantz (1993): "Distributed Morphology and the Pieces of Inflection”. En Hale, K. y S. Keyser (eds.): The View from Building 20. Cambridge, MIT Press, págs. 111-176.

Halle, Morris y Alec Marantz (1994): “Some Key Features of Distributed Morphology”. 
En Carnie, A; H. Harley y T. Bures (eds.): Papers on Phonology and Morphology. MITWPL, 21, págs. 275-288.

Hardman de Bautista, Martha (1982): "The mutual influence of Spanish and the Andean languages”, Word, 33, 1-2, págs. 143-157.

[Ka] Kany, Charles (1969): Sintaxis hispanoamericana. Madrid, Gredos.

Klee, Carol y Alicia Ocampo (1995): "The expression of Past Reference in Spanish Narratives of Spanish-Quechua Bilingual Speakers". En Silva Corvalán, C. (ed.): Spanish in Four Continents. Studies in language contact and bilingualism. Washington, Georgetown University Press.

Kornfeld, Laura (2004): Formación de palabras en la sintaxis desde la perspectiva de la Morfología Distribuida.Tesis de doctorado, Universidad de Buenos Aires.

Krivoshein, Natalia y Feliciano Acosta (2007): Gramática guaraní. Asunción, Servilibro.

Lefebvre, Claire y Pieter Muysken (1988): Mixed categories: Nominalizations in Quechua. Dordrecht, Kluwer Academic Publishers.

Liuzzi, Silvio y Pablo Kirtchuk (2010): “Tiempo y aspecto en guaraní”, Amerindia, 14, págs. 9-41.

Martín, Herminia (1976): “Un caso de interferencia en el español paceño", Filología, XVII-XVIII, págs. 119-130.

Melià, Bartomeu, Luis Farré y Alfonso Pérez (1997): El guaraní a su alcance. Un método para aprender la lengua guaraní del Paraguay. Asunción, CEPAG.

Merma Molina, Gladys (2007): Contacto lingüístico entre el español y el quechua: un enfoque cognitivo-pragmático de las transferencias morfosintácticas en el español andino peruano. Tesis de doctorado, Universidad de Alicante.

Olbertz, Hella (2005): "Dizque en el español andino ecuatoriano: conservador e innovador”. En Olbertz, H. y P. Muysken (eds.): Encuentros y conflictos: bilingüismo y contacto de lenguas. Madrid/Frankfurt, Iberamericana/Vervuert, págs. 77-94.

Olbertz, Hella (2009): "Mirativity and exclamatives in functional discourse grammar: evidence from Spanish" En Keizer, E. y G. Wanders (eds.): The London papers I. Web Papers in Functional Discourse Grammar, vol. 82. Amsterdam, Functional Grammar Foundation, págs. 66-82.

Palacios Alcaine, Azucena (1999): Introducción a la lengua y cultura guaraníes.Valencia, Universitat de València.

Palacios Alcaine, Azucena (2008): "Paraguay". En Palacios Alcaine, A. (coord.): El español en América. Barcelona, Ariel, págs. 279-300.

Reuse, Willem de (2003): "Evidentiality in Western Apache (Athabascan)". En Aikhenvald, A. y R. M. W. Dixon (eds.): Studies in Evidentiality. Amsterdam/Philadelphia, John Benjamins, págs. 79-100.

Sánchez, L. (2004): "Functional convergence in the tense, evidentiality and aspectual 
systems of Quechua Spanish bilinguals", Bilingualism: Language and Cognition, 7, 2, págs. 147-162.

Schumacher de Peña, Gertrude (1975): "Observaciones sobre el sistema verbal del español andino". En Materiales descriptivos para la enseñanza del castellano como segunda lengua. Lima, Instituto Nacional de Investigación y Desarrollo de la Educación, págs. 63-104.

Velázquez-Castillo, Maura (2010): Handout de la comunicación "Alineamiento semántico y el sistema Aspecto-Modal (AM): El caso del guaraní", presentada en el $I V$ Simposio sobre el estado actual del conocimiento del Gran Chaco Meridional (XXX Encuentro de Geohistoria Regional), Resistencia, 19-21 de agosto.

Vendler, Zeno (1967): Linguistics in Philosophy. Ithaca and London, Cornell University Press.

Vidal de Battini, Berta (1980): Cuentos y leyendas populares de la Argentina. Buenos Aires, Ediciones culturales argentinas.

Páginas web (consultadas entre octubre de 2011 y junio de 2012):

[W1] http://www.foro.fullaventura.com

[W2] http://www.lajaula.com.py

[W3] http://twitoaster.com

[W4] http://www.elforro.com

[W5] http://www.diariopopular.com.py

[W6] http://twitter.com

[W7] http://www.tocorre.com

[W8] http://www.taringa.net

[W9] http://www.diarioparaguayo.com

[W10] http://www.lanpy.com

[W11] http://tvparaguayadesplieguecomentarios.blogspot.com

[W12] http://www.franjanegra.com

[W13] http://www.franjeado.com

[W14] http:// motores.com.py

[W15] http://clubcerro.mforos.com

[W16] http://www.contrapuntoya.com.ar

[W17] http://twitoaster.com

[W18] http://www.popular.com.py

[W19] http://www.portalguarani.com

[W20] http://www.cronica.com.py 


\title{
EL USO DE ENTONCES/ASÍ QUE EN CONTEXTO NARRATIVO SOBRE DATOS DEL PRESEEA-BUENOS AIRES
}

\author{
ClaUdia BORZI \\ Consejo Nacional de Investigaciones Científicas y Técnicas - Universidad de Buenos Aires \\ cborzi@filo.uba.ar
}

\begin{abstract}
Resumen
En este trabajo se estudian comparativamente los usos de entonces y de así que en el marco del Enfoque Cognitivo-Prototípico, que presupone que cada forma tiene un significado $\mathrm{y}$ una función propios, los que, a su vez, responden a distintas intenciones comunicativas del hablante. Siguiendo una metodología cualitativa y cuantitativa se analizan datos provenientes del nivel sociocultural alto del PRESEEA_BUENOS AIRES (Proyecto para el Estudio Sociolingüístico del Español de España y de América de la Ciudad de Buenos Aires) 2000-2010. Se identifica un contexto de uso particular para cada una de las formas: entonces en tematización de información y así que en abandono de turno. Se diferencian los contextos narrativos de los argumentativos. Se describe el uso más prototípico de cada una de las formas en el contexto narrativo. Se comparan los resultados con los obtenidos por Borzi (1997) sobre el cuerpo de datos oral de El Habla Culta de la Ciudad de Buenos Aires (PILEI) 1965-1969.
\end{abstract}

PALABRAS CLAVE: Enfoque cognitivo prototípico, PRESEEA_BAIRES, Marcadores, Conectores, entonces, así que.

\begin{abstract}
We compare the use of entonces and asi que in the framework of the Prototypical-cognitive view, which assumes that each form has its proper meaning and function. Meaning and function, which respond to the speaker's communicative intentions. Through a qualiquantitative methodology, we analyze data coming from a high socio-cultural level of the PRESEEA_BUENOS AIRES (Proyecto para el Estudio Sociolingüístico del Español de España $y$ de América de la Ciudad de Buenos Aires) 2000-2010. We identify a particular contextual use for each one of the forms: entonces with thematic information and asi que when abandoning a turn. We distinguish narrative and argumentative contexts. We describe the more prototypical use of each form in the narrative context. The results are compared with Borzi (1997), a former work performed on the oral data set El Habla Culta de la Ciudad de Buenos Aires (PILEI) 1965-1969.
\end{abstract}

KEY WORDS: Prototypical Cognitive Framework, PRESEEA_BAIRES, Markers, Connectors, entonces, así que.

\section{Introducción}

En el presente trabajo se estudian los usos de entonces y así que sobre parte del cuerpo de datos oral del Proyecto para el Estudio Sociolingüístico del Español de España y de América de la Ciudad de Buenos Aires 2000-2010 (PRESEEA-BUENOS AIRES). Se 
comparan los resultados con los obtenidos por Borzi (1997) sobre el cuerpo de datos de El Habla Culta de la Ciudad de Buenos Aires (HCBA) ${ }^{1}$ recolectado entre 1965 y 1969. Se reconsidera el estado de la cuestión respecto de estas formas en las gramáticas del español y en artículos especializados. El trabajo se desarrolla en el marco del Enfoque Cognitivo-Prototípico, en la línea de autores como Langacker (1987 y 1991) y Lakoff (1987), quienes, entre otros presupuestos teóricos, sostienen que todo uso es significativo y merece ser descrito, por lo que se espera que las formas bajo estudio tengan, cada una, significado particular y cumplan una función propia en cada contexto de uso, razón por la cual se estudian los contextos de cada forma de manera contrastiva tratando de justificar en dicha comparación la elección de una o de otra.

Se trabajan ejemplos como (1) y (2) que muestran contextos semejantes, en tanto existe una relación semántica de consecutividad en ambos casos, pero que a su vez abren la posibilidad de que elementos contextuales más específicos estén motivando uno u otro uso.

(1) y (2) Inf. -[...] cerraron todas las persianas, del departamento ENTONCES dice quédense quietos porque si alguien hace algo los mato a todos, nosotros vamos a bajar ahora, se ve que había una camioneta o algo esperándolos, y bueno y nos vamos ASÍ QUE vos sabés que se fueron y nos quedamos todos en la mesa sentados que nos podríamos haber asomado por el balcón y los veíamos, nada, no nos movíamos, viste quedamos un rato como en shock todos quietos hasta que bueno después llamamos a la policía. [PRESEEA_BAIRES SS 1/17]

En el trabajo no se tienen en cuenta casos como (3), donde la forma funciona como pronombre adverbial (García Fernández, 1999: \$48.1.3.3) que indica acontecimiento contemporáneo con otro o inmediatamente posterior (como en Ya no estaremos aquí para entonces - NGLE, 2009: $\$ 17.9 \mathrm{~h}-$ ).

(3) Enc. -iAlquilabas en el centro o alquilabas medio retirado?

Inf. -Siempre fuera, en... playas chiquititas, casi desconocidas, qué sé yo, Aguas Verdes que todavía es medio desconocida, en aquel ENTONCES era más desconocida. [PRESEEA_BAIRES JE 4]

\footnotetext{
${ }^{1}$ La transcripción de dicho cuerpo de datos es una selección de encuestas grabadas dentro del "Proyecto de estudio coordinado de la norma lingüística culta de las principales ciudades de Iberoamérica y de la Península Ibérica" patrocinado por el Programa Interamericano de Lingüística y Enseñanza de Idiomas (PILEI); materiales editados por la Dra. Ana María Barrenechea y publicados en 1987 por el Instituto de Filología y Literaturas Hispánicas "Dr. Amado Alonso" de la Facultad de Filosofía y Letras de la Universidad de Buenos Aires, en dos tomos, bajo el título El Habla Culta de la Ciudad de Buenos Aires. Materiales para su Estudio.
} 
Tampoco se analizan casos donde se mantiene el significado anafórico sin evocar un tiempo ni pretérito ni futuro en relación con la enunciación en sí, sino de futurohipotético, por lo que se puede postular (4) como un estadio intermedio entre el adverbio y el conector. Se descartan también casos en los que no se puede determinar la coherencia discursiva entre los conectados.

(4) Inf. - [...] yo creo lo primero que necesita es que haya conciencia urbanística en todo sentido, porque ENTONCES [EN ESE CASO] San Telmo también va a ser más limpio,... es bastante sucio. Esteh... en todo lo que hace a la urbanidad, eso es lo que más necesita San Telmo ahora. [PRESEEA_BAIRES JE10]

\section{El problema y el marco teórico}

Como adelantamos, los ejemplos (1) y (2) permiten preguntarnos si estos usos están en variación libre, es decir, si el hablante elige arbitrariamente una u otra forma sin tener la intención de manifestar un significado diferente con cada una de ellas y si en consecuencia estas son intercambiables en dichos contextos sin provocar cambio de significado o si no es así. Dado el presupuesto teórico enunciado en el apartado anterior, según el cual el hablante (consciente o inconscientemente) siempre dice lo que quiere decir, corresponde pensar que cada uso en cada mensaje persigue un objetivo comunicativo determinado, y que el hablante elige cada forma. La existencia de una elección plantea la pregunta: ¿Por qué usa a veces entonces y otras veces así que en contextos semántica y pragmáticamente semejantes?

Siendo que nos apoyamos en los principios de la Gramática Cognitiva, se mencionan a continuación algunos de los aspectos puntuales que se ponen a prueba con la presente investigación. En primer lugar, y coherentemente con lo previamente dicho, si sostenemos que cada forma en cada contexto tiene un significado y una función, desde un primer momento no coincidimos con aquellos autores que consideran que puede haber formas usadas como meras muletillas, es decir, sin significado (como por ejemplo sugieren Fuentes Rodríguez (1987: 144) y Domínguez (2010: 372) en relación con entonces).

En segundo lugar, como se sabe, el enfoque considera que las categorías tienen en general límites difusos y que los atributos de cada miembro de una categoría no están necesariamente todos presentes en todos los miembros de cada categoría ni lo están en la misma medida. Por el tema que se desarrolla en el presente trabajo se evalúa este presupuesto, porque, como veremos, ciertos atributos, a saber, la capacidad deíctica y anafórica y la temporalidad que presenta entonces, no están vigentes en la misma medi- 
da en todos los contextos, como ocurre por ejemplo en los entornos con tematización en comparación con los entornos continuativos y argumentativos.

En tercer lugar, se busca también aportar evidencia a favor de la propuesta de que las formas con significados o funciones semejantes sí se agrupan entre sí. Concepto que muchas teorías manejan de manera exactamente inversa, presuponiendo que dada una construcción, por economía, el hablante prefiere tener una sola forma para marcar determinado significado y no más de una (Cf. Pereira Scherre y Naro, 1991). Sin embargo, como se mostrará, entonces se agrupa con $y$ cuando marca, al igual que la conjunción copulativa, continuidad dentro de la narración.

Recordemos finalmente que los planteos teóricos de la Gramática Cognitiva, entre los que se encuentran los particularmente enunciados, imponen una metodología específica a las investigaciones llevadas a cabo dentro de dicho marco. En principio, se espera que se opere sobre usos auténticos contextualizados, porque el significado de una forma solamente se concreta dentro del mensaje en una situación particular de uso. Como se dijo, los ejemplos provienen de un cuerpo de datos auténtico, recolectado según estrictas pautas sociolingüísticas y los resultados se comparan con otro estudio también desarrollado sobre otro corpus de características semejantes, pero temporalmente anterior. Según el enfoque, también se espera se lleve a cabo un estudio no solamente cualitativo sino también cuantitativo, para lograr así una validación social. Digamos por último que de los análisis esperados para completar la descripción de una forma (comparación con la(s) otra(s) forma(s) con la(s) que varía en un contexto dado y consigo misma) en este caso se lleva a cabo la primera comparación y no en todos los contextos, dado que el contexto argumentativo, por su complejidad se deja pendiente para un futuro trabajo.

\section{Revisión del estado de la cuestión}

Para esta apretada reseña se toman como ejes dos problemas: qué significado atribuyen los autores a entonces y a así que y qué función les atribuyen, ya sea en el marco de la oración o del discurso, según qué autor se esté revisando.

Respecto de entonces todos los gramáticos (así por ejemplo Bello, 1980 [1847]); la Gramática de la Real Academia de 1931; Roca Pons (1960), R. Seco (1978); Alcina Franch y Blecua (1975), y más cerca en el tiempo la NGLE describen el significado temporal deíctico y anafórico manifestado en casos como entonces yo no estaba aquí o ya no estaremos aquí para entonces (NGLE, 2009: \$17.9g y h). Categorialmente lo clasifican como adverbio. Describen su contenido diciendo que la forma alude a un significado básico: temporal anafórico de tiempo pasado que puede llegar a mostrar posterioridad. 
Algunos autores lo caracterizan en oposición a ahora (como un no-ahora; así por ejemplo Roca Pons y García Fernández (1999)).

Los autores que siguen asignan a entonces no solamente significado temporal sino también lógico o consecutivo, así lo dicen tanto los diccionarios de la Real Academia de 1984, de Casares 1979, y de Moliner (1981), como Butt y Benjamin (1988), Matte Bon (1992), Veciana (1984), Cortés Rodríguez (1991), Fuentes Rodríguez (1987), Vigara Tauste, quien habla de un significado "aproximadamente" consecutivo (1992: 408) y Álvarez (1991, 1995 y 1999).

A pesar de que el Diccionario de la Academia de 1984 y Casares categorizan la forma en ambos usos (temporal y consecutivo) como adverbio, otros autores acompañando el significado consecutivo de entonces lo analizan como conjunción Moliner (1981), Butt y Benjamin (1988), Veciana (1984), Cortés Rodríguez (1991), Fuentes Rodríguez (1987), y más recientemente Zorraquino y Portolés (1999: \$63.3.3.11) y la NGLE (2009: $\$ 30.13 \tilde{n})$. Este significado consecutivo queda asociado en algunos casos a la proposición condicional, lo que deja en claro que están operando sobre el carácter argumentativo del contexto en el que tratan entonces y otras veces a la proposición causal. Fuentes Rodríguez, por ejemplo, nos dice que entonces sustituiría a toda la cláusula causal, por lo que a su entender esto es "un primer paso en el proceso de lo temporal a lo causativo" (1987: 142). La NGLE (2009: \$17.9.i) presenta entonces como conjunción, correlativa en la apódosis de una oración con prótasis condicional con si y se puede entender que la NGLE propone que entonces sustituye a la prótasis ${ }^{2}$. Otros autores proponen distinta clase de palabra para esta forma: para Roca Pons es un adverbio demostrativo que funciona como pronombre relativo con antecedente. Matte Bon lo llama "demostrativo" siguiendo la línea de Franch y Blecua.

Cortés Rodríguez y Fuentes Rodríguez asocian el valor consecutivo con la clase de palabra conector extra-oracional (lo hacen en la línea en que Koch y Oesterreicher (1990) se refieren a marcas de cesura superestructural —Gliederungssignale-). Cortés Rodríguez y Fuentes Rodríguez de la función conector extra-oracional llegan a la función expletiva. Fuentes Rodríguez propone una cadena de sucesivas derivaciones desde el uso adverbial temporal a la forma expletiva: adverbal > conector $>$ partícula continuativa > fático > muletilla. Este "valor fático" (o de continuación de turno) ocupa además a Gili Gaya (1961), Lope Blanch (1984), Koch y Oesterreicher (Turn-

\footnotetext{
${ }^{2}$ Nos dice "su valor ilativo proviene de su capacidad para hacer referencia a una prótasis condicional anterior y, en último extremo, de su condición de demostrativo: "Si Pedro tiene razón, entonces (= 'si Pedro tiene razón’) más vale que esperemos.” (2009: \$30.13ñ).
} 
Beibehaltung) y Vigara Tauste. Casado Velarde (1998: 65), presenta la forma entonces como marcador que permite mantener la atención "interlocutiva" caso que puede acercarse al fático de Fuentes y al de continuación de turno de Koch y Oesterreicher.

Butt y Benjamin y Koch y Oesterreicher mencionan casos de entonces en inicio de turno -Anfangs/Eroeffnungssignale -, relacionados con el cambio de hablante. En el presente trabajo se analizan usos semejantes, pero asociados con la tematización de información. En Borzi (1997) se tratan los casos con entonces en inicio de turno introduciendo conclusión interrogativa con intención confirmatoria.

Casado Velarde (1998: 65) presenta entonces como marcador textual consecutivo, entendiendo por "marcador" formas reguladas idiomáticamente en una lengua concreta para expresar una determinada función textual (1998: 61).

Álvarez no incluye entonces cuando trata los conectores de coordinación consecutiva (sí menciona así que), sino como adverbio en "función cohesiva", asociándolo con por lo tanto o en consecuencia. Los llama después "enlaces extra-oracionales" consecutivos (1999: 3793). Semánticamente, dice que tienen significados discursivos más amplios que las conjunciones coordinantes y significados periféricos, que no llega a desarrollar puntualmente. Ofrece una detallada descripción sintáctica y prosódica: libertad posicional, posible acumulación; carácter tónico y entorno entonacional marcado por pausas.

Zorraquino y Portolés ${ }^{3}$ incluyen entonces al tratar los marcadores discursivos en virtud de su posible autonomía ${ }^{4}$. Como conector consecutivo le reconocen un cierto sentido de consecuencia como hacía Fuentes Rodríguez. Mencionan las siguientes funciones a) relaciona un miembro del discurso anterior, aunque sin constituir su paráfrasis, b) aporta "nuevas informaciones sobre un tópico al que servirían de comentario" (1999: 4107). Consideramos digna de ser destacada la preocupación de Zorraquino y Portolés por la calidad de la información, porque, como se verá, el presente trabajo alude a la calidad de la información tanto en los contextos de tematización como en los narrativos. Por su parte, son muy interesantes las diferenciaciones de Vigara Tauste, quien opera sobre usos coloquiales; señala que "da nueva orientación o progresión de la in-

\footnotetext{
${ }^{3}$ Zorraquino y Portolés (1999: 4057) definen los marcadores del discurso como unidades lingüísticas invariables que no ejercen una función sintáctica en la predicación oracional cuya función en el discurso es guiar, de acuerdo con sus distintas propiedades morfosintácticas, semánticas y pragmáticas las inferencias que se realizan en la comunicación.

${ }^{4}$ Los autores mencionan un caso donde el interlocutor solicita al hablante la conclusión o explicación de lo que ha dicho: -Si dijéramos siempre la verdad no sería posible la convivencia//-¿Entonces...?// -Yo huyo de estos tipos que que te saludan diciendo: [...].
} 
formación" (1992: 409). Caracteriza entonces como ilativo y como marca de "vacilaciones" (1992: 251). La caracterización de un entonces ilativo, es compartida por Zorraquino y Portolés (1999: \$63.3.3.11) y por la NGLE (2009: \$30.13ñ). Vigara Tauste (1992: 126) también ejemplifica con casos cercanos a los que aquí se llama "tematizadores" aunque no los describe.

En interrogación (combinado o solo); acumulado con pero o con $y$, y tomando como antecedente las palabras del interlocutor entonces es descripto por Moliner (1981), Fernández Ramírez (1986: \$86) al tratar preguntas reflejas, por Zorraquino y Portolés (1999: \$63.3.3.11), y por Matte Bon, quien va más allá y se refiere al caso ¿Y entonces? ¿Qué pasó? (1992: 301) que incita a seguir hablando. No se trata el contexto interrogativo en el presente trabajo, aunque sí se estudió sobre el HCBA (Borzi, 1997: 134).

La apretada síntesis que antecede atestigua que distintos autores han detectado los usos que se tratan aquí en relación con entonces y, como se verá, el presente trabajo coincide con muchas de las apreciaciones previamente reseñadas. Quizás la caracterización de entonces en contexto de tematización esté aquí formulada con mayor claridad. Consideramos, sin embargo, que el presente trabajo se diferencia de los mencionados en que aquí se intenta, partiendo de una metodología no solo cualitativa sino también cuantitativa, dar una respuesta a cuál o cuáles de estas funciones son las más (y las menos) típicas en el uso de la forma y cuáles son los atributos de significado más salientes, para poder ir identificando, conforme la distribución cuantitativa, su significado y para qué la usa el hablante. Creemos que la descripción que se propone aquí ofrece la posibilidad de sistematizar los usos y organizar mejor la caracterización.

En cuanto a así que, los autores, atendiendo al contexto consecutivo en el que se usa, interpretan la relación de las cláusulas que conecta como una subordinación, probablemente por la presencia de la forma que. Así ocurre con Lenz (1935); Gili Gaya (1961), el Esbozo de la Real Academia, Butt y Benjamin (1988); M. Seco (1989) y Alcina Franch y Blecua (1975).

Hay sin embargo autores que consideran que entre las cláusulas conectadas por así que se establece una relación de coordinación. Así lo hacen Bello; la Gramática de la Academia de 1931 y Kovacci (1990), quien basa su decisión en la imposibilidad de acumular así que con $y$ o con $o$, condición que las gramáticas consideran definitoria para decidir si la forma es o no una conjunción coordinante.

\footnotetext{
${ }^{5}$ Los siguientes autores no tratan esta forma ni como pronombre, ni como adverbio ni como conector conjuntivo: Kany (1969); Pottier (1962); Beinhauer (1978).
} 
Los autores que atienden a los casos en que así que inicia oración, analizan este marcador como una unión extra-oracional (así lo hacen Gili Gaya (1961) y Vigara Tauste (1992) por ejemplo) o en ciertos contextos lo ven como una marca de expresividad, por ejemplo Vigara Tauste (1992: 120).

Zorraquino y Portolés no tratan la construcción así que sino la forma así cuando aparece sola como marcador conector consecutivo introduciendo la conclusión (1999: $\$ 63.3 .3 .10)$. Lo mismo hace la NGLE (2009: $\$ 30.13$ y $\$ 30.13 \mathrm{n}$ ) clasificando así, junto con entonces, entre los conectores discursivos adverbiales y mencionando su significado consecutivo. La NGLE señala finalmente que son también adverbios demostrativos ${ }^{6}$.

En resumen, los autores estudian entonces y así que por separado, sin contemplar que comparten contextos, hecho que ameritaría una comparación. En relación con así que, más allá de las diferencias en el tipo de relación sintáctica que asignan, no tienen en cuenta, por ejemplo, el contexto de abandono de turno. En relación con entonces y en cuanto al significado, priorizan el valor temporal que asocian al adverbio, aluden a un valor pronominal (anafórico) en segunda instancia y desde allí llegan al valor demostrativo (deíctico). El significado consecutivo lo asocian a otra clase de palabra, la conjunción. Admiten usos sin significado, planteo con el que no coincidimos y si bien ofrecen una gama amplísima de registros, no dan una descripción unificada de los contextos registrados. Cuando aluden a la calidad de la información de la cláusula que introduce se refieren a la presencia de información nueva, aunque no detectan los contextos de información tematizada. Por otro lado, la detallada descripción del comportamiento de la forma que ofrece Álvarez no está acompañada, lamentablemente, de una clara justificación.

\section{Hipótesis}

Frente a la riqueza de análisis que ofrece la bibliografía, la hipótesis particular que se defiende en el presente trabajo en relación con entonces es que, en la oralidad, activa no solamente su valor mostrativo temporal anafórico, valor semántico que fundamenta su uso en contexto de tematización de información, sino también activa la capacidad de mostración hacia adelante es decir que orienta la información de izquierda a derecha dentro de la Complicación en fragmentos narrativos. En cuanto a así que, se sostiene que, en la oralidad, constituye un límite, lo que justifica su uso como marca de abando-

${ }^{6}$ El Diccionario de Partículas del español (DPDE) de Briz, Pons Bordería y Portolés no trata las formas bajo estudio. 
no de turno y a su vez justifica su especialización en focalizar la Coda o Resolución en fragmentos narrativos, explotando de esta manera también su capacidad para marcar posterioridad (NGLE, 2009: \$23.16k) o catáfora (NGLE, 2009: \$17.9k).

\section{Metodología}

Se analizan ejemplos de 11 Entrevistas de Nivel Sociocultural Alto en 3 bandas etarias, que reúnen aproximadamente 6 horas 50 minutos de grabación, partiendo de la primera transcripción de las muestras del PRESEEA-BUENOS AIRES. Se tuvieron en cuenta, para el estudio de los contextos en los que varían entonces y así que, solamente aquellas entrevistas en las que el mismo hablante usa ambas formas bajo estudio, pensando que esos contextos presentan óptimas condiciones para estudiar la variación porque es el mismo hablante el que percibe las diferencias contextuales que favorecen el uso de una o de otra forma. Se lleva a cabo un análisis cualitativo y cuantitativo. En virtud del análisis del corpus se formulan variables dependientes e independientes, se las correlaciona en tablas de doble entrada y se consideran los valores absolutos y los porcentajes. Se aplican la prueba de significación estadística del chi cuadrado $\left(X^{2}\right)$ que permite comprobar si hay dependencia entre las variables y el valor de odds ratio (o.r.) que marca la importancia del factor independiente considerado. Se sigue así en lo fundamental a García (1985) y a Martínez (2009).

\section{Análisis}

Se identifican diferentes contextos de uso de entonces y de así que. Dos de ellos muestran una distribución contrastiva: el correspondiente a abandono de turno y el correspondiente a tematización de información. En el restante contexto estudiado, que atiende al género discursivo del fragmento con contexto consecutivo, las formas varían pudiéndose identificar características particulares que favorecen la elección de una o de la otra.

\subsection{Contexto conversacional de la entrevista: los turnos}

En el marco del intercambio conversacional de la entrevista semiestructurada que rodea a los usos bajo análisis, y de la negociación de los interlocutores (Briz, 1998), se encontraron casos en los que el hablante marca al interlocutor su intención de abandonar el turno, usando en particular una de las formas bajo análisis. El contexto de uso presentó en los ejemplos del corpus las siguientes características formales: a) Acumula- 
ción de partículas previas (véase, por ejemplo en (5), la presencia de $y$, claro, por supuesto previas a así que e incluso inmediatamente posteriores ${ }^{7}$; b) Presencia de pausas semilargas o largas en el entorno previo y siguiente inmediato ${ }^{8}$ incluso mediato (como se ve en (5)). En lo referente a las características de contenido, se evidencia un claro cambio o cierre del (sub)tópico de conversación que se ve en casi todos los casos, reforzado por la intervención inmediata del entrevistador, en general, con la formulación de una pregunta. En (5) se percibe el paso del tópico (el robo del celular que sufrió una jovencita) a un sub-tópico (la caracterización de la persona que le ofreció ayuda a la damnificada). Se agrega el ejemplo (6) con entonces, el único que se ajusta a las características de abandono de turno: la forma se da antecedida por pausa, en un entorno fonético semejante al de abandono y la entrevistadora interviene rápidamente formulando otra pregunta que propone un sub-tópico (las próximas vacaciones) aceptado por la encuestada'.

(5) -[el teléfono] funciona lo más bien, pero bueno no tiene ni camarita ni mp nada, ni nada

-Y está perfecto, funciona para qué...

-Sí las funciones para qué... y claro, por supuesto ASÍ QUE...

-El chico.... con el que estaba... el que la ayudó.

-Y ese pobre [...] [PRESEEA_BAIRES SS 1/10]

(6) - ¿Y por qué... ibas en micro, por qué no ibas en auto, por ejemplo?

-Bueno, en esa época porque no tenía auto, creo (risas), pero bueno, pero bueno, si no porque... igualmente aunque hubiese tenido un auto, no... porque como voy a la

\footnotetext{
${ }^{7}$ Resulta interesante ver en el siguiente caso cómo refuerza, el entrevistado, la intención de abandonar el turno, repitiendo así que y agregando una marca posterior, bueno:

-Por eso. Para mí que [los ladrones] tenían un dato porque justo no estaba.

-Viste que hacen...

-Ehhhh una inteligencia, claro, para mí sí, ASÍ QUE... ASÍ QUE bueno...

-¿Y en Mendoza cómo fue?

${ }^{8}$ El siguiente ejemplo presenta pausa media previa representada por coma: [...] y uno termina mimetizándose, también, termina sintiéndose tan incómodo como la persona que tiene al lado, ASÍ QUE ...

-Y más allá del Bicentenario, ¿solés festejar las fechas patrias? [PRESEEA-BAIRES S/S216]

${ }^{9}$ La oposición se plantea como [+abandono de turno] versus otros, porque se encontró solamente 1 caso en el que se puede pensar que entonces se está usando para mantener el turno:

-No, este tiene, este tiene pero, pero es viejo [el ascensor], sí, no sé de qué año será.

¿Y qué, y ENTONCES este... te gusta vivir ahí?

-Ehhhh me gusta pero me gustaría más vivir afuera. [PRESEEA_BAIRES SS 1/2]
} 
montaña a andar por la montaña al auto lo tendría que usar solo para llegar hasta el lugar y para volver nada más, ENTONCES...

-Y si pudieras elegir, ¿qué preferirías hacer las próximas vacaciones?

-Eh... Me gustaría hacer algún... algún viaje [...] [PRESEEA_BAIRES SS 1]

\begin{tabular}{|c|c|c|c|}
\hline & 1 Abandono de turno & 2 Otros & \\
\hline \multirow[t]{3}{*}{ A Asíque } & 20 & 80 & 100 \\
\hline & $20 \%$ & $80 \%$ & $100 \%$ \\
\hline & $95,24 \%$ & $33,90 \%$ & \\
\hline \multirow[t]{5}{*}{ B Entonces } & 1 & 156 & 157 \\
\hline & $0,64 \%$ & $99,36 \%$ & $100 \%$ \\
\hline & $4,76 \%$ & $66,10 \%$ & \\
\hline & 21 & 236 & 257 \\
\hline & $100 \%$ & $100 \%$ & \\
\hline
\end{tabular}

Odds ratio $=39$

Tabla 1. Contexto de abandono de turno

La lectura vertical de la columna 1 de la Tabla 1 muestra una clara tendencia de así que como marca de abandono de turno (95,24\%, 20/21 de así que versus solamente un $4,76 \%, 1 / 21$ de entonces). En consonancia con los resultados obtenidos sobre el PRESEEA_BAIRES, en el HCBA, de entre todos los casos que marcaban abandono de turno, un 94,74\%, 18/19 de casos tenía así que y solamente un 5,26\%, 1/19 entonces. Como se advierte, los porcentajes son muy similares. Por su parte, la lectura horizontal de la Tabla 1 muestra un porcentaje interesante (Celda A1 20\%, 20/100) de entre todos los casos de así que en esta función, que explota la consonancia de este conector en contextos que marcan límite ${ }^{10}$. En el HCBA, sobre el total de casos de así que se encontró un 14,88\%, 18/121 marcando abandono de turno, se dan porcentajes también cercanos.

${ }^{10}$ El Diccionario de la Real Academia de 1984; Casares y el Esbozo (1973: \$3.21.3.c) aluden a un significado temporal de así que (Así que escuchaba mentar la palabra tisis, desfallecía), que no se registró ni en el HCBA ni en PRESEEA, pero que resulta muy interesante porque indica un límite temporal entre dos hechos y es un significado que puede verse como fundamento de la tendencia a participar de los contextos de abandono de turno y de cesura superestructural, como se tratará más adelante. 


\subsection{Contexto conversacional: la información}

Se considera en este caso el tipo de información de la cláusula que introducen las formas bajo análisis, algo que tiende a repercutir en la posición de dicha cláusula en el contexto conversacional.

Siguiendo básicamente los principios de la Escuela de Praga (Firbas, 1992) se identifican distintos tipos de información conocida (o accesible): aquella que ha sido mencionada de manera literal en el discurso previo (como ocurre en (7)); aquella información no mencionada literalmente con anterioridad, pero que el hablante evalúa como que puede ser inferida partiendo del conocimiento enciclopédico compartido con el interlocutor $^{11}$; aquella información que el interlocutor puede inferir (deducir) del contexto lingüístico previo sin necesidad de apelar a información enciclopédica específica ${ }^{12}$, o aquella información evidente, de inmediata interpretación porque lo designado está presente en la situación de enunciación ${ }^{13}$.

Respecto de la información nueva (o inaccesible) reconocemos los siguientes subtipos: información nueva porque el hablante no identifica el objeto designado en el momento de la enunciación, aunque presupone su existencia (es decir información nueva de manera absoluta para hablante y oyente) ${ }^{14}$; o información nueva porque no ha sido mencionada de manera (relativamente) literal en el discurso previo; o porque (el hablante cree que) el interlocutor no conoce el objeto ${ }^{15}$, o nueva porque el interlocutor

\footnotetext{
${ }^{11}$ En el siguiente ejemplo, ambos hablantes trabajan en el ámbito científico y su conocimiento enciclopédico les permite deducir que publicaciones importantes alude a publicaciones en revistas internacionales y a revistas indexadas:

-Dos en el período, de esos tres años, estamos hablando de publicaciones importantes, quiere decir...

-Ah, en revistas internacionales.

-... entonces en revistas indexadas, ¿no? Revistas que estén en Scielo que estén en Latindex. [PRESEEA_BAIRES SS218]

${ }^{12}$ Como en el siguiente ejemplo, donde la información subrayada, que sigue a entonces, se puede inferir del contexto lingüístico previo:

- ¿En la casa anterior tenías buena relación con los vecinos o son medio anónimos?

-Eh... yo soy anónima para ellos porque no estoy en todo el día en mi casa ENTONCES ellos me ven entrar de vez en cuando... [PRESEEA_BAIRES JS6]

${ }^{13}$ Como ocurre en el siguiente caso donde tenemos $1^{\circ}$ persona del singular nominativa y presente actual en la cláusula que sigue al conector: [...] funciona como un pueblo chiquito, ENTONCES yo pienso que voy a extrañar por todo el aspecto cultural que tiene Buenos Aires. [PRESEEA_BAIRES JE8].

${ }^{14}$ Como ocurre en Se lo preguntaré al estudiante que sepa de informática.

${ }^{15}$ Como ocurre en Se lo preguntaré a un estudiante que sabe de informática.
} 
no puede deducir la información ni del conocimiento enciclopédico ni de lo previamente dicho, como se da en (7).

En este caso se presentó pertinente la presencia/ausencia de información conocida por mencionada en el discurso previo que era introducida por el conector, la que al ser retomada casi literalmente permite decir que la forma entonces participa en la tematización de información a partir de la cual se continúa luego con una predicación. En (7), después de una digresión de la encuestada y de una intervención de la encuestadora, la encuestada retoma el turno y reinicia el relato en donde lo había abandonado. Entonces recupera información conocida, la tematiza (alude a la ausencia de respuesta por parte de quien entraba) que sirve de punto de partida para la introducción de otra información nueva para el interlocutor (abrió la puerta - entró con cuatro [personas] más). Se destaca en el ejemplo el texto en cuestión. Se registraron 17 casos en este contexto de tematización, un $10,83 \%, 17 / 157$, un porcentaje un tanto menor que el registrado en el HCBA, aunque cercano, que era de un 16,66\%, 37/222.

(7) -¿Cómo fue eso que te robaron?

- Y Jerónimo llegaba de la facultad a la noche y [...] llegaba de la facultad, y entonces oigo la llave y le digo Jerónimo ¿sos vos?, ¿Jerónimo? y no me contestaba, por eso ahora, te digo que cada vez que abren la puerta tengo que preguntar inmediatamente quién es y que alguien me responda rápido porque te juro que es lo único que me quedó esa impresión.

-Te quedó un trauma...

-ENTONCES Jerónimo no contestaba, cuando abrió la puerta en un momento entró con cuatro más y por un momento yo pensé que eran compañeros de la facultad. [PRESEEA_BAIRES SS 1/6]

Vigara Tauste ejemplifica casos semejantes sin describirlos en el sentido en que se hace aquí (1992: 126). Koch y Oesterreicher (1990) tratan casos semejantes como Anfangs-/Eröffnungssignale en cambio de turno. Aquí se corrobora que, aunque en ciertos ejemplos se da dicho cambio de turno, como en (7), no es necesario que haya cambio de turno para que haya tematización, lo que se advierte en (8):

(8) $-i Y$ en Egipto viste las Pirámides?

-Y en Egipto fuimos a las Pirámides, anduvimos en camello, pero ahí ya fue como un shock cultural, te digo que es todo tan diferente que... Fue el lugar que tuvimos como un cimbronazo porque la comida, la escri..., todo, todo es distinto...

-¿Cómo es?

-Diferente. ENTONCES ahí por ejemplo no pudimos quedarnos en un albergue. [PRESEEA SS 1/1] 
Así que no se da en contextos de este tipo. Seguidamente se presenta un ejemplo en el que, aunque la información que sigue al conector es información previamente mencionada (si bien no totalmente literal), no podemos pensar que se trate de una tematización sino que la analizamos como una información ecoica que cierra lo previamente dicho. En (9) se ve claramente que la encuestadora inicia otro par con una pregunta que se vuelve retórica en el contexto, de orientación negativa: ¿espectáculos al aire libre? $\mathrm{No}^{16}$. Se registraron 6 casos de así que $(6 \%, 6 / 100)$ en este contexto eco de cierre de un tópico o sub-tópico; un porcentaje mayor que el registrado en el HCBA, donde había solo un 2,64\%,1/38 de casos de así que en un contexto semejante.

(9) -Porque bueno es, justamente es un tipo, es un espectáculo visual, por lo tanto verlo en cine, digo, es una experiencia absolutamente distinta que bajarse el video...

[...]

-Y bueno, la verdad es que es espectacular lo que han logrado.

-Mjm, qué cosa. ASÍ QUE preferís ir al cine, antes que... ¿espectáculos al aire libre? No.

-No, hace muchísimos años que no voy... [PRESEEA_BAIRES SS3]

\subsection{Género del fragmento en el contexto conversacional de la entrevista}

En el transcurso de una entrevista se dan momentos donde en un mismo turno o en la cadena cooperativa de turnos tienen lugar fragmentos de intención más narrativa y otros de intención más argumentativa ${ }^{17}$. Este criterio contextual no ha sido tenido en cuenta por los gramáticos como definitorio cuando describieron el uso de estos dos conectores, aunque sí se han ocupado de entonces autores que estudian marcadores del discurso en particular. Así Domínguez (2010: 370-371) dice que entonces "organiza la narración" y en nota 13 , frente a un caso particular ${ }^{18}$ agrega que aporta en ese caso al

\footnotetext{
${ }^{16}$ La NGLE contempla usos semejantes a este que clasifica como conjunción ilativa que inicia período e incluso turno discursivo. Su ejemplo: ¿Así que encontraste a Neno acostado con tu mujer? (2009: 46.12.1)

${ }^{17}$ Asumimos, como recientemente retoma Domínguez (2010: 365), que los textos no son homogéneos en lo referente al tipo textual y que en un discurso conversacional se espera que se sucedan fragmentos narrativos, argumentativos y descriptivos sin que haya una explícita señal.

${ }^{18}$ El ejemplo (3) de la autora dice "Quedaron en escaparse en un tren de las seis de la tarde/creo que era/ y no apareció// Entonces él se fue a Casablanca/ empezó a vivir su vida" En el presente trabajo y dada la intención claramente narrativa del fragmento donde se encuentra el ejemplo citado se analizan
} 
enunciado una doble instrucción, ordenadora y argumentativa. Más adelante, a propósito del mismo ejemplo, agrega que es "marcador de la progresión temporal de la narración" (2010: 373). La autora no menciona ni así que ni entonces como marcadores propios de argumentaciones (2010: \$3.4), aunque sí da un ejemplo de entonces en un fragmento argumentativo (2010: 373) en el marco de textos narrativos. Como la autora no cuantifica ni compara de manera sistemática los tipos textuales entre sí ni las dos formas dentro de un mismo tipo textual no resulta del todo claro el criterio que permite decidir cuáles son conectores que pueden ser considerados propios de uno o de otro tipo textual.

Como se aprecia en la Tabla 2 que sigue, el género del fragmento se presenta como un atributo contextual de influencia en la elección de una u otra forma dentro de una conexión consecutiva entre las cláusulas. Siguen ejemplos donde prevalece la intención narrativa, casos (10) y (11) que ejemplifican las celdas A1 y B1 de la Tabla 2 respectivamente y otros donde prevalece la intención argumentativa, casos (12) y (13) que ejemplifican respectivamente las celdas A2 y B2 de la misma tabla.

(10) -[...] Poco tiempo, lo que pasa que como allá quedaron mis abuelos yo iba, iba todos los veranos, ya de chico iba allá, ENTONCES me encontraba con el carnaval y los corsos que se hacian en la calle San Martín y... y bueno y yo me disfrazaba también. [PRESEEA_BAIRES JM5]

(11) - ¿Qué hicieron?

-Eh nos fuimos a un hotel, y nos quedamos unos días, después fuimos a la embajada, nos conectamos con una gente de la embajada ASÍ QUE salíamos con unas chicas de la embajada, que nos llevaron a un club ahí en El Cairo, [...] [PRESEEA-BAIRES SS13]

(12) -[...] la verdad que no hizo nada al respecto; y la policía metropolitana no está cuando se la necesita, y están ganando sueldos por arriba de los cinco mil pesos, cuando los docentes no llegan ni a los dos mil doscientos; ENTONCES me parece que tenía que haber mejorado más la educación pública y además el la... [PRESEEA_BAIRES SS48]

(13) -[... ¿ ¿cómo te imaginás que hubiese sido tu vida, sin [la carrera en] sistemas?

-Eh... Creo que hubiese... me las... me hubiese... eh adaptado, a la... creo que a sistemas me adapté, no es que lo siento mi vocación ASİ QUE creo que me hubiese adaptado de la misma manera. [PRESEEA_BAIRES JD1]

estos contextos como continuativos por presentar causa/resultado. Los casos que quedan clasificados como argumentativos presentan un entorno de justificación/consecuencia. 


\begin{tabular}{|c|c|c|c|}
\hline & 1 Narrativo & 2 Argumentativo & \\
\hline \multirow[t]{3}{*}{ A Entonces } & 87 & 52 & 139 \\
\hline & $67,59 \%$ & $37,41 \%$ & $100 \%$ \\
\hline & $76,99 \%$ & $52 \%$ & \\
\hline \multirow[t]{5}{*}{ B Asíque } & 26 & 48 & 74 \\
\hline & $35,14 \%$ & $64,86 \%$ & $100 \%$ \\
\hline & $23,01 \%$ & $48 \%$ & \\
\hline & 113 & 100 & 213 \\
\hline & $100 \%$ & $100 \%$ & \\
\hline
\end{tabular}

Odds ratio: $3 X^{2}: 4,41(p>0,05)$

Tabla 2. Contexto de fragmento narrativo versus contexto de fragmento argumentativo

De la lectura vertical de la columna 1 de la Tabla 2 se puede concluir que el contexto narrativo favorece claramente la elección de entonces en lugar de así que (76,99\%, 87/113 -celda A1- versus 23,01\%, 26/113 -celda B1). En el HCBA se encontró que el contexto narrativo favorecía la elección de entonces en un 81,19\%, 82/101 frente a un 18,81\%, 19/101 de elección de así que. En la lectura vertical de la Columna 2 de la misma tabla se ve también que el contexto argumentativo no favorece ninguna de las dos formas en particular ya que estas presentan un 52\%, 52/100 versus un 48\%, 48/100 en las celdas A2 y B2 respectivamente. Algo semejante mostró el cuerpo de datos del HCBA donde se encontró que el contexto argumentativo no favorecía en particular a ninguna de las dos formas: $49,02 \%, 75 / 153$ para entonces versus $50,98 \%, 78 / 153$ para así que.

Resulta también muy interesante la lectura horizontal de la misma Tabla 2 porque da cuenta del contexto que más favorece en particular a cada uno de los conectores: el contexto narrativo es propicio para la elección de entonces (celda A1 67,59\%, 87/139), mientras que el argumentativo lo es para así que (celda B2 64,86\%, 48/74). Es decir que la mayor parte de los usos de entonces se da en contexto narrativo, mientras que la mayor parte de los usos de así que se da en contexto argumentativo ${ }^{19}$.

\footnotetext{
${ }^{19}$ Es interesante el caso siguiente de causa invertida que muestra la adecuación de así que en contexto argumentativo al ser usado como introductor de la apódosis de una oración con cláusula condicional, contexto donde, dada la presencia de una prótasis con $s i$, los gramáticos esperarían entonces:

-¿Vuelven a veces?
} 


\subsection{1. ¿Son los contextos narrativos de entonces iguales que los de así que?}

La observación de la Tabla 2 nos permite ver que si bien en contexto narrativo con conexión consecutiva entre las cláusulas prevalece la elección de entonces, hay un porcentaje no desdeñable de casos de así que que conviven con el relato. Desde el punto de vista metodológico, se espera que se expliquen todos los usos para dar mayor fuerza a las hipótesis defendidas y porque de esa manera se da cuenta de qué fenómeno contextual es el que pesa más en cada caso. Dado esto, el presente apartado bucea dentro de los fragmentos narrativos buscando si los conectores llegan a constituirse en marcas de cesura superestructural. Se siguen los planteos de van Dijk (1978: 143 y 153 a 158) para el análisis de la superestructura de los fragmentos narrativos. Se resumen brevemente sus propuestas, en el marco de los cuales se llevó a cabo el análisis y se explican los ejemplos. Como sabemos, para van Dijk, la coherencia lineal o microestructural y la coherencia global (macro-estructural y superestructural), que reviste características jerárquicas, se asignan al texto.

La coherencia microestructural, que da cuenta de la relación lineal entre proposiciones, presenta tres factores que permiten fundamentar dicha asignación: la coherencia condicional, la coherencia funcional y la distribución de la información. Estos tres factores funcionando simultáneamente permiten asignar coherencia microestructural a dos o más proposiciones.

La coherencia condicional, en términos de van Dijk (1985), se asigna cuando el ordenamiento de proposiciones en secuencias responde a conexiones por relaciones temporales o de causa/resultado, que, en la superficie, queda señalizada por identidad o semejanza léxica, artículos indefinidos/definidos, correlaciones entre los tiempos verbales, el orden de palabras, el orden de las oraciones, el uso de pronombres o adverbios que anafórica o catafóricamente permiten recuperar designados, y el uso de conectores que conectan estados de hechos.

Corresponde ahora atender a la coherencia superestructural de la narración, que es el género textual al que responden los fragmentos bajo análisis en este apartado. Van Dijk reconoce dentro de la superestructura narrativa distintas funciones a asignar a las macro-proposiciones. Las funciones donde prevalecen las acciones de personas constituyen la Historia (que se opone a la Moraleja, entendida como conclusión práctica). La

-Sí, vuelven siempre, no a veces. Si vuelven a Buenos Aires vuelvenn a mi casa, seguro, salvo que vengan en otras condiciones, digamos, vengan con pareja, hijos eh... pero a veces con pareja han vuelto también a casa, SI vuelven ASÍ QUE debe ser bueno el lugar. [PRESEEA-BAIRES J/E3] 
Historia se abre en la Trama y la Evaluación (reacción del narrador frente a la trama). La Trama queda constituida por uno o más Episodios. Cada Episodio está formado por un Marco (donde se presentan el tiempo, el lugar y las circunstancias) y por un Suceso, resultado de la Complicación (como secuencia de acciones), y por la Resolución o Coda (que soluciona el conflicto y cierra la secuencia de acciones de la Complicación).

A partir de estos conceptos, se analizaron los contextos que rodeaban a cada forma bajo estudio dentro del cuerpo de datos y se detectaron dos contextos diferenciados. Uno muestra proposiciones, dentro de la Historia, como parte de la Trama, donde el conector aparece reforzando la secuencia de acciones en la Complicación de un Suceso. A ese contexto se lo llamó "continuativo" o "ilativo" (retomando el término de la NGLE) y se lo mide en la Tabla 3, en la columna 1. El otro contexto detectado donde se daban las formas es la cesura superestructural de la Resolución, donde se inicia la Resolución de un Suceso. Este contexto se mide en la Tabla 3, en la columna 2. Como los fragmentos dentro de los cuales aparecen las dos formas bajo estudio son narrativos, los totales considerados en la Tabla 3, son los correspondientes a la columna 1 de la Tabla 2: 87 casos de entonces y 26 de así que.

El ejemplo (14) muestra la forma entonces funcionando entre proposiciones, dentro de la Historia, como parte de la Trama, conectando la secuencia de acciones en la Complicación de un Suceso. Es importante tener presente que entonces no marca el inicio de la Complicación, es decir que no está funcionando como una marca de cesura superestructural, esto lo diferencia fuertemente del conector con el que se lo está comparando.

En (14) entonces funciona como un conector de estados de hechos, en la Complicación de un Suceso. Complicación en la que marca conexión temporal de anterioridad $>$ posterioridad (se recibió en el Colegio $>$ le quedó una materia sin aprobar $>$ rindió el examen de dicha materia > no pudo empezar los estudios en la Facultad); secuencia reforzada por la correlación de los tiempos verbales (todos los verbos están en pretérito simple), por el orden de las palabras y de las cláusulas que se acumulan ordenadas icónicamente con el orden de los hechos de izquierda a derecha, y además, como decíamos, por la presencia de conectores, dado que encontramos tanto las formas $y$ como entonces, la que no ha perdido totalmente su valor temporal. Se advierte también que hay una relación no solamente temporal entre las proposiciones conectadas por entonces, sino que identificamos claramente una relación de causa/resultado. Sin embargo, lo interesante y lo que en particular nos preocupa destacar aquí por ser la característica que fundamentalmente diferencia entonces de así que, es que entonces no está señalando una parte de la superestructura, sino que, todo lo contrario, está participando de la cadena de acciones. Entre rindió [mal la materia] y no pudo empezar [el Ciclo Básico Común -curso de ingreso a la Universidad de Buenos Aires-] hay solamente relación de 
causa real (anterioridad)/resultado (posterioridad) en los hechos, no estamos ante una cesura superestructural donde se pase de la Complicación a la Resolución. En relación al factor distribución de la información (tercer factor para asignar coherencia condicional), a izquierda y a derecha de entonces se presenta información nueva. Véase (14) como ejemplo de la celda A1 de la Tabla 3.

A diferencia de lo previamente explicado, en (15) se ve claramente que la forma así que señaliza el inicio de la Coda o Resolución, donde hay cambio de tiempo verbal (de pretérito simple - agarró; sacó- a presente - tiene-, forma reforzada por la presencia de un adverbio temporal -ahora-). Es interesante también cómo el hablante vuelve a la secuencia de acciones retomando el pretérito simple: le di mi celular. El caso (15) ejemplifica la celda B2 de la Tabla 3.

(14) [...] se recibió el año pasado y bueno le quedó una materia que la rindió mal, ENTONCES no pudo empezar a hacer el CBC en la primer mitad del año, y se anotó en el UBA XXI, rindió... no sé qué materia rindió un parcial que se sacó un ocho bien, y en el segundo no sé. [PRESEEA_BAIRES SS 1/27]

(15) - Y sí porque es hora de siesta no hay nadie.

-Claro, la agarró un tipo así le dice hacé que me conocés, qué se yo, qué tenés, tenés plata, el celular todo, viste... y le sacó el celular, ASÍ QUE ahora tiene mi celular, le di mi celular que es un celular que no tiene nada. [PRESEEA_BAIRES SS7]

La lectura vertical de la Tabla 3 nos permite decir que en contexto narrativo el hablante prefiere elegir entonces cuando intenta mantener la continuidad en la narración (la celda A1 presenta 93,83\%, 76/81 de los casos de entonces y así que en ese contexto), mientras que prefiere elegir así que en la cesura superestructural para marcar la Coda o Resolución (la celda B2 presenta el 65,62\%, 21/32 de los casos de así que y de entonces en ese contexto $)^{20}$. Domínguez no menciona así que entre los marcadores discursivos de cierre narrativo (2010: 376 y ss.). La lectura horizontal de la misma Tabla 3 corrobora estos resultados, porque el 87,36\%, 76/87 (Celda A1) sobre el total de los

\footnotetext{
${ }^{20}$ En el ejemplo siguiente se ve un interesante contraste entre el uso argumentativo de entonces en un marco de descripción de hechos "siempre que sean hechos excepcionales, festejos familiares entonces se hacen en domingo" versus la conclusión evaluativa "hay muchas tareas, así que el domingo es corto":

- [...] el sábado todo lo que quieran, el domingo salvo algún caso excepcional, algún cumpleaños de familia o algo que nos haya quedado pendiente de no poder hacer el sábado ENTONCES se hace el domingo, pero siempre pensando en volver temprano a casa porque hay que terminar tareas, revisar las mochilas, planchar los guardapolvos, ASÍ QUE el domingo es medio corto... y preparar por supuesto la ropa para toda la semana, ¿no? que no es... [PRESEEA_BAIRES SS36]
} 
casos de entonces en fragmentos con intención narrativa se dan en el desarrollo de los hechos, mientras que así que acumula la mayor parte de sus usos 80,77\%, 21/26 (Celda B2) sobre el total de sus casos en estos fragmentos, en el lugar de la cesura superestructural.

\begin{tabular}{|c|c|c|c|}
\hline & $1+$ Continuidad & $2+$ Coda o resolución & \\
\hline \multirow[t]{3}{*}{ A Entonces } & $76^{21}$ & $11^{22}$ & 87 \\
\hline & $87,36 \%$ & $12,64 \%$ & $100 \%$ \\
\hline & $93,83 \%$ & $34,38 \%$ & \\
\hline \multirow[t]{5}{*}{ B Asíque } & $5^{23}$ & 21 & 26 \\
\hline & $19,23 \%$ & $80,77 \%$ & $100 \%$ \\
\hline & $6,17 \%$ & $65,62 \%$ & \\
\hline & 81 & 32 & 113 \\
\hline & $100 \%$ & $100 \%$ & \\
\hline
\end{tabular}

Odds ratio: $29 \quad X^{2}: 45,84(p>0,05)$

Tabla 3. Los conectores en contexto narrativo

Los resultados descritos para el PRESEEA y para el HCBA nos hacen ubicar la forma entonces no como ordenador discursivo, según analiza Domínguez, sino como un conector continuativo o ilativo entendido en tanto conector de acciones sucesivas. Es decir que, si bien coincidimos con la autora y con otros estudiosos reseñados previamente en cuanto a que entonces interviene en la progresión temporal (y agregamos de causa/resultado) de la narración, disentimos en que en los fragmentos narrativos conversacionales la mayor parte de los usos funcione como ordenador discursivo, dado que

${ }^{21}$ Algunos de estos casos, que por el momento no se tratan por separado porque los totales que se están manejando en este trabajo son reducidos, podrían analizarse como marcas que permiten solamente mantener el canal abierto, partículas fáticas. En Borzi (1997) sobre el HCBA se registró un $12,16 \%, 27 / 222$ del total de casos de entonces que se caracteriza por presentar marcas léxicas y prosódicas de duda en el entorno y cambio de (sub)tópico.

${ }^{22}$ Ejemplo de esta celda:

- [...] porque en ese momento había menos tránsito y la propia avenida Coronel Díaz era un buen, una buena vía de escape, ENTONCES era muy común que se robara allí...

- Mirá vos, me estás dando miedo, ahora que estoy acá... [PRESEEA_BAIRES SS29]

${ }^{23}$ Ejemplo de esta celda: cuando tengo alguna idea todavía la escribo y ayer estaba harta de hacer correcciones a la tesis, ASÍ QUE eh... dejé todo y me puse a escribir un cuento. [PRESEEA_BAIRES J/E1] 
se espera que el ordenador organice superestructuralmente el discurso ${ }^{24}$. La mayor parte de los usos de entonces (que se asemejan además a los ejemplificados por Domínguez) se mantienen a nivel de la coherencia lineal, local o microestructural y esa es su función más típica. Hay solamente un 12,64\%, 11/87 de casos de entonces funcionando en cesura superestructural, no es esta su función más típica en la narración. Lo previamente descrito también sirve para mostrar la ventaja de cuantificar. No basta con partir de casos auténticos, sino que sobre dichos casos corresponde determinar cuál es el caso que prototípicamente representa la función que los hablantes prefieren para esa forma en ese contexto y es para determinar esa preferencia para lo que resulta útil el uso de la cuantificación.

Por el contrario, la forma así que sí se presenta típicamente en cesura superestructural en la narración y sí ordena el discurso.

\subsection{Acumulación con otro conector de la misma orientación semántica y funcional}

Como dijimos al inicio del trabajo (Cf. Apartado 2), el enfoque presupone que el hablante no siempre busca economía en la construcción del discurso, en el sentido de usar una sola marca para cada función. El uso depende (entre otras cosas), por un lado, del interés del hablante por lograr su objetivo comunicativo y, por otro, de la evaluación de la situación que lo llevará a reforzar o no un señalamiento determinado. En consecuencia es lícito preguntarnos ahora si se registra alguna marca en particular que ponga más en evidencia para el interlocutor la intención continuativa que favorece la elección de entonces en contexto narrativo, ya que por el contrario parece que es la búsqueda de señalamiento de un límite lo que guía el uso de así que en esos contextos.

En el presente apartado se estudia si los conectores bajo estudio se acumulan con otros conectores y, si es así, cuál es el aporte que se logra con dicha acumulación. Domínguez (2010: 370) señala que entonces es uno de los marcadores más frecuentes y que se acumula con $y$. Justifica acertadamente esta acumulación citando a Briz (1993: 41) quien afirma que $y$ coadyuva en la función narrativo-progresiva. Domínguez sostiene que desempeñan la misma función y que podría anularse uno de estos, creemos perti-

\footnotetext{
${ }^{24}$ No lo es dada la clasificación de Zorraquino y Portolés, en la que los ordenadores se espera que organicen la información. Tampoco funcionaría entonces en contexto narrativo prototípicamente como un marcador metadiscursivo en la clasificación de Briz (1998) porque no controla ni organiza el mensaje. Es decir que en fragmentos narrativos, aunque haya ciertos casos que sí lo hagan (un 12,64\%, 11/87 -celda A2 de la Tabla 3-) no es su función típica demarcar ni ordenar la conversación, ni señalar las partes del discurso ni su estructura.
} 
nente en este caso señalar el grado de énfasis mayor que favorece la acumulación, y aclarar que los contextos donde entonces se acumula con $y$ no son idénticos a aquellos en los que no se acumulan, aunque solo o con $y$ se trate siempre de fragmentos narrati$\operatorname{vos}^{25}$. Los contextos en los que hay acumulación muestran distinto equilibrio a izquierda y a derecha de los conectores que aquellos en los que no hay acumulación. Un poco más adelante desarrollamos esta concepción de la coordinación como relación discursiva y la importancia que esta conceptualización otorga al equilibrio entre los conectados. Corresponde decir también que Domínguez no explica cómo afectaría esta acumulación al principio de economía que subyace a las teorías y en particular a las teorías gramaticales, dado que se trata aquí de un conector. En el cuerpo de datos bajo análisis, en contexto narrativo, se encontró que había una acumulación recurrente de entonces con $y$, algo que, como muestra la Tabla 4, no se da en el mismo contexto con así que, el que no se acumula con ninguna otra forma ni cuando coincide en contexto continuativo ni cuando marca coda narrativa. La conjunción copulativa, prototípica de la relación de coordinación, une constituyentes que presentan un alto equilibrio semántico, pragmático, sintáctico y prosódico a izquierda y a derecha del conector, con la única ruptura que da el hecho de que, en la linealidad, un constituyente (una cláusula en nuestro caso) está ubicado posicionalmente antes que el otro $^{26}$. En lo referente al equilibrio semántico entre los conectados, remitimos al trabajo pionero de Lang (1977), quien postula que el interlocutor construye un Integrador Común o Marco de Integración Global para unir en sus semejanzas los conectados de una coordinación ((compró) un auto y una moto > (compró) vehículos). En lo referente a la calidad de la información de los conectados y a la localización de los respectivos acentos principales, ambos conectados coordinados tienden a presentar información nueva señalada con el acento principal del constituyente ${ }^{27}$. Los constituyentes clausales coordinados presentan dos acciones encadenadas o sucesos de un mismo episodio con igual importancia en el discurso que cumplen a su vez igual función retórica, lo que redunda en equilibrio semántico-pragmático. Los tiempos y el modo verbal de ambos constituyentes tienden a ser idénticos y las cláusulas están ordenadas icónicamente según el orden de los hechos favoreciéndose una interpretación de anterioridad / posterioridad en los casos no marcados. El caso (16) presen-

\footnotetext{
${ }^{25}$ No se desarrolla este análisis en el presente trabajo, porque compete a la descripción de la forma entonces comparada consigo misma, es decir, la descripción de todos los contextos de uso de esa forma y no aquellos en los que varía con así que o con otro marcador o conector.

${ }^{26}$ Véase al respecto la propuesta de Haiman (1985) y una aplicación a casos con entonces del español de la Argentina en Borzi (1997: 149-153).

${ }^{27}$ Esta característica fue enunciada para el español por Contreras (1978).
} 
ta un contexto semejante al descripto; ejemplifica la celda A1, que en la lectura vertical de la Tabla 4 muestra en comparación con así que un 100\% de las ocurrencias en dicha celda.

(16) -[...] No, qué primera, ya era deep blue, se llamaba "deep blue", era una computadora muy moderna y jugó una partida con Kasparov, que era el campeón mundial de ajedrez, y le ganó, la computadora. Y ENTONCES yo escribí un editorial para el diario en ese momento que se titulaba: “¿Estás contenta, Deep Blue?" y el editorial trataba. [...] [PRESEEA_BAIRES JM12]

\begin{tabular}{|c|c|c|c|}
\hline & $1+y$ & $2-y$ & \\
\hline \multirow[t]{3}{*}{ A Entonces } & 24 & 63 & 87 \\
\hline & $27,59 \%$ & $72,41 \%$ & $100 \%$ \\
\hline & $100 \%$ & $70,79 \%$ & \\
\hline \multirow[t]{5}{*}{ B Asíque } & 0 & 26 & 26 \\
\hline & $0 \%$ & $100 \%$ & $100 \%$ \\
\hline & $0 \%$ & $29,21 \%$ & \\
\hline & 24 & 89 & 113 \\
\hline & $100 \%$ & $100 \%$ & \\
\hline
\end{tabular}

Tabla 4. Acumulación de las formas bajo estudio con ' $y$ '

La lectura vertical de la columna 1 de la Tabla 4 es contundente, entonces se acumula con $y$, un conector de su misma orientación semántica, cumpliendo una función ilativa o continuativa conectando una secuencia de acciones o sucesos de un mismo episodio. En el HCBA también se dio una celda cero en relación con así que. En el HCBA hay un porcentaje también importante sobre todos los casos de entonces que lo muestran combinado con $y, 17,12 \%, 38 / 222$, aunque este es menor que el que se presenta en el cuerpo de datos bajo análisis aquí.

\section{Conclusiones}

Los resultados obtenidos sobre parte del PRESEEA_BAIRES y los obtenidos sobre el HCBA nos permiten afirmar que tanto entonces como así que varían en contexto consecutivo en el español hablado de Buenos Aires. Como se dijo, un estudio contrastivo empírico cuali-cuantitativo, que diferencia los contextos, nos orienta hacia una descripción sistemática de dichas formas en tanto permite identificar con qué significados y en qué funciones prefiere usar el hablante más frecuentemente cada una de estas. 
En primer lugar, como se concluyó en Borzi (1997) sobre datos del HCBA, encontramos que en el PRESEEA_BAIRES, a la manera de los marcadores discursivos, entonces funciona como tematizador de información y así que como marca de abandono de turno. En esos contextos, entonces activa su significado mostrativo temporal anafórico (significado registrado por la NGLE, 2009: \$17.9g-i), mientras que así que "constituye un límite hacia adelante" y expresa posterioridad (NGLE, 2009: \$23.16k) o catáfora (NGLE, 2009: \$17.9k).

Se puede afirmar también que en contexto de intención narrativa, entonces es un conector que preferentemente conecta secuencias de acciones o estados de hechos, dentro de la Complicación. Por su parte, así que, también en contexto narrativo, focaliza la Coda o Resolución. Se sostiene, de esta manera, que preferentemente entonces funciona como conector continuativo o ilativo, no como ordenador del discurso, mientras que sí funciona como ordenador discursivo así que, porque interviene señalizando la superestructura narrativa. En estos contextos entonces no solamente activa su significado mostrativo temporal de anterioridad, simultaneidad y posterioridad para intervenir en contextos de sucesión temporal, sino también para intervenir en contextos de causa real/resultado.

Si bien no se tratan en este trabajo los contextos argumentativos sobre el PRESEEA, sí podemos decir que según resultados de Borzi (1997) (sobre discurso oral) y de Borzi (2004) (sobre discurso escrito) es en fragmentos argumentativos donde más prototípicamente entonces orienta la información de izquierda a derecha y ordena el discurso, interviniendo en la señalización de la superestructura argumentativa.

Digamos por otro lado que sobre el total de casos de entonces analizados (100\%/157) se registró 1 caso (un 0,64\%, 1/157) en abandono de turno; 17 casos en contexto de tematización $(10,82 \%, 17 / 157), 87$ casos en contexto narrativo $(55,42 \%, 87 / 157)$ y 52 en argumentativo $(33,12 \%, 52 / 157)$, estos últimos no sub-analizados en el presente trabajo.

Sobre el total de casos de así que (100\%/100) se registraron 20 casos en contexto de abandono de turno, 6 casos ecoicos, 26 en contexto de intención narrativa y 48 en contexto de intención argumentativa, estos últimos tampoco fueron sub-analizados en el presente trabajo.

El análisis contrastivo cualitativo y cuantitativo nos permitió aportar evidencia respecto de los contextos de uso más típicos de cada uno de los dos conectores y mostrar que no son intercambiables entre sí y que siempre aportan significado. 


\section{Referencias bibliográficas}

Alcina Franch, Juan y José Manuel Blecua (1975): Gramática Española. Barcelona, Ariel.

Álvarez Menéndez, Alfredo (1991): "Conectores y grupos oracionales consecutivos", Lingüística Española Actual, 13/1, págs. 117-132.

Álvarez, Alfredo. (1995): Las construcciones consecutivas. Madrid, Arco/Libros.

Álvarez, Alfredo (1999): "Las construcciones consecutivas". En Bosque, Ignacio y Violeta Demonte, (dirs.), págs. 3739-3804.

Beinhauer, Werner (1978): El español coloquial. Madrid, Gredos.

Bello, Andrés (1980) [1847]: Gramática de la lengua castellana. Madrid, EDAF.

Borzi, Claudia (1997): Syntax, Semantik und Pragmatik der Konnektoren entonces, así que und (tal/..) que (Diss.). Ludwig-Maximilians-Universität, Munich, Profidruck.

Borzi, Claudia (2004): "Sintaxis de entonces en corpus escrito". En Arnoux, Elvira y María Marta García Negroni (eds.), Homenaje a Oswald Ducrot. Buenos Aires, EUDEBA, págs. 47-76.

Bosque Ignacio y Violeta Demonte, (dirs.) (1999): Gramática Descriptiva de la Lengua Española, Madrid, Espasa.

Briz Gómez, Antonio (1993). Los conectores pragmáticos en la conversación coloquial (II): su papel metadiscursivo. Español Actual 59, 39-56.

Briz Gómez, Antonio (1998): El español coloquial en la conversación. Esbozo de pragmalingüística. Barcelona, Ariel.

Briz, Antonio, Salvador Pons Bordería y José Portolés (coords.): Diccionario de partículas discursivas del español. http://www.dpde.es/

Casado Velarde, Manuel (1998): "Lingüística del texto y marcadores del discurso". En Martín Zorraquino, María Antonia y Estrella Montolío Durán (eds.), Marcadores del discurso. Madrid, Arco/Libros, págs. 55-70.

Casares, Julio (1979): Diccionario ideológico de la lengua española. Barcelona, G. Gili.

Contreras, Heles (1978): El orden de palabras en español. Madrid, Cátedra.

Cortés Rodríguez, Luis (1991): Sobre conectores expletivos y muletillas en el español hablado. Málaga, Editorial Librería Ágora.

Domínguez García, María Noemí (2010): "Los marcadores del discurso y los tipos textuales”. En Loureda Lamas, Óscar y Esperanza Acín Villa (coords.). Los estudios sobre marcadores del discurso en español, hoy. Madrid, Arco/Libros, págs. 359-413.

Fernández Ramírez, Salvador (1986): Gramática Española. 4. El verbo y la oración. Madrid, Arco/Libros.

Firbas, Jan (1992): Functional Sentence Perspective in Written and Spoken Comunica- 
tion. Cambridge, Cambridge University Press.

Fuentes Rodríguez, Catalina (1987): Enlaces Extraoracionales. Sevilla, Alfar.

García, Erica (1985): “Shifting variation”, Lingua, 67, págs. 189-224.

García Fernández, Luis (1999): "Los complementos adverbiales temporales. La subordinación temporal”. En Bosque, Ignacio y Violeta Demonte (dirs.), págs. 3129-3208.

Gili Gaya, Samuel (1961): Curso Superior de Sintaxis Española. Barcelona, Biblograf.

Haiman, John (1985): “Symetry”. En Haiman, John (ed.), Iconicity in Syntax. Amsterdam, John Benjamins, págs. 73-75

Kany, Charles (1969): Sintaxis hispanoamericana. Madrid, Gredos.

Koch Peter \& Wulf Oesterreicher (1990): Gesprochene Sprache in der Romania: Französisch, Italienisch, Spanisch. Tübingen, Niemeyer.

Kovacci, Ofelia (1990/92): El comentario gramatical, vols. 1 y 2. Madrid, Arco/Libros.

Lakoff, George (1987): Women, fire and dangerous things. Chicago, University Press.

Lang, Ewald (1977): Semantik der koordinativen Verknüpfung. Berlin, Akademie Verlag

Langacker, Ronald (1987): Foundations of Cognitive Grammar. Theoretical Prerequisites, vol. 1. Stanford, Stanford University Press.

Langacker, Ronald (1991): Foundations of Cognitive Grammar. Descriptive Application, vol. 2. Stanford, Stanford University Press.

Lenz, Rodolfo (1935): La oración y sus partes. Madrid, Nueva Revista de Filología Española.

Lope Blanch, Juan M. (1984): “Anomalías en el habla popular de México”. En Schwartz de Lerner, Lía e Isaías Lerner (eds.), Homenaje a Ana María Barrenechea. Madrid, Castalia, págs. 99-104.

Martín Zorraquino, María Antonia y José Portolés Lázaro (1999): "Los marcadores del discurso". En Bosque, Ignacio y Violeta Demonte (dirs.), págs. 4051-4213.

Martínez, Angelita (2009): "Metodología de la investigación lingüística: el enfoque etnopragmático". En Narvaja de Arnoux, Elvira (dir.), Escritura y producción de conocimiento en las carreras de posgrado. Buenos. Aires, Santiago Arcos editor, págs. 259-286.

Matte Bon, Francisco (1992): Gramática comunicativa del español, vol. 2. Madrid, Difusión.

Moliner, María (1981): Diccionario de uso del español. Madrid, Gredos.

Pereira Scherre, María Marta y Anthony Julius Naro (1991): "Marking in discourse: 'Birds of a feather", Language Variation and Change, 3, págs. 23-32.

Pottier, Bernard (1962): Systématique des éléments de relation. Étude de morphosyntaxe structurale romane. Paris, Klincksieck.

Real Academia Española (1931): Gramática. Madrid, Espasa Calpe. 
Real Academia Española (1973): Esbozo de una Nueva Gramática de la Lengua Española. Madrid, Espasa Calpe.

Real Academia Española (2009): Nueva gramática de la lengua española. Madrid, Espasa.

Real Academia Española (1984): Diccionario de la lengua española. Madrid, Espasa Calpe.

Roca Pons, José (1960): Introducción a la gramática. Barcelona, Vergara.

Seco, Rafael (1978): Manual de gramática española. Madrid, Aguilar.

Seco, Manuel (1989): Gramática esencial del español. Madrid, Aguilar.

Van Dijk, Teun A. (1980) [1978]: La ciencia del texto. Buenos Aires, Paidós,

Van Dijk, Teun A. (1985): “Semantic Discourse Analysis”. En Van Dijk, Teun A. (ed.),

Handbook of discourse analysis - Dimensions of Discourse. Orlando, Florida, págs. 103-136.

Veciana, Roberto (1984): “'Entonces’, sus usos”, Yelmo, 60/61, págs. 12-23.

Vigara Tauste, Ana María (1992): Morfosintaxis del español coloquial. Madrid, Gredos. 



\title{
LOS ACTOS SILENCIOSOS EN LA CONVERSACIÓN DE LOS JÓVENES ESPAÑOLES: ¿(DES)CORTESÍA O “ANTICORTESÍA”?
}

\author{
LAura CAmargo Fernández y BeAtriz MÉndeZ Guerrero \\ Universitat de les Illes Balears \\ laura.camargo@uib.es - beatriz.mendez@uib.es
}

\begin{abstract}
Resumen
El silencio es un elemento tan complejo y diverso como habitual en la comunicación humana, por lo que debe ser atendido en la investigación pragmática. Para ello, ha de conocerse qué lo motiva y qué funciones cumple en la interacción conversacional. Los estudios sobre cortesía verbal aportan referencias esenciales sobre el fenómeno silencioso asociándolo a la descortesía (Leech, 1983; Brown y Levinson, 1987; Jaworski, 1997; Haverkate, 1994; Sifianou, 1997). Asimismo se ha considerado el silencio como un componente cultural que puede ser interpretado de manera positiva o negativa pero jamás como un elemento vacío (Cestero, 1999; Nakane, 2007).

En este trabajo se mostrará que muchos silencios propios de la conversación en español no constituyen actos que dañen la imagen del interlocutor, sino que son simples estrategias comunicativas intencionales que pueden, en algunos contextos, relacionarse con la anticortesía (Zimmermann, 2003). Para demostrarlo, se presentará: 1) una taxonomía de las funciones pragmáticas del silencio en la conversación informal en español; 2) una escala de (des)cortesía a partir de aspectos como las duración del silencio y el coste/beneficio que tiene este para hablante y destinatario; y 3) la relación entre silencio y "anticortesía”.
\end{abstract}

PALABRAS CLAVE: Silencio, Pragmática, (Des)cortesía, Anticortesía, Conversación espontánea.

\begin{abstract}
As a complex, diverse but also very common element in human communication, silence needs to be investigated by Pragmatics. In order to understand the phenomenon, we have to know what motivates silence and what functions it accomplishes during conversational interaction. The studies in Politeness have provided essential references on the silent phenomenon, often associating it to impoliteness (Leech, 1983; Brown y Levinson, 1987; Jaworski, 1997; Haverkate, 1994; Sifianou, 1997). Silence is also regarded as a cultural component that can be interpreted in a positive or negative way, but never as an empty element (Cestero, 1999; Nakane, 2007).

In this paper it will be shown that many silences in Spanish conversation are not Face Threatening Acts, but elements acting as intentional communication strategies that might, in some contexts, interact with Anti politeness (Zimmermann, 2003). To demonstrate this thesis, we will present: 1) a pragmatic taxonomy of silence's functions in Spanish informal conversation; 2) a scale of impoliteness including aspects such as the duration of silence and the cost/benefit both for speaker and addressee; and 3) the relationship between silence and Anti politeness.
\end{abstract}

KEY WORDS: Pragmatics, Impoliteness, Anti politeness, Spontaneous conversation. 


\section{Introducción}

El silencio es concebido en gran parte de la cultura occidental, principalmente en las sociedades orientadas hacia la cortesía positiva, como una prueba de falta de cooperación lingüística; por tanto en estas culturas ha sido habitualmente interpretado negativamente como un acto de descortesía. Sin embargo, recientes estudios (Camargo y Méndez, en prensa) indican que hay que mostrar cautela al asignar grados de (des)cortesía al silencio, ya que estos dependerán en gran medida del contexto en el que se produzca el acto silencioso.

Numerosos autores (Leech, 1983; Brown y Lenvison, 1987; Jaworski, 1993; Haverkate, 1994; Sifianou, 1997) han abordado el estudio de los actos silenciosos desde un enfoque sociopragmático llevados por la necesidad de proporcionar apuntes sobre los comportamientos (des)corteses de los individuos y sobre el papel del silencio en ellos. De manera general, los estudios sobre cortesía verbal tratan de explicar el comportamiento de los individuos en la interacción conversacional y la manera en que este se evalúa. El interés radica en que ni las personas se han conducido siempre de igual modo, ni lo hacen de forma homogénea en las distintas culturas $y$, aunque la variedad ha existido siempre, este tiempo de cercanías globales ha contribuido a hacerla patente y a requerir alguna explicación a nuestros aciertos y desaciertos comunicativos cotidianos, para así facilitar los cada vez más frecuentes intercambios interculturales. Por todo ello, en primer lugar, han de conocerse las causas que motivan el silencio y las funciones que cumple en la conversación.

Es sabido que el modo en que nos dirigimos a una persona depende no solo de nuestra intención comunicativa, sino también de otros factores como el grado de confianza, las diferencias de edad, de jerarquía, el sexo de los hablantes, etc. En otras palabras, entre hablante y oyente existe una relación social que se organiza en torno a dos ejes básicos: un eje horizontal, determinado por el grado de conocimiento previo, de confianza y proximidad, que da lugar a relaciones en un plano de igualdad; y un eje vertical que establece diferencias de jerarquía basadas en la edad, el estatus, los conocimientos adquiridos, etc. (Kerbrat-Orecchioni, 1992: 74). Los estudios sobre la cortesía verbal se ubican en la pragmática precisamente por ser esta la perspectiva lingüística que se ocupa del lenguaje en su contexto de uso y aunque no todos los estudios sigan esta línea "la pragmática $[\ldots]$ no debería prescindir de ejemplos basados en intercambios comunicativos reales" (Camargo, 2006: 83). En este trabajo seguimos la propuesta de Bravo (2003, $2004,2010)$ de hablar de pragmática sociocultural para los trabajos sobre cortesía verbal, pues enfatiza su carácter eminentemente social y contextual. La autora confiere un lugar central al concepto de imagen social (face). Al no considerar los aspectos positivo y 
negativo -propuestos por Brown y Levinson (1987) y que serán vistos más adelante-, presenta los conceptos de autonomía y afiliación. El primero se refiere a la percepción que tiene un individuo de sí mismo y que los demás tienen de él como alguien con entidad propia en el grupo, mientras que el segundo "agrupa aquellos comportamientos en los cuales se refleja cómo una persona desea verse y ser vista por los demás en cuanto a aquellas características que la identifican con el grupo" (Bravo, 2003: 106).

Ciertamente, en los intercambios comunicativos, estos dos parámetros (autonomía y afiliación) están expuestos continuamente al devenir conversacional, pudiendo a lo largo de la misma realizarse actos que los amenacen. En este marco de potenciales amenazas a la imagen es donde, según Brown y Levinson (1987: 65), actúa la cortesía, promoviendo estrategias comunicativas para evitar o minimizar la amenaza a la imagen social.

Partiendo de estas consideraciones, en este estudio presentaremos: 1) algunas de las funciones más representativas del silencio en la conversación en español; 2) una taxonomía pragmática basada en los 1825 actos silenciosos recogidos en un corpus de conversaciones espontáneas de 15 horas de duración entre 10 informantes jóvenes (5 mujeres y 5 hombres); 3) una escala de (des)cortesía a partir de aspectos como la duración y el coste-beneficio para los hablantes; y 4) la relación existente el silencio y la anticortesía.

\section{Hacia una taxonomía pragmática del silencio}

Como se ha dicho, los silencios son fenómenos altamente culturales y pueden ser interpretados de forma positiva o negativa, pero jamás como elementos vacíos. Por ello, abogamos por acometer su estudio desde la pragmática y por abandonar el estereotipo del silencio como fenómeno imposible de abordar desde una óptica lingüística. Los estudios que se han realizado hasta el momento sobre paralenguaje y pragmática intercultural han concluido que la española es una cultura poco propicia al silencio en la que hay una clara preponderancia de la palabra y en la que el silencio puede interpretarse como un elemento "molesto" (Haverkate, 1994: 58). Pero eso no significa que el silencio no aparezca en nuestro discurso y mucho menos que no tenga que ser estudiado.

Entendemos por silencio (Camargo y Méndez, en prensa) "la ausencia de habla superior a un segundo que se utiliza para comunicar; es, por tanto, una estrategia paralingüística relevante que trasmite información, estructura la conversación o expresa emo- 
ciones y que está claramente determinada por factores contextuales, sociales y culturales". De este modo, dichos actos comunicativos son omisiones de habla intencionales ${ }^{1}$ que a menudo se realizan de manera voluntaria y otras veces de forma inconsciente y que pueden ser más significativas que la propia palabra. Esto último se desprende de la idea de Searle (2001: 274) que explica que "no todos los estados conscientes son intencionales, ni todos los estados intencionales son conscientes". En consecuencia, los silencios en la interacción serán, como decimos, siempre intencionales pero no serán necesariamente conscientes. Frente a estos signos comunicativos se hallaría el mutismo (Jaworski, 1993; Kurzon, 1997) o quietud (Poyatos, 1994), que es la ausencia de habla que no comunica, aquí entendida como "no conversacional". Estos últimos elementos no formarán parte de nuestro análisis. Tampoco serán abordadas aquí las pausas, ausencias de habla con un periodo de tiempo comprendido entre 0 y 1 segundos (Cestero, 1999: $35)^{\prime 2}$.

El uso del silencio - que no debe confundirse, como ya se ha dicho, con el mutismo o la quietud-casi siempre lleva implícita la intención de callar, la de no decir algo y, de esta forma, puede ser también un medio indirecto para conseguir determinados objetivos (Escandell, 2006: 37). Por consiguiente, comunicar implicará siempre una actividad de interpretación constante apoyada, entre otros elementos, por valores socioculturales. Este proceso de interpretación se volverá más relevante, si cabe, en el caso del silencio para el que necesitamos, en la mayoría de ocasiones, del conocimiento de unos parámetros socioculturales compartidos (Vivas, 2011: 26). Podemos decir, por tanto, que el silencio es un elemento altamente contexto-dependiente ${ }^{3}$.

\footnotetext{
${ }^{1}$ Entiéndase que el silencio, cuando aparece en la interacción, no puede considerarse nunca un elemento vacío (esto es, no puede ser mutismo). En palabras de Mateu (2001: 274): “[en la conversación] el silencio absoluto, asignificativo, no existe, pues indicaría vacuidad total, incomunicación, y ello entraría en contradicción con uno de los principios básicos de la Teoría de la Comunicación. Como defiende la Escuela de Comunicación de Palo Alto: no es posible no comunicar". De modo que en este trabajo se entenderán como significativos todos los silencios presentes en la conversación.

${ }^{2}$ Ya advertimos de que en este trabajo utilizaremos indistintamente los términos "silencio" y "acto silencioso" como equivalentes, sobre todo, por motivos estilísticos, pero serán objeto de nuestro estudio todas las ausencias de habla superiores a 1 segundo que tengan intención comunicativa.

${ }^{3}$ Para futuros estudios sobre el silencio, proponemos atender la noción de significados presumibles presentada por Levinson (2000) incorporando, eso sí, factores culturales que son determinantes sobre el uso de este elemento paralingüístico. El autor explica que, en el proceso inferencial, los hablantes se sirven de unos principios universales cognitivos (significados presumibles) que guían la construcción e interpretación de los enunciados y conducen a su implicatura. Tales principios funcionan por defecto y de manera constante, de forma que el hablante tiene en mente tanto lo que se dice como lo que
} 
En las últimas décadas y desde distintos enfoques lingüísticos -como la etnografía de la comunicación, la semiótica o el análisis de la conversación- se han presentado algunas taxonomías sobre el silencio que destacan su carácter como elemento altamente comunicativo.

Saville-Troike (1985: 16-17), al referirse al comportamiento comunicativo de los seres humanos, propone una clasificación etnográfica en la que distingue tres tipos de silencios: "aquellos determinados institucionalmente", "los promovidos por el grupo" y "el silencio individual". Entre los primeros se encontrarían, por ejemplo, los silencios rituales, los de los grupos religiosos, los propios del tabú, los indicativos de jerarquías sociales, etc.; entre los segundos se distingue entre el silencio situacional, el silencio normativo y el silencio simbólico; por último, entre los silencios determinados individualmente, se señalan los interactivos (entre los que se encuentra el sociocontextual, el lingüístico y el psicológico) y los no interactivos (constituidos por el silencio contemplativo o meditativo y el inactivo).

Un enfoque más funcional es el de Jaworski $(1993,1997)$, que interpreta los conceptos de silencio y habla como integrantes de un continuum y no como términos antagónicos y propone, a su vez, una escala del silencio desde los valores más negativos a los más positivos. Los valores más negativos estarían relacionados: con la expresión y/o muestra de varios estados emocionales y cognitivos; con la manera de señalar transiciones en la vida colectiva (ritos, ceremonia, etc.); o con los actos de resistencia, muestras de respeto, desafío al poder o autocensura. Por otro lado, los valores más positivos tendrían que ver: con los comportamientos silenciosos por motivos estéticos o artísticos; con lo que se deja sin decir, o a la habilidad de escuchar.

Gallardo $(1993,1996)$, desde el análisis de la conversación, diferencia y define el silencio, un silencio y una pausa. El silencio, que es la "ausencia de habla durante un tiempo amplio", no forma parte de la conversación. Según Gallardo, este tipo de silencio queda excluido de la interacción y se encuentra en distribución complementaria respecto a esta; un silencio sí pertenece, en cambio, a la conversación y es el que se da entre intervalos; por último, las pausas serían los silencios presentes dentro de un mismo turno de habla.

Poyatos (1994), desde sus trabajos sobre comunicación no verbal, también se refiere a las funciones positivas y negativas del silencio y lo hace desde un punto de vista interactivo. Como funciones positivas menciona el silencio natural del ambiente, el silencio

podría haberse dicho. Así, la interpretación preferida de los actos comunicativos dependerá, pues, de esos significados presumibles que son interpretaciones sistemáticas. 
de "rapport" ("siendo las palabras innecesarias para la comunicación, crecen en profundidad los sentimientos mutuos"), el silencio del amor compasivo ("que une en lugar de separar") y el silencio profesional (entre médico paciente, etc.). Como funciones negativas distingue entre el silencio para expresar actitudes negativas (como negación de comunicación) y el silencio manipulativo ("utilizado intencionalmente sabiendo que la ansiedad que causa está en proporción directa a su duración”) (Poyatos, 1994: 179-180).

En el análisis del discurso, Bilmes (1994) ha distinguido entre silencio absoluto u objetivo (absolute silence) y el silencio notable (notable silence), cuyo principal subtipo es el silencio conversacional. El primero de ellos hace referencia a la simple ausencia de sonido; en cambio, el segundo denota una ausencia relevante de sonido, "it is only when talk is relevant that we get conversational silence" (1994: 74). A su vez, este autor divide el silencio conversacional en dos subtipos: el explícito, el "no decir nada" ante un estímulo verbal, lo que indica una falta de interés, y el implícito, cuando se contesta con palabras pero solo "por decir algo": "some silences are obscured by words" (Bilmes, 1994: 83).

Kurzon $(1997,2007)$, desde un punto de vista semiótico, explica las relaciones "contrarias" entre el habla y el silencio, pues entiende que una persona no puede hablar y estar en silencio al mismo tiempo. En la interacción ideal, se alternan habla-silenciohabla: cuando una persona habla, la otra escucha (Kurzon, 1997: 11). Sin embargo, en esta explicación el mismo autor observa una paradoja cuando se plantea que la ausencia de comunicación (sin interacción) no implica silencio, porque este se entiende como actividad comunicativa. Posteriormente, planteará una clasificación de los silencios en las interacciones sociales. Así, distingue entre silencios conversacionales (equivalen a un acto de habla); silencios temáticos (mientras que en los silencios conversacionales el hablante no tiene nada que decir, en los temáticos ocurre que no tiene nada que decir respecto al tema que están tratando: política, religión, machismo...); silencios textuales (si en los silencios temáticos se guarda silencio sobre un tema específico, este tipo de silencio se produce en contextos en los que se lee un texto en silencio; sería, por tanto, el silencio propio de las bibliotecas); silencio situacional (mientras que el silencio textual se produce cuando los hablantes están leyendo en silencio, el situacional es el que se produce en algunos lugares que son propicios para ello como tribunales, escuelas, hospitales, funerarias, prisiones, campos de batalla, etc.) (Kurzon, 2007: 1666-1684).

Por su parte, Cestero (1999: 30-31), partiendo de un estudio global de la comunicación no verbal, propone una clasificación de las funciones comunicativas de los signos paralingüísticos y quinésicos entre los que se encuentran los silencios. Apunta a la plurifuncionalidad de los signos no verbales, los cuales pueden cumplir las siguientes funciones: añadir información al contenido o sentido de un enunciado verbal o matizarlo 
(especificando su contenido, confirmándolo, reforzándolo, debilitándolo, contradiciéndolo o camuflándolo); comunicar sustituyendo al lenguaje verbal; regular la interacción; subsanar deficiencias verbales; o intervenir en conversaciones simultáneas.

Nakane $(2005,2007$ y 2010) presenta un enfoque más cultural en el que el silencio se entiende como un fenómeno influido por múltiples factores sociales y culturales y aboga por la importancia de considerar la intencionalidad del silencio como uno de los aspectos más importantes. De esta manera, identifica el silencio como intencional (el que se utiliza voluntariamente como estrategia) y no intencional (provocado involuntariamente, debido a la ansiedad extrema, la vergüenza o el pánico).

Finalmente, y en el marco de una lingüística de corte más estructuralista, Ephratt (2008) revisa el modelo comunicativo clásico de Jakobson y asigna al silencio cada una de las funciones que se incluían en este modelo. Respecto a la función referencial, dice del silencio como signo lingüístico (signo cero) que trasmite información; de la función emotiva plantea que es una forma icónica afectiva de expresar emociones; en cuanto a la función conativa concluye que el silencio se utiliza tanto en los actos de habla directos como en los indirectos; en la función poética habla de la censura, las metáforas y las elipsis como algunas de sus representaciones; en la función fática, el silencio se utiliza para mantener un contacto permanente y de alianza; y en la función metafísica, el silencio es, entre otras cosas, una "marcador discursivo".

Todas estas clasificaciones nos han llevado a proponer una taxonomía pragmática sobre el silencio en la conversación en español (Camargo y Méndez, en prensa) a partir del análisis de un corpus de conversaciones espontáneas entre hombres y mujeres de 15 horas de duración que utilizaremos en este estudio. Distinguimos en un primer nivel entre silencios discursivos, silencios estructuradores y silencios epistemológicos y psicológicos. 


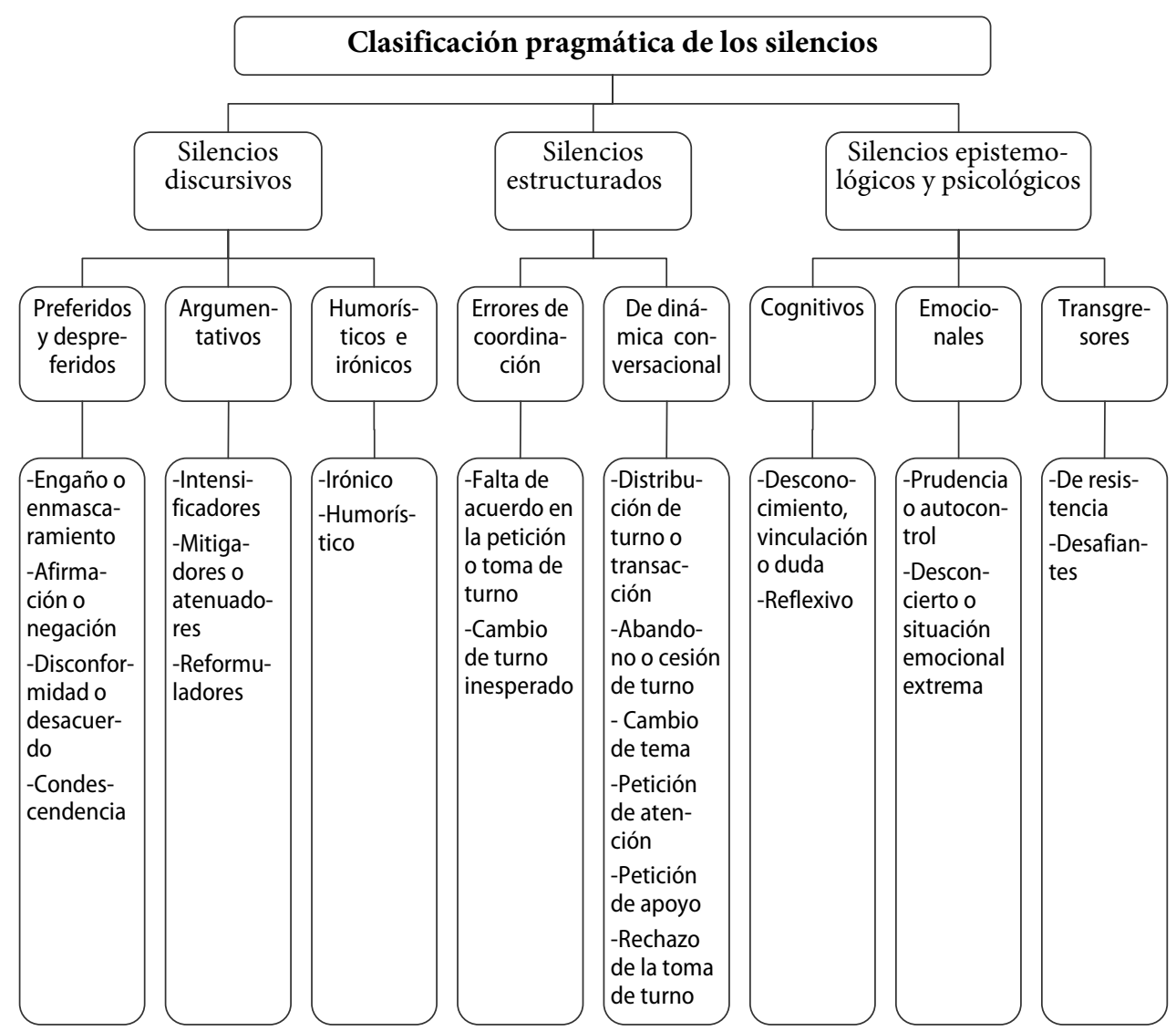

Figura 1. Taxonomía pragmática de los actos silenciosos (Camargo y Méndez, en prensa)

Los silencios discursivos tienen la finalidad de indicar una función comunicativa y facilitar tanto el procesamiento como la producción del discurso. Estos silencios orientan al receptor sobre la intención comunicativa del orador y cuentan con un significado determinado por el contexto y la situación comunicativa. Consideramos este tipo de silencios como mecanismos que nos asisten en el procesamiento inferencial, que es el que hace posible la interpretación completa de los enunciados. Además de orientar las inferencias, estos silencios, muchas veces, propician la comunicación haciendo que el discurso avance. En esta categoría encontraríamos los silencios preferidos y despreferidos (engaño o enmascaramiento, afirmación o negación, disconformidad o desacuerdo y condescendencia); los silencios argumentativos (intensificadores, mitigadores o atenuadores y reformuladores) y los silencios humorísticos e irónicos. 
(1) Ejemplo de silencio discursivo [EF.2.I4;I5]

I4 e I5 son amigos, tienen entre 20 y 25 años. Tema: I4 le comenta a I5 lo difícil que resulta aparcar en una calle en concreto, con lo que I5 no está de acuerdo.

I4: me parece súper complicado aparcar en esta calle y más a estas horas// es imposible del todo

I5: ///(2) depende/ por las tardes no es tan complicado

I4: chico/ pues en mi caso no hay manera// tengo más mala suerte

I5: bueno mujer///(1) tampoco es para tanto///(1) igual es que no buscas bien

En (1) el informante recurre al silencio para disentir con su interlocutor sobre lo que está expresando de manera más implícita. Ante la posible respuesta despreferida, I5 opta por callar y no mostrar tan explícitamente su desacuerdo con tal de que su interlocutor no entienda esta intervención como un ataque hacia él (que no se vea como el blanco de la objeción) y que esta situación no afecte a la relación entre los participantes. Por ello el silencio adquiere un valor de refutación, de desacuerdo; en suma, el hablante realiza un movimiento discursivo que contradice el enunciado anterior (o determinados aspectos del mismo) manifestando una posición contraria a lo expuesto.

Los silencios estructuradores forman parte de la estructura interna de la conversación española, ya que no siempre se produce una distribución regular de los turnos y a menudo se solapan, se superponen parcialmente o no se inician a tiempo. Siendo así, puede considerarse que el silencio resultante de esta distribución no siempre regular de los turnos forma parte de la interacción conversacional. Aquí situamos los silencios por errores de coordinación (falta de acuerdo en la petición o toma de turno y cambio de turno inesperado); y los silencios de dinámica conversacional (distribución de turno o transacción, abandono o cesión de turno, cambio de tema, petición de atención, petición de apoyo y rechazo de la toma de turno).

(2) Ejemplo de silencio estructurador [CE.3.H0;H4] (2088-2098)

H0 y H4 son amigos, tienen entre 20 y 25 años. Tema: H4 es músico y están hablando de su profesión.

\footnotetext{
${ }^{4}$ En el apartado 6 se presentan las convenciones de transcripción utilizadas. Entiéndase que en cada ejemplo serán únicamente objeto de análisis los silencios destacados en gris. La forma en la que presentaremos los silencios será la siguiente: tres barras y un número entre paréntesis que indica los segundos que dura dicho silencio: "///(2)" = silencio de 2 segundos de duración. El resto de silencios estarán representados de la misma forma pero permanecerán en el mismo color que el resto del texto. Por último, las pausas (por ser ausencias de habla inferiores a un segundo) se representarán con doble barra: //.
} 
H0: y lo mismo cuando cantas en un coro// que tienes otra voz a lo mejor por debajo y tú ya no sabes cuándo tienes que entrar (risas= TODOS) y es un lío y: ¡ah:! ¡terrible!

H4: ya pero eso es acostumbrarte///(1) es que eso:///(1) es normal que te pase// pero cuando llevas muchos años tocando no:// es más cuando llevas muchos años tocando/ si no escuchas la otra voz// ya es cuando tú dices// hey hey: que aquí

H0: que aquí pasa algo

H4: sí

H0: voy yo fuera///(1,5)

H4: incluso:///(1) cuando tú:// nosotros contamos compases ¿no?///(1) lo sabes ¿no? lo de: uno// dos// tres

Como apuntábamos anteriormente, en la conversación pueden producirse periodos de habla discontinua (Sacks et al., 1974) a causa de errores de coordinación entre los hablantes que dan lugar, entre otras cosas, a solapamientos y silencios. En el ejemplo (2) puede observarse cómo el silencio se produce por una conclusión abrupta o inesperada del turno de H0. A consecuencia de este ofrecimiento de turno inesperado, $\mathrm{H} 4$ se ve en la "obligación" de tomar la palabra e iniciar un nuevo turno de habla.

Por último, los silencios epistemológicos y psicológicos surgen en relación al estado psicológico o emocional de los hablantes en la interacción. Las personas tendemos a expresar nuestros sentimientos y emociones a través del discurso, pero también mediante la falta de él. De este modo, uno de los indicadores más representativos en la conversación española de las emociones, sentimientos, estados de ánimo, deseos, dudas o vacilaciones, voluntades y grado de interés es el silencio. Formarían parte de este tipo los silencios cognitivos (desconocimiento, vacilación o duda y los reflexivos); los silencios emocionales (prudencia o autocontrol y desconcierto o situación emocional extrema); y los silencios transgresores (aquellos que muestran resistencia ante las demandas del interlocutor).

(3) Ejemplo de silencio epistemológico y psicológico [CE.5.H0;H7] (1556-1561)

H0 (mujer) y H7 (hombre) son amigos, tienen entre 20 y 25 años. Tema: hablan del precio de la comida en el extranjero.

H7: no no/ no/ era otra cosa que era de: España// no sé por qué/ no/ tomates eran de España/ eran baratos

H0: ¿qué llamas barato?// ¿un euro y medio?

H7: no/ era más barato que aquí/ no me acuerdo/ no sé/ pero yo es que ahora no compro///(1) no los compro yo ahora// no no sé a qué precio están ahora// los de "ramallet" son carísimos/ pero allí no había///(4) 
H0: qué curioso

El tipo de silencio de (3) debilita en alguna medida el contenido de la enunciación, pues el hablante manifiesta inseguridad, ya que o bien desconoce lo que está diciendo y, por ello, duda o vacila en la explicación, o bien no recuerda en ese preciso instante lo que quiere comunicar.

La siguiente tabla recoge, a modo de síntesis, las taxonomías propuestas hasta la fecha en relación al silencio que han sido explicadas en este apartado.

\section{Taxonomías lingüísticas de los silencios}

\begin{tabular}{|c|c|c|c|}
\hline Saville-Troike (1985) & Jaworski $(1993,1997)$ & Gallardo $(1993,1996)$ & Poyatos (1994) \\
\hline $\begin{array}{l}\text { "El silencio es parte } \\
\text { integral del marco } \\
\text { cultural del habla" }\end{array}$ & $\begin{array}{l}\text { "El silencio y el } \\
\text { habla como un } \\
\text { continuum" (desde } \\
\text { formas más cercanas } \\
\text { al silencio a otras } \\
\text { más propias del } \\
\text { habla) }\end{array}$ & $\begin{array}{l}\text { “El silencio es la } \\
\text { ausencia de habla } \\
\text { durante un tiempo } \\
\text { amplio y no forma } \\
\text { parte de la conversa- } \\
\text { ción. Un silencio, en } \\
\text { cambio, sí pertenece } \\
\text { a la conversación y } \\
\text { se produce durante } \\
\text { un intercambio” }\end{array}$ & $\begin{array}{l}\text { "El silencio } \\
\text { sería la ausencia } \\
\text { de sonido } \\
\text { mientras que la } \\
\text { quietud hace } \\
\text { referencia a la } \\
\text { ausencia de } \\
\text { movimiento" }\end{array}$ \\
\hline $\begin{array}{l}\text {-Silencios institucionales } \\
\text {-Silencios grupales } \\
\text {-Silencios individuales }\end{array}$ & $\begin{array}{l}\text {-Expresión de sentimien- } \\
\text { tos y pensamientos } \\
\text {-Ritos, ceremonias } \\
\text {-Actos de resistencia } \\
\text {-Muestra de respeto } \\
\text {-Desafío al poder } \\
\text {-Autocensura } \\
\text {-Motivos estéticos o } \\
\text { artísticos } \\
\text {-Habilidades de escu- } \\
\text { char }\end{array}$ & $\begin{array}{l}\text {-El silencio } \\
\text {-Un silencio } \\
\text {-La pausa }\end{array}$ & $\begin{array}{l}\text {-Funciones positi- } \\
\text { vas } \\
\text {-Silencio natural } \\
\text {-Silencio de } \\
\text { "rapport" } \\
\text {-Silencio del amor } \\
\text {-Silencio profesio- } \\
\text { nal } \\
\text {-Funciones nega- } \\
\text { tivas } \\
\text {-Para expresar } \\
\text { actitudes negati- } \\
\text { vas } \\
\text {-Silencio manipu- } \\
\text { latorio }\end{array}$ \\
\hline
\end{tabular}



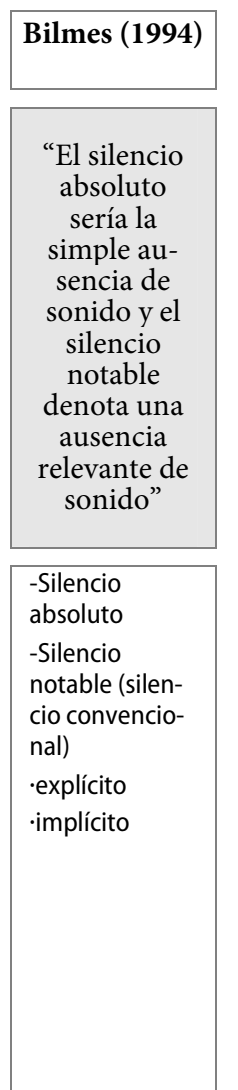

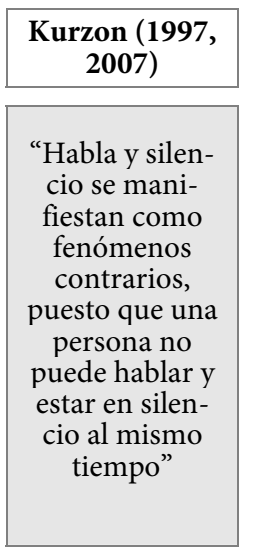

-Silencios conversacionales

-Silencios temáti$\cos$

-Silencios textuales

-Silencios situacionales

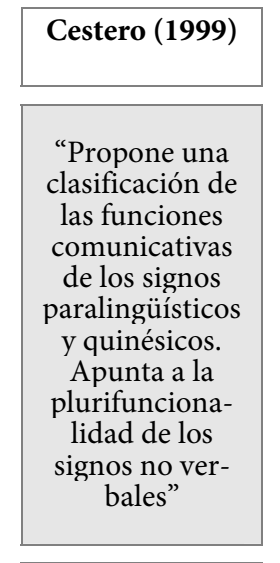

-Añadir información o matizarla

-Comunicar sustituyendo al lenguaje

-Regular la interacción verbal

-Subsanar deficiencias verbales

-Intervenir en conversacionesimultáneas

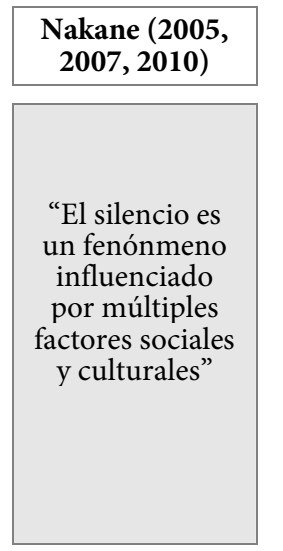

-Funciones positivas

-silencio natural -silencio de "rapport"

-silencio del amor -silencio profesional

-Funciones negativas

- para expresar

actitudes negati-

vas

-silencio manipulativo

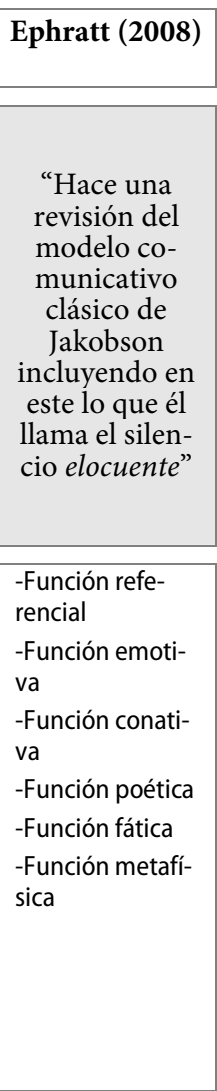

Figura 2. Cuadro-resumen de estudios sobre el silencio

\section{3. (Des)cortesía y silencio}

Basándose en el concepto de imagen propio de las sociedades orientales (en especial de la china), Goffman (1967: 5) definió el concepto de face como "the positive social value a person effectively claims for himself by the line others assume he has taken during a particular contact", o, lo que es igual, la imagen pública que los individuos construyen de sí mismos. Todos los estudios posteriores sobre la cortesía, entendida como un conjunto de estrategias conversacionales destinadas a evitar o mitigar los conflictos que surgen en las interacciones cotidianas, son en alguna medida deudores de esta definición goffmaniana. Como se sabe, sin embargo, la obra más citada y seguida —incluso para avanzar sobre ella, matizarla y mejorarla críticamente- es la que firmaron Brown y Levinson en 1987. Los autores de Politeness expusieron las estrategias desarrolladas por los sujetos en la interacción conversacional para cooperar en el mantenimiento de 
su imagen. Esta necesidad de mantener y salvaguardar la imagen viene de su vulnerabilidad y de la gran cantidad de actos potencialmente amenazadores para la misma que Brown y Levinson denominaron FTAs (Face Threatening Acts). Según explican, la imagen tiene dos vertientes: la positiva, o la necesidad de ser aceptado, de ser solidario y de agradar a los demás, y la negativa, o la necesidad de conservar la independencia, tener libertad de acción y de que los demás no se impongan (Brown y Levinson, 1987: 62 y ss.).

A partir de este trabajo, es mucho lo que se ha desarrollado esta vertiente sociocultural de la pragmática, ampliando el ámbito de estudio de la cortesía hasta la (des)cortesía y reconociendo también otros niveles posibles como la acortesía y la supercortesía (Kerbrat-Orecchioni, 2004: 49). Al igual que ocurre con la cortesía, el nivel de (des)cortesía debe evaluarse siempre en contexto y en función de la cultura de la que se trate. Esto es así hasta tal punto que puede pensarse que en muchas de nuestras interacciones sociales el fin último no es alcanzar o mantener una armonía y evitar o mitigar conflictos, tal y como proponían Brown y Levinson (1987), sino crear un conflicto en el cual encajarían algunos actos descorteses cotidianos. Para dichos casos, tal y como propone Bernal (2007), la visión de la cortesía resulta quizás demasiado positiva u optimista al considerarla como algo deseable y a lo que se debe aspirar, sin tener en cuenta que, para ciertos hablantes, esto puede no ser tan importante.

Por otro lado, cabe destacar que autores como Mills (2003) han catalogado la descortesía como un elemento "especialmente difícil de clasificar" (Mills, 2003: 134), ya que, en ocasiones, ni para los mismos participantes está claro si alguien ha sido (des)cortés o no. A ello se suma que muchas veces su efecto es acumulativo: leves amenazas pueden llegar a constituir descortesía tras una acumulación de incidentes: "It is only when impolite acts are 'addep up', or viewed in a cumulative way, and when it is assumed that the speaker intended to be impolite that they constitute a threat to the face of the hearer and to the community of practice" (Mills, 2003: 136).

En cualquier caso, como señala Albelda (2004), es fundamental tener en cuenta tanto el tipo de relación existente entre los interlocutores como las variables sociológicas de los participantes, la temática que se está tratando y la finalidad discursiva. En general, los actos amenazadores para la imagen en la cultura española son aquellos que dañan el prestigio público de la persona a la que van dirigidos, que le hacen quedar mal, que le critican o insultan, en definitiva, que le humillan o le empujan a desempeñar alguna tarea sin respetar su libertad de acción. Lingüísticamente, se pueden manifestar de muchas formas como, por ejemplo, a través de imperativos, insultos, reprimendas, por medio de énfasis prosódico, con apelaciones directas al tú, a olvidos o equivocaciones, etc., que afectan o implican la esfera personal del tú (Albelda, 2004: 334). 
Al hablar de los aspectos metalingüísticos de la cortesía, Leech (1997: 222) plantea que ciertas conductas conversacionales como hablar a destiempo, interrumpiendo, o permanecer inadecuadamente en silencio tienen implicaciones descorteses. Por su parte, Haverkate (1994) afirma que seguir la conversación y evitar el silencio en la lengua/cultura española es un tipo de cortesía metalingüística. De estas palabras se desprende la idea de que los hablantes son conscientes de que el silencio es "molesto" en nuestra sociedad y que no se debe "abusar" de su uso.

Sifianou (1997) subraya que las sociedades con una orientación a la cortesía negativa valoran más el silencio que las sociedades en las que predomina la cortesía positiva. Esta hipótesis se deduce de las propias definiciones de cortesía positiva y negativa. Mientras que la cortesía negativa se centra en el deseo de que el hablante sea libre, la cortesía positiva se basa en la pertenencia al grupo de personas que comparten puntos de vista. Esta afirmación -advierte Sifianou- no debe interpretarse en el sentido de que el silencio no tenga cabida en una sociedad con una orientación a la cortesía positiva o que el hecho de hablar se reduzca al mínimo en sociedades consideradas de cortesía negativa; simplemente significa que los silencios variarán en su función interpersonal dependiendo de la lengua/cultura en cuestión.

Más recientemente, Kaul de Marlangeon (2008) ha presentado una tipología del comportamiento comunicativo descortés en la cultura hispanohablante aludiendo a un acto silencioso en particular. La autora agrupa los actos descorteses según la intención del hablante y el grado de lesión que se inflige al receptor. Entre las categorías descorteses que propone se encuentra lo que denomina silencio abrumador, del que dice que "no es una mera ausencia de respuesta, una pregunta o una aserción; el oyente esgrime deliberadamente su silencio para indicar desacuerdo con el hablante, a pesar de que el contexto de situación y el compromiso entre los interlocutores le impelerían a una respuesta concordante y a un encadenamiento preferido de aquiescencia" (Kaul de Marlangeon, 2008: 261).

Dicho todo lo anterior, a la hora de establecer una relación entre (des)cortesía y silencio, se deben tener en cuenta factores que determinarán en qué medida el silencio es (des)cortés. Para nuestro análisis, nos hemos basado en las nociones de duración y coste-beneficio.

\subsection{Duración de los actos silenciosos y (des)cortesía}

$\mathrm{Al}$ ser la española una cultura de cortesía positiva en la que predomina la palabra, defendemos que los actos silenciosos representarán mayor riesgo para la imagen social del hablante (face) cuanto más largos sean y que, por tanto, pueden ser interpretados 
como más descorteses. Se entiende que la face es la imagen pública que cada individuo tiene y reclama para sí. Según Brown y Levinson (1987), esta imagen presenta dos vertientes: por un lado, el deseo de no sufrir imposiciones; y por otro, el deseo de ser apreciado. Así las cosas, no dañar la imagen ajena y salvaguardar la propia son la mejor manera de entablar y mantener buenas relaciones sociales. Siguiendo la idea de Campos y Romera (2012), pensamos que esta imagen de los hablantes no es monolítica, es decir, no es estática, sino que se negocia en cada encuentro dependiendo de la situación en la que nos hallemos y de la relación social, siempre única, existente entre los interlocutores.

En lo que a los datos del estudio se refiere, hay que destacar, en primer lugar, que el análisis se basa en un corpus de conversaciones espontáneas, recogidas mediante la técnica de grabación secreta ${ }^{5}$, de 15 horas de duración. La muestra cuenta con las interacciones de 10 hablantes españoles jóvenes ( 5 mujeres y 5 hombres menores de 25 años) de distinta procedencia ( 8 de ellos han nacido y vivido en Mallorca, aunque sus familias son peninsulares, y los otros 2 son valencianos). Las conversaciones se produjeron de manera totalmente natural y espontánea, y tuvieron lugar en contextos altamente familiares y en localizaciones muy frecuentadas por los informantes. Para la medición y el tratamiento de los silencios se utilizaron los programas PRAAT y SPSS respectivamente, y las grabaciones, además, fueron transcritas mediante las convenciones de PRESEEA $^{6}$. En lo que se refiere a la selección de los hablantes del corpus, conviene precisar que el muestreo se realizó de forma intencionada (descartando así el factor azar) y que estos informantes constituyen un grupo social compacto ya que son miembros de una red social muy concreta: jóvenes universitarios menores de 25 años y con una relación de familiaridad muy alta entre ellos. Decidimos hacerlo así con el fin de conseguir muestras lo más informales y espontáneas posibles. Los hablantes, que desconocían que estaban siendo grabados, se mostraron totalmente naturales y espontáneos en sus intervenciones ${ }^{7}$.

\footnotetext{
${ }^{5}$ Todos los informantes dieron su consentimiento al finalizar la grabación.

${ }^{6}$ PRESEEA (2008): “Marcas y etiquetas mínimas obligatorias”, Versión 1.2. 31-01-2008.

http://www.linguas.net/preseea.

${ }^{7}$ Un problema recurrente en este tipo de estudios es delimitar los elementos que forman parte en mayor medida del idiolecto del hablante y de su variedad social o dialectal. Somos conscientes de que incluso un individuo perteneciente a un grupo homogéneo y compacto puede presentar rasgos propios o exclusivos que no comparte con otros miembros del grupo. Es decir, puede haber hablantes más callados y otros más locuaces. Lo que ha primado en este estudio al realizar la selección de los informantes ha sido el hecho de lograr conversaciones espontáneas y en las que a los participantes les unieran lazos estrechos, ya que es en estos contextos de espontaneidad y cercanía en los que creemos que el
} 
En el corpus de datos manejado se observan un total de 1825 actos silenciosos de los cuales solo un tercio son silencios (662 casos). A partir del análisis de estos silencios y de la relación que guardan con las pausas hemos podido catalogar algunos silencios como más corteses y otros como más descorteses, y lo hemos hecho en base a dos criterios: las funciones que suponen un mayor coste para el oyente y la duración de los silencios.

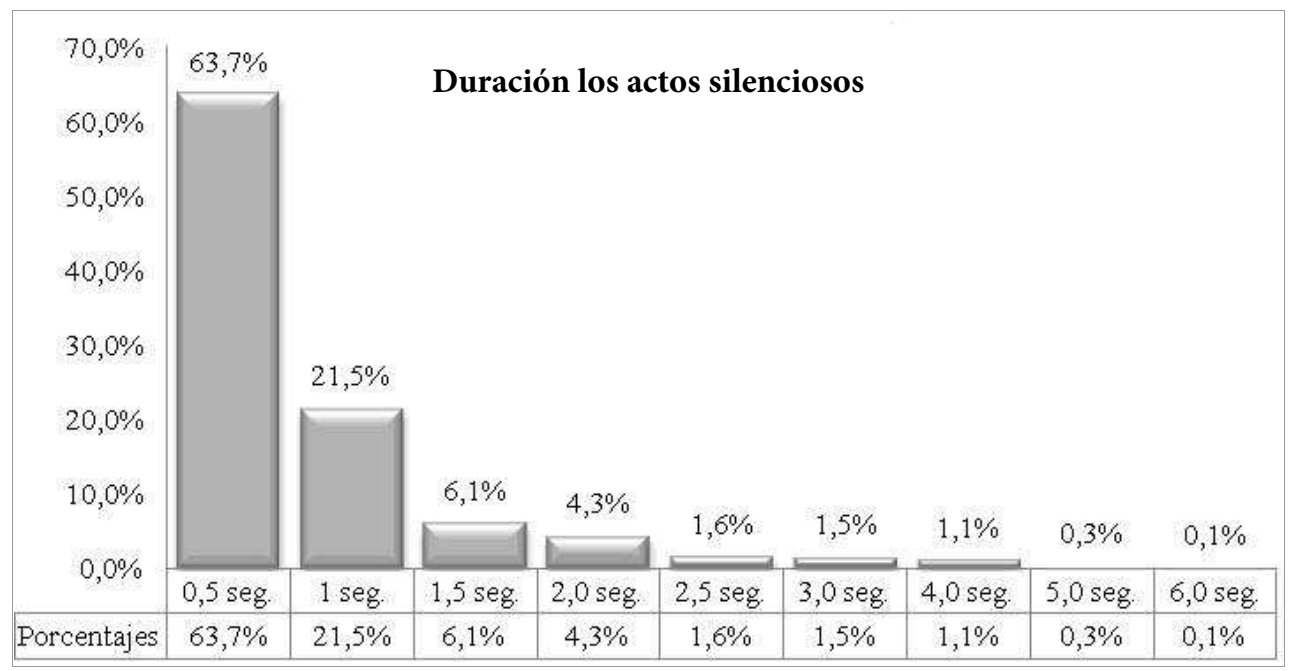

Figura 3. Porcentajes de duración de los 1825 actos silenciosos recogidos en la muestra

El primer dato relevante de la gráfica es que casi dos tercios de los actos silenciosos recogidos en el corpus son pausas, es decir, su duración es inferior a un segundo. Esto, unido a la baja frecuencia con la que aparecen silencios superiores a dos segundos, permite reforzar la idea de partida de que la cultura española es poco dada al silencio. Presentamos este dato para ilustrar lo anterior, puesto que ya advertimos que las pausas no forman parte de nuestro estudio. Las cifras que se indican a continuación representan

silencio "se permite" más o no se ve tanto como una amenaza. Es necesario insistir, también, en que la relación social entre los participantes no está fijada de antemano en la conversación, sino que se establece y se negocia en cada encuentro comunicativo, dependiendo de los factores lingüísticos y extralingüísticos que intervengan en cada interacción. Por otra parte, este análisis habrá que contrastarlo con un corpus de conversación más formal, con el fin de determinar si en contextos formales -en los que las relaciones sociales son diferentes a las analizadas aquí- los silencios se utilizan con las mismas funciones y en la misma medida. 
los porcentajes de los actos silenciosos aparecidos en la muestra en relación a la función que desempeñan y a su duración.

\begin{tabular}{|c|c|c|c|c|c|c|c|c|c|c|}
\hline & $\begin{array}{c}\text { Auto- } \\
\text { control }\end{array}$ & $\begin{array}{c}\text { Descono- } \\
\text { cimiento }\end{array}$ & $\begin{array}{c}\text { Refle- } \\
\text { xivo }\end{array}$ & $\begin{array}{c}\text { Petición } \\
\text { Apoyo o } \\
\text { Atención }\end{array}$ & $\begin{array}{c}\text { Intensifi- } \\
\text { cador }\end{array}$ & $\begin{array}{c}\text { Mitiga- } \\
\text { dor }\end{array}$ & Humor & Ironía & $\begin{array}{c}\text { Refor- } \\
\text { mulador }\end{array}$ & $\begin{array}{c}\text { Cambio } \\
\text { de tema }\end{array}$ \\
\hline$<1$ & $62,2 \%$ & $52,1 \%$ & $57,6 \%$ & $45,8 \%$ & $60,9 \%$ & $76,2 \%$ & $73,5 \%$ & $42,9 \%$ & $86,7 \%$ & $15,4 \%$ \\
\hline$\geq 1$ & $38,8 \%$ & $47,9 \%$ & $42,4 \%$ & $54,2 \%$ & $39,1 \%$ & $23,8 \%$ & $25,5 \%$ & $57,1 \%$ & $13,3 \%$ & $84,6 \%$ \\
\hline
\end{tabular}

Figura 4. Tabla de porcentajes de los actos silenciosos según su duración ${ }^{8}$

Como se aprecia en la tabla, las funciones que tienen un mayor índice de producción como ausencias de habla más largas son los silencios por cambio de tema, los silencios irónicos, y, a poca distancia, los silencios por petición de atención y apoyo (véanse, como muestra de ello, los ejemplos 4, 5, 6 y 7 que a continuación se presentan). Ya en otro nivel, por debajo del 50\%, observamos aquellos a los que se recurre por desconocimiento, vacilación o duda, los reflexivos, los intensificadores y los de autocontrol. Por último, con niveles inferiores, hallaríamos los silencios humorísticos y al final de la tabla los reformuladores y mitigadores. Estas funciones estarían más habitualmente representadas por pausas.

(4) Ejemplo de silencio por cambio de tema [CE.4.H0;H6] (949-962)

H0 y H6 son amigas, tienen entre 20 y 25 años. Tema: hablan de sus hábitos y costumbres.

H0: ¡ay! no me apetece comer comida basura otra vez// ando siempre mala del estómago// me he acostumbrado este año a malcomer// como iba corriendo del

\footnotetext{
${ }^{8}$ Algunos de los silencios que proponemos en la taxonomía no han quedado representados en la muestra posiblemente debido a que son más propios de otro tipo de contextos más formales, públicos o institucionales. Pensamos que este es el caso de los silencios preferidos y despreferidos ya que en conversaciones tan informales como las analizadas y entre hablantes con un grado de familiaridad tan alto se han utilizado estrategias más directas y explícitas para mostrar disconformidad o desacuerdo optando así por no enmascarar los actos disentivos. En el caso de los silencios por errores de coordinación, tampoco han quedado representados al existir una tendencia en nuestro corpus espontáneo a disputar los turnos de palabra a través de numerosas interrupciones y solapamientos que no dejan lugar a este tipo de ausencias de habla. Por último, algunos tipos de silencios afectivos tampoco aparecen en los datos recogidos, ya que entre este grupo de amigos tan cercanos y tan jóvenes la expresión de sentimientos se realiza mayormente a través de la verbalidad. Por todo ello, para futuros estudios sobre el silencio, vemos muy necesario el análisis de los actos silenciosos en otros contextos diferentes a los estudiados aquí para poder determinar si existen diferencias con las funciones aquí recogidas y también con las funciones que se proponen en la taxonomia presentada en el apartado 3 del presente artículo, que, como ya se ha comentado, provienen de un trabajo anterior (Camargo y Méndez, en prensa) y que nos ha servido de base de partida en este estudio.
} 
curro a clase y comía por el camino si es que comía///(1) y y estoy chunga chunga del estómago desde hace tiempo// no me apetece// comer aquí///(1) así que me parece que me pillaré un bocata de los de: arriba/ un sándwich

H6: bueno/ los de arriba están buenos/ a mí me gustan///(3) madre mía que yo: me tengo que poner a estudiar

El silencio de (4) cumple una función primordial en la conversación: propiciar el cambio de tema haciendo que esta avance. Esta función es una de las que presenta duraciones más altas en la muestra analizada. En este caso, H6 lo utiliza para conectar distintos temas de manera armoniosa sin que ello provoque una transición abrupta organizando las estructuras del discurso y conectándolas entre sí.

(5) Ejemplo de silencio irónico [CE.4.H0;H6] (949-962)

$\mathrm{H} 0, \mathrm{H} 1, \mathrm{H} 2$ y $\mathrm{H} 3$ son amigas, tienen entre 20 y 25 años. Tema: hablan de un simulacro de robo y bomba que ha presenciado en su lugar de trabajo.

$\mathrm{H} 2$ : "que he puesto una bomba, que no me toques las narices"// ha sido lo mejor porque estaba P./ yo con L. me estaba partiendo

H1: eh pero ¡qué guay tío!

H2: "que he sido trabajadora de aquí y me habéis puteado y ahora os he puesto una bomba"

H0: y ella "observaciones, dos puntos, exempleada" (risas= H0)/// (2)

H1: real como la vida misma///(1) yo lo voy a hacer

H2: y yo

Como juegos del lenguaje que son, las ironías necesitan y crean complicidad, pues "generalmente, los hablantes saben cuándo cuentan con unos mínimos acuerdos entre los participantes en la interacción para ser comprendidos [...]. El juego irónico y humorístico exige y genera, por tanto, complicidad, de forma que muchas transgresiones se construyen sobre la comunión de experiencias, expectativas y bagaje cultural que existe entre los interlocutores" (Camargo, 2009: 100-102). En el caso de (5), es la expresión "real como la vida misma" seguida de un elocuente silencio la que activa la complicidad entre los participantes y obliga a poner en marcha procesos inferenciales para la correcta recuperación de la implicatura irónica: "esto no ocurre nunca en la vida real".

(6) Ejemplo de silencio por petición de apoyo [CE.2.H0;H4] (888-903)

H0 (mujer) y H4 (hombre) son amigos, tienen 25 años. Tema: hablan de la falta de comunicación que se producen en relaciones de pareja.

H0: entonces/ yo como soy más cortés/ voy a intentar// emitir utilizar menos el silencio/ recurrir menos al silencio que tú 
H4: pero yo no lo intento llenar// claro/ claro/ pero yo no lleno el hueco porque para mí no me crea un problema// a las mujeres os crea un problema// más///(1) ¿vale?/ sobre todo en relación de pareja///(1) ¿vale?///(1) el novio callado os da más problema a una chica que a un// tío

H0: efectivamente

H4: vale pero

H0: $\quad$ y tenemos la sensación de que hay falta de comunicación

H4: exacto

H0: pero es porque hay falta de comunicación H4/ no es una sensación/ si tú no hablas y hablo yo sola como con una pared/ tú qué quieres que haga/ yo me molesto

H4: pero a ver hay cosas que ya se dicen solas///(1,5) ¿sabes?

El silencio en (6) se utiliza como un recurso apelativo para reclamar al oyente que coopere en la construcción de la interacción mostrando seguimiento del enunciado en marcha (Cestero, 2000: 114). Este tipo de silencios también suelen reforzar el valor ilocutivo del acto en el que aparecen y se utilizan como formas de hacer progresar la conversación.

(7) Ejemplo de silencio por petición de atención [CE.4.H0;H6] (740-748)

H0 y H6 son amigas, tienen entre 20 y 25 años. Tema: hablan del trabajo.

H6: y a mí si me lo hubieran dicho/ "mira que: se lo vamos a ofrecer a ella por este tema" pues yo "pues vale" ¿sabes?// yo hubiera dicho que sí/ hizo bien ¿sabes?// pero me da rabia que siendo ella la que vino a mí a decírmelo///(1) ¿sabes?// ¿por qué no me dijo a mí?///(1) porque yo no le dije nada a ella a mí me la rempampinflaba///(1) pero da rabia///(1) que va: con doble: cara/ ahora ya lo veo H0: pero si esto ha sido siempre

En el ejemplo (7) se aprecia cómo H6 intenta asegurarse de que su interlocutora sigue su discurso. En este caso, el silencio adquiere un valor fático y de mantenimiento de contacto, dado que el hablante reafirma lo dicho, llama la atención sobre el mensaje y pide la atención del oyente, si bien no espera su respuesta. Se trata, por tanto, de un uso estratégico del silencio.

\subsection{Impacto de los actos silenciosos en la imagen del interlocutor}

La cortesía, como principio regulador de la distancia social, puede definirse en términos de "coste" y "beneficio". Esta depende del coste o del beneficio que suponga el cumplimiento de la acción para el destinatario o el emisor. Así, la acción es intrínsecamente más "descortés” cuanto mayor es el coste para el destinatario y menor su benefi- 
cio; y, viceversa, es más "cortés" cuanto mayor sea el coste para el emisor y mayor el beneficio para el destinatario (Escandell, 2006: 364). Siguiendo esta idea de la que también parten Lakoff (1973), Leech (1983) y Brown y Levinson (1987), pensamos que aquellos silencios que supongan un mayor coste para los hablantes serán más descorteses que aquellos que, por el contrario, no tengan un riesgo tan alto para su imagen.

En función del impacto que pueden tener los actos comunicativos sobre las relaciones sociales, Escandell (1996), inspirándose en Leech (1983), propone una clasificación en la que recurre a los parámetros de coste-beneficio para asignar grados de (des)cortesía. De esta forma, distingue entre: (1) acciones que apoyan (o mejoran) la relación social; (2) acciones indiferentes; (3) acciones que entran en conflicto con la relación social; y (4) acciones dirigidas frontalmente contra la relación entre los interlocutores. Esta clasificación es la que hemos utilizado en el análisis para determinar los niveles de (des)cortesía de los silencios y lo hemos hecho atendiendo al riesgo que puede tener sobre la imagen ( face) cada una de las funciones de los silencios planteadas.

- Acciones que apoyan (o mejoran) la relación social: beneficio para el destinatario y coste para el emisor. Aquí se incluyen los silencios mitigadores o atenuadores, humorísticos, por autocontrol, los preferidos o despreferidos y los silencios por errores de coordinación. Esta agrupación nace al considerar que entre los jóvenes con una relación de amistad muy estrecha estos silencios tienen un menor riesgo para la imagen de los hablantes. Es decir, que el peligro para la relación social, independientemente de que finalmente esa amenaza desemboque o no en un acto descortés (véase el apartado de anticortesía), es muy bajo.

La función mitigadora o atenuadora de los silencios es utilizada por los hablantes de la muestra con el fin de mantener un equilibrio en la interacción y para proteger su propia imagen social y la de su interlocutor. Algo parecido ocurre con los silencios humorísticos que entre jóvenes están especialmente orientados al refuerzo de la solidaridad y a estrechar los lazos grupales. Por otra parte, las ausencias de habla por autocontrol también comportan un bajo coste para el receptor, ya que los hablantes (quizá teniendo en cuenta el dicho popular "más vale callar que errar") tienden a pensar antes de hacer explícito su discurso. Aunque ciertamente hay que destacar que este último tipo de silencios no es muy frecuente en el habla informal y espontánea de los hablantes

\footnotetext{
${ }^{9}$ Es importante aclarar que no necesariamente en todos los casos en los que exista riesgo para la face se verá esta afectada, ya que es imposible determinar con total certeza si nuestro acto silencioso va a causar un efecto (des)cortés sobre el oyente, se quedará en una sencilla amenaza, o no tendrá, incluso, ninguno de los dos efectos. Sobre esta cuestión se volverá más adelante al hablar de anticortesía.
} 
jóvenes de este corpus. Este es el caso también de los silencios preferidos y despreferidos que no han quedado representados en la muestra, pero a los que asignamos un valor de bajo coste para el receptor, pues se presentan como estrategias más indirectas o implícitas para ocultar o enmascarar los actos comunicativos. La inclusión de los errores de coordinación en este grupo se justifica por ser una confusión o falta de acuerdo involuntaria en la distribución de los turnos y no haber una intencionalidad expresa por parte de los interlocutores en la falta de coordinación.

- Acciones indiferentes: equilibrio entre coste y beneficio para los interlocutores. Formarían parte de este grupo los silencios reformuladores, los reflexivos, los intensificadores y aquellos a los que se recurre por desconocimiento. En este caso parece no haber un riesgo excesivamente alto en relación a si pueden causar daño o no sobre alguno de los hablantes, pero sin duda los beneficios sobre el interlocutor no son tan patentes, de ahí que los incluyamos en un estadio intermedio.

Los silencios reformuladores se erigen como estrategias para construir la argumentación y son utilizados principalmente para estar seguros de que el oyente comprende totalmente lo expresado cuando se comunica algo, por lo que no se vislumbra un claro desequilibrio entre el coste y el beneficio que aportan al receptor. En el caso de los reflexivos ocurre algo similar y es que los hablantes tienden a callar y reflexionar más su mensaje para que este sea claro y se entienda. Este silencio tampoco es muy frecuente entre los jóvenes del corpus analizado. Los silencios intensificadores son utilizados como estrategias enfatizadoras y cooperativas que se vinculan a la idea de fuerza argumentativa y que pretenden garantizar la buena marcha de la conversación y la atención del interlocutor. En último lugar, los silencios por desconocimiento, vacilación o duda tienen una función retardadora, pues el hablante gana tiempo para pensar y formular su intervención de forma exitosa, por lo que tampoco parece que supongan un coste demasiado grande para el receptor.

- Acciones que entran en conflicto con la relación social: implican algún coste para el destinatario. En estos últimos clasificaríamos los silencios por petición de atención, los que piden apoyo, los irónicos y los que propician el cambio de tema. Entiéndase que a estos silencios conllevan un riesgo mayor que el resto por poder causar con mayor facilidad (aunque no necesariamente tenga que ser así) un daño para la relación social de los interlocutores, en el sentido de que las acciones que promueven o demandan pueden ser malinterpretadas más fácilmente por los hablantes causando así actos considerados descorteses.

La función petición de atención se presenta en el corpus como una llamada de atención sobre el mensaje, se recurre a una función fática con la intención de reafirmar lo dicho y de llamar la atención del oyente, si bien no se espera respuesta. Por su parte, los 
silencios por petición de apoyo son sin duda un recurso apelativo o de petición de información adicional. Esta estrategia comunicativa es muy frecuente entre los jóvenes de nuestro corpus cuando reclaman la colaboración de su interlocutor o le piden más información marcando enfáticamente estas peticiones mediante el uso del silencio. Al pedir a los hablantes que hagan un mayor esfuerzo cognitivo y/o comunicativo y verse la libertad individual de estos potencialmente coartada, apreciamos en estos silencios un mayor coste para el receptor, por lo que han sido incluidos en un estadio más cercano a la descortesía. En cuanto a los silencios irónicos - como se ha dicho- en las muestras aparecen como un mecanismo de complicidad y afiliación entre los interlocutores y en su mayoría se enmarcan en las ironías de efecto positivo (Alvarado, 2005; Padilla y Alvarado, 2010), ya que no llevan implícita la burla o mofa sobre los interlocutores, pero aun así implican un riesgo mayor sobre la face que otros silencios al poder ser malinterpretados más fácilmente ${ }^{10}$. Los silencios por cambio de tema también están enmarcados en este nivel por el mayor coste que suponen para el receptor en los casos en los que no se utilizan de manera exitosa. El hablante puede pensar que es el momento ideal para introducir un nuevo tema y cumplir así con la tarea de mantener "viva" la conversación, pero si "comete un error" dando por concluido un tema e introduciendo otro nuevo cuando su interlocutor no lo considera oportuno, se puede producir un conflicto y verse su imagen gravemente dañada ya que puede parecer que se muestra poco interesado.

-Acciones dirigidas frontalmente contra la relación entre los interlocutores, es decir, acciones que pretenden acrecentar la distancia o destruir las relaciones existentes. En este tipo se incluyen los silencios por resistencia y los desafiantes, que son los que consideraremos más descorteses.

El silencio como forma de resistencia es una estrategia discursiva de subversión pasiva o indirecta (Martín Rojo, 2011). Este mecanismo entraña un mayor riesgo para la imagen del interlocutor y se utiliza sobre todo en contextos en los que existe una relación asimétrica entre los participantes como una manifestación de lucha por el poder. Estas formas de resistencia tienen un efecto libertador frente a las imposiciones del interlocutor, de ahí que el mayor coste sea para el receptor. En cuanto a los silencios desafiantes, son un intento deliberado de no cooperar con el interlocutor en relaciones

\footnotetext{
${ }^{10}$ En otros contextos estos mismos silencios pueden ser utilizados por los hablantes con efectos más negativos (como burla o crítica hacia algo o hacia alguien) y en estos casos el riesgo para la imagen del receptor será aún mayor.
} 
de poder-sumisión (Kurzon, 1995). El orador tiene siempre la opción del discurso y la del silencio y opta por este último para enfrentarse a su interlocutor. ${ }^{11}$

La tabla que sigue recoge las funciones pragmáticas del silencio en relación al costebeneficio de los actos comunicativos.

\begin{tabular}{|c|c|c|c|}
\hline $\begin{array}{l}\text { Actos silenciosos } \\
\text { que apoyan (o } \\
\text { mejoran) la rela- } \\
\quad \text { ción social } \\
\text { +beneficio para el } \\
\text { receptor } \\
\text {-coste para el receptor }\end{array}$ & $\begin{array}{l}\text { Actos silenciosos } \\
\text { indiferentes }\end{array}$ & $\begin{array}{l}\text { Actos silenciosos } \\
\text { que entran en con- } \\
\text { flicto con la rela- } \\
\quad \text { ción social } \\
\text { + coste para el recep- } \\
\text { tor }\end{array}$ & $\begin{array}{l}\begin{array}{l}\text { Actos silenciosos } \\
\text { dirigidos frontal- } \\
\text { mente contra la } \\
\text { relación }\end{array} \\
\text { Acrecientan la distan- } \\
\text { cia o destruyen rela- } \\
\text { ciones existentes }\end{array}$ \\
\hline $\begin{array}{l}\text { - Mitigadores } \\
\text { - Humorísticos } \\
\text { - Autocontrol } \\
\text { - Preferidos o despre- } \\
\text { feridos } \\
\text { - Errores de coordina- } \\
\text { ción }\end{array}$ & $\begin{array}{l}\text { - Reformuladores } \\
\text { - Reflexivos } \\
\text { - Intensificadores } \\
\text { - Desconocimiento }\end{array}$ & $\begin{array}{l}\text { - Petición de Atención } \\
\text { - Petición de Apoyo } \\
\text { - Irónicos } \\
\text { - Cambio de tema }\end{array}$ & $\begin{array}{l}\text { - Por resistencia } \\
\text { - Desafiantes }\end{array}$ \\
\hline
\end{tabular}

Figura 5. Tabla de funciones de los actos silenciosos en relación al parámetro coste-beneficio (a partir de Leech (1983) y Escandell (1996))

Tras este análisis y atendiendo a la duración y al coste-beneficio de las funciones de los actos silenciosos, proponemos la siguiente gradación en la que, como se puede observar, los actos silenciosos que suponen un mayor coste para el receptor son a la vez los más largos en duración y, por tanto, los más descorteses; de la misma forma, los más breves son a su vez los que le aportan un mayor beneficio o entrañan menor riesgo para la imagen, por lo que consideramos que serán los menos descorteses ${ }^{12}$.

\footnotetext{
${ }^{11}$ Estas funciones de los silencios tampoco han quedado reflejadas en los datos analizados, ya que este tipo de actos comunicativos no son frecuentes entre los hablantes de la muestra, quienes mantienen una relación social muy próxima.

${ }^{12}$ El análisis que acabamos de presentar ha sido contrastado con los resultados obtenidos en otro estudio efectuado a ocho informantes (4 hombres y 4 mujeres) del grupo Val.Es.Co (Briz, 1995). Este análisis se ha realizado con la intención de reducir el factor azar y de verificar que los resultados obtenidos no son fruto de la casualidad o se reducen al estilo comunicativo propio de un grupo concreto. Para ello revisamos un total de 157 fragmentos en las que aparecían silencios (dos transcripciones íntegras). Cabe destacar que los resultados obtenidos en este análisis son muy similares a los presentados en este trabajo. En primer lugar, observamos que el $70,1 \%$ de los silencios que aparecen en
} 


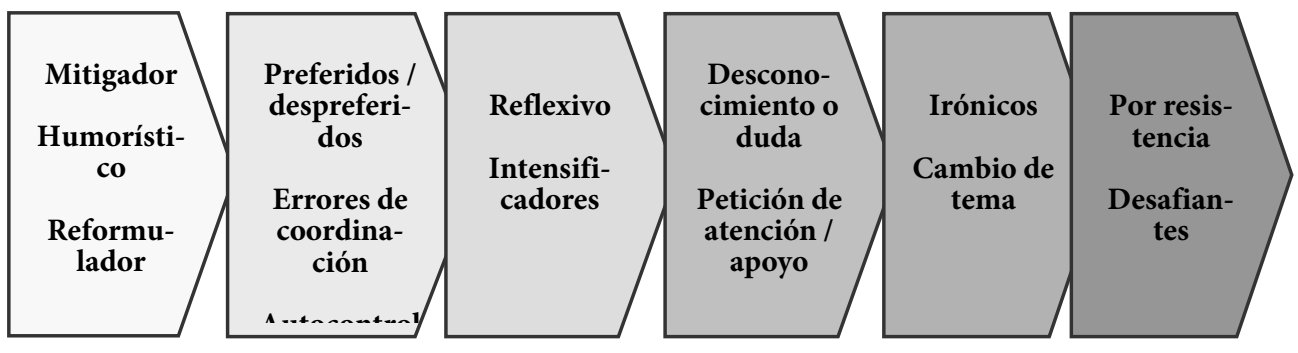

\section{Cortesía}

Descortesía

Figura 6. Tabla de niveles de (des)cortesía según la duración y las funciones de los actos silenciosos

\section{Anticortesía y silencio}

En la lengua/cultura española, como se ha dicho, el silencio conversacional siempre tiene un valor comunicativo concreto (mitigar, enmascarar, ironizar, reflexionar, afirmar, desafiar...), pero no ocurre lo mismo con su valor social, el cual está determinado por los condicionamientos contextuales (Brenes, 2009) y por la relación social de los participantes (Camargo y Méndez, en prensa). Tal y como apuntó Zimmermann (2003: 48), entre los jóvenes existen actos que estructural y funcionalmente se pueden caracterizar como contrarios a los actos corteses descritos en la teoría de la cortesía, ya que no quieren evitar la amenaza potencial de ciertos actos de habla y no quieren decir algo positivo sobre el interlocutor; se trata de los actos anticorteses, que aunque amenazan la identidad del otro, no desembocan en una ofensa hacia el interlocutor y no representan descortesía, sino una actividad antinormativa (Zimmermann, 2003: 57) o una estrategia comunicativa propia de una comunidad de práctica determinada.

Val.Es.Co no superan el segundo de duración (recordemos que en nuestro análisis ascendían a 393 más del $60 \%$ del total de los 662 de la muestra); ello nos lleva a pensar que los silencios largos son minoritarios entre los jóvenes españoles. En segundo lugar, los silencios por reformulación, autocontrol, mitigación e humor son más breves (con una duración media de entre 1,1s. y 1,3s.) que los actos silenciosos por petición de atención, petición de apoyo, cambio de tema (que oscilan entre 1,8s. y 3,3s. de media), a los que asignábamos un valor más alto de descortesía. Y, por último, y basándonos en la clasificación coste-beneficio que presentamos en este trabajo (Escandell, 2006), en los casos de Val.Es.Co se asocian costes más altos para el receptor en los silencios de petición (atención y apoyo) y cambio de tema que en aquellos que reformulan, mitigan, humorizan o intensifican el mensaje, cuestión que también coincide con los resultados de nuestro estudio. 
Partimos de esta idea de Zimmermann $(2003,2005)$ al considerar que en contextos en los que la relación de familiaridad y el grado de confianza entre los hablantes es muy alto, los silencios responden más a parámetros relacionados con la anticortesía que con actos de habla descorteses, por lo que puede afirmarse que no tienen la intencionalidad de dañar la imagen del interlocutor. En la comunidad de hablantes analizada (jóvenes universitarios españoles con lazos de confianza y amistad estrechos), se emplean recursos tal vez "inesperados" en otros grupos de hablantes, como el silencio, al que ellos recurren sin una intencionalidad descortés. Para este grupo de hablantes no es más que un mecanismo propio de su estilo comunicativo. La clave para esto puede estar en la existencia de una relación de amistad muy grande. Estos comportamientos aparentemente descorteses responden, como decimos, a una estrategia conversacional propia del grupo que causa un efecto social concreto: crear afiliación y cercanía entre el grupo y sus participantes. Consideramos que entre hablantes con una relación social tan estrecha y en conversaciones prototípicas coloquiales como las recogidas, los silencios no están funcionando como FTAs, esto es, como actos de amenaza de la imagen del interlocutor al que van dirigidos. El contexto espontáneo y la relación social de familiaridad son los que posibilitan que estos actos que han sido considerados por la tradición sociopragmática descorteses funcionen de manera diferente en estos intercambios comunicativos. En palabras de Bernal (2007: 77), lo descrito aquí serían "comportamientos de descortesía no auténtica con efectos interpersonales positivos". Coincidimos con la autora cuando afirma que más que actos "antinormativos" hacia el estilo comunicativo propio de los adultos y que se emplean con la finalidad de "atacar el sistema", son comportamientos que se dan entre jóvenes en un clima de confianza y alta cercanía interpersonal y en contextos informales y espontáneos. Entre nuestros informantes, por tanto, el silencio actúa como un mecanismo que, dentro de las normas de su grupo, ni amenaza ni daña la imagen, los caracteriza e identifica además de distanciarlos de otros grupos, reforzando sus relaciones, creando afiliaciones y generando complicidades ${ }^{13}$. Por ello, antes de asignar grados o niveles de (des)cortesía al silencio o a cualquier otro fenómeno discursivo, se deberá tener en cuenta quién lo produce, quién lo recibe y

\footnotetext{
${ }^{13}$ En futuros trabajos deberá realizarse un estudio comparativo entre este grupo de hablantes jóvenes universitarios con otros que atiendan a otras variables (distinta edad, sexo, nivel de instrucción...) para determinar hasta qué punto estos resultados, que actualmente vinculamos únicamente a hablantes jóvenes universitarios, son extrapolables o otros grupos de habla o comunidades de práctica que también tengan una relación social muy próxima, pero que no sean ni tan jóvenes ni con estudios superiores.
} 
dónde tiene lugar dicho acto; solo de esta manera se podrán llevar a cabo estudios fiables en el plano conversacional.

La tesis que defendemos es que el silencio, recurso comunicativo poco frecuente en español, necesariamente causará un efecto social ${ }^{14}$ (Bravo, 1996: 13) en la relación entre los hablantes. Este efecto, que se conocerá a partir del acto perlocutivo ${ }^{15}$ que provoque la ausencia de habla en el oyente, deberá ser necesariamente tenido en cuenta y nos indicará si el acto silencioso ha causado daño alguno sobre el receptor o si ha sido interpretado por el este como una actividad normativa dentro del grupo, pertinente y sin efectos descorteses ${ }^{16}$. De esta manera, que un silencio sea (des)cortés o anticortés dependerá del efecto que cause sobre la relación social. Entre los hablantes analizados en este trabajo predominan los actos anticorteses sobre los descorteses, pues la finalidad de su uso es principalmente comunicativa y no suponen una amenaza para la imagen.

También podrían relacionarse estos actos con el "comportamiento diplomático" o politic behaviour (Watts, 1989) que Meier (1995) prefiere denominar appropriate behaviour (comportamiento apropiado) y que Kerbrat-Orecchioni (2004) -como se comentó en páginas anteriores- propone llamar acortesía. Estos fenómenos han sido definidos como "la ausencia normal de un marcador de cortesía" (Kerbrat-Orecchioni, 2004: 49) esperada para una determinada situación comunicativa y que es considerada como adecuada por los participantes en ese contexto concreto. Barros (2011) los califica como "comportamientos comunicativos no marcados" en el sentido de que son los exigidos

\footnotetext{
${ }^{14}$ Bravo (1996: 13) entiende por efecto social "las consecuencias ya positivas ya negativas, que una determinada actividad comunicativa pueda tener sobre el clima social imperante en la situación en el momento de su ocurrencia".

${ }^{15}$ El principal inconveniente de decir que son los actos perlocutivos o efectos sociales los que nos permitirán saber el valor sociopragmático que dan los oyentes al silencio, como ya apunta Brenes (2009: 149), es que "siempre quedará la duda acerca de si lo manifestado por los interactuantes proyecta el verdadero impacto que los fragmentos de la conversación efectuaron sobre ellos, ya que la acción evaluativa del receptor puede ser estratégica en dos sentidos. Por un lado, alguien puede sentirse afectado por una expresión descortés, pero, al mismo tiempo, no exteriorizar dicho sentimiento de agravio o, simplemente, fingir no sentirse injuriado para que, de esta manera, el emisor no alcance su objetivo (Arndt y Janney, 1987; Mills, 2005). Por otro, el receptor puede enfatizar su sentimiento de afrenta con la finalidad de denigrar la imagen del receptor, mostrando que no es una persona considerada hacia los demás". En el caso del silencio entre este grupo de hablantes este hecho no se producirá muy a menudo puesto que se sabe que en intercambios entre hablantes con un grado de proximidad y la relación social tan cercana no suelen ocultarse o enmascararse los sentimientos, ni existe tampoco una intención de denigrar la imagen del receptor.

${ }^{16}$ Bernal (1997: 86-87) propone que en aquellos "contenidos descorteses en potencia" se vislumbrará un efecto descortés cuando el receptor evidencie un rechazo, se muestre claramente en desacuerdo o, incluso, realice a su vez actividades de amenazas a la imagen del interlocutor.
} 
por la situación de habla entre esa comunidad de práctica, pues existen situaciones en las que no aparecen marcadores de cortesía, pero ello no indica que el acto sea descortés. Así pues, un mismo comportamiento podrá dar cuenta de categorías diferentes, según las normas propias de la sociedad (o en este caso comunidad de práctica) en que se produzcan. No ha de olvidarse que "lo discursivo se encuentra al servicio de lo social" (Briz, 2004: 68), por tanto, "la (des)cortesía no se encuentra codificada en el elemento lingüístico en sí mismo, sino que es un efecto social que surge de la confrontación del valor verbal [o no verbal] aportado por dicho elemento y las normas de comportamiento propias de una situación comunicativa" (Brenes, 2009: 116). Por consiguiente, si un silencio no crea ningún "efecto social" en un determinado grupo, no deberá ser considerado descortés, sino que podrá considerarse acortés. En cambio, si lo que ocurre es que el silencio es una estrategia discursiva propia del grupo de hablantes -que lo identifica y diferencia de otros grupos- pero que no tiene efectos (des)corteses, podrá considerarse como anticortés. En el momento en que el silencio tenga efectos negativos para la relación social, podríamos hablar ya de descortesía.

\section{Conclusiones}

El hablante de una lengua está provisto de recursos comunicativos que provienen de su entorno social y de sus experiencias comunicativas previas, los cuales parcialmente comparte con otras personas (grupo o comunidad de práctica). Estos recursos, entre los que se incluye el silencio, se ponen en marcha en la interacción y se proyectan en los significados emergentes de la misma, creando nuevas alternativas y distintas consideraciones en cuanto a la cortesía se refiere, siempre en función del contexto. La cortesía, considerada un fenómeno sociocultural, se confirma, se actualiza, se modifica o se revierte en la situación de interlocución real y concreta. Para el caso del silencio, la cortesía debe medirse en términos de duración y coste-beneficio.

A raíz de la noción de anticortesía acuñada por Zimmermann (2003), se ha argumentado que aquellos actos considerados tradicionalmente descorteses que no desembocan en una ofensa hacia el interlocutor deben dejar de considerarse como tales, puesto que en muchas ocasiones son meras estrategias comunicativas propias de una comunidad de práctica que actúan en favor del éxito comunicativo. Precisamente a esto responden, normalmente, los silencios en contextos en los que la relación de familiaridad y el grado de confianza entre los hablantes es muy alto. En conclusión, puede afirmarse que en un clima de intimidad donde se dan buenas relaciones entre los interlocutores, en principio, tendrá lugar una conversación sin tensiones en la que el silencio no resultará un elemento que dañe la imagen social (face) de los participantes, sino un compo- 
nente más de la interacción. Lo que realmente indicará si el silencio es un acto (des)cortés o anticortés será el acto perlocutivo que propicie en el destinatario, es decir, no será hasta después de conocer su reacción ante el acto que se acaba de producir cuando podrá asignarse un valor sociopragmático al acto silencioso. Lo anterior lleva a concluir que, al igual que toda unidad pragmática, el silencio es altamente contextodependiente.

Por último, aunque aquí no se han podido abordar estos aspectos, la quinésica y algunos elementos paralingüísticos frecuentemente acompañan al vacío de palabras y comunican contenidos en simbiosis con el silencio. Esta cuestión deberá sin duda tratarse en futuros estudios en los que se cuente con un corpus de análisis audiovisual, para así poder conocer en mayor detalle la relación que se establece entre dichos elementos y los parámetros de cortesía.

\section{Convenciones de transcripción}

- Solapamientos.

(:) Alargamientos.

(-) Truncamiento o sílaba cortada.

(i!) Tono animado.

(?) Pasajes inciertos en la grabación.

$(<$ risas $=$ especificación del emisor $>)$ Risas.

(“") Citas o fragmentos en estilo directo.

(/) Pausas mínimas, es decir, que no lleguen a 0 ‘5seg.

(//) Pausas de entre 0`5 y 1 seg.

(///2) Silencios de más de 1 seg. (se especificará su duración).

(///2) Para destacar el silencio objeto de análisis.

Recibido: $25-X-2012$

Aceptado: 26-VI-2013

\section{Referencias bibliográficas}

Albelda Marco, M. (2004): "Cortesía en diferentes situaciones comunicativas. La conversación coloquial y la entrevista sociológica semiformal.” En Bravo, D. y A. Briz (eds.): Pragmática sociocultural: estudios sobre el discurso de cortesía en español. Barcelona, Ariel, págs. 109-134. 
Alvarado Ortega, B. (2005): "La ironía y la cortesía: una aproximación desde sus efectos”, ELUA, 19, págs. 33-47.

Arndt, H. y R. Janney (1987): InterGrammar: Toward an integrative model of verbal, prosodic and kinesic choices in speech. Berlín, Mouton de Gruyter.

Barros García, M. J. (2011): La cortesía valorizadora en la conversación coloquial española: estudio pragmalingüistico. Granada, Universidad de Granada.

Bernal Linnersand, M. (2007): Categorización sociopragmática de la cortesía y de la descortesía: Un estudio de la conversación coloquial española. Estocolmo, Universidad de Estocolmo.

Bilmes, J. (1994): "Constituting silence: Life in the world of total meaning", Semiótica, 98, págs. 73-87.

Bravo, D. (1996): La risa en el regateo: Estudio sobre el estilo comunicativo de negociadores españoles y suecos. Estocolmo, Universidad de Estocolmo.

Bravo, D. (2003): "Actividades de cortesía, imagen social y contextos socioculturales: una introducción”. En Bravo, D. (ed.): Actas del I Coloquio del Programa EDICE. Estocolmo, Universidad de Estocolmo, págs. 98-108.

Bravo, D. (2004): “Tensión entre la universalidad y relatividad en las teorías de la cortesía”. En Bravo, D. y A. Briz (eds.): Pragmática sociocultural: estudios del discurso de cortesía en español. Barcelona, Ariel, págs. 15-33.

Bravo, D. (2010): "Pragmática socio-cultural. La configuración de la imagen social como premisa socio-cultural para la interpretación de actividades verbales y no verbales de imagen". En Orletti, F. y L. Mariottini (eds.): (Des)cortesía en español. Espacios teóricos y metodológicos para su estudio. Roma-Estocolmo, Universidad de Roma Tre-Universidad de Estocolmo, págs. 12-45.

Brenes Peña, M. E. (2009) La agresividad verbal y sus mecanismos de expresión en el español actual. Sevilla, Universidad de Sevilla.

Briz Gómez, A. (1995): La conversación coloquial (Materiales para su estudio). Valencia, Cuadernos de Filología de la Universidad de Valencia.

Briz Gómez, A. (2004): "Cortesía verbal codificada y cortesía verbal interpretada en la conversación”. En Bravo, D. y A. Briz (eds.): Pragmática sociocultural: estudios sobre el discurso de cortesía en español. Barcelona, Ariel, págs. 67-93.

Brown, P. y S. Levinson (1987): Politeness. Some universals in language usage. Cambridge, Cambridge University Press.

Camargo Fernández, L. (2006): "Cuestiones metodológicas de la investigación en pragmática: ¿¿de dónde proceden nuestros ejemplos?”. En Calzón, J. A. et al. (eds.): Orientaciones Metodológicas, Actas I Congreso internacional de filología hispánica: jóvenes investigadores. Oviedo, Universidad de Oviedo, págs. 81-92.

Camargo Fernández, L. (2009): "La metapragmática". En Ruiz Gurillo, L. y X. Padilla 
García (eds.): Dime cómo ironizas y te diré quién eres. Una aproximación pragmática a la ironía. Frankfurt, Peter Lang, págs. 89-107.

Camargo Fernández, L. y B. Méndez Guerrero (en prensa): "Los actos silenciosos en el habla de las jóvenes españolas. Estudio sociolingüístico”, LinRed.

Campos Prats, M. y M. Romera Ciria (2012): "Sobre el concepto de face y (des)cortesía en la cultura española". Comunicación presentada en el XLI Simposio SEL. Valencia, Universitat de València.

Cestero Mancera, A. M. (1999): Comunicación no verbal y enseñanza de lenguas extranjeras. Madrid, Arco/Libros.

Cestero Mancera, A. M .(2000): El intercambio de turnos de habla en la conversación. Alcalá de Henares, Servicio de Publicaciones de la Universidad de Alcalá.

Ephratt, M. (2008): “The functions of silence”, Journal of Pragmatics, 40, págs. 19091938.

Escandell Vidal, M. V. (2006): Introducción a la pragmática. Barcelona, Ariel.

Gallardo Pauls, B. (1993): "La transición entre turnos conversacionales: silencios, solapamientos e interrupciones", Contextos, 11, págs.189-220.

Gallardo Pauls, B. (1996): Análisis conversacional y pragmática del receptor. Valencia, Ediciones Episteme (colección sinapsis).

Goffman, E. (1967): “On Face-Work”. En Goffman, E. (ed.): Interaction Ritual. New York, Anchor Books, págs. 5-46.

Haverkate, H. (1994): La cortesía verbal. Estudio pragmalingüístico. Madrid, Editorial Gredos.

Jaworski, A. (1993): The power of silence. Social and pragmatic perspectives. Newbury Park, SAGE.

Jaworski, A. (1997): Silence. Interdisciplinary perspectives. Berlin-New York, Mouton de Gruyter.

Kaul de Marlangeon, S. (2008): "Tipología del comportamiento verbal descortés en español, en cortesía y conversación: de lo escrito a lo oral. En Briz, A. et al. (eds.): III Coloquio Internacional. Programa EDICE. Valencia: Universitat de València, págs. 254-266.

Kerbrat Orecchioni, C. (1992): Les interactions verbales. Paris, Armand Colin.

Kerbrat Orecchioni, C. (2004): “¿Es universal la cortesía?”. En Bravo, D. y A. Briz (eds.): Pragmática sociocultural: estudios sobre el discurso de cortesía en español. Barcelona, Ariel, págs. 39-54.

Kurzon, D. (1995): “The right of silence”, Journal of Pragmatics, 23, págs. 55-69.

Kurzon, D. (1997): Discourse of silence. Amsterdam, John Benjamins.

Kurzon, D. (2007): “Towards a typology of silence”, Journal of Pragmatics, 39, págs. 
1663-1688.

Lakoff, R. (1973): “The logic of politeness, or Minding your P's and Q's”, Proceedings of the Ninth Regional Meeting of the Chicago Linguistic Society, pp. 345-356.

Leech, G. (1983): Principles of pragmatics. London, Longman.

Leech, G. (1997): “Introducing Corpus Annotation”. En Garside, R., Leech, G. y T. McEnery (eds.): Corpus Annotation. London/New York, Longman, págs. 1-18.

Levinson, S. (2000): Presumptive meanings. Cambridge, MTT Press.

Martín Rojo, L. (2010): Constructing inequality in multilingual classrooms. New York, Mouton de Gruyter.

Mateu Serra, R. M. (2001): El lugar del silencio en la comunicación. Lleida, Universitat de Lleida.

Meier, A. J. (1995): “Passages of politeness”, Journal of Pragmatics, 24, págs. 381-392.

Mills, S. (2003): Gender and politeness. Londres, Cambridge University Press.

Mills, S. (2005): “Gender and impoliteness”, Journal of Politeness Research, 1 (2), págs. 263-280.

Nakane, I. (2005): "Negotiating silence and speech in the classroom", Multilingua, 24, págs. 75-100.

Nakane, I. (2007): Silence in the multicultural classroom: perspections and performance. Amsterdam, John Benjamins.

Nakane, I. (2010): “The role of silence in interpreted pólice interviews", Journal of Pragmatics, 43, págs. 2317-2330.

Padilla García, X. A. y B. Alvarado Ortega (2010): "Being polite through Irony". En Koike, D. A. y L. Rodríguez-Alfaro, (eds.): Dialogue in Spanish. Studies in functions and contexts. Amsterdam, John Benjamins, págs. 55-68.

Poyatos, F. (1994): La comunicación no verbal (vol. I: "Cultura, lenguaje y conversación”). Madrid, Istmo.

PRESEEA (2008): “Marcas y etiquetas mínimas obligatorias”, Versión 1.2. 31-01-2008. http://www.linguas.net/preseea. Acceso: 20-09-2012.

Sacks, H., Schegloff, E. A. y Jefferson, G. (1974): “A simplest systematics for the organization of turn-taking for conversation”, Language, 50, págs. 696-735.

Saville-Troike, M. (1985): "The place of silence in an integrated theory of communication”. En Tannen, D. y M. Saville-Troike (eds.) Perspectives on silence. Norwood, Alex Publishing Corporation, págs. 3-18.

Searle, J. (2001): Mente, lenguaje y sociedad. Madrid, Alianza.

Sifianou, M. (1997): “Silence and politeness". En Jaworsky, A. (ed.): Silence. Interdisciplinary perspectives. Berlin-New York: Mouton de Gruyter, págs: 63-84.

Vivas Márquez, J. (2011): El relativismo cultural del silencio. Una propuesta para el aula 
de ELE desde la pragmática intercultural. Salamanca, Universidad de Salamanca.

Watts, R. J. (1989): "Relevance and relational work: Linguistic politeness as politic behaviour”, Multilingua, 8, págs. 131-166.

Zimmermann, K. (2003): "Constitución de la identidad y anticortesía verbal entre jóvenes masculinos hablantes de español". Actas del Primer Coloquio del Programa EDICE. Estocolmo, Universidad de Estocolmo, págs. 47-59.

Zimmermann, K. (2005): “Construcción de la identidad y anticortesía verbal”. En Bravo, D. (ed.) Estudio de la (des)cortesía en español: categorías conceptuales y aplicaciones a corpora orales y escritos. Estocolmo, Programa EDICE, Universidad de Estocolmo, págs. 245-271. 


\title{
RECONSIDERING SYLLABIC MINIMALITY IN SPANISH TRUNCATION
}

\author{
ANTONIO GRAU SEMPERE \\ Fairfield University \\ agrausempere@fairfield.edu
}

\begin{abstract}
Resumen
Se sabe que la palabra mínima en español contiene una sola sílaba que domina a dos moras. También se ha demostrado que el pie métrico mínimo en español es monosilábico bimoraico. Así, este estudio sostiene que el tamaño mínimo de los truncamientos en español es igualmente monosílabico bimoraico y ofrece un análisis basado en la Teoría de la Optimidad
\end{abstract}

PALABRAS CLAVE: truncamientos, español, palabra mínima, pie mínimo, Teoría de la Optimidad.

\section{Moraic minimal word in Spanish}

It is well proven that Spanish requires the smallest word to contain no fewer than two moras: rés 'head of cattle', pán 'bread', séd 'thirst', cán 'dog'1. In optimality theoretical terms, FOOTMINo is dominated by PRWD-TO-FT².

\footnotetext{
${ }^{1}$ Examples follow Spanish spelling conventions, except stressed syllables, which are always marked with a stress mark over the vocalic nucleus 'á,' regardless of spelling.

${ }^{2}$ In Optimality Theory (henceforth OT, Prince and Smolensky 1993), unlike other earlier developments in Generative Phonology, there are no rules or derivations. The right output is obtained through the interaction of different components or functions of the grammar: The function GEN(erator) generates for every possible linguistic entry $e$, the group of possible linguistic analyses or candidates (A, B, C...). Furthermore, the function EVAL(autor) evaluates the candidates through a ranking of constraints. The grammar of every language is one possible ordering of the same universal set of constraints, or CON. There are two kinds of OT constraints, markedness constraints, which penalize a certain type of surface structure; and faithfulness constraints, which preserve input-output
} 
(1) PRWD-TO-FT » FoOTMino

a. PRWD-TO-FT (a. k. a. Rooting, Hammond, 1997: 44): a Prosodic Word must dominate at least a foot. (One ${ }^{\star}$ per footless PrWds).

b. FootMin $\sigma$ : feet are minimally disyllabic. (One ${ }^{\star}$ per monomoraic feet).

(2) PRWD-TO-FT » FOOTMINo

\begin{tabular}{|l|c|c|}
\cline { 2 - 3 } \multicolumn{1}{c|}{ Input: $r e s$} & PRWD-TO-FT & FOOTMIN \\
\hline a. $($ rés $)$ & & $*$ \\
\hline b. rés & $\star !$ & \\
\hline
\end{tabular}

Stressed monomoraic examples exist, but are restricted to the following categories (based on Dunlap, 1991: 75):

(3) Spanish monosyllabic monomoraic words

$\begin{array}{lll}\text { a. Functional words: } & \text { á } & \text { 'to' } \\ & d e ́ & \text { 'of } \\ \text { b. Interjections: } & j o ́ & \text { 'whoa!' } \\ & t a ́ & \text { 'beware' } \\ \text { c. Onomatopoeia: } & \text { cló } & \text { 'cluck' } \\ \text { d. Irregular verbs: } & d a ́ & \text { '(s)he gives', imperative 'give' } \\ & d i ́ & \text { 'I gave', imperative 'say' } \\ & v e ́ & \text { '(s)e sees', imperative 'go' } \\ & v i ́ & \text { 'I saw' } \\ & v a ́ & \text { '(s)he goes' } \\ & \text { sé } & \text { 'I know', imperative 'be' } \\ \text { e. Personal pronouns } & y o ́ & \text { 'I' } \\ & \text { tú } & \text { 'you' } \\ \text { f. Other words: } & \text { fé } & \text { 'faith' } \\ & \text { té } & \text { 'tea' } \\ & \text { pré } & \text { 'soldier's daily pay' } \\ & \text { gró } & \text { 'grogram' } \\ & \text { pró } & \text { 'profit' }\end{array}$

or base-truncated form identity. Graphically, OT uses evaluation tableaux. Input and the set of candidates are located at the leftmost vertical column. Constraints are in the top horizontal line divided by a solid line to represent domination. Violations are marked with an asterisk ' '. Fatal violations are marked with '?'. The winner candidate is marked with ' irrelevant since the winner has previously been decided. 
Examples in subsections a-c are non-lexical words and are not subject to minimal word requirements. Only a small number of imperatives and other non-verbs are truly exceptional. According to Dunlap (1991: 75), a search of approximately 70,500 words only yielded a handful of truly monosyllabic monomoraic words and shortenings (gró, pró) in subsection $\mathrm{f}$. In conclusion, despite the existence of a few counterexamples, the hypothesis that the minimal content word in Spanish is bimoraic is solid.

The minimal word in the world's languages is usually a foot (Kager, 1999: 144, but see Crowhurst, 1991/2). Accordingly, it has been proposed for Spanish that the minimal word is a bimoraic monosyllable (among others, Dunlap, 1994). However, as seen above, monomoraic minimal content words are possible in Spanish. Any monosyllabic content word forms a foot, and consequently a PrWd, regardless of its weight.

The hypothesis that all Spanish content words are stressed implies that even light monosyllabic prosodic words build a foot. The claim this study supports is that this behavior is the result of PRWD-TO-FT, and MAX and DEP constraints outranking FOOTMIN $\mu$.

(4) PrWD-TO-FT » FOOTMin $\mu$

FOOTMIN $\mu$ : feet are minimally bimoraic. (One ${ }^{*}$ per monomoraic feet)

A monomoraic word like Spanish té is put under the scrutiny of the previous ranking.

(5) PRWD-TO-FT » FOOTMin $\mu$

\begin{tabular}{|l|c|c|}
\cline { 2 - 3 } \multicolumn{1}{c|}{ Input: $t e$} & PRWD-TO-FT & FOOTMINM \\
\hline a. $\left(t \dot{e}_{\mu}\right)$ & & $*$ \\
\hline b. $t \dot{e}_{\mu}$ & $* !$ & \\
\hline
\end{tabular}

Spanish offers no evidence of vowel lengthening to satisfy minimal word requirements as in Italian (D'Imperio and Rosenthall, 1999). A highly ranked constraint such as NOLONGVOWELS would eliminate surface sub optimal long vowels in this language. The next ranking is responsible for this pattern.

(6) NoLONGVOWELS » FoOtMin $\mu$

NOLONGVOWELS (Rossenthall, 1994: 15): vowels are only dominated by one mora. (One * per long vowel).

We can see the effects of the previous ranking in the next tableau. 
(7) NoLONGVOWELS » FOOTMIN $\mu$

\begin{tabular}{|l|c|c|}
\cline { 2 - 3 } \multicolumn{1}{c|}{ Input: $t e$} & NoLONGVOWELS & FOOTMIN $\mu$ \\
\hline a. $\left(t \dot{e}_{\mu}\right)$ & & $*$ \\
\hline b. $t \dot{e}_{\mu \mu}$ & $* !$ & \\
\hline
\end{tabular}

Dep constraints penalizing segmental epenthesis are also needed to account for candidates that add an additional syllable to comply with FoOTMiNo. DEP IO V disallows the addition of vowels, while Dep IO C does not tolerate the epenthesis of consonants. These constraints crucially dominate FoOTMin $\sigma$ and FoOTMin $\mu$.

(8) DeP IO C, DEP IO V » FOOTMIN $\mu$

a. DEP IO C: output consonants must have input correspondents. (One * per every output consonant without an input correspondent).

b. DEP IO V: output vowels must have input correspondents. (One * per every output vowel without an input correspondent).

(9) Dep IO C, Dep IO V » FootMins, FootMin $\mu$

\begin{tabular}{|l|c|c|c|}
\cline { 2 - 3 } \multicolumn{1}{c|}{ Input: $t e$} & DEP IO C & DEP IO V & FOOTMIN $\mu$ \\
\hline a. $(t e ́)$ & & & $*$ \\
\hline b. $(t e ́ e)$ & & e! & \\
\hline c. $($ téte $)$ & $\mathrm{t} !$ & $\mathrm{e} !$ & \\
\hline
\end{tabular}

The next section explores Spanish main stress assignment in non-verbs and concludes that Spanish also accepts monosyllabic bimoraic feet.

\section{Moraic minimal foot in Spanish regular non-verbal main stress assignment}

According to the principles of regular non-verbal stress assignment accepted by many linguists, summarized below, the minimal foot in Spanish is bimoraic ${ }^{3}$.

(10) Spanish regular non-verbal stress assignment

a. Final heavy syllables form a monosyllabic bimoraic foot, i.e., $m e(l o ́ n)_{\mathrm{Ft}}$ 'melon', $\operatorname{pen}(\text { dón })_{\mathrm{Ft}}$ 'slut'

\footnotetext{
${ }^{3}$ Among others, Harris (1983, 1992, 1995); Den Os and Kager (1986); Dunlap (1991); Morales Front (1994); Rosenthall (1994); D’Introno et al (1995); Eddington (2000); Piñeros (2001); Bárkányi (2002a, b); Alvord (2003); Face (2004).
} 
b. Final light syllables form a disyllabic trochaic foot with the preceding syllable, i.e., pre(sénte) $)_{\mathrm{Ft}}$ 'present', computa(dóra) $)_{\mathrm{Ft}}$ 'computer'

c. According to the previous generalizations the possible regular feet in Spanish are $\left(\sigma^{\prime} \mathrm{L}\right)$ and $\left(H^{\prime}\right)$, where $\sigma$ stands for any stressed syllable, regardless of weight, $\mathrm{L}$ for a light syllable and $\mathrm{H}$ for a heavy syllable.

The OT formalization of the previous generalizations requires FOOTMIN $\sigma$ be outranked. First, the ranking of TrocheE and FoOTMin $\mu$ over FoOtMino ensures the emergence of a monosyllabic bimoraic candidate, even if it violates syllable binarity.

(11) Trochee, FootMin $\mu$ » FootMin $\sigma$

TrOCheE(a. k. a. RHTYPE = T, Kager, 1999: 172): feet have initial prominence. (One ${ }^{\star}$ for every iambic foot).

(12) Trochee, FootMin $\mu$ » FootMino

\begin{tabular}{|c|c|c|c|c|}
\hline \multicolumn{2}{|r|}{ Input: melón } & TROCHEE & FOOTMIN $\mu$ & FoOtMino \\
\hline 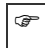 & a. me(lón) & & & * \\
\hline & b. (melón) & $\star !$ & & \\
\hline & c. (me)lón & & *! & \\
\hline
\end{tabular}

The candidate $c$ (mé)lon would also be ruled out by highly ranked WSP and AFR. AFR prevents a heavy penultimate syllable to form a monosyllabic foot, whereas the action of both constraints guarantees a heavy stressed ultimate or penultimate syllable.

(13) WSP, AFR » FOOTMINo

a. WSP: (Kager 1999: 155): heavy syllables are stressed. (One * for every heavy unstressed syllable).

b. AFR (Align (FOOT, Right, PRWD, Right), Kager, 1999: 163): every foot stands at the right edge of the PrWd. (One * per segment between the right edge of a foot and the right edge of the PrWd

(14) WSP, AFR „ FOOTMINo

\begin{tabular}{|l|c|c|c|}
\cline { 2 - 4 } \multicolumn{1}{c|}{ Input: presente } & WSP & AFR & FоOTMINo \\
\hline a. $p r e(\operatorname{sénte)}$ & & & \\
\hline b. $p r e s e n(t e ́)$ & $* !$ & & $*$ \\
\hline c. $p r e(\operatorname{sé} n) t e$ & & $t ! e$ & $*$ \\
\hline
\end{tabular}

(15) WSP, AFR » FOOTMINo

\begin{tabular}{|l|c|c|c|}
\cline { 2 - 4 } \multicolumn{1}{c|}{ Input: pedón } & WSP & AFR & FoOTMINo \\
\hline \multirow{2}{*}{ a.pen(dón) } & & & $*$ \\
\hline
\end{tabular}




\begin{tabular}{|c|c|c|c|}
\hline b. $($ pen)dón & $* !$ & d!on & $*$ \\
\hline c. (pendón) & $* !$ & e! & \\
\hline
\end{tabular}

The next section outlines some Spanish productive truncatory patterns and concludes that the shape of Spanish truncated words is minimally bimoraic, the size of the minimal word/foot in the same language ${ }^{4}$.

\section{Major Spanish truncatory patterns}

Truncation is the process in which a source word or base, usually a noun or adjective, is shortened not in an arbitrary way, but to conform to a process specific shape target. In Spanish we find truncation patterns where segmental material from the edges of some prosodic words is removed, producing typically disyllabic paroxytone truncated words, as in, $(\text { Trunc. }=\text { Truncated form }, \ldots=\text { at least one syllable })^{5}$. In this study, truncated words that omit segmental material from the right and left edges of a base word will be referred to as Type A and B respectively, as seen in examples a-b below. ${ }^{6}$

(16) Truncation patterns

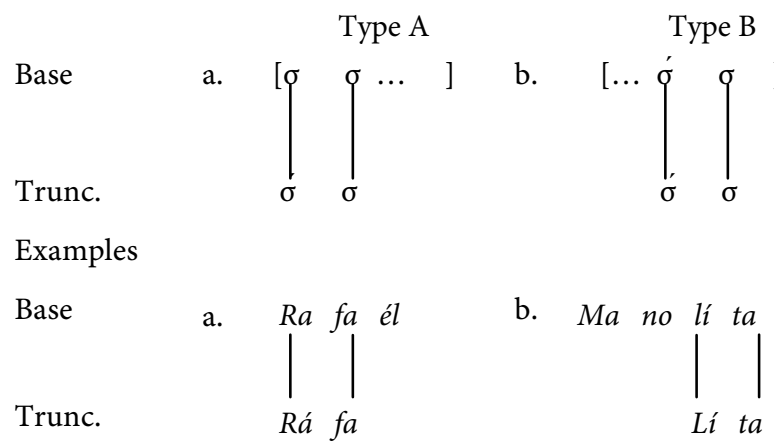

\footnotetext{
${ }^{4}$ This pattern seems to coincide with Spanish ancestor Latin. According to the data in Biville (1989), Latin truncated hypocoristics are normally two syllables long, e.g., Aphro < Aphrodita. However, the few monosyllabic nicknames attested are bimoraic, e.g., Pól < Poledépol.

${ }^{5}$ See Feliu (2001) for a trisyllabic truncation pattern.

It is unusual, but we can find a handful of examples of Spanish truncated hypocoristics that omit segmental material from both edges: Elizabéth > Líz, Fernándo > Nán, Hipólito > Póli, Pólo. The minimal size of these examples seems to be bimoraic.

${ }^{6}$ Segmental changes in the syllabic onset are not dealt with in this study since they do not affect syllabic weight.
} 


\subsection{Type A}

The majority of Type A truncated words are disyllabic. Canonical penultimate stress is displayed in the abbreviated form. Examples of hypocoristics include Rafaél $>$ Ráfa, Alejándro > Álex, Javiér > Jávi, Francísco > Fráncis. This process occurs in common nouns such as bicicléta $>$ bíci 'bicycle', profesór $>$ prófe 'professor', motocicléta $>$ móto 'motorcycle', película > péli 'film', or in the adjective divertído > diver 'fun'.

The second major Type A truncation pattern found in Spanish coincides with its Type B counterpart and includes monosyllabic bimoraic truncated words, which normally keep the leftmost edge of their source. The study of the Spanish hypocoristic data found in Boyd Bowman (1955), van Wijk (1964), Urawa (1985), Hoffman (1969), Costenla Umaña (1982), Casado Velarde (1984, 1999), Albaigés Olivart (1984, 1995), Fajardo (1990), Hamans (1996) and Roca \& Felíu (2003a) brings into light too many examples to ignore

(17) Type A monosyllabic bimoraic examples

$$
\begin{aligned}
& \text { Albérto }>\text { Ál Cristína }>\text { Crís Fermína }>\text { Fér } \quad \text { Gustávo }>\text { Gús Orlándo }>\text { Ór } \\
& \text { Alfónso }>A \text { Al Crístina }>\text { Críst Fernándo }>\text { Fér Jórge }>\text { Jór Paulína }>\text { Páu } \\
& \text { Artúro }>A \text { Ar Cristóbal }>\text { Crís Francísca }>\text { Frán Nélson }>\text { Nél Raymúndo }>\text { Ráy } \\
& \text { Bárbara }>\text { Bár Édgar }>E \text { Éd Francísco }>\text { Frán Norbérto }>\text { Nór } \\
& \text { Costánza }>\text { Cós Eugénia }>\text { Éu Gilbérto }>\text { Gíl Norbérto }>\text { Nóy }
\end{aligned}
$$

There seems to be a difference between the creation of truncated hypocoristics and the truncation of common nouns, in which monosyllabic truncated forms are very unusual. Some exceptions, which may receive a morphological explanation, are: exmarido 'ex-husband' / exmujer 'ex-wife' / exnovio, -a 'ex-boyfriend', 'ex-girlfriend' > ex. Other examples are: propagánda > próp 'propaganda', publicidád > púb 'commercial break'.

Spanish generally disfavors Type A monosyllabic truncated words ending in a vowel. Examples are scarce; the study of the Latin American and Spanish hypocoristic data in Boyd Bowman (1955), van Wijk (1964), Urawa (1985), Hoffman (1969), Costenla Umaña (1982), Casado Velarde (1984, 1999), Albaigés Olivert (1984, 1995) Fajardo (1990), Hamans (1996) and Roca \& Felíu (2003a) only yields a handful of examples: Clé $<$ Clementína, Dí < Diána, Fló < Florencio, -a, Sú < Susána, Ró > Rocío, Pe $<$ Penélope. This asymmetry (bimoraic but not monomoraic monosyllabic truncated words are possible) supported by the observation of the data so far, suggests that only truncated words that adhere to the minimal bimoraic word-size requirement are possible. 


\subsection{Type B}

In Type B truncated words, the stressed syllable of the base and the final unstressed syllable, in paroxytone base words, are kept. In other words, according to the principles of regular non-verbal stress assignment previously outlined, Type B truncated words discard material not contained within the main stressed foot.

In the following chart, example $a$ displays paroxytone-based Type B truncation, whereas example $b$ exhibits the truncation of a monosyllabic foot in oxytone base words.

(18) Spanish Type B truncation
Base
a. $\left.\begin{array}{rllll}{[\ldots} & ( & \sigma^{\prime} & f & )_{\mathrm{Ft}}\end{array}\right]$
b. $\left.\quad\left[\ldots \quad\left(\left.\right|_{\mathrm{H}} ^{\mathrm{H}}\right)_{\mathrm{Ft}}\right)_{\mathrm{Ft}}\right]$
Trunc.
Examples

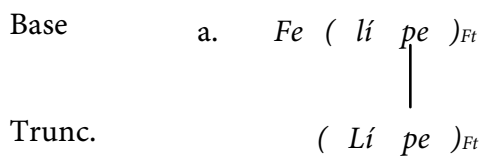
b. Je $\left(\left.\right|_{(\text {sús })_{F t}}\right.$

There is dialectal variation in truncated hypocoristics obtained from bases with an oxytone stress. Peninsular Spanish generally retains the last stressed closed syllable of the base in the truncated form. The stressed syllable in the truncated word matches the stressed syllable in the base in all dialects. On the other hand, some Latin American Spanish dialects may add an epenthetic gender marking ending ( $-o$ or $-a)$, as seen in below, to some truncated hypocoristics formed from oxytone bases ending in a consonant?.

(19) Latin American Spanish

Model
Base
Trunc.

Example

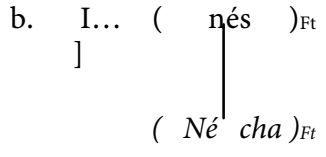

\footnotetext{
${ }^{7}$ It must be noticed that all these hypocoristics are attested in Peninsular Spanish as well
} 
The addition of an extra vowel affects the prosodic structure of the truncated form by adding an extra syllable that is not present in the source. More examples of this pattern are the following: Joaquín > Quino, Isabél > Béla, Valentín > Tíno, Jesús > Súso, Ramón > Móncho.

Piñeros (2002) notes this variation among Spanish dialects regarding monosyllabic Type B truncated words and proposes the use of two optimality theoretical coda condition constraints (CODACOND), a "strict" version that bans any coda with any point of articulation and a "relaxed" version, which allows coronal codas to surface. Piñeros suggests that the dialects in which the strict version of CODACOND dominates, an epenthetic vowel is inserted, thus forming a disyllabic truncated word $($ Tín $<0>)$. Conversely, in the dialects that allow monosyllabic truncated words, the relaxed CODACOND constraint prevails.

Roca and Felíu (2003a, 2003b) reject Piñeros' phonological analysis and the use of relaxed CODACOND constraint for different reasons. First, the constraint is ad-hoc, motivated only to take care of the epenthetic vowel in truncates. Second, Piñeros' analysis does not explain cases in which the final vowel changes: Matílde > Tíla, Silvéstre > Véto. The same authors claim morphology plays a decisive role in the shaping of Spanish truncated words. First, the usual epenthetic vowel in Spanish is $e$. Second, the selected epenthetic vowel seems to coincide with the masculine or feminine gender desinence: $a$ for feminine names and $o$ for masculine names. For instance, considering the examples seen above, Joaquín > Quíno are male names and Isabél > Béla are feminine names. Therefore, the masculine desinence $-o$ is assigned to the former and the feminine desinence $-a$ is asigned to the latter. According to Felíu and Roca, the desinences are not present in the base form since they are lexically marked desinenceless.

More Type B examples displaying paroxytone stress include the following: Ernestina $>$ Tína, Enriquéta > Quéta, Manolíta > Lita, Teodóra > Dóra. On the other hand, there are a considerable number of oxytone-based Type B truncation examples:

(20) Type B monosyllabic bimoraic examples

$\begin{array}{lllll}\text { Abigáil }>\text { Gáil } & \text { Concepción }>\text { Chón } & \text { Froilán }>\text { Lán } & \text { Manuél }>\text { Mél } & \text { Samuél > Mél } \\ \text { Agustín }>\text { Tín } & \text { Daniél }>\text { Nél } & \text { Hernán }>\text { Nán } & \text { Martín }>\text { Tín } & \text { Sebastián }>\text { Tán } \\ \text { Anáis }>\text { Náis } & \text { Delfín }>\text { Fín } & \text { Inés }>\text { Nésh } & \text { Moisés }>\text { Chés } & \text { Sebastián }>\text { Tián } \\ \text { Ascensión }>\text { Chón } & \text { Efraín }>\text { Pín } & \text { Isabél }>\text { Bél } & \text { Montserrát }>\text { Rát } & \text { Senén }>\text { Nén } \\ \text { Asunción }>\text { Chón } & \text { Efrén }>\text { Frén } & \text { Ismaél }>\text { Mél } & \text { Omár }>\text { Már } & \text { Tomás }>\text { Más } \\ \text { Babét }>\text { Bét } & \text { Elisabét }>\text { Bét } & \text { Jesús }>\text { Chús } & \text { Pantaleón }>\text { Lón } & \text { Valentín }>\text { Tín } \\ \text { Beatríz }>\text { Tíz } & \text { Encarnación }>\text { Chón } \text { Joaquín }>\text { Quín } & \text { Rafaél }>\text { Fáy } & \end{array}$




$\begin{array}{llll}\text { Beatríz }>\text { Tísh } & \text { Estér }>\text { Téy } & \text { Leonór }>\text { Nóy } & \text { Ramón }>\text { Món } \\ \text { Benjamín }>\text { Mín } & \text { Fermín }>\text { Mín } & \text { Marilín }>\text { Lín } & \text { Salomón }>\text { Món }\end{array}$

Notice that all the previous examples are hypocoristics. There are very few examples of Type B truncated common nouns attested: autobús > bús 'bus', compañéro > néro 'mate', chiquíllo, -a > quíllo, -a 'boy/girl.

\subsection{OT analysis}

The following chart displays a summary of the Spanish truncatory patterns discussed in the previous section:

(21) Spanish truncatory processes and shapes

$\begin{array}{lll} & \text { Type A } & \text { Type B } \\ \text { Disyllabic } & \text { Fernándo }>\text { Férnan } & \text { Enriquéta }>\text { Quéta } \\ \text { Monosyllabic } & & \\ \text { a. Bimoraic } & \text { Fernándo }>\text { Fér } & \text { Valentín }>\text { Tín } \\ \text { b. Monomoraic } & - & -\end{array}$

Type A truncated words yield both monosyllabic and disyllabic truncated results (e.g., Frán < Francísco, Ráfa < Rafaél). The minimal word/foot size requirements play the role of allowing both types of feet to surface. The stressed syllable invariantly conforms to the trochaic pattern. This analysis explains why closed but not open syllables can constitute a truncated word in Spanish. The size of an open monomoraic syllable does not adhere to the minimal word, and foot, requirements, which is the reason why it almost never surfaces.

(22) Spanish Type A truncation

Base Form

Fernándo
a. Monosyllabic (bimoraic) truncated form:
Fér ${ }^{*} F e ́$
b. Disyllabic truncated form:
Férnan

As supported previously, oxytone words ending in a heavy syllable form a monosyllabic bimoraic foot, whereas a final light syllable forms a disyllabic trochaic foot with the previous syllable. Therefore, Type B hypocoristics such as Nór $<$ Leo (nór) Ft $_{\mathrm{Ft}}$ and disyllabic Type $\mathrm{B}$ forms, e.g., Tína $<$ Ernes $(\text { tina })_{\mathrm{Ft}}$, also truncate the main foot of the source, conforming to the original trochaic pattern (Piñeros, 1998, 2000a, 2000b, 2002). 
(23) Spanish Type B truncation

$\begin{array}{lll}\text { Base Form } & \text { Main foot } & \text { Type B Truncated form } \\ \text { a. Final bimoraic syllable } & \text { Leo (nór)Ft } & \text { Nór } \\ \text { b. Final monomoraic syllable } & \text { Ernes (tína)Ft } & \text { Tína }\end{array}$

This model just outlined differs from other studies. Before the work of Piñeros $(1998,2000 a, 2000 b, 2002)$ there was consensus among the different linguists who analyzed Spanish truncatory morphology. They all agreed in considering that the template to which Spanish truncated words conform was disyllabic. Weeda (1992) analyzed Types A and B truncated forms in Costa Rican Spanish and concludes that their template is a syllabic trochee. Prieto i vives (1992) and Lipski (1995) offered a templatic analysis that relied on prosodic circumscription (McCarthy and Prince 1990, 1993, 1995a, Lombardi and McCarthy 1991) and templatic morphology to account for the data. Colina (1996), based on Prieto i Vives' (1992) Type A data also supports a disyllabic trochaic template and analyze the data from an optimality theoretic standpoint.

On the other hand, Piñeros $(1998,2000 a, 2000 b, 2002)$ support a trochaic (bimoraic or disyllabic) template and analyze the data from an optimality theoretic standpoint. For instance, Piñeros (2002) offers an optimality theoretic analysis of mainly Type B truncatory process in Spanish that relies on the ranking of different constraints to obtain binary trochaic truncated words. For his analysis, Piñeros (2002) follows Benua (1995) in applying some truncation-specific correspondence constraints. In Piñeros' (2002) analysis, the undominated hierarchy FOOTBIN, PARSE- $\sigma$ ALIGN-FT-R (also known as RESTRICTOR, responsible for delimiting or "restricting" the size of the prosodic word, McCarthy and Prince 1995) is responsible for a prosodic word of exactly two syllables or two moras long in Spanish. On the other hand, foot-sensitive Type B truncation is treated in a different manner. Piñeros assumes a constraint MAX FT BT that in the output form preserves the integrity of the foot already present in the base.

The effects of the Restrictor hierarchy, FOOTBIn, PARSE- $\sigma$, ALIGN-FT-R, are exemplified next with the input bicicléta 'bicycle' and its Type A truncated word bicis.

(24) Restrictor constraints (Piñeros, 2002: 442)

a. FoOtBin (PIE-BINARIO in Piñeros' article): metrical feet are binary at a moraic or syllabic analysis.

\footnotetext{
${ }^{8}$ This ranking exemplifies the effects of RESTRICTOR constraints only. Any disyllabic candidate would win. Further analyses are needed to obtain the right optimal candidate.
} 
b. PARSE- $\sigma$ (AFILIAR- $\sigma$ ): syllables are parsed into feet.

c. Align-Ft-R (Alinear(PIE)): the right edge of a foot coincides with the right edge of a prosodic word.

(25) FootBin, PARse- $\sigma$, Align-FT-R (Piñeros 2002: 442)

\begin{tabular}{|l|c|c|c|}
\cline { 2 - 4 } \multicolumn{1}{c|}{ Base: bicicleta } & FOOTBIN & PARSE- $\sigma$ & ALIGN-FT-R \\
\hline a. $($ bici) (cleta) & & & (bici)! \\
\hline b. $($ bi) (ciclé) & & $b i !$ & \\
\hline c. $($ bici) & & & \\
\hline d. $(b i)$ & $\star !$ & & \\
\hline
\end{tabular}

The only possible prosodic word resulting from the RESTRICTOR filter is, then, disyllabic or bimoraic. Align-FT-R rejects candidates consisting of more than one foot, Parse- $\sigma$ filters out candidates with unparsed material and FOOTBIN is responsible for eliminating candidates with feet that are too small or too big. The winning candidate is obtained at the cost of violating MAX BT SEG, as some segmental material from the base is erased after truncation takes place. For this reason, Piñeros states that truncation needs MAX BT SEG to be outranked by RESTRICTOR (citing Benua, 1995). As expected by the previous ranking, the analysis of bases starting with a heavy syllable adequately predicts the emergence of either a monosyllabic bimoraic or a disyllabic truncate.

(26) FootBin, PARSE- $\sigma$, Align-FT-R (Piñeros, 2002: 442)

\begin{tabular}{|l|c|c|c|}
\cline { 2 - 4 } \multicolumn{1}{c|}{ Base: Raymúndo } & FOOTBIN & PARSE- $\sigma$ & ALIGN-FT-R \\
\hline a. (Ray) (múndo) & & & (múndo)! \\
\hline b. Ray (múndo) & & Ray! & \\
\hline c. (Ráy) & & & \\
\hline d. (Ráymun) & & & \\
\hline
\end{tabular}

In addition, Piñeros notes that the observation that all truncated words are trochaic implies that the Trochee constraint is undominated.

(27) Additional constraints in Piñeros' (2002) analysis

a. MAX BT SEG (MAX): every segment in the (B)ase has a correspondent in the (T)runcated form

b. Trochee (TROQUeO): every foot is left prominent

The resulting ranking TROCHEE, RESTRICTOR » MAX BT SEG is put to the test in the following tableau with an input colégio 'school' and its Type A truncated word cóle. 
(28) Trochee, Restrictor» MAX BT Seg (Piñeros, 2002: 443)

\begin{tabular}{|l|c|c|c|}
\cline { 2 - 4 } \multicolumn{1}{l|}{ Base: colégio } & TROCHEE & RESTRICTOR & MAX BT SEG \\
\hline a. co(légio) & & co! (PARSE- $\sigma)$ & \\
\hline b. (cóle) & & & gio \\
\hline c. (colé) & $* !$ & & gio \\
\hline d. (có) & & $* !$ & legio \\
\hline
\end{tabular}

In accord with the ranking in, the resulting prosodic word is a moraic syllabic TROCHEE. Trochee rejects disyllabic candidate $c$. However, when analyzing bases with a heavy initial syllable, the previous ranking does inadequately predict the emergence of only a disyllabic candidate. MAX BT Seg imposes a preference for longer truncates, thus disallowing monosyllabic attested truncated words such as Ráy, as seen in the following tableau.

(29) Trochee, Restrictor» MAX BT Seg (Piñeros, 2002: 443)

\begin{tabular}{|l|c|c|c|}
\cline { 2 - 4 } \multicolumn{1}{c|}{ Base: Raymúndo } & TROCHEE & RESTRICTOR & MAX BT SEG \\
\hline a. (Ray) & & & mun do! \\
\hline b. (Ráymun) & & & $d o$ \\
\hline c. (Raymún) & $* !$ & & $d o$ \\
\hline
\end{tabular}

The analysis proposed in this essay attempts to correct Piñeros' inadequacy just outlined above. In addition, it provides a coherent OT formalization of the data, including word minimality and stress assignment. As previously explored, this study supports the hypothesis that the minimal size of not only the foot and the word, but also the truncated word is bimoraic. An OT formalization in line with the previous analyses on word minimality and stress assignment occupies the rest of this section.

The ranking of ALL FEET LeFT (AFL) and AlL FEET Right (AFR) over MAX BT Seg determines the preference for hypocoristics to form only one foot, as seen in the next tableau. The winning truncated candidate necessarily violates MAX BT SEG.

(30) AFR, AFL » MAX BT SEG

a. AFR (Align (FoOT, Right, PRWD, Right), Kager, 1999: 163): every foot stands at the right edge of the PrWd. (One* per segment between the right edge of a foot and the right edge of the PrWd).

b. AFL (ALIGN (FOOT, LEFT, PRWD, LEFT), Kager, 1999: 163): every foot stands at the left edge of the PrWd. (One * per segment between the left edge of a foot and the left edge of the PrWd). 
c. MAX BT SEG (Benua, 1995: 80): every segment in the base has a correspondent in the truncated form. (One ${ }^{*}$ per deleted element).

(31) AFR, AFL » MAX BT SEG

\begin{tabular}{|l|c|c|c|}
\cline { 2 - 4 } \multicolumn{1}{c|}{ Base: Enriqueta } & AFR & AFL & MAX BT SEG \\
\hline a. (Queta) & & & en ri \\
\hline b. Enri (quéta) & & en!ri & \\
\hline c. (Enri) (quéta) & que!ta & en!ri & \\
\hline
\end{tabular}

The previous ranking partially establishes the preference for Spanish truncated forms to form a single foot, eliminating unparsed syllables or secondary feet, at the cost of minimally violating BT Maximality. Furthermore, MAX BT SEG is ranked below FoOTMAX $\mu$ to prevent the surfacing of a candidate that forms a long foot, as in the next tableau.

(32) FоотMAX $\mu$ : feet are maximally bimoraic. (One ${ }^{*}$ for every mora in excess of two in a foot).

(33) FOOTMAX $\mu$ » MAX BT SEG

\begin{tabular}{|l|c|c|}
\cline { 2 - 3 } \multicolumn{1}{c|}{ Base: Enriqueta } & FоотMAX $\mu$ & MAX BT SEG \\
\hline a. (Queta) & & en $r i$ \\
\hline b. (Enriquéta) & ${ }^{*}$ !** & \\
\hline c. (Riquéta) & $\star !$ & en \\
\hline
\end{tabular}

Type B hypocoristics discard the segmental material to the left of the main foot of the base. This generality is partially captured by highly ranked HEADMATCH, which preserves the head of the main foot from the base in the truncated form, over MAX BT SEG.

(34) HeadMatch » MAX BT SeG

HeAdMatch (McCarthy, 2000: 183): if $\alpha$ is in $\mathrm{H}^{\prime}(\operatorname{PrWd})$ and $\alpha \Re \beta$, then $\beta$ is in $\mathrm{H}^{\prime}(\operatorname{PrWd})$. (One * for every segment between the head of PrWd in B and the head of PrWd in T)

HEADMATCH ensures the head of the base form is the same in the truncated form, as in the next tableau. ${ }^{9}$

\footnotetext{
9 An additional candidate ${ }^{*}$ Riqué, which adheres to HEADMATCH, is banned by highly ranked TrocheE.
} 
(35) HeAdMATCH » MAX BT SEG

\begin{tabular}{|l|c|c|}
\cline { 2 - 3 } \multicolumn{1}{c|}{ Base: Enriqueta } & FоOтMAX $\mu$ & MAX BT SEG \\
\hline a. Queta & & en $r i$ \\
\hline b. Ríque & qu!e & en \\
\hline c. Énri & n!rique & que \\
\hline
\end{tabular}

Type B nicknames ending in a heavy stressed syllable only keep the stressed monosyllabic foot from the base form, thus violating FoOTMino, e.g., Tín < Valentín. A possible candidate Léntin, which respects foot binarity without having to epenthesize any segments, is banned by HEADMATCH.

(36) HEADMATCH » FOOTMino

\begin{tabular}{|l|c|c|}
\cline { 2 - 3 } \multicolumn{1}{c|}{ Base: Valentín } & HeADMATCH & FoOTMino \\
\hline a. Tín & & $*$ \\
\hline b. Léntin & $!^{\star}$ & \\
\hline
\end{tabular}

In addition to this ranking, TROCHEE » IAMB prevents disyllabic iambic hypocoristics from appearing, e.g., ${ }^{\star}$ Lentín. Given the results of the previous rankings, no segments to the left of the stressed syllable in the base are maintained in the Type B truncated form in Spanish.

Type B nicknames ending in a heavy stressed syllable do not keep only the rightmost foot in some Latin American Spanish dialects, as candidate b shows in the tableau below. Instead, some segmental material is epenthesized to comply with foot syllable minimalism.

(37) DEP BT SEG: (Benua, 1995: 80): every segment in the truncated form has a correspondent in the base. (One ${ }^{\star}$ for each epenthetic segment).

(38) FoOTMINo » DEP BT SEG

\begin{tabular}{|l|c|c|}
\cline { 2 - 3 } \multicolumn{1}{c|}{ Base: Valentín } & FOоTMINo & DEP BT SEG \\
\hline a. Tíno & & $o$ \\
\hline b. Tín & $!^{*}$ & \\
\hline
\end{tabular}

On the other hand, for Spanish dialects that do not need to epenthesize any segments to comply with syllable minimalism DEP BT SEG outranks FOOTMINo, allowing a monosyllabic bimoraic nickname. 
(39) DeP BT SEG » FoOTMino

\begin{tabular}{|l|c|c|}
\cline { 2 - 3 } \multicolumn{1}{c|}{ Base: Valentín } & DEP BT SEG & FoOTMINo \\
\hline a. Tín & & $*$ \\
\hline b. Tíno & $o !$ & \\
\hline
\end{tabular}

ALIGN HEAD RIGHT and FOOTMINo are not strictly ranked with one another; in some instances, ALIGN HEAD Right dominates FOOTMINo producing monosyllabic results and in other cases, the ranking is reversed, yielding the more productive foot sensitive results, contradicting the OT principle of strict domination. Strict domination is one of the main principles in OT, which states that a constraint $\mathrm{C} 1$ can be ranked with another constraint $\mathrm{C} 2$ in two ways: either $\mathrm{C} 1 » \mathrm{C} 2$ or $\mathrm{C} 2$ » $\mathrm{C} 1$. $\mathrm{C} 2, \mathrm{C} 1$ occurs when no empirical data supports either ranking.

The issue of variation has not been dealt with satisfactorily in OT. Different approaches have been put forward within OT to answer to variation. One way to analyze variation in OT is to posit co-phonologies (among others, Inkelas and Orgun, 1995), or different constraint rerankings within one grammar, where each co-phonology selects a different output.

(40) Co-phonologies

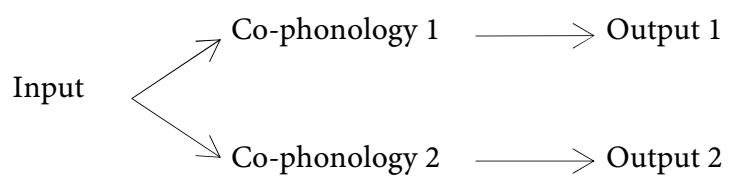

According to Kager (1999: 405), this approach has the disadvantage of predicting that each co-phonology is independent from one another, allowing co-phonologies to produce very different outputs. Kager concludes that this prediction is inadequate as candidates in variation are usually similar.

Free ranking of constraints (Anttila, 1997, Anttila and Cho, 1998) is another solution to variation in OT. When two constraints are freely ranked, the evaluation branches in two directions: in one branch, $\mathrm{C} 1 » \mathrm{C} 2$ and in the other branch, C2 » $\mathrm{C} 1$. Kager (1999: 406) offers a formal definition of free ranking, copied here:

(41) Interpretation of free ranking of constraints C1, C2

Evaluation of the candidate set is split into two subhierarchies, each of which selects an optimal output. One subhierarchy has $\mathrm{C} 1 » \mathrm{C} 2$ and the other $\mathrm{C} 2 » \mathrm{C} 1$. 
The principle of strict domination is preserved under free ranking in each subhierarchy. On the other hand, Kager (1999: 407) notes that the main disadvantage of free ranking is that it is not clear whether free ranking grammars are learnable or not.

Back to truncation, the same constraint ranking responsible for Type B truncates is active in Type A.

(42) AFR AFL » MAX BT SEG

\begin{tabular}{|l|l|l|c|}
\cline { 2 - 3 } \multicolumn{1}{c|}{ Base: Saturníno } & AFR & AFL & MAX BT SEG \\
\hline a. Sátur & & & nino \\
\hline b. (Sátur) nino & ni!no & & \\
\hline c. (Sátur) (nino) & ni!no & sa!tur & \\
\hline
\end{tabular}

As in Type B, Type A truncated forms only build one foot due to the action of highly ranked constraints AFR/L over MAX BT SEG. Unparsed syllables or additional feet are not allowed. The winning candidate a minimally violates MAX BT SEG. Another coincident ranking is FоOтMAX $\mu$ » MAX BT Segwhich avoids the surfacing of long footed words such as *(Saturníno) complying with MAX BT SEG. Additionally, the ranking TROCHEE » Iamb is active to ensure the occurrence of trochaic feet.

Highly ranked anchoring constraints are crucial for Type A truncation. ANCHOR BT Ldominates ANCHOR BT R to preserve the left edge of the base form, as shown in the tableau below.

(43) ANCHOR BT R » ANCHOR BT L

ANCHOR BT R/L (McCarthy and Prince, 1995: 123): Any element at the right/left periphery of $B$ has a correspondent at the right/left periphery of $T$. (One ${ }^{*}$ per any epenthesized or erased segment).

(44) Anchor BT L » Anchor BT R

\begin{tabular}{|l|c|c|}
\cline { 2 - 3 } \multicolumn{1}{c|}{ Base: Saturníno } & ANCHOR BT L & ANCHOR BT R \\
\hline a. Sátur & & nino \\
\hline b. Níno & s!atur & \\
\hline c. Túrni & s!a & \\
\hline
\end{tabular}

The previous ranking allows truncated forms to keep the segmental material to the left edge of the prosodic word.

Contrary to Type B truncated words, the winning candidate in the previous tableaux, Sátur, forms a disyllabic foot that does not preserve the right-aligned stress in 
the base form. For this reason, highly ranked HEADMATCH is outranked by TROCHEE and ANCHOR BT L, as in the tableau below.

(45) ANCHOR BT L, TrocheE » HeAdMATCH

The following tableau exemplifies the effects of this ranking.

(46) ANCHOR BT L, TROCHEE » HEADMATCH

\begin{tabular}{|l|c|c|c|}
\cline { 2 - 4 } \multicolumn{1}{c|}{ Base: Saturníno } & ANCHOR BT L & TROCHEE & HEADMATCH \\
\hline a. Sátur & & & tur \\
\hline b. Saní & & $\star !$ & \\
\hline c. Turní & $s ! a$ & $\star !$ & \\
\hline
\end{tabular}

Candidate $b$ conforms to ANCHOR BT L by keeping the first syllable of the base and to HEADMATCH by adding the head in the base. However, the result is an iambic foot, penalized by Trochee.

The optimal candidate Sátur departs from Type A stress assignment and Type B truncation by not complying with highly ranked WSP, a constraint that does not allow unstressed heavy syllables. In Type A truncation, as the result of TETU, respecting the syllable constituency of the base prevails over general foot-wellformedness considerations ${ }^{10}$. To account for this behavior, this study proposes a constraint WT-IDENT BT $\sigma$, modified from Wt-Ident BT, previously described in Kager (1999), which penalizes shortening or lengthening of vowels from input to output and also applies to syllables, preventing BT syllable shortening, e.g., Sátur $>{ }^{\star}$ Sátu, to observe WSP.

(47) WT-IDENT BT $\sigma »$ WSP

WT-IDENT BT $\sigma$ (modified from Kager, 1999: 269): if $\alpha \in$ Domain ( $f$ ); If $\alpha$ is monomoraic, then $f(\alpha)$ is monomoraic; If $\alpha$ is bimoraic, then $f(\alpha)$ is bimoraic. (One ${ }^{\star}$ for every shortened or lengthened syllable in the truncated form).

The next tableau displays the effects of the previous ranking and establishes the preference for a nickname Sátur, even if it disobeys WSP.

\footnotetext{
${ }^{10}$ Nevertheless, notice that Spanish present unpredictable variation in truncated forms ending in a consonant. These final consonants are optional in some Spanish forms, e.g., Spanish Ródol $\sim$ Ródo < Rodólfo. Final consonants are either left behind, as in Máti<Matílde, or they are obligatorily present, e.g., Róber < Robérto. This unpredictability may be the result of the free ranking of WT-IDENT BT $\sigma$ and WSP.
} 
(48) WT-IDENT BT $\sigma »$ WSP

\begin{tabular}{|l|c|c|}
\cline { 2 - 3 } \multicolumn{1}{l|}{ Base: Saturníno } & WT-IDENT BT $\sigma$ & WSP \\
\hline a. Sátur & & $*$ \\
\hline b. Sátu & $\star !$ & \\
\hline
\end{tabular}

To account for Spanish monosyllabic bimoraic Type A truncatory pattern, the constraint Align Head Right is freely ranked with FOоTMiNo, as in the next tableau.

(49) Align Head Right (Align (HEAd, Right, PRWD, Right)): every prosodic word ends with the head of the main foot. (One ${ }^{\star}$ per syllable between the head of the main foot and the right edge of PrWd)

(50) Trochee, Align Head Right » FootMino

\begin{tabular}{|l|c|c|c|}
\cline { 2 - 4 } \multicolumn{1}{c|}{ Base: Fernándo } & Trochee & Align HeAd Right & FootMino \\
\hline a. Fér & & & $*$ \\
\hline b. Férnan & & nan! & \\
\hline c. Fernán & ${ }^{*} !$ & & \\
\hline
\end{tabular}

The constraint FootMin $\mu$, dominating ALIGN HeAD Right also prevents the existence of monosyllabic monomoraic truncated words in Spanish. In addition, the next tableau motivates the domination of Trochee over Align Head Right. For instance, a name such as Spanish Rafaél can only produce a Type A hypocoristic Ráfa, as FoOTMin $\mu$ bans a potential candidate ${ }^{\star} R a ́$, as seen in the next tableau.

(51) Footmin $\mu$, TrocheE » Align HeAd Right

\begin{tabular}{|l|c|c|c|}
\cline { 2 - 4 } \multicolumn{1}{c|}{ Base: Rafaél } & FoоTMin $\mu$ & TROCHEE & ALIGN HEAD Right \\
\hline a. Ráfa & & & $*$ \\
\hline b. Rá & $* !$ & & \\
\hline c. Rafá & & $* !$ & \\
\hline
\end{tabular}

The previous two tableaux support the observation that Spanish only allows Type A monosyllabic truncated words when the leftmost syllable is heavy: highly ranked FoOTMin $\mu$ only allow monosyllabic bimoraic truncated forms to occur ${ }^{11}$.

\footnotetext{
${ }^{11}$ The possibility of making the leftmost light syllable in the base heavy in the truncated form by lengthening is banned in Spanish by WT-IDENT BT, which prohibits lengthening or shortening of syllables in a BT correspondence.
} 
In sum, the promotion of ALIGN HEAD RIGHT in Spanish explains the surfacing of monosyllabic truncated forms. In Spanish, FootMin $\mu$ is ranked over ALIGN HEAD RIGHT, allowing only monosyllabic bimoraic truncated forms to surface.

\section{Summary of conclusions}

The analysis of Spanish truncation processes provided in this study supported the view that they conform to the moraic word/foot minimum. Type B truncated words copy a version of the main stress foot of the source word. These truncations can be disyllabic or monosyllabic, depending on the stress placement of their source. Paroxytone source words build a disyllabic foot and, thus, yield a disyllabic trochaic truncated form. Oxytone bases form a monosyllabic bimoraic foot that may be preserved in the abbreviated form. On the other hand, Type A truncated words can be disyllabic or monosyllabic, provided they are bimoraic.

Recibido: 02-X-2012

Aceptado: 20-V-2013

\section{References}

Albaigés Olivart, J. M. (1984): Diccionario de nombres de personas. Barcelona, Publicacions i Edicions de la Universitat de Barcelona.

Albaigés Olivart, J. M. (1995): Enciclopedia de los nombres propios. Barcelona, Planeta.

Alvord, S. M. (2003): “The psychological unreality of quantity sensitivity in Spanish: experimental evidence", Southwest Journal of Linguistics, 22 (2), 1-12.

Anttila, A. (1997): "Deriving variation from grammar". In Hinskens, F., R. van der Hout and L. Wetzels (eds.): Change and phonological theory. Amsterdam: John Benjamins, págs. 35-68.

Anttila, A. and Young-mee, Y. C. (1998): "Vatiation and change in Optimality Theory", Lingua, 104, 31-56.

Bárkányi, Z. (2002a): “A fresh look at quantity sensitivity in Spanish”, Linguistics, 40 (2), 375-94.

Bárkányi, Z. (2002b): "Primary stress in Spanish". In Satterfield, T. et al. (eds.): Current issues in Romance languages. Amsterdam: John Benjamins, 17-31.

Benua, L. (1995): "Identity effects in morphological truncation". In Beckman, J., L. Walsh and S. Urbanczyk (eds.): University of Massachusetts occasional papers in Linguistics, 18. Amherst: GLSA, 77-136.

Biville, F. (1989): “Un processus dérivationnel méconnu du Latin: la dérivation par 
troncation", L'information Grammaticale, 42, 15-22.

Boyd-Bowman, P. (1955): "Cómo obra la fonética infantil en la formación de los hipocorísticos”, Nueva Revista de Filología Hispánica, 9, 337-366.

Casado Velarde, M. (1984): “Acortamientos léxicos en español actual”, Iberorromania, 20, 1-8.

Casado Velarde, M. (1999): "Otros procesos morfológicos: acortamientos, formación de siglas y acrónimos”. In Bosque, I. and V. Demonte (eds.): Gramática descriptiva de la lengua española. Madrid, Spain: RAE-Espasa Calpe, 5075-5096.

Colina, S. (1996): "Spanish truncation processes: the emergence of the unmarked", Linguistics, 34, 1199-1218.

Costenla Umaña, A. (1982): "Los hipocorísticos costarricenses”, Estudios de Lingüística Hispánica, B (1), 5-51.

Crowhurst, M. J. (1991): "Minimality and foot structure in metrical phonology and prosodic morphology", Unpublished Ph.D. dissertation. Tucson, Arizona, The University of Arizona. (Distributed by The Indiana University Linguistics Club, Bloomington, 1992).

D'Imperio, M. and S. Rosenthall (1999): "Phonetics and phonology of main stress in Italian", Phonology, 16, 1-28.

D’Introno, F., E. del Teso y R. Weston (1995): Fonética y fonología actual del español. Madrid, Cátedra.

Den Os, E. and R. Kager (1986): "Extrametricality and stress in Spanish and Italian", Lingua, 69, 23-48.

Dunlap, E. (1991): "Issues in the moraic structure of Spanish", Unpublished Ph.D. dissertation. Amherst, Massachusetts, University of Massachusetts.

Eddigton, D. (2000): "Spanish stress assignment within the Analogical Modeling of Language”, Language, 76, 92-109.

Face, T. L. (2004): "Perceiving what isn't there: non-acoustic cues for perceiving Spanish stress". In Face, T. L. (ed.): Laboratory approaches to Spanish phonology. Berlin, Germany: Mouton de Gruyter, 117-141.

Fajardo, A. (1990): “Truncamientos léxicos en español actual”, Lebende Sprachen, 35 (3), 132-133.

Felíu, E. (2001): "Output constraints on two Spanish word-creation processes", Linguistics, 39, 871-891.

Hamans, C. (1996): “A lingo of abbrevs", Lingua Posnaniensis, 38, 69-78.

Hammond, M. (1997): “Optimality Theory and prosody”. In Archangeli, D. and D. T. Langendoen (eds.): Optimality Theory. An overview. Cambridge, MA: Blackwell, 33-59. 
Harris, J. W. (1983): Syllable structure and stress in Spanish. A non-linear analysis. Cambridge, MA, MIT Press.

Harris, J. W. (1992): Spanish stress: The extrametricality issue. Bloomington, IN, Indiana University Linguistics Club.

Harris, J. W. (1995): "Projection and edge marking in the computation of stress in Spanish". In Goldsmith, J. A. (ed.): The handbook of phonological theory. Cambridge, MA, Blackwell, 867-887.

Hoffman, R. J. (1969): “The derivation of Spanish hypocoristics”. In Binnick, R. I. et al. (eds.): Papers from the Fifth Regional Meeting of the Chicago Linguistic. Chicago, IL, University of Chicago Press, 366-373.

Inkelas, S. and C.Orhan Orgun (1995): "Level ordering and economy in the lexical phonology of Turkish”, Language, 71, 763-793.

Kager, R. (1999): Optimality Theory. Cambridge, MA, Cambridge University Press.

Lipski, J. M. (1995): "Spanish hypocoristics: towards a unified prosodic analysis", Hispanic Linguistics, 6-7, 387-434.

Lombardi, L. and J. J. McCarthy (1991): "Prosodic circumscription in Choctaw morphology", Phonology, 8, 37-71.

McCarthy, J. J. (2000): "The prosody of phase in Rotuman", Natural Language and Linguistic Theory, 18, 147-197.

McCarthy, J. J. and A. Prince (1990): "Foot and word in prosodic morphology: the Arabic broken plural", Natural Language and Linguistic Theory, 8, 209-283.

McCarthy, J. J. and A. Prince (1993): "Prosodic morphology I: Constraint interaction and satisfaction", Unpublished Manuscript. Amherst, Massachusetts, University of Massachusetts.

McCarthy, J. J. and A. Prince (1995): "Prosodic morphology". In Goldsmith. J. A. (ed.): The handbook of phonological theory. Cambridge, MA, Blackwell, 318-366.

Morales-Front, A. (1994): "A constraint based approach to Spanish phonology", Unpublished Ph.D. dissertation. Urbana-Champaign, Illinois, University of Illinois.

Piñeros, C. E. (1998): "Prosodic morphology in Spanish: constraint interaction in wordformation", Unpublished Ph.D. dissertation. Columbus, Ohio: The Ohio State University.

Piñeros, C. E. (2000a): "Prosodic and segmental unmarkedness in Spanish truncation", Linguistics, 38, 63-98.

Piñeros, C. E. (2000b): "Foot-sensitive word minimization in Spanish", Probus, 12, 291324.

Piñeros, C. E. (2001): "Vowel weightlessness and stress retraction in Spanish", Unpublished manuscript. Iowa City, Iowa: University of Iowa. 
Piñeros, C. E. (2002): “Truncamientos en español”, Bulletin of Hispanic Studies, 79 (4), 437-459.

Prieto i Vives, P. (1992): "Truncation processes in Spanish", Studies in Linguistic Sciences, 22 (1), 143-158.

Prince, Alan, and Paul Smolensky (1993): "Optimality Theory: Constraint Interaction in Generative Grammar." Unpublished manuscript. Rutgers University and The Johns Hopkins University.

Roca, I. and E. Felíu (2003a): "Morphology in truncation: the role of the Spanish desinence". In Booij, G. and J. van Marle (eds.): Yearbook of morphology 2002. Dordrecht, Germany, Kluwer, 187-243.

Roca, I. and E. Felíu (2003b): "Morphology and Phonology in Spanish word truncation". In Booij, G., J. DeCesaris, A. Ralli and S. Scalise (eds.): Topics in morphology: selected papers from the Third Mediterranean Morphology Meeting (Barcelona, September 20-22, 2001). Barcelona, Spain, IULA, 311-329.

Rosenthall, S. (1994): "Vowel/glide alternation in a theory of constraint interaction", Unpublished Ph.D. dissertation. Amherst, Massachusetts: University of Massachusetts.

Urawa, M. (1985): “Muestra de hipocorísticos en el español bogotano”, Thesaurus, 40, 51-102.

Van Wijk, H. L. A. (1964): “Los hipocorísticos hondureños”, Romanistisches Jahrbuch, $15,302-312$.

Weeda, D. S. (1992): “Word truncation in prosodic morphology", Unpublished Ph. D. dissertation. Austin, Texas: The University of Texas. 



\title{
LA (AUTOANTONIMIA) $A L$-DDAD EN LAS LENGUAS, SEGÚN LA TEORÍA "EL ESQUEMA BÁSICO DE LA REFERENCIA"
}

\author{
ABEER HUSSEIN ABID \\ Universidad de Bagdad \\ abirabd@yahoo.es
}

\begin{abstract}
Resumen
En nuestro artículo, vamos a analizar qué quiere decir de autoantonimia (al-ddad), las razones de su aparición en la lengua según las opiniones de los antiguos lingüistas árabes, y, finalmente, vamos a escoger algunas palabras autoantónimas, tanto en la lengua árabe como en la lengua española, dando explicaciones de su aparición según nuestra teoría "el esquema básico de la referencia", que es una teoría desarrollada a partir del legado árabe y la teoría cognitiva, por eso hemos usado la terminología de la gramática cognitiva. Según esta teoría, el signo lingüístico es la interacción entre cuatro componentes: la percepción, la imaginación, la comprensión y la simbolización. Nuestra teoría pretende ser la base de una lingüística moderna y holística, muy diferente de la lingüística tradicional. Es el primer artículo académico sobre el tema de las palabras autoantónimas en la lengua española.
\end{abstract}

PALABRAS CLAVE: la autoantonimia, o Al-ddad.
Abstract

In our article, we will discuss what it means to "autantonym" or "contronym", the reasons for its appearance on the tongue as viewed by the ancient Arab linguists. We will choose some words "autantonym" or "contronym" both in Arabic and in Spanish language, giving explanations of the language appeared in our theory "the basic scheme of reference", which is a theory developed from the Arabic legacy and cognitive theory, so we have used the terminology of cognitive grammar. According to this theory, the linguistic sign is the interaction of four components: perception, imagination, understanding and symbolization. Our theory will be in the future based on a modern and holistic linguistics very different from traditional linguistics. It is the first academic paper on the subject of words "autantonym" or "contronym" in the Spanish language.

KEY WORDS: the "autantonym" or "contronym".

\section{Consideraciones generales y metodológicas}

En nuestra tesis hemos desarrollado una teoría de la referencia de los significados "el esquema básico de la referencia"1, partiendo de una teoría de la referencia en el legado

\footnotetext{
${ }^{1}$ Para más información sobre esta teoría, véase Hussein Abid (2008 y 2011): El esquema básico de la referencia. Un modelo del significado esquemático aplicado a las preposiciones españolas y árabes. $\mathrm{Pu}-$
} 
árabe y usando la terminología de la gramática cognitiva, porque se acerca más a los conceptos árabes, si no es que son los mismos. En esta teoría, hemos afirmado que la referencia es la interacción entre cuatro componentes: la percepción, la imaginación, la comprensión y el signo lingüístico o simbolización, que están íntimamente relacionados, de manera que no puede faltar ninguno de ellos porque constituyen un todo holístico que pertenece a otro nivel más profundo.

Respecto a la percepción, hay algo muy importante de lo que no nos damos cuenta en la vida cotidiana, y tampoco en las teorías del significado: hay un sentido o percepción holística que nos hace percibir con todos los sentidos al mismo tiempo, es decir, no percibimos estímulos aislados sino que percibimos totalidades organizadas. El ser humano, al percibir un conjunto de sensaciones, las organiza en algo holístico que en la teología escolástica se llama la percepción o el sentido holístico².

En lo referente a la imaginación, tenemos que decir que sin ella nada tendría significado en el mundo. Tal como afirma al-Gazālì, el conocimiento no tiene sentido, a menos que una imagen tenga lugar en el alma, o al-nafs, y se corresponda con lo que registra la percepción. Si no aparece esta imagen en al-nafs, no es posible organizar una palabra que indique esta imagen ${ }^{3}$.

En cuanto a la comprensión, hemos demostrado que el nivel de la comprensión desempeña un papel esencial en la imaginación, y, por supuesto, en la simbolización, ya que concreta todas estas cosas.

Todo conocimiento se debe medir por el nivel de comprensión. Conocer equivale a comprender de una determinada manera, y tiene dos aspectos. Por una parte, se basa en nuestra experiencia, la cual se inserta en nuestra cultura, costumbres, religión, clima, etc. Como resultado de esto surge una comprensión compartida entre los hablantes de una comunidad de habla, lo que llamamos comprensión colectiva. Por otra parte, la comprensión se basa en la experiencia individual, que depende de la interacción entre al-nafs y el cuerpo, su sistema perceptivo y su sistema nervioso, estados de ánimo, humor, especificidad, nivel de estudios, clase social etc. De todo esto surge una comprensión individual, según la cual cada individuo comprende o capta el mundo. La comprensión supone la totalidad de nuestro ser.

blicado en Alemania, U.S.A. y U. K. Editorial Académica Española; y Universidad de Alicante. En www. Eltallerdigital.com.

${ }^{2}$ Un discurso del al-Ṣadir, Muḥammad Muḥammad Șādiq, en la oración del viernes.

${ }^{3}$ Al-Gazālī, Abū Ḥāmid (m. 505 de la hégira, 1112 d. c.), ms:( 1983): Mi'yār al-'ilm fì fann al-manțiq, Beirut, Dār al-Andalus, $4^{\mathrm{a}}$ ed., nota pág.47. 
Hay distintos niveles de comprensión imaginativa de la realidad, de manera que nuestra categorización u organización de la información adquirida sobre un concepto se basa en dos orientaciones íntimamente relacionadas y complementarias, que no se pueden separar una de otra. Dichas orientaciones son un nivel vertical y otro horizontal. Todo es parte de todo.

En esta teoría hemos probado que los significados no son lingüísticos, mientras que la referencia a ellos - la simbolización - sí que es lingüística. Los significados, con independencia de las lenguas, son iguales: son las realidades ilimitadas y abstraídas del tiempo, lugar, sentidos y emociones. La simbolización estriba en llamar la atención sobre una parte de un significado e intentar ponerlo de relieve por medio de la lengua, es decir, por medio del símbolo o la palabra, dependiendo del nivel de comprensión imaginativa.

En esta teoría hemos comprobado que los aspectos metafóricos e imaginativos cubren todos los aspectos del lenguaje, como han demostrado los lingüistas cognitivistas americanos $^{4}$. La primera función del lenguaje es significar. Así, la gramática no constituye solamente un nivel formal y autónomo de representación, sino también un nivel imaginativo y significativo.

También probamos que no hay unos límites concretos entre dualidades como la semántica y la pragmática. Así, en nuestra comprensión imaginativa y enciclopédica de una entidad o significado existe una escala de centralidad que está basada en criterios tanto inherentes, que no pueden ser omitidos, como periféricos, que dependen de la comprensión colectiva de una comunidad de habla y de la comprensión individual de una persona. Por eso, igual que hay una comprensión colectiva y otra individual, también hay un significado periférico colectivo o social y un significado periférico individual. Un concepto es como un punto de acceso a una red compleja, ilimitada, continua y modificable según la comprensión imaginativa, y sus rasgos son sus relaciones con otros puntos de la red. Llegamos a esta conclusión tras haber analizado el significado central y periférico, los dominios cognitivos, y la base y el perfil ${ }^{5}$.

\footnotetext{
${ }^{4}$ Lakoff, George y Johnson, Mark (1986): Metáforas de la vida cotidiana. Versión española de Carmen González Marín, Madrid, Cátedra; y Lakoff, George y Johnson, Mark (1980): Metaphors we live by, the University of Chicago.

${ }_{5}^{5}$ Langacker, Ronald W. (1991): Concept, Image and Symbol: the Cognitive Basis of Grammar, Berlín y Nueva York: Mouton de Gruyter, págs.4-5; y Langacker, Ronald W. (1993): Foundations of cognitive grammar. Theoretical prerequisites, California, Standford University, Volumen I; Anīs, Ibrāhīm (1976): Dalālat al-alfāz, El Cairo, al- Anŷlū al- mișriyya, 3ª ed., pág. 106; Cuenca, María Josep y Hilfer-
} 
Hemos comprobado según nuestro planteamiento que la polisemia y la sinonimia son el fenómeno por el cual una sola imagen esquemática superordinada y convencional presenta muchos significados inspirados por ella, es decir, que se diferencian de ella por llamar la atención de otro rasgo o dominio cognitivo y se intenta ponerlo de relieve, según la comprensión individual, en primer lugar - antes de ser convencionalizada-, y luego se convencionaliza por la comprensión colectiva, es decir, se codifica o registra. Así nace la polisemia o sinonimia, y luego la homonimia o la monosemia.

En esta investigación vamos a plantear el fenómeno de Al-ḍd, normalmente traducido en español como palabras autoantónimas ${ }^{6}$, y según nuestra teoría vamos a comprobar que es un tipo de polisemia.

\section{Introducción}

Los lingüistas no árabes suelen quedar perplejos a la hora de interpretar el fenómeno Al-ḍdad en la lengua árabe, en el que los arabistas, y entre ellos los españoles, han quedado sorprendidos ante este fenómeno. El jefe del tribunal de la defensa de mi tesis me pidió que le explicara este fenómeno según mi teoría "el esquema básico de la referencia"; pues me dijo que no podía imaginar que una palabra tuviera dos significados opuestos, y en ese momento le expliqué la palabra albayn البين que significa la separación, o la relación o el enlace, que comentaré más adelante. Esto me animó a plantear este fenómeno según mi teoría sobre el significado, lo que facilitará la comprensión de un fenómeno que, seguramente, es general en todas las lenguas, pero no se da cuenta de él.

ty, Joseph (1999): Introducción a la lingüística cognitiva, Barcelona, Ariel; Cifuentes Honrubia, José Luis (1994): Gramática cognitiva, fundamentos críticos, Salamanca, Eudema.

${ }^{6}$ La palabra 'autoantónima' fue acuñada por Arturo Ortega Morán Said, donde afirma que "He recibido algunos correos mencionando que la palabra autoantónimo ya aparece en la red con anterioridad a este artículo a veces en su forma separada auto-antónimos. Es cierto, por eso vale aclarar que la propuesta de este nombre, la hice por primera vez en la red, en una discusión en el Foro del Español del Centro Virtual Cervantes. Esto fue el 3 de septiembre del 2002. Quedó documentado en esta dirección: http://cvc.cervantes.es/foros/leer_asunto.asp?vCodigo=11237\#37622” (3-7-2012), véase Ortega, Arturo Morán (Said: 2009) "Autoantónimos" en Mundo hispanohablante. Donde afirma que en la lengua inglesa los términos "autantonym" y "contronym" fueron acuñados originalmente por Joseph T. Shipley en 1960 y Arenque Jack en 1962, respectivamente. Un término relacionado, pseudo-contronym, fue propuesto por David Morice en 1987. 
Este tipo de antonimia - autoantonimia - es muy habitual en la lengua árabe y es común en la poesía, la prosa y las parábolas, lo que hace más necesario todavía su conocimiento.

Hay mucha discrepancia entre los filólogos árabes por este fenómeno, porque hay filólogos que lo aceptan en la lengua, mencionando gran cantidad de razones y motivos para su existencia, entre estos filólogos encontramosQuțrub (m. 206 de la hégira), Alașma ì (m. 215 h.), Al-saŷistānī (m. 248 h.), Ibn Al- sikìt (m. 244 h.), Abu Qasim bn Salām (m. 222 h), Al- 'nbarì (m. 328 h.) y Abū Al-țayb Ábd Al-Wahid bn Álì Al- halabì (m. 351 h.) y otros? ${ }^{7}$ La aceptación de la autoantonimia es lo que encontramos claramente en sus libros.

Algunos de ellos, niegan totalmente la autoantonimia, y entre ellos está Ibn Darstuwayh, quien ha escrito un libro titulado "Anulación de la autoantonimia", en el que niega todos las palabras autoantónimas ${ }^{8}$.

También encontramos muchos lingüistas que consideran este fenómeno en la lengua árabe como un tipo de falta de sabiduría y elocuencia - sin darse cuenta de que este fenómeno está en todas las lenguas-. Estos son a los que Al- 'nbarì llama "gente que desprecia a los árabes"'.

En nuestra investigación, vamos a analizar qué quiere decir autoantonimia, las razones de su aparición en la lengua según las opiniones de los antiguos lingüistas árabes, luego, vamos a escoger algunas palabras autoantónimas, tanto en la lengua árabe como en la lengua española, y daremos explicaciones de su aparición en la lengua según nuestra teoría "el esquema básico de la referencia". No pretendemos ser totalizadores, sino sólo sugerir posibles métodos de análisis según nuestro modelo de la referencia, destacando el papel esencial de la comprensión imaginativa en la simbolización, la cual revela parte de la realidad, dependiendo de lo que llama la atención, e intenta resaltarla.

Esperamos facilitar la tarea para los investigadores en otras muchas lenguas, porque no encontramos precedentes sobre este tema — solo algunos diálogos entre los amigos

\footnotetext{
${ }^{7}$ Abū Al- țayb, Abd Al-Waḥid bn 'Alī, ms. (1996): Al- aḍad fì kalan al-'arab. Edición crítica del doctor 'Izat Ḥasan, Damasco, Dār Țalas, 2a ed., pág. 13.

${ }^{8}$ Al-Suyūțī, Abū Bakar bn 'Abd AL- Raḥmān Ŷalāl Al- din ms. (m. 1505d. c.) (sin fecha): al-Muzhir fì 'ulūm al- luga wa 'anwa'u-ha. Edición crítica de Muḥammad Aḥmad Ŷād al-Mawla y otros, Dār alFikra, volumen I, pág.396; Al-'nbarī, Muhammad bn Qasim, ms. (m. 940 d. c.) (1987): Al- aḍdad. Edición crítica de Muḥammad abū Al- fạ̣l Ibrahīm, Bairut, Al-maktaba al- 'aşryya, pág. 8.

${ }^{9}$ Al- 'nbarī, Muḥammad bn Qasim, ms. (m. 940 d. c.) (1987): Al- ạ̣dad, pág.1.
} 
en internet-, aunque podemos encontrar las palabras autoantónimas en cualquier lengua.

\section{Definición de la autoantonimia}

Según los dialectólogos, el concepto de las palabras autoantónimas es diferente de lo que significan vocablos antónimos - aunque para nosotros los dos conceptos salen de la misma imagen esquemática superordinada oposición-. La antonimia es la oposición entre dos palabras complementarias ${ }^{10}$. Entonces, en la antonimia se estudian las palabras que no existen en un mismo lugar o tiempo, como la relación entre negro, blanco, rojo, etc. Mientras que la autoantonimia se dedica o se interesa en estudiar las palabras que comparten el mismo significante, pero sus significados son opuestos, como en la palabra عifā que puede significar en algunos contextos زاد ' 'aumentar', نصاد 'crecer', y en otros significa ندرس ، محا 'borrar, desaparecer', por eso los antiguos lingüistas árabes consideran la autoantonimia como un tipo de polisemia ${ }^{11}$.

\section{Las razones de la aparición de la autoantonimia en la lengua}

Los filólogos árabes mencionan varios razones o motivos de la aparición de los autoantónimos, como por ejemplo, motivos por derivación, motivos fonéticos, motivos semánticos o pragmáticos, así como por la visión diferente de las cosas, por optimismo o pesimismo, por pertenecer a dos dialectos o épocas diferentes, por analogía con otras lenguas, $y$, al igual que la antonimia, por cambiar el sentido de una palabra ${ }^{12}$.

Como hemos probado en nuestra teoría (Hussein Abid, 2009, 2011), todos los aspectos del lenguaje son de naturaleza imaginativa; existe un conjunto de tipos de relaciones de semejanza y analogía entre forma y significado - sea fónica, gráfica o motivada por metáfora, metonimia o analogía-, que no es arbitraria, es decir, los esquemas metafóricos e imaginativos cubren todos los aspectos del lenguaje. En todos estos tipos, la comprensión imaginativa desempeña un papel muy importante, que, posteriormente, adquiere un carácter convencional debido a la comprensión colectiva que comparten los hablantes de una comunidad de habla. Así, la gramática no constituye solamente un

\footnotetext{
${ }^{10}$ Cifuentes Honrubia, José Luis (2006): “Relaciones semánticas”. En: www. Liceus.com, pág. 5.

${ }^{11} Y$ ūnis 'Alī, Muḥammad Muḥammad (1993): Waṣf al luga al- 'arabiyya dalāliyan, fì ḍaw' mafhūm aldalāla al- markaziyya. Dirāsa ḥawla al- ma'na wa ẓilāl al-ma'na, Trípoli, Universidad del Fātḥ, pág. 359.

${ }^{12}$ Op. cit., pág. 360.
} 
nivel formal y autónomo de representación, sino también un nivel imaginativo y significativo. Por eso vamos a ver que casi todas estas razones participan en la existencia de una palabra autoantónima.

También demostraremos que no hay unos límites concretos entre la semántica y la pragmática. Así, en nuestra comprensión imaginativa y enciclopédica de una entidad o significado existe una escala de centralidad que está basada en criterios tanto inherentes, que no pueden ser omitidos, como periféricos, que dependen de la comprensión colectiva de una comunidad de habla y de la comprensión individual de una persona que pertenece a esta comunidad.

\section{Algunas palabras autoantónimas en la lengua árabe}

\section{1. القانع alq̄̄ni ‘}

Algunos lingüistas como Al-aşma ‘̄i, Al-saŷistānī, Ibn Al-sikìt creen que cada palabra que tiene dos sentidos opuestos, es autoantónima, aunque sus significados opuestos derivan de dos raíces o nombres de acción diferentess مصدانع Como en la palabra القانع alqāni 'que puede significar 'satisfecho' o 'mendigo'; mientras que otros como Abū Alțayb excluye la palabra القانع القانع de las autoantónimas, alegando que la palabra , que significa 'satisfecho', su raíz es al-qana a a القناعه 'la satisfacción', mientras que القانع con sentido de 'mendigo' viene de al-qunū 'القنوع 'la humildad o sumisión'13.

Cuando buscamos en los diccionarios y los libros de antonimia (autoantonimia) en la lengua árabe ${ }^{14}$, encontramos que algunos filólogos distinguen entre القتاعه 'la satisfacción' y القنوع 'la humildad', y no relacionan entre ellas de ninguna manera,

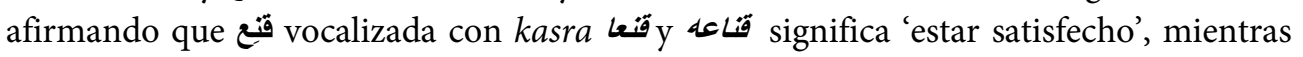

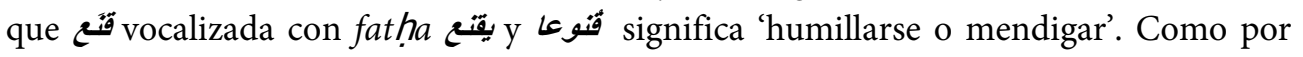
ejemplo en la súplica:

\footnotetext{
${ }^{13}$ Abū Al- țayb, Abd Al-Wahid bn 'Alī, ms. (1996:): Al- aḍa fì kalan al-'arab, pág. 363.

${ }^{14}$ Cortés, Julio (1996): Diccionario de árabe culto moderno. Árabe-español, Madrid, Gredos; Corriente, F. (1977): Diccionario árabe-español, Madrid, Instituto hispano-árabe de cultura; Ibn Manẓūr, Abū LFaḍil, Ŷamāl Al- dīn Muhammad bn Makram, ms. (sin fecha): Lisān al- 'arab, Beirut, Dār Șādir; Alŷawahirī, Ismā'il bn Ḥamād (1987): Al- șaḥ āh fị al-luga. Edición crítica de Aḥamad 'Abd Al- gafūr 'Ațār, Beirut, Dār Al-' ilm l- Al-malayin, 4 ed.; Ibn Al- sikìt, Abū Yūsif Ya' qub Isḥaq, ms. (1913) : Alaḍdad. (dentro de tres libros sobre Al- aḍdad.), Editor Wgast Hfnar, Beirut, Dār Al-mašriq, pág. 243; Al- 'nbarī, Muḥammad bn Qāsim, ms. (m. 940 d. c.) (1987): Al-aḍdad, pág. 66; Abū Al- țayb, Abd AlWaḥid bn 'Alī, ms. (1996): Al- aḍdad fì kalan al-'arab, pág. 578.
} 


\section{نسال الله القناعه ونعوذ بالله من القنوع}

pedimos de Dios la satisfacción y nos refugiamos en Él de la humildad

Otros lingüistas no diferencian entre القنوع alqanà á y القناعه al/qunū , así usan en significado del القناعهy viceversa, como en el ejemplo:

خير الغنى القنوع وشر الفقر الخضوع

la mejor riqueza es la satisfacción y la peor pobreza es la humildad

De la misma manera interpretan la aleya:

واطعموا القانع والمعتر 36/22

y alimentad a los necesitados y a los mendigos (Melara Navío, A. G. 22/34) ${ }^{15}$.

$\mathrm{y}$ alimentad al mendigo y al necesitado ${ }^{16}$.

Melara Navío interpreta القانع con sentido de 'satisfacción' (los necesitados que no piden de la gente), mientras que en la segunda traducción interpreta la palabra القانع con su sentido opuesto que es 'humildad' (los mendigos que piden limosna). Asimismo,

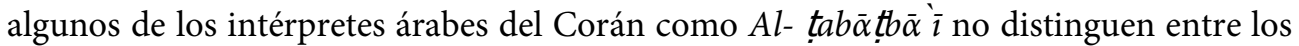
dos significados, sino que consideran que القانع es 'el pobre, tanto si pide de la gente como si no pide'17. Mientras que Al-Suyūțī considera que لقانع 'es 'el que necesita, pero no pide de la gente', es decir, 'está satisfecho'18.

Al- frā afirma que القانع es 'el que pide limosna (el mendigo), y acepta lo que van a dar tanto sea poco como sea mucho'19.

En el diccionario "Lisān al- 'arab" se arguya que "puede ser que se llame el mendigo قانع está satisfecho, porque acepta lo que dan y está contento con lo que tiene, por eso las dos palabras salen de la misma raíz que es الرضان la complacencia"20.

Entonces, vemos que la palabra القانع alqāni' tiene dos sentidos opuestos que son 'satisfecho' y 'mendigo', y salen de la misma imagen esquemática superordinada —más

\footnotetext{
${ }^{15}$ Melara Navío, A.G (1417 de hégira): El noble Corán y su traducción en lengua española, Reino de Arabia Saudita, Complejo del rey Fahd, 1417 de hégira.

${ }^{16}$ Véase, la traducción del Corán en http://quran.al-shia.org/es/id/2/113.html (5-7-2012).

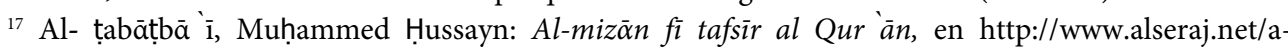
k/quran/mizan/miz.htm (5-7-2012).

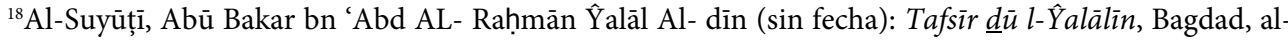
Dār al- 'Arabiyya.

${ }^{19}$ Al- ŷawahirī, Ismā'il bn Ḥamād (1987): Al- șaḥāh fì al-luga, s.v. . ق̈.

${ }^{20}$ Ibn Manẓūr, Abū L- Faḍil, Ŷamāl Al- dīn Muhammad bn Makram, ms. (sin fecha): Lisān al- 'arab, s.v. قنع
} 
simple- que es الرضا 'la complacencia', pero الرضا بلقون سؤال significa 'la complacencia sin pedir (limosna)', mientras que القنوع 'la complacencia con pedir (limosna)', como en el esquema:

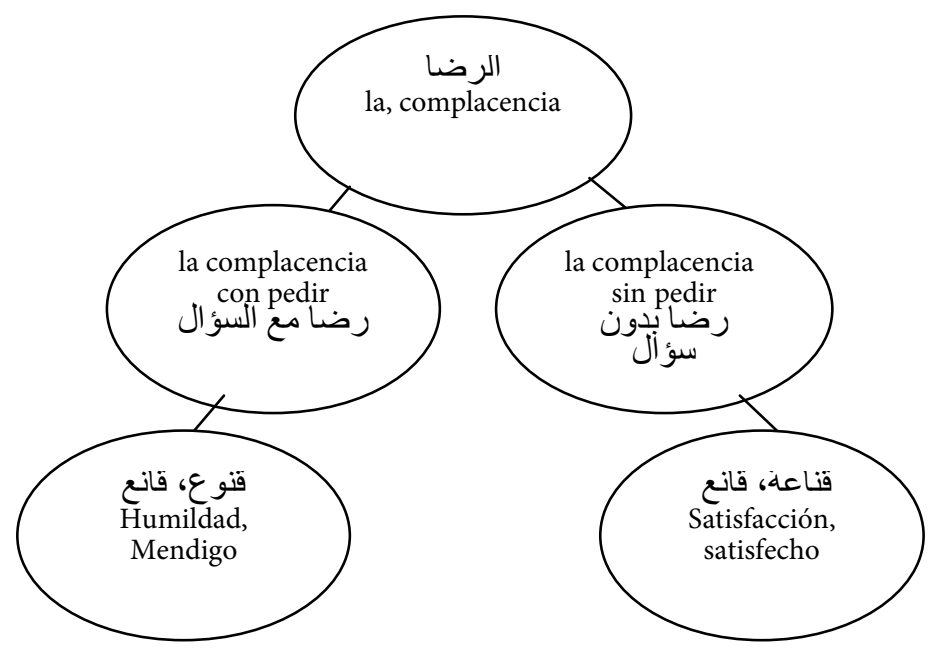

Figura 1. Estructura polisémica de la complacencia

La parte superior de la figura 1 denota el nivel superordinado de la imagen esquemática la complacencia, abajo se designan dos sentidos - usos convencionalizados de la palabra complacencia-. Podemos notar que entre ambos está perfilada una flecha discontinua que designa una cierta relación entre los dos conceptos. Según la categorización, se muestra que el eje horizontal indica que las categorías no son discretas, sino relacionadas entre ellos por algunos rasgos comunes. $\mathrm{Y}$ todo depende de la comprensión imaginativa de una realidad. Por otro lado, las dos flechas que vinculan el esquema de arriba - la imagen esquemática más simple o superordinada - son continuas, indicando según el planteamiento de la categorización que la jerarquía vertical va de lo más abstracto a lo más específico o concreto.

También esto demuestra que las categorías complejas se organizan a partir de una vinculación eslabonada entre los miembros centrales y otros miembros, y entre éstos y otros. Como en la figura siguiente: 


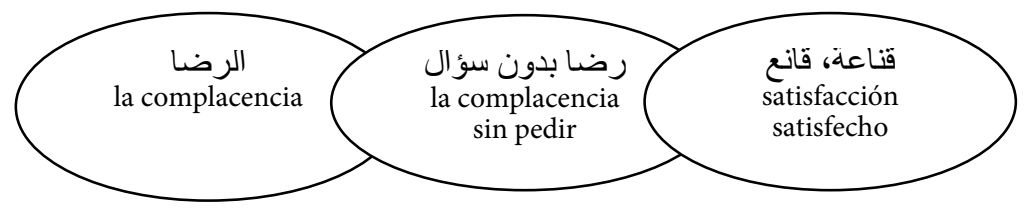

Figura 2: El eslabón de la estructura polisémica de la complacencia con el sentido de satisfecho

Vemos que la complacencia no se relaciona directamente con la satisfacción, sino a través de la imagen compleja la complacencia sin pedir. Lo mismo ocurre con humildad, donde se vincula con la complacencia por medio de la complacencia con pedir, como en la siguiente figura:

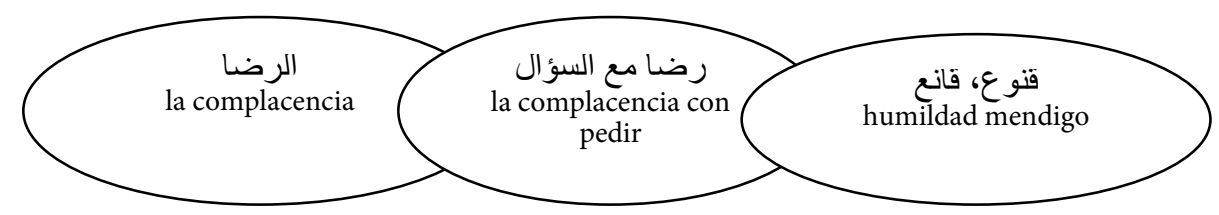

Figura 3: El eslabón de la estructura polisémica de la complacencia con el sentido de mendigo

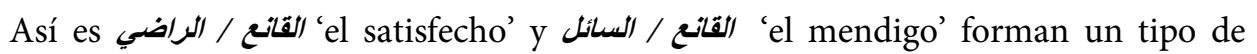
homonimia ${ }^{21}$ en árabe actual, porque constituyen dos significados opuestos -autoantónimos- para el hablante actual. Pero si se siguen los pasos de su evolución en el pasado, se ve que los dos significados salen de la misma imagen esquemática simple: la complacencia, como mencionamos más arriba. De este modo, el cambio de la polisemia a la homonimia del vocablo القانع puede representarse en la figura 4:

${ }^{21}$ Para más información véase nuestro artículo: Hussein Abid (Abeer: 2009): "Sinonimia, polisemia y homonimia en lengua árabe”, en $M E A H$, número 58, págs. 155-174. 


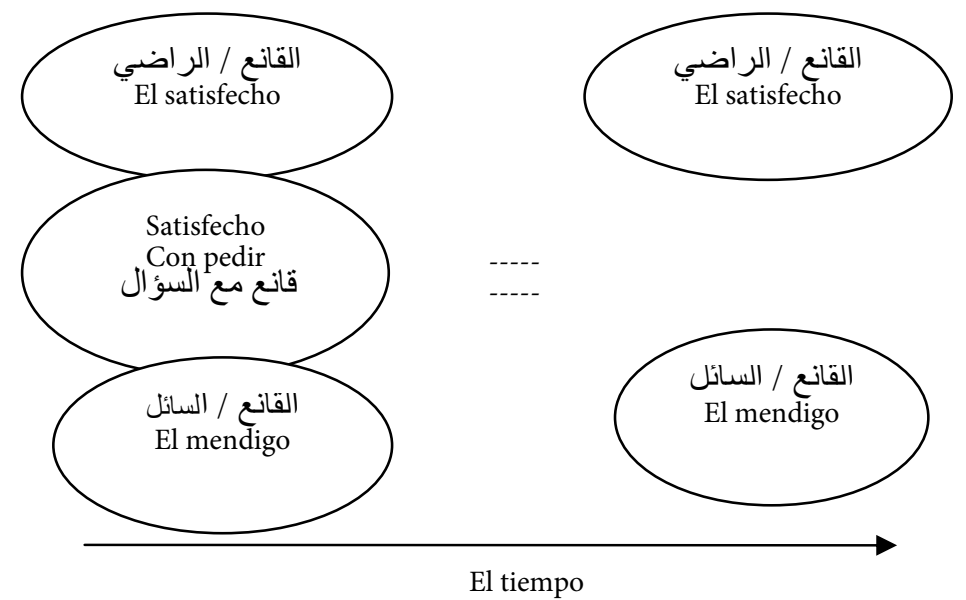

Figura 4: Paso de la polisemia a la homonimia de la palapra القانع

Así, a largo del tiempo se pierde el nexo que existe entre los dos sentidos opuestos de القانع , es decir, el resultado de estas relaciones son estructuras semánticas que construyen encadenamientos de significados, donde no todos los nudos de la red están directamente vinculados unos con otros. Ahora tendríamos una cadena basada en una relación de semejanza de familia ${ }^{22}$. Contemporáneamente, ésta es la base de la teoría de las categorías radiales de Lakoff, categoría compleja de Langaker y semejanza o aire de familia de Ludwig Wittgenstern ${ }^{23}$.

Asimismo, de la imagen, قناعه 'satisfacción', sale مقنعه 'velo', قناع 'máscara', مقنع 'enmascarado', porque uno de los dominios cognitivos de قناعه 'satisfacción', es decir, una de las imágenes que viene a la mente al mencionar la palabra قناعه 'satisfacción', es ستر الحاجة 'ocultar la necesidad'. Al mismo tiempo surgen de las dos imágenes, complejas la رضا مع السؤال complacencia con pedir y رضا بون سؤال la complacencia sin pedir, cualidades opuestas, como por ejemplo: sumisión/ orgullo, etc.

Todo esto muestra que el significado es de naturaleza enciclopédica, y se explica como una red compleja o radial que une los numerosos nudos de conocimiento que configuran una palabra. Una red de estas características es abierta e infinita y puede reproducir tanto relaciones jerárquicas de nivel de esquematicidad como extensiones

${ }^{22}$ Cuenca, María Josep y Hilferty, Joseph (1999): Introducción, págs. 134, 133, 136).

${ }^{23}$ Lakoff, George y Johnson, Mark (1986): Metáforas; Cuenca, María Josep y Hilferty, Joseph (1999): Introducción, págs. 132. 
entre el centro y la periferia, así como grados de fijación cognitiva. Las redes de conocimiento no deben interpretarse como mapas donde se sitúan los conceptos, sino como un concepto - dominio cognitivo o imagen- que sirve como un punto de acceso a una red. Esto lo podemos esquematizar en la figura 5:

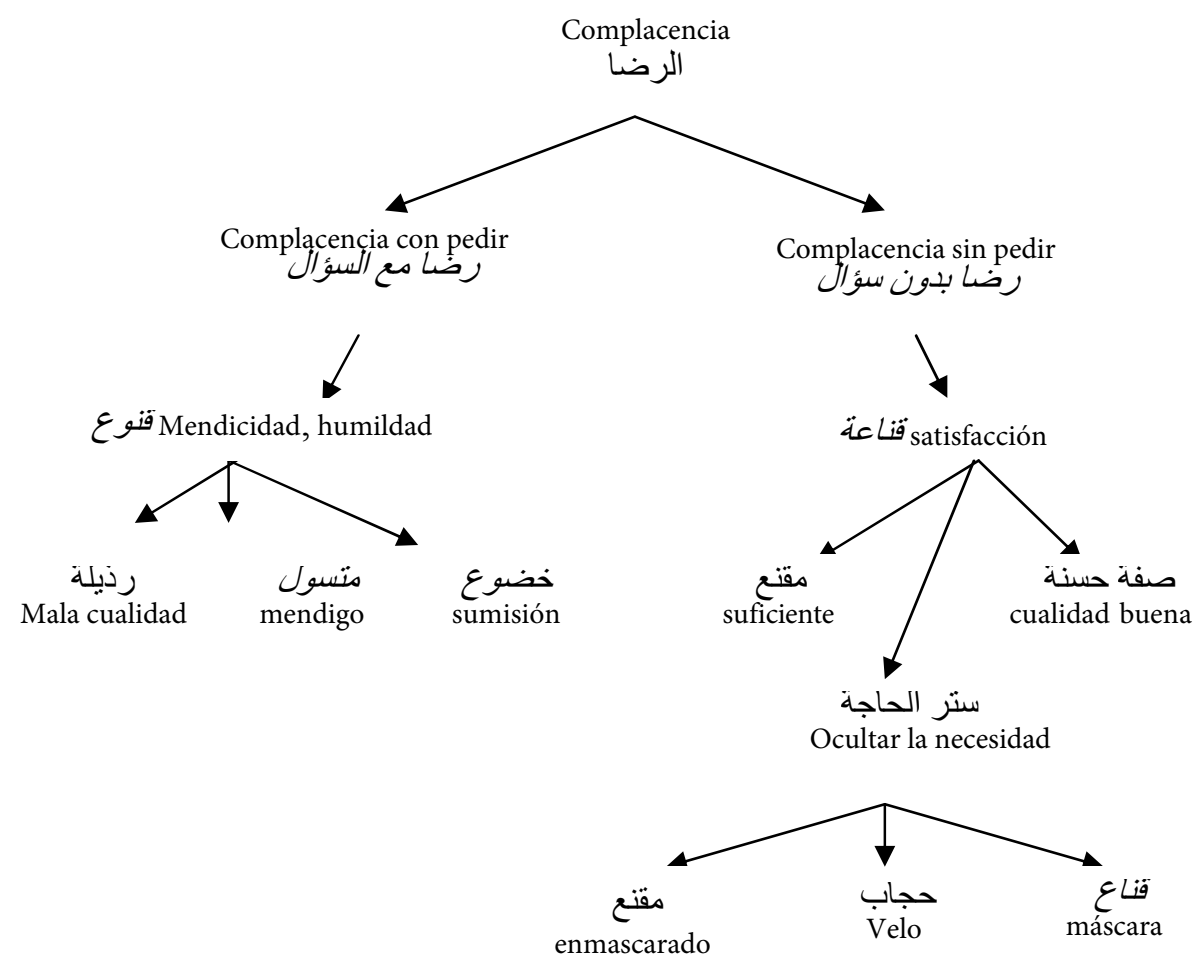

Figura 5: Parte de la red ilimitada de la palabra complacencia, y sus palabras autoantónimas

\section{2. عن 'afā}

عí áā forma una palabra autoantónima en árabe porque en algunos contextos puede significar ندaumentar, 'crecer' y en otros significa محا ، اندرس 'borrar, desaparecer'. Así vemos en la interpretación de la siguiente aleya:

ثم بدلنا مكان السيئه الحسنه حتى عفوا وقالوا 94/7 
Inmediatamente pusimos, en lugar del mal, el bien hasta que ellos borraron de su memoria el castigo y dijeron (Juan Vernet ${ }^{24}, 7 / 93$ )

Y luego les dábamos bienestar en lugar de mal. Pero cuando se veían prósperos decían (Melara Navío, A. G. 7/94)

Según la comprensión imaginativa de Juan Vernet, عignifica 'borrar', mientras que Melara Navío percibe que عف 'ver prósperos', que uno de sus dominios cognitivos es 'abundante', 'opulento, etc.', es decir, comprende عفا en esta aleya como un tipo de aumento. De la misma manera hacen los intérpretes árabes ${ }^{25}$, comprendiendo la palabra عفا de manera opuesta en la misma aleya.

En nuestra investigación sobre la palabra عف en los libros de autoantonimia y diccionarios árabes, encontramos que عale de la imagen esquemática superordinada prototipo- عفا الشعر اوالنبات 'crecer el pelo o la planta'26. Así se dice el profeta -sobre él sea la paz- en al- hadiz — dicho atrubuido al profeta-:

$$
\text { تُحفى الشوارب وثُعفى اللحى }
$$

Que se afeite el bigote y deje crecer la barba.

O en el enunciado:

$$
\text { عفت الريح الاثار (اثثار الديار) }
$$

El viento borró las huellas de las casas (esto ocurre en el desierto).

Ibn Al- i ŕābì comentó este enunciado, afirmando que en la frase El viento borró las huellas de las casas significa que 'el polvo aumenta hasta que cubre las casas', luego 'borra las huellas'.

Vemos que de la imagen عُ عَấ que significa 'aumentar el polvo' nace la imagen borrar las huellas, y con el paso del tiempo de éste surge otros sentidos de borrar, como عن 'perdonar', es decir 'borrar las faltas o pecados', العافيه 'la salud', que se puede imaginar como 'borrar la enfermedad y aumentar la salud', etc. Esto significa que la extensión del significado no es pura casualidad, sino que trabaja con operaciones cognitivas, mentales e imaginativas por medio de la metáfora y la metonimia, pero con el paso del tiempo se olvida su desarrollo significativo, mientras que si pudiéramos seguir estos pasos uno a uno encontraríamos el significado real de una palabra, y luego

${ }^{24}$ Vernet, Juan (1980): El Corán, Barcelona, Plaza y Juanes, $1^{\text {a }}$ ed.

${ }^{25}$ Al- țabātbā̀ '̀, Muḥammed Ḥussayn: Al-mizōn; Al-Suyūțī, Abū Bakar bn 'Abd AL- Raḥmān Ŷalāl Aldīn (m. 911 de la hégira) (sin fecha): Tafsīr $\underline{d} \bar{u} l$ - $\hat{Y}$ alālīn, aleya 7/93.

${ }^{26}$ Ibn Manẓūr, Abū L- Faḍil, Ŷamāl Al- dīn Muḥammad bn Makram, ms. (sin fecha): Lisān al- 'arab;

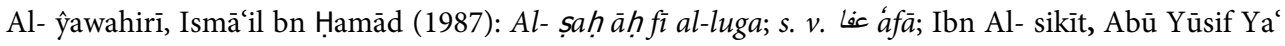
qub Isḥaq, ms. (1913): Al- ạ̣dad, pág. 8; Al- 'nbarī, Muḥammad bn Qāsim, (m. 328 h.), ms. (1987): Alạ̣dad, págs.86-88. 
pasos uno a uno encontraríamos el significado real de una palabra, y luego veríamos que este significado sigue desarrollándose y adquiere cada día un sentido nuevo y se interpreta en cada ámbito lingüístico de manera diferente y concreta. Todo esto puede esquematizarse en la siguiente figura:

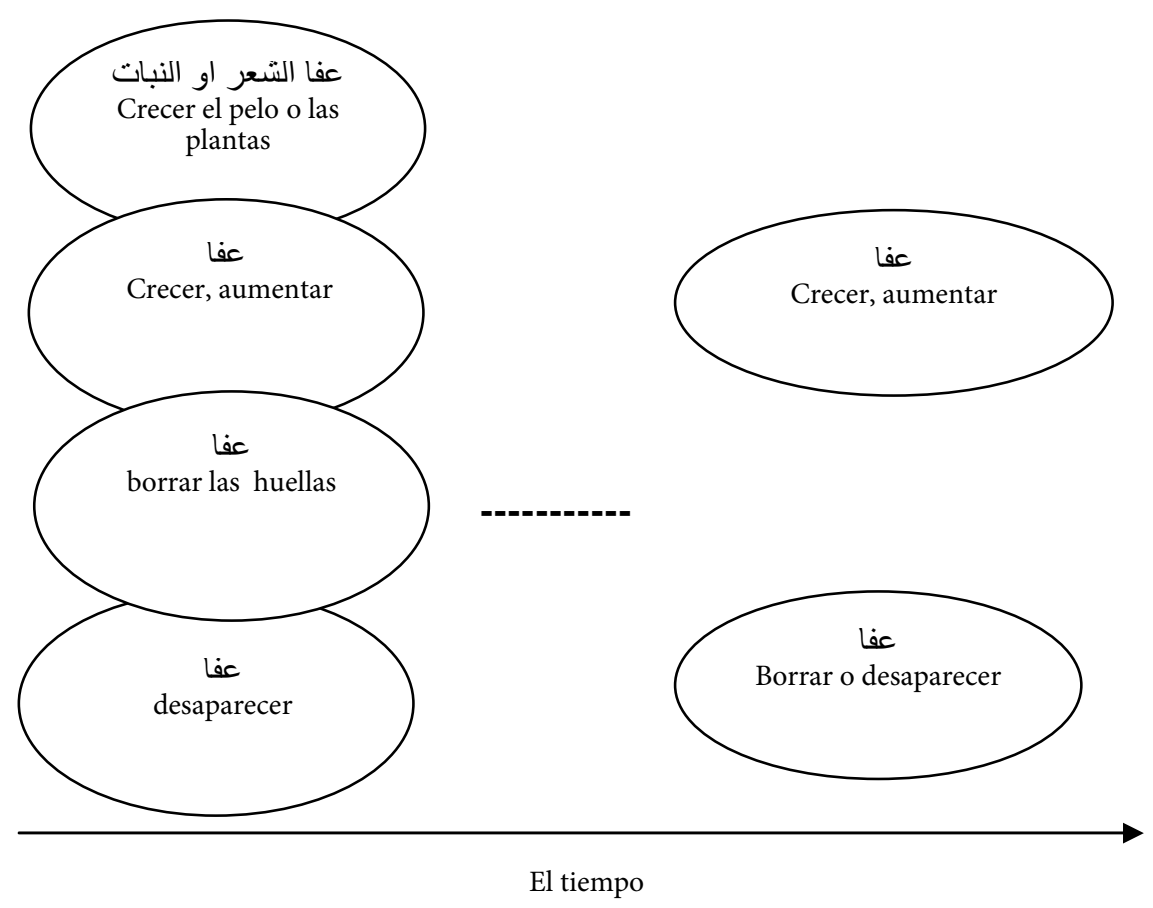

Figura 6: Paso de la polisemia a la homonimia de la palabra láfā

\section{3. al-ấfih}

La misma palabra العافيه 'salud' que acabamos de ver que sale de la imagen esquemática superordinada عفا 'crecer' forma autoantonimia, ya que en árabe clásico y casi en todos los dialectos árabes significa 'salud', como se dice por ejemplo en la súplica: 
واوجدني حلاوة العافيه، واذقني برد السلامهـ27

Hazme degustar la dulzura de la salud, y permíteme saborear el deleite de estar $\operatorname{sano}^{28}$.

Sin embargo, en el dialecto marroquí العافيه significa 'fuego'. En una ocasión, hablando con una chica marroquí en España, le dije: الله بعطيك العافيه', literalmente "Que Dios te de la salud" que es la forma habitual del dialecto iraquí. La chica se enfadó y me respondió: (ان شاء الله تثعل فيك (العافيه), literalmente "Ojalá que te quemes -el fuego-".

En ese momento me quedé sorprendida, no entendí nada de lo que dijo. Más tarde pregunté a otra amiga marroquí sobre el significado de la palabra العافيه al-áfih en su dialecto; y me explicó que la palabra العافيه al-'áfih significa en este dialecto 'el fuego', porque como tienen temor por el fuego, o son pesimistas por el fuego, así lo denominan salud.

Esto mismo lo podemos encontrar en otras muchas palabras autoantónimas en árabe, como السليم:al-salim, que puede significar 'sano' o 'mordido por una serpiente o herido de muerte', porque auguran el bien del sano, por eso llaman al mordido o herido de muerte $s a n o^{29}$. Así, en el dialecto iraquí se dice al enfermo, 'herido o accidentado' -que deriva de mejores'. De igual forma, en árabe llamamos al ciego, basyir 'persona que ve', por optimismo. Y llaman a una مهره potra bonita o bella, fea para que no la envidien, ${ }^{30}$ etc.

Todo esto muestra que la realidad se puede concebir de manera ilimitada según el nivel de la comprensión imaginativa, colectiva e individual, que nace de nuestras experiencias y entornos. Pero debemos aceptarlas todas para incrementar nuestras dimensiones de esta misma realidad.

Así, en gramática cognitiva, el tratamiento del polo semántico de un enunciado fomenta la activación de más espacio - para nosotros imagen esquemática- congruente

\footnotetext{
${ }^{27}$ Imán Zayn al- 'Ābidīn 'Alī ibn Al Ḥusayn (P) (sin fecha): As-Sahifa al-Kamilah, Súplica número XV ante la enfermedad.

${ }^{28}$ As-Sayyadiiah, Traducción: María Isabel Amoretti, Muhammad Mu'allemi Zadeh y Nestor Daniel Pagano, Edición digital: Biblioteca Islámica Ahlul Bait (P), en www.biab.org (8-7-2012), Súplica número XV ante la enfermedad, pág. 58.

${ }^{29}$ Al-saŷistānī (m. 248 h.) ms. (1913): Al- aḍdad (dentro de tres libros sobre Al-aḍdad), Editor Wgast Hfnar, Beirut, Dār Al-mašriq, pág. 114; Al- 'nbarī, Muḥammad bn Qāsim, ms. (sin fecha): Al- aḍdad, pág.106; Abū Al- țayb, Abd Al--Waḥid bn 'Alī, ms. (1996): Al- aḍad fì kalan al-'arab, pág. 217.

${ }^{30}$ Al- 'nbarī, Muhammad bn Qāsim, (m. 328 h.), ms. (1987): Al-aḍdad, pág. 284; Abū Al- țayb, Abd Al--Wahid bn 'Alī, ms. (1996): Al- aḍad fì kalan al-'arab, pág. 250.
} 
de conocimiento. Dichas estructuras de conocimiento se llaman dominios cognitivos que, según María Josep Cuenca y Joseph Hilferty,

son representaciones mentales de cómo se organiza el mundo y pueden incluir un amplio abanico de informaciones, desde los hechos más indiscutibles y comprobados empíricamente hasta los errores más flagrantes, las imaginaciones más peregrinas o las supersticiones. Es, por tanto, importante insistir en la naturaleza inherentemente enciclopédica de la semántica, lo que nos lleva a no disociar los aspectos denotativos (estrictamente léxicos) de los connotativos (tradicionalmente considerados como atribuibles al contexto, a lo pragmático) ${ }^{31}$.

\section{4. الجون al- ŷawn}

Se trata de una palabra autoantónima porque en algunos contextos se refiere al color blanco, como por ejemplo se denomina el sol, جونه, es decir blanca, mientras que la palabra الجون en otros contextos que pertenecen a otros dialectos árabes, significa el color

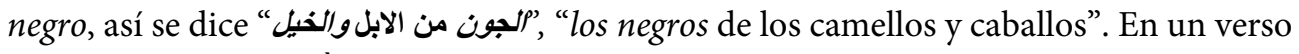
de la poetisa $\mathrm{Al}$ - jansā', en que dice ${ }^{32}$ :

\section{لن اصالح قوما كنت حربُهُ حتى يعود بياضا جونة القار}

No voy a reconciliarse con una gente que estaba en guerra con ellos

Hasta que vuelva el negro de alquitrán blanco.

La imagen esquemática superordinada -el prototipo- de la palabra الجون es 'el color', se trata de una palabra persa que se traslada a la lengua árabe por el contacto con el pueblo iraní y luego se difunde entre los dialectos árabes. Por eso en un barrio o una comunidad de habla árabe se nombra el color blanco جون, mientras que en otra se llama جون al color negro, es un tipo de metonimia "la parte por el todo"33.

\footnotetext{
${ }^{31}$ Cuenca, María Josep y Hilferty, Joseph (1999): Introducción. págs. 70-71.

${ }^{32}$ Ibn Al- sikīt, Abū Yūsif Ya' qub Isḥaq, ms. (1913): Al- aḍdad., pág. 190; Al- 'nbarī, Muḥammad bn Qāsim, ms. (sin fecha): Al- aḍdad, pág.112; Ibn Fāris Aḥmad bn Zakariyya ms. (1399 H. - 1979 DC.): Miqyās al-luga. Edición crítica de 'Abd Al-salām Muhammad Hārūn, Dār al- fikr, 6 volúmenes; alFayrūz ābādī, Maŷd al-Dīn bn Ya'qūb, ms. (1952): al-Qāmūs al-Muhịț, Egipto, Editorial Mușțafà alBābī al-Ḥalabī, $2^{\text {a }}$ ed., s. v. جون.

${ }^{33}$ Para más información véase "la metáfora y la metonimia", en Hussein Abid, Abeer $(2008,2011)$ : El esquema básico de la referencia, págs. 87-100.
} 


\section{5. البين albayn}

La imagen esquemática superordinada - el prototipo- de la palabra البين albayn es la distancia entre dos puntos, como en la figura:

Figura 7: Representación esquemática del significado simple o superordinado de البين albayn

Según la comprensión imaginativa de algunas personas, en algunas situaciones se percibe البين como un tipo de separación, diferencia, etc., mientras que se imagina en otros contextos como un tipo de enlace, conexión, unión, relación, etc. Así البين forma una palabra autoantónima como se nota en las siguientes aleyas:

\section{لقد تقطع بينكم وضل عنكم ما كنتم تزعمون}

se han roto ya los lazos que con ellos os unían, se esfumado vuestras pretensiones (Cortés, J. 6/94) ${ }^{34}$.

Vuestro vinculo se ha roto y os ha extraviado aquello que afirmabais (Melara Navío, 6/95).

En esta aleya se entiende que la palabra البين significa un tipo de 'vínculo' o 'lazo'. Mientras que en la siguiente aleya se imagina como un tipo de 'diferencia, separación':

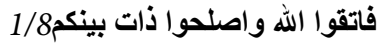

¡Temed a Dios! Arreglad vuestra diferencia! (Juan Vernet, 8/1).

Asimismo en estos versos ${ }^{35}$ :

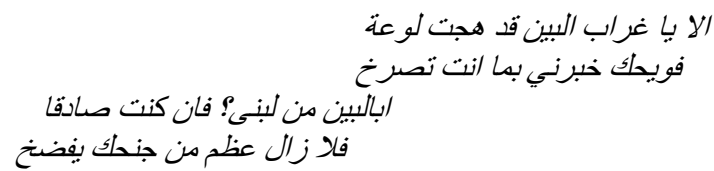

¡Oh cuervo de la separación!, me has provocado ansiedad

¡Maldito seas! dime qué estás gritando, ¿mi separación de Lubna? Si es así, que continúen brotando los huesos de tus alas.

${ }^{34}$ Cortés, J. (traductor) (2000): El Corán, Qum-Irán, Ansariyan.

${ }^{35}$ Yūnis ‘Alī, Muḥammad Muḥammad (1993): Wașf, pág. 175. 


\section{6. السهيع al-samī}

Es una palabra autoantónima que puede significar 'el oyente quien escucha u oye' o 'quien hace oír', eso ocurre por un cambio fonético en el verbo de la forma morfológica

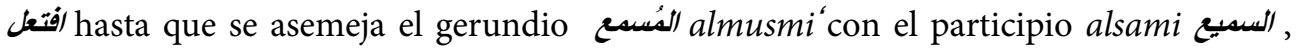
como en la aleya, porque la pronunciación de este alsami es más fácil:

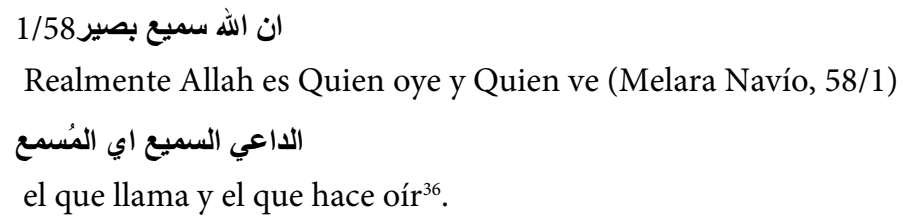

\section{Algunas de las palabras autoantónimas en la lengua española (según mi experiencia)}

En mi estancia en España he descubierto algunas palabras autoantónimas por mi contacto con los españoles. He aquí hay algunas de ellas:

\section{1. Regular}

La palabra regular, tal y como la aprendí según los diccionarios españoles ${ }^{37}$ significa 'normal, corriente', عادي, lo cual según nuestra comprensión imaginativa en árabe عادي da un sentido de 'bien'. Un día pregunté a una amiga española sobre la salud de su madre que estaba enferma, y me respondió que "está regular". Yo me alegré y le dije "gracias a Dios", luego ella continuó sorprendida diciéndome que "está muy mal"; en aquel momento yo cambié mi cara y mis palabras, diciéndole "iay que lastima!". Entonces comprendí que la palabra regular significa 'mal' también. Según mi comprensión imaginativa, los españoles auguran mal de algo malo como la enfermedad, por eso lo llaman regular.

\footnotetext{
${ }^{36}$ Al- 'nbarī, Muḥammad bn Qāsim, ms. (sin fecha): Al- aḍdad, pág. 83.

${ }^{37}$ Cortés, Julio (1990): Diccionario de árabe culto moderno; Corriente, F. (1977) Diccionario árabeespañol, Madrid, Instituto hispano-árabe de cultura; y (1988), español-árabe, Madrid, Instituto hispano-árabe de cultura; Sánchez, Aquilino (2001): Gran diccionario de uso del español actual, Madrid, SGEL; Real Academia Española (1960): Diccionario histórico de la lengua española, Madrid, EspasaCalpe; y (2001), Diccionario de la lengua española, España, Rota papel, vigésima segunda edición.
} 


\section{2. Adiós}

También adiós forma una palabra autoantónima en español, porque significa 'hola', La descubría cuando encontraba con gente que conocía en la calle y me decían jadiós! que significa ¡hola!

\section{Conclusiones}

Siguiendo los objetivos propuestos en esta investigación, hemos llegado a las siguientes conclusiones, todas ellas relacionadas entre sí y mutuamente complementarias:

1. La autoantonimia, según nuestro planteamiento del significado, es el fenómeno por el cual una sola imagen esquemática superordinada y convencional presenta dos significados -imágenes - inspirados por ella y opuestos — sentidos autoantónimos-, es decir, que se diferencia de ella por intentar llamar la atención de otro rasgo o dominio cognitivo más preeminente, según la comprensión individual en primer lugar antes de ser convencionalizada - y luego se convencionaliza por la comprensión colectiva, es decir, se codifica. Así nace la autoantonimia.

2. La autoantonimia no sucede por casualidad, sino por operaciones cognitivas en las que la imaginación y la comprensión imaginativa juegan un papel primordial en su simbolización, es decir, el fenómeno de la autoantonimia no es pura casualidad, sino que se da mediante operaciones cognitivas, mentales e imaginativas por medio de la metáfora, la metonimia o la analogía, etc., en las que la comprensión imaginativa de una comunidad de habla juega un papel principal en su formación, pero con el paso del tiempo se olvida su desarrollo significativo, mientras que si pudiéramos seguir estos pasos uno a uno encontraríamos el significado real de una palabra - la imagen esquemática superordinada - como hemos hecho en nuestro trabajo.

3. Tanto en el significado simple como en el significado complejo existe un tipo de redes polisémicas que muestran una organización interna en torno a una imagen esquemática superordinada, donde no todos los nudos de la red están directamente vinculados con esta imagen.

4. Todo esto apoya nuestro punto de vista de analizar la extensión del significado y creación de palabras - la simbolización - de manera no arbitraria, y confirma también que el significado es imaginativo, enciclopédico, y tiene relación con nuestra experiencia en el mundo exterior, es decir, con nuestro nivel de comprensión imaginativa.

5. Algunas veces la razón para la autoantonimia es por intervención de los dialectos de una lengua, es decir, cuando en dos dialectos de una lengua uno de ellos establece un significante - símbolo- para un significado y el otro adopta el mismo significante para 
otro significado, sin saber el uno del otro - como pasa ahora entre los dialectos de los países árabes, por la diferencia de la comprensión colectiva-, y luego se difunden los dos significados entre los dos dialectos, como hemos visto en la palabra autoantónima .

Recibido: 04-XI-2012

Aceptado: 31-VII-2013

\section{Referencias bibliográficas}

Anīs, Ibrāhīm (1976): Dalālat al-alfāz, El Cairo, al- Anŷlū al- mișriyya, $3^{a}$ ed.

Abū Al- țayb, Abd Al-Wahhid bn 'Alī, ms. (1996): Al- aḍad fì kalan al-'arab. Edición crítica del doctor Izat Ḥasan, Damasco, Dār Țalas, $2^{\mathrm{a}}$ ed.

Cifuentes Honrubia, José Luis (1994): Gramática cognitiva, fundamentos críticos. Salamanca, Eudema.

Cifuentes Honrubia, José Luis (2006): “Relaciones semánticas”, en www.liceus.com.

Corriente, F. (1977): Diccionario árabe-español. Madrid, Instituto hispano-árabe de cultura.

Corriente, F. (1988): Diccionario español-árabe. Madrid, Instituto hispano-árabe de cultura.

Cortés, J. (traductor) (2000): El Corán. Qum-Irán, Ansariyan.

Cortés, Julio (1996): Diccionario de árabe culto moderno. Árabe-español. Madrid, Gredos.

Cuenca, María Josep y Hilferty, Joseph (1999): Introducción a la lingüística cognitive. Barcelona, Ariel.

Ibn Fāris Aḥmad bn Zakariyya ms. (1399 H. - 1979 DC.): Miqyās al-luga. Edición crítica de AAbd Al-salām Muḥammad Hārūn, Dār al- fikr, 6 volúmenes.

Al-Fayrūz ābādī, Maŷd al-Dīn bn Ya'qūb, ms. (1952): al-Qāmūs al-Muhịţ. Egipto, Editorial MuȘțafà al- Bābī al-Ḥalabī, $2^{a}$ ed.

Al-Gazālī, Abū Ḥāmid (m. 505 de la hégira, 1112 d. c.), ms:( 1983): Míyār al-'ilm fĩ fann al- manțiq, Beirut, Dār al- Andalus, $4^{\mathrm{a}}$ ed. http://quran.al-shia.org/es/id/2/113.html. (8-7-2012)

Hussein Abid, Abeer (2009): "Sinonimia, polisemia y homonimia en lengua árabe", $M E A H, 58$, págs. 155-174.

Hussein Abid, Abeer (2008, 2011): El esquema básico de la referencia. Un modelo del significado esquemático aplicado a las preposiciones españolas y árabes. Publicado en Alemania, U.S.A. y U. K. Editorial Académica Española; y Universidad de Alicante. En www. Eltallerdigital.com. 
Lakoff, George y Johnson, Mark (1980): Metaphors we live by. University of Chicago (versión española de Carmen González Marín. Madrid, Cátedra).

Langacker, Ronald W. (1991): Concept, image and symbol: the cognitive basis of grammar. Berlin y New York, Mouton de Gruyter.

Langacker, Ronald W. (1993): Faundations of cognitive grammar. Theoretical prerequisites. Standford: Stanford University Press, Volumen I.

Ibn Manẓūr, Abū L- Faḍil, Ŷamāl Al- dīn Muḥammad bn Makram, ms. (sin fecha): Lisān al- 'arab, Beirut, Dār Șādir.

Melara Navío, A.G. (1417 de hégira): El noble Corán y su traducción en lengua española, Reino de Arabia Saudita, Complejo del rey Fahd.

Al- `nbarī, Muḥammad bn Qāsim (m. 328 h.), ms. (1987): Al- aḍdad. Edición crítica de Muḥammad abū Al- fạ̣l Ibrahīm, Bairut, Al-maktaba al- 'aşryya.

Ortega, Arturo Morán Said: "Autoantónimos" en Mundo hispanohablante, 2009, http://cvc.cervantes.es/foros/leer_asunto.asp?vCodigo=11237\#37622”. (3-7-2012) http://quran.al- shia. org/es/id/2/113.html (5-7-2012).

Real Academia Española (1960): Diccionario histórico de la lengua española. Madrid, Espasa-Calpe.

Real Academia Española (2001): Diccionario de la lengua española. Madrid: EspañaCalpe.

Sánchez, Aquilino (2001): Gran diccionario de uso del español actual. Madrid, SGEL.

Al-Saŷistānī (m. 248 h.), ms. (1913): Al- aḍdad. (dentro de tres libros sobre Al- aḍdad), Editor 'Wgast Hfnar, Beirut, Dār Al-mašriq.

Ibn Al- Sikìt, Abū Yūsif Ya' qub Isḥaq, ms. (1913): Al- aḍdad. (dentro de tres libros sobre Al- aḍdad. ), Editor 'Wgast Hfnar, Beirut, Dār Al-mašriq.

Al-Suyūțī, Abū Bakar bn 'Abd AL- Raḥmān Ŷalāl Al- dīn (m. 911 de la hégira) (sin

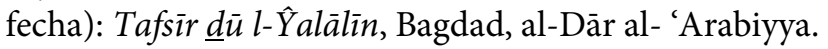

Al-Suyūțī, Abū Bakar bn 'Abd AL- Raḥmān Ŷalāl Al- din (sin fecha): al-Muzhir fí 'ulūm al- luga wa 'anwa'u-ha. Edición crítica de Muḥammad Aḥmad Ȳād al-Mawla y otros, Dār al- Fikra, vol. I.

Al- țabāṭō̄ '̄̄, Muḥammed Ḥussayn: Al-mizān fì tafsīr al Qur 'ān, en http://www.alseraj.net/a-k/quran/mizan/miz.htm (5-7-2012).

Vernet, Juan (1980): El Corán. Barcelona, Plaza y Juanes, 1 ed. 1.

Al- Ŷawahirī, Ismāicil bn Ḥamād (1987): Al- șạ̣āh fî̀ al-luga.

Yūnis 'Alī, Muḥammad Muḥammad (1993): Waṣf al luga al- 'arabiyya dalāliyan, fị ḍaw' mafhūm al- dalāla al- markaziyya. Dirāsa ḥawla al- ma'na wa ẓilāl al-ma'na. Trípoli, Universidad del Fātḥ.

Imán Zayn al- 'Ābidīn 'Alī ibn Al Ḥusayn (P): as-Sayyadiiah, Traducción: María Isabel 
Amoretti, Muhammad Mu'allemi Zadeh y Nestor Daniel Pagano, Edición digital: Biblioteca Islámica Ahlul Bait (P), en www.biab.org (8-7-2012).

Imán Zayn al- 'Ābidīn 'Alī ibn Al Ḥusayn (P) (sin fecha): As-Sahifa al-Kamilah, en la lengua árabe. Bagdad, al-Dār al- 'Arabiyya. 


\title{
LAS ETIQUETAS DISCURSIVAS: DEL MANTENIMIENTO A LA CONSTRUCCIÓN DEL REFERENTE ${ }^{1}$
}

\author{
ANNA LÓPEZ SAMANIEGO \\ Universitat de Barcelona \\ alopezsam@ub.edu
}

\begin{abstract}
Resumen
Las etiquetas discursivas se definen en este artículo como sintagmas nominales anafóricos que condensan el contenido de una o más predicaciones del discurso y las categorizan o conceptualizan de acuerdo con el plan del discurso elaborado por el emisor (ej. este fenómeno, tal argumento). El objetivo de este artículo es caracterizar el funcionamiento anafórico de las etiquetas discursivas. Para ello, se parte de un análisis manual de corpus con el propósito de identificar las diferentes unidades sintáctico-discursivas que pueden funcionar como antecedente textual de una etiqueta discursiva. Una vez delimitadas e identificadas estas unidades, se analiza la capacidad de cada una de ellas para funcionar como expresiones referenciales, siguiendo la concepción de referencia definida por la gramática cognitiva, que gira en torno a la noción de anclaje (grounding). El análisis realizado permite, por una parte, situar el etiquetaje discursivo en el continuo entre las relaciones de anáfora directa y las de anáfora indirecta; y por otra, diferenciar tres posibilidades de funcionamiento cognitivo de las etiquetas discursivas (mantenimiento del referente, reifica-
\end{abstract}

\begin{abstract}
Discourse labels are defined in this article as anaphoric noun phrases that encapsulate or summarize the contents of one or more predications and categorize these contents according to the discourse plan designed by the speaker (eg. this phenomenon, that argument). The aim of this paper is to characterize the anaphoric value of discourse labels. Starting from a manual corpus analysis of the syntactic-discursive units functioning as antecedent of a discourse label, the article analyses the ability of each one of these units to operate as a referring expression. This stage of the analysis focuses on the concept of reference defined by cognitive grammar, which is based on the notion of grounding. The analysis will serve to pinpoint the precise location of discourse labelling along the continuum between direct anaphora and indirect anaphora. Finally, I will argue that the syntactic-discursive unit acting as textual antecedent also serves to distinguish three different ways in which discourse labels can deal with the discourse referent: continuity, reification and construction of reference. In more general terms, this article emphasizes the need to take the type of textual antecedents
\end{abstract}

\footnotetext{
${ }^{1}$ Este artículo se enmarca en el proyecto Estrategias de textualización del discurso profesional en soportes multimodales. Análisis y propuestas de mejora (FFI2011-28933), financiado por el Ministerio de Ciencia e Innovación. Una versión anterior de su contenido se presentó en el VIII Congreso Internacional de la Asociación Española de Lingüística Cognitiva (AELCO), celebrado en la Universidad de Almería en octubre de 2012. Quiero dar las gracias a los profesores Pedro Gras, Estrella Montolío y Raquel Taranilla por haberse prestado a comentar diversos aspectos del contenido de este artículo, así como al revisor anónimo, por sus atentos comentarios y correcciones.
} 
ción del referente o construcción del referente), en función de la unidad sintácticodiscursiva que actúa como antecedente textual. Este artículo pone de relieve la necesidad de tener en cuenta estas unidades a la hora de caracterizar el funcionamiento de procedimientos de encapsulación como las etiquetas discursivas.

PALABRAS CLAVE: anáfora léxica, etiquetas discursivas, referencia, encapsulación, anclaje. into account when describing procedures of encapsulation as discourse labelling.

KEY WORDS: lexical anaphora, discourse labels, reference, encapsulation, grounding.

\section{Introducción}

Los mecanismos anafóricos constituyen uno de los fenómenos gramaticales que han despertado mayor interés entre los enfoques cognitivos. Conceptos de corte cognitivo como los de modelo mental (Johnson-Laird, 1980), activador o disparador del antecedente (Cornish, 1986) o accesibilidad (Ariel, 1990) han transformado, en los últimos treinta años, la concepción tradicional de las relaciones anafóricas. Como es bien sabido, hasta los años 80 del siglo pasado, la explicación lingüística de los procedimientos anafóricos se basaba en un enfoque gramático-textual, según el cual las expresiones anafóricas se consideraban elementos lingüísticos cuya interpretación dependía de la de un segmento del texto previo, el antecedente. Estas explicaciones tradicionales se elaboran a partir del estudio de un tipo de relaciones anafóricas que habían constituido el principal foco de atención de los gramáticos generativistas; a saber, las anáforas pronominales que tienen un antecedente nominal con el que mantienen una relación semántica de correferencia y una relación morfosintáctica de concordancia de género y número, esto es, anáforas que pueden funcionar en el seno de la oración. Un ejemplo de este tipo de anáforas es el que se propone en (1), donde el pronombre átono la tiene el mismo referente que el sintagma nominal subrayado (la mecanógrafa):

(1) De haber sabido que aquella era la última vez que vería con vida a la mecanógrafa, quizá Kurt se hubiera girado para mirarla desde el umbral. (Menéndez Salmón, La ofensa, 2007, p.19)

Esta concepción tradicional de la anáfora preside trabajos como los Escavy (1987), Mederos (1988) o Fuentes (1991), en el ámbito hispánico, así como también diversos trabajos más recientes, como los estudios computacionales sobre el procesamiento automático de la anáfora (Mitkov, 2002), entre otros. Sin embargo, a partir de los años 80 empieza a competir con otra concepción más amplia del fenómeno, elaborada gracias a las aportaciones realizadas desde dos métodos empíricos estrechamente relacionados 
con la lingüística cognitiva: la psicología cognitiva, con su explicación dinámica del procesamiento del discurso a partir de modelos mentales, y la lingüística de corpus, que llama la atención sobre una serie de fenómenos anafóricos "atípicos", que no habían tenido en cuenta las descripciones lingüísticas tradicionales.

En tanto que enfoque metodológico que defiende la necesidad de partir del análisis de ejemplos reales extraídos de corpus, la principal aportación de la lingüística de corpus a los estudios sobre la anáfora consiste en advertir la existencia de fenómenos anafóricos "atípicos", es decir, que no poseen las propiedades que caracterizan a las anáforas consideradas canónicas y que, en consecuencia, presentan dificultades para ser explicados desde el tipo de definiciones propuestas hasta el momento. Un ejemplo claro lo constituyen los casos de anáfora indirecta, en los que un sintagma nominal anafórico (no ya un pronombre) se interpreta a partir de un segmento textual no correferencial, que posibilita la interpretación de la expresión anafórica, generalmente, mediante procesos inferenciales (Schwarz-Friesel, 2007: 7). Tal es el caso, por ejemplo, de las anáforas asociativas (Hawkins, 1978; Escavy, 1999; Kleiber, 2001), como la que se ejemplifica en (2):

(2) Juan Sanguino da clase en un aula que tiene 18 ordenadores, en los que trabajan los alumnos de dos en dos. Los pupitres no están llenos. (CREA, España, El País, 17/3/2003, "Revolución tecnológica en las aulas")

En el ejemplo, el sintagma destacado los pupitres es una anáfora indirecta asociativa, ya que designa una entidad que debe inferirse a partir de un sintagma no correferencial presente en la oración anterior (un aula). En este fragmento, los pupitres son 'los pupitres que están en el aula de Juan Sanguino', interpretación que se alcanza mediante una inferencia del tipo 'en las aulas suele haber pupitres', basada en una relación meronímica (todo-parte). La investigación basada en corpus reales demuestra que mecanismos anafóricos como el del ejemplo anterior, que no se ajustan por completo a las definiciones lingüísticas tradicionales del concepto de anáfora, no solo no constituyen excepciones o desviaciones de la norma general, sino que, además, son frecuentes y comunicativamente eficaces.

Por su parte, la psicología cognitiva ha desarrollado en las últimas décadas teorías sobre el proceso de comprensión de textos, como la teoría de los modelos mentales, que explican por qué el lector puede interpretar sin problemas procedimientos anafóricos como el ejemplificado en (2). A partir del concepto de modelo mental, que alude a las representaciones mentales que el lector construye durante el proceso de comprensión de un texto (Johnson-Laird, 1983: 381), esta teoría explica el procesamiento del discurso como la construcción en línea, durante el proceso de lectura, de una representación 
mental compleja del contenido del texto, a la que van incorporándose de forma sucesiva y acumulativa representaciones de las distintas entidades y relaciones que aparecen en el discurso. Dado que estos modelos mentales se almacenan en la memoria del lector, este puede acceder directamente a ellos para interpretar las expresiones anafóricas. El lector interpreta, por tanto, las expresiones anafóricas sin necesidad de retroceder en la lectura, reactivando entidades o relaciones que se encuentren, en mayor o menor grado, activas en la memoria. Además, dado que en la memoria del lector coexisten con el modelo mental del texto otros modelos mentales en los que se organiza su conocimiento del mundo, no es necesario que una entidad se mencione explícitamente en el texto para que resulte, en cierto grado, activa en la memoria durante el proceso de comprensión. Así, expresiones anafóricas como los pupitres en el ejemplo de (2) invitan al lector a poner en foco entidades que ya estaban activas en su representación mental del aula mencionada previamente.

Desde las teorías de corte cognitivo, las expresiones anafóricas se conciben, pues, como mecanismos de mantenimiento del referente, expresiones que permiten mantener la representación mental de determinadas entidades del discurso activa o accesible (Ariel, 1988, 1990; Figueras, 2002) en la memoria durante la comprensión de un texto. El mecanismo léxico de mantenimiento del referente que aquí se denomina etiquetaje discursivo constituye, al igual que la anáfora asociativa ejemplificada en (2), un fenómeno de anáfora indirecta que no se ajusta a las explicaciones gramaticales tradicionales. El objetivo de este artículo es analizar este mecanismo de anáfora léxica a la luz de las aportaciones realizadas por los enfoques cognitivos y, en particular, por la gramática cognitiva. Más concretamente, se pretende poner de relieve la necesidad de tener en cuenta los distintos tipos de unidades discursivas que pueden actuar como antecedentes textuales de este tipo de expresiones anafóricas a la hora de explicar su funcionamiento anafórico, discursivo y cognitivo.

La estructura del artículo es la siguiente. En primer lugar, se define el mecanismo objeto de estudio y se plantean las bases del análisis de corpus realizado para identificar las unidades textuales que pueden funcionar como antecedente de las etiquetas discursivas. A continuación, se presentan los resultados del análisis del corpus y se discute el valor referencial de las unidades identificadas, teniendo en cuenta el concepto de anclaje (grounding) que la gramática cognitiva considera como requisito para que una expresión lingüística pueda perfilar una entidad del discurso. La identificación y análisis de las unidades del discurso que pueden actuar como antecedente de las etiquetas discursivas se aplica, finalmente, a la caracterización del tipo de relación anafórica en la que se fundamenta el etiquetaje discursivo y, además, a la distinción de tres posibilidades de funcionamiento cognitivo de las EEDD. 


\section{Las etiquetas discursivas: un mecanismo anafórico "atípico"}

El mecanismo que aquí se denomina etiquetaje discursivo, que constituye una elaboración y redefinición de la clase de mecanismos de cohesión anafórica identificada por Halliday y Hasan como nombres generales (1976: 274-275), presenta algunas características que dificultan su explicación desde las definiciones gramático-textuales de la anáfora. Como se expondrá a continuación, el segmento discursivo cuyo contenido reactivan las etiquetas discursivas presenta varias diferencias con respecto al antecedente nominal correferencial de las relaciones anafóricas consideradas paradigmáticas por los enfoques tradicionales. Tales diferencias han llevado a algunos autores a cuestionar la naturaleza anafórica de este mecanismo.

\subsection{Definición y delimitación}

Las etiquetas discursivas (en adelante, EEDD) son sintagmas nominales que condensan o encapsulan el contenido de una o más predicaciones y lo categorizan o conceptualizan de acuerdo con el plan del discurso elaborado por el emisor (López Samaniego, 2011 y en prensa b). En el siguiente ejemplo, la ED este plan condensa en un sintagma nominal el contenido expuesto en la oración compleja subrayada y, al mismo tiempo, lo conceptualiza como un plan, esto es, como una acción o conjunto de acciones diseñadas para lograr un objetivo:

(3) Maliki ha logrado el respaldo del Parlamento a un acuerdo con Estados Unidos sobre los términos y los plazos de la retirada de los ejércitos extranjeros de Irak. $\underline{A}$ finales del próximo junio, los soldados estadounidenses deberían regresar a sus bases y permanecer estacionados en ellas como paso previo a la definitiva salida del país en 2011. Los diputados iraquíes han dado su respaldo, además, a la celebración de un referéndum para ratificar este plan. (El País, 4/12/2008, "Horizonte de retirada")

Este mecanismo discursivo ha recibido diversas denominaciones en las últimas décadas, cada una de las cuales va unida a delimitaciones del fenómeno ligera o notablemente discrepantes ${ }^{2}$. El término etiquetas discursivas o, mejor, etiquetaje discursivo se

\footnotetext{
2 Las principales denominaciones que ha recibido el fenómeno son: nombres contenedor (container nouns) (Vendler, 1968), nombres generales (general nouns) (Halliday y Hasan, 1976), nombres portadores (carrier nouns) (Ivanič, 1991), nombres inespecíficos (unspecific nouns) (Winter, 1992), encapsuladores (Sinclair, 1993; Conte, 1996; Borreguero, 2006, González, 2008 y Llamas, 2010), etiquetas (labels) (Francis, 1994), nombres envoltorio (shell nouns) (Schmid, 1998) y nombres señaladores (signalling nouns) (Flowerdew, 2003), entre otros.
} 
propone para designar un tipo de procedimiento léxico de encapsulación de información proposicional que se diferencia, por una parte, de otros procedimientos de encapsulación pronominal o gramatical, como los pronombres neutros, y por otra, de otros procedimientos de encapsulación léxica, como la nominalización repetitiva o la nominalización sinonímica (López Samaniego, en prensa). La nominalización repetitiva se da cuando un encapsulador nominaliza el verbo principal de la predicación encapsulada, como se muestra en el ejemplo de (4):

(4) Obama considera una prioridad actuar en Afganistán, y es muy probable que solicite un compromiso suplementario de los aliados presentes en aquella región. (...) Si esa solicitud se plantea, será necesario redefinir los objetivos de la intervención que, en medio de la creciente ofensiva talibán, ya no sería, o no sólo, de "reconstrucción" del devastado país. (El País, 26/11/2008, "Estrategia de seguridad")

En la nominalización sinonímica, en cambio, el nombre encapsulador (petición) es un sinónimo de la nominalización del verbo principal de la predicación encapsulada (solicitud - solicitar), tal como se ilustra en la siguiente versión alternativa del ejemplo anterior:

(4') Obama considera una prioridad actuar en Afganistán, y es muy probable que solicite un compromiso suplementario de los aliados presentes en aquella región. (...) Si esa petición se plantea, será necesario redefinir los objetivos de la intervención que, en medio de la creciente ofensiva talibán, ya no sería, o no sólo, de "reconstrucción" del devastado país.

Los procedimientos anafóricos ejemplificados en (4) y en (4') se deslindan del etiquetaje discursivo porque la estructura de sintagmas nominales anafóricos como los de estos ejemplos es más fiel a la formulación lingüística del antecedente: al igual que las EEDD, encapsulan un contenido proposicional, pero, a diferencia de estas, no lo categorizan, sino que se limitan a repetir léxica o sinonímicamente la base léxica del verbo principal. Las EEDD que constituyen el objeto de este artículo llevan a cabo, además de la encapsulación de un segmento discursivo, un proceso de categorización del contenido de dicho segmento en función de los propósitos discursivos del emisor. Su capacidad categorizadora y su menor semejanza formal con el antecedente textual amplían el alcance referencial de las EEDD, esto es, les permiten condensar el contenido de una mayor variedad de unidades discursivas.

\subsection{El valor anafórico de las etiquetas discursivas}

Como ya se ha mencionado, el funcionamiento anafórico de las etiquetas discursivas presenta algunos rasgos que dificultan su explicación a partir de la concepción gramáti- 
co-textual tradicional del concepto de anáfora presentada en el primer apartado. Estos rasgos son, fundamentalmente, dos: en primer lugar, el antecedente textual es difuso (Fernández Ramírez, 1951/1987; Halliday y Hasan, 1976: 53; Mederos, 1988: 73; Francis, 1994: 88), más extenso y complejo que un sintagma nominal, de modo que su delimitación puede resultar difícil; en segundo lugar, dado que la naturaleza referencial de este antecedente difuso es, cuando menos, discutible, la relación semántica que mantiene con la etiqueta discursiva no parece ser estrictamente correferencial. Así pues, los dos conceptos principales en torno a los que gira la caracterización tradicional de anáfora, el de antecedente y el de correferencialidad, se ponen en cuestión a la hora de caracterizar este fenómeno. Las divergencias mencionadas entre el funcionamiento de las EEDD y el de las anáforas correferenciales consideradas durante tanto tiempo como prototípicas explican que algunos de los autores que se han aproximado al estudio de este mecanismo discursivo vacilen a la hora de considerarlo como anafórico (Mederos, 1988: 122; Conte, 1996: 2).

Dadas las peculiaridades que presenta el segmento discursivo encapsulado por los nombres que actúan como EEDD, algunos autores han acuñado nuevos términos para evitar el uso del término convencional de antecedente, como realización léxica (Winter, 1992: 151; Francis, 1994: 83), información de apoyo (Apothéloz, 1995b: 144) o contenido (Schmid, 2000). No obstante, aquí se defiende que tal segmento puede considerarse antecedente, siempre que este se conciba en la línea que proponen las explicaciones cognitivas del fenómeno anafórico. Estas teorías, que parten de la concepción de la comprensión del discurso defendida por la teoría de los modelos mentales (Cornish, 1999; Lagacker, 1991/2002: 91 y ss.), distinguen claramente entre el antecedente textual y el referente. A grandes rasgos, los enfoques cognitivos consideran el antecedente como el segmento textual que introduce en la memoria del lector la representación mental de una determinada entidad, ya sea de forma directa, como ocurría en la anáfora correferencial del ejemplo de (1), o bien de forma indirecta o inferencial, como ocurría en (2). La representación mental evocada es el referente, que puede ser activado por una expresión referencial o reactivado cuando aparece una expresión anafórica.

En otras palabras, para los enfoques cognitivos, el antecedente textual funciona, tanto en anáforas directas como en anáforas indirectas, como activador o disparador de la referencia (antecedent-trigger) (Cornish, 1986: 8), como el segmento de la superficie textual que permite al lector construir la representación mental de una entidad del discurso. Esta representación mental formada a partir del texto se completa a menudo con información aportada por el resto del contexto discursivo que rodea al antecedente y también por el conocimiento del mundo del interlocutor. Es decir, incluso en casos claros de correferencia, como el del ejemplo (1), el pronombre la no remite estricta- 
mente a la mecanógrafa, sino más concretamente a 'la mecanógrafa a la que Kurt no volvería a ver con vida', añadiendo además otra información que pueda haberse proporcionado sobre este personaje en el contexto previo. En la representación mental que el lector elabora de este referente confluyen, pues, una serie de datos proporcionados por el texto hasta el momento, independientemente de cuál sea el segmento textual concreto que activa su construcción como entidad del discurso ${ }^{3}$.

Esta concepción del antecedente textual como activador de la referencia puede aplicarse también al segmento textual condensado por la $\mathrm{ED}$, que permite al lector incorporar en el modelo mental del discurso la representación mental del referente de la ED, que se ve enriquecida por el contexto discursivo que rodea tanto a este antecedente como a la propia ED. Así, en el caso del ejemplo de (3), el plan al que se alude con la etiqueta discursiva destacada en negrita es 'el plan de retirada progresiva de las tropas estadounidenses de Irak entre junio de 2009 y 2011' mencionado en la oración subrayada, pero es, además, un plan pendiente de ratificar en referéndum por los iraquíes, y un plan consensuado por Irak y los EEUU, tal como se indica en la información contextual que rodea al antecedente y a la $\mathrm{ED}^{4}$.

En cuanto al tipo de relación semántica que existe entre la ED y su antecedente textual, los autores que se han ocupado de analizar este mecanismo discursivo presentan posiciones divergentes. Por una parte, algunos autores se inclinan por considerar que existe entre ambos segmentos textuales una relación de anáfora directa periférica, ya que evitan emplear el término correferencia, sustituyéndolo por otros que evocan una relación de identidad no estrictamente referencial como equivalencia de significado (Francis, 1994: 85) o identidad experiencial (Schmid, 1999a: 118; 2000: 29). Otros autores asimilan la relación anafórica que establecen las EEDD, y también los pronombres neutros, con la anáfora asociativa (Apothéloz, 1995a: 43; Apótheloz y Reichler-Béguelin, 1999), ya que consideran que no existe una expresión correferencial que funcione como antecedente, sino un verbo o una estructura predicativa que dispara la interpretación.

\footnotetext{
${ }^{3}$ Cornish denomina antecedente a esta interpretación contextual del referente, que comprende una serie de información descriptiva aportada sobre este a lo largo del discurso, y reserva el de disparador del antecedente para el elemento, textual o contextual, que activa esta interpretación (1999: 41 y ss.). Dado que esta terminología contrasta con la establecida en la tradición hispánica, para evitar confusiones se denomina aquí antecedente al elemento que activa la interpretación (un segmento textual en el caso de las EEDD) y referente, a la representación mental de una entidad discursiva.

${ }^{4}$ Se comparte aquí la concepción evolutiva o acumulativa de la referencia que defienden autores como Brown y Yule (1983: 178), Charolles y Schnedecker (1993) o Reboul (1997), según la cual la información presentada en los predicados en los que se integran los antecedentes de las expresiones anafóricas van incorporándose progresivamente a la representación del referente.
} 
Por último, algunos autores adoptan posturas más matizadas y sitúan este mecanismo discursivo "en el límite entre la relación referencial y la de sentido" (Cuenca, 2000: 68). Estas divergencias entre los autores justifican la conveniencia de un análisis en mayor profundidad de la relación anafórica que existe entre las EEDD y su antecedente textual.

\section{Metodología}

El principal argumento que se ha aducido para poner en cuestión la naturaleza correferencial de las relaciones de etiquetaje discursivo es que un antecedente de contenido predicativo, como el que presentan este tipo de expresiones anafóricas, no constituye una expresión referencial en sentido estricto y, por tanto, que dos expresiones no pueden tener un mismo referente si una de ellas no es una expresión referencial (Lyons, 1977/1980: 188, citado por Schmid, 2000: 28). Siguiendo este razonamiento, para poder determinar qué tipo de relación anafórica existe entre las EEDD y su antecedente textual, es necesario trasladar el foco de interés de los nombres que pueden funcionar como EEDD al tipo de unidades discursivas que pueden encapsular estos nombres. Una vez identificados los distintos tipos de antecedente, habrá que examinar si puede considerarse que estos tienen valor referencial y pueden, en consecuencia, considerarse correferenciales a la ED.

El análisis realizado se desarrolla en las dos fases mencionadas: la primera consiste en identificar y clasificar los tipos de unidades que funcionan como antecedente de las EEDD en un determinado corpus, y la segunda, en analizar si estas unidades poseen valor referencial. Para la primera fase, se maneja un corpus formado por los 120 editoriales de prensa publicados en El País entre noviembre y diciembre de 2008 (54.546 palabras). El discurso periodístico y, en concreto, el género editorial, constituye un buen ámbito de estudio de las EEDD, dado que presenta una serie de características que parecen favorecer la aparición de estos mecanismos discursivos, según ha descrito la bibliografía. Al igual que las noticias de prensa, estudiadas por Borreguero (2006), se trata de textos que poseen un carácter "informativamente denso", esto es, que condensan grandes cantidades de información en poco espacio; que presentan abundantes expresiones abstractas y valorativas, por ser textos expositivo-argumentativos; y que están redactados por escritores expertos o profesionales. De ahí que algunos autores ya se hayan interesado por analizar las funciones de este mecanismo en el editorial de prensa (Bertucci, 2006; López Samaniego, en prensa; Izquierdo y González Ruiz, en prensa). El tipo de análisis realizado para localizar las EEDD y sus antecedentes ha sido la búsqueda manual y el total de EEDD identificadas en el corpus es de 301. 
Tras identificar el tipo de unidades o segmentos discursivos que actúan como antecedente textual de las EEDD ${ }^{5}$, la segunda fase del análisis consiste en analizar el valor referencial de dichos segmentos, es decir, su capacidad para activar un referente en el modelo mental del discurso construido por el lector. Esta capacidad se examina tomando como punto de referencia el concepto de anclaje (grounding) que la gramática cognitiva considera como requisito para que una expresión presente capacidad referencial.

\section{Análisis}

Antes de abordar el análisis de las unidades que pueden funcionar como antecedente de las EEDD, es necesario resolver algunas dificultades que plantea el análisis de este mecanismo discursivo. La primera es la dificultad que comporta identificar $-\mathrm{y}$, por tanto, delimitar - un antecedente que la bibliografía ha calificado como difuso. La mayor parte de los autores que han estudiado este fenómeno discursivo han sorteado este problema designando el antecedente textual de las EEDD con expresiones deliberadamente vagas como "proposition-like pieces of information" (Schmid, 2000: 4). En el extremo contrario, algunos autores han intentado precisar tipos de unidades informativas que pueden desempeñar esta función, como es el caso de González Ruiz:

Lo particular de este mecanismo de cohesión es que (...) tiene como antecedente a un fragmento textual que puede ser de diversa extensión y complejidad conceptual (un sintagma, parte de un enunciado, un enunciado o más de uno, todo un párrafo o varios, segmentos textuales mayores, que incluso se pueden presentar discontinuamente). (González Ruiz, 2009: 247)

Tal como muestra esta cita, pese a su carácter difuso, existen intentos de delimitar los antecedentes de las EEDD, aunque para ello es necesario combinar unidades sintácticas, como sintagma o cláusula, con unidades semánticas propias del discurso, como la unidad párrafo, ya que el antecedente puede trascender el límite sintáctico de la oración.

Dado que el presente estudio pretende identificar estas unidades sintácticodiscursivas que funcionan como antecedente de las EEDD a partir de un análisis sistemático de corpus, antes que nada, es necesario establecer un criterio unitario para deli-

\footnotetext{
${ }^{5}$ Existen en la bibliografía en español diversos intentos de delimitar unidades del discurso, tanto en la conversación oral (Briz et al., 2003) como en textos escritos (Garrido, 2011). Tales unidades suelen establecerse de acuerdo con criterios de unidad temática o funcional. Dado que nuestro propósito aquí no es tanto describir unidades del discurso como identificar qué tipo de segmentos (más o menos complejos estructuralmente, continuos o discontinuos) activan la representación del referente de las etiquetas discursivas, no se seguirá ninguna de estas delimitaciones.
} 
mitar estas unidades de forma consistente. El criterio de delimitación del antecedente adoptado consiste en seleccionar la unidad textual mínima que proporcione la interpretación más relevante de la ED en el contexto o predicación en el que esta aparece. De hecho, puede defenderse que este criterio se aplica en todos los casos de referencia anafórica: el segmento textual que suele identificarse como antecedente con propósitos analíticos es siempre el segmento mínimo cuyo significado se ajusta a la lectura de la expresión anafórica seleccionada por el entorno discursivo en el que esta aparece, aunque la representación mental construida a partir de este segmento suela enriquecerse con otra información sobre el referente procedente del contexto discursivo o del conocimiento del mundo. Tal como se ha expuesto en el apartado 2.2., incluso en las relaciones anafóricas más convencionales, en las que se considera que el antecedente textual es un sintagma nominal, como la mecanógrafa en el ejemplo de (1), la representación mental del referente se enriquece mediante el resto de información acumulada sobre esta entidad a lo largo del discurso ('la mecanógrafa a la que Kurt no volvería a ver con vida'). Para poder identificar de forma unívoca la unidad textual concreta que activa la interpretación de las EEDD en el corpus analizado, se ha tenido en cuenta, sobre todo, el contexto o predicación en el que se inserta la ED (la predicación anafórica), que, tal como sugieren diversos autores, permite determinar múltiples aspectos de la interpretación de las expresiones anafóricas, como el tipo de entidad a la que aluden (Kleiber, 1990b; Cornish, 1999).

Una vez adoptado un criterio de delimitación del antecedente textual, es necesario todavía acotar otro aspecto, relativo al alcance anafórico mínimo de una ED, esto es, a cuál es la unidad textual mínima cuyo significado puede condensar una ED. Los distintos autores que han tratado de describir la unidad que funciona como antecedente en este mecanismo discursivo presentan, también, diferentes posturas al respecto. Así, gran parte de los autores establecen la cláusula como unidad mínima que puede encapsular una etiqueta discursiva (Francis, 1994; Schmid, 2000; Consten, Knees y Schwarz-Friesel, 2007: 83; Borreguero, 2006: 81), en tanto que algunos aceptan la posibilidad de una unidad inferior (Ivanič, 1991), como el sintagma nominal (González Ruiz, 2009). En este punto, este artículo se alinea con la postura de los segundos autores. En efecto, existe un tipo de sintagmas nominales que poseen una estructura predicativa y expresan el mismo tipo de significado que una predicación. Se trata de los que tienen como núcleo una nominalización, como el sintagma subrayado en el siguiente ejemplo:

(5) Con una mayoría parlamentaria de un solo escaño, el primer ministro conservador griego, Costas Karamanlis, no puede permitirse el menor error. Desgastado por escándalos económicos en el entorno gubernamental y en vísperas de una huelga general, convocada para mañana por la reforma de las pensiones, la política de 
privatizaciones y el coste de la vida, el error trágico ha sido la muerte de un adolescente de 15 años por disparos de la policía en un barrio conflictivo de Atenas. (El País, 9/12/2008 "Grecia, desbordada")

La relación entre el sintagma subrayado y el destacado en negrita puede considerarse de etiquetaje discursivo por dos motivos: de un lado, porque los sintagmas nominales que contienen una nominalización junto con los argumentos que subcategoriza constituyen un modo alternativo al verbal de expresar una relación predicativa, relación que se define, en definitiva, por su significado más que por su estructura sintáctica (Cornish, 1992: 168; Tamayo, 2000-2001; Bosque y Gutiérrez-Rexach, 2009: 260), y de otro, porque, al igual que ocurre con las cláusulas u oraciones, el significado del nombre y de sus argumentos se condensa en un sintagma nominal (el error trágico) que lo encapsula y categoriza (en este ejemplo, avanzando su contenido de forma catafórica).

\subsection{Resultados del análisis: el antecedente textual de las etiquetas discursivas}

Una vez resueltas las dificultades que plantea el análisis, se presentan los resultados obtenidos al identificar y analizar los antecedentes textuales de las 301 ocurrencias de etiquetas discursivas examinadas. Además de los sintagmas nominales con estructura predicativa mencionados al final del apartado anterior, el resto de unidades textuales identificadas como antecedentes de las EEDD en el corpus analizado son las siguientes:

- Una cláusula finita dependiente (esto es, una oración subordinada con verbo conjugado):

(6) Es verdad que IU ha sido víctima de la polarización política durante la anterior legislatura. Pero esta explicación no basta para dar cuenta de una constante pérdida de influencia tras cada cita electoral. (El País, 17/11/2008, "Congreso en falso")

- Una cláusula finita independiente (una oración simple) ${ }^{6}$ :

(7) En los últimos años, IU ha buscado su espacio político en las posiciones que dejaba libres el obligado pragmatismo de un PSOE de nuevo en el Gobierno. Esta última estrategia no sólo se vio obstaculizada por el voto útil que acabó desencadenando el tipo de oposición desarrollada por el PP; los dirigentes de IU no supieron elabo-

\footnotetext{
${ }^{6}$ Se sigue aquí la definición de oración simple prototípica como unidad de sentido y entonación, con un sujeto y un predicado que se organiza alrededor de un verbo conjugado, que no se encuentra inserta en ninguna otra construcción y que constituye una unidad comunicativa completa (Cuenca, 2007: 20).
} 
rar un proyecto autónomo ni transmitir un mensaje coherente. (El País, 17/11/2008, "Congreso en falso")

- Una cláusula no finita, generalmente de infinitivo (oraciones de infinitivo o de gerundio):

(8) La forma más realista de desalojar a la ilegalizada ANV de la alcaldía de Azpeitia es la moción de censura. Las otras fórmulas que se están barajando no sirven a ese objetivo porque la disolución en bloque del consistorio es imposible con la ley en la mano y la eventual reforma de la misma no podría aplicarse con carácter retroactivo. (El País, 8/12/2008, "Moción en Azpeitia")

- Una oración compleja, con dos o más verbos conjugados (y, en consecuencia, dos o más relaciones predicativas), unidos por coordinación o por subordinación:

(9) No basta con decir que el Gobierno de Aznar conocía la existencia de vuelos ilegales y secretos con destino al limbo jurídico de Guantánamo. La maquinaria de la Administración española se puso al servicio de la Administración de Bush para facilitarlos y para disimular las evidencias de su tránsito por España. En la operación participaron altos funcionarios de los ministerios de Asuntos Exteriores y Defensa, y también del gabinete internacional de la Presidencia del Gobierno. (El País, 2/12/2008, "Cómplices de la vergüenza")

- Dos o más oraciones, coordinadas o yuxtapuestas:

(10) El nuevo marco normativo está justificado por el fuerte impacto que la crisis económica está ya produciendo en el mundo de la inmigración. La nueva situación augura, por una parte, problemas de supervivencia a los inmigrantes residentes en España y, por otra, un retraimiento de los flujos migratorios, compatible sin embargo con un posible recrudecimiento de la inmigración irregular. Y se agravará el reto que supone atender a la formación y capacitación profesional de los cientos de miles de trabajadores inmigrantes en paro y a la integración de sus familias, lo que sin duda constituye el mejor antídoto contra eventuales brotes xenófobos en el futuro. En este escenario se enmarca la primera reforma en profundidad -medio centenar de sus 71 artículos- de la vigente Ley de Extranjería impulsada por el Gobierno de Aznar en 2001. (El País, 20/12/2008, "Otra inmigración, otra ley")

- Uno o más párrafos (generalmente, los inmediatamente anteriores):

(11) Tailandia está al borde del precipicio, disyuntiva entre un nuevo golpe militar o los enfrentamientos fratricidas en las calles, que ya se están cobrando vidas. La crisis política nunca desactivada, que comenzó a ritmo lento hace cuatro años, ha adquirido una dinámica imparable que amenaza con dinamitar los fundamentos mismos de la todavía llamada tierra de las sonrisas. En medio del caos callejero en Bangkok, cuyo aeropuerto permanecía ayer ocupado por las turbas, el primer min- 
istro Somchai Wongsawat, elegido democráticamente, ha rechazado la inadmisible conminación del jefe del Ejército, general Poachinda, para que dimita y convoque elecciones anticipadas.

Este escenario de golpe de Estado es el resultado de la estrategia desesperada de la extrema derecha realista, representada por la antigubernamental Alianza Popular para la Democracia. (El País, 27/11/2008, "Caos en Tailandia").

- El tema del texto previo o, más concretamente, como se muestra en el ejemplo, una serie de segmentos del texto que desarrollan, de forma continua o discontinua, aspectos directamente relacionados con el tema principal':

(12) Los colectivos gays, que pidieron una rectificación de la Reina por sus opiniones sobre matrimonios entre homosexuales, se dieron ayer por satisfechos con la nota difundida por la Casa del Rey. Tales opiniones figuran en un libro que recoge conversaciones de doña Sofía con la periodista Pilar Urbano. La nota precisa que el libro no recoge "con exactitud" las palabras de la Reina y que eran opiniones vertidas "en un ámbito privado". El asunto ha dado lugar a una polémica que, como cabía esperar, ha trascendido a gays, colectivos pro aborto o mujeres maltratadas y ha acabado por enredar, de una forma u otra, a los partidos políticos.

Resulta necesario precisar, de entrada, que lo que está en discusión ahora no son las opiniones concretas que figuran en el libro, a pesar de que alguna de ellas cuestiona leyes aprobadas por el Parlamento, o del conflicto que puedan causar con otros gobiernos, como el de George Bush, a causa de la guerra de Irak. Lo inaceptable es el hecho de que la Reina se pronuncie públicamente sobre asuntos políticos controvertidos como lo son el aborto, la eutanasia, la religión en las escuelas (para enseñar a los niños el origen de la vida, ni más ni menos) o las bodas entre homosexuales. En este sentido, resultaría igual de cuestionable que la Reina opinase exactamente lo contrario en todos y cada uno de los temas sobre los que se ha pronunciado. Es imposible representar a todos los españoles si se toma partido por lo que piensan algunos de ellos. Si la Corona opina abiertamente sobre cuestiones controvertidas, será la institución misma la sometida a controversia; y así ha sido.

El libro fue revisado y avalado por la Casa del Rey, según su autora, lo que no ha sido desmentido. Por tanto, ha habido un error en esa Casa: si la Reina se expresó de la manera que figura en el libro, alguien debería haberle hecho notar lo impropio de tal decisión; y en última instancia, alguien con responsabilidad para ello debería haber impedido el error.

\footnotetext{
${ }^{7}$ En este último caso, los segmentos textuales concretos que proporcionan la interpretación de la ED resultan especialmente difíciles de delimitar con precisión. Es por este motivo por el que se ha seleccionado una denominación de la unidad de tipo semántico y alcance más vago (tema del texto previo).
} 
Más allá de este episodio, hay síntomas de un cierto desgaste de la institución, sobre todo entre los jóvenes, para quienes acontecimientos como el 23-F quedan lejos. (El País, 1/11/2008, "La Reina toma partido")

Las frecuencias de uso de cada una de estas unidades sintáctico-discursivas que actúan como antecedente de una ED en el corpus examinado se ordenan y concretan en la Tabla 1. En ella se indica tanto el número de EEDD que tienen como antecedente una determinada unidad, en la columna central, como el porcentaje que cada uno de estos números representa sobre el total de etiquetas discursivas examinadas (301):

\begin{tabular}{lll}
\hline ANTECEDENTE TEXTUAL & No OCURRENCIAS & $\begin{array}{l}\text { PORCENTAJE SOBRE EL TOTAL } \\
\text { DE EEDD }\end{array}$ \\
Cláusula finita dependiente & 95 & $31.5 \%$ \\
Sintagma nominal & 51 & $17 \%$ \\
Cláusula no finita & 51 & $17 \%$ \\
Oración compleja & 27 & $9 \%$ \\
Oraciones yuxtapuestas o coordinadas & 26 & $8.6 \%$ \\
Cláusula finita independiente & 18 & $6 \%$ \\
Tema del texto previo & 17 & $5.6 \%$ \\
Uno o más párrafos & 12 & $4 \%$ \\
No identificable o ambiguo & 4 & $1.3 \%$ \\
\hline
\end{tabular}

Tabla 1. Unidades sintáctico-discursivas que funcionan como antecedente de las EEDD, ordenadas por frecuencia

Aunque el corpus analizado no es suficientemente representativo para permitir extrapolar frecuencias de uso, los resultados reflejados en la tabla permiten realizar algunas observaciones de interés. En primer lugar, a partir del criterio de delimitación presentado al inicio de este apartado, ha resultado posible identificar y delimitar la mayor parte de los antecedentes de las EEDD analizadas, a excepción de 4 casos, en los que el antecedente resultaba no identificable o ambiguo. En segundo lugar, en el corpus examinado se ha identificado un número elevado de sintagmas nominales con estructura predicativa que funcionan como antecedentes de EEDD (el 17\% del total). Esta constatación apunta a que, a la hora de abordar un análisis de este tipo de encapsuladores, es relevante decidir si se van a tener en cuenta los casos en los que se recupera un sintagma nominal complejo de estas características, ya que la decisión puede alterar considerablemente los resultados. Por último, la tabla muestra una acusada tendencia de las EEDD a tener como antecedente unidades textuales inferiores a la oración, como cláu- 
sulas subordinadas y sintagmas nominales, que suman el $65 \%$ de las ocurrencias ${ }^{8}$. De forma complementaria, se detecta un uso bastante menos frecuente en el corpus de EEDD que condensan unidades textuales más heterogéneas y abstractas, como el contenido de uno o varios párrafos o el tema del texto, que no llegan a sumar el 10\% de las ocurrencias analizadas.

En el apartado 2.2 de este artículo se mencionaban las reticencias de diversos autores a considerar correferencial la relación de etiquetaje discursivo, ya que se ponía en duda el valor referencial que podía tener un antecedente con estructura predicativa. En este apartado se ha comprobado que pueden actuar como antecedente de una ED unidades sintáctico-discursivas diversas, de modo que la segunda parte del análisis consiste en plantearse si puede asignarse valor referencial a alguna de ellas.

\subsection{Análisis de los resultados: valor referencial de las unidades identificadas}

Si en algo coinciden la mayor parte de las disciplinas que se han ocupado del estudio de los procedimientos de referencia (como la filosofía del lenguaje, la gramática tradicional o la pragmática) es en la identificación de estos, a grandes rasgos, con expresiones nominales, cuyas marcas de determinación les permiten funcionar como expresiones referenciales, al identificar una entidad individualizada. No obstante, en los últimos años la gramática cognitiva ha ampliado el ámbito de aplicación de la referencia a otros tipos de entidades y de categorías sintácticas. Langacker (1991: 91 y ss.) define la referencia, en términos cognitivos, como el proceso por el cual los participantes en un acto comunicativo establecen de forma coordinada "contacto mental» con una misma ocurrencia o instancia $\mathrm{t}^{\mathrm{i}}$ de un tipo $\mathrm{T}$. La principal diferencia con las teorías anteriores es que en la gramática cognitiva esta función de seleccionar una instancia o ejemplar concreto perteneciente a un tipo de entidades no se atribuye únicamente a marcas gramaticales como los determinantes o a categorías sintácticas como el sintagma nominal, sino que se pone en relación directa con la capacidad de coordinar la atención de los interlo-

\footnotetext{
${ }^{8}$ Es importante precisar que la elevada frecuencia de cláusulas dependientes (finitas o no finitas) como antecedente de una ED se explica, fundamentalmente, porque estas se integran en uno de los patrones de aparición de las EEDD más recurrentes, al menos, en el corpus periodístico manejado: el patrón $<$ art. def. $+\mathrm{ED}+d e+$ o. completiva apositiva $>$. En concreto, 93 de las 146 cláusulas dependientes que funcionan como antecedente de las EEDD identificadas en el corpus ocupan la posición de la oración completiva en este patrón. Sobre este patrón, identificado por Schmid como entorno recurrente de aparición de las EEDD para el inglés (2000), puede leerse en español López Samaniego (2011: 444 y ss.; en prensa b) y, sobre el funcionamiento gramatical del patrón, Leonetti (1999: 2090).
} 
cutores hacia una misma entidad en el modelo mental del discurso, mediante el concepto de anclaje (grounding).

En efecto, la condición que establece la gramática cognitiva para que una expresión pueda perfilar una instancia concreta es que esté anclada, es decir, situada con respecto al acto de habla y a los participantes (Langacker, 1991). Teniendo en cuenta este concepto de anclaje, Langacker analiza, en su trabajo de 2008, el valor referencial de las principales unidades del discurso. En el siguiente epígrafe se aplica este análisis a las unidades identificadas como antecedente de las EEDD.

\subsubsection{Anclaje y unidades sintáctico-discursivas}

Como ya se ha mencionado, uno de los principales impedimentos para considerar expresiones referenciales a las unidades que funcionan como antecedente de las etiquetas discursivas es que se trata de unidades superiores al sintagma nominal, que no han sido consideradas tradicionalmente como expresiones referenciales. No obstante, en el epígrafe anterior se ha mostrado que las EEDD también pueden tener como antecedente un sintagma nominal, siempre que este presente una estructura predicativa. Este tipo de antecedentes nominales de las EEDD no parecen plantear problemas formales para ser considerados expresiones referenciales, ya que constituyen sintagmas nominales con marcas de determinación. En cambio, desde el punto de vista semántico, sí presentan alguna diferencia con respecto a las expresiones referenciales prototípicas, especialmente porque no designan entidades concretas, sino abstractas, entidades que suelen presentarse en el discurso mediante cláusulas. Algunos autores consideran el significado abstracto de expresiones como estas difícilmente compatible con el valor referencial (Cuenca, 2000: 68; Escandell, 2004: 46).

Es cierto que, a diferencia de las entidades concretas o de primer orden, las entidades eventivas o abstractas que designan los sintagmas nominales con estructura predicativa no se corresponden fácilmente con entidades materiales o tangibles en el mundo externo al texto. Tampoco parece fácil que puedan corresponderse con una representación mental unitaria, ni menos aún figurativa. Sin embargo, ello no impide que puedan representarse mentalmente como entidades discursivas. De hecho, son diversos los autores que, desde enfoques cognitivos, han defendido en los últimos años que entidades abstractas como los eventos pueden representarse como entidades discursivas en los modelos mentales del discurso, esgrimiendo dos argumentos fundamentales: (i) que un evento puede actuar como antecedente de una expresión pronominal (Langacker, 2008: 270), generalmente de tipo demostrativo (Hegarty, 2003: 894); y (ii) que los eventos, igual que las entidades individuales, también entran en relación con otros eventos en el 
texto, por lo que tienen que poder representarse mentalmente de forma directa igual que aquellas (Garnham, 2001: 10). Así pues, los sintagmas nominales con estructura predicativa constituyen expresiones referenciales que no designan entidades físicas individuales, sino entidades complejas, relaciones entre entidades individuales que no siempre pueden observarse en el mundo físico, pero que sí pueden representarse mentalmente de forma esquemática como entidades del discurso ${ }^{9}$.

Por lo que respecta a las expresiones con núcleo verbal, han presentado tradicionalmente mayores dificultades que las nominales para ser consideradas como estructuras con capacidad referencial, debido a motivos como que suelen contener en su seno diferentes expresiones referenciales que designan, por ejemplo, a los participantes en el evento o hecho descrito. No obstante, teniendo en cuenta la concepción de la referencia elaborada desde la gramática cognitiva, puede defenderse que algunas de las unidades sintáctico-discursivas identificadas en el análisis presentan la capacidad de perfilar una instancia anclada, esto es, poseen capacidad referencial. En efecto, Langacker defiende que, del mismo modo en que los sintagmas nominales (nominales en su teoría) perfilan una entidad concreta perteneciente al tipo denotado por el nombre que actúa como núcleo, las cláusulas finitas perfilan una entidad concreta que pertenece al tipo denotado por el verbo y pueden designar también, en consecuencia, referentes discursivos (2008: 270-271) ${ }^{10}$. La principal diferencia entre ambos tipos de expresiones se encuentra en el modo de designar o referir: mientras que los sintagmas nominales perfilan objetos y los anclan en el espacio, las cláusulas perfilan procesos o relaciones entre entidades observadas en su evolución temporal (Langacker, 2009: 290) y los anclan en el tiempo. Dado que los objetos perduran en el tiempo y coexisten en el espacio, la principal función referencial de los sintagmas nominales consiste en identificar a qué entidad concreta del tipo X se está haciendo referencia. En cambio, los procesos o eventos perfilados por cláusulas son transitorios y se suceden en el tiempo, de modo que lo relevante para poder designarlos es determinar su existencia, esto es, establecer si han ocurrido o no y cuándo (Langacker, 2009: 151). De ahí que las marcas modales y temporales des-

\footnotetext{
${ }^{9}$ De hecho, las principales clasificaciones de órdenes referenciales (tipos de entidades a las que puede hacerse referencia) elaboradas desde distintos enfoques semánticos incluyen estas entidades abstractas, que son las de segundo y tercer orden (Lyons, 1977/1980: 387-391), o bien, en la gramática funcional de Dik (1997: 136), de segundo (eventos), tercero (conceptos) y cuarto orden (actos de habla).

${ }^{10}$ También algunos autores han defendido, desde la gramática, el valor referencial de algunas cláusulas, aplicando argumentos similares a los de Langacker: "Las cláusulas sustantivas de tiempo finito son propiamente referenciales: la flexión temporal que el verbo incorpora posibilita la referencia a eventos determinados, específicos, por lo que difícilmente una cláusula sustantiva puede funcionar como expresión descriptiva." (Fernández Leborans, 1999: 2417).
} 
empeñen en las cláusulas una función de anclaje paralela a la que desempeñan los determinantes en los sintagmas nominales.

Así pues, las cláusulas finitas prototípicas, esto es, las oraciones simples, pueden perfilar un evento unitario, una instancia u ocurrencia del tipo de proceso denotado por el verbo, anclada en el tiempo gracias a la flexión del verbo principal (Langacker, 2008: 4142). Las cláusulas finitas dependientes también presentan esta capacidad, aunque no en todos los casos: cuanto más autónomas son con respecto del verbo de la oración principal, esto es, cuanto más se aproximan a una cláusula finita prototípica, mayor es su capacidad para perfilar un evento unitario y, en consecuencia, para poseer valor referencial. Así, estas cláusulas presentan mayor capacidad referencial cuando están ancladas en el tiempo mediante la flexión temporal del verbo y cuando poseen un sujeto propio explícito (Langacker, 2008: 426 y ss.), como ocurría en la cláusula subrayada en el fragmento de (6), que se recupera aquí:

(6bis) Es verdad que IU ha sido víctima de la polarización politica durante la anterior legislatura. Pero esta explicación no basta para dar cuenta de una constante pérdida de influencia tras cada cita electoral.

La cláusula subordinada sustantiva subrayada en el ejemplo perfila un proceso anclado en el tiempo por la flexión verbal (es anterior al acto de habla) e incluso mediante un complemento temporal (durante la anterior legislatura), y posee, además, un sujeto propio que experimenta el proceso $(I U)$. El único aspecto del anclaje en que esta cláusula depende del predicado de la oración principal es su estatuto epistémico: la oración principal de (6bis) constituye un predicado de actitud proposicional que presenta el evento que designa la subordinada como real o verdadero según el hablante.

No obstante, no todas las cláusulas finitas dependientes se comportan como la del ejemplo de (6). En casos como el del ejemplo de (13), la cláusula dependiente subrayada no perfila por sí misma ningún evento singularizado, pues dependen de la oración principal tanto la interpretación de su sujeto (Irán) como su anclaje temporal y modal (se sitúa en un futuro virtual o posible, tal como apunta el significado léxico del verbo principal temer):

(13) En Venezuela, el mandatario ruso firmó con el presidente Chávez un acuerdo de cooperación nuclear, que debería culminar en la construcción de una central atómica venezolana, para la producción de energía eléctrica, según asegura el líder bolivariano. Las similitudes con el caso de Irán, de quien Estados Unidos y Occidente temen que persiga la obtención del arma nuclear, son evidentes, aunque $\mathrm{Ca}$ racas aún no haya iniciado ese camino. (El País, 1/12/2008, "Moscú vuelve al Caribe"). 
De hecho, en este ejemplo, el carácter no anclado del segmento encapsulado facilita que la ED ese camino se emplee con un valor anafórico algo distinto del que viene ejemplificándose hasta aquí: como anáfora de sentido ${ }^{11}$. En estos casos, la relación semántica que mantienen los dos segmentos discursivos relacionados indica identidad del tipo de entidad denotada, pero no del ejemplar concreto designado: ese camino no se refiere al camino indicado anteriormente (a 'la posible (y temible) persecución del arma nuclear por parte de Irán'), sino únicamente al tipo de camino 'perseguir la obtención del arma nuclear', que en la cláusula que contiene la ED se refiere a una acción todavía no iniciada por Caracas. Este ejemplo puede equipararse, por tanto, con los casos de anáfora de identidad de sentido <tipo-ejemplar> (RAE y AALE, 2009: \$14.5p), que se ejemplifican con oraciones como la siguiente, en la que el hablante está hablando claramente de dos ejemplares distintos (el suyo y el de una tercera persona) del mismo tipo (el libro X):

(14) No le ofrezcas este libro, ya lo tiene. (Ejemplo de Kleiber, 1990a)

En casos como el de (14), no existe correferencia entre las dos expresiones destacadas, sino que su relación de identidad se debe a que pertenecen a un mismo tipo de entidades. De igual modo, en el ejemplo de (13) se ponen en relación dos eventos concretos del tipo 'perseguir la obtención de un arma nuclear', que cuentan con distintos participantes y anclaje temporal.

Las cláusulas no finitas, por su parte, presentan el mismo problema que las cláusulas finitas dependientes de ejemplos como el de (13) para ser consideradas expresiones referenciales, pero este impedimento se da en todos los casos. Las cláusulas no finitas no pueden perfilar eventos anclados porque se construyen en torno a un verbo no flexionado; por ello, tanto su anclaje temporal como, normalmente, la interpretación de su sujeto dependen necesariamente de la oración en la que se insertan. Es por ese motivo por el que Langacker (2008: 438) considera que describen un evento de forma generalizada, que denotan un tipo de predicado, como ocurría en el ejemplo de (8), que se retoma aquí:

(8bis) La forma más realista de desalojar a la ilegalizada ANV de la alcaldía de Azpeitia es la moción de censura. Las otras fórmulas que se están barajando no sirven a ese objetivo porque la disolución en bloque del consistorio es imposible con la ley

\footnotetext{
${ }^{11}$ Este concepto se emplea aquí en su acepción más restringida, tal como lo acuñan Grinder y Postal (1971), para designar anáforas que tienen el mismo sentido que su antecedente, pero no el mismo referente, esto es, aluden al mismo tipo de entidad que su antecedente, pero no al mismo caso o ejemplar. En la acepción más amplia, el término se emplea como equivalente al de anáfora indirecta.
} 
en la mano y la eventual reforma de la misma no podría aplicarse con carácter retroactivo. (El País, 8/12/2008, "Moción en Azpeitia").

En este fragmento, la ED ese objetivo recupera el predicado "desalojar a la ilegalizada ANV de la alcaldía de Azpeitia", sin importar quién ni cuándo realice esa acción. Este tipo de cláusulas, por su falta de anclaje, resultan también especialmente adecuadas para llevar a cabo anáforas de sentido tipo-ejemplar como la ejemplificada en (13).

Por último, por lo que respecta al resto de las unidades identificadas, todas ellas superiores a la oración simple, las dificultades para considerarlas expresiones referenciales aumentan. Se trata de unidades que comprenden desde la oración compleja hasta la suma de segmentos del texto que desarrollan aspectos del tema principal (ejemplificadas en 9-12) y que, por su naturaleza supraoracional, perfilan más de un evento unitario, más de una relación anclada. Su capacidad de perfilar una entidad unitaria se ve, en consecuencia, comprometida. El límite entre estas unidades y la oración simple, de tipo gradual, se encuentra, según Langacker, en la oración compleja:

It is not so obvious, however, that a complex sentence containing multiple finite clauses should always be analyzed as having only one overall referent. The more complex the sentence (...) the more implausible this seems. (2008: 416)

Así pues, a partir de las oraciones complejas que perfilan más de un evento o entidad abstracta, incluyendo unidades más complejas como párrafos completos o el tema del texto, el antecedente de las EEDD ya no puede considerarse una expresión referencial, dado que no solo contiene más de una expresión referencial nominal, sino que, además, perfila más de un evento o entidad anclada.

\subsubsection{Conclusiones del análisis: el etiquetaje discursivo como relación anafórica}

Como se ha observado en el análisis anterior, algunas de las unidades sintácticodiscursivas que funcionan como antecedente de las etiquetas discursivas poseen capacidad referencial, es decir, pueden perfilar por sí mismas entidades discursivas ancladas; a saber: los sintagmas nominales con estructura predicativa, las cláusulas finitas independientes y algunas de las dependientes, y alguna oración compleja. Por tanto, si se recupera el problema que se planteaba al inicio de este artículo acerca de la correferencialidad de las EEDD (o de los procedimientos de encapsulación en general), la postura más adecuada parece ser la que considera que esta relación anafórica se encuentra a medio camino entre la anáfora directa o correferencial y la anáfora indirecta.

El análisis realizado permite, además, precisar esta postura, indicando en qué casos estas relaciones anafóricas pueden considerarse correferenciales y en cuáles no, en función del valor referencial que, como acaba de exponerse, puede asignarse a las distintas 
unidades que actúan como antecedente. Este análisis permite situar las relaciones de etiquetaje discursivo con mayor precisión en lo que autores como Schwarz-Friesel denominan el "continuum entre anáfora directa y anáfora indirecta» (2007: 3). En los extremos de este continuo se encuentran las ocurrencias o ejemplos más claros de correferencia y de anáfora indirecta, mientras que, en el centro, se ubica la frontera difusa entre ambos tipos: los casos en los que la ED tiene como antecedente una cláusula finita subordinada o una oración compleja. La distribución de las relaciones de etiquetaje discursivo en este continuo se representa en la siguiente figura:

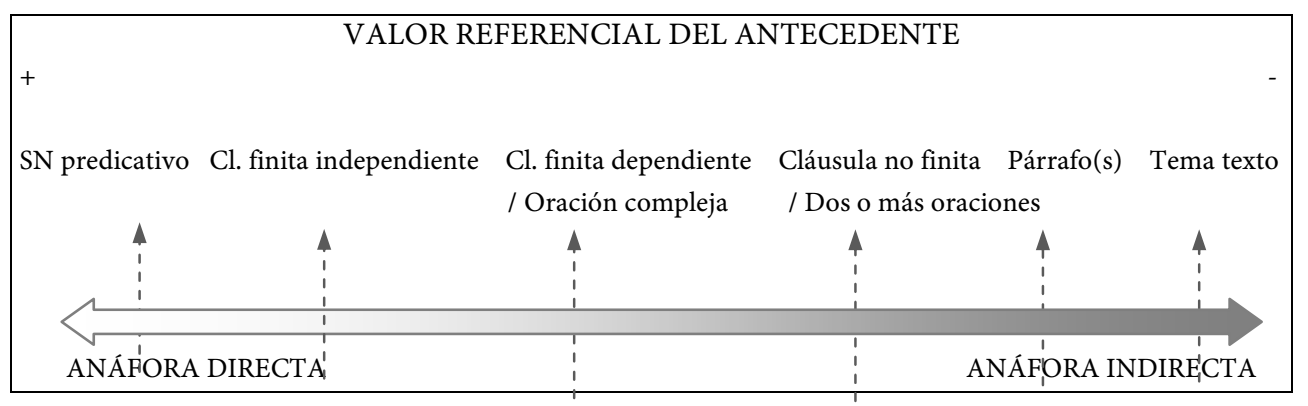

Figura 1. Distribución de las relaciones de etiquetaje discursivo en el continuo entre anáfora directa y anáfora indirecta

Así pues, las EEDD pueden funcionar como anáforas correferenciales, de un modo muy similar al modo en que funcionan las anáforas directas prototípicas ejemplificadas en la introducción de este artículo, o bien como anáforas indirectas, cuando reactivan contenidos complejos expresados por unidades discursivas que no perfilan un referente unitario. El tipo de relación de anáfora indirecta que se da en estos últimos casos es el que Schmid ha denominado experiential identity o identidad de experiencia, que se produce cuando un sintagma nominal y un segmento del discurso más o menos difuso o complejo contribuyen a formar la representación mental de una misma experiencia real o virtual (2000: 29). A pesar de que este autor atribuye este tipo de relación anafórica a todas las ocurrencias de nombres que actúan como EEDD, el análisis realizado hasta aquí indica que es más adecuado considerar que esta identidad de experiencia se da en los casos en los que el antecedente de las EEDD no perfila una entidad anclada, esto es, tal como se indica en la figura, cuando el antecedente es una cláusula no finita, una cláusula compleja, un conjunto de cláusulas o de párrafos continuos o discontinuos, o bien el tema general del texto previo. 


\section{Conclusiones: las etiquetas discursivas, del mantenimiento a la construcción del referente}

El propósito de este artículo ha sido analizar el valor referencial de las unidades sintáctico-discursivas que pueden actuar como antecedente de una ED, a fin de proporcionar una explicación más precisa del tipo de relación anafórica que establece este mecanismo discursivo. A partir del análisis desarrollado, puede concluirse que esta relación se distancia de la anáfora directa a medida que el antecedente pierde su capacidad para perfilar un evento o entidad anclada en el modelo mental del discurso elaborado por los participantes. En este sentido, se ha propuesto una ordenación de estos antecedentes en función de tal capacidad. La clasificación propuesta no solo permite situar con mayor precisión las relaciones de etiquetaje discursivo en el continuo que va de la anáfora directa a la indirecta, sino que permite diferenciar, además, las funciones cognitivas que la ED puede realizar sobre la representación mental del antecedente.

Las principales funciones cognitivo-discursivas de los nombres que actúan como EEDD han sido identificadas por Schmid, que describe tres: (i) la delimitación de un segmento discursivo como unidad (conceptual partitioning), (ii) la transformación de dicho segmento en una entidad unitaria, gracias a su recategorización gramatical como expresión nominal (reifying), y (iii) la categorización de dicha entidad en el discurso, que consiste fundamentalmente en darle un nombre como entidad del discurso, integrando así el contenido encapsulado en una entidad conceptual que lo engloba (conceptual integration) (1999a: 120; 1999b; 2000: 362-369). La segunda de estas funciones relaciona la recategorización gramatical del antecedente (de una estructura verbal a una nominal) con una transformación en el modo de concebir la entidad referida, esto es, con una reificación, por la que un contenido abstracto se convierte en una "cosa" u objeto unitario conceptualmente delimitado (Langacker, 1987; 2008: 107). Siguiendo uno de los principios básicos de la gramática cognitiva, se modifica el modo de construcción del significado (construal) al cambiar la categoría gramatical que lo expresa. Al pasar a construirse nominalmente, el contenido del antecedente ya no se conceptualiza como un proceso o relación entre entidades anclada en el tiempo, sino como una entidad unitaria y delimitada, más fácil de manejar en la continuación del discurso (Langacker, 2000: 219; 2008: 105).

Algunos autores han asociado esta operación de reificación de un antecedente proposicional que realizan los encapsuladores en general (no solo las EEDD, sino también los pronombres neutros, por ejemplo) con una operación de creación de nuevas entidades discursivas, que no habían sido introducidas en el discurso como entidades unitarias (Apothéloz, 1995b: 144; Conte, 1996: 4; Schwarz-Friesel, Consten y Knees, 2007; 
Consten y Knees, 2008: 190). De acuerdo con estos autores, las expresiones anafóricas que condensan el contenido de una o más proposiciones convierten en un objeto o entidad del discurso un contenido informativo que no había sido presentado previamente como tal, a diferencia de lo que ocurre con otras expresiones que simplemente reactivan referentes que ya han sido presentados en el texto mediante un sintagma nominal. El análisis desarrollado en este artículo pone de relieve la necesidad de reconsiderar la relación que existe entre el etiquetaje discursivo y la creación o construcción de nuevos referentes del discurso, e incluso la necesidad de que este mecanismo vaya siempre unido a un proceso de reificación. Tal como se pretende apuntar a modo de conclusión, la reificación conceptual y la creación de nuevos referentes discursivos no se dan en todos los usos de las EEDD ni (cabe esperar) en todos los procedimientos de encapsulación en general.

El análisis realizado permite diferenciar tres tipos de funcionamiento cognitivo de las EEDD en función del tipo de unidad sintáctico-textual que actúe como antecedente. En primer lugar, en aquellos casos en los que la ED encapsula un sintagma nominal con estructura predicativa, esto es, un antecedente de contenido predicativo ya reificado, la función realizada por la ED consiste fundamentalmente en mantener activo el referente en la memoria del destinatario, condensando toda la información aportada para su representación mental (esto es, los argumentos del verbo nominalizado, principalmente), pero sin que se produzca, en este caso, una recategorización o reificación. Es lo que ocurre en el ejemplo de (15), donde el sintagma nominal subrayado introduce un referente eventivo reificado en la representación mental del discurso y la ED lo mantiene en foco, renombrándolo o reconceptualizándolo como una decisión:

(15) El rechazo del Parlamento Europeo a la ampliación de la jornada laboral hasta 65 horas semanales, en caso de acuerdo entre empresario y trabajador, tiene una elevada carga simbólica. Con esa decisión, los parlamentarios están transmitiendo el mensaje de que existe un modelo laboral europeo que no debe erosionarse por el hecho de que otros modelos busquen el aumento de la productividad sobre la base de más horas trabajadas a cambio de menos salario. (El País, 18/12/2008, "La jornada tiene límites").

Un segundo tipo de funcionamiento de las EEDD puede identificarse cuando estas encapsulan el contenido de una proposición expresada o construida mediante una estructura verbal con valor referencial. En los casos en los que el antecedente es una cláusula finita independiente (o bien una cláusula finita dependiente o una oración compleja que perfilan un evento unitario y anclado), la ED reactiva o mantiene activo un referente introducido en el texto mediante una cláusula u oración y lo recategoriza o re- 
construye como entidad unitaria del discurso, lo reifica. Es lo que ocurre en el ejemplo de (16):

(16) La Audiencia Nacional viene investigando los vuelos secretos con destino a Guantánamo desde que se supo que algunos de ellos transitaron por España. $\mathbf{E l}$ proceso se encontraba paralizado a falta de pruebas y documentos: ahora se han conocido pruebas de vuelos militares, diferentes a los de la CIA pero con implicaciones similares. (El País, 2/12/2008, "Cómplices de la vergüenza")

En el ejemplo, la ED el proceso transforma el modo de conceptualizar el contenido subrayado: si en la oración subrayada se construye como un proceso anclado en el tiempo, que se desarrolla en distintas fases secuenciales y se concibe como una relación entre distintas entidades del discurso, con la aparición de la ED pasa a construirse como un objeto unitario delimitado, concebido de forma sintética o estática como unidad anclada en el espacio.

Una última posibilidad de funcionamiento cognitivo de las EEDD es la que se da cuando el antecedente no perfila un evento unitario, sino (i) un tipo de evento, (ii) una serie de eventos o de ideas relacionadas o (iii) un bloque informativo complejo, esto es, cuando el antecedente es una oración no finita (ejemplo 8), una oración compleja que perfila más de un evento o un conjunto de oraciones coordinadas o yuxtapuestas (ejemplos 9 y 10), o el contenido de uno o más párrafos o segmentos del texto (ejemplos 11 y 12), respectivamente. Es en estos casos en los que puede afirmarse claramente que, además de producirse una recategorización y reificación del antecedente, la ED construye un nuevo referente discursivo. Más concretamente, cuando el antecedente es una cláusula no finita, en ejemplos como el de (8), la ED crea un nuevo referente al perfilar una instancia concreta del tipo de proceso denotado por la cláusula, mientras que en ejemplos como los de (9) a (12), las EEDD funcionan propiamente como lo que algunos autores han denominado anáforas recapitulativas (Vivero García, 1997) o resumitivas (Maillard, 1974; cit. por Peña Martínez, 2004).

En estos últimos casos, la ED delimita el contenido de una serie de cláusulas que se presentan en el discurso de forma continua o discontinua, lo reifica y lo resume en un concepto unitario complejo. La naturaleza heterogénea o plural de este tipo de antecedentes textuales complejos se refleja en el hecho de que la ED seleccionada puede aparecer en singular, componiendo así una entidad discursiva compleja, resultado de la suma de un conjunto de eventos o proposiciones, como ocurría en los ejemplos (9) a (12), pero también puede aparecer en plural, como sucede en el ejemplo de (17):

(17) La comparecencia parlamentaria del ministro Moratinos para explicar la autorización del Gobierno de Aznar a los vuelos a Guantánamo obtuvo el beneplácito del PP. A diferencia de otros casos de control al Ejecutivo, este aval de la oposición 
carece de valor para dar carpetazo al asunto: los vuelos investigados afectan al Gobierno del PP, que concedió la autorización, y al del PSOE, que no la revocó. Quizá no fue informado de la existencia de esta autorización, como afirma, pero sí se le requirió información por parte de la comisión del Parlamento Europeo encargada de esta investigación y de la Audiencia Nacional. También tuvo noticia de la posible participación española por boca de la secretaria de Estado norteamericana, Condoleezza Rice. Al parecer, estos estímulos no fueron suficientes en su día para que el Gobierno de Zapatero hiciera lo que ha hecho ahora: informar y anunciar la entrega a la justicia de los documentos publicados por EL PAÍS. (El País, 14/12/2008, "Vuelos compartidos")

En casos como el del ejemplo, en los que la ED aparece en plural, aludiendo a un conjunto de entidades, se mantiene, mediante una única expresión nominal, la referencia a dos entidades eventivas individuales ya presentadas en el texto como tales (se le requirió información por parte de la comisión del Parlamento Europeo encargada de esta investigación y de la Audiencia Nacional = estímulo 1; tuvo noticia de la posible participación española por boca de la secretaria de Estado norteamericana, Condoleezza Rice $=$ estímulo 2). La posibilidad de condensar una serie de eventos presentados en el texto mediante cláusulas por medio de una ED singular o de una ED plural se debe, a mi modo de ver, a la existencia de dos posibilidades de reificación del antecedente: o bien se reifica el conjunto de eventos referidos como partes de un evento unitario singular, como ocurría en el ejemplo de (12); o bien se reifica cada uno de los eventos relacionados como entidades individuales discretas y se elige una ED plural, como ocurre en $(17)^{12}$. En este último caso, más que un caso de construcción de referente se trata de un ejemplo de referencia múltiple (split reference), en el que un sintagma nominal plural reactiva una serie de referentes. Pese a su naturaleza múltiple, autores como Webber $e t$ al. (2003: 555) incluyen este tipo de referencia entre los casos de anáfora correferencial.

En suma, el análisis desarrollado ha mostrado que el examen de los distintos tipos de antecedente que puede encapsular una ED puede arrojar luz tanto sobre el tipo de relación anafórica que pueden establecer estos mecanismos (directa, indirecta e incluso de sentido tipo-ejemplar) como acerca de las distintas funciones que pueden tener estas EEDD sobre la representación cognitiva del discurso, ya sea manteniendo activo un referente ya presentado (ejemplo 15); transformando un referente presentado como proceso en un objeto unitario delimitado (reificándolo), como ocurría en (16); o bien

\footnotetext{
${ }^{12}$ A su vez, el hecho de que esta segunda opción, la recuperación de una serie de eventos mediante una ED singular, no sea posible para los casos en los que el antecedente es un sintagma nominal con estructura predicativa, tal como ha demostrado Hegarty (2003), podría explicarse, a mi juicio, porque la ED no puede reificar el antecedente nominal en estos casos.
} 
construyendo un nuevo referente discursivo que aglutina y resume una serie de eventos o proposiciones presentadas en el texto, como sucede en los ejemplos (12) o (17).

Cabe añadir a lo anterior que, además de las funciones descritas sobre la representación mental de los referentes del discurso, las EEDD desempeñan otras funciones discursivas estrechamente relacionadas con esta, como la capacidad de reconceptualizar o modificar la categorización cognitiva del antecedente. En efecto, gracias a su significado léxico, las EEDD pueden añadir información nueva sobre el antecedente (por ejemplo, una valoración subjetiva del emisor sobre este), focalizar un dominio en el que conceptualizarlo (como entidad proposicional, mental o eventiva, por ejemplo, orientando así la interpretación del emisor), así como mantener o modificar su estatuto ontológico. Dado que estas funciones más propiamente discursivas no dependen tanto de la capacidad anafórica encapsuladora de las EEDD como del significado de la ED seleccionada y del tipo de predicado en el que esta aparece, deberán ser objeto de futuros estudios.

Recibido: 30-XI-2012

Aceptado: 30-VII-2013

\section{Referencias bibliográficas}

Apothéloz, D. (1995a): Rôle et fonctionnement de l'anaphore dans la dynamique textuelle. Genève, Droz.

Apothéloz, D. (1995b): "Nominalisations, référents clandestins et anaphores atypiques", Travaux Neuchâtelois de Linguistique (TRANEL), 23, págs. 143-173.

Ariel, M. (1988): "Referring and accessibility", Journal of Pragmatics, 24, págs. 65-87.

Ariel, M. (1990): Accessing noun-phrase antecedents. London, Routledge.

Bertucci, R. A. (2006): “Anáforas encapsuladoras: uma análise em textos de opinião", Revista letras, 70, págs. 207-221.

Borreguero, M. (2006): "Naturaleza y función de los encapsuladores en los textos informativamente densos (la noticia periodística)", Cuadernos de Filología Italiana, 13, págs. 73-95.

Briz, A.; A. Hidalgo; X. Padilla; S. Pons; L. Ruiz Gurillo; J. Sanmartín; E. Benavent; M. Albelda; M. J. Fernández y M. Pérez (2003): "Un sistema de unidades para el estudio del lenguaje coloquial”, Oralia, 6, págs. 7-61.

Brown, G. y G. Yule (1983): Discourse analysis. Cambridge, Cambridge University Press.

Charolles, M. y C. Schnedecker (1993): "Coréférence et identité: Le problème des référents évolutifs", Langages, 27 (112), págs. 106-126.

Consten, M., M. Knees y M. Schwarz-Friesel (2007): "The function of complex ana- 
phors in texts. Evidence from corpus studies and ontological considerations". En Schwarz-Friesel, M., M. Consten y M. Knees (eds.): Anaphors in text: cognitive, formal and applied approaches to anaphoric reference. Amsterdam/Philadelphia, John Benjamins, págs. 81-102.

Consten, M. y M. Knees (2008): "Complex anaphors in discourse". En Benz, A. y P. Kühnlein (eds.): Constraints in discourse. Amsterdam/Philadelphia, John Benjamins, págs. 181-199.

Conte, M. (1996): "Anaphoric encapsulation", Belgian Journal of Linguistics, 10, págs. 110.

Cornish, F. (1986): Anaphoric Relations in English and French: A Discourse Perspective. London, Croom Helm.

Cornish, F. (1992): "So be it. The discourse-semantic roles of so and it", Journal of Semantics, 9, págs. 163-178.

Cornish, F. (1999): Anaphora, discourse, and understanding: Evidence from English and French. Oxford, Oxford University Press.

Cuenca, M. J. (2000): Comentario de textos: Los mecanismos referenciales. Madrid, Arco/Libros.

Cuenca, Ma J. (2007): La sintaxi. Barcelona, UOC.

Dik, S. C. (1997): The theory of Functional Grammar. Part I: The structure of the clause. Berlin/New York, Mouton de Gruyter.

Escandell, M. V. (2004): Fundamentos de semántica composicional. Barcelona, Ariel.

Escavy, R. (1987): El pronombre. Categorías y funciones pronominales en la teoría gramatical. Murcia, Secretariado de Publicaciones de la Universidad de Murcia.

Escavy, R. (1999): "La anáfora asociativa como mecanismo de cohesión textual", Revista de Investigación Lingüística, 2 (2), págs. 111-128.

Fernández Leborans, M. J. (1999): "La predicación: Las oraciones copulativas". En Bosque, I. y V. Demonte (dirs.): Gramática descriptiva de la lengua española. Madrid, Espasa-Calpe, págs. 2357-2460.

Fernández Ramírez, S. (1951/1987): Gramática española. 3.2. El pronombre. Madrid, Arco Libros.

Figueras, C. (2002): "La jerarquía de la accesibilidad de las expresiones referenciales en español", Revista Española de Lingüística, 32 (1), págs. 53-96.

Flowerdew, J. (2003): "Signalling nouns in discourse", English for Specific Purposes, 22 (4), págs. 329-346.

Francis, G. (1994): "Labelling discourse: An aspect of nominal-group lexical cohesion". En Coulthard, M. (ed.): Advances in Written Text Analysis. London, Routledge, págs. 83-101. 
Fuentes, C. (1991): "El pronombre: dimensión enunciativa", Estudios de Lingüística de la Universidad de Alicante, 7, págs. 159-173.

Garnham, A. (2001): Mental models and the interpretation of anaphora. Hove, Psychology Press.

Garrido, J. (2011): "Unidades y relaciones en la construcción del discurso". En Actas del IX Congreso de Lingüística General. Valladolid, Universidad de Valladolid, págs. 976-990.

González Ruiz, R. (2009): "Algunas notas en torno a un mecanismo de cohesión textual: La anáfora conceptual". En Penas, M. A. y R. González (eds.): Estudios sobre el texto. Nuevos enfoques y propuestas. Frankfurt am Main, Peter Lang, págs. 247-278.

Grinder, J. y P. M. Postal (1971): "Missing antecedents", Linguistic Inquiry, 2 (3), págs. 269-312.

Halliday, M. A. K. y R. Hasan (1976): Cohesion in English. London, Longman.

Hawkins, J. (1978): Definiteness and indefiniteness: A study in reference and grammaticality prediction. London, Croom Helm.

Hegarty, M. (2003): "Semantic types of abstract entities", Lingua, 113, págs. 891-927.

Ivanič, R. (1991): "Nouns in search of a context: A study of nouns with both open-and closed-system characteristics", International Review of Applied Linguistics in Language Teaching, 29 (2), págs. 93-114.

Izquierdo, D. y R. González Ruiz (en prensa): "La evaluación a través de etiquetas discursivas en un género de opinión: análisis de un corpus de editoriales de $\mathrm{ABC}$ y El País". En C. Llamas Saíz, C. Martínez Pasamar y M. Casado Velarde (eds.) Léxico y argumentación en el discurso público. Frankfurt, Peter Lang.

Johnson-Laird, P. N. (1980): "Mental Models in Cognitive Science", Cognitive Science, 4, págs. 71-115.

Kleiber, G. (1990a): "Article défini et démonstatif: Approche sémantique versus approche cognitive (une réponse à Walter de Mulder)". En Kleiber, G. y J. Tyvaert (eds.): L'anaphore et ses domaines. Paris, Klincksieck, págs. 199-227.

Kleiber, G. (1990b): "Quand il n'a pas d'antécédent", Langages, 97, págs. 24-50.

Kleiber, G. (2001): L'anaphore associative. Paris, Presses Universitaires de France.

Langacker, R. W. (1987): "Nouns and verbs", Language, 63 (1), págs. 53-94.

Langacker, R. W. (1991/2002): Concept, image, and symbol: The cognitive basis of grammar. Berlin/New York, Walter de Gruyter.

Langacker, R. W. (1991): Foundations of Cognitive Grammar. Descriptive Application. Stanford, Stanford University Press.

Langacker, R. W. (2000): "Estructura de la cláusula en la gramática cognoscitiva", Revista Española de Lingüística Aplicada, Extra 1, págs. 19-65. 
Langacker, R. W. (2008): Cognitive grammar: A basic introduction. New York, Oxford University Press.

Leonetti, M. (1999): "La subordinación sustantiva: Las subordinadas enunciativas en los complementos nominales". En Bosque, I. y V. Demonte (dirs.): Gramática descriptiva de la lengua española. Madrid, Espasa, págs. 2083-2104.

Llamas, C. (2010): "Interpretación del discurso ajeno: La anáfora conceptual metafórica en la noticia periodística", Revista de Investigación Lingüística, 13, págs. 107-126.

López Samaniego, A. (2011): La categorización de entidades del discurso en la escritura profesional. Las etiquetas discursivas como mecanismo de cohesión léxica. Universitat de Barcelona. Tesis doctoral: http://www.tdx.cat/handle/10803/48757 (16-112012).

López Samaniego, A. (en prensa): "Etiquetas discursivas, hiperónimos y encapsuladores: una propuesta de clasificación de las relaciones de cohesión anafórica", RILCE.

López Samaniego, A. (en prensa b): Las etiquetas discursivas: cohesión anafórica y categorización de entidades del discurso. Pamplona, EUNSA.

Lyons, J. (1977): Semántica. Barcelona, Teide, 1980.

Maillard, M. (1974): "Essai de typologie des substituts diaphoriques", Langue Française, 21, págs. 55-71.

Mederos, H. (1988): Procedimientos de cohesión en el español actual. Santa Cruz de Tenerife, Publicaciones Científicas del Excelentísimo Cabildo Insular de Tenerife.

Méndez, E. (2003): "Nominalización y tipo de texto". En Girón Alconchel, J. L. et al. (eds.): Estudios ofrecidos al profesor José Jesús de Bustos Tovar. Madrid, Universidad Complutense de Madrid, págs. 1015-1031.

Mitkov, R. (2002): Anaphora resolution. New York, Longman.

Peña Martínez, G. (2004): "La anáfora lexical y el discurso de divulgación científica: aproximación contrastiva". En López Carrillo, R. y J. Suso (eds.): Congrès International de Linguistique Française, vol. I, Granada, págs. 783-794.

Picallo, M. C. (1999): "La estructura del sintagma nominal: Las nominalizaciones y otros sustantivos con complementos argumentales" En Bosque, I. y V. Demonte (dirs.): Gramática Descriptiva de la Lengua Española. Madrid, Espasa Calpe, págs. 363-393.

Real Academia Española y Asociación de Academias de la Lengua Española (RAE y AALE) (2009): Nueva gramática de la lengua española. Madrid, Espasa-Calpe.

Reboul, A. (1997): "Combien y at-il de poulets ici? Les référents évolutifs, identité et désignation". En Kleiber, G. et al. (eds.): La continuité référentielle. Paris, Klinsieck, págs. 149-179.

Ribera, J. (2008): La cohesió lèxica en seqüències narratives. Servei de Publicacions de la Universitat de València. Tesis doctoral.

Schmid, H. (1998): "Constant and ephemeral hypostatization: Thing, problem and 
other 'shell nouns'". En Caron, B. (eds.): Proceedings of the 16th International Congress of Linguists (Paris, July 20-25, 1997). Oxford, Pergamon.

Schmid, H. (1999a): "Cognitive effects of shell nouns". En Van Hoek, K., A. A. Kibrik y L. Noordman (eds.): Discourse studies in cognitive linguistics: selected papers from the fifth International Cognitive Linguistics Conference. Amsterdam/Philadelphia, John Benjamins, págs. 111-132.

Schmid, H. (1999b): "Towards a functional-cognitive lexicology of nouns". En Falkner, W. y H. J. Schmid (eds.): Words, lexemes, concepts, approaches to the lexicon: studies in honour of Leonhard Lipka. Tübingen, Gunter Narr Verlag, págs. 219-226.

Schmid, H. (2000): English abstract nouns as conceptual shells: From corpus to cognition. Berlin-New York, Walter de Gruyter.

Schwarz-Friesel, M. (2007): "Indirect anaphora in text: A cognitive account". En Schwarz-Friesel, M., M. Consten y M. Knees (eds.): Anaphors in text: cognitive, formal and applied approaches to anaphoric reference. Amsterdam/Philadelphia, John Benjamins, págs. 3-20.

Sinclair, J. M. (1993): "Written discourse structure". En Sinclair, J. M., M. Hoey y G. Fox (eds.): Techniques of description: Spoken and Written Discourse. London / New York, Routledge, págs. 6-31.

Tamayo, F. J. (2000-2001): "El grupo nominal como estructura predicativa", Pragmalingüística, 8-9, págs. 297-312.

Vendler, Z. (1968): Adjectives and nominalizations. The Hague/Paris, Mouton.

Vivero García, M. D. (1997): "La anáfora desde una perspectiva textual". En Homenaje al Prof. J. Cantera. Madrid, Servicio de Publicaciones de la Universidad Complutense, págs. 533-544.

Webber, B., J. Joshi, M. Stone y A. Knot (2003): "Anaphora and Discourse Structure", Computational Linguistics, 29/4, págs. 545-587.

Winter, E. O. (1992): "The notion of unspecific versus specific as one way of analysing the information of a fund-raising letter". En Mann, W. C. y S. A. Thompson (eds.): Discourse description: diverse linguistic analyses of a fund-raising text. AmsterdamPhiladelphia, John Benjamins, págs. 131-170. 



\title{
REDES POLISÉMICAS Y NIVELES DE INTERPRETACIÓN. REPRESENTACIÓN SEMÁNTICA DE UNIDADES LINGÜÍSTICAS COMPLEJAS: EL CASO DE VAMOS
}

\author{
FERnANDO POLANCO MARTíneZ \\ Universidad de Barcelona \\ polanco@ub.edu
}

Resumen

La polifuncionalidad de marcadores funcionalmente complejos como vamos no se reduce a la mera variación contextual a partir de un único significado invariante, sino que revela, más bien, su naturaleza heterosémica, esto es, polisémica y policategorial. Estos elementos complejos presentan más de un significado convencional asociado a determinadas funciones discursivo-interactivas con rasgos gramaticales y semántico-pragmáticos estables diferenciados, así como varios sentidos contextuales con distinto grado de prominencia derivados de la interacción de los significados codificados con determinados contextos. Por ello, para el tratamiento semántico-funcional de esta unidad discursiva, en este trabajo proponemos un modelo polisémico radial (Lakoff, 1987; Hansen, 2005; Evans, 2004, 2006). Creemos que un modelo polisémico de este tipo permite describir y explicar adecuadamente (i) la variabilidad categorial, semántica y funcional de unidades discursivas complejas como vamos; (ii) los vínculos que existen entre los distintos usos de estas unidades; y, en definitiva, (iii) la estructura gramático-funcional subyacente de estos elementos.

PALABRAS CLAVE: Marcadores del discurso, Partículas discursivas, Pragmática, Semántica cognitiva, Gramática interaccional.
Abstract

The polifunctionality of complex discoursive markers like Spanish conversational particle vamos can not be reduced to contextual variation from a single invariant meaning. It reveals, rather, the heterosemic nature of this linguistic unit, that is, polysemous and polycategorial character. These kind of complex units present more than one conventional meaning linked to particular discoursiveinteractive functions whith stable grammatical, semantic and pragmatic treats, as well as several contextual senses with degrees of cognitive prominence derived from interaction of coded meanings with particular contexts. Because of that, for treating the semantics of this linguistic unit, in this paper we propose a model of polysemy network (Lakoff, 1987; Hansen, 2005; Evans, 2004, 2006). We hold that such a model allows to adequately describe and explain (i) the categorial, semantic and functional variability of complex linguistic units like vamos; (ii) the ties between the different uses of these kind of units; and (iii), in short, the grammatical and functional structure underlying them.

KEY WORDS: Discourse markers, Discoursive particles, Pragmatics, Cognitive Semantics, Interactional Grammar. 


\section{Introducción}

La expansión funcional que caracteriza a muchos marcadores discursivos, especialmente a los llamados marcadores conversacionales (Martín Zorraquino y Portolés, 1999), suele ir acompañada también de una consecuente ampliación de los valores semánticos de estas unidades. La casuística semántico-funcional de estos elementos es variada y supone generalmente un reto especificar la relación entre sus distintos usos y los valores semánticos derivados. El caso de vamos no constituye una excepción y representa un buen ejemplo de lo anterior:

(1) O sea, en su momento, hubo tesis por las cuales el segundo canal iba a ser un canal que se podría haber financiado sin publicidad, vamos a costa del presupuesto, [...]. (CREA; Debate: las nuevas televisiones, 10/12/87, TVE 1)

(2) (...) luego viene Daniel, que Daniel es muy curioso $<$ PAUSE $>$ bueno, tiene catorce años, es el pequeño de los niños, pero tiene un espabile encima, vamos, que ese sí que no parece que tiene catorce años porque es demasiado espabilado, se pasa de rosca, pero es supergracioso, nos partimos con él. (CREA; Entrevista CSC008, mujer, 20 años)

(3) [...] es que bueno, por no hacer muy extensiva la intervención en cuanto a los grupos, vamos, en cuanto a los factores de riesgo. (CREA; Debate: El Sida, 23/04/87, TVE 1)

(4) y el de la autoescuela le dice pero tío pero ¿¡de qué vas \!? ¿¡tú estás loco!?/ ¿cómo te vas-? si acabas de empeZAAR $\downarrow$ no has venío ningún día a clase/ vamos o s(e)a// yo si quieres yo te apunto// tú eres el que vas a tener QUE PAGAR/ que me apuntes $\downarrow$ que me apuntes $\downarrow$ que me apuntes $\downarrow$ que me apuntes $\downarrow$ es cantidad de cabezón $\downarrow$ que me apuntes $\downarrow$ total quee lo puso de tal forma que lo tuvo que apuntar// yy ¿cuándo fue eel-? sí $\downarrow$ el- el martes pasado $\downarrow$ creo que fue examen (Briz y grupo Val.Es.Co, 2002: 113 [L.15.A.2])

(5) A: ¿yy alguna fiesta del barrio?// ¿de cuando eras pequeña?

B: yo no he ido- no he sido muy de barrio (chasquido)// pero vamos recuerdo las Fallas sobre todo las Fallas// es cuando más yo/vamos cuando yo he trabaja(d)o más en eel- ¡uy! Perdón hee colabora(d)o o he esta(d)o así más en el barrio (...). (Preseval, [conv. 1, líneas 74-78]; http://www.uv.es/preseval/ppal.htm)

(6) Bueno, es decir, oye $<P A U S E>$ qué quieres, no sé. Dicen de que $<P A U S E>$ dicen Cruz y Raya de que yo hablo inseguro. Es que pienso que $<P A U S E>$ vamos, o sea, no estoy de acuerdo, pero $<$ PAUSE $>$ vamos, no sé, ¿no? O sea, yo creo $<P A U S E>$ yo que usted<PAUSE> vamos, no sé, ¿verdad, señor Gil?

(7) Pues venga, vamos, dale. (CREA; En una feria de barrio, Madrid, 08/08/91) 
(8) Yo también te buscaré algo, (...), solo falta que nos digas qué es... vamos, no te preocupes que seguro no le faltará nada. (http://www.foropadres.com/ viewtopic.php? $\mathrm{f}=90 \& \mathrm{t}=8102$ )

(9) A: ¿Te gusta (mostrando un vestido)?

B: ¡Vamos! Te va a quedar estupendo.

(10) www.elmundo.es/elmundo/2009/05/28/catalejo/1243510544.html por su_r00t el 28-05-2009 13: 51 UTC, publicado el 28-05-2009 15: 15 UTC

"Ha habido una tergiversación de los hechos teñidos de mentiras y falsedades", asegura un representante de la SGAE sobre el peculiar acceso -y registro según el afectado- a la casa de Juan José Coronel. La sociedad se remite al acta levantada por el juez que entró en la casa y asegura que "no se ha infringido la legalidad".

95 comentarios en: actualidad, sociedad karma: 774

etiquetas: sgae, juan josé coronel, registro, domicilio

negativos: usuarios: 464 anónimos: 604 compartir:

\#1 "No se ha infringido la legalidad".... anda, igual que con las descargas!!

votos: 86 , karma: 754

por perga el 28-05-2009 13: 53 UTC

\#12 Vamos no me jodas!!!! QUE LES DENUNCIE A LOS 5, (...).

por aitorbs el 28-05-2009 14:05 UTC

(http://meneame.net/story/sgae-ha-habido-tergiversacion-hechos)

Este marcador desarrolla funciones diversas relacionadas con la reformulación ${ }^{1}$ (13), la rearticulación ${ }^{2}(4-6)$ y la modalidad $^{3}(7-10)$. Las distintas lecturas que permiten los

\footnotetext{
${ }^{1}$ En este trabajo, aplicamos la etiqueta de reformulación a las operaciones de reformulación parafrástica que implican una relación variable de equivalencia conceptual entre el miembro reformulado y el miembro reformulador (Polanco, 2010). En cualquier caso, por reformular entendemos un volver a decir lo mismo de otra manera. Por ello, las operaciones discursivas que reflejan los ejemplos (4-6) no responden a lo que aquí entendemos por reformular, sino que implican un cambio en la dirección discursiva (4) o una operación continuativa no reformuladora (5-6).

${ }^{2}$ Tomamos el concepto de "rearticulación" de Luis Cortés y Ma Matilde Camacho (2005: 211-217). La rearticulación comprende funciones relacionadas con la reorganización y reparación discursivas de vamos (Polanco, 2010).

${ }^{3}$ En este trabajo, entendemos la modalidad como una función pragmática en sentido amplio, como concepto que engloba distintas funciones que sirven para expresar la actitud del hablante hacia la situación comunicativa, el interlocutor o el mensaje (propio y ajeno, explícito o implícito). Esta categoría agrupa valores pragmáticos como el acuerdo y el desacuerdo, el refuerzo, la matización, la faticidad y la expresividad. En algunos casos, estas funciones pragmáticas se asocian con valores convencionalizados, de modo que caen dentro de alguna de las categorías semánticas de la modalidad. En nues-
} 
ejemplos anteriores podrían achacarse a un caso de vaguedad semántica, esto es, a un enriquecimiento pragmático a partir de la interrelación del significado-función principal de vamos con el contexto. Y, de hecho, como expondremos en el apartado siguiente, esta es la consideración semántico-funcional que ha recibido generalmente este marcador. Sin embargo, si bien el recurso a un significado invariante permite explicar bien las funciones equifuncionales - por ejemplo, las funciones discursivo-textuales de reformulación y rearticulación (ejemplos 1-7) -, no parece tan evidente que esta perspectiva se aplique adecuadamente a todos los usos sincrónicos de este elemento discursivo.

En nuestra opinión, la polifuncionalidad de vamos no se reduce a la mera variación contextual a partir de una función predominante (o, lo que es igual, un único significado invariante). Más bien revela que este elemento discursivo es polisémico y presenta (i) más de un significado convencional asociado a determinadas funciones discursivointeractivas con rasgos gramaticales y semántico-pragmáticos estables diferenciados y (ii) varios sentidos contextuales con distinto grado de prominencia derivados de la interacción de los significados codificados con determinados contextos. Por ello, en este trabajo proponemos un modelo polisémico radial (Lakoff, 1987; Hansen, 2005; Evans, 2004, 2006) para el tratamiento semántico-funcional de esta unidad discursiva. Creemos que un modelo polisémico de este tipo permite describir y explicar adecuadamente (i) la variabilidad categorial, semántica y funcional de unidades discursivas complejas como vamos; (ii) los vínculos que existen entre los distintos usos de estas unidades; $y$, en definitiva, (iii) la estructura gramático-funcional subyacente de estos elementos.

En los siguientes apartados, exponemos las limitaciones que plantea un enfoque homonímico o monosémico para el tratamiento semántico de vamos (2.1. y 2.2., respectivamente), así como las ventajas que aporta una consideración polisémica de este elemento discursivo (2.3.). En el aparado 3, abordaremos la configuración del modelo polisémico que proponemos en este trabajo. Y, por último, en el apartado 4 se determinarán los sentidos codificados que conforman la red semántica de vamos.

\section{Variación funcional y representación semántica: ¿polifuncionalidad y/o polisemia?}

La variación semántica de los marcadores discursivos puede tratarse, fundamentalmente, desde tres enfoques metodológicos (Hansen, 1998a: 85 y ss.; 1998b): (i) una postura maximalista u homonímica, (ii) una postura minimalista o monosémica o (iii)

tro caso, como veremos en el apartado 4, las funciones conativa y fática de vamos convencionalizan valores semánticos relacionados con la modalidad deóntica. 
una postura polisémica. La visión homonímica trata la variación interpretativa como parte del contenido semántico de las palabras y representa esta variación mediante distintos sentidos no relacionados en el lexicón (una forma, más de un significado). En cambio, la perspectiva monosémica concibe el significado de una palabra como una constante de naturaleza abstracta (subespecificada) que cobra vida en el uso y que deriva distintas interpretaciones en función del contexto y de la situación comunicativa (una forma, un significado). La perspectiva polisémica, por el contrario, asume que el componente semántico de un elemento lingüístico puede estar constituido por varios sentidos convencionales relacionados, bien por medio de un componente semántico común (Wierzbicka, 1996; Travis, 2005), bien mediante una relación de encadenamiento a partir de relaciones de semejanza de familia o a través de la extensión desde un prototipo (Lakoff, 1987; Hansen, 1998b, 2005; Croft y Cruse, 2004; Evans, 2004, 2005).

\subsection{Homonimia}

La definición tradicional de homonimia establece que una misma forma léxica comparte más de un significado no relacionado (al menos, en el nivel sincrónico), en oposición al criterio clásico de polisemia, según el cual una forma léxica posee dos o más significados relacionados (Lyons, 1977: 550). No obstante, la línea que separa la homonimia de la polisemia es, a veces, poco nítida, y depende teóricamente de la aplicación de una perspectiva de análisis sincrónica o diacrónica (Croft y Cruse, 2004: 111). Así ocurre, por ejemplo, con las palabras banco o gato, que codifican significados como entidad financiera y asiento, y animal y herramienta, respectivamente. Estos significados pueden entenderse como significados independientes no relacionados entre sí, asociados a dos entradas en el lexicón, en cuyo caso se conciben como formas homónimas. No obstante, también podría hablarse de polisemia si se propone que existe una vinculación semántica entre ambos significados, ya sea mediante un componente semántico común ${ }^{4}$ (perspectiva sincrónica), ya sea por medio de una vinculación metafóricometonímica (perspectiva diacrónica).

\footnotetext{
${ }^{4}$ Dentro del marco teórico del Metalenguaje Semántico Natural, por ejemplo, la diferencia entre homonimia y polisemia se fundamenta en la noción de significado invariante compartido. En este sentido, las definiciones de un elemento polisémico deben compartir un núcleo semántico (una invariante semántica) o una invariante semántica parcial, parcial en tanto que esta invariante no da cuenta por sí misma de todo el significado, pero invariante porque está presente en todos los usos del lexema (Wierzbicka, 1988, 1996; Travis, 2005). Por tanto, allí donde no haya una invariante semántica parcial habrá homonimia.
} 
Asimismo, según el criterio clásico, la relación semántica entre formas léxicas homógrafas o derivadas pertenecientes a clases gramaticales distintas debería imputarse a un caso de homonimia. Desde este punto de vista, vamos podría considerarse un ejemplo de homonimia, ya que presenta, como se verá en el apartado 4 , un comportamiento gramatical divergente que permite su clasificación en tres posibles categorías: verbo, interjección y conector parentético ${ }^{5}$. Sin embargo, esta consideración semántica desestima el hecho de que la relación entre sentidos puede extenderse más allá de los límites categoriales entre lexemas, como parecen demostrar algunos estudios dentro del marco teórico de la semántica cognitiva (Brugman, 1988) o que aplican esta perspectiva teórica al estudio de los marcadores discursivos (Hansen, 1998b, 2005; Waltereit, 2006). En este sentido, siempre que pueda establecerse un punto de contacto entre los distintos significados que expresa una forma lingüística, aunque estos significados se asocien a categorías gramaticales diferentes de una misma forma (como en el caso de formas como bueno, vamos o vaya, por ejemplo), creemos que es preferible desestimar la opción de la homonimia y establecer una explicación más coherente con la estructura semántica subyacente. Al cabo, los hablantes pueden percibir que los diferentes usos de una palabra están relacionados de alguna manera, aunque no sean capaces de establecer cuál es el vínculo exacto que los une (es decir, aunque las relaciones semánticas entre las distintas lecturas no sean apriorísticamente transparentes).

El enfoque homonímico, en nuestra opinión, no tiene en cuenta la relación semántica que existe frecuentemente entre los distintos sentidos homónimos, tal como demuestran algunos estudios diacrónicos sobre marcadores discursivos (Brinton, 1996; Traugott, 1997; Traugott y Dasher, 2002; Waltereit, 2006). Obvia, igualmente, que la relación entre los sentidos de una forma léxica, sujeta generalmente a un proceso de evolución y reinterpretación, o fruto de este proceso, puede establecerse a partir de parecidos de familia (Hansen, 1998b, 2005, 2006). Por ello, no parece una opción semántica adecuada para explicar los distintos sentidos de unidades complejas como vamos.

\footnotetext{
5 Tomamos la etiqueta categorial de conector parentético de Cuenca $(2001,2002)$. Según esta autora, buena parte de los denominados conectores discursivos (Pons, 1998; Montolío, 2001) presenta un comportamiento sintáctico-funcional bastante homogéneo a pesar de su diversidad formal, lo cual permite proponer una caracterización de estos elementos como clase de palabras diferenciada. En este sentido, el vamos reformulador y rearticulador presenta características gramaticales y funcionales comunes con los conectores parentéticos de Cuenca.
} 


\subsection{Monosemia}

Desde una perspectiva monosémica, como se ha apuntado antes, se atribuye una relación de uno a uno entre la forma lingüística y el significado asociado a esta (en el caso de los marcadores discursivos, generalmente entre su función principal y un sentido vinculado con ella). Un marcador, por tanto, codifica un significado invariante abstracto, del que los sentidos derivados son interpretaciones enriquecidas contextualmente. La vaguedad semántico-funcional (la polisemia funcional) se resuelve, pues, pragmáticamente.

En el caso de vamos, son varios los autores que han atribuido a este marcador una función primaria relacionada con la (re)formulación y/o con la modalidad enunciativa, funciones que se asocian con el significado del marcador. Así, por ejemplo, en relación con la función reformuladora, Briz $(1993,1998)$ incluye a vamos entre los marcadores metadiscursivos reformuladores, como atenuador explicativo que introduce un segmento discursivo que "precisa lo anterior, que reformula o concluye un proceso de argumentación precedente" (1998: 223, nota 35) 6 . Asimismo, Portolés (2001: 143) atribuye a vamos un valor reformulador recapitulativo que introduce una conclusión o recapitulación a partir de un segmento anterior. Por último, Cortés y Camacho (2005: 219) asignan a vamos una función primaria reformulativa como marcador textual de progresión temática que contribuye al desarrollo del tópico discursivo, encadenando las diferentes unidades discursivas que conforman el texto (actúa, pues, como un marcador conectivo cohesionador [2005: 192]).

En cuanto a la función modal de vamos, Fuentes (1998: 178) define el valor principal de este marcador como Es lo que yo quiero decir, valor que aúna su función reformuladora con la subjetividad enunciativa del hablante 7 . Por su parte, Martín Zorraquino (1999: 4177-4180) clasifica a vamos entre los marcadores enfocadores de la alteridad al considerar que su función primaria es reforzar la imagen positiva del hablante, ya que favorece "la comunión, con su propio discurso, de los participantes en la conversación,

\footnotetext{
${ }^{6} \mathrm{Al}$ actuar como atenuador, cabría pensar que vamos asume un valor modal primario que comparece con el valor metadiscursivo reformulador, en la línea de Fuentes (1998), aunque no queda especificado por el autor.

${ }^{7}$ Fuentes asigna a vamos un valor modal de énfasis en la subjetividad, es decir, de refuerzo del acto de habla, que coactúa con la función reformuladora. Para esta autora, la perspectiva discursiva del hablante se intensifica mediante el uso del marcador, que comunica tanto la intención de volver a decir de otra forma o de focalizar ciertos argumentos (función metadiscursiva) como la actitud del hablante respecto de su propia enunciación (función modal).
} 
al incluirlos en la misma esfera enunciativa, a través de la primera persona verbal que la partícula contiene" (1999: 4178). Finalmente, Chodorowska-Pilch (1999) otorga a este valor de cortesía de vamos la misma relevancia funcional, considerándolo el valor definitorio de este elemento ${ }^{8}$.

Esta postura metodológica permite, en principio, abordar la variación y la representación semántico-funcional de forma aparentemente económica y no redundante. Con todo, en nuestra opinión, presenta ciertas desventajas para el tratamiento de muchos marcadores gramaticalizados o en vías de gramaticalización como el que nos ocupa porque:

(i) se desestima (o queda sin explicar) el proceso de expansión semántica que experimenta una misma forma, es decir, cómo se origina el significado instruccional del marcador;

(ii) no permite explicar la relación entre los usos discursivos (conectivos y no conectivos) y los no discursivos (valores oracionales e interjectivos, entre otros), teniendo en cuenta que la mayoría de los MD son fruto de un proceso de gramaticalización desde usos léxicos;

(iii) no se explica cómo se desarrollan las distintas lecturas de un marcador, es decir, qué factores intervienen en la derivación de las posibles interpretaciones de un marcador y por qué se derivan esas lecturas y no otras;

(iv) no da cuenta de los distintos grados de prominencia de los diferentes sentidos que puede activar una misma unidad lingüística en contexto, esto es, de los diferentes grados de prototipicidad semántica;

(v) no permite especificar semánticamente las diferencias entre los distintos marcadores de una misma (sub)clase funcional con idéntico cometido pragmático9.

Incluso asumiendo que fuera posible encontrar una invariante de significado para vamos que permitiera subsumir todos sus usos sincrónicos, como se propone para otras

\footnotetext{
${ }^{8}$ Esta autora afirma que el marcador vamos funciona principalmente como un marcador discursivo interpersonal y no como una estrategia para expresar una nueva formulación.

${ }^{9}$ Los marcadores discursivos, especialmente los marcadores gramaticalizados, son unidades polivalentes que pueden funcionar en distintos niveles del discurso. Sin embargo, cada marcador actúa en el contexto conversacional con un valor determinado (principal o más saliente), que viene dado por su "naturaleza léxica, su emplazamiento sintagmático y, en correlación con éste, su naturaleza, su entorno prosódico” (Briz, 1998: 221).
} 
unidades lingüísticas polifuncionales desde otros modelos teóricos ${ }^{10}$, quedaría abierta la cuestión del alcance de ese significado básico y de la plausibilidad y rentabilidad psicolingüísticas de una generalización semántica de ese tipo. Por un lado, cabe preguntarse si dicho significado básico engloba todos los posibles y heterogéneos usos de esta forma lingüística, o solo los distintos usos equifuncionales (a saber, el verbal, el interjectivo y el discursivo). Y, por otro lado, plantea la cuestión de si los usuarios de una lengua generalizan realmente al máximo en la interpretación de unidades discursivas de este tipo (es decir, si deducen los sentidos puntuales a partir de un significado sumamente esquemático en función del contexto) ${ }^{11}$. $\mathrm{O}$ si algunas de estas interpretaciones con una frecuencia elevada presentan un grado de autonomía y de saliencia suficientes que permite considerarlas como significados independientes y fácilmente accesibles en la memoria discursiva del hablante, posibilidad interpretativa esta que reduciría considerablemente el coste cognitivo en la interpretación.

En cualquier caso, la posibilidad de encontrar invariantes semánticas, cuando esto es posible, no representa, en nuestra opinión, un argumento decisivo contra la representación polisémica de la variación funcional, dado que no impide: (i) reconocer la posibilidad, en el plano sincrónico, de establecer más de un significado básico a partir del que

\footnotetext{
${ }^{10}$ Algunas propuestas teóricas abordan la relación entre los distintos sentidos de un marcador como resultado de la interacción de un significado invariante con determinados factores contextuales que seleccionan el respectivo significado contextual. De esta manera se intenta dar cuenta de los mecanismos que intervienen en la desambiguación semántica de estos elementos. Estos mecanismos restrictores pueden consistir en principios generales de interpretación, como el Principio de Relevancia (Blakemore, 1987, 2002; Montolío, 1998, 2001; Portolés, 1998, 2001; Archakis, 2001; Murillo, 2000, 2003); en un sistema de parámetros pragmáticos que selecciona el respectivo significado contextual (Sweetser 1990; Redeker, 1991, 2006); en la referencia a un dominio comunicativo, entendido este como dominio cognitivo (Fischer, 2000a, 2000b, 2006a, 2006b, 2010) o función pragmática (Pons, 1998a, 2006) al que atienden los hablantes en función de la situación comunicativa y de la relación entre los interlocutores (por ejemplo, la gestión del habla, la retroalimentación comunicativa o la gestión de los turnos de habla); o en un contexto estructural y semántico particular que determina la lectura puntual del marcador (Nemo, 2002, 2006). Con todo, pese a que con estos enfoques metodológicos se establecen mecanismos estructurales, pragmáticos y cognitivos que permiten restringir las distintas interpretaciones contextuales de un marcador, sigue sin resolverse en qué medida dichas interpretaciones son meramente contextuales (pese a que, en muchos casos, esta parece una opción contraintuitiva) o presentan grados distintos de autonomía que permiten distinciones semánticas pertinentes y motivadas.

${ }^{11}$ Esta objeción apunta a lo que Croft (1998: 156 y ss.) denomina falacia de la generalidad (the generallity fallacy), que consiste en identificar la capacidad del lingüista para establecer una invariante semántica con la manera como los hablantes interpretan el significado en contexto. En principio, que un analista pueda aislar un componente de significado presumiblemente común a todos los usos de una forma lingüística no implica que los hablantes actúen del mismo modo.
} 
se derivan determinados sentidos contextuales; (ii) asumir, desde una perspectiva diacrónica, que los sentidos sincrónicos derivan de algún sentido anterior, que puede seguir activo o no en la actualidad y que no tiene por qué ser el sentido más representativo para el hablante, ni necesariamente el sentido básico; y (iii) concebir la organización del conocimiento que tiene el hablante de estas unidades como una red compleja de sentidos relacionados entre sí, esto es, como un complejo semántico estructurado.

\subsection{El modelo polisémico cognitivo}

Como hemos apuntado anteriormente, la polifuncionalidad de marcadores complejos como vamos no se reduce a la mera variación contextual a partir de un único significado invariante, sino que revela la naturaleza heterosémica ${ }^{12}$ de este elemento discursivo, esto es, su carácter polisémico y policategorial.

Visto desde la perspectiva de la Semántica Cognitiva, la polisemia no exige que los diferentes sentidos relacionados compartan un significado nuclear en todas sus posibles acepciones; esto puede ser más o menos evidente en algunos casos, pero no es imprescindible. Los distintos sentidos de una misma forma léxica pueden estar estructurados en forma de red, mediante una relación de semejanza de familia, de modo que un sentido puede estar relacionado solo con otro de los sentidos de la estructura y no con todos ellos (Lakoff, 1987; Taylor, 1995; Evans, 2005). Lo que mantiene la estructura es el encadenamiento de sentidos que conforman la estructura conceptual radial, no un núcleo semántico compartido que vertebra toda la estructura.

En nuestra opinión, con un modelo polisémico de tipo radial se pueden modelar adecuadamente las relaciones de solidaridad formal y semántico-pragmáticas que existen entre los distintos valores funcionales de unidades lingüísticas complejas como vamos. Un modelo de este tipo permite:

(i) dar cuenta del carácter evolutivo gradual de la mayoría de los MD: ciertos sentidos surgen a partir de sentidos ya existentes, lo cual condiciona el contenido semántico de los nuevos valores y establece determinadas pautas para la ampliación funcional;

\footnotetext{
${ }^{12}$ Tomamos el concepto de heterosemia de Frantisek Lichtenberk, quien utiliza este término para referirse a casos en los que dos o más significados o funciones "that are historically related, in the sense of deriving from the same ultimate source, are borne by reflexes of the common source element that belong in different morphosyntactic categories" (1991: 475).
} 
(ii) representar de manera coherente la relación semántica motivada que existe entre las distintas funciones que desarrolla una misma forma intercategorialmente (en el caso de vamos, por ejemplo, las funciones verbal, interjectiva y discursiva) e intracategorialmente (en el caso de vamos, como MD, funciones relacionadas con la (re)formulación, la estructuración conversacional y el refuerzo argumentativo; como interjección, funciones relacionadas con la relación interpersonal, la modalidad, etc.);

(iii) relacionado con el punto (i), representar la variación semántica de estos elementos como una estructura compleja con distintos grados de prototipicidad.

Al introducir el punto de vista evolutivo a la descripción sincrónica, puede explicarse de forma coherente la emergencia motivada de nuevos valores a partir de los ya existentes, esto es, el surgimiento de nuevos significados como extensiones metafóricas y/o metonímicas graduales de significados anteriores (Hansen, 2006; Waltereit, 2006). Como muestra la figura 1 , los nuevos significados convencionalizados pueden convertirse, a su vez, en generadores de implicaturas que se reinterpretan contextualmente, se generalizan y acaban afianzándose, produciendo así un nuevo ciclo de extensiones semánticas.

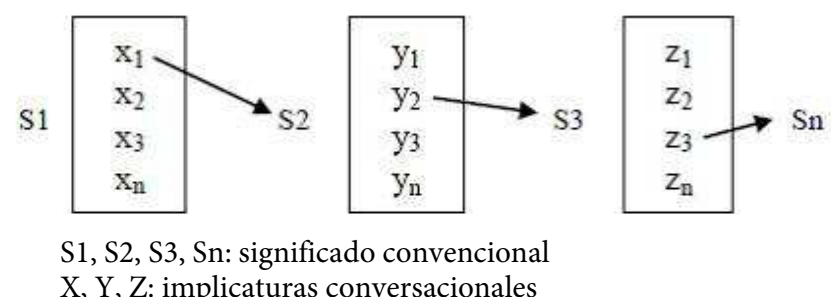

Figura 1. Ciclo de extensión semántico-funcional

La ampliación y especialización funcional conlleva cambios en las propiedades formales (por ejemplo, la pérdida de independencia estructural y comunicativa) y semántico-pragmáticas que dan lugar a traspasos categoriales, y favorece la creación de nuevos nódulos o espacios categoriales en la red compleja que conforma toda unidad lingüística (del rango que sea). En este sentido, un enfoque polisémico permite tratar casos como el de vamos como categorías complejas (o radiales [Lakoff, 1987]) con una estructura interna compuesta de diversos sentidos, entendidos estos como estructuras con unas determinadas características formales, semánticas y pragmáticas. 
El uso e interpretación de vamos, como el de las estructuras lingüísticas en general, tiene mucho que ver con el conocimiento metalingüístico y metapragmático ${ }^{13}$ que poseen de ellas los hablantes (lo que en este trabajo denominamos marco de interpretación). Buena parte de este conocimiento es convencional (o posee un grado elevado de convencionalidad), esto es, forma parte de lo que un hablante sabe acerca del uso e interpretación de ciertas estructuras. Con todo, asumir que los distintos sentidos que puede desplegar un marcador complejo mantienen relaciones de parentesco entre sí no significa que todas las interpretaciones posibles en contexto deban atribuirse a significados codificados.

De hecho, una de las objeciones que suele hacerse al modelo de red polisémica es, precisamente, la descripción altamente granular del significado o análisis de especificación completa que se propone en algunos trabajos ${ }^{14}$. Una descripción semántica de este tipo es cuestionable porque no permite distinguir entre la información codificada por una expresión léxica y la información derivable del co(n)texto y la situación comunicativa ${ }^{15} ; y$, no menos importante, porque un análisis granular tan amplio no ofrece suficientes garantías de plausibilidad psicolingüística. Por ello, para evitar la falacia de la polisemia $^{16}$ (Sandra, 1998), es necesario aplicar criterios de análisis más restrictivos.

Una objeción similar puede hacerse a algunos estudios sobre marcadores discursivos realizados desde un enfoque polisémico cognitivo, como el propuesto por Hansen (2005) para el marcador francés enfin ${ }^{17}$. La autora analiza un total de 14 usos diferentes del marcador para los que propone una reducción de sentidos a tres centrales o prototípicos y once derivados o periféricos. Sin embargo, el problema de la arbitrariedad per-

\footnotetext{
${ }^{13}$ Sobre el concepto de conciencia metapragmática, véanse Verschueren $(2000,2002)$ y Portolés (2004). ${ }^{14}$ Los trabajos de Brugman (1988), Lakoff (1987) y Brugman y Lakoff (1988) son ejemplos paradigmáticos de este tipo de análisis semántico. Así, por ejemplo, en el estudio de Brugman y Lakoff (1988) sobre las preposiciones inglesas, llega a proponerse para la preposición over una red semántica compuesta por 24 sentidos distintos.

${ }^{15}$ Para algunas críticas a este tipo de análisis semántico, véanse, entre otros, Sandra (1998), Sandra y Rice (1995), Evans (2000), Boogart (2009).

${ }^{16}$ Una sobreespecificación semántica de este tipo, tan poco restrictiva, induce a pensar que la posibilidad de poder establecer un número relativamente alto de sentidos diferentes relacionados para un elemento léxico implica que el usuario de la lengua debe de representar el significado (o significados) de las palabras de esta forma. Sin embargo, como arguye Sandra (1998), este razonamiento puede considerarse falaz, ya que no necesariamente todo posible sentido de una palabra en contexto responde a un componente de significado independiente, incluso desde un acercamiento intuitivo al significado léxico.

${ }^{17}$ En este estudio, Hansen propone una red semántica de tipo radial de orientación evolutiva, inspirada en el modelo de prototipos de Geeraerts (1994).
} 
siste, ya que en la distribución entre sentidos centrales y periféricos no se aplica ningún criterio fundamentado que explique la distribución propuesta. No obstante, pese a que esta propuesta polisémica parece una mejor opción descriptiva para los marcadores discursivos que otras aproximaciones de corte monosémico y una alternativa metodológica mejor fundamentada que la propuesta polisémica de especificación completa que hemos comentado arriba, el trabajo de Hansen no deja de ser una aproximación intuitiva que no acaba de justificar la diferenciación entre los sentidos prototípicos como sentidos independientes (relacionados evolutivamente dentro de la red semántica) y los sentidos satélite (derivados contextualmente de los anteriores y, por tanto, no almacenados en el lexicón como sentidos independientes).

Sin obviar la subjetividad potencial a la que está expuesto cualquier análisis lingüístico (en definitiva, el analista es también un usuario más de alguna lengua), es necesario sustentar metodológicamente la descripción semántica de un elemento lingüístico con pautas de análisis falsables ${ }^{18}$. En este sentido, tal como propone Evans (2001: 727), es preciso desarrollar criterios que permitan, por un lado, distinguir los diferentes sentidos que conforman la red semántica de un elemento léxico; y por otro, determinar el o los sentidos centrales o primarios de ese elemento léxico. Por ello, para el establecimiento de la red semántica de vamos proponemos una adaptación del modelo polisémico propuesto por Andrea Tyler y Vyvyan Evans (2001, 2003), posteriormente implementado por Evans (2004), a saber, el Modelo de polisemia fundamentada (principled polyse$m y)$.

\section{El modelo de polisemia fundamentada ${ }^{19}$}

El Modelo de polisemia fundamentada (de ahora en adelante, MPF) ha sido desarrollado, principalmente, para el análisis semántico de categorías léxicas conceptuales. No

\footnotetext{
${ }^{18}$ Sandra y Rice (1995) arguyen que cualesquiera de los análisis de la estructura de red polisémica realizados hasta el momento, incluyendo el análisis del que pudiera constituir el sentido primario de la red semántica, es relativamente arbitrario, puesto que refleja las preferencias personales (cuando no la propia imaginación) del analista. Esta crítica se fundamenta en la ausencia de criterios delimitados y falsables que parece caracterizar los estudios cognitivos sobre la polisemia de algunas preposiciones inglesas, como el enfoque de especificación completa (full-specification approach) que aplica Lakoff (1987) al estudio de la preposición over, del que Sandra sostiene que "what is lacking from the exercise is a set of scientifically valid principles" (Sandra, 1998: 371).

${ }^{19}$ Para el desarrollo original de este modelo polisémico, véanse principalmente Tyler y Evans, 2001, 2003; Evans y Tyler, 2004a, 2004b; y Evans, 2004, 2005.
} 
obstante, creemos que es posible su implementación teórica en categorías gramáticofuncionales, como trataremos de demostrar con el análisis semántico de vamos.

Partiendo de la propuesta de Evans (2004, 2006), los principios fundamentales del MPF pueden resumirse en los siguientes puntos:

(i) Un lexema puede presentar, en el nivel sincrónico, cierto número de sentidos distintos almacenados de modo independiente en la memoria semántica, que se derivan históricamente de un primer sentido original.

(ii) En el nivel sincrónico, los distintos sentidos pueden analizarse como elementos relacionados dentro de una red semántica. Estos se organizan a partir un sentido básico o sancionador (sanctioning sense, Langacker [1987: 157]) que presenta típicamente (aunque no forzosamente) similitudes con el sentido diacrónicamente más temprano. El sentido sancionador se toma como sentido prototípico, ya que constituye el sentido de citación al que los hablantes recurrirán con más probabilidad en respuesta a la pregunta "¿qué significa la palabra X?"20. Con todo, como apunta Hansen (2005), hay que prever la posibilidad de que haya más de un significado básico (o sancionador) que sea igualmente prominente para los hablantes. De hecho, como se verá más adelante, esto es lo que parece ocurrir en el caso de vamos.

(iii) Los distintos sentidos de una forma léxica son, en definitiva, el resultado de un proceso dinámico de extensión semántica, pese a que es posible que los usuarios de una lengua no reconozcan con nitidez una relación sincrónica entre todos ellos. De hecho, modelar las relaciones entre sentidos en términos de una estructura radial permite identificar diferentes grados de parentesco, con miembros periféricos menos relacionados con el sentido sancionador que los miembros más centrales (Lakoff, 1987; Langacker, 1987; Tyler y Evans, 2003; Evans, 2004).

\footnotetext{
${ }^{20}$ No obstante, de aquí no se sigue que el sentido sancionador deba coincidir con el sentido más frecuente, tal como se desprende del uso de muchas palabras polisémicas cuyo(s) sentido(s) prototípi$\operatorname{co}(\mathrm{s})$ no coincide(n) con el sentido más utilizado estadísticamente, sino con el más relevante desde el punto de vista cognitivo; esto es, con el sentido más prominente y fácilmente reconocible. Piénsese, por ejemplo, en la expresión 'coño', cuyo sentido más prominente sea seguramente la manera vulgar de nombrar el órgano sexual femenino, aunque estadísticamente quizá sean más frecuentes los usos interjectivos relacionados con la expresión de sorpresa, rechazo, enfado, etc.
} 


\subsection{La configuración del modelo polisémico}

Para la configuración del modelo polisémico, partimos de la idea de que vamos constituye una unidad lingüística, esto es, un emparejamiento convencional de forma y sentido (Lakoff, 1987; Taylor, 2003; Tyler y Evans, 2003; Sandra y Rice, 1995).

El polo semántico de este emparejamiento se estructura en forma de una red semántica organizada en torno a un sentido básico o sancionador (o más de uno, si fuera el caso, tal como se ha apuntado antes) ${ }^{21}$, que no tiene por qué coincidir, en principio, con el sentido diacrónicamente más antiguo o sentido original (origination sense, Evans y Tyler [2004b]). No obstante, puesto que el primer significado más antiguo (diacrónicamente) puede continuar todavía activo en la red semántica sincrónica, el sentido original y el sentido básico (o uno de ellos) pueden solaparse, como ocurre en el caso de vamos (ver \$3.1.2.4). La propuesta de un sentido básico o sancionador se basa en el hecho de que los hablantes parecen categorizar intuitivamente los sentidos a partir de un prototipo léxico (Lakoff, 1987; Taylor, 2003; Evans y Green, 2005). La red semántica de una palabra puede organizarse a partir del sentido sancionador en forma de estructura radial, lo cual favorece la comprensión de grados de parentesco entre los distintos sentidos y permite dar cuenta de la apariencia de encadenamiento dentro de las categorías (Lakoff, 1987).

\footnotetext{
${ }^{21}$ Una forma léxica particular no tiene por qué partir necesariamente de un solo sentido sancionador a partir del cual los usuarios de la lengua categoricen todos los demás sentidos asociados con un elemento léxico (Sandra y Rice, 1995). En este sentido, la polisemia no se define necesariamente como un fenómeno estrictamente sincrónico en el que se mantiene una relación entre los distintos sentidos de una forma léxica dada, de la que los hablantes son plenamente conscientes. Sin embargo, esta es una cuestión para la que no parece haber aún suficiente evidencia empírica. Si, como arguyen Evans y Tyler (2004b), la evidencia experimental demostrara que los hablantes fallan sistemática y consistentemente a la hora de percibir la relación entre algunos sentidos, podría ponerse en tela de juicio la consideración de que el fenómeno de la polisemia constituye un fenómeno de naturaleza completamente sincrónica.

Por tanto, mientras sea plausible mantener que todos los sentidos de una determinada red semántica están relacionados diacrónicamente, en el lexicón habrá diferencias en el parentesco percibido entre distintos sentidos, debido a la rutinización y el afianzamiento (pragmatic strengthening), fenómenos que desdibujarían la motivación original para derivar sentidos nuevos desde otros preexistentes, como el sentido primario. Los diferentes procesos de cambio lingüístico provocan que no todos los sentidos asociados con una forma determinada puedan reconocerse como sincrónicamente relacionados. Es decir, aunque la extensión semántica esté muy motivada, puede dar lugar a una red semántica que el hablante (e, incluso, el analista) conciba como solo parcialmente motivada (Evans y Tyler, 2004b: 165 nota 9$)$.
} 
Asimismo, en relación con el análisis semántico que presentamos en este trabajo, es necesario hacer dos distinciones relevantes: por un lado, entre sentido central (o sentidos centrales, como veremos después) y sentido periférico (Hansen, 2005); por otro lado, entre sentido y elaboración de un sentido particular.

En el primer caso, entendemos por sentido central un sentido de la red semántica a partir del cual se organizan otros sentidos con distintos grados de afinidad semántica respecto de aquel. Estos sentidos más periféricos pueden ser extensiones semánticas del sentido central o extensiones de sentidos derivados del sentido central, de modo que los sentidos periféricos presentan distintos grados de prototipicidad, esto es, de alejamiento del centro categorial.

En cuanto a la segunda dicotomía, sentido frente a elaboración, un sentido constituye un significado distinto e identificable, mientras que una elaboración pertenece a la naturaleza del contenido semántico de un sentido afianzado particular (Evans, 2005). Es decir, tal como lo entendemos en este trabajo, una elaboración es el desarrollo contextual de un sentido afianzado.

\subsubsection{Determinación de los sentidos de la red semántica}

En este apartado, establecemos los criterios que se tendrán en cuenta para distinguir los significados codificados de los significados co(n)textuales y efectos de sentido derivados. Siguiendo a Evans $(2004,2005)$, se proponen tres criterios de análisis:

a) Criterio semántico (meaning criterion). Un sentido será diferente de otro si aporta un significado adicional que no esté ya presente en ningún otro sentido asociado con la estructura analizada. Este criterio se fundamenta en el supuesto de que un sentido será diferente de otro si presenta un significado distinto.

b) Criterio de elaboración semántica ${ }^{22}$ (concept elaboration criterion). Un nuevo sentido presentará patrones o esquemas de elaboración semántica únicos o claramente distintos; es decir, presentará distintas tendencias de selección semántica. Este criterio alude a los elementos léxicos que coaparecen en relación sintagmática o colocacional con el lexema analizado y atañe, por tanto, a la modificación cotextual de un sentido básico. En el caso que nos ocupa, también pueden establecerse tendencias de selección semántica, teniendo en cuenta que

\footnotetext{
${ }^{22}$ Utilizamos el término semántico en lugar de conceptual dadas las características semánticas del tipo de unidades lingüísticas que estamos tratando: codifican instrucciones de procesamiento o significado procedimental, no conceptual.
} 
algunas de las instrucciones de vamos se asocian a relaciones sintagmáticas prototípicas entre este elemento y ciertos actos de habla.

c) Criterio gramatical (gramatical criterion). Un nuevo sentido manifestará dependencias estructurales únicas o claramente diferenciadas. Este criterio concierne, pues, a las tendencias de selección formal o gramatical que determinan en qué construcciones gramaticales puede aparecer un lexema. Para que un sentido sea distinto, debe mostrar un comportamiento gramatical distintivo.

De los tres criterios expuestos, el más importante es, en principio, el criterio semántico, puesto que es el que permite distinguir sentidos diferenciados. No obstante, debido a la innegable influencia que ejerce el co(n)texto a la hora de identificar el uso particular de un sentido determinado, sería preciso tener en cuenta al menos alguno de los otros dos criterios. La razón, en definitiva, es ajustar al máximo los juicios de distintividad semántica por parte del analista, para evitar una proliferación innecesaria de sentidos que, en muchos casos, son explicables como resultado de inferencias (con distinto grado de activación) a partir del uso de un sentido básico en un contexto determinado ${ }^{23}$.

Los criterios anteriores tomados en conjunto permiten perfilar mejor la atribución de significados codificados dentro de la red semántica asociada con el lexema analizado. Asimismo, este modelo aporta la ventaja de que los criterios expuestos "offer a rigorous and relatively consistent (i.e. inter-subjective) methodology for assessing what counts as a diferent sense" (Evans, 2004: 43). En este sentido, creemos que suponen una pauta metodológica firme en la que fundamentar el análisis polisémico de elementos discursivos complejos como el que nos ocupa ${ }^{24}$.

\footnotetext{
${ }^{23}$ Para una revisión crítica, desde una perspectiva cognitivista, sobre la necesidad de acotar el número de sentidos asociados con una forma léxica determinada, véase Sandra y Rice (1995) y Tyler y Evans (2001).

${ }^{24}$ No obstante, no puede obviarse que determinar qué significados constituyen en realidad sentidos distintos de una forma léxica continúa siendo una cuestión empírica abierta - esta reserva atañe también, sin duda, a la plausibilidad del establecimiento de un único sentido invariante o básico-. Por otra parte, también debe considerarse el hecho de que la interpretación de significados diferentes no tiene por qué seguir una única vía de afianzamiento y estructuración en la memoria semántica, idéntica para todos los hablantes de una misma comunidad. En el caso de vamos, por ejemplo, puede ocurrir que algunos hablantes deriven significados contextualmente mientras que otros ya hayan convencionalizado esos mismos componentes de significado (dependerá, en buena medida, de la experiencia discursiva previa con elementos de estas características, del conocimiento metalingüístico del hablante-oyente, de sus habilidades lingüístico-discursivas, etc.).
} 


\subsubsection{Determinación del sentido sancionador o central}

Para determinar el sentido sancionador de la red semántica de vamos, esto es, el sentido central sobre el que se organizan los demás sentidos, hemos tenido en cuenta los siguientes criterios: el sentido registrado más antiguo (\$3.1.2.1); el predominio de algún sentido en la red semántica (\$3.1.2.2); y la predictibilidad de expansión semántica $(\$ 3.1 \cdot 2 \cdot 3)^{25}$.

\subsubsection{El sentido registrado más antiguo}

Según este primer criterio, el sentido sancionador será aquel sentido sincrónico que mantenga una relación más estrecha con el sentido documentado más antiguo, puesto que este primer sentido posiblemente desempeñara un papel relevante en el desarrollo posterior de nuevos sentidos. De ahí que el primer sentido registrado diacrónicamente abogue por la centralidad dentro de la red semántica.

A partir de los datos diacrónicos de que disponemos ${ }^{26}$, el sentido de vamos más antiguo diacrónicamente que ha podido servir de motor originador de la posterior extensión semántico-funcional de este elemento es el propio de su uso como subjuntivo independiente: el de exhortación ${ }^{27}$. Tal como plantea el Esbozo de la RAE (1973: \$3.13.2a),

\footnotetext{
${ }^{25}$ Evans propone también un cuarto criterio, el de la experiencialidad, que no adoptaremos en nuestro análisis. En el caso del sustantivo time estudiado por Evans, la experiencia del tiempo en el nivel fenomenológico ayuda a determinar el sentido sancionador. La experiencia subjetiva del hablante sobre el tiempo implica la conciencia de la duración del tiempo, del tiempo como magnitud temporal. Esto da lugar, según Evans, a la habilidad del hablante para distinguir la actividad y el momento presentes de un momento ya pasado, y su habilidad para calibrar el transcurso de los eventos (Evans, 2004, 2005). Por tanto, el criterio de la experiencialidad establece que el componente semántico que mejor se ajuste con esta experiencia vivida del tiempo será, probablemente, el sentido sancionador de la red semántica (en el estudio citado, es el sentido de duración).

${ }^{26}$ Para vamos, véanse Gonzalez Ollé (2002) y Romero (2006).

${ }^{27}$ Como pone de manifiesto González Ollé (2002), la forma vamos que interesa en este trabajo procede de una $1^{\text {a }}$ persona del plural del presente de subjuntivo ( $<$ lat. vadimus) y no del presente de indicativo (Martín Zorraquino y Portolés, 1999: 4178), como cabría esperar por la identidad formal con esta forma verbal. Las formas vamos y vais se utilizaron, hasta el siglo XVI, como alomorfos del presente de subjuntivo vayamos y vayáis (< lat. vadamus y vadatis, respectivamente). El origen subjuntivo de vamos permite explicar, en nuestra opinión, la posterior evolución de la forma verbal hacia valores interjectivos, en los que pervive el valor modal deóntico de exhortación propio del subjuntivo independiente. De lo contrario, la evolución de vamos presentaría una trayectoria evolutiva divergente, y difícil de explicar, respecto de la de otras formas subjuntivas de verbos de movimiento, como vaya y venga, en las que el paso del significado de "movimiento" al de "modalidad deóntica" se justifica de
} 
el uso del subjuntivo en español ha ido ligado a la expresión modal de las actitudes del hablante hacia el evento descrito, bien para evaluarlo (duda, posibilidad, desconocimiento, etc.), bien para mostrar el compromiso del hablante con su realización efectiva (deseo, exhortación, mandato, etc.). Es precisamente el segundo grupo de valores, propios del subjuntivo en oraciones independientes, el que incide sobre la capacidad del hablante de instar a la realización del evento o de controlarlo (Toledo, 2001: 41). Como apunta Romero (2006: 54), los verbos de movimiento muestran "una gran flexibilidad para descategorizarse y recategorizarse" en interjecciones y marcadores discursivos a partir de las formas de subjuntivo (vamos, vaya y venga, por ejemplo) e imperativo (an$d a)$.

A medida que vaya desdibujándose el valor verbal de movimiento en vamos, irán perfilándose, mediante el refuerzo de implicaturas, los valores modales deónticos implícitos en esta forma subjuntiva, entre los que figuran el de exhortación (vamos conativo) y el de aceptación enfática (vamos fático). Junto con el refuerzo implicatural, los procesos de reconceptualización metafórica han incidido también en la extensión semánticofuncional de vamos, especialmente en el surgimiento del valor formulativo de este elemento. Al fin y al cabo, la consideración metafórica o metonímica del proceso depende de la perspectiva que se adopte. Así, si se focaliza el inicio y el final del proceso desde el vamos subjuntivo al vamos marcador discursivo, puede verse un cambio metafórico, de dominio (espacial > volitivo > discursivo). Si se realiza un análisis evolutivo, secuencial, cobra mayor peso el refuerzo de implicaturas, de sentidos secundarios que pasan a un primer plano en determinados contextos (contigüidad de significados, refuerzo pragmático, metonimia). Si se analizan sincrónicamente, los nuevos sentidos y funciones que se van afianzando no desplazan a los significados anteriores, sino que conviven, creando una red polisémica de sentidos relacionados entre sí.

El valor exhortativo del subjuntivo independiente que hemos comentado continúa vigente en el plano sincrónico de vamos en contextos en los que la forma verbal constituye un acto de habla directivo, como muestra los siguientes ejemplos:

(11) a. Vamos nosotros, que ellos ya vendrán

b. Vamos para allá cuanto antes, que llegaremos tarde

forma sencilla por el debilitamiento del primer valor y un refuerzo implicatural de los valores modales intrínsecos al subjuntivo, en contextos de uso independiente. De otra parte, como señala González Ollé (2002: 132), la función modal que atribuye Fuentes (1998) a vamos, en que la subjetividad y la enfatización del hablante son rasgos destacados, se corresponde mejor con el modo verbal subjuntivo que con el indicativo. 
Se produce, por tanto, un solapamiento entre el sentido original y uno de los sentidos actuales. Ahora bien, aunque el valor modal de exhortación es muy fuerte en el uso verbal, tanto que puede confundirse con el uso interjectivo en muchos casos, el comportamiento gramatical distinto que muestran ambos usos permite hablar de dos sentidos diferentes ${ }^{28}$. La forma verbal se interpreta en contextos en los que vamos: (i) indica la voluntad del hablante de realizar un movimiento real con una meta concreta; y (ii) no ha cancelado su sintaxis verbal (Company, 2004a, 2004b), esto es, su capacidad de regir argumentos: (a) puede explicitarse el sujeto que realiza el movimiento (sujeto prototípico), con el que concuerda (Vamos nosotros/tú, yo y Pepe, que ellos ya vendrán); (b) puede haber complementos locativos o temporales que dependen de la forma verbal ( $\mathrm{Va}$ mos para allá cuanto antes, que llegaremos tarde).

\subsubsection{El predominio en la red semántica}

En segundo lugar, además del valor registrado más antiguo, debe considerarse el predominio que pueda ejercer algún sentido dentro de la red semántica (frecuencia de tipo). Este predominio en la red semántica puede ayudar a precisar el sentido sancionador.

Según lo que hemos podido comprobar en el corpus analizado, el sentido predominante en la red semántica de vamos no es el que se corresponde con el uso verbal que hemos comentado en el apartado anterior, sino el interjectivo y, especialmente, el formulador. Teniendo en cuenta que el sentido central o básico se plantea como aquel que responde con mayor facilidad a la pregunta “¿qué significa X?”, y que el valor más frecuente no se corresponde siempre con el valor más representativo (es decir, con el valor más saliente, que se activa con mayor rapidez o facilidad fuera de contexto; ver nota 20), la frecuencia de uso constituye un criterio relativo para determinar el sentido sancionador de una red polisémica como la que planteamos, en la que se tiene en cuenta la evolución diacrónica de una forma lingüística.

\subsubsection{La predictibilidad de expansión semántica}

En tercer lugar, a partir de la idea defendida anteriormente de que la extensión semántica está fundamentada y motivada, y de que las extensiones semánticas se derivan del uso contextualizado (la lengua es un sistema fundamentado en el uso), el sentido

\footnotetext{
${ }^{28}$ Las características gramaticales de los usos interjectivos de vamos se tratarán en los apartados dedicados al análisis de los sentidos codificados ( $\$ 4.1 .1 .3$ y $\$ 4.1 .2 .3)$.
} 
sancionador será aquel del que puedan derivarse -o haberse derivado- con mayor naturalidad los demás sentidos de la red semántica. Como hemos visto antes, el valor del que se han derivado los demás sentidos de vamos es, sin duda, el valor verbal en su uso como subjuntivo libre.

\subsubsection{El sentido sancionador o central}

De la aplicación de los tres criterios aducidos anteriormente, dos de ellos, el del sentido más antiguo registrado y el de la predictibilidad de expansión semántica, apuntan claramente hacia el sentido verbal (valor exhorativo) como sentido sancionador de la red semántica de vamos. Sin embargo, pese a que este sentido ha sido el origen del cambio semántico-funcional posterior de estos elementos, parece quizás menos claro que deba constituirse en el centro categorial.

Si bien, desde una perspectiva evolutiva, el sentido sancionador original constituye el centro vertebrador de la red polisémica y puede seguir activo en el plano sincrónico, hay que prever la posibilidad de que otros sentidos evolucionados posteriormente hayan alcanzado un grado de autonomía semántico-funcional suficiente que los convierta en sentidos prominentes para los hablantes. Esto es, que sean percibidos sincrónicamente como sentidos básicos que, a su vez, se han convertido - o pueden hacerlo- en generadores de nuevos sentidos (en función del criterio de predictibilidad de expansión semántica que hemos comentado antes). Nada impide que un sentido evolucionado posteriormente constituya la lectura dominante en el plano sincrónico, dado el carácter flexible de las categorías prototípicas, cuyos núcleos cambian a lo largo del tiempo (Traugott y Dasher, 2002: 8).

Aunque no es infrecuente que coexistan ambos significados (el histórico y el central), como ocurre en el caso de vamos, creemos que es necesario realizar una distinción metodológica entre significados sancionadores originales en el plano diacrónico y significados sancionadores básicos sincrónicamente (Hansen, 2005: 41). De este modo, se capta adecuadamente la intuición de que los sentidos de una unidad lingüística están relacionados entre sí mediante vínculos de distinta naturaleza, conformando una estructura compleja pero cohesionada.

Igualmente, puede integrarse la tendencia monosémica hacia un sentido invariante o central como elemento vertebrador de la categoría, entendiendo el sentido invariante como uno de los sentidos prominentes de la red semántica a partir del que se interpre- 
tan contextualmente otros sentidos ${ }^{29}$. En el primer caso, en el que se percibe una relación estructurada entre los diferentes sentidos de una forma lingüística, se concibe la categoría en su conjunto, de forma holística, de modo que todos los significados conforman un todo, una unidad (figura 2A). En el segundo caso, en el que se focaliza un sentido de la estructura semántica, realizamos una parcelación de un todo inaprehensible a priori, pero intuible (figura $2 \mathrm{~B}$ ).

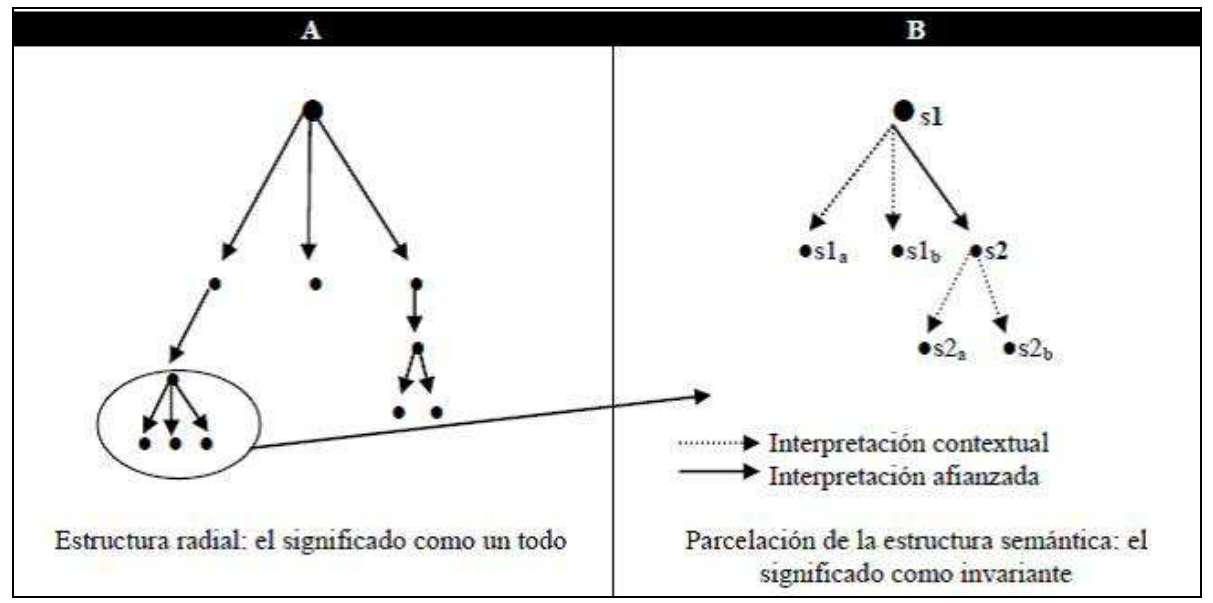

Figura 2. Estructura semántica radial y componentes de significado de un elemento lingüístico

Las interpretaciones puntuales parten de un significado más básico que se enriquece contextualmente; estos sentidos pueden unificarse en el sentido básico más abstracto, en tanto que parte constitutiva, o pueden afianzarse, asumiendo rasgos de comportamiento funcional divergentes respecto del sentido básico y no unificables con él, dando lugar a nuevos sentidos susceptibles, a su vez, de variación contextual. En este sentido, polisemia y monosemia pueden convivir dentro de la red semántica, ya que no todos los sentidos tienen que originar necesariamente nuevos sentidos independientes (aunque esta sea una tendencia natural ${ }^{30}$.

\footnotetext{
${ }^{29}$ Esta consideración permite salvar objeciones al modelo polisémico como la que plantea Boogart (2009: 220). Según este autor, el modelo polisémico, al desestimar la necesidad de establecer un significado invariante, no permite determinar cuál es el vínculo común entre los distintos usos de una forma lingüística.

${ }^{30}$ En cualquier caso, tal como lo entendemos en este trabajo, la diferencia entre polisemia (un signo, varios sentidos independientes relacionados) y monosemia (un signo, un significado independiente,
} 
En el caso de unidades lingüísticas polifuncionales y policategoriales como vamos, consideramos que la atribución de un único sentido sancionador o básico no parece una solución adecuada. Estos elementos presentan sentidos fuertemente afianzados, con características gramaticales y semántico-pragmáticas diferenciadas, que se muestran como candidatos legítimos a ocupar la posición de centro categorial. Asimismo, cada uno de estos sentidos constituye, a su vez, el motor generador de otros subsentidos que no dependen ya del sentido original sino de forma incidental. De este modo, la divergencia semántica apunta no ya hacia una consideración polisémica respecto de un significado central, que puede mantenerse para una descripción parcelada de la red semántica (como trata de representar la figura 2B), sino hacia un comportamiento multicategorial, esto es, heterosémico. De ahí que consideremos factible, y probablemente más adecuado a la realidad funcional de vamos, la atribución de más de un sentido central $^{31}$ dentro de la red semántica sincrónica de estos elementos, tal como tratamos de demostrar en el siguiente apartado.

\section{La red semántica de vamos}

Una vez establecidos los fundamentos teóricos del modelo polisémico que queremos aplicar a vamos y los criterios que sustentan la modelación de la red semántica de este elemento complejo, en este apartado se desarrollarán los sentidos codificados de dicha red semántica.

La forma vamos representa un recurso lingüístico que se usa de manera convencional en determinados contextos protototípicos para llevar a cabo funciones relacionadas con:

a) la (re)organización de la materia discursiva (reformulación y rearticulación; de manera genérica, marcar continuación discursiva);

varios sentidos contextuales) es una cuestión de grado evolutivo y de saliencia cognitiva. Los distintos sentidos que en un momento del proceso evolutivo de un signo (sincronía) pueden ser reducibles a una invariante (análisis monosémico), pueden derivar en sentidos independientes a medida que se afianzan las interpretaciones contextuales (refuerzo y convencionalización de implicaturas; diacronía); igualmente, los sentidos que un usuario de la lengua puede percibir como interpretaciones contextuales de un sentido más básico, otro puede percibirlos como sentidos independientes (con propiedades formales, distribucionales y semántico-pragmáticas distintas), claramente distinguibles.

${ }^{31}$ Como ya habíamos señalado anteriormente, es preferible distinguir entre la polisemia vinculada con un sentido de la red semántica (polisemia intracategorial) y la polisemia global de la estructura semántica de una unidad lingüística dada, que afecta a más de un sentido afianzado y, en consecuencia, a más de una categoría gramatical (polisemia intercategorial o heterosemia). 
b) la mostración del (des)acuerdo con un (inter)locutor presencial o virtual, mostrando la (dis)conformidad con un punto de vista, con una intención o con un determinado estado de cosas (función fática ${ }^{32}$; modalidad deóntica);

c) la voluntad del hablante de influir en la conducta de su interlocutor (función conativa; modalidad deóntica) ${ }^{33}$.

Las funciones mencionadas constituyen funciones genéricas de vamos ${ }^{34}$. Estas funciones, asimismo, se vinculan prototípicamente con determinados contextos funcionales que prevén, a su vez, la aparición de estos elementos discursivos como elementos prototípicos para vehicular dichas funciones (Polanco, 2010). En este sentido, puede decirse que estas funciones básicas constituyen también sentidos afianzados dentro de la red polisémica de este elemento discursivo, a saber: el sentido conativo (4.1.1), el sentido fático (4.1.2) y el sentido formulativo (4.1.3).

\subsection{Los sentidos codificados}

\subsubsection{Vamos conativo: la exhortación}

Los ejemplos (9) y (10) del apartado 1, que repetimos a continuación, ilustran el sentido conativo de vamos:

(9bis) < PER001"> <OVERLAP><VOCAL "INTERROGACIÓN" "¿EH?"></OVERLAP> bien, entonces ya vamos a darnos un poco de prisa, que si no no va a darnos tiempo a todos, y además hacer algunos comentarios que tengo que hacer.

$<$ PER002"> Pues venga, vamos, dale. (CREA; En una feria de barrio, Madrid, $08 / 08 / 91)$

\footnotetext{
${ }^{32}$ Para la denominación de las funciones interjectivas de vamos, tomamos la clasificación funcional que propone Cuenca (2001: 3215-3231), basada en las funciones comunicativas de Jakobson (1960): expresiva, conativa, fática, metalingüística y representativa.

${ }^{33}$ A estos valores, pueden sumarse valores pragmáticos vinculados con el estado emocional y mental del hablante en el momento de la enunciación (sorpresa, rechazo, enfado, etc.), que suelen añadirse de manera tangencial a los valores funcionales prototípicos en función de variables no controlables de la situación comunicativa.

${ }^{34}$ Constituyen también funciones genéricas de las construcciones discursivo-interactivas derivadas de vamos, entre otras [vamos que si + enunciado ecoico] o [A, pero vamos, $\left.\mathrm{A}^{\prime}\right]$ :

Pues sí que está bueno, sí, vamos que si está bueno. (refuerzo ilocutivo y acuerdo enfático)

Este tío está loco, pero vamos, loco perdido. (refuerzo ilocutivo-argumentativo)

Para una descripción detallada de las características gramaticales y semántico-funcionales de estas construcciones discursivas, véase Polanco, 2010.
} 
(10bis) Yo también te buscaré algo, aunque le di a mi sobrino, aun me quedan cosillas, solo falta que nos digas qué es... vamos, no te preocupes que seguro no le faltará nada. (http://www.foropadres.com/viewtopic.php?f=90\&t=8102)

Para poder determinar que los ejemplos anteriores muestran un sentido independiente distinto del sentido verbal, deben cumplirse al menos dos de los tres criterios aducidos en el apartado 3.1.1.: por un lado, que estos ejemplos proporcionan un significado adicional no presente en el sentido verbal (criterio semántico); y, por otro, que el sentido conativo presenta patrones de elaboración semántica distintos (criterio de elaboración semántica) y/o características gramaticales distintivas (criterio gramatical) respecto del sentido verbal.

\subsubsection{El criterio semántico}

A diferencia del sentido verbal, en los ejemplos (9bis) y (10bis) vamos expresa la intención del hablante de influir en la conducta de su interlocutor, bien para que este realice alguna acción que beneficia al hablante, bien para que modifique su actitud psicológica, generalmente en beneficio del interlocutor. De acuerdo con el criterio semántico, las ocurrencias anteriores apuntan a una lectura modal deóntica (exhortación), en la que la instrucción del movimiento espacial ha dejado de interpretarse. Ahora, el valor que prima es la exhortación a realizar una determinada acción; esto es, se focaliza la meta del movimiento (la voluntad del hablante) y el papel del interlocutor en la consecución de la meta, dejando al sujeto hablante, implícito en el morfema plural de vamos, en un segundo plano.

\subsubsection{El criterio de elaboración semántica}

La lectura conativa se interpreta en contextos en los que vamos no indica ya un movimiento en el espacio, sino en los que se focaliza la voluntad del hablante de que se realice determinado evento o de que cambie un determinado estado de cosas. Este nuevo sentido modal (deóntico ${ }^{35}$ ) se elabora en términos de una reconceptualización del movimiento espacial en movimiento volicional (en la mente del oyente), a partir del refuerzo contextual del valor exhortativo implícito en la forma subjuntiva: se focaliza la

\footnotetext{
${ }^{35} \mathrm{~A}$ diferencia de otros autores, como Martín Zorraquino (1999), quien reserva el término "marcador de modalidad deóntica" para los marcadores que expresan el acuerdo con el interlocutor, en este trabajo tomamos una concepción de la modalidad deóntica menos restrictiva, tal como la define Palmer (1986), que permite incluir las formas que codifican la intención del emisor de influir sobre el destinatario (Gras et al., 2005).
} 
intención del hablante de conseguir cierta meta (la realización de una acción real o mental) mediante un cambio de posición actitudinal por parte del oyente (movimiento volicional) y no el movimiento para alcanzar cierta meta. El sentido conativo puede funcionar como un acto de habla independiente, cuando se sobreentiende contextualmente la acción exhortada, aunque suele ir acompañado de un acto de habla directivo que explicita dicha acción.

La implicatura convencional que se deriva con el uso conativo de vamos puede parafrasearse como

El hablante quiere que haga esto [la acción expresada en el acto de habla directivo que acompaña a vamos o la acción implícita a que la que apunta vamos, si esta ha sido expresada por otro (inter)locutor o se sobreentiende contextualmente].

\subsubsection{El criterio gramatical}

Según este criterio, relativo a la distintividad gramatical, el sentido conativo muestra claramente un comportamiento gramatical diferenciado respecto del sentido verbal. Como acabamos de señalar, el vamos conativo se interpreta en contextos en los que el hablante exhorta al oyente a que realice determinada acción o cambie de actitud. A diferencia del vamos verbal, el vamos conativo:

(i) no concuerda con el sujeto de la cláusula que representa el evento que debe realizarse (Vamos ${ }^{*}$ [nosotros], ve tú primero ${ }^{36}$;

(ii) no admite complementos verbales, y si aparecen argumentos modales, temporales o locativos, estos dependen del verbo del enunciado directivo (Vamos, deprisalya,

\footnotetext{
${ }^{36}$ Podría argüirse que este argumento es relativamente cierto, en tanto que sí puede haber concordancia entre vamos y el sujeto de la oración que representa el evento que debe realizarse, como parecen demostrar ejemplos del tipo Vamos, calmémonos todos o Vamos, comeremos nosotros primero. Sin embargo, esta concordancia es aparente, ya que en los ejemplos anteriores vamos no representa una acción acorde al lexema verbal (no se exhorta al movimiento), dado que la realización de la acción de la oración siguiente no implica un movimiento o desplazamiento para su consecución. En realidad, aunque vamos sigue implicando una primera persona del plural, en tanto que el hablante queda incluido, tal como se desprende de la interpretación de las formas verbales de las oraciones que siguen a vamos, ya no se interpreta un valor verbal, sino un valor modal de exhortación a la realización de la acción indicada por el acto de habla directivo que acompaña a vamos. Por otra parte, en los ejemplos anteriores no puede sustituirse vamos por formas verbales afines sin que el resultado produzca extrañeza o agramaticalidad: ${ }^{*}$ Marchemos/Partamos, calmémonos todos. En cambio, vamos, como forma interjectiva conativa que es, sí puede aparecer acompañada de otras interjecciones equifuncionales, a modo de refuerzo ilocutivo: Vamos,venga/va, calmémonos todos; o sustituirse por otra interjección de función similar: Venga, comeremos nosotros primero.
} 
acaba que lo necesito; Vamos, (andando/vete) para casa rápidamente, que te esperan hace rato);

(iii) no admite sujeto; en caso de que aparezca un SN susceptible de interpretarse como sujeto, que puede ser tanto prototípico como no prototípico (Vamos, cacharro asqueroso, arranca ya [aludiendo a un ordenador, por ejemplo]), lo hace separado por pausa de vamos y del enunciado directivo, o pospuesto a este, y o bien no presenta concordancia con ningún elemento del enunciado (Vamos, muchacho, que nos esperan), o bien concuerda con el verbo del enunciado directivo (Vamos, tú, que no te enteras);

(iv) no admite negación $\left({ }^{\star}\right.$ No vamos, espabila);

(v) no admite paráfrasis mediante elementos verbales afines ( ${ }^{*}$ Partamos/ Dirijámonos/marchemos, no te preocupes, que todo pasa), pero puede coaparecer con formas interjectivas conativas deverbales (Vamos, va/venga, adelanta ya /Anda, vamos, no te lo tomes asî).

Por otro lado, el vamos conativo muestra un comportamiento prototípicamente interjectivo y responde afirmativamente a los rasgos que caracterizan a las interjecciones frente a otros elementos discursivos no interjectivos, a saber:

(i) Puede constituir (y generalmente así lo hace) un enunciado autónomo no elíptico; cuando se acompaña de un acto de habla directivo que expresa la "acción" que debe realizar el interlocutor, el vamos conativo presenta una curva entonativa independiente del acto de habla directivo.

(ii) Tiene significado modal (modalidad deóntica): expresa la intención del hablante de influir en la conducta de su interlocutor.

(iii) Tiene entonación marcada.

(iv) En estilo indirecto, puede separarse del miembro discursivo que le sigue mediante la conjunción que (Portolés, 2001: 69-70).

De lo anterior se sigue que el vamos conativo ha cancelado su sintaxis verbal (Company, 2004a) y muestra un comportamiento claramente interjectivo: constituye una unidad semántica y comunicativa, puede aparecer solo ocupando turno como enunciado autónomo no elíptico y se acompaña de enunciados con verbo en forma imperativa (actos de habla directivos). En definitiva, los tres criterios considerados permiten asumir que la lectura conativa de vamos (ejemplos 9bis y 10bis) constituye un sentido independiente. 


\subsubsection{Derivación del sentido conativo}

El paso de un significado espacial a otro modal deóntico parte de un cambio en el foco de atención del hablante-oyente y se fundamenta en el refuerzo de significados modales secundarios implícitos en el uso de la forma verbal que en determinados contextos empiezan a cobrar mayor peso interpretativo. La voluntad de negociar la interacción emisor-receptor y, posteriormente, de regular la comunicación implicitan un refuerzo progresivo tanto de la subjetividad del hablante en su enunciación, como de la informatividad (strengthening of informativeness, Traugot y König [1991]). Este cambio semántico es de carácter metonímico, en tanto que surge de la focalización y refuerzo en determinados contextos de significados contiguos que actuaban en un segundo plano interpretativo (refuerzo implicatural).

Así, puede defenderse que la interpretación conativa (modal deóntica) se deriva de una implicatura conversacional a partir de una interpretación no estereotípica del uso verbal de vamos. A partir del momento en que vamos no alude a un movimiento físico conjunto (que sería la situación estereotípica señalada por la forma verbal), sino que exhorta al hablante a realizar una determinada acción solicitada por el hablante, el oyente reinterpreta el valor verbal de desplazamiento hacia un valor modal deóntico: ahora lo que debe moverse es la voluntad del oyente para realizar un cambio de actitud o llevar a cabo un acción conforme con la voluntad del hablante. Es decir, se refuerza el valor modal implícito en la forma verbal y se focaliza en el sujeto hablante. El movimiento y cambio de posición del oyente parten de la posición del hablante, de su voluntad, en tanto que la finalidad es satisfacer el acto directivo explícito o implícito que acompaña a vamos. En este sentido, persiste de algún modo el significado original de desplazamiento conjunto de hablante y oyente.

En cualquier caso, como apuntábamos antes, no resulta sencillo determinar si lo metafórico facilita el refuerzo de ciertos implícitos, o si este refuerzo activa una reconceptualización metafórica del valor verbal originario. Tal como intentamos esquematizar a continuación, podría defenderse que a medida que se van reforzando ciertas implicaturas, se va afianzando la reconceptualización del movimiento espacial en movimiento volicional (cambio metafórico): 
DESPLAZARSE (EN EL ESPACIO) IMPLICA UN CAMBIO DE POSICIÓN PARA

ALCANZAR UNA META (hay un punto de origen, direccionalidad y un punto final)

(yo+tú (+otros)) • $\longrightarrow$ (meta locativa)

MOVERSE EL OYENTE POR SU MENTE IMPLICA UN CAMBIO DE POSICIÓN MENTAL PARA CONSEGUIR ALGO (lo que pide el hablante)

(yo) $\bullet$ tú/vos. $\longrightarrow \bullet$ (meta: acción o cambio de estado)

Implicatura conversacional: El hablante no va a moverse y yo tampoco tengo que moverme, no tengo que ir a ningún sitio; luego, lo que quiere el hablante es que haga algo (refuerzo del valor exhortativo implícito en la forma verbal), lo que pide con su enunciado es que cambie mi posición mental por la suya/sume mi posición mental a la suya.

\subsubsection{Vamos fático: el (des)acuerdo enfático}

Los siguientes ejemplos muestran el sentido fático de vamos: acuerdo (11) y desacuerdo (12):

(11)A: ¿Te gusta (mostrando un vestido)?

B: VAmos $\downarrow / \operatorname{vamo}(:) s \uparrow^{37}$

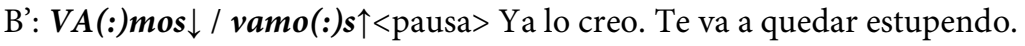

(12) SGAE: 'Ha habido una tergiversación de los hechos'

www.elmundo.es/elmundo/2009/05/28/catalejo/1243510544.html por su_r00t el 28-05-2009 13: 51 UTC, publicado el 28-05-2009 15: 15 UTC

"Ha habido una tergiversación de los hechos teñidos de mentiras y falsedades", asegura un representante de la SGAE sobre el peculiar acceso -y registro según el afectado- a la casa de Juan José Coronel. La sociedad se remite al acta levantada por el juez que entró en la casa y asegura que "no se ha infringido la legalidad".

\footnotetext{
${ }^{37}$ Con estas grafías representamos el esquema entonativo de vamos en función fática (ver tabla 1 y gráficos 1 y 2). Debido a la ausencia de ocurrencias de vamos con valor fático en el corpus analizado que presentaran un nivel acústico adecuado para realizar el análisis espectrográfico, los datos prosódicos que ofrecemos se fundamentan en un análisis espectrográfico realizado a partir de cinco elocuciones de hablantes distintos que expresaban ejemplos de réplica, acuerdo y acuerdo enfático. Con todo, reconocemos que estos datos son solo orientativos y requieren de un mayor número de acurrencias para asegurar su carácter prototípico. Asimismo, queremos agradecer la ayuda que nos brindó la Dra. Ana Fernández para la realización del análisis espectrográfico en el laboratorio de fonética de la Universidad de Barcelona.
} 
95 comentarios en: actualidad, sociedad karma: 774
etiquetas: sgae, juan josé coronel, registro, domicilio
negativos: 3 usuarios: 464 anónimos: 604 compartir:

\#1 "No se ha infringido la legalidad"..... anda, igual que con las descargas!!

votos: 86, karma: 754

por perga el 28-05-2009 13: 53 UTC

\#2 Conste que no la envío por defenderlos, más bien al contrario, los odio con todas mis fuerzas. Es para que veamos lo rápido que han saltado acojonados. Para otras cosas bien que se callan

votos: 36 , karma: 341

por su_r00t el 28-05-2009 13: 55 UTC

\#3 Pues tienen razón, hay tergiversación, se la estamos leyendo en este meneo.

votos: 14, karma: 137

por ronko el 28-05-2009 13: 55 UTC

\#12 Vamos no me jodas!!!! QUE LES DENUNCIE A LOS 5, por cierto ¿quien es el hijo de puta que ni siquiera se identifico? y ahora a decir que se han transgiversado las cosas, y un huevo!!!! QUE LOS DERECHOS DE AUTOR LOS RECAUDEN LAS PUTAS, QUE SUS HIJOS MIRA LA QUE ESTAN MONTANDO.

votos: 16, karma: 142

por aitorbs_el 28-05-2009 14:05 UTC

(http://meneame.net/story/sgae-ha-habido-tergiversacion-hechos)

\subsubsection{El criterio semántico}

Tal como muestran los ejemplos anteriores, vamos indica la actitud del hablante respecto del oyente y su enunciación, bien para mostrar acuerdo (11), bien para mostrar desacuerdo (12); las ocurrencias anteriores apuntan, pues, a una lectura modal deóntica. A diferencia del vamos conativo, que también codifica un valor modal deóntico, el vamos fático no expresa una exhortación a realizar una determinada acción (no es un acto directivo implícito), sino una valoración del estado de cosas expresado por un interlocutor real o potencial o de la situación comunicativa.

El vamos fático deriva, en nuestra opinión, una implicatura convencional que podría parafrasearse como

El hablante cree que [lo que digo/lo que dice X/el estado de cosas X] es [muy aceptable/inaceptable]. 


\subsubsection{El criterio de elaboración semántica}

El valor fático que acabamos de comentar se elabora prototípicamente a partir de contextos dialógicos en los que el hablante manifiesta en una intervención reactiva su valoración sobre lo dicho, ordenado o preguntado por otro en un turno iniciativo previo, o respecto de un estado de cosas explícito o implícito en el contexto comunicativo. El vamos fático puede ir acompañado de actos de habla justificativos con los que el hablante contextualiza las razones de su (des)acuerdo. Por el contrario, el valor conativo, que también se elabora prototípicamente en contextos dialógicos, constituye generalmente una intervención iniciativa o reactivo-iniciativa con la que el hablante trata de modificar un estado de cosas o la actitud de su interlocutor y suele introducir actos de habla directivos que explicitan la acción o el cambio deseados por el hablante. En este sentido, puede establecerse que ambos usos interjectivos de vamos despliegan interpretaciones estables diferenciadas: en el primer caso, valorar la proposición expresada por un (inter)locutor distinto del hablante, mostrando (des)acuerdo; en el segundo caso, modificar un estado de cosas o la actitud del interlocutor.

Ambos valores, el conativo y el fático, retienen en parte el sentido exhortativo original, en tanto que no deja de percibirse implícitamente una invitación al interlocutor a participar de la intención comunicativa del hablante. Este valor implícito de cooperación intersubjetiva entre hablante y oyente podría considerarse, como hacen algunos autores $^{38}$, el sentido de base de esta interjección. En este sentido, tanto la interpretación conativa como la fática se entenderían como elaboraciones contextuales a partir de este valor cooperativo. No obstante, como trataremos de demostrar más adelante en la descripción del valor formulativo (\$4.1.3), el sentido de cooperación se interpreta, más bien, como una implicatura generalizada a partir del valor inclusivo de vamos. Como tal implicatura, puede cancelarse contextualmente, sobre todo en contextos replicativos en los que el hablante muestra su desacuerdo con el interlocutor.

\subsubsection{El criterio gramatical}

El vamos fático ha perdido su capacidad sintáctica verbal originaria (no selecciona argumentos, no puede negarse ni parafrasearse por otro elemento verbal con un significado similar) y muestra un comportamiento prototípicamente interjectivo:

\footnotetext{
${ }^{38}$ Por ejemplo, Martín Zorraquino (Martín Zorraquino y Portolés, 1999) y Chodorowska (1999).
} 
1) Aparece en contextos sintáctico-conversacionales ocupando turno indepediente como intervención reactiva a un acto iniciativo previo formulado por otro interlocutor; puede acompañarse de actos justificativos que no exhortan directamente al hablante a realizar una acción o a modificar su actitud.

2) Tiene significado modal (modalidad deóntica): expresa el rechazo o la aceptación-confirmación del punto de vista o la propuesta de otro (inter)locutor o de un determinado estado de cosas.

3) Tiene un contorno prosódico marcado que se asocia convencionalmente con alguno de los dos valores fáticos mencionados.

4) En estilo indirecto, puede separarse del miembro discursivo que le sigue mediante la conjunción que.

Por otro lado, como tratamos de mostrar en la tabla 1, el vamos fático se diferencia del vamos conativo en varios rasgos co(n)textuales: representa un acto reactivo, constituye un acto valorativo no directivo, puede acompañarse de actos justificativos no exhortativo, expresa aceptación o rechazo y presenta rasgos prosódicos estables.

\begin{tabular}{|c|c|}
\hline vamos fático & vamos conativo \\
\hline $\begin{array}{l}\text { - Constituye un acto reactivo } \\
\text { - Constituye un acto valorativo no directivo } \\
\text { no exhortativos } \\
\text { - Expresa rechazo o aceptación de un punto } \\
\text { de vista ajeno } \\
\text { - Presenta rasgos prosódicos estables y siste- } \\
\text { matizables: pico tonal de la primera sílaba y } \\
\text { entonación descendente final (gráfico 1). } \\
\text { Asimismo, cuando vamos expresa un acto } \\
\text { de confirmación, de mostración enfática del } \\
\text { acuerdo, puede presentar una ligera varia- } \\
\text { ción en el esquema entonativo: entonación } \\
\text { circunfleja }{ }^{39} \text { final, con ligero alargamiento } \\
\text { de la última vocal de vamos/vaya (gráfico } \\
\text { 2). }\end{array}$ & $\begin{array}{l}\text { - Constituye un acto iniciativo o reactivo- } \\
\text { iniciativo } \\
\text { - Constituye un acto directivo implícito } \\
\text { - Suele introducir actos de habla directivos } \\
\text { que especifican la acción exhortada } \\
\text { - Expresa la intención del hablante de mo- } \\
\text { dificar la actitud de su interlocutor } \\
\text { - Presenta mayor variabilidad prosódica } \\
\text { (los rasgos prosódicos de este uso son } \\
\text { menos sistematizables) }\end{array}$ \\
\hline
\end{tabular}

Tabla 1. Rasgos diferenciales del vamos fático y conativo

\footnotetext{
${ }^{39}$ La entonación circunfleja implica un ascenso y descenso tonal en la misma sílaba (Martínez Celdrán y Fernández, 2007).
} 
Los rasgos prosódicos desempeñan un papel importante en la desambiguación semántica de esta interjección. Tal como defendemos en este trabajo, la entonación forma parte del conocimiento metalingüístico convencional que el hablante asocia con el uso e interpretación del vamos fático; esto es, el contorno prosódico constituye, junto con otros componentes de índole gramatical y pragmático-funcional, un rasgo especificado en el marco de interpretación asociado a esta interjección.

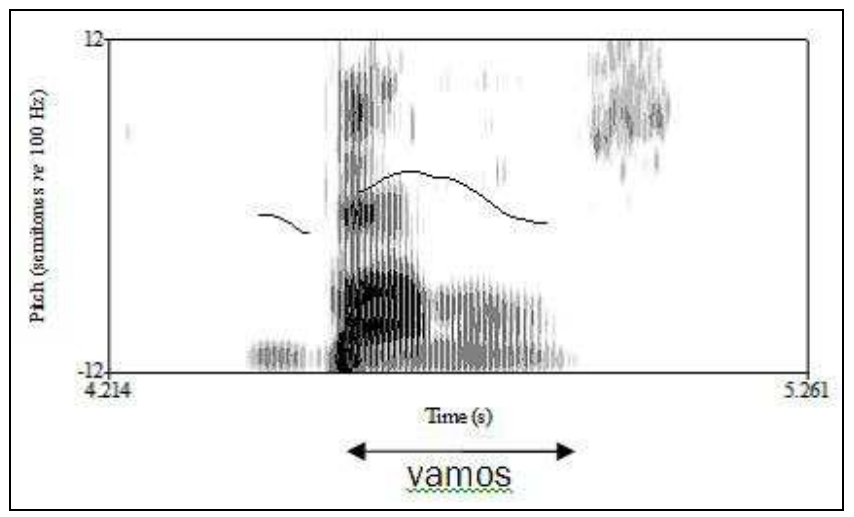

Gráfico 1. Espectograma de vamos en función fática

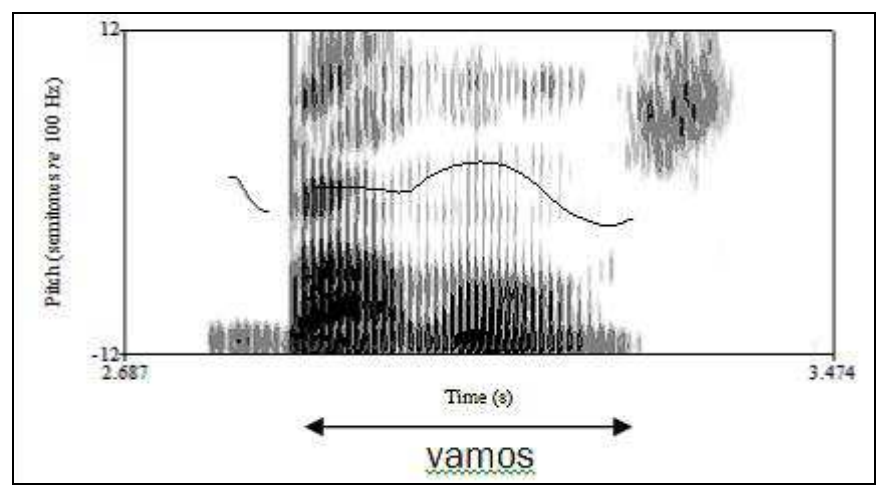

Gráfico 2. Espectograma de vamos circunflejo en función fática (acuerdo enfático)

En suma, los tres criterios considerados muestran un comportamiento gramáticofuncional y una interpretación estable de vamos en función fática que permiten considerarlo como un sentido independiente de la red semántica de la forma vamos. 


\subsubsection{Derivación del sentido fático}

La hipótesis explicativa que proponemos en este apartado se fundamenta principalmente en una reconstrucción pragmática basada en las diferencias contextuales que muestra el uso fático de vamos respecto del uso conativo ${ }^{40}$.

El valor fático podría haber surgido como una implicatura conversacional particularizada a partir del uso conativo en contextos no directivos, esto es, cuando vamos se utiliza para exhortar al interlocutor no a realizar alguna acción, sino a aceptar el punto de vista del hablante. El uso de vamos se produce, pues, en un contexto dialógico atípico que actúa a modo de escenario crítico (critical stage, [Diewald, 2002: 103]). Este nuevo escenario, según Diewald, produce ambigüedades estructurales y semánticas que invitan a una interpretación alternativa y funciona generalmente como estadio intermedio en la gramaticalización de nuevas estructuras (Traugott, 2010). En el caso que nos ocupa, el cambio de posición estructural de vamos (acto iniciativo + acto de habla directivo $>$ acto reactivo [+ acto de habla justificativo]) propicia su interpretación como reacción valorativa a lo expuesto por el interlocutor o a un estado de cosas explícito o implícito en el contexto comunicativo y se empieza a asociar este nuevo uso con la manifestación del (des)acuerdo del hablante.

\subsubsection{Vamos formulativo}

Los ejemplos (1)-(6) del apartado 1, que repetimos a continuación, muestran algunas ocurrencias de vamos con valor formulativo:

(1bis) O sea, en su momento, hubo tesis por las cuales el segundo canal iba a ser un canal que se podría haber financiado sin publicidad, vamos a costa del presupuesto, [...]. (CREA; Debate: las nuevas televisiones, 10/12/87, TVE 1)

(2bis) (...) luego viene Daniel, que Daniel es muy curioso<PAUSE $>$ bueno, tiene catorce años, es el pequeño de los niños, pero tiene un espabile encima, vamos, que ese sí que no parece que tiene catorce años porque es demasiado espabilado, se pasa de rosca, pero es supergracioso, nos partimos con él. (CREA; Entrevista CSC008, mujer, 20 años)

(3bis) [...] es que bueno, por no hacer muy extensiva la intervención en cuanto a los grupos, vamos, en cuanto a los factores de riesgo. (CREA; Debate: El Sida, 23/04/87, TVE 1)

\footnotetext{
${ }^{40}$ Esta hipótesis es claramente provisional y esperamos poderla confirmar en trabajos posteriores con datos diacrónicos de los que carecemos en el presente estudio.
} 
(4bis) y el de la autoescuela le dice pero tío pero ¿¡de qué vas $\downarrow$ !? ¿¡tú estás loco!?/ ¿cómo te vas-? si acabas de empeZAAR $\downarrow$ no has venío ningún día a CLASE/vamos o s(e)a// yo si quieres yo te apunto// tú eres el que vas a tener QUE PAGAR/ que me apuntes $\downarrow$ que me apuntes $\downarrow$ que me apuntes $\downarrow$ que me apuntes $\downarrow$ es cantidad de cabezón $\downarrow$ que me apuntes $\downarrow$ total quee lo puso de tal forma que lo tuvo que apuntar// yy ¿cuándo fue eel-? sí $\downarrow$ el- el martes pasado $\downarrow$ creo que fue examen (Briz y grupo Val.Es.Co, 2002: 113 [L.15.A.2])

(5bis) A: ¿yy alguna fiesta del barrio?// ¿de cuando eras pequeña?

B: yo no he ido- no he sido muy de barrio (chasquido)// pero vamos recuerdo las Fallas sobre todo las Fallas// es cuando más yo/ vamos cuando yo he trabaja(d)o más en eel- ¡uy! Perdón hee colabora $(d)$ o o he esta $(d) o$ así más en el barrio (...). (Preseval, [conv. 1, líneas 74-78]; http://www.uv.es/preseval/ppal.htm)

(6bis) Bueno, es decir, oye $<P A U S E>$ qué quieres, no sé. Dicen de que $<P A U S E>$ dicen Cruz y Raya de que yo hablo inseguro. Es que pienso que $<P A U S E>$ vamos, o sea, no estoy de acuerdo, pero $<$ PAUSE $>$ vamos, no sé, ¿no? O sea, yo creo $<P A U S E>$ yo que usted $<$ PAUSE $>$ vamos, no sé, ¿verdad, señor Gil?

Igual que con los sentidos verbal, conativo y fático, para poder determinar si los ejemplos anteriores muestran un sentido independiente, deben cumplirse al menos dos de los tres criterios que venimos aduciendo. Por un lado, que estos ejemplos proporcionan un componente semántico no presente en los sentidos descritos anteriormente (criterio semántico). Por otro, que el sentido formulativo presenta patrones de elaboración semántica distintos (criterio de elaboración semántica) o características gramaticales distintivas (criterio gramatical) respecto de los sentidos que hemos consignado en los apartados anteriores.

\subsubsection{El criterio semántico}

Las ocurrencias de vamos en los ejemplos anteriores muestran algunos de los distintos valores funcionales relacionados con la formulación discursiva, a saber, reformulación parafrástica (ejemplo 1bis), reformulación recapitulativa (ejemplo 2bis), reformulación rectificativa (ejemplo 3bis), rearticulación comentadora (ejemplo 4bis), rearticulación relanzadora (ejemplo 5bis) y rearticulación de relleno (ejemplo 6bis) ${ }^{41}$. Pese a la

\footnotetext{
${ }^{41}$ La función rearticuladora, como apuntamos en la nota 2, se vincula con la reorganización discursiva. Pero esta función reorganizativa puede llevarse a cabo mediante operaciones discursivas diferentes: (i) introducir un cambio de perspectiva enunciativa con el que se inicia un nuevo tópico para aclarar o matizar la intención del decir (rearticulación comentadora o digresiva); (i) impulsar el habla tras un titubeo más o menos apreciable, concluyendo la unidad discursiva que ha quedado incompleta antes
} 
divergencia funcional que presentan los ejemplos anteriores, todos ellos apuntan hacia una interpretación funcional de base especializada en la formulación discursiva. Este valor se interpreta como valor de fondo en todas las ocurrencias del corpus analizado, lo cual permite pensar en el sentido de formulación como en uno de los sentidos básicos de la red semántica que proponemos para vamos.

A diferencia de los sentidos propuestos en los apartados anteriores, el sentido de formulación ya no implica un desplazamiento físico del hablante [y otros] (sentido ver$b a l)$, ni expresa la intención del hablante de influir en la conducta de su interlocutor (sentido conativo), así como tampoco muestra el (des)acuerdo del hablante respecto del interlocutor (sentido fático). El significado de formulación retiene en parte el significado de prospección relacionado con la instrucción verbal de origen, pero orientado ahora hacia un espacio virtual, el del discurso. A este valor de prospección discursiva subyacente, el marcador vamos añade un significado vinculado con su función discursiva más prototípica: la formulación. El hablante indica que el movimiento discursivo que señala el MD se realiza para añadir más información. Esta instrucción se derivaría de la anterior por un proceso de implicatura conversacional generalizada a partir del principio I[nformatividad] ("lo que se dice de manera estereotípica, se interpreta de manera estereotípica", Levinson, 2004) que acaba por convencionalizarse: El hablante se mueve y me pide que me mueva con algún propósito. En el discurso, este propósito es el de añadir más información.

\subsubsection{El criterio de elaboración semántica}

La indicación ostensiva de un movimiento prospectivo en el discurso se interpreta como una marca de relevancia informativa orientada al interlocutor (una llamada de atención al interlocutor, función fática) y al enunciado (focalización) ${ }^{42}$. Esta llamada de atención implicita la intención del hablante de hacer algo, dado que el movimiento se realiza con alguna finalidad. En el espacio discursivo, la finalidad de avanzar en el discurso se relaciona con la ampliación de información. Esta inferencia, que podríamos parafrasear como El hablante quiere avanzar en el discurso [y me exhorta/invita a acompañarlo] porque quiere decir algo más, aparecería en un principio como una implicatura conversacional particularizada (como una implicatura débil) que se va afianzando en

del marcador (rearticulación de relanzamiento); o (iii) rellenar silencios potenciales, a modo de pausa oralizada, en contextos de habla discontinua (rearticulación de relleno) (Polanco, 2010: \$5).

${ }^{42}$ Pons (1998) también advierte una función similar en elementos interjectivos como mira y oye, a la que denomina función fática interna. 
la medida en que la exhortación al movimiento se reinterpreta como un avanzar conjunto del hablante y su(s) interlocutor(es) dentro del espacio discursivo, esto es, cuando la atención del interlocutor se dirige hacia el objeto discursivo.

En contextos discursivo-textuales, la exhortación al movimiento se reinterpreta como un movimiento virtual dentro de un espacio también virtual, de modo que la instrucción original subyacente (Desplacémonos desde el lugar X hasta el lugar Y para realizar Z) se elabora en términos metafóricos como un desplazamiento desde una posición enunciativa a otra para realizar una acción discursiva determinada (reformular o rearticular el propio discurso). Se trata, además, de una implicatura convencionalizada, y no generalizada, porque no es cancelable y se mantiene estable en todos los usos discursivo-textuales de este marcador.

El valor inclusivo de vamos, que hemos representado en la paráfrasis del valor formulativo como [y me exhorta/invita a acompañarlo], ha sido considerado por algunos autores como el valor que define la función principal de este marcador, a saber, la de reforzar la imagen positiva del hablante (Martín Zorraquino y Portolés, 1999: 41774180; esta autora clasifica a vamos entre los marcadores enfocadores de la alteridad), es decir, como un marcador discursivo interpersonal (Chodorowska-Pilch, 1999).

En nuestra opinión, el valor cooperativo de animar al interlocutor a sumarse a la perspectiva enunciativa del hablante que propone Martín Zorraquino (o, según nuestra propuesta, la invitación al oyente a acompañar al hablante en su movimiento prospectivo en el espacio del discurso), es un implícito que se deriva del significado inclusivo del marcador y que, en principio, se interpreta por defecto a partir del valor plural del marcador. Ahora bien, como demuestra el análisis en corpus, este valor puede neutralizarse en función de las variables de la situación comunicativa, sin que la eliminación de la lectura cortés distorsione en absoluto la función (re)formulativa, que permanece en todos los contextos analizados. Esto es lo que ocurre, por ejemplo, en los siguientes casos:

(13) Pero qué dices, hombre, eso no es así; vamos, que no es verdad.

(14) Pero tú eres tonto, de verdad; vamos, tonto perdido.

En estos ejemplos, vamos introduce una reformulación (16) y un refuerzo del enunciado previo al marcador (17) que matiza la valoración negativa que expresa el hablante, además de otros posibles valores modales de carácter expresivo en función del patrón entonativo. Sin embargo, la reformulación es potencialmente lesiva para el oyente: en ambos casos, hay un refuerzo, y no una mitigación, de la fuerza expresiva del enunciado reformulado. En consecuencia, el deseo de implicar a todos los interlocutores en la misma perspectiva enunciativa, como sugiere Martín Zorraquino, es, a nuestro enten- 
der, dudoso, puesto que difícilmente se sumará el oyente a la "perspectiva enunciativa del hablante" cuando esta es sumamente lesiva para él. Igualmente, el refuerzo ilocutivo que imprime vamos al enunciado reformulador tampoco contribuye a salvaguardar las imágenes del interlocutor, contrariamente a lo que propone Chodorowska-Pilch (1999).

Todo lo anterior impide, pues, la consideración del valor cooperativo de vamos como sentido central del marcador o como un valor codificado por este. Con todo, no puede obviarse que este valor inclusivo persiste en el significado del marcador a partir de la forma morfológica de plural, valor que se interpreta - cuando es relevante contextualmente- como una estrategia interactiva para integrar al interlocutor en la perspectiva del emisor. Ahora bien, pese a que el valor inclusivo de vamos es un valor implícito que se activa por defecto, es cancelable, esto es, puede anularse contextualmente. Por ello, consideramos que es mejor tratar el valor cooperativo de vamos como una implicatura conversacional generalizada (Levinson, 2004).

En suma, puede decirse que vamos establece la intención manifiesta del hablante de avanzar en el discurso ( $y$ contextualmente la intención de sumar al interlocutor en dicho avance, esto es, a su punto de vista) para realizar algún tipo de acción discursiva relacionada con la formulación.

\subsubsection{El criterio gramatical}

El vamos formulativo muestra un comportamiento gramatical claramente diferenciado tanto del vamos verbal, como del vamos interjectivo (conativo y fático). Por una parte, pese a conservar parte del significado léxico de origen relacionado con la prospección discursiva, el vamos formulativo no mantiene ninguna de las características verbales originales: no puede seleccionar argumentos de ningún tipo, ni admite la negación ni la paráfrasis con elementos verbales afines. Por otra parte, a diferencia de lo que ocurre con el vamos conativo y fático, cuya posición estructural prototípica en un contexto dialógico es una intervención iniciativa y reactiva, respectivamente, el vamos formulativo aparece prototípicamente en contextos pragmático-discursivos monológicos que no constituyen una respuesta reactiva a la intervención de otro locutor ${ }^{43}$. Asimismo,

${ }^{43}$ El uso de vamos (que) en contextos dialógicos de heterorreformulación puede adquirir un valor replicativo cuando la conclusión que explicita el hablante evidencia el rechazo o una contraexpectativa respecto del estado de cosas representado implícitamente en el acto de habla de su interlocutor:

A: ¿Has traído lo que te dije?

B: Pues, verás, es que...

A: Vamos, que te has olvidado. Si es que siempre me haces lo mismo. 
el vamos formulativo tampoco responde a los rasgos prototípicos que caracterizan a la interjección:

(i) No constituye un enunciado autónomo; como sugiere Wilkins a propósito de otras interjecciones con función discursiva (1992: 126, nota 5), el vamos formulativo presenta un grado elevado de integración prosódica en la curva entonativa del enunciado (re)formulador.

(ii) No tiene valor modal (salvo en la función de refuerzo ilocutivo-argumentativo, en que el valor modal epistémico se interpreta como una implicatura generalizada $)^{44}$, sino metadiscursivo.

(iii) No presenta una entonación marcada como rasgo inherente (aunque el patrón discursivo del marcador puede verse modificado contextualmente para expresar valores pragmáticos puntuales, como sorpresa, rechazo, enfado, etc.).

En definitiva, los tres criterios considerados permiten asumir que la lectura formulativa constituye un sentido independiente de la red semántica de vamos.

\subsubsection{Derivación del sentido formulativo}

La evolución del sentido verbal al sentido formulativo de vamos, igual que ocurría con el sentido conativo, participa tanto de una extensión metafórica del ámbito semántico y de uso original, como de un refuerzo de implicaturas derivadas de usos no convencionales.

Por un lado, se produce una ampliación metafórica del significado fuente desde un ámbito físico, en el que el movimiento se realiza en un espacio físico real (Yo y otros nos movemos desde aqui hasta otro lugar distinto del espacio que ocupamos), hacia un ámbi-

También se puede interpretar un valor replicativo en contextos monológicos de carácter polifónico en los que el hablante muestra el rechazo respecto de un punto de vista ajeno que no reproduce lo dicho por el interlocutor, sino por un tercero:

Que vaya a la central, que recoja el pedido, que lo lleve al destinatario, no te lo pierdas, en Gerona, y que luego vuelva a la central a recoger los pedidos que vayan entrando entretanto... Y eso a la una y media. Vamos, que se deben pensar que todo eso se hace en un plis.

En estos contextos, pese a que se interpreta contextualmente un valor fático de desacuerdo, creemos que sigue primando la función reformulativa, en tanto que el hablante formula una conclusión que se deriva implícitamente de la situación comunicativa.

${ }^{44}$ El valor epistémico de intensificación ilocutiva de vamos no forma parte de su significado, sino que es un implícito que surge como efecto de la marcación ostensiva del enunciado sobre el que incide el marcador y por la relación contrastiva paradigmática de vamos con otros elementos modales que podrían haberse utilizado en el mismo contexto (Polanco, 2010). 
to no físico, en el que el movimiento supone un cambio de posición virtual. Este cambio de posición puede realizarse o bien mediante una exhortación al oyente para que lleve a cabo una acción o un cambio de actitud, de modo que se produzca un movimiento volitivo por parte del oyente hacia la posición mental del hablante (función conativa y función fática de (des)acuerdo); o bien mediante un movimiento del hablante en el espacio virtual del discurso.

Además del cambio metafórico que se opera en el ámbito de actuación de este marcador, por el que se pasa de un dominio espacial a un dominio discursivo (mediante la metáfora EL DISCURSO ES UN ESPACIO [POR EL QUE MOVERSE]), también interviene un refuerzo implicatural. Este refuerzo de implicaturas conversacionales, como ocurría en el paso del valor verbal al valor conativo, se deriva también de un uso no estereotípico de vamos en contextos en los que no se alude a un movimiento espacial real, ni a la voluntad del hablante de influir en el oyente (salvo por el hecho de implicarlo con el plural morfológico del marcador). En estos nuevos usos de vamos, prima la voluntad del oyente de controlar el discurso, de regular el acto comunicativo y negociar la interacción con el interlocutor. Se interpreta, en suma, la intención del hablante de avanzar en el discurso y de mantener el turno de palabra para añadir información, al tiempo que trata de implicar al interlocutor en la acción discursiva, en su punto de vista. En cierto modo, como hemos apuntado antes, sigue persistiendo el significado original de desplazamiento conjunto a través de un espacio virtual, el propio discurso.

DESPLAZARSE (EN EL ESPACIO) IMPLICA UN CAMBIO DE POSICIÓN PARA

ALCANZAR UNA META (hay un punto de origen, direccionalidad y un punto final)

$($ yo+tú $(+$ otros $)) \bullet \longrightarrow \bullet($ meta locativa $)$

EL DISCURSO ES UN ESPACIO POR EL QUE NOS PODEMOS DESPLAZAR

(PROSPECTIVA O RETROACTIVAMENTE)

(yo)+(tú+otros) $\longrightarrow \bullet$ (meta discursiva: añadir información, mantener el turno)

Implicatura conversacional: El hablante y yo no vamos a movernos, no tenemos que ir a ningún sitio; luego, lo que quiere el hablante es avanzar en su discurso para añadir algo a lo que ya ha dicho; eso es posible porque de algún modo el discurso es como un espacio por el que nos movemos adelante para decir cosas, atrás para recuperar lo dicho, etc.

\subsection{Elaboraciones frente a sentidos}

En este trabajo, hemos centrado la atención en la descripción de los sentidos básicos de la red semántica de vamos. Estos sentidos básicos representan, como hemos tratado 
de demostrar, sentidos codificados de este elemento discursivo. No obstante, como apuntamos en el apartado 2.1.1, la interacción de un sentido básico con determinados contextos discursivos da lugar a diferentes elaboraciones de ese sentido con distintos grados de saliencia y de afianzamiento en la red semántica - y, en consecuencia, con un grado de dependencia variable del contexto de uso- en función del distinto grado de fijación del esquema discursivo en que aparece ${ }^{45}$.

Algunos de estos contextos presentan un grado elevado de estabilidad estructural y de fijación pragmático-discursiva que permite considerarlos como esquemas o construcciones discursivas asociados a determinadas interpretaciones construccionales por defecto (Polanco, 2010: \$7). Así, ciertas interpretaciones de vamos, entre ellas las de reformulación parafrástica o de equivalencia conceptual (ejemplo 1), recapitulativa o de síntesis conceptual (ejemplo 2) y rectificativa (ejemplo 3), pueden entenderse como sentidos construccionales inducidos por defecto por el esquema discursivo en que se insertan estos marcadores. Estas interpretaciones, pese al grado elevado de afianzamiento que presentan, constituyen, sin embargo, elaboraciones de un sentido afianzado más abstracto que las engloba, a saber, el sentido de formulación. Estas elaboraciones forman parte de la estructura semántica del sentido de base formulación y son componentes semánticos potenciales que se activan automáticamente en determinados contextos enunciativos (esto es, cuando el sentido de base interactúa con un esquema discursivo concreto) y se interpretan por defecto, como una implicatura generalizada, siempre que se utiliza en dicho contexto. En este sentido, puede concebirse que estas elaboraciones a partir del sentido de formulación de vamos son previsibles y están, en buena medida, especificadas en el marco de interpretación de la construcción y del propio elemento discursivo (Polanco, 2010: \$7.2.3.). Constituyen, pues, sentidos periféricos de la red semántica de vamos.

Las interpretaciones de reformulación parafrástica, rectificación y recapitulación, en tanto que diferentes formas de formular, pueden entenderse como facetas $^{46}$ del sentido

\footnotetext{
${ }^{45}$ El propósito de este apartado es el de presentar la potencialidad explicativa que puede tener un tratamiento construccional de los contextos funcionales de aparición de vamos para la descripción semántico-funcional de este tipo de elementos discursivos complejos. Por ello, en este apartado no ahondamos en los aspectos teóricos relacionados con el modelo gramatical de tipo construccional basado en el uso que defendemos en este trabajo, tarea que queremos desarrollar en futuros trabajos.

${ }^{46}$ Tomamos el concepto de Allan Cruse (Croft y Cruse, 2004). Con el concepto de faceta, este autor se refiere a ciertos sentidos de una palabra que presentan un grado notable de autonomía pero que necesitan de un contexto concreto para ser interpretados. Las facetas poseen autonomía relacional (cada faceta puede participar en sus propias relaciones de sentido, con independencia del comportamiento de otras facetas) y autonomía composicional (las facetas se relacionan composicionalmente con de-
} 
de formulación, esto es, como subpartes de un todo. En tanto que partes constitutivas del significado de vamos, dichas interpretaciones más concretas son componentes de significado del total semántico de la palabra $\mathrm{y}$, en buena medida, son aislables como tales componentes de significado, lo cual asemeja estas interpretaciones con los sentidos plenos.

Lo mismo puede decirse de algunas interpretaciones más concretas derivadas de alguno de los sentidos construccionales anteriores. Así, por ejemplo, las interpretaciones de recapitulación y conclusión que pueden adquirir marcadores de reformulación recapitulativa como en fin o en definitiva, o vamos y vaya cuando se utilizan en un contexto recapitulativo, pueden entenderse como elaboraciones de un sentido más abstracto, a saber, el de sintesis conceptual. La síntesis conceptual de un segmento discursivo previo puede realizarse bien recapitulando o resumiendo el contenido de ese segmento (15), bien explicitando una conclusión derivada explícita o implícitamente de ese contenido (16).

(15)Venga va aunque sean las tantas y sólo sea pa responder a Chelu, [los amish son algo así como el "Pirulas" pero mucho mas rústicos, vamos los tíos estos que van como los judíos ortodoxos, ya sabes en plan "skinetta". Sólo se alimentan de productos no manufacturados es decir los que se extraen directamente de las huertas, en las que trabajan con maquinaria primitiva, nada de M.C.I.A. y maquinaria pesada (como lo hacían nuestros tatarabuelos) y son muuuuuu respetuosos con el medio ambiente]. Vamos que [viven en el siglo XXI, pero actúan como si lo hiciesen a principios del XIX]. (http://es.groups.yahoo.com/group/ fortunetellersclub/message/3254)

(16) (...) /y yo la verdad es que con mi hermano y con mi cuñada me llevo muy bien / tengo una relación bastante agradable / y con los niños también / además los veo bastante / los saco a pasear / loos- vamos/ un día a la semana me encargo de ellos o sea que... (Preseval, [conv. 1, líneas 31-35])

En tanto que diferentes formas de sintetizar, las interpretaciones más concretas de recapitulación y conclusión pueden entenderse también como facetas del sentido de sintesis conceptual. No obstante, pese a que ambas lecturas presentan cierta autonomía relacional y composicional (ver nota 45), carecen de autonomía atencional (esto es, no

terminados elementos que afectan la interpretación de esa faceta concreta, es decir, que inciden solo en una porción del significado total del otro elemento). Sin embargo, no poseen autonomía atencional (no son unidades de sentido que se excluyan mutuamente), dado que pueden unificarse en una interpretación global o conjunta prototípica que las contiene, lo cual demuestra, según Cruse, que las facetas carecen de estatus pleno de sentido independiente (Croft y Cruse, 2004: 163). Para ser interpretados, estos sentidos dependen de un determinado contexto que los active. 
constituyen unidades de sentido que se excluyen mutuamente), puesto que pueden unificarse en un sentido más abstracto que las engloba, el sentido de síntesis conceptual. Ambas lecturas pertenecen, en buena medida, a tipos ontológicos diferentes (presentan una distancia semántica importante) y exhiben un grado de autonomía que induce a concebirlas como sentidos plenos; sin embargo, la posibilidad de unificación semántica justifica que no puedan considerarse estas interpretaciones como sentidos autónomos dentro de la red semántica. Se trata también, pues, de sentidos construccionales periféricos en la red semántica de vamos, con un grado de prototipicidad menor que los anteriores, dado que son el resultado de reinterpretaciones a partir de sentidos más genéricos.

Por último, algunas de las elaboraciones de un sentido particular son interpretaciones puntuales en situaciones comunicativas concretas. A diferencia de los sentidos construccionales, que son inducidos por las relaciones de solidaridad distribucional y composicional que mantienen el elemento léxico y un cotexto prototípico, las interpretaciones puntuales están sujetas a las variaciones que pueda presentar la situación comunicativa. Así ocurre, por ejemplo, con algunos de los valores pragmático-modales (enfado, irritación, resignación, etc.) y epistémicos (atenuación-refuerzo ilocutivo) de vamos, que pueden añadirse a otros valores discursivos (prototípicos) de este elemento en función de variaciones ocasionales en el patrón entonativo.

\subsection{Representación de la red semántica de vamos}

Como hemos tratado de demostrar en los apartados anteriores, la polifuncionalidad de vamos no es una mera cuestión de variación contextual a partir de un único significado invariante, sino que revela que este elemento discursivo despliega un rango de significados diferenciados en el nivel de la lengua. Estos valores funcionales de vamos (reformulación y rearticulación, función fática y función conativa; véase $\$ 3$ ) presentan un grado de autonomía y de saliencia elevados que permite considerarlos como significados independientes.

Estos significados, que representamos en círculos grises en la red polisémica de la figura 3, son extensiones diacrónicas del sentido verbal original (representado en un círculo negro), pero constituyen también sentidos centrales de la red semántica, en tanto que elementos semánticos independientes ligados a propiedades de selección semántica y gramatical diferenciadas. A su vez, estos significados centrales constituyen sentidos sancionadores de otros valores contextuales (representados en círculos blancos), con distinto grado de saliencia y afianzamiento dentro de la red polisémica. Estos valores contextuales, como hemos comentado en el apartado anterior, responden a 
interpretaciones construccionales derivadas de la interrelación entre el sentido central y determinados contextos prototípicos o esquemas discursivos (este vínculo por defecto se representa en la red semántica mediante una flecha continua).

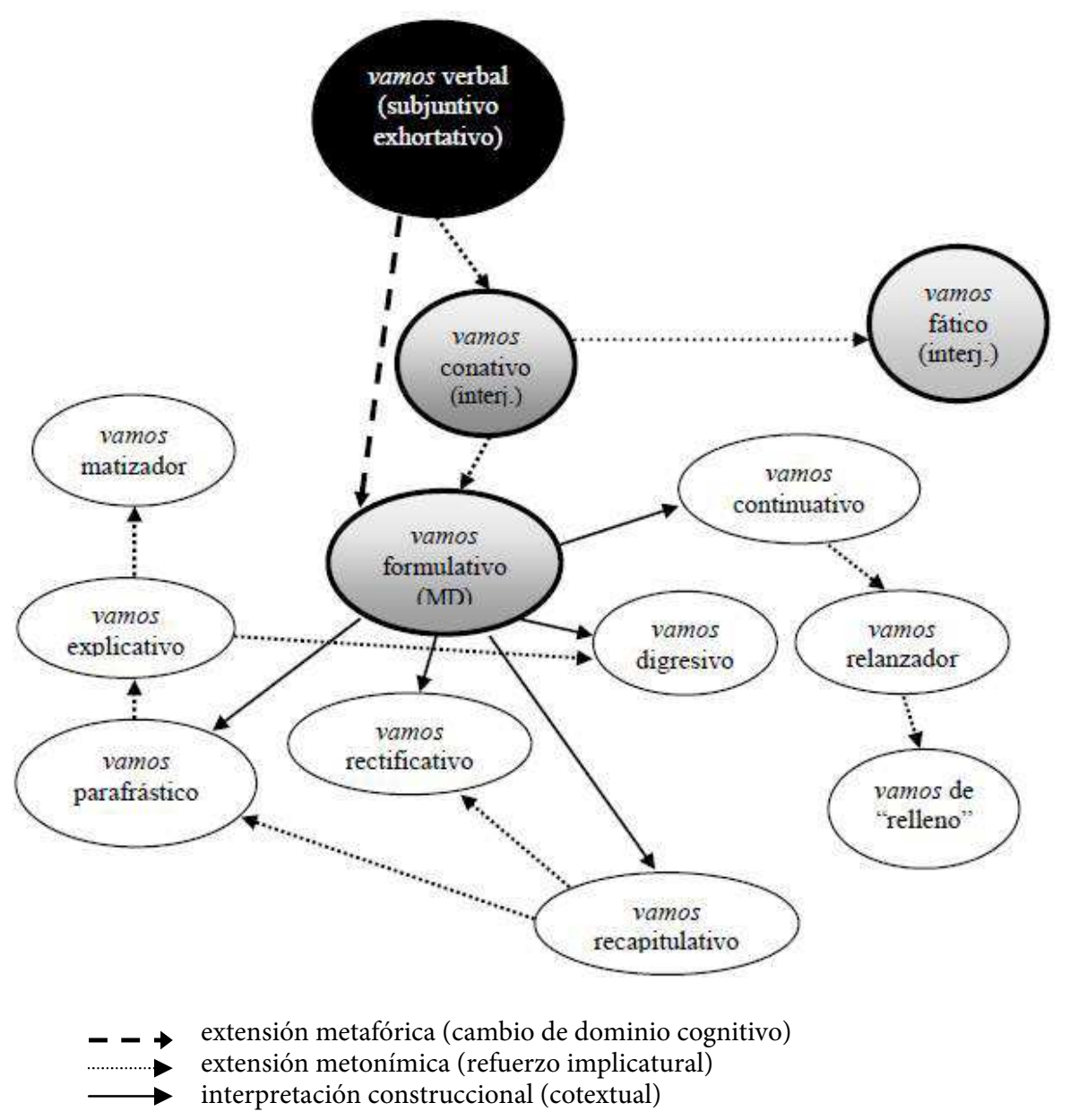

Figura 3. Red polisémicas (sincrónica) de vamos 


\section{Conclusión}

En este trabajo hemos defendido que la polifuncionalidad de vamos pone de manifiesto la naturaleza heterosémica de este tipo de elementos lingüísticos, esto es, su naturaleza policategorial y polisémica. Estos elementos, fuera de contexto, son formas lingüísticas acategoriales asociadas a un complejo, pero estructurado, entramado de rasgos sintácticos, semánticos, pragmático-discursivos y prosódicos. Solo cuando dichas formas lingüísticas se contextualizan, como hemos visto que ocurre en el caso de vamos, se activa una parte de su estructura de rasgos subyacente y podemos hablar entonces de un vamos verbal, interjectivo o marcador discursivo.

Por ello, la descripción semántico-funcional de elementos complejos como vamos requiere de modelos descriptivos que puedan mostrar de forma coherente y cohesionada (esto es, de forma integral) todos los rasgos funcionales que intervienen prototípicamente en el uso e interpretación de estos elementos. De ahí, en nuestra opinión, la idoneidad de aplicar un modelo polisémico radial a la descripción de vamos. Para su configuración, hemos adaptado el modelo propuesto por Evans (2004), el Modelo de polisemia fundamentada. Este modelo aporta la ventaja de proponer una serie de criterios falsables para el establecimiento de los sentidos codificados de las unidades lingüísticas polisémicas. En el caso de vamos, hemos partido de la idea de que este elemento constituye un emparejamiento convencional de forma y sentido, cuyo polo semántico se estructura en forma de una red semántica organizada en torno a tres sentidos básicos, a saber: el sentido conativo (relacionado con la voluntad de influir en la conducta del interlocutor), el sentido fático (relacionado con el (des)acuerdo) y el sentido formulativo (relacionado con las funciones metadiscursivas de (re)formulación). Estos significados son extensiones diacrónicas del sentido verbal como subjuntivo independiente original (representado en un círculo negro en la fig. 3), pero constituyen también sentidos centrales de la red semántica, en tanto que elementos semánticos independientes ligados a propiedades de selección semántica y gramatical diferenciadas.

Además de los sentidos convencionales que acabamos de mencionar, vamos activa determinados sentidos contextuales que parecen interpretarse por defecto, añadidos al significado nuclear, cuando este elemento forma parte de ciertos contextos funcionales prototípicos o esquemas funcionales (Polanco, 2010). Estas interpretaciones funcionales más específicas son el producto de la interrelación entre un determinado sentido básico o convencional y ciertos esquemas discursivos prototípicos y están fuertemente motivadas por esa interrelación. Estos sentidos, que hemos denominado sentidos construccionales, pueden concebirse como lecturas por defecto, en tanto que se activan automáticamente en función de dicha interrelación. Y son también, al mismo tiempo, interpre- 
taciones cancelables, esto es, interpretaciones que pueden anularse si existe presión contextual en una dirección interpretativa distinta. Por ello, pese a su fijación semántico-cognitiva, no son sentidos codificados, pero sí sentidos con un alto grado de convencionalidad, fácilmente accesibles en la memoria discursiva del hablante (esto es, en el marco de interpretación asociado a vamos). Son, pues, sentidos periféricos de la red semántica de vamos.

Recibido: 27-VII-2012

Aceptado: 25-I-2013

\section{Referencias bibliográficas}

Archakis, A. (2001): "On discourse markers: evidence from Modern Greek", Journal of Pragmatics, 33, págs. 1235-1261.

Blakemore, D. (1987): Semantic constraints on relevance. Oxford, Blackwell.

Blakemore, D. (1993): “The relevance of reformulations", Language and Literature, 2:2, págs. 101-102.

Blakemore, D. (2002): Relevance and linguistic meaning. The Semantics and Pragmatics of Discourse Markers. Cambridge, Cambridge University Press.

Boogart, R. (2009): "Semantics and pragmatics in construction grammar: The case of modal verbs". En Bergs, A. y G. Diewald (eds.): Contexts and Constructions. Amsterdam/Philadelphia, John Benjamins.

Brinton, L. J. (1996): Pragmatic markers in English. Grammaticalization and discourse functions. Berlin-New York, Mouton de Gruyter.

Briz, A. (1993a): "Los conectores pragmáticos en español coloquial (I): su papel argumentativo", Contextos, XI/21-22, págs. 145-188.

Briz, A. (1993b): "Los conectores pragmáticos en español coloquial (II): su papel metadiscursivo", Español Actual, 59, págs. 39-56.

Briz, A. (1998): El español coloquial en la conversación. Esbozo de pragmagramática. Barcelona, Ariel, 2001.

Brugman, C. (1988): The story of over: Polysemy, semantics and the structure of the lexicon. New York, Garland Press.

Brugman, C. y G. Lakoff. (1988): "Cognitive topology and lexical networks". En Small, S., Cottrell, G. y M. Tannenhaus (eds.): Lexical Ambiguity Resolution. San Mateo, CA, Morgan Kaufman, págs. 477-507.

Chodorowska-Pilch, M. (1999): "On the polite use of 'vamos' in Peninsular Spanish", Pragmatics, 9/3, págs. 343-356.

Company, C. (2004a): “¿Gramaticalización o desgramaticalización? Reanálisis y sub- 
jetivización de verbos como marcadores discursivos en la historia del español", RFE, LXXXIV, 1, págs. 29-66.

Company, C. (2004b): "Gramaticalización por subjetivización como prescindibilidad de la sintaxis", NRFH, 52:1, págs. 1-28.

Cortés, L. y M. M. Camacho (2005): Unidades de segmentación y marcadores del discurso. Madrid, Arco Libros.

Croft, W. (1998): "Linguistic evidence and mental representations", Cognitive Linguistics, 9, págs. 151-173.

Croft, W. y D. A. Cruse (2008): Cognitive Linguistics. Cambridge, Crambridge University Press.

Cuenca, Ma . J. (2001): "Los conectores parentéticos como categoría gramatical", LEA, XXIII: 2, págs. 211-235.

Cuenca, Ma. J. (2002): "Els connectors textuals i les interjeccions". En Solà. J y otros (dirs.): Gramática del català contemporani, vol. 3, cap. 31. Barcelona, Editorial Empúries, págs. 3173-3237.

Diewald, G. (2002): “A model for relevant types of contexts in grammaticalization”. En Wischer, I. y G. Diewald (eds): New reflections on Grammaticalization. Amsterdam, John Benjamins, págs. 103-120.

Evans, V. (2004): The structure of time: Language, Meaning and Temporal Cognition. Amsterdam, John Benjamins.

Evans, V. (2005): “The meaning of time: Polysemy, The Lexicon and Conceptual Structure", Journal of Linguistics, 41:1, págs. 1-39.

Evans, V. (2006): "Lexical Concepts, Cognitive Models and Meaning-Construction", Cognitive Linguistics, 17: 4, págs. 491-534.

Evans, V. (2009): How Words Mean: lexical concepts, cognitive models and meaning construction. Oxford, Oxford University Press.

Evans, V. y M. Green (2005): Cognitive Linguistics. An Introduction. Edinburgh, Edinburgh University Press.

Evans, V. y A. Tyler (2004a): "Rethinking English 'prepositions of movement' : the case of to and through". En Cuyckens, H. de Mulder, W. y T. Mortelmans (eds.): Adpositions of movement (special issue of the Belgian Journal of Linguistics 17). Amsterdam, John Benjamins, págs. 247-270.

Evans, V. y A. Tyler (2004b): "Spatial experience, lexical structure and motivation: the case of in". En Radden, G. y K-U. Panther (eds.): Linguistic studies in motivation. Berlin, Mouton de Gruyter, págs. 157-192.

Fischer, K. (2000a): From Cognitive Semantics to Lexical Pragmatics. The Functional Polysemy of Discourse Particles. Berlin and New York, Mouton de Gruyter.

Fischer, K. (2000b): "Discourse particles, turn-taking, and the semantics-pragmatics 
interface", Revue de Sémantique et Pragmatique, 8, págs. 111-137.

Fischer, K. (ed.) (2006a): Approaches to Discourse Particles. Studies in Pragmatics (vol. 1), Amsterdam, Elsevier.

Fischer, K. (2006b): "Frames, constructions and invariant meanings: the functional polysemy of discourse particles". En Fischer, K. (ed.), págs. 427-448.

Fischer, K. (2010): "Beyond the Sentence: Constructions, Frames and Spoken Interaction", Constructions and Frames, 2 (2), págs. 185-207.

Fuentes Rodríguez, C. (1987): Enlaces extraoracionales. Sevilla, Alfar.

Fuentes Rodríguez, C. (1998): "Vamos: un conector de gran complejidad". En Martín Zorraquino, Ma. A. y E. Montolío Durán (eds.), págs. 177-192.

Fuentes Rodríguez, C. (2009): Diccionario de conectores y operadores del español. Madrid, Arco Libros.

Geeraerts, D. (1993): "Vagueness's puzzles, polysemy's vagaries", Cognitive Linguistics, 4, págs. 223-272.

González Ollé, F. (2002): "Vamos. De subjuntivo a marcador (con un excurso sobre imos)". En Álvarez de Miranda, P. y J. Polo (eds.): Lengua y diccionarios. Estudios ofrecidos a Manuel Seco. Madrid, Arco Libros, págs. 117-135.

Gras, P., Polanco, F. y M. Santiago (2005): "Forma, función y evolución del marcador conversacional venga en español". En López Cano, P. (coord.): Actas VI Congreso de Lingüística General, págs. 1621-1635.

Hansen, M. M. (1998a): The Function of Discourse Particles. A study with special reference to spoken standard French, Amsterdam/Philadelphia, John Benjamins Publishing Company.

Hansen, M. M. (1998b): "The semantic status of discourse markers", Lingua, 104, págs. 235-260.

Hansen, M. M. (2005): "From propositional phrase to hesitation marker. The semantic and pragmatic evolution of French enfin", Journal of historical pragmatics, 6:1, págs. 37-68.

Hansen, M. M. (2006): "A dynamic polysemy approach to the lexical semantics of discourse markers (with an exemplary analysis of french toujours)". En Fischer, K. (ed.), págs. 21-41.

Lakoff, G. (1987): Women, Fire and Dangerous Things: What Categories Reveal About the Mind. Chicago, University of Chicago Press.

Langacker, R. (1987): Foundations of Cognitive Grammar I. Theoretical Prerequisites. Stanford, Standford University Press.

Loureda, O. y E. Acín (coords.) (2010): Los estudios sobre marcadores del discurso en español, hoy. Madrid, Arco Libros. 
Lyons, J. (1977): Semantics. Cambridge, Cambridge University Press.

Lyons, J. (1997): Semántica lingüistica. Una introducción. Barcelona, Paidós.

Martín Zorraquino, Ma . A. y E. Montolío Durán (coords.) (1998): Los marcadores del discurso. Teoría y análisis. Madrid, Arco Libros.

Martín Zorraquino, Ma . A. y J. Portolés (1999): "Los marcadores del discurso". En Bosque, I. y V. Demonte (dirs.): Gramática descriptiva de la lengua española, vol. 3. Madrid, Espasa Calpe, págs. 4051-4213.

Matsui, T. (2002): "Semantics and pragmatics of a Japanese discourse marker dakara (so/in other words): a unitary account", Journal of Pragmatics, 34, págs. 867-891.

Montolío Durán, E. (1998): "La Teoría de la Relevancia y el estudio de los marcadores discursivos”. En Martín Zorraquino, M. A. y E. Montolío Durán (eds.), págs. 177192.

Montolío Durán, E. (2001): Conectores de la lengua escrita. Barcelona, Ariel.

Murillo, S. (2000): "English explicatory reformulative discourse markers: Conceptual or procedural?". En Navarro, M. P. y otros (eds.): Transcultural Communication: Pragmalinguistic Aspects. Zaragoza, Anubar, págs. 131-138.

Murillo, S. (2004): “A relevance reassessment of reformulation markers”, Journal of Pragmatics, 36, págs. 2059-2068.

Nemo, F. (2002): "But (and Mais) as Morpheme(s)”, D.E.L.T.A., 18, págs. 87-114.

Nemo, F. (2006): "Discourse Particles as Morphemes and as Constructions". En Fischer, K. (ed.), Approaches to Discourse Particles, vol. 1 de Studies in Pragmatics, Amsterdam, Elsevier, págs.

Polanco, F. (2010): Variación funcional y polisemia. Marcadores conversacionales procedentes de verbos de movimiento: el caso de vamos y vaya. Tesis doctoral. Departamento de Filología Hispánica. Universidad de Barcelona.

Pons Borderia, S. (1998): Conexión y conectores. Estudio de su relación en el registro informal de la lengua. Cuadernos de Filología, anejo 27. Valencia, Universitat de València.

Pons Borderia, S. (2006): "A functional approach to the study of discourse markers". En Fischer, K. (ed.), págs. 77-99.

Portolés, J. (2001): Marcadores del discurso. Barcelona, Ariel, 1998.

Portolés, J. (2004): Pragmática para hispanistas. Madrid, Síntesis.

Redeker, G. (1990): "Ideational and pragmatic markers of discourse structure", Journal of Pragmatics, 14, págs. 367-381.

Redeker, G. (1991): "Linguistic markers of discourse structure”, Linguistics, 29, págs. 1139-1172.

Romero Aguilera, L. (2006): "La gramaticalización de verbos de movimiento como 
marcadores del discurso: el caso de vamos", Res Diacronicae, 5, págs. 46-56.

Sandra, D. (1998): "What linguists can and can't tell you about the human mind: a reply to Croft", Cognitive Linguistics, 9: 4, págs. 361-378.

Sandra, D. Y S. Rice (1995): "Network analices of prepositional meaning: mirroring whose mind the linguist's or the language user's?", Cognitive Linguistics, 6:1, págs. 89-130.

Schourup, L. (2001): “Rethinking 'well'”, Journal of Pragmatics, 33, págs. 1025-1060.

Sweetser, E. (1990): From Etymology to Pragmatics: Metaphorical and Cultural Aspects of Semantic Structure. Cambridge, Cambridge University Press.

Taylor, J. (2003): Linguistic categorization: prototypes in linguistic theory. Oxford, Oxford University Press.

Toledo Huerta, A. (2001): “¿Un viaje de ida y vuelta?: la gramaticalización de vaya como marcador y cuantificador”, Anuari de Filologia, XXIII, F: 11, Barcelona, Universitat de Barcelona, págs. 39-63.

Traugott, E. C. (1997): "The role of the development of discourse markers in a theory of grammaticalization" (conferencia leída en la $12^{\text {th }}$ International Conference on Historical Linguistics, Manchester, 1995; version escrita de noviembre de 1997): http://www.stanford.edu/ traugott/papers/discourse.pdf (23-03-2007]).

Traugott, E. C. (2010): "Contexts and gramatical constructions". Comunicación en el 6th International Conference on Construction Grammar (ICCG-6), Praga, septiembre de 2010.

Traugott, E. C. y E. König (1991): “The Semantic-Pragmatics of Grammaticalization Revisited”. En Traugott, E. C. y B. Heine (eds.): Approaches to Grammaticalization. Amsterdam, John Benjamins, págs. 189-218.

Travis, C. E. (2005): Discourse Markers in Colombian Spanish: A Study in Polysemy. Berlin/New York, Mouton de Gruyter.

Travis, C. E. (2006): "The natural semantic metalanguage approach to discourse markers”. En Fischer, K. (ed.), págs. 219-241.

Tyler, A. y V. Evans (2001): "Reconsidering prepositional polysemy networks: the case of over", Language, 77: 4, págs. 724-765.

Tyler, A. y V. Evans (2003): The Semantics of English Prepositions: Spatial Scenes, Embodied Experience and Cognition. Cambridge, Cambridge University Press.

Verschueren, J. (2000): "Notes on the role of metapragmatic awareness in language", Pragmatics, 10:4, págs. 439-456.

Verschueren, J. (2002): Para entender la pragmática. Madrid, Gredos.

Waltereit, R. (2006): "The rise of discourse markers in Italian: a specific type of language change”. En Fischer, K. (ed.), págs. 61-76. 
Wierzbicka, A. (1988): The semantics of grammar. Amsterdam/Philadelphia, John Benjamins.

Wierzbicka, A. (1996): Semantics. Primes and Universals. Oxford/New York, Oxford University Press. 



\title{
PARODY AS EVALUATION: ABOUT A TELEVISION SKETCH IN SPANISH $^{1}$
}

\author{
LEONOR RUIZ GURILLO \\ University of Alicante \\ Leonor.Ruiz@ua.es
}

\begin{abstract}
Resumen
En este artículo se analiza un sketch televisivo, procedente del programa Saturday Night Live español. El sketch es un tipo de parodia muy relacionada con la sátira (Simpson, 2003:123). Como texto humorístico, se observan los rasgos de la sátira y de la parodia como tal. El repaso a la bibliografía sobre humor y en especial de la General Theory of Verbal Humor -GTVH- (Attardo, 2001a y 2008) permite contemplar las diversas fuentes de conocimiento propuestas desde la situación de la parodia y determinar que es el blanco de la burla la más importante. La discusión teórica se completa con el examen de diversas teorías sobre la sátira y la parodia, como las de Rossen-Knill \& Henry, 1997; Pueo, 2002; Simpson, 2003. Todo ello conduce a la idea de que en la parodia el elemento primordial es el acto cómico. Para lograrlo, el hablante o escritor emplea diversos elementos evaluativos. Así, en primer lugar, se examina la evaluación como parte de la narración (Labov y Waletzky, 1967). Ahora bien, dicha concepción de evaluación ha de ser completada necesariamente con la que la entiende como procedimiento (Kotthoff, 2003; Partington, 2007 y 2011). En este caso, tanto las marcas (elementos kinésicos, sonrisa,...) como los indicadores del humor (fraseología, polisemia, pseudoabarcadores,...) son elementos evaluativos.
\end{abstract}

\begin{abstract}
This article has as its aim to analyze a TV sketch from the Spanish Saturday Night Live show. The sketch is a type of parody very closely related to satire (Simpson, 2003:123). As a humorous text, it shows the features characterizing both satire and parody. A review of the bibliography on humor and especially of the General Theory of Verbal Humor - GTVH- (Attardo, 2001a and 2008) permits to study the different knowledge resources proposed from the parody situation and determine which target is the most important. The theoretical discussion is completed with the examination of several theories about satire and parody, such as those of RossenKnill \& Henry, 1997; Pueo, 2002; or Simpson, 2003. All of this leads to the idea that the comic act is the essential element in parody. The speaker or writer uses a variety of evaluative elements in order to achieve it. Thus, evaluation is firstly analyzed as a part of the narration (Labov \& Waletzky 1967). However, that evaluation concept must necessarily be completed with the one which understands evaluation as a procedure (Kotthoff, 2003; Partington, 2007 and 2011). In this case, both the markers (kinesic elements, smile,...) and indicators of humor (phraseology, polysemy, pseudocomprehensive elements,...) are evaluative elements.
\end{abstract}

\footnotetext{
${ }^{1}$ This research was supported by the Spanish Ministry of Economy and Competitiveness through the grant FFI2012-30941 "Innovaciones lingüísticas del humor: géneros textuales, identidad y enseñanza del español [Linguistic innovations of humor: textual genres, identity and Spanish learning]. For further information visit http://dfelg.ua.es/griale/ and http://humoria.blogspot.com
} 
PALABRAS CLAVE: parodia, sketch, sátira, humor, blanco de la burla.
KEY WORDS: parody, sketch, satire, humor, target.

\section{Introduction}

This article presents the analysis of parody as a form of humor. More precisely, the analysis focuses on a television sketch from the Spanish Saturday Night Live show. The sketch is a type of parody and this, in turn, "is undeniably the closest form of verbal humour to satire" (Simpson, 2003: 123). For Méndez (2004), parody is a humor category based on intertextuality, since it dialectically opposes an original text to the one built as a parody. It has an ideological component and, as far as television is concerned, it implies a frivolous use of information.

The treatment of this sketch permits to make some reflections on the relationships between humor, satire and parody. Thus, $\$ 2$ shows the pragmatic model for humor developed by the General Theory of Verbal Humor (hereinafter, GTVH) of V. Raskin and S. Attardo. The consideration of parody as a humorous text entails the development of various approaches to its specific features in $\$ 3$. $\$ 4$ contains an analysis of the evaluative aspects that surround parody, understood both as a structural part of the story and as a procedure which makes it possible to persuade the audience. Once these aspects have been settled, they are applied to analyze one of the sketches from the Saturday Night Live show in $\$ 5$. The video, which is available from Youtube, has been transcribed following the keys of the Val.Es.Co Research Group 2 . It lasts 3 minutes and 15 seconds. Finally, the article ends with some conclusions that permit to consolidate an analytical model which can be exported to other examples of parody (\$6).

\section{A pragmatic model for verbal humor}

During the last few years, the GRIALE research group has developed an analysis of irony and humor from the linguistic point of view and, more precisely, from a pragmatic perspective. Our specific model (see especially Ruiz-Gurillo, 2010 and 2012) is supported on the inferential processes which permit to understand humor and focuses on performing the following tasks:

-It tries to show generalizations in the utilization of humor.

\footnotetext{
${ }^{2}$ These transcription keys can be found in www.valesco.es.
} 
-It seeks to observe every side of the communicative phenomenon: the selected genre; the predominant text (or sequence); the context where the said humorous genre is used; to whom the mockery is addressed; which scripts are opposed in incongruity and how that incongruity is resolved; which logical mechanisms contribute to resolve it; and which mutual relationships exist between those logical mechanisms and the linguistic and paralinguistic choices carried out by the speakers/writers.

-It analyzes markers and indicators as footprints of the conscious or unconscious choices made by speakers when they use language.

Based on these premises, humor presents a set of generalizations that can be studied, which in turns makes it possible to teach or learn the aspects surrounding the utilization of this pragmatic awareness (Ruiz-Gurillo, 2006) ${ }^{3}$. The examination of the different existing theories about the pragmatic explanation of humor has led us to adopt the GTVH as the most suitable model to achieve these aims, as will be shown below.

In 1985, V. Raskin proposed his Script-based Semantic Theory of Humor (hereinafter, SSTH), which, as its name indicates, is based on the notion of script. Such a cognitive construction, also known as frame or schema by other authors, implies a structured information area which the speaker internalizes and which represents the knowledge owned by that speaker about a part of the world (Raskin, 1985: 81). The theory was improved with the arrival of Salvatore Attardo, after which they both (Attardo \& Raskin, 1991) proposed the General Theory of Verbal Humor) (hereinafter, GTVH).

Following this proposal, S. Attardo carried out a linguistic analysis of verbal humor in 1994. That analysis collects the achievements of such disciplines as semiotics or psychology. In 2001 (Attardo, 2001a), he devised a GTVH that could be applied to texts from diverse registers, to different situations (mass media) and to a variety of historical periods. The analysis consequently deals with texts which are longer than jokes, such as novels, short stories, television sitcoms, movies or games. Amongst others, it takes into

\footnotetext{
${ }^{6}$ Following Jef Verschueren's position, a conception of pragmatics as a perspective is defended. Pragmatics is therefore a cognitive, social and cultural science of language and communication which refers to the utilization of language. Using language implies making a continuous linguistic choice where three key concepts are involved, namely: variability, which determines the range of possible choices; negotiability, through which these choices can be carried out in accordance with flexible principles and strategies; and adaptability; which makes it easier for human beings to make linguistic choices that can be negotiated from a range of variable options, seeking to satisfy the communicative needs (Verschueren, 2002: 129-130 and 2009). These choices can be totally automatic or fully conscious; they all form part of language use.
} 
account criteria like the linear nature of the text, the importance of beginnings and ends of humorous structures, the roles of humor in the narration, or the humorous plot.

The SSTH is a semantic theory; the GTVH is a broader linguistic theory. Unlike the former, the GTVH is supported on six knowledge resources, which are initially applied to jokes and show a hierarchical relationship with one another (Attardo, 2001a: 22-27 and 2008: 108). These six resources, which are listed below, will determine whether any given text can be described as humorous or not:

1. Script Opposition, the basis of the SSTH and of any humorous text.

2. Logical Mechanism, which corresponds to the resolution phase in incongruityresolution models. It is the mechanism whereby the incongruity of Script Opposition is playfully and/or partially explained away. ${ }^{4}$. Different types of logical mechanisms exist, among them juxtaposition, false analogy or chiasmus.

3. Situation, essential to understand humorous texts and their inferences.

4. Target or what is known as 'butt' of the joke or humorous text. Group or individual stereotypes belong here. However, this knowledge resource may be optional because some forms of humor do not have as their aim to ridicule anyone in particular.

5. Narrative Strategy, i.e. the genre of the joke or the humorous text.

6. Language, that is, choices related to lexis, syntax, phonology, etc.

Therefore, the knowledge resources used by the humorous text are hierarchically organized as we have briefly described in Figure 1 following Attardo (2008: 28):

\footnotetext{
${ }^{4}$ The formulation for the logical mechanism presented by Attardo (2008: 108) has been chosen here. This formulation is much clearer than the one which appeared in Attardo (2001a: 25-26), where he additionally recognizes that it is the most problematic of the six parameters which form the knowledge resources for humorous texts.
} 


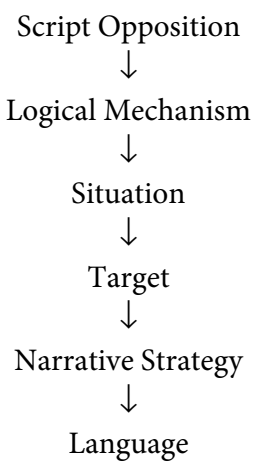

Figure 1: Hierarchical organization of knowledge resources for humorous texts according to the GTVH

This model works very well in short texts, like jokes, but it has also proved effective in longer texts. In this respect, the application of the GTVH to fragments longer than jokes offers at least four assumptions (Attardo, 2001a: 206 and 2008: 110):

1. The analysis of texts as a vector, where each humorous utterance can be coded and analyzed according to the GTVH proposal, which takes into account aspects such as script opposition, the logical mechanisms which are implemented for the resolution of incongruity or the language used.

2. The distinction between jab lines and punch lines ${ }^{5}$, the latter being the climaxes with which the humorous text is closed; jab lines may appear anywhere in the text and are completely integrated into the narrative where they appear.

3. As a consequence of it, the importance accorded to the relative distribution of the lines in the text.

4. A taxonomy and analysis of humorous plots, where the following types are distinguished:

4.1. Humorous plot with a punch line, the maximum exponent of which is the joke;

\footnotetext{
${ }^{5}$ Using the boxing metaphor, S. Attardo puts on a level the jab lines and punch lines procedures with the types of basic blows: the jab is a fast, direct blow, launched with the front hand from the on-guard position, and is understood as the most important blow available to a boxer, as it provides him with a sufficient amount of his own guard capacity and leaves very few chances for him to be punched by the opponent (Source: http://es.wikipedia.org/wiki/Boxeo; consulted on: August 4th, 2010). The punch is regarded as a final blow within this analogy, in this case of the joke or any other humorous text.
} 
4.2. Humorous plot with a metanarrative disruption; a text including one or more interruptions of the narrative conventions typical of this genre; these interruptions have a humorous nature;

4.3. Humorous plot with a humorous central complication: these are essentially texts where the central complication of the story is humorous in itself. Attardo (2008:112-113) sees it as the most interesting category among humorous plots, but also as the most problematic one.

This proposal has proved its validity over time, due to which both the SSTH of V. Raskin and the GTVH of V. Raskin and S. Attardo have become "the two most influential linguistic humor theories of the last two decades" (Brône, Feyaerts \& Veale, 2006: 203). It is therefore a widely accepted theory in linguistic research studies. In our opinion, this is due to the fact that the proposal is more far-reaching than others, since it permits to observe generalizations in the logical mechanisms used by humor in its various expressions, it understands narrative strategies as an inherent characteristic of humor, and does not forget the importance of lexical, grammatical or phonological choices. It also assigns an outstanding role to the communicative situation where the humorous text develops as well as to the addressee of the mockery. These six aspects consequently offer an integrated explanation of the communicative event represented by the humorous text, whether it is a joke, a monologue or a parody $y^{6}$.

Of these six knowledge resources, target appears as the most outstanding one in the case of parody because mockery represents one of the comic act foundations (RossenKnill \& Henry, 1997, see below). In turn, the knowledge resource identified as target organizes different humor procedures such as the provision of evaluative elements which make it easier to achieve the effects sought by the text; for instance, social or political criticism and persuasion.

\section{Satire, parody, sketch}

According to Pueo (2002), parody has become widespread in the current postmodern times; in other words, nearly everything can be parodied. For Méndez (2004), parody is a humor category based on intertextuality. Therefore, it is built on enunciative procedures, as opposed to other expressions of humor which are constructed using linguistic procedures. In this respect, Charaudeau (2006:32) pointed out that two recip-

${ }^{6}$ About a revised model for humorous texts, according to GRIALE Research Group, see Ruiz-Gurillo (2012) and Ruiz-Gurillo (2013). 
rocally-feeding texts coexist in parody: the original text is the reference; the parodic text finds its foundation in the mockery based on the original.

Following Simpson's approach (2003: 123), it is advisable to examine parody relating it to its closest form: satire. In this sense, satire is defined as a discursive practice frequently integrated into the different everyday humor practices. As such, it comprises several elements:

- The satirist, or producer of the text

- The satiree, i.e. the addressee, whether it is the reader or the listener

- The satirized, i.e. the target attacked or criticized in the satirical discourse

With regard to its linguistic properties, it works as a higher-rank discourse, since it uses a primary genre with which it establishes a dialectical relationship ${ }^{7}$. In this way, it activates a previous real or possible discursive event which becomes an echoic discourse of the satirical text. It is the dissonance between the original domain and the dialectical one that creates a pragmatic framework for interpretation. Furthermore, as Lefort (1999) equally warns us, satire fulfills an ideological role. It is the case of television parody, understood as a "critical and social response to the serious, legitimized discourses transmitted by the mass media through the traditional news programs" (Méndez, 2004: 186). More precisely, it contains:

(...) a kind of humor based on totally different contents linked to the current news in the media, which turns it into a type of discourse that does not exclusively seek laughter as a response by the viewer but a deeper effect which tries to provoke reflexive reactions that make the viewer adopt a critical stance and evaluate the topics which are the object of humor (Méndez, 2004: 163).

According to Méndez (2004 and 2009), the expressions of humor on Spanish television have evolved: there was a time when they were not autonomous, as they appeared integrated into other programs. Furthermore, they occupied much less time within the program grid. An increase of humor in television program grids with the aim of attracting the audience is detected halfway through the 1990s, coinciding with the consolidation of private channels. In this context, there was an increase of TV sitcoms, both selfproduced and foreign ones, cartoons for grown-ups, humorous monologues (La noche de la comedia [The comedy night], El club de la comedia [The comedy club]), special humor programs made by acclaimed comedians like Los Morancos or Cruz y Raya), or news programs and magazines. All of this has led to the creation of new formats, "to-

\footnotetext{
${ }^{7}$ This is why Simpson (2003: 215) does not see parody as a discursive genre strictly speaking.
} 
tally new and original discursive subgenres in the Spanish television panorama" (Méndez, 2004: 158). In fact, even some supposedly serious contents, such as the news or sports, are suffering a ludic frivolization. In this context, Méndez analyzes the magazine Caiga quien caiga [Whoever may fall] during its early stage, when it was directed by the comedian known as "el Gran Wyoming." This sort of media humor is defined as informative parody.

Summing up, parody can be said to represent a humorous discursive practice close to satire. In recent times, parody has become a highly frequent discursive exercise in television programs, which is why television or informative parody can actually be described as a specific expression of humor. These developments are illustrated by means of Figure 2:

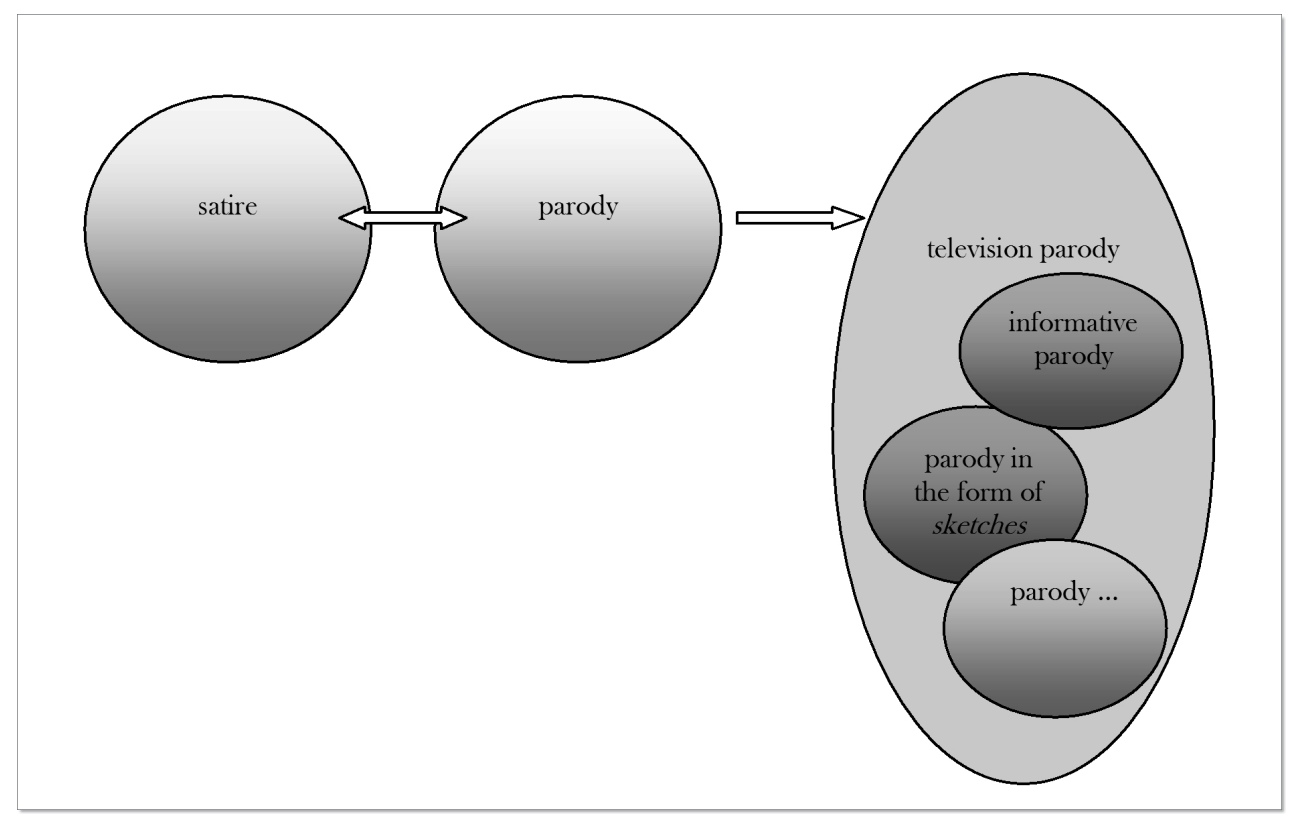

Figure 2: Relationships between satire and parody and the (possible) types of television parody

Assuming that satire and parody share their basic features, Rossen-Knill \& Henry (1997) argue that verbal parody is a speech act, as defined by J. Searle, and propose four essential features identifying it:

1. The intentional verbal representation of the object of parody, which includes a linguistic form and a target (events, actions, beliefs and thoughts...). 
2. The flaunting of the verbal representation, according to which the speaker tries to remind or bring the previous act or event that is being parodied to the listeners' memory with its representation and, secondly, tries to help listeners recognize it. It is achieved at least with laughter and with the infringement of pragmatic maxims or principles ${ }^{8}$.

3. The critical act, which ridicules the object of parody. Both the intentional representation and the flaunting carried out by the speaker remind the listener of the event which is being ridiculed. Therefore, there may be simply a joke about something or contempt may be shown in relation to the object of criticism.

4. The comic act, the final essential act of verbal parody. Seeking to achieve 'comicity' or humor, the speaker restricts the language used in order to produce the intentional representation of the object of parody, flaunts that representation and restricts criticism; in short, it integrates or manipulates these three types of acts with the aim of creating the comic act.

In this context, they propose the following model for verbal parody:

${ }^{8}$ Levinson (2000) suggests a maxim for the speaker and a corollary for the interlocutor as pragmatic principles. Quantity, Q-principle (Levinson, 2000: 76):

Speaker's maxim: Do not provide information which is weaker than the knowledge of the world that you own; more precisely, select the strongest element in the paradigm.

Interlocutor's corollary: The information offered by the speaker is the strongest one that he can provide.

Manner, M-principle (Levinson, 2000: 136-137):

Speaker's maxim: Indicate a normal situation by means of non-marked expressions.

Interlocutor's corollary: A marked expression describes a non-stereotypical situation.

Informativity (I-principle) (Levinson, 2000: 114):

Speaker's maxim: Provide minimum information which suffices to achieve your communicative aims.

Interlocutor's corollary: Elaborate on the content of the speaker's utterance until the specific interpretation is found.

With regard to the inferential processes triggered by humor, they mainly occur as an infringement of the Informativity principle proposed by Levinson (2000). Referents in humor multiply by means of indicators such as polysemy, homonymy, ambiguity, synonymy or the use of pseudocomprehensive elements. The other two pragmatic principles, the Manner principle and the Quantity principle, are equally infringed in humor, although they depend on the humorous context facilitating the infringement of the Informativity principle. For further information about the way in which these principles are infringed in irony and humor, see Ruiz Gurillo (2010). 


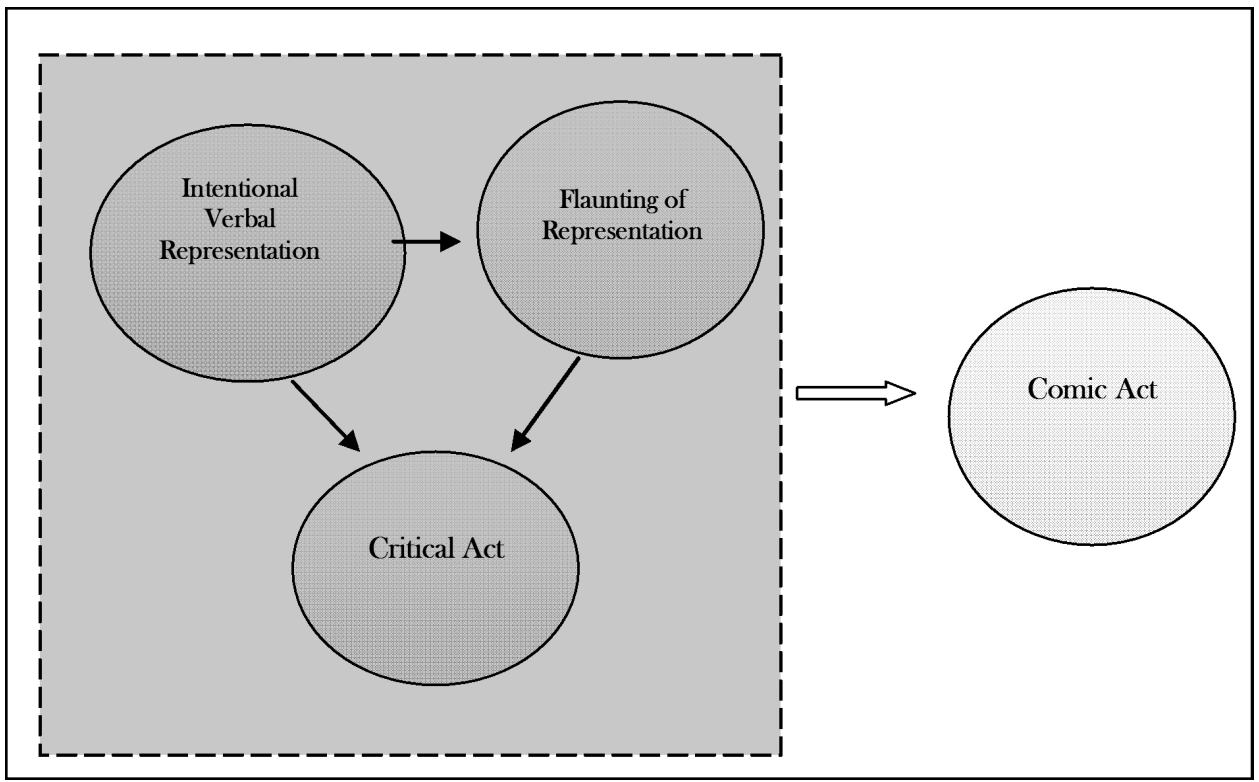

Figure 3: A model of verbal parody according to Rossen-Knill \& Henry (1997:736)

Therefore, parody is based on intertextuality or, to put in another way, it dialectically opposes an original text to the text built as parody. It has an ideological component and, in the case of television, it implies a frivolous use of information. For this reason, it is important to consider which language is used, who is the addressee of the mockery, which procedures are used to flaunt that parody, who is criticized and how and, finally, how 'comicity' or humor is produced.

\section{The evaluative aspects of parody}

Rossen-Knill \& Henry (1997) explain that the comic act of parody is achieved, amongst other aspects, through the selection of a linguistic form and a target. In our view, these linguistic elements represent evaluative elements at the service of mockery, the foundation of parody and, consequently, of humor. According to a widely accepted concept of evaluation (Labov \& Waletzky, 1967), evaluation is a part of the narration. Therefore, stories would have an initial situation, a climax, an evaluation and a resolu- 
tion. Nevertheless, some of these authors (Laforest, 1996; Silva Corvalán, $1987^{9}$ ) point out that evaluation is not only a structural part of the account but also a function or procedure which helps maintain the interest throughout the story. Therefore, instead of being understood as a structure, evaluation is a discursive function of the narration, more specifically, a linguistic expression of the opinion transmitted by the speaker/writer (Bednarek, 2009). Its main role consists in persuading the addressee about a system of values or transmitting social or political criticism, amongst others, to that addressee.

Evaluation has been analyzed in its relationship with irony (Kotthoff, 2003; Partington, 2007 and 2011). For the latter author, evaluation is present in practically every form of linguistic communication, where it becomes a persuasion tool which helps the speaker/writer transmit a certain way of thinking to the audience (Partington, 2011: 1787). It can consequently impose a system of values in an explicit or implicit way. In this respect, irony markers are a tool for social control or criticism and, consequently, for persuasion. Their role is relevant in argumentative texts such as those found in newspapers or political debates (Partington, 2007).

Different evaluation methods are utilized in the case of parody. According to Rossen-Knill \& Henry (1997), parody integrates an intentional verbal representation comprised by a specific linguistic form and a target of the mockery. Following the GTVH proposal presented in $₫ 2$, the target becomes one of the main knowledge resources. A variety of linguistic elements are used to achieve the mockery and, consequently, to persuade the audience about a state of affairs. Both the linguistic markers and the linguistic indicators represent evaluative expressions at the service of persuasion and criticism, more precisely of the comic act and the critical act. In this respect, suprasegmental markers (pauses, rising and suspended tonemes, intensity) or morphological ones (discourse markers) are used. A variety of humorous indicators are present as well, among which stand out polysemy, ambiguity or phraseology. Therefore, these linguistic and extralinguistic elements become evaluative expressions contributing to the comic act of parody.

Figure 4 offers a summary of the evaluation aspects related to parody:

\footnotetext{
${ }^{9}$ In her opinion, the parts of the oral narration are the summary, despite not being very frequent in these expressions, the orientation, the complication of the action, the evaluation, the result or resolution, and the coda (Silva Corvalán, 1987: 267).
} 


\begin{tabular}{|l|l|}
\hline $\begin{array}{l}\text { Evaluation is a part of the narration } \\
\text { Presentation }\end{array}$ & Evaluation is a persuasion procedure (comic act) \\
$\begin{array}{ll}\text { Exposition-illustration } & \text {-Kinesic elements: smile, gestures of support } \\
\text { Evaluation } & \text {-Paralinguistic elements: pauses, intensity } \\
\text { Coda } & \text {-Linguistic elements: evidentials, discourse } \\
& \text { markers, phraseology, polysemy } \\
\end{array}$ \\
\end{tabular}

Figure 4: Evaluation in parody

\section{A type of parody: the sketch on TV}

The previous theoretical foundations developed in $₫ 2,3$ and 4 will now be the reference for our analysis of a sketch taken from a television show, Saturday Night Live, broadcast by the channel Cuatro in Spain - a program based on the American model with the same name- . A sketch is a comic scene which lasts between 5 and 10 minutes, usually performed in a theatre or on television. The sketches constructed for the program, which is broadcast live, parody news or everyday situations before a real audience in the recording room. The sketch in question is supported on the structure of infomercials for medicines and uses sociocultural data such as the economic crisis and the increase in the number of unemployed people in Spain. More precisely, the actor José Luis Gil, better known by his roles in TV series such as Aqui no hay quien viva [No one can live here] and La que se avecina [What is drawing near] plays here Dr. Lilly and shows us the two new medicines for the crisis, Melasuda [Couldntgivedamn] and Keosden [Fukyall]. Melasuda [Couldntgiveadamn] is the first conscience-anesthetizing pill, recommended for power consciences such as Bush, Zapatero or Bill Gates:

(1)

Dr. Lilly: hola/hola// soy el doctor Lilly de los laboratorios Hoffman y estoy aquí para PREsentarles una nueva GAMA de medicamentos para sobrevivir a estos tiempos tan difíciles// por fin se legaliza en nuestro país la primera píldora anestesiadora de conciencias

[Dr. Lilly: hello/hello// I'm doctor Lilly from the Hoffman laboratories and I'm here to PREsent (before) you a new RANGE of medicines to survive these terribly difficult times// the first conscience- anesthetizing pill has finally been legalized in our country] 
People who have to face real problems such as unemployment, crisis, mortgages or love-life situations are advised to take Keosden [Fukyall] and Keosden forte [Fukyall forte]:

(2)

Dr. Lilly: (...) Keosden está especialmente indicado en casos de hipotecas abusivas $\uparrow /$ situaciones laborales precariaas $\uparrow$ y situaciones sentimentales rutinarias// que sus problemas son demasiado gordos $\uparrow$ ¡NO SE PREOCUPE! también tenemos Keosden Forte

[Dr. Lilly: (...) Fukyall is especially recommended in cases of outrageous mortgages $\uparrow /$ precarioous work situations $\uparrow$ and routine love-life situations// if your problems are too serious $\uparrow$ DO NOT WORRY! we also have Fukyall Forte]

The postulates established by Rossen-Knill \& Henry (1997), and the analysis of markers and indicators as evaluation procedures, indicators and markers will be analyzed according to the GTVH proposal. Let us start with the strategies utilized in this sketch. For instance, the language adopts a formal tone and has been carefully planned. The interpersonal goal is to persuade the audience to buy the advertised medicines and, therefore, the text is essentially expository-argumentative. That is the reason why Dr. Lilly explains the qualities of the medicines Melasuda [Couldntgiveadamn] and Keosden [Fukyall] and backs those qualities specifying their composition:

(3)

Dr. Lilly: Melasuda $\uparrow$ anestesia sus reparos morales hasta difuminarlos del todo/Melasuda $\uparrow$ lleva extracto de melasudina $\downarrow$ valeriana $\downarrow$ hierba de relax del Tibet y diez miligramos de opio

[Dr. Lilly: Couldntgiveadamn $\uparrow$ anesthetizes your moral reservations until they bcome completely blurred/Couldntgiveadamn $\uparrow$ contains extract of couldntgiveadamnine $\downarrow$ valerian $\downarrow$ relax herb from Tibet and ten milligrams of opium]

(4)

Dr. Lilly: KEOSDEN/ Keosden lleva una composición similar a Melasuda pero con un POQUITO de ácido lisérgico que cambia su percepción de la realidad para que usted sea capaz de mandarlo todo a la mierda

[Dr. Lilly: FUCKYOU/ Fukyall has a composition similar to (that of) Couldntgiveadamn but with a LITTLE BIT of lysergic acid which changes your perception of reality for you to decide that everything can go to hell]

Real testimonies are used to illustrate the effectiveness of these false medicines. The contraindications given by the voice offscreen equally appear on the screen with white letters on a blue background (as it happens in real medicine commercials): 
(5)

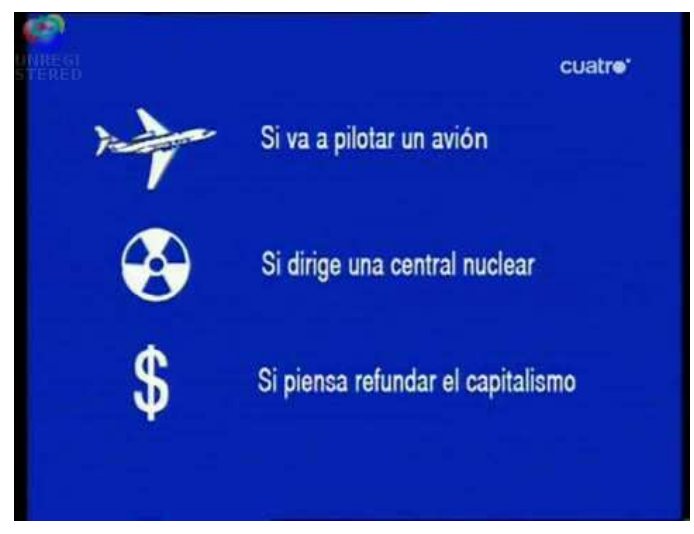

[If you are going to fly a plane/If you run a nuclear power station/If you plan to refound capitalism]

The false medicines are presented in containers resembling those of real medicines, with black letters printed on a white or green background, as is the case with Keosden [Fukyall]:

(6)

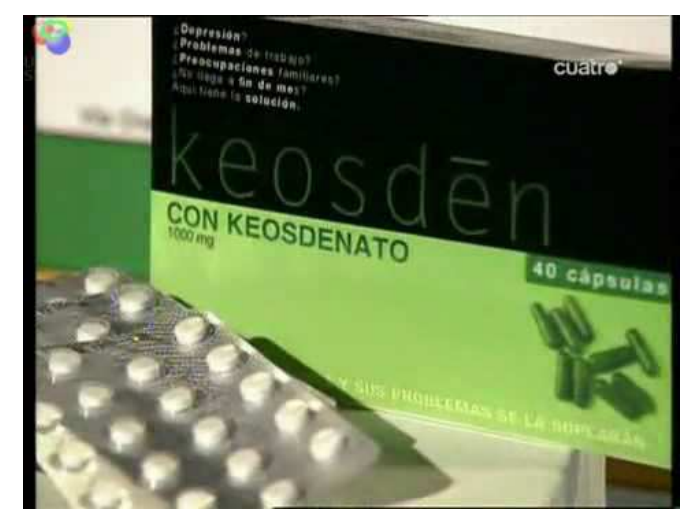

Furthermore, their properties are supposedly backed by their 'serious' composition [e.g. 'con keosdenato' = with Fukyallate] as it happens with the aforementioned lysergic acid, commonly known as LSD, a hallucinogenic compound. In other words, the infomercial about the medicines Melasuda [Couldntgiveadamn] and Keosden [Fukyall] has the structure and the basic parts of a serious infomercial about any medicine. The narrative strategy of humor is built upon these foundations. In this case, there is a presen- 
tation of the problem, an exposition of events, an evaluation and a coda, which are specified in Figure 5 below:

\begin{tabular}{|c|c|}
\hline Presentation & $\begin{array}{l}\text { por fin se legaliza en nuestro país la primera píldora anestesiadora de conciencias } \\
\text { [the first conscience-anesthetizing pill has finally been legalized in our country] }\end{array}$ \\
\hline Exposition-illustration & $\begin{array}{l}\text { Melasuda } \uparrow \text { lleva extracto de melasudina } \downarrow \text { valeriana } \downarrow \text { hierba de relax del Tibet y } \\
\text { diez miligramos de opio } \\
\text { [Couldntgiveadamn } \uparrow \text { contains extract of couldntgiveadamnine } \downarrow \text { valerian } \downarrow \text { relax } \\
\text { herb from Tibet and ten milligrams of opium] } \\
\text { escuchemos ahora TESTIMONIOS } \\
\text { [Let's listen to some TESTIMONIES now }\end{array}$ \\
\hline Evaluation & $\begin{array}{l}\text { porque en este mundo lo que mata ES LA PREOCUPACIÓN } \\
\text { [because what kills in this world is WORRY] }\end{array}$ \\
\hline Coda & $\begin{array}{l}\text { si lo compran Melasuda// y si no lo compran Keosden// forte } \\
\text { [if you buy it Couldntgiveadamn// and if you don't buy it Fukyall// fortel }\end{array}$ \\
\hline
\end{tabular}

Figure 5: Parts of the sketch as a narrative-expository text

Nevertheless, despite the structural room reserved for the evaluation of the story, humor markers and indicators act as procedures in the construction of parody and social criticism. It is obvious that the medicines Melasuda [Couldntgiveadamn] and Keosden [Fukyall] comprise - supposedly 'serious'- active principles such as melasudina [couldntgiveadamnine] and keosdenato [fukyallate], built through phraseological derivation, which emulate the active principles of real medicines.

Therefore, with regard to the target, it could be said that the sketch denounces the politicians, economists and entrepreneurs who have led their fellow citizens to a situation of crisis. Seeking to flaunt this specific language and the people to whom the mockery is addressed, the actors build an echo of an initial situation, that of the infomercial about a medicine, in which are inserted other echoes such as the action of politicians and entrepreneurs. The intentional verbal representation consequently uses evaluative elements, among which stand out markers and indicators.

The Intentional Verbal Representation described by Rossen-Knill \& Henry (1997) entails the infringement of pragmatic principles; according to Levinson (2000) and Rodríguez-Rosique (2009) the quality prerequisite is firstly infringed through the construction of an obviously false context which evokes the original one. Certain markers contribute to the generation of this humorous environment, such as kinesic elements (gestures of support or assent) or laughter. We can see the importance of gestures when it comes to present the medicine in (7): 
(7)

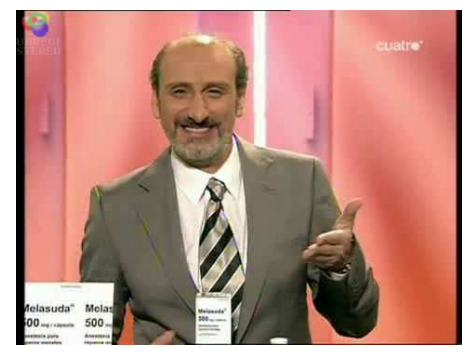

In (8), Dr. Lilly reinforces the testimony provided by the film director Alex Raminovich with his facial expression:

(8)

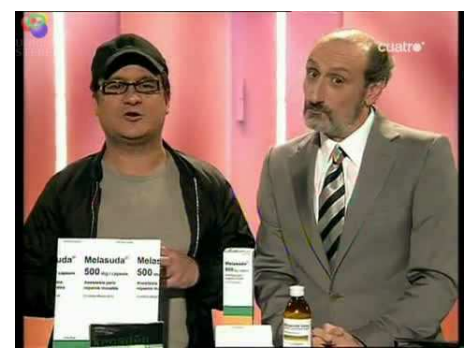

Also suprasegmental elements such as pauses, tonemes or intensity in the voice contribute to the parody. Thus, the intensity used by Dr. Lilly when uttering certain words in (9) helps understand the benefits of this medicine. In turn, Cándido Zamora shows his anger by means of intensity:

(9)

Dr. Lilly: que no hombre que no/ se trata de $\rightarrow$ / KEOSDEN/ Keosden lleva una composición similar a Melasuda pero con un POQUITO de ácido lisérgico que cambia su percepción de la realidad para que usted sea capaz de mandarlo todo a la mierda Zamora: ¡PUES HALA! ¡A LA MIEERDA! ¡KEOSDEN!

[Dr. Lilly: no way/ man/ no way/ it is $\rightarrow$ / FUKYALL/ Fukyall has a composition similar to (that of) Couldntgiveadamn but with a LITTLE BIT of lysergic acid which changes your perception of reality for you to decide that everything can go to hell

Zamora: COME ON THEN! TO HEELL! FUKYALL!]

In that context, the medicines Melasuda [Couldntgiveadamn] and Keosden [Fukyall] show their effectiveness as conscience anesthetizers, a strange indication for a medicine: 
(10)

Dr. Lilly: para todos los demás $\uparrow /$ Melasuda $\uparrow /$ o Keosden

[Dr. Lilly: for all the others $\uparrow /$ Couldntgiveadamn $\uparrow /$ or Fukyall]

The Informativity principle is infringed too, since the multiplication of referents is present at all times; in fact, the names of these medicines refer to two highly common rude formulas used in spontaneous, everyday speech which show lack of interest in something: ique os den! [Fuck y'all!] and ¡me la suda! [I couldn't give a damn!] (Alvarado, 2010). The fact that they are sometimes used as formulas and sometimes as the names of the advertised medicines causes a continuous infringement of the Informativity principle. This is additionally reinforced by the violation of the Manner principle, as these everyday formulas are marked expressions:

Dr. Lilly: para todos los demás $\uparrow /$ Melasuda $\uparrow /$ o Keosden/ porque en este mundo lo que mata ES LA PREOCUPACIÓN/ cómprelo en su farmacia más cercana/ o no// a mí me la suda

Público: (RISAS)

Dr. Lilly: si lo compran Melasuda// y si no lo compran Keosden// forte

[Dr. Lilly: for all the others $\uparrow /$ Couldntgiveadamn $\uparrow /$ or Fukyall/ because what kills in this world IS WORRY/ buy it at the nearest drugstore/ or not// I couldn't give a damn

Audience: (LAUGHTER)

Dr. Lilly: if you buy it Couldntgiveadamn// and if you don't buy it Fukyall// forte]

The infringement of the Manner principle also becomes visible in the constant use of the specialized language that is typical of medicine:

Dr. Lilly: Keosden está especialmente indicado en casos de hipotecas abusivas $\uparrow /$ situaciones laborales precariaas $\uparrow$ y situaciones sentimentales rutinarias

[Dr. Lilly: Fukyall is especially recommended in cases of outrageous mortgages $\uparrow$ / precarioous work situations $\uparrow$ and routine love-life situations

With specific regard to the infringement of the Informativity Principle, certain indicators outstandingly act as evaluative procedures. First, the generation of pseudocomprehensive elements, that is, the creation of a class that exhausts itself in its integrating elements but which can only be understood in a humorous way. In other words, an echo of the precautions or side effects that real medicines can cause is used to make explicit the 'humorous' situations under which the medicine must be avoided: 
(13)

Voz en off: evite tomar Melasuda o Keosden si va a pilotar un avión $\downarrow$ si dirige una central nuclear $\downarrow$ o si piensa refundar el capitalismo

[Offscreen voice: avoid taking Couldntgiveadamn or Fukyall if you are going to fly a plane $\downarrow$ if you run a nuclear power station $\downarrow$ or if you plan to refound capitalism]

However, the evaluative indicator most often used throughout the text is the presence of ambiguity, which clearly infringes the Informativity principle. We can see in (14) — the punch line of the humorous text - that the verb matar [kill] is used both in its proper sense and figuratively:

Dr. Lilly: para todos los demás $\uparrow /$ Melasuda $\uparrow /$ o Keosden/ porque en este mundo lo que mata ES LA PREOCUPACIÓN

[Dr. Lilly: for all the others $\uparrow /$ Couldntgiveadamn $\uparrow /$ or Fukyall/ because what kills in this world IS WORRY]

The flaunting of the intentional representation of parody is reinforced by the laughter among the audience, which responds in this way to the jokes included in the sketch.

On the other hand, the critical act implies a joke about the parodied situations, the behavior of politicians or entrepreneurs. The sketch makes available a remedy against its conscience-related illnesses to any suffering mind - whether it is the mind of a relevant figure or that of an average citizen-. For this reason, the criticism is addressed both to the important figures who rule us and to the whole population ruled by them. These medicines have been created for them all. Furthermore, there is a veiled attack against television infomercials, which sell any type of medicine or remedy, even those with dubious effectiveness.

Within the framework of this model, the flaunting of the representation permits this sketch to echo a serious text, infomercials about medicines in this case, using this echoing procedure to manage a veiled criticism both about this type of information and about the actions of politicians and entrepreneurs in relation to the crisis. The sketch fulfills its humorous objectives precisely because the utilization that is made of language turns out to be an example of metapragmatic awareness (Verschueren, 1999 and 2009): the scriptwriters or comedians observe the range of variables among the possible choices; negotiate those choices in context; and, finally, adapt to the possible options which permit them to achieve their basic goal, to amuse the audience. Therefore, the linguistic and paralinguistic choices that we find in this sketch are markers and indicators of humor and facilitate the inference process carried out by the addressees, a process in which the serious text echoed by this humorous genre acts as the framework. 
In short, the sketch turns out to be funny because it is well managed: the actors follow the previously established script for parody. They reinforce their performances with kinesic elements, such as smiles or gestures of support, which gradually appear on the screen; also with paralinguistic elements that highlight the linguistic aspects, such as the utilization of pauses before introducing the main topics and the use of intensity or prosody. In fact, a large part of the 'comicity' or humor stems from the exaggerated, even ridiculous use of these paralinguistic elements as verbal support, as explicit expressions of evaluation. Likewise, the intentional use of language (the utilization of highly common rude expressions as commercial names of medicines, the use of those marked expressions) is restricted to achieve the comic effect. Summing up, the sketch echoes serious infomercials but includes a veiled criticism of them, simultaneously questioning the behavior of politicians and other relevant figures.

\section{Conclusions}

This article shows one way in which a specific form of humor, parody —and, more precisely a type of it, television parody - can be analyzed. The situation where these humorous texts occur, along with their television-related function, served as a reference framework for our analysis. Furthermore, considering it as a satirical discourse permits to establish a connection with this broader form of humorous discourse. In fact, the consideration of verbal parody as a speech act —following Rossen-Knill \& Henry (1997) - provided with an explanation that we have integrated into the six knowledge resources collected in the GTVH. It is consequently formed by an intentional verbal representation of the parody target (both the linguistic form and the target); there is a flaunting of that representation; and a critical act takes place too. These three aspects are restricted in the comic act, the essence of verbal parody. Such foundations were the basis for our analysis of a television sketch which, adopting the format of an infomercial about 'serious' medicines, advertises two conscience-anesthetizing medicines, Melasuda [Couldntgiveadamn] and Keosden [Fukyall]. We have studied evaluation as a structural part of the narration, but also as the procedure which, thanks to markers such as prosody, intensity and laughter, and to indicators such as phraseology, pseudocomprehensive elements, polysemy or ambiguity, permits to persuade the audience about a state of affairs and, more precisely, to take a stance before the outrageous behavior of politicians and entrepreneurs.

The GTVH model described here and illustrated for parody, specifically for a television sketch about the medicines Melasuda [Couldntgiveadamn] and Keosden [Fukyall] may be exported to other television parodies, such as the television programs based on 
informative parody (El intermedio [The intermission]), where the target appears as the most important knowledge resource. However, the development of narrative strategies by means of aspects related to the genre, register and type of text used may contribute to the explanation of other genres like the humorous monologue (Ruiz-Gurillo, 2012).

Figure 6 summarizes the most outstanding aspects which were taken into account for the analysis of evaluation in parody:

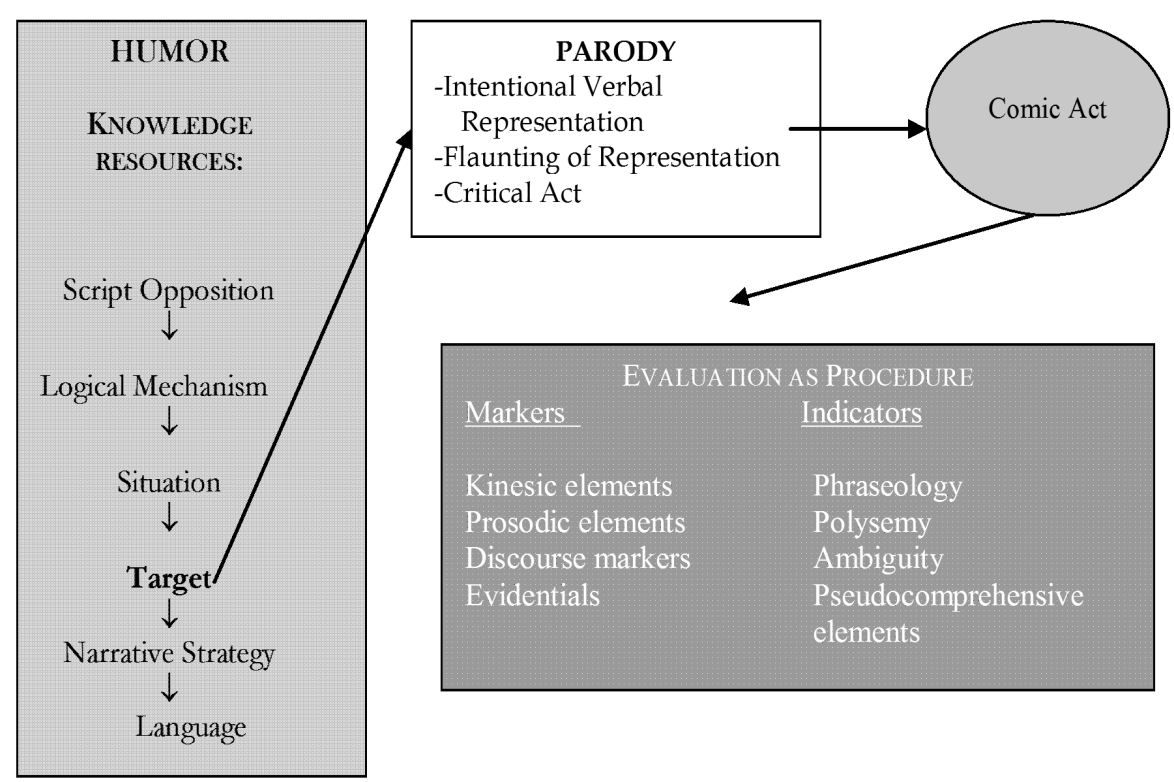

EVALUATION AS STRUCTURE:

Presentation, Exposition-illustration, evaluation and coda

Figure 6: Evaluation in parody

Recibido: 22-IX-2012

Aceptado: 14-IV-2013

\section{Bibliographic references}

Adam, J-M (2001): Les textes: types et prototypes. Récit, description, argumentation, explication et dialogue (Des réponses originales à l'analyse des textes: la reconnaisance des séquences). Paris, Nathan.

Alvarado, Ma B. (2010): Las fórmulas rutinarias del español. Teoría y aplicaciones. 
Frankfurt, Peter Lang.

Attardo, S. \& V. Raskin (1991): "Script theory revis(it)ed: Joke similarity and joke representation model”, Humor, 4 (3-4), págs. 293-347.

Attardo, S., Ch. F. Hempelmann \& S. Di Maio (2002): "Script oppositions and logical mechanisms: Modelling incongruities and their resolutions", Humor, 15 (1), págs. 3-46.

Attardo, S. (1994): Linguistic Theories of Humor. Berlin, Mouton de Gruyter.

Attardo, S. (1997): "Locutionary and perlocutionary cooperation: the perlocutionary cooperative principle”, Journal of Pragmatics, 27, págs. 753-779.

Attardo, S. (1999): "The place of cooperation in cognition", European Conference of Cognitive Science (ECCS'99). Siena, Italy, October. 27-30, págs. 459-464.

Attardo, S. (2001a): Humorous Texts: A Semantic and Pragmatic Analysis. Berlin, Mouton de Gruyter.

Attardo, S. (2001b): "Humor and Irony in Interaction: From Mode Adoption to Failure of Detection". In Anolli, L., R. Ciceri \& G. Riva (eds.): Say not Say: New perspectives on miscommunication. Amsterdam: IOS Press, págs. 165-185.

Attardo, S. (2003a): "Multimodal markers of irony and sarcasm”, Humor, 16 (2), págs. 243-260.

Attardo, S. (2003b): "Introduction: the Pragmatics of humor", Journal of Pragmatics, 35, págs. 1287-1294.

Attardo, S. (2004): “Preface”, Humor, 17 (4), págs. 351-352.

Attardo, S. (2006): “Cognitive linguistics and humor”, Humor, 19 (3), págs. 341-362.

Attardo, S. (2008): "A primer for the linguistics of humor". In Raskin, V. (ed.): The Primer of Humor Research. Berlin, Mouton de Gruyter, págs. 101-155.

Attardo, S., J. Eisterhold, J. Hay \& I. Poggi (2003): "Multimodal markers of irony and sarcasm", Humor, 16 (2), págs. 243-260.

Bednarek, M. (2009): "Dimensions of evaluation. Cognitive and linguistic perspectives", Pragmatics \& Cognition, 17:1, págs. 146-175.

Bordería, E. et alii (2010): La risa periodística. Teoría, metodología e investigación en comunicación satírica. Valencia, Tirant lo Blanch.

Brône, G. (2008): "Hyper- and misunderstanding in interactional humor", Journal of Pragmatics, 40, págs. 2027-2061.

Brône, G. \& K. Feyaerts (2003): "The cognitive linguistics of incongruity resolution: Marked reference-point structures in humor", Paper delivered at the $8^{\text {th }}$ International Cognitive Linguistics Conference. (La Rioja (Spain), 20-25 June 2003).

Brône, G., K. Feyaerts \& T. Veale (eds.). (2006): Cognitive Linguistics meets Humor Research: Current trends and new developments. Berlin, Mouton de Gruyter. 
Brône, G., K. Feyaerts \& T. Veale (2006): "Introduction: Cognitive linguistics approaches to humor”, Humor, 19 (3), págs. 203-228.

Charaudeau, P. (2006): “Des catégories pour l'humour?", Question de communication, 10, págs. 19-41.

Curcó, C. (1995): "Some observations on the pragmatics of humorous interpretations. A relevance-theoretic approach", UCL Working Papers in Linguistics, págs. 727-47.

Curcó, C. (1996): “The implicit expression of attitudes, mutual manifestness and verbal humour", UCL Working Papers in Linguistics 8, págs. 89-99.

Curcó, C. (2000): "Irony: Negation, echo and metarepresentation", Lingua, 110, págs. 257-280.

Ermida, I. (2008): The language of comic Narratives. Humor Construction in Short Stories. Berlin, Mouton de Gruyter.

Feyaerts, K. (2006): "Towards a Dynamic Account of Phraseological Meaning: Creative Variation in Headlines and Conversational Humour", International Journal of English Studies, vol. 6 (1) (University of Murcia), págs. 57-84.

Hunston, S. \& G. Thompson (eds) (2000): Evaluation in Text. Authorial Stance and the Construction of Discourse. Oxford, Oxford University Press.

Kotthoff, H. (2007): "Oral genres of humor: On the dialectic of genre knowledge and creative authoring”, Pragmatics, 17, 2, págs. 263-296.

Labov, W. J. Waletzky (1967): "Narrative analysis: oral versions of personal experience". In Helms, J. (ed.): Essays on the verbal and visual arts. Seatle, University of Washington Press , págs. 12-44.

Laforest, M. (1996): "De la manière d'écouter les histoires, la part du narrataire". In M. Laforest (ed.): Autour de la narration. Québec, Nuit Blanche, págs. 73-95.

Lefort, B. (1999): "Le discours comique et sa réception: le cas des histoires drôles". In Rosier, L. \& J-M. Defays (eds.): Approches du discours comique. Mardaga, págs. 113132.

Levinson, S. C. (2000): Presumptive Meanings. The Theory of Generalized Conversational Implicature. Cambridge, Massachusetts.

Méndez García de Paredes, E. (2004): "Humor y televisión en España”, L’humour hispanique Lyon, Université de Lyon II, págs. 147-190.

Partington, A. (2007): "Irony and reversal of evaluation", Journal of Pragmatics, 39, 9, págs. 1547-1569.

Partington, A. (2011): "Phrasal irony: Its form, function and exploitation", Journal of Pragmatics, 43, págs. 1786-1800.

Pueo, J. C. (2002): Los reflejos en juego. Una teoría de la parodia. Valencia, Tirant lo Blanch. 
Raskin, V. (1985): Semantic Mechanisms of Humor. Reidel, Dordrecht.

Raskin, V. (1998): “Humor”. In Mey, J. (ed.): Concise Encyclopedia of Pragmatics. Amsterdam, Elsevier, págs. 354-359.

Raskin, V. (2004): “Afterword”, Humor, 17-4, págs. 429-436.

Raskin, V. (2008): "Theory of humor and practice of humor research: Editor's notes and thoughts". In Raskin, Victor. (ed.): The Primer of Humor Research. Berlin, Mouton de Gruyter, págs. 1-16.

Raskin, V. (ed.) (2008): The Primer of Humor Research. Berlin, Mouton de Gruyter.

Rodríguez-Rosique, S. (2009): "Una propuesta neogriceana". En Ruiz-Gurillo, L. y X. A. Padilla García (eds.), págs. 109-132.

Rossen-Knill, D. F. \& R. Henry (1997): “The pragmatics of verbal parody", Journal of Pragmatics, 27, págs. 719-752.

Ruiz-Gurillo, L. y X. A. Padilla García. (eds.) (2009): Dime cómo ironizas y te diré quién eres. Una aproximación pragmática a la ironía. Frankfurt, Peter Lang.

Ruiz-Gurillo, L. (2006): Hechos pragmáticos del español. Alicante, Universidad de Alicante.

Ruiz-Gurillo, L. (2010): "Para una aproximación neogriceana a la ironía en español", Revista Española de Lingüística, 40/2, págs. 95-124.

Ruiz-Gurillo, L. (2012): La lingüistica del humor In español. Madrid, Arco/Libros.

Ruiz-Gurillo, L. (2013): “Narrative strategies in Buenafuente's humorous monologues”. In Ruiz-Gurillo, L. \& M. Belen Alvarado-Ortega (eds.), págs. 107-140.

Ruiz-Gurillo, L. \& M. Belen Alvarado-Ortega (eds.) (2013): Irony and Humor: From Pragmatics to Discourse. Amsterdam, John Benjamins.

Schoentjes, P. (2003): La poética de la ironía. Madrid, Cátedra.

Silva Corvalán, C. (1987): "La narración oral española, estructura \& significado. En Bernárdez, Enrique. (Comp.): Lingüística del texto. Madrid, Arco-Libros, págs. 265292.

Simpson, P. (2003): On the Discourse of Satire. Amsterdam, John Benjamins.

Sperber, D. y D. Wilson (1994): La relevancia, comunicación y procesos cognitivos. Madrid, Visor.

Sperber, D. (ed.) (2000): Metarepresentations. A multidisciplinary perspective. Oxford, University Press.

Timofeeva, L. (2008): Acerca de los aspectos traductológicos de la fraseología española. En: http://rua.ua.es/dspace/handle/10045/7707.

Veale, T., K. Feyaerts \& G. Brône (2006): "The cognitive mechanisms of adversarial humor", Humor, 19-3, págs. 305-338.

Verschueren, J. (1999): Understanding Pragmatics. London, Arnold. 
Verschueren, J. (2009): “The pragmatics perspective”. In Verschueren, J. \& J-O Östman (eds.) (2009): Key Notions for Pragmatics. Handbook of Pragmatics Highlights, 1. Amsterdam, John Benjamins, págs. 1-27.

Wilson, D. \& D. Sperber (2004): "La Teoría de la Relevancia", Revista de Investigación Lingüística, vol. VII, págs. 233-282. [Translation of Wilson, D. \& D. Sperber (2004): "The Theory of Relevance". In Horn, L. \& G. Ward (eds.) The Handbook of Pragmatics. Blackwell, Oxford, págs. 607-632].

Wilson, D. (2000): "Metarepresentation in linguistic communication." In Sperber, D. (ed.), págs. 411-448.

Wilson, D. (2006): “The pragmatics of verbal irony: Echo or pretence?", Lingua, 116, págs. 1722-1743.

Yus, F. (1995-1996): "La teoría de la relevancia y la estrategia humorística de la incongruencia-resolución”, Pragmalingüística 3-4, págs. 497-508.

Yus, F. (2002): "Stand-up comedy and cultural spread: The case of sex roles", Babel AFIAL, 10, págs. 245-292.

Yus, F. (2003): "Humor and the search for relevance", Journal of Pragmatics, 35, págs. 1295-1331.

Yus, F. (2004): "Pragmatics of humorous strategies in El club de la comedia." In Márquez-Reiter, R. \& M. E. Placencia (eds): Current Trends in the Pragmatics of Spanish. Amsterdam, John Benjamins, págs. 320-344.

Yus, F. (2009): "Saturación contextual en la comprensión de la ironía". En Ruiz-Gurillo, L. y X. A. Padilla García (eds.), págs. 309-331. 


\title{
DE LA COGNICIÓN AL DISCURSO: EL EFECTO DE LA PROMINENCIA COGNITIVA Y LA INFORMATIVIDAD TEXTUAL EN EL ESTUDIO DE LA VARIACIÓN DE LOS SUJETOS PRONOMINALES
}

\author{
MARÍA JOSÉ SERRANO \\ Universidad de la Laguna \\ mjserran@ull.edu.es
}

\begin{abstract}
Resumen
La prominencia cognitiva se basa en el proceso de atención, modelado en términos de activación mental de estructuras conceptuales. Por su parte, el concepto de informatividad se relaciona con el nivel de procesamiento mental que requiere un texto en función del grado de novedad o de imprevisibilidad que tiene para sus receptores. De acuerdo con ello, en español, la variación entre la expresión (preverbal y posverbal) y la omisión del sujeto ( $Y o$ vengo/ $\varnothing$ vengo) puede ser una manifestación formal de las variaciones en la prominencia cognitiva de los referentes. La idea de que la informatividad textual guarda cierta relación con la colocación de las unidades en la cláusula puede aplicarse al estudio de la posición preverbal o posverbal del sujeto pronominal (Yo vengo/Vengo yo). Bajo una metodología cualitativa, se considera que estas posibilidades variables, fundamentadas cognitivamente y que ofrecen posibilidades para la construcción de un significado socioestilístico, constituyen uno de los objetivos del enfoque que aplicamos para el estudio de la variación en los sujetos pronominales en español.
\end{abstract}

PALABRAS CLAVE: prominencia cognitiva, informatividad textual, sujetos pronominales, variación, sintaxis.

\begin{abstract}
Linguistic units suggest semantic frames that conceptualize meanings and target concrete interpretations. Cognitive salience is one of these conceptualizations based on the attention process shaped by mental accesibility of structures. By its part, informativeness is a textual discursive device related to the level of mental effort needed by speakers/hearers in processing texts by means of its new or unexpected nature. In Spanish language, variation between expression and omission of pronominal subjects (Yo vengo/ Ø vengo; I come) can be explained as formal signs of cognitive salience of its referents. Informativeness is also related to the position of elements in the sentence, so preverbal or posverbal position of these pronouns (Yo vengo/Vengo yo) may be analyzed with such textual procedure. By a cualitative methodology, the fact that these variants contribute to create sociostylistic meanings in discourse and communicative interaction is the main goal of our ongoing research of variation of pronominal subjects in Spanish.
\end{abstract}

KEY WORDS: Salience, textual informativeness, pronominal subjects, variation, syntax.

\section{Introducción}

En este trabajo se propone la descripción de dos herramientas analíticas cognitivas y textuales utilizadas para explicar la variación de los sujetos pronominales en español, esto es, la prominencia cognitiva y la informatividad textual. El propósito de esta inves- 
tigación no es solamente señalar la naturaleza teórica de dichas nociones, sino la utilidad que ofrecen para el estudio de este fenómeno variable. Para ello, en primer lugar se realizará un resumen crítico de la prominencia cognitiva y de la informatividad textual y, en segundo, se presentarán varios ejemplos de cómo se aplican en la definición, análisis y determinación de las variantes del sujeto pronominal en español a partir de los resultados obtenidos en algunas investigaciones anteriores. La metodología empleada es cualitativa, ya que ofrece una aplicación hermenéutica de las mencionadas nociones al estudio de la variación como paso previo para emprender el correspondiente análisis estadístico.

1. La prominencia como operación de conceptualización cognitiva. Algunas precisiones teóricas y su aplicación a la expresión (preverbal o posverbal) y omisión del sujeto en español

La variación morfosintáctica se produce en virtud de la naturaleza icónica, simbólica y gradual de la gramática (cf. Langacker, 1991, 2009; Croft y Cruse, 2008); las construcciones y formas gramaticales conducen a la creación de cierto significado que puede ser utilizado con fines e intenciones concretos por distintos hablantes y en distintas situaciones comunicativas.

Para perfilar las características cognitivas de la variación gramatical es útil centrarse en una de las principales hipótesis de la lingüística cognitiva, consistente en que el uso del lenguaje está marcado por operaciones de conceptualización: todas las unidades lingüísticas evocan un marco semántico que conceptualiza su significado y lo orienta hacia una interpretación determinada. Con ello se cuestiona la identidad de significado o la sinonimia en el lenguaje y, paralelamente, se invalida la semántica de carácter veritativo-condicional o la remisión al referente para su descripción (Croft y Cruse, 2008: 65; Langacker, 1999). Para ser realmente cognitivas, las operaciones de conceptualización han de tener un correlato en algún proceso psicológico general. Además, son también conceptualizaciones de la experiencia que se quiere comunicar, de modo que se corresponden con uno de los postulados básicos de la lingüística cognitiva: el experiencialismo o la corporeización de los significados lingüísticos (Vega, 2005; Lakoff, 1987; Talmy, 1988). Ello se aparta también de una concepción de la lengua como independiente de la realidad circundante y afirma su condición inherentemente social, lo cual determina que el lenguaje es parte de una capacidad cognitiva más general, de base fundamentalmente cerebral (López García, 2010).

Estos principios resultan de gran utilidad para el estudio de la variación morfosintáctica, toda vez que se ha comprobado que para su estudio ya no resulta eficiente basar 
la investigación en la búsqueda de la identidad significativa de las formas (Serrano, 2011a). Antes bien, es precisamente la diferencia de significado lo que puede ayudar a comprender el funcionamiento de las variantes formales y a relacionarlo con distintos aspectos sociales y comunicativos (Aijón Oliva y Serrano, 2010a; Serrano y Aijón Oliva, 2011) $)^{1}$.

Una de las operaciones de conceptualización que resulta útil para estudiar la variación como coexistencia de opciones significativas que pueden crear estilos comunicativos es la prominencia cognitiva. Su base reside en el proceso de atención, concepto procedente de la psicología cognitiva y modelado en términos de activación mental de estructuras conceptuales. En la lengua existen unidades que pueden estar más fijadas en la atención del hablante/oyente, y por ello resultar más prominentes, lo cual conduce a que su significado y su función se conceptualicen de un modo u otro y a que, al mismo tiempo, puedan ser comparables o no a otras estructuras.

La prominencia se puede analizar teniendo en cuenta dos aspectos: el foco y el ámbito de atención ${ }^{2}$. El primero es el punto sobre el que se centra la atención, mientras que el segundo consiste en aquello que rodea al foco, a partir del cual las unidades pueden ser más o menos accesibles. De hecho, la noción de prominencia está estrechamente relacionada con la accesibilidad de los referentes (Ariel, 1990; Chafe, 1976; Gundel y Fretheim, 2009); así, aquel referente que está activado en el foco de la atención del hablante resultará más accesible, es decir, estará activado en la mente del hablante. Por lo tanto, un elemento lingüístico será más prominente si obtiene la mayor accesibilidad en un punto concreto del discurso, aunque se considera que las unidades prominentes (pronombres, determinantes, deícticos, etc.) suelen estar activadas en la mente del hablante, independientemente del contexto. Por ejemplo, en la frase Comemos a las dos, el sujeto (pronominal o léxico) correlacionado con la desinencia verbal nosotros es prominente o accesible independientemente del contexto. En otro enunciado como María fue a la farmacia, espero que no esté enferma, el sujeto de esté resulta prominente (ella) y además su referente léxico, que ya ha sido mencionado previamente (María), es accesible por medio de la desinencia verbal. En suma, esta noción viene impuesta de

\footnotetext{
${ }^{1}$ Es cierto que la función de la conceptualización en el lenguaje se hace más que evidente cuando en un mismo idioma existen expresiones alternativas para lo que parecen ser situaciones equivalentes desde el punto de vista veritativo-funcional (Croft y Cruse, 2008: 65); es decir, las variantes gramaticales en sentido tradicional.

2 Estos términos son asimilables a los que maneja Langacker (2009: 48) de punto de referencia (que sería análogo al foco de atención) y dominio (que constituiría el ámbito de atención).
} 
alguna forma por las estructuras lingüísticas usadas para representar la escena comunicativa (Langacker, 2009: 112).

La prominencia cognitiva se corresponde, pues, con un determinado nivel de activación o accesibilidad del referente. En una línea teórica similar, aunque sin efectuar remisión expresa al plano cognitivo ${ }^{4}$, las escuelas funcionalistas utilizan los términos topicalización y tematicidad (Halliday, 1967; Givón, 2001).

Desde perspectivas pragmáticas, el estatus informativo de los elementos textuales también puede relacionarse con la prominencia. Así, los elementos ya conocidos a través del discurso previo serán, por lo general, más prominentes y tenderán a situarse al inicio de la cláusula ${ }^{6}$ (Prince, 1981: 230; Levinson, 1983: 88; Chafe, 1976). Sin embargo, la prominencia cognitiva no se relaciona exclusivamente con el estatus nuevo/conocido del contenido proposicional, ni debería definirse a partir de él.

De hecho, una de las soluciones más comunes para caracterizar la prominencia o los conceptos funcionales análogos de topicalización o tematicidad es aludir a la transmisión de contenidos ya conocidos y a la posición sintáctica inicial. Aunque estos aspectos sean recurrentes en la mayor parte de las descripciones, la prominencia cognitiva añade una noción basada en el foco de atención o accesibilidad de los referentes en cuanto a su grado de activación en la conciencia de los hablantes, algo que no parece ser tenido en cuenta (al menos de forma explícita) en los enfoques no cognitivos. Lambrecht (1998:

\footnotetext{
${ }^{3}$ La prominencia cognitiva no deja de ser una noción amplia, pero su utilidad dependerá de cómo se relacione con otros factores o se aplique a algunos de forma concreta (Geeraerts, Dirven y Taylor, 2006: 37-38). Una vertiente de su aplicación es la relacionada con aspectos de organización sintáctica de la información, como la que aquí se expone (Evans y Pourcel, 2009).

${ }^{4}$ El tratamiento de la cognición en las escuelas funcionalistas parece estar en un segundo plano, aunque a juzgar por los temas tratados por ellas (como la topicalización o tematización) su estudio debería figurar entre sus preocupaciones fundamentales. Así lo sostiene Langacker (1999: 22), aludiendo a la necesidad de una complementariedad entre los enfoques funcionales y los propiamente cognitivistas. ${ }^{5}$ Aun así, Langacker (1991: 306) reconoce que el término topicalidad en la gramática cognitiva puede recibir una interpretación simple, admitiendo la diferente secuenciación que pueden tener los elementos en una cláusula y su naturaleza semántica. De esta forma, un sujeto situado al inicio de la frase puede ser topical y al mismo tiempo exhibir un nivel muy elevado de prominencia. Tal sería el caso de la frase Le gusta el chocolate, donde le ocupa la posición habitual del sujeto (topical) y chocolate la de complemento directo, pese a que el verbo no es transitivo. Sin embargo, considera que es un término más encaminado a estudiar cuestiones de organización discursiva 'extrínseca' que estrictamente cognitivas. Véase Langacker (2004: 21-60) para una detallada comparación entre las nociones de tópico y punto de referencia.

${ }^{6}$ Numerosos estudios han apuntado a la relación entre la información conocida y la accesibilidad o prominencia; Giora (2003) realiza un análisis exhaustivo de cómo las palabras con significado conocido o accesible suelen ser relevantes para la comprensión y la producción del lenguaje.
} 
160) señala que el concepto de tópico viene definido por su relación con otros referentes de contenidos proposicionales próximos y de la información contextual compartida entre hablante y oyente (Prince, 1981), lo cual difiere esencialmente de las nociones de accesibilidad e identificabilidad.

De acuerdo con lo anterior, podría afirmarse que, en español, la variación entre la expresión y la omisión del sujeto puede ser una manifestación formal de las variaciones en la prominencia cognitiva de los referentes. Cuando el sujeto está activado en el foco de atención, es accesible o prominente y no es necesaria su formulación (o el hablante no considera que lo sea para sus propósitos comunicativos) ${ }^{7}$.

La omisión del sujeto, como variante de la expresión (y de la colocación del sujeto expreso en la cláusula), constituye una opción comunicativa para el hablante; de modo que, si bien en algunos casos la omisión parece obligatoria por la propia prominencia del referente (María se ha comprado una casa y tiene que pagar la hipoteca), en otros el hablante tiene la opción de expresarlo u omitirlo, consiguiendo así un significado concreto en el discurso (María se ha comprado una casa y ella tiene que pagar la hipoteca). Cuando el pronombre se expresa, se supone que su referente posee un nivel más bajo de prominencia y que existe alguna necesidad o intención discursivo-cognitiva que induce su expresión formal, que se pone de manifiesto en la interacción dando lugar a distintos significados que crean estilos comunicativos. Esta posibilidad variable, fundamentada cognitivamente y que ofrece recursos para la construcción de significados socioestilísticos, constituye el objetivo de este enfoque para el estudio de la variación sintáctica ${ }^{8}$.

Así pues, es posible proponer una matriz de prominencia con las variantes de expresión y omisión del sujeto, basada en ese nivel de atención o accesibilidad gradual que poseen en el discurso los referentes.

\begin{tabular}{lcc}
\hline & Sujeto omitido & Sujeto expreso \\
\hline Prominencia cognitiva & + prominente & - prominente \\
\hline Tabla 1. Gradualidad de la prominencia en el sujeto expreso y omitido
\end{tabular}

El sujeto omitido suele ser fácilmente identificable, bien a través de las desinencias verbales (lo que de entrada otorga mayor prominencia a los sujetos de primera o segunda persona) o bien a través de su previa mención en el discurso.

\footnotetext{
${ }^{7}$ De hecho, la variación lingüística ha de entenderse como la posibilidad de elegir una forma sobre otras para llevar a cabo determinados fines comunicativos, como ya hemos avanzado.

${ }^{8}$ Este trabajo forma parte del desarrollo del proyecto de I+D "Los estilos de comunicación y sus bases cognitivas en el estudio de la variación sintáctica en español” (FFI2009-07181/FILO).
} 
(1) Ø Quiero decirles que ya el TDT de San Roque en La Laguna está operativo len el área metropolitana yo les recomiendo\que se vayan $\emptyset$ olvidando de la televisión analógica $\backslash y$ para que nos $\varnothing$ puedan ver Igracias a Retevisión\vayan Ø sintonizándonos en TDT\en toda el área metropolitana\y en el sur nos pueden ver\pero en el 90\% de la isla $\varnothing$ no van a poder ver sin TDT $\varnothing$ tienen repetidores en Izaña \en Los Campitos $\backslash y$ en La Corona de San Roquely esto no tiene nada que ver con la Unelco\pásense $\varnothing$ a la TDT\Ø les recomiendo que cuanto más pronto mejor $($ CCEC $<$ Ma10Scan $>)$

Del mismo modo que el sujeto expreso es menos prominente que el omitido, es necesario determinar el nivel de prominencia relativa que adquieren las variantes preverbal y posverbal del primero.

En primer lugar, hay que tener en cuenta que en la lengua española el orden sintáctico prototípico es el que presenta al sujeto en posición preverbal SVO 9 . De acuerdo con estos esquemas, y aceptando que el sujeto es de entrada la perspectiva primaria desde la que se contempla una escena discursiva (Dik, 1981: 71; García, 2009: cap. 2), es fácil suponer que el grado de activación mental o prominencia que pueda tener el sujeto en un orden natural y prototípico (SV) será mayor que en una variación sobre dicho orden prototípico (VS). Que VS sea la forma marcada o no prototípica conduce a pensar que la posición posverbal no está tan accesible en el foco de atención del hablante, es decir, no posee naturalmente la capacidad de atraer la atención y potenciar la prominencia de los elementos (Croft y Cruse, 2008: 73) ${ }^{10}$. A ello se suma la infrecuencia, novedad o imprevisibilidad del citado esquema VS. Algunos autores han notado que la posición posverbal del sujeto pronominal es muy poco frecuente en la lengua española (Bentivoglio, 1988, 1989; Aijón Oliva y Serrano, 2010b; Serrano y Aijón Oliva, 2011; Serrano, 2012; Posio, 2012).

Otro aspecto que podría apoyar la menor prominencia del sujeto posverbal es su asimilación a las características formales y semánticas de los objetos sintácticos (Alonso Cortés, 2002:319). La relación entre la transitividad de la cláusula y la posición del suje-

\footnotetext{
9 Desde Nebrija, la tradición gramatical tiende a convenir que el orden SVO es el más característico de la lengua española. Gili Gaya es uno de los autores que más atención dedican a este aspecto, señalando que el sujeto suele ocupar la primera posición porque es el elemento que adquiere una mayor relevancia (1976: 85). Al respecto, véase también Fried (2009).

${ }^{10}$ Es posible que un sujeto posverbal, a través de la continuidad textual, adquiera prominencia cognitiva y se convierta en accesible, con lo cual pueda ser omitido en secuencias siguientes. No obstante, si sigue apareciendo expreso y en posición posverbal aunque el contexto señale que está activado o es accesible, habrá que suponer alguna motivación discursivo-pragmática o estilística por parte del hablante.
} 
to ha sido observada por algunos estudiosos. Delbecque $(2005: 4,9)$ concluye que en construcciones transitivas es más frecuente el sujeto antepuesto, mientras que en las intransitivas predomina la tendencia a la posposición ${ }^{11}$. Asimismo, el sujeto pospuesto tenderá a interpretarse menos como agente o iniciador del proceso o acción denotados por el verbo y más como afectado por estos.

En un estudio de los verbos que suelen coaparecer con una u otra posición del sujeto se ha podido concluir que, de forma general y siguiendo la clasificación de Hopper y Thompson (1980: 252), la posición preverbal asumiría algunos de los rasgos de la transitividad prototípica o alta (cf. Serrano, 2012). Por otra parte, dado que la colocación posverbal del sujeto supone una ruptura del esquema prototípico de la oración (SVO) y de la correspondiente transitividad alta, esto podría significar cognitivamente una objetualización del sujeto y una tendencia de la cláusula a asumir significados informativos. La posición posverbal se conceptualizaría en el ámbito, no en el foco de atención; por lo tanto, no sería prominente, debido a sus características de marcadez y objetualización sintáctica, puede adoptar rasgos textuales relacionados con la informatividad textual. Esta posición es susceptible de exigir un mayor esfuerzo y procesamiento interpretativos, al ser la menos probable o prototípica y presentar generalmente los contenidos como inesperados, imprevistos y, con ello, más realzados o subrayados en el plano comunicativo. Podemos sustentar estas afirmaciones sobre la mayor informatividad de la posición posverbal con la observación de algunas cuestiones discursivo-pragmáticas y textuales.

\section{La informatividad textual o discursiva. Algunas precisiones teóricas y su aplicación a la expresión (preverbal o posverbal) y omisión del sujeto en español}

El concepto de informatividad se relaciona con el nivel de procesamiento mental que requiere un texto en función del grado de novedad o de imprevisibilidad que capta en sus receptores (Beaugrande y Dressler, 1997: 201), esto es, alude al nivel de conocimiento que se tiene del mismo, pero, aún más importante, al esfuerzo que implica su comprensión. Normalmente la informatividad se relaciona con el contenido del texto, que a su vez se explica por el nivel de coherencia en la textualidad; se deduce que la coherencia es la que determina si un texto es más o menos informativo en detrimento de otros elementos considerados auxiliares desde un punto de vista textual, como el fonético o el morfológico. Estos elementos no están en el foco de atención de los inter-

11 El estudio está basado en sujetos no pronominales. 
locutores; lo que hace que un texto se sitúe en dicho foco es la coherencia como nivel textual, y no la gramática por sí misma. Por lo tanto, no es que un contenido informativo se presente como información nueva o imprevista, sino que las características semánticas de ese contenido, su selección y su disposición en el texto contribuyen a que haya que emplear un mayor esfuerzo de procesamiento. Con ello, dicho contenido se interpreta como inesperado, imprevisto o nuevo, desplazando la atención sobre esa cláusula o texto, y con ello, el foco informativo.

Hay que señalar que, desde esta perspectiva discursivo-textual, el concepto de foco de atención es claramente diferente al propuesto por la lingüística cognitiva para la prominencia. Beaugrande y Dressler (1997: 201) consideran que la atención es la concentración de la mayor parte de los recursos de procesamiento del sistema cognitivo disponibles para el tratamiento de una única tarea. De este modo, la informatividad de un texto (a la cual se llega por la coherencia textual) está basada también en una focalización de la atención de los hablantes y oyentes. Mientras que la prominencia se basa en el grado de atención que recibe algo activado o accesible para el hablante, la informatividad se corresponde con el grado de novedad o de imprevisibilidad textual; lo menos probable es lo más informativo.

La informatividad, así entendida, presupone un mayor esfuerzo de procesamiento, esto es, a mayor imprevisibilidad, improbabilidad o novedad habrá mayor informatividad, lo que suscita también mayor atención entre los hablantes y oyentes. Beaugrande y Dressler (1997: 42) proponen la comparación entre los ejemplos:

Llámenos antes de cavar una zanja. Probablemente no podrá telefonearnos después.

Llámenos antes de cavar una zanja. Cabe la posibilidad de que haya un cable soterrado. Si usted rompe ese cable, se quedará sin servicio telefónico...

Siguiendo a los autores, el primer ejemplo resulta más informativo que el segundo: el texto presenta el contenido no solamente como nuevo o inesperado, sino que incita al oyente a reflexionar sobre su significado; queda comunicativamente subrayado porque se evocan más posibilidades significativas, ya que no se da ninguna pauta o pista para procesar la razón por la cual el oyente no podrá telefonear, al contrario que en el segundo. Este requiere menos procesamiento que el primero y, aunque incluye más datos sobre la razón de la imposibilidad de acceder a la línea telefónica, este segundo texto, así formulado, capta menos la atención del oyente que el primero; es, por tanto, menos informativo. Procesar un texto o cláusula con más informatividad requiere más atención, y esto puede sugerir paralelamente otros rasgos discursivos y estilísticos como los de solemnidad, argumentación, contundencia, (des)cortesía, realce pragmático, etc. 
Estos significados resultantes son muy útiles para estudiar los fundamentos variables y sociosituacionales del estilo lingüístico ${ }^{12}$.

Según se observa, además, la informatividad es una herramienta de estudio textual que se puede identificar a partir del comportamiento global del texto como vehículo comunicativo; un bajo nivel de informatividad puede provocar la indiferencia del oyente hacia el texto por considerarlo consabido o presupuesto, lo cual, de alguna manera, puede interferir en la efectividad de la comunicación ${ }^{13}$.

En el discurso, la informatividad se presenta de distintas formas y su determinación es compleja. Hay unidades lingüísticas que la potencian o bien la disminuyen; por ejemplo, las palabras funcionales o que marcan relación (artículos, preposiciones y conjunciones) tienen un bajo nivel de informatividad, es decir, aparecen con tanta frecuencia que pasan inadvertidas. Así, la mayor presencia de elementos predecibles y activados o más accesibles atenúa el esfuerzo necesario para procesar la cláusula como conjunto. En los siguientes ejemplos, la introducción de un elemento como desde luego puede reducir la informatividad de Hoy te has portado bien.

Desde luego, hoy te has portado bien

Hoy te has portado bien

En esto no solamente influye la introducción del marcador, sino el significado conjunto del enunciado, así como su inserción en una cláusula y en un texto más amplios. Repercute también la posición relativa de los elementos; nótese que en Hoy te has portado bien, desde luego, la informatividad recae sobre desde luego, lo que paralelamente podría subrayar o reforzar el contenido del segmento precedente.

Estos cambios en el foco suceden porque los textos que se amoldan al conocimiento compartido y conocido por los interlocutores logran menos expectación o atención que aquellos que se presentan como imprevistos o impredecibles (aunque ello no implica que lo sean). Así, una frase como:

12 La interrelación entre texto y situación comunicativa es algo pendiente de explorar, como reconocen los autores (1997: 16). Por otra parte, la informatividad puede verse como un recurso para dar prominencia a elementos que no la tienen: al atraer la atención sobre ellos en un primer momento, se logrará que en cláusulas subsiguientes se vuelvan cognitivamente más prominentes, de modo que la atención pasa del texto a la cognición.

${ }^{13}$ Hay muchas situaciones en la vida cotidiana que, por ser habitualmente conocidas o predecibles por los hablantes, requieren muy poco procesamiento. Una de ellas puede ser, como bien apuntan Beaugrande y Dressler (1997: 15), las instrucciones que se dan en los aviones de cómo ponerse el chaleco salvavidas. Esta sería una situación comunicativa muy poco informativa, pese a la importancia de su contenido. 
Por favor, apaguen las luces al salir

capta menos la atención (o es menos informativa) que si un mensaje similar se configura textualmente de este modo:

Les recordamos la necesidad imperiosa de evitar gastos innecesarios dejando la luz apagada

Esto obedece a que el primer mensaje ya está activado o es accesible para el hablante, ya que se trata de una frase reiteradamente expuesta y de conocimiento compartido. En cambio, la segunda se formula discursivamente de un modo más original a través de la adición de elementos inesperados o novedosos en el mismo contexto. Así pues, una de las manifestaciones más evidentes de la informatividad es la elección de vocablos y construcciones sintácticas que, en conjunto, resulten nuevos, inesperados o imprevisibles para los hablantes y oyentes y que al mismo tiempo evoquen más posibilidades expresivas o de significado, obteniendo así la máxima focalización ${ }^{14}$.

En este sentido, las frases hechas o utilizadas con mucha frecuencia (como por ejemplo Por favor, apaguen las luces al salir), los modismos, los marcadores del discurso, los artículos y las preposiciones propiciarán un menor grado de informatividad que los elementos centrales o nucleares de la predicación, como los sustantivos o los verbos, que se supone concentran la parte más relevante de la comunicación transmitida ${ }^{15}$.

No obstante, medir y predecir la informatividad de un texto no es una tarea fácil; para ella deberían contemplarse numerosos factores más allá de la coherencia. Ha habido algunos intentos de medir la informatividad según probabilidades estadísticas (Shannon y Weaver, 1949), aunque sin demasiado éxito.

\subsection{La informatividad en la variación de los sujetos pronominales}

La idea de que la informatividad discursiva guarda cierta relación con la colocación de las unidades en la cláusula puede aplicarse, obviamente, al estudio de la posición preverbal o posverbal del sujeto en la cláusula (para la variación entre la expresión y la

\footnotetext{
${ }^{14}$ Como bien señalan Beaugrande y Dressler (1997: 76), ser consciente del conocimiento compartido no excluye la creatividad de la comunicación textual, pero sí hace posible que los interlocutores encuentren una orientación para esa creatividad.

${ }^{15}$ Esto conecta, por otra parte, con la idea bastante extendida de que con un número menor de palabras se evocan más ideas que con muchas de ellas. Sin embargo, tal suposición no está exenta de problemas; la selección de las palabras y oraciones de un mensaje y su ordenación deben hacerse cuidadosamente en cada situación comunicativa, para que la comunicación no se vea interferida y para que la interpretación sea la adecuada.
} 
omisión es más relevante la prominencia cognitiva, como se ha visto). El lugar donde se sitúe un elemento sintáctico y la mayor o menor informatividad que pueda adquirir dependerá de variados factores. Sin embargo, de forma general, los estudiosos están de acuerdo en que existe una tendencia a fijar un punto de orientación en el texto antes de presentar información nueva o imprevista; ese punto de orientación es el que permite que la atención se focalice sobre algo nuevo e inesperado (Beaugrande y Dressler, 1997: 128).

Érase una vez un cazador llamado Savari. Estaba muy orgulloso de su fuerza y de su puntería...

En este ejemplo, la atención o focalización la reciben Un cazador llamado Savari y todo lo que sigue, que se ha creado a partir del punto de orientación Érase una vez, el cual constituye una frase prominente $o$ accesible para los oyentes.

Retomando las características de la prominencia señaladas anteriormente, este punto de referencia coincide con el foco de atención o punto de referencia, mientras que el resto de la cláusula lo ocuparía el ámbito de atención o dominio. Como se observa, en la conceptualización de la prominencia el foco es lo que suscita la atención, lo que es más accesible o está activado en la atención o conciencia del hablante. Por el contrario, desde la teoría de la informatividad, lo focal no es ese punto de referencia, sino el resto de la cláusula o el texto, que es destacado o subrayado mediante la atracción de la atención.

Siguiendo a Beaugrande y Dressler (1997: 214), las técnicas de organización de las secuencias lingüísticas constituirían una de las fuentes de expectativas que comparten los interlocutores en la comunicación. De forma habitual, se considera que los contenidos nuevos o inesperados suelen aparecer hacia el final de la cláusula y con una entonación elevada. Por el contrario, los elementos con un bajo nivel de informatividad lo hacen al inicio de las emisiones y presentan una tendencia a ser sustituidos por formas pronominales: Las vacaciones las paso en la playa $>$ Las paso en la playa.

En la misma línea, Firbas (1966) había señalado distintas funciones pragmáticas articuladas en torno a las nociones informativas de tema y rema, que condensan la perspectiva funcional de la frase: el rema es la parte más informativa-comunicativa, mientras que el tema es el punto de partida sobre el cual se construye esa información. Esto puede indicar que, paralelamente, desde un punto de vista cognitivo, el mensaje se estructura como una progresión de la menor a la mayor informatividad (cf. Fried, 2009: 292).

Desde una perspectiva pragmática, Padilla García (2001: 247) considera que las diferencias entre el orden SV y el VS están fundamentadas en la perspectiva que toma el hablante ante las situaciones; la anteposición del sujeto señala la independencia o falta 
de compromiso del hablante con respecto al contenido descrito, mientras que en la posición VS la acción y el sujeto se funden en la perspectiva del hablante.

Anteriormente se señaló que el sujeto posverbal ocupaba la escala más baja de la prominencia. Dado que tradicionalmente se ha establecido que las soluciones pospuestas o finales se reservan para presentar contenidos no esperados, imprevistos, nuevos o no accesibles, todo parecería indicar que, de acuerdo con lo expuesto, un sujeto posverbal tiene un nivel de prominencia menor que sus variantes preverbal y omitida.

En este punto cabría preguntarse si el nivel más bajo de prominencia puede relacionarse con un incremento de la informatividad, entendidos como magnitudes parcialmente opuestas y graduales.

Uno de los indicios que apuntarían a la informatividad de los sujetos pospuestos es, como se sugirió anteriormente, su asimilación a los objetos sintácticos. Algunas investigaciones han concluido que los tipos de verbo con mayor tendencia a la posposición del sujeto son los que pertenecen a las categorías semánticas de reacción psicológica o de función presentativa, tales como aterrar, gustar, entristecer, espantar, emocionar, importar, interesar, ser probable, parecer, resultar, así como algunos intransitivos como aparecer, continuar, durar, existir, ocurrir o llegar (Morales, 1982: 208). A conclusiones parecidas llega Bentivoglio $(1988,1989)$ añadiendo los verbos copulativos a la lista ${ }^{16}$. Sin embargo, un análisis de la naturaleza de los verbos con usted/ustedes pospuesto muestra que este se da con una alta frecuencia cuando este es transitivo o copulativo (87\%) (cf. Serrano, 2012).

Esta elevada frecuencia entre verbos transitivos podría apoyar la idea de que el sujeto pospuesto, al ocupar la posición sintáctica típica de los objetos, asume alguna de sus características y al mismo tiempo se aparta del prototipo de transitividad prototípica. En otro estudio (Serrano, 2012) se apunta a que el esquema VS se aproxima a un modelo de transitividad baja o no prototípica, ya que comparte algunas de las funciones señaladas por Hopper y Thompson (1980: 252), tales como:

a) El sujeto no constituye el origen del evento, sino su término.

(2) Lo están viendo ustedes ahora mismo \se caía el techo de este baño \pero esta no es la única zona afectada \no se muevan porque en unos momentos se lo mostraremoslen Canarias Directo $\backslash(C C E C<M a E n C a n d i r>)^{17}$.

\footnotetext{
${ }^{16}$ La investigación estudia los sujetos no pronominales.

17 Ejemplos extraídos del Corpus Conversacional del Español de Canarias (CCEC).
} 
b) No hay acción o transferencia del agente hacia el paciente. Dado que el agente y el paciente ocupan la posición posverbal, la transferencia del argumento es menos intensa.

(3) Tiene inquietudes en el mundo de la músicalsiempre las ha tenido $\backslash$ en el campo de cantautor presenta usted Itanto aquí como en Madrid una especie de formato nuevo \Canarias pueblo Canarias canción\y también toca otras especialidades \por llamarlo asílfue la época de los $S$. ¿qué recuerdos tiene de esa época?/ (CCEC $<$ MaDiTag $>$ ).

c) De acuerdo con lo anterior, se puede decir que la acción no es puntual o que la transferencia del argumento es transicional, aunque ello dependerá del tipo de verbo y del resto de los elementos de la cláusula.

(4) Ya de hecho están ustedes con el marlel patrimonio de todos los canarios $\backslash(. .) l$. que es esa labor de divulgación lo han estado ustedes repitiendo $\backslash(\mathrm{CCEC}<\mathrm{MaDi}$ RoyCo $>$ ).

d) La agentividad se reduce, no hay afectación del objeto (o no en el mismo grado que en la configuración prototípica SVO); lo afectado es el sujeto que asume la posición de objeto.

(5) Quizás no sea un día para la poesíalpero reconoce usted que el premio Nobel Pablo Nerudaly se atrevería usted a recitarnos algunos de sus poemas?/ (CCEC $<$ MaDiTag $>$ ).

La cercanía sintáctica de los sujetos posverbales a los objetos de las cláusulas con verbo transitivo certifica su condición de contenido objetual. De hecho, la transitividad se concibe como el paso de un flujo o corriente de energía del agente hacia el paciente; es lo que Langacker (1991: 285-286) denominó modelo de evento canónico. En las construcciones prototípicas SVO el agente (fuente) ejerce una acción sobre el paciente (meta) transmitiendo el flujo a través del lexema verbal. Así, en el ejemplo María come peras, que presenta el esquema prototípico SVO, el flujo de energía pasa de María (agente) a peras (paciente) a través del verbo come.

La percepción de esa corriente dependerá de los participantes en la escena y de su ordenación en la cláusula, de modo que en el orden SVO el flujo será mayor que cuando se altera ese orden básico. Así pues, la inversión de los valores prototípicos de agentividad y afectación en VSO puede dar lugar a una disminución del flujo de energía, de modo que el agente pierde buena parte de sus propiedades y se asimila más al paciente. Retomando el ejemplo anterior, si el sujeto se presenta pospuesto: Come peras María, el flujo de energía disminuye, ya no hay acción del agente sobre el paciente, y el sujeto se asimila a esta última noción al ocupar el lugar sintáctico destinado para los objetos. Así pues, la posición preverbal incrementa el flujo de energía y su propia agentividad o 
responsabilidad en el proceso, mientras que la solución pospuesta apuntaría a una reducción de la agentividad, lo cual puede incidir en su afectación y objetualización.

En suma, estos rasgos presentes en el sujeto posverbal se corresponden con unos contenidos nocionalmente concebidos como resaltados, nuevos o inesperados, perfectamente compatibles con la transmisión de informatividad.

Por tanto, el sujeto posverbal posee la menor prominencia con respecto al posverbal (y al omitido), pero, inversamente, es el más informativo de los tres. Por lo tanto, al esquema 1 se puede añadir la colocación del sujeto expreso. Como puede observarse, el sujeto preverbal ocupa el nivel intermedio de esa gradualidad entre la prominencia y la informatividad.

\begin{tabular}{cccc}
\hline & Sujeto omitido & Sujeto preverval & Sujeto posverbal \\
\hline Prominencia cognitiva & + prominente & +/- prominente & - prominente \\
\hline Tabla 2. Gradualidad de la prominencia en las tres variantes del sujeto
\end{tabular}

Tabla 2. Gradualidad de la prominencia en las tres variantes del sujeto

Y se puede realizar otra escala en referencia a la informatividad textual.

\begin{tabular}{lccc}
\hline & Sujeto omitido & Sujeto preverval & Sujeto posverbal \\
\hline Informatividad textual & - informativo & $+/$ - informativo & + informativo \\
\hline
\end{tabular}

Tabla 3. Gradualidad de la informatividad en las tres variantes del sujeto

3. De la cognición al discurso. La conexión entre la prominencia cognitiva y la informatividad textual. El desplazamiento del foco de atención al foco de información

De acuerdo con lo anterior, es posible relacionar la noción cognitiva de prominencia con la de informatividad textual para basar en ellas el estudio de la variación de los pronombres de sujeto. Aunque proceden de distintos enfoques hermenéuticos, comparten algunas características básicas de aplicación discursivo-pragmática. Una de ellas, y quizá la más importante, es la noción de foco. En la conceptualización de la prominencia, el foco de atención recae en la mente del hablante sobre su conocimiento de los referentes en el discurso. Esto hace que, en principio, si un sujeto no se formula, será porque está activado o es accesible cognitivamente; $y$ a la inversa, su eventual formulación recubrirá alguna motivación estilística, sociosituacional, discursivo-pragmática, etc. La prominencia va decayendo según el sujeto va desprendiéndose de la activación mental y se textualiza; por eso un sujeto omitido será más prominente que uno preverbal, y este aún más que el posverbal, que ocupará el nivel más bajo, como ya se ha señalado. El foco de atención prominente en el sujeto posverbal es el más bajo de la escala, pudiendo llegar a ser mínimo o inexistente. 
Por el contrario, cuando el sujeto se expresa, su presencia en el discurso podrá corresponderse también con alguna razón discursiva, como la informatividad, que a su vez dará lugar a distintos significados interactivos. El sujeto posverbal adquiere el mayor foco de información, que va disminuyendo en el preverbal y es menor en el omitido.

Se puede proponer que en esta escala de prominencia/informatividad se produce un desplazamiento del foco de atención (+prominente) al foco de información (+informativo), lo que ocurre de forma gradual entre las tres variantes.

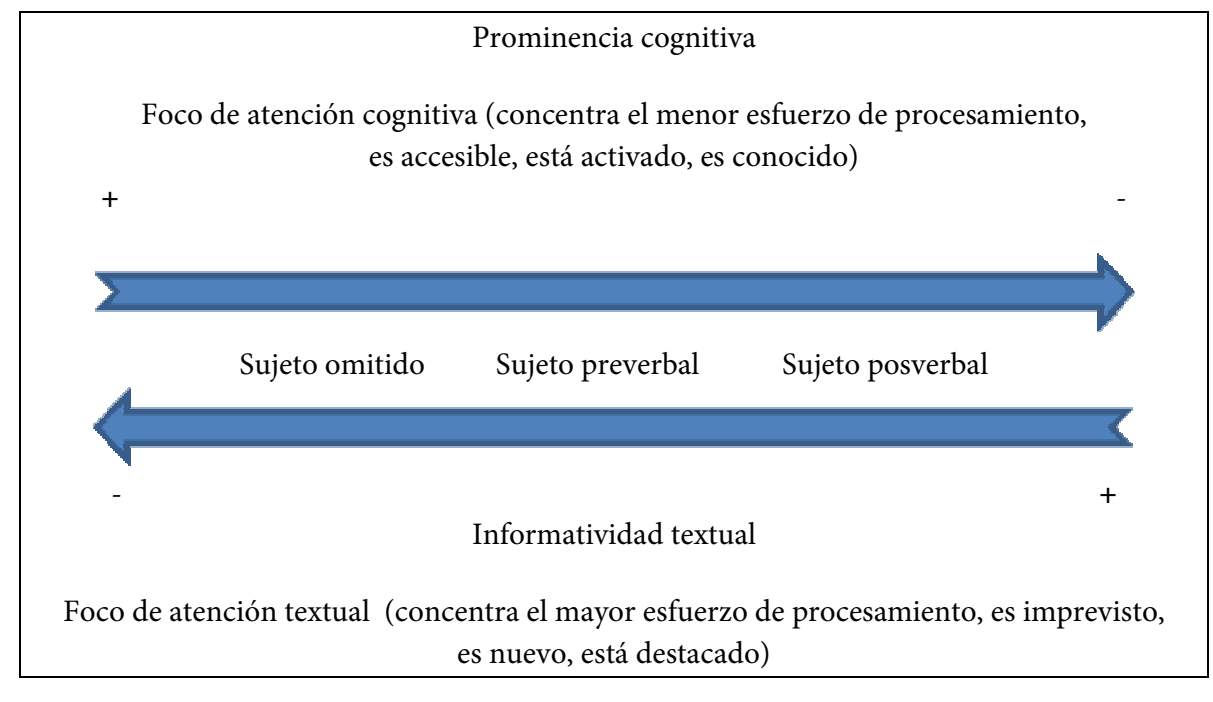

Gráfico 1. Gradualidad de la prominencia cognitiva y la informatividad

Los resultados de algunas investigaciones sobre la expresión/omisión del sujeto y su colocación preverbal/posverbal han podido confirmar la distinta gradación entre la prominencia cognitiva y la informatividad textual, que dan lugar a distintos significados en el discurso y en la interacción comunicativa.

Dichas nociones han sido relevantes para determinar el significado discursivopragmático que adquieren las variantes en la interacción comunicativa a partir de sus fundamentos cognitivos, y que puede dar lugar a un estilo comunicativo creado en conjunción con los elementos sociosituacionales que coaparecen con las variantes. La prominencia cognitiva y la informatividad textual se entienden como un continuum gradual, de forma que las tres variantes del sujeto pronominal participan en mayor o menor medida de ambas nociones, según los esquemas propuestos. 
La variación entre la expresión y la omisión (yo creo/creo, usted(es)/ø, nosotros/ ø) se ha estudiado de acuerdo a la prominencia cognitiva, mientras en que los casos de colocación preverbal o posverbal fueron aplicadas ambas nociones. Esto sucede así porque la posición preverbal, que constituye la categoría intermedia en la escala de prominencia-informatividad, participa simultáneamente de las dos categorías.

La aplicación de las nociones de prominencia cognitiva e informatividad textual ha podido explicar satisfactoriamente las propiedades cognitivas que subyacen a la variación. A continuación se presentan sucintamente algunos resultados obtenidos con respecto a la expresión/omisión de la primera y la segunda persona del paradigma, así como a su colocación preverbal o posverbal.

3.1. La expresión/omisión de la primera y segunda personas pronominales (yo, usted/ustedes, nosotros)

A través de un estudio cualitativo y cuantitativo sobre la expresión del sujeto de primera persona ( $y o$ ) en las construcciones (yo) creo en textos de dos corpus de los medios de comunicación ${ }^{18}$, se comprobó que la expresión del pronombre es más frecuente en aquellas situaciones comunicativas como los debates políticos, donde predomina la función argumentativa.

(6) La gente que venía de la Península no sabía valorar un trajelyo creo que las personas famosas \que vienen aquí al Carnaval deberían de ser invitados\yo creo que podía haber un|||un jurado más específico sobre el tema que estamos tratando $\backslash$ (CCEC $<$ MaTe09>CarnI).

Por su parte, la omisión ( $\varnothing$ creo) es más frecuente en proposiciones donde se produce la formulación de hipótesis y contenidos generales, como se observa en el siguiente ejemplo.

(7) B: Ella tuvo una neumonía en junio|||y estuvo quince días en casal

A: Yo por lo que he leído en prensaltengo la idea de que tu madre\|dejó escrito algo

C: No sabemos $\$ creo que fue algo sobre un dinero que le debia $\backslash$ para que se le pagara $\backslash(C C E C<M a T e 09>)$

Esta variación se produce gracias a las conceptualizaciones cognitivas expuestas: el sujeto omitido es prominente y accesible, lo cual lo hace idóneo para la formulación de

18 Corpus de Lenguaje de los Medios de Comunicación de Salamanca y Corpus Conversacional del Español de Canarias. 
tales contenidos y en las situaciones sociocomunicativas apropiadas, como entre aquellos hablantes que intentan transmitir una imagen de objetividad profesional, como los periodistas. El grupo socioprofesional de los políticos se inclina por la forma con el sujeto expreso yo creo para elaborar sus argumentos. En cuanto a la variación según el sexo/género, encontramos diferencias en cuanto a la frecuencia total de aparición de la forma creo, lo que puede apuntar a distintas orientaciones epistémico-evidenciales en la interacción discursiva (Aijón Oliva y Serrano, 2010b).

Sobre el pronombre usted/ustedes y sus variantes expresa y omitida hemos encontrado algunos resultados similares fundamentados en estas nociones (Serrano y Aijón Oliva, 2010b). Se observa que la expresión del sujeto es más frecuente en aquellos ejemplos donde se desea resaltar su responsabilidad en la acción descrita; en el siguiente ejemplo se coloca el pronombre usted en posición posverbal: Presenta usted, indicando como responsable a la segunda persona de la acción descrita, por lo tanto queda subrayado pragmáticamente en virtud de la informatividad que conlleva.

(8) Presenta usted una nueva denuncia con su sentencia || $\mid$ insistir en que se ejecute la sentencialen el año 2000 fue?/en el año que puso usted la denuncialpues esa sentencia que tiene usted del 2003 intente que se ejecute por todos los medios posibles yendo a ese juzgadolque se investigue si este señor tiene sueldo $\backslash$ salario o pensiones $\backslash($ CCEC $<$ Ma10ElEnv $>$ ).

Por su parte, la expresión en posición preverbal puede dar lugar a significados relacionados con la cortesía, como cuando se quiere dignificar al referente del sujeto haciéndolo presente en la escena comunicativa por medio de la expresión.

(9) Usted conoce profundamente La Laguna \usted ha sido un estudioso de La Laguna $\backslash$ (...) usted lo relataría con cierto toque de ironía \pero sin que se le escape nadalel argumento es muy lagunero ¿no?/ (CCEC $<$ MA1020min $>$ ).

En cambio, la omisión puede servir como un recurso expresivo para difuminar dicha presencia en el contenido descrito, como cuando se tratan temas comprometidos o controvertidos para el interlocutor, como lo es el ejemplo siguiente, donde este interroga a su entrevistada sobre el fallecimiento de su hijo. La omisión del sujeto en ambas cláusulas interrogativas evita focalizar sobre ella para que responda a las preguntas.

(10) ¿Cómo se enteraron $\emptyset$ ?/ (del fallecimiento de su hijo)¿Sabe Ø cuándo va a ser el funeral?/¿Le ha llamado el Presidente Zapatero? \(CCEC $<M a 10 R e>)$.

De hecho, la expresión del sujeto produce un significado menos epistémico que la omisión y conduce a una mayor subjetividad que esta última, porque la predicación se centra en los sujetos. La omisión, en virtud de la prominencia cognitiva, conduce a la creación de estilos más tendentes a la objetividad. Al igual que en la investigación ante- 
rior, encontramos más casos de usted/ustedes omitido entre aquellos hablantes y situaciones que en general requieren la adopción de este estilo comunicativo, como los periodistas y los programas de entretenimiento. Por su parte, los políticos y el género textual de los debates son más proclives a la elaboración de estilos más subjetivos.

El caso del pronombre nosotros revela un comportamiento discursivo diferente al de las otras variantes estudiadas. En textos conversacionales del Corpus Conversacional del Español de Canarias hemos encontrado que se trata de la variante con mayor tendencia a la omisión y que adquiere significados en el discurso que no aparecen (al menos con la misma frecuencia) en la variante expresa ${ }^{19}$. Este pronombre no tiene un referente definido en la lengua española, ni se trata exactamente del plural de la primera persona del paradigma. En esta investigación (Serrano, 2011b) se obtienen dos significados de esta forma: una que incluye al interlocutor y a la audiencia (' $y o+$ otras personas excluyendo la audiencia, tú/vosotros/ustedes) y otra que lo incluye ('yo + otras personas incluyendo la audiencia, tú/vosotros/ustedes). Estas dos posibilidades deícticas se producen con mucha mayor frecuencia en la omisión y más escasamente con la expresión.

La omisión del sujeto constituye una opción comunicativa para el hablante, esto es, si bien en algunos casos la omisión parece obligatoria por la propia prominencia del referente, en otros el hablante tiene la opción de expresarlo u omitirlo, consiguiendo con la expresión un significado mucho más concreto en el discurso que el que aporta la variante omitida.

En el siguiente ejemplo se habla de la admisión de inmigrantes y de la incapacidad para proveerles de empleo. En él, el sujeto nosotros aparece omitido; se supone que se refiere al conjunto de ciudadanos, a los habitantes de Canarias ('yo y todos los demás ciudadanos'), que no podemos darles trabajo.

(11) Pero chica $\emptyset$ no podemos $\backslash$ que no hay trabajo para los de aquí $(C C E C<E l E n 08>)$.

En este otro ejemplo extraído de una asamblea de trabajadores el referente es más concreto, pero, al igual que en el ejemplo anterior, resulta prominente en el discurso, de modo que no hay necesidad de formularlo.

(12) Y lo que sí hemos hecho ø es comentar el paso de T. como delegada sindical por la baja de J.C. $\backslash($ CCEC $<$ ElEn08>).

19 Por otra parte, esto da cuenta de la escasa utilidad que tiene desechar los contextos que no son alternantes en el estudio de la variación morfosintáctica. 
Por el contrario, cuando el pronombre se expresa, cabe suponer que su referente posee un nivel más bajo de prominencia con respecto al omitido, pero su formulación se ve inducida por alguna necesidad o intención discursivo-cognitiva y pragmática que se pone de manifiesto en la interacción y que, paralelamente, conlleva un incremento de su informatividad.

(13) Que nosotros hemos tomado decisiones en reuniones $y$ después el resto de la gente no está informada de lo que hay que hacer $($ CCEC $<$ ElEn08>).

En este caso, la prominencia cognitiva ha permitido confirmar la idea de que la variación sintáctica conlleva siempre el enfoque cognitivo de distintos significados. Ello se proyecta en las conversaciones cotidianas como una posibilidad de expresión de ideas epistémico-evidenciales, seguras o neutrales a partir de los distintos valores de inclusión/exclusión del referente en la omisión.

\subsection{La colocación preverbal/posverbal}

La informatividad textual comienza a percibirse a partir del sujeto expreso y llega a su máximo nivel cuando el sujeto adopta la posición posverbal, como se apuntó anteriormente. De acuerdo a lo expuesto en apartados anteriores, el pronombre usted/ustedes y su posición con respecto al verbo muestra valores opuestos en torno a la gradación entre prominencia e informatividad. La posición preverbal es la prototípica y, en contraste con la posverbal, adquiere un mayor nivel de prominencia cognitiva que esta y uno más bajo de informatividad. Dado que se trata de una variante del sujeto expreso, dicha prominencia conlleva un significado basado en un incremento de la agentividad del sujeto sobre la acción verbal:

(14) La crisis sucesoria que usted intenta negar es absolutamente necesaria en el partido socialista\porque tendrán que rearmarse para una nueva etapa \ustedes tendrán que rearmarse para un éxito electoral $\backslash(M a E n<E l E n v>)$.

La expresión del sujeto (en este caso, de segunda persona, en esta posición y en virtud de la mencionada agentividad) conduce a presentar el contenido matizado en la perspectiva del hablante, que se hace prominente y protagonista en la escena comunicativa y con ello se asocia a su esfera personal, de donde surge la interpretación del enunciado de forma argumentativa. De este modo, el sujeto expreso preverbal da lugar a una emisión basada en la perspectiva del hablante sobre las situaciones, muy común en contextos interactivos en los que es necesario hacer presente a la segunda persona del discurso, y que, al mismo tiempo, sirve para la expresión de opiniones y argumentos. 
La expresión de usted preverbal introduce una opinión personal basada en la agentividad y prominencia del sujeto.

(15) Bueno\usted además trabaja también perfectamente bien la maderalel broncellos brillantes y los topacios $y$ ha hecho también una incursión en la joyería arquitectónica \ $(M a E n<E l E n v>)$.

Por su parte, cuanto este pronombre aparece en posición posverbal, ocupa la posición sintáctica típica de los objetos, de modo que cabría esperar que asimile alguna de las características de los objetos de las construcciones transitivas sin dejar de exhibir, al mismo tiempo, las propiedades de prominencia/informatividad descritas ${ }^{20}$.Esta posición supone una ruptura del esquema prototípico sujeto-verbo y una consecuente asimilación del sujeto al objeto sintáctico, que cognitivamente podría significar la tendencia de la cláusula a asumir significados informativos a través de dicha posición. Un análisis de los ejemplos con sujeto posverbal del corpus da a entender que esta variante se produce con una alta frecuencia cuando el verbo es transitivo o copulativo.

Los verbos transitivos más frecuentes con sujeto posverbal son tener, hacer y ver. Existe una tendencia de esta posición a coaparecer con verbos transitivos o copulativos, como se observa en los siguientes ejemplos:

(16) Y por la mañanalademás de este excepcional programaltienen ustedes la compañíalde una mujerlexcepcional también $\backslash$ no vean la de cosas que tiene que contarnos $\backslash$ escuchen $\backslash$ escuchen $\backslash_{¿}$ lo apuntaron $\backslash n o$ ? $($ MaEn $<$ Vimige $>$ ).

El polo más extremo de la no agentividad del pronombre usted/ustedes posverbal puede relacionarse, por tanto, con la posición prototípica de la objetualidad sintáctica. Sin embargo, estaríamos ante una transitividad no prototípica o baja. Así pues, la afectación que sufre el sujeto en esta posición sintáctica da lugar a un significado informativo, basado en la reducción de la agentividad, que presupone que la cláusula o todo el texto que lo contiene presente la información como nueva; y que adquiere características nocionales basadas en aspectos como la informatividad-focalización-epistemicidad. Todo ello puede dar lugar a una dimensión general basada en un incremento de la literalidad o la fuerza pragmática de lo expresado. Mediante la focalización en el interlocutor, el significado que adquiere el texto está más orientado a la objetividad, favoreciendo que la serie de instrucciones ofrecidas parezcan reales o consabidas para el oyente.

$20 \mathrm{El}$ pronombre usted/ustedes antepuesto en los textos de los medios de comunicación es menos frecuente que el posverbal. Este pronombre se aparta del comportamiento del resto del paradigma verbal, presentando una mayor frecuencia de aquella posición. En los textos conversacionales del mismo corpus, la posposición constituye solamente un $17.2 \%$ del total. 
(17) Presenta usted una nueva denuncia con su sentencia \|||insistir en que se ejecute la sentencialen el año 2000 fue?/en el año que puso usted la denuncia \pues esa sentencia que tiene usted del 2003 intente que se ejecute por todos los medios posibles yendo a ese juzgado\que se investigue si este señor tiene sueldo \salario o pensiones $\backslash$ (CCEC <MaDiRoyCo $>$ ).

Así pues, la posición preverbal constituiría un caso de transitividad alta o prototípica y la posición posverbal de baja o no prototípica, que al mismo tiempo podrían estar asociadas a una gradualidad de la subjetividad. La posición verbo-sujeto aparece con mayor frecuencia con verbos transitivos y el sujeto adopta la posición del objeto, con lo cual el texto y la cláusula adquieren significados informativos-focalizadores y epistémicos. La alta frecuencia de la posición sujeto-verbo en géneros textuales como los debates políticos, que conllevan un elevado nivel de argumentación y de interacción, indica que esta posición construye un significado basado en la perspectiva del hablante sobre las situaciones, esto es, más subjetivo que la posición verbo-sujeto.

En esta investigación pudo confirmarse la escala de prominencia cognitiva/informatividad propuesta, en la que la posición preverbal es más prominente pero menos informativa que la posverbal. La variación sociosituacional muestra que la posición preverbal es en general característica de los textos de debates políticos, la categoría socioprofesional de los políticos y los hombres, con lo cual estas dimensiones, combinadas con los significados de las variantes, orientarían el estilo construido hacia el polo de la subjetividad (Serrano, 2012).

La gradualidad de la prominencia y la informatividad de la colocación preverbal o posverbal puede manifestarse asimismo en significados relacionados con la cortesía verbal. Ello, además de incrementar la fuerza ilocutiva de la emisión, podrá suponer una estrategia para dignificar la imagen de dicho referente cuando el contenido de la cláusula le atribuya una acción o cualidad considerada positiva.

A partir del significado descrito para la posición preverbal, el referente del pronombre de sujeto expreso se hace presente explícitamente en la escena comunicativa, lo cual puede constituir un recurso estilístico de cortesía dignificadora, al asumir la responsabilidad del contenido proposicional.

(18) A: Yo no digo que tengan mala fe $\backslash$ pero la forma $\backslash$ el motivo \lejos de ayudarla, la están hundiendo más yo es lo que digo lyol| esa gente no vale nada|pero una cosa que me enseñaron a mí es el respeto hacia la gentel y a la piba la tiene:::n $\backslash$ amargada (...) en el mundo hay de todo|hay de toda la gama que tú quieras \gordo\flaco \lo que tú quieras (CCEC $<$ MaEn08>).

Por lo que respecta a la posición posverbal, el aumento de la informatividad que lo caracteriza puede conllevar la percepción de una mayor afectación. Con cierta frecuen- 
cia, los casos de sujeto posverbal se producen en contextos peyorativos a partir del carácter objetual que sugiere esta posición, que puede servir para proteger la imagen del interlocutor a partir de la autopeyoración. Así, por ejemplo, el sujeto de primera persona $(y o)$ en posición posverbal puede constituir un recurso de autopeyoración, al centrar la responsabilidad del evento en el referente del sujeto.

(19) A: claro/ claro/ a ver porque/ me imagino yo que como ella ya laseguridad social le empieza a pagarles a ellos yo creo que pronto le empieza a pagar la seguridad social a ellos $\backslash$

B: sí/ yo creo que sí

A: sî la seguridad social paga una parte proporcional

B: ¿aunque estés de baja?/

A: o te manda una carta de despido y tú ya empiezas a negociar/son 25 días por año/(CCEC $<$ MaPly0307>)

De todos modos, estos valores estarán en función de la intención comunicativa del hablante y de la situación de la enunciación, que serán los que finalmente determinarán el estilo comunicativo de (des)cortesía (cf. Serrano y Aijón Oliva, 2010a).

\section{Conclusiones}

Los factores cognitivos y textuales que influyen en la tres variantes del sujeto pronominal en español (expreso preverbal, expreso posverbal y omitido) permiten proporcionar una base interpretativa sólida para definir el significado que se crea con cada una de ellas. Como propiedades opuestas, la prominencia cognitiva y la informatividad textual, aunque proceden de constructos teóricos diferentes, constituyen el eje sobre el cual se pueden establecer los distintos significados y valores de las variantes creados en la interacción comunicativa, que paralelamente podrán dar lugar al desarrollo de estilos comunicativos diferenciados (Serrano y Aijón Oliva, 2011). Hemos querido destacar la importancia del análisis de las propiedades internas de la gramática que subyacen a todo fenómeno de variación como paso indispensable para poder comprender su distribución social y estilística.

Recibido: 26-IV-2012

Aceptado: 14-II-2013

\section{Referencias bibliográficas}

Aijón Oliva, M. A. y Serrano, M. J. (2010a): "Las bases cognitivas del estilo lingüístico", Sociolinguistic Studies 4, 1, págs. 115-144. 
Aijón Oliva, M. A. y Serrano, M. J. (2010b): "El hablante en su discurso: expresión y omisión del sujeto de creo", Oralia 13, págs. 7-38.

Aijón Oliva, M. A. y Serrano, M. J. (2012): “Towards a comprehensive view of variation in language: The absolute variable”, Language \& Communication 32, págs. 80-94.

Alonso Cortés, A. (2002): Lingüística. Madrid, Cátedra.

Ariel, M. (1990): Accessing noun phrase antecedents. Londres, Routledge.

Beaugrande, R. y Dressler, W. U (1997): Introducción a la Lingüística del texto. Barcelona, Ariel.

Bentivoglio, P. (1988): "La posición del sujeto en el español de Caracas: un análisis de los factores lingüísticos y extralingüísticos". En Hammond, R. M. y M.C. Resnick (eds.), Studies in Caribbean Spanish Dialectology. Washington, D.C., Georgetown University Press, págs. 13-23.

Bentivoglio, P. (1989): "Función y significado de la posposición del sujeto nominal en el español hablado", en Estudios sobre el español de América y lingüística afroamericana, Bogotá, Instituto Caro y Cuervo, págs. 40-57.

Chafe, W. L. (1976): "Givenness, contrastiveness, definiteness, subjects, topics, and point of view". En Li, C. (ed.), Subject and Topic. New York, Academic Press, págs. 25-55.

Croft, W. y Cruse, A. (2008): Lingüística Cognitiva. Madrid, Akal.

Crystal, D. (1985): A dictionary of linguistics and phonetics. New York, Blackwell.

Delbecque, N. (2005): "El análisis de corpus al servicio de la gramática funcional y cognoscitiva. Hacia una interpretación de la alternancia sujeto-verbo/verbo-sujeto". En Knauer, G. y V. Bellosta von Colbe (eds.), Variación sintáctica: un reto para las teorías de la sintaxis. Tübingen, Niemeyer, págs. 51-74.

Dik, S. C. (1981): Functional grammar. Dordrecht, Foris.

Evans, V. y Pourcel, S. (2009): New directions in cognitive linguistics. Amsterdam, Benjamins.

Firbas, J. (1966): "Non-thematic subjects in contemporary English", Travaux Linguistique de Prague 2, págs.239-256.

Fried, M. (2009): “Word order”. En Frank, B., J. O. Östman y J. Verschueren (eds.), Grammar, meaning and Pragmatics. Amsterdam, Benjamins, págs. 289-300.

García, E. C. (2009): The motivated syntax of arbitrary signs. Cognitive constraints on Spanish clitic clustering. Amsterdam, Benjamins.

Geeraerts, D., Dirven, R. y Taylor, J. J. (2006): Cognitive Linguistics: Basic readings. Berlín, Mouton de Gruyter.

Gili, Gaya, S. (1976): Curso superior de sintaxis española. Barcelona, Biblograf.

Giora, R. (2003): Salience, context and figurative language. Oxford, University Press. 
Givón, T. (2001): Syntax. An introduction. Amsterdam, Benjamins.

Givón, T. (1995): Functionalism and Grammar. Amsterdam, Benjamins.

Gundel, J. K. y Fretheim, T. (2009): "Information structure". En Frank, B., J.O. Östman y J. Verschueren, (eds.), Grammar, Meaning and Pragmatics. Amsterdam: Benjamins, págs. 146-160.

Halliday, M. A. K. (1967): "Notes on transitivity and theme in English" Part 2., Journal of Linguistics, 3, págs. 199-244.

Hopper, P. y Thompson, S. (1980): "Transitivity in Grammar and Discourse", Language, 56, págs. 252-299.

Lakoff, G. (1987): Women, fire, and dangerous things: What categories reveal about the mind. Chicago, Chicago University Press.

Lambrecht, K. (1998): Information structure and sentence form. Cambridge, University Press.

Langacker, R. W. (2004): "Form, meaning and behavior". En Contini-Morava, E., R.S. Kirsner \& B. Rodríguez Bachiller (eds.), Cognitive and communicative approaches to language. Amsterdam, Benjamins, págs. 21-40.

Langacker, R. W. (1991): Foundations of cognitive grammar. Berlín, Mouton de Gruyter.

Langacker, R. W. (1999): Grammar and conceptualization. Berlín, Mouton de Gruyter.

Langacker, R. W. (2009): Investigations in cognitive grammar. Berlín, Mouton de Gruyter.

Levinson, S. (1983): Pragmatics. Cambridge, University Press.

Lockwood, D., G., Fries, P.H. y Copeland, J.E. (2000): Functional approaches to language, culture and cognition. Amsterdam, Benjamins.

López García, A. (2010): Pluricentrismo, hibridación y porosidad en la lengua española. Madrid/Frankfurt, Iberoamericana/Vervuert.

Morales, A. (1982): "La perspectiva dinámica oracional en el español de Puerto Rico". En Alba, O. (ed.) El español del Caribe. Santiago de los Caballeros, RD, Universidad Católica Madre y Maestra, págs. 203-219.

Padilla García, X. A (2001): El orden de palabras en español coloquial. Tesis doctoral, Universidad de Valencia.

Posio, P. (2012): "The functions of postverbal pronominal pubjects in spoken Peninsular Spanish and European Portuguese", Studies in Hispanic and Lusophone Linguistics 5,1, págs. 149-190.

Prince, E. F. (1981): “Toward a taxonomy of given-new information”. En Cole, P. (ed.), Radical Pragmatics. New York, Academic Press, págs. 223-255.

Serrano, M.J. (2011a): "Morphosyntactic variation in Spain”. En Díaz Campos, M. (ed.), The Handbook of Hispanic Sociolinguistics. Oxford, Wiley-Blackwell, págs. 188-204. 
Serrano, M. J. (2011b): “'Otras personas y yo’. Variación socioestilística del pronombre nosotros en conversaciones espontáneas". En Serrano (ed.), Variación Variable. Almería, Círculo Rojo/Ministerio de Ciencia e Innovación, págs. 93-126.

Serrano, M. J. (2012): "El sujeto pronominal usted/ustedes y su posición: variación y creación de estilos comunicativos", Spanish in Context 9, 1, págs. 109-131.

Serrano, M. J. y Aijón Oliva, M. A. (2010a): "La posición variable del sujeto pronominal en relación con la cortesía interactiva”, Pragmalingüística 18, págs.170-204.

Serrano, M. J. y Aijón Oliva, M. A. (2010b): "Sociocommunicative style and its cognitive properties: subject expression and placement of the Spanish subject (usted/ustedes)". En Cognitive Sociolinguistics: Language Variation in its structural, conceptual and cultural dimensions. Landau, Universität Koblenz-Landau, págs. 5070.

Serrano, M. J. y Aijón Oliva, M. A. (2011): "Syntactic variation and communicative style”, Language Sciences 33, págs. 138-153.

Shannon, C. y Weaver, W. (1949): The Mathematical theory of Communication. Urbana, University of Illinois Press.

Talmy, L. (1988): "Force dynamics in language and cognition", Cognitive Science 12, págs. 49-100.

Vega, M. (2005): “Lenguaje, corporeidad y cerebro”, Signos, 38, págs. 157-176. 



\title{
ESPECIFICACIÓN SEMÁNTICA VERSUS NEUTRALIZACIÓN ENTRE ESPAÑOL Y PORTUGUÉS. SU FORMALIZACIÓN EN LOS DICCIONARIOS BILINGÜES
}

\author{
IGNACIO VÁZQUEZ DIÉGUEZ \\ Universitat de Barcelona \\ ivazquez@ub.edu
}

\section{Resumen}

Las lenguas española y portuguesa poseen un elevado número de voces comunes que se usan en la lengua cotidiana de modo diferente. Dicha afirmación se verifica en portugués en una especificación semántica en el uso de las voces habituales que no presenta el castellano. Los diccionarios bilingües español-portugués deberían partir de la frecuencia de uso y marcarla en la microestructura a través de los discriminadores de contexto. Hasta épocas recientes estos diccionarios, confeccionados a la sombra de la RAE, atendían a un registro culto, casi literario de la lengua. Es nuestro propósito demostrar la importancia de especificar apropiadamente los marcadores de contexto para ofrecer el equivalente portugués adecuado de la acepción española.

PALABRAS CLAVE: lexicografía, especificación semántica, frecuencia de uso, españolportugués.

\section{Abstract}

Spanish and Portuguese have a very high number of words in common that are used in a different way in daily speech. This statement is based on the semantic specification verified in certain words of common usage in the Portuguese language, which does not occur in Spanish. Spanish-Portuguese bilingual dictionaries should start from the premise of frequency of use and it should be well specified in their microstructure by using disambiguation marks of context. Until recent times, those dictionaries - made under the shadow of RAE - used to be created in accordance to a cultured (formal) - almost literary- register of language. We intend to demonstrate the importance of specifying properly those disambiguation marks in order to provide the correct Portuguese equivalent to the Spanish sense (meaning)

KEY WORDS: lexicography, semantic specification, frequency of use, SpanishPortuguese.

\section{Introducción}

Pretendemos en este trabajo reflexionar sobre un aspecto esencial de la lexicografía bilingüe: el tratamiento y la disposición de los equivalentes en la microestructura. Dicha disposición se verá centrada en el español y portugués peninsulares ${ }^{1}$.

\footnotetext{
${ }^{1}$ Se utilizan, por lo tanto, solamente diccionarios publicados en España y Portugal que tratan las variantes europeas.
} 
Como el propio título indica, la especificación semántica frente a la neutralización, regidas por la frecuencia de uso, se perfilan como los dos criterios esenciales para disponer esa información. Revisaremos estos conceptos con ayuda de algunos ejemplos.

A ningún español le parecerá raro escuchar o, en este caso, leer frases como las siguientes:

Logró despertar un gran afecto en la pequeña Amaranta Úrsula, que era idéntica a ella, y a quien enseñó a leer (Cien años de Soledad, García Márquez, 1967) y

Añadió el Moñigo: - ¿Y si le enseña la carta a la Sara? (El camino, Miguel Delibes, 1950)

De la misma manera que ningún portugués se extrañará al leer las siguientes oraciones:

[...] pois é deveras, estou ensinando a ler à Margarida (O Seminarista, Bernardo Guimarães, 1872) y

Mostrou todos os dentes alvos num riso juvenil (Os Avisos do Destino, José Régio, 1910)

Ahora bien, cualquier español tendrá una impresión diferente al leer:

Roque se remangó el pantalón izquierdo y mostró un círculo de piel arrugada y débil (El camino, Miguel Delibes, 1950)

Esa frase, aun escrita por un español (como es el caso), alerta al lector peninsular: si no conoce al escritor podrá pensar que se trata de un autor americano, si lo conoce, pensará que lee una frase redactada en un registro más culto o cuidado, propio de la escritura. Si leyese "[...] y enseñó un círculo de piel arrugada y débil", seguramente no se produciría ninguna reacción mental ya que se utiliza el verbo habitual.

Un portugués ante las frases escritas en su lengua lee en ambos casos los verbos de uso corriente, sin cambios de registro (tampoco pensaría que el autor de la segunda es americano, ya que el uso de esas estructuras es igual en Portugal y en Brasil).

El DRAE (2001, 21 a ed.) define mostrar en su primera acepción de la siguiente manera: "1. tr. Manifestar o poner a la vista algo; enseñarlo o señalarlo para que se vea". Como se observa, utiliza el verbo enseñar en la definición, verbo este que, en el mismo diccionario se define como sigue en sus dos acepciones más comunes: "1. tr. Instruir, doctrinar, amaestrar con reglas o preceptos. [...] 4. tr. Mostrar o exponer algo, para que sea visto y apreciado." Como también se observa, emplea el verbo mostrar en la definición de la cuarta acepción, la segunda más habitual en el registro normal.

En el español peninsular usual, el verbo enseñar ha ampliado su campo de acción cotidiano en detrimento del verbo mostrar. Frente al portugués, que separa los dos ámbitos semánticos (aleccionar $=$ ensinar por un lado y exhibir $=$ mostrar por otro, y por 
tanto especifica semánticamente el verbo ensinar para una sola acción), el español neutraliza las dos acciones en un solo verbo, enseñar, de mayor frecuencia de uso.

Ese desdoblamiento que practica el portugués en el uso del léxico es percibido reiteradamente por los oídos/ojos de un español que aprende a hablar/leer esa lengua; al principio se convierte en una intuición, pero, cuando ya posee una competencia digna de la lengua portuguesa, a medida que domina mejor el idioma, esa sospecha se afianza. $\mathrm{Y}$ ello sucede en el par de lenguas que se tratan debido a la proximidad existente entre ellas. Existe una coincidencia muy elevada de léxico patrimonial entre español y portugués, pero el uso dado a ese vocabulario difiere en un gran número de casos.

Si consideramos que el diccionario es una herramienta fundamental en el aprendizaje de un idioma extranjero, la cuestión primordial que dirige este trabajo descansa en la siguiente premisa: se hace perentoria la necesidad de disponer correctamente la información de cada acepción atendiendo al uso real de las dos lenguas según la frecuencia de uso.

\section{De la intuición a la evidencia}

El principal escollo que se presenta ante algunas afirmaciones lanzadas en el punto anterior radica en la dificultad de justificarlas de modo científico. ¿Cómo se miden cuantitativamente las intuiciones aunque la experiencia de la lengua indique que son evidencias?

Como ya se ha afirmado, la lengua española y la portuguesa comparten una considerable cantidad de léxico común, debido, principalmente, a la fuente común latina, y específicamente al latín vulgar iberorrománico, y más concretamente el del occidente peninsular (esta afirmación, no obstante, no significa que en todos los casos los vocablos sean equivalentes exactos en todos los contextos). Conocidos filólogos han ofrecido su testimonio al respecto, como Iordan (1964), quien afirmó que español y portugués constituyen una unidad léxica. Posteriormente, Ulsh (1971: X) manifestó que "probably upwards of 85 per cent of Portuguese vocabulary consists of words which have a cognate in Spanish", afirmación secundada en tiempos más recientes por Carlinga (1997). No obstante, nos basaremos en el estudio de Richman (1965) que aporta datos empíricos que verifican esta aseveración y que nos ayudarán a materializar la intuición. En dicho trabajo, Richman analizó las 6.500 palabras más comunes del español ${ }^{2}$ y las comparó

\footnotetext{
${ }^{2}$ El vocabulario básico para que un aprendiz pueda comunicarse. Se basó, a su vez, en las obras de Milton Buchanan (1927) y Brown, Carr y Shane (1945).
} 
con las respectivas portuguesas para comprobar la cantidad de cognados (entendemos por cognados, palabras que comparten el mismo étimo, no necesariamente el mismo significado) que existían entre ambas lenguas.

Resumimos en seis puntos las conclusiones a las que llegó:

a) El español es léxicamente más próximo al portugués que al italiano, y más cercano del italiano que del francés. Comparte el $96 \%$ de sus palabras más frecuentes con el portugués; $76 \%$ con el italiano y $63,6 \%$ con el francés.

b) Más de la mitad de las palabras en español y portugués que carecen de un cognado en la otra lengua son nombres.

c) La proximidad léxica entre las lenguas románicas es considerablemente mayor teniendo en cuenta el vocabulario general que el especializado.

d) El $91 \%$ de las 6.500 palabras más frecuentes usadas en portugués presentan cognados en español.

e) La lengua portuguesa tolera la coexistencia de sinónimos mucho más que la lengua española, por consiguiente, posee un vocabulario más numeroso que la española.

f) El 38\% de las palabras españolas que carecen de cognados en portugués se relacionan con el portugués por una raíz común pero no presentan cognados porque carecen, sea de un significado común, sea de la misma formación.

En relación a la observación e), Richman (1971: 56) declara que:

There are many Sp. words which have at least two equivalents in Port. In these instances, one of the equivalents is a cognate of the Sp. word, while the other equivalent is of an entirely different etimology; or Port. has two different formations based on a single Latin root, while Sp. has only one. [...] The ocurrence of this phenomenon over and over again shows that Portuguese has a wider variety of lexical choice, and perhaps a greater capacity for conveying different shades of meaning than Spanish $[\ldots]$

Y tras otras consideraciones, acaba ponderando en la página 57 que "Whether the greater lexical richness of Port. does or does not provide the language with a semantic superiority over Sp., the fact remains that Port. has more words than does Sp. to express the most common concepts".

Cuantitativamente, Mendes (1998) ofrece las cifras que, según los últimos estudios, atestiguan que en español las palabras heredadas del latín son el 23\%; los préstamos representan el $41 \%$ y las creaciones vernáculas el $35 \%$. Con todo, si se considera la frecuencia de uso, las palabras heredadas del latín representan el $81 \%$, los préstamos el $10 \%$ y las creaciones vernáculas el $8 \%$. Además, el $80 \%$ de los préstamos (es decir, el $80 \%$ del $41 \%$ ) son de origen latino, lo que aumenta la frecuencia de voces latinas en el 
léxico habitual. En cuanto a la lengua portuguesa, esta "apresenta percentagens bem semelhantes, o que justifica a proximidade das línguas no que diz respeito ao léxico" (Mendes, 1998: 93). Si no tenemos en cuenta las creaciones vernáculas, obtenemos un $65 \%$ de léxico estrictamente común y que coincide con los cognados de Richman ${ }^{3}$.

Además, para acabar de perfilar la cuestión, se ofrece al lector, tomando como diccionario base ${ }^{4}$ el de la editorial Larousse publicado en 2010, el esqueleto de la letra jota (hemos buscado una de poca extensión debido a las obvias necesidades de acotar el espacio). Se observan los siguientes datos: el lemario español consta de 146 entradas y el portugués de 111. En la dirección español-portugués, se echa mano de 78 cognados equivalentes también semánticamente y de 42 vocablos que corresponden a cognados o formaciones vernáculas usados con un sentido diferente, neologismos, extranjerismos, etc. (marcados en cursiva). En la dirección portugués-español aparecen 86 cognados equivalentes también semánticamente y 20 vocablos que corresponden a cognados, formaciones vernáculas, etc. (se marcan en cursiva). Finalmente, se advierte el dato definitivo que afianza la idea originaria del estudio, la tendencia del español a neutralizar en una voz usual dos o más sentidos que mantiene la lengua portuguesa (el hecho también se da en sentido contrario aunque los datos demuestran que es menos frecuente): la lengua española genera 26 lemas cuyas dos o más acepciones en la lengua fundamental precisan de una voz portuguesa diferente para cada contexto; en la dirección portugués-español solamente se producen 5 casos (marcado en negrita) 5 . Las palabras portuguesas que aparecen sangradas a la derecha (javali, jarro, jarrão, jasmim, joia, joalharia, joalheiro, joanete, judiaria, judeu, jogo, juiz, jogada, jogador, jogar, jogral, juizo, julgamento, joule, julho, juramentado, júri y julgar) deberían estar alfabetizadas en otro lugar pero se presentan atendiendo al equivalente español.

\footnotetext{
${ }^{3}$ Un 10\% del léxico fundamental está representado por los llamados falsos amigos (Montero, 2007).

${ }^{4}$ Por varias razones, pero fundamentalmente dos: es el último bilingüe publicado y hemos trabajado en él, lo que nos ha permitido obtener datos cuantitativos exactos a través de la informática.

${ }^{5}$ En una letra de mayor envergadura, la $a$, los datos indican una situación semejante: la dirección español-portugués presenta 1.900 lemas, de los que 230 presentan dos o mas contextos con una palabra portuguesa diferente para cada uno de ellos; la dirección portugués-español contiene 1.878 lemas de los que 76 se desdoblan en más de una acepción con necesidad de diferentes voces españolas para cada contexto.
} 


\begin{tabular}{|c|c|c|c|}
\hline Español $>$ portugués & Portugués $>$ español & Español > portugués & Portugués $>$ español \\
\hline$-\mathrm{j}: \mathrm{j}$, jota $\mathrm{m}$. & $-j: \mathrm{j}$, jota $\mathrm{f}$. & $\begin{array}{l}\text {-jodido: } 1 \text {. (complica- } \\
\text { do) fodido, tramado / } \\
\text { 2. (enfermo) mal / } 3 . \\
\text { (estropeado) lixado / } 4 . \\
\text { (mísero) maldito }\end{array}$ & \\
\hline & -já: ya & & -joelheira: rodillera \\
\hline -jabalí: javali & -javali: jabalí & & -joelho: rodilla $f$. \\
\hline -jabalina: dardo & & -jofaina: palangana & \\
\hline -jabón: 1. sabão / 2. & & -jolgorio: paródia f. & \\
\hline (tocador) sabonete & & & \\
\hline -jabonar: ensaboar & & & -jóquer: comodín \\
\hline $\begin{array}{l}\text {-jabonera: sabonetei- } \\
\text { ra }\end{array}$ & & -jornada: jornada & -jornada: jornada \\
\hline -jaca: 1. faca / 2. & & -jornal: ordenado & \\
\hline & -jacaré: caimán & & $\begin{array}{l}\text {-jornal: diario, perió- } \\
\text { dico }\end{array}$ \\
\hline -jacinto: jacinto & $\begin{array}{l}\text {-jacinto: jacinto } \\
\text {-jackpot: (jogo) bote }\end{array}$ & $\begin{array}{l}\text {-jornalero: jornaleiro } \\
\text {-jornalismo: periodis- } \\
\text { mo }\end{array}$ & -jornaleiro: jornalero \\
\hline $\begin{array}{l}\text {-jactancioso: } \\
\text { ja(c)tancioso }\end{array}$ & $\begin{array}{l}\text {-ja(c)tancioso: jactan- } \\
\text { cioso }\end{array}$ & -jornalista: periodista & \\
\hline -jactarse: ja(c)tar-se & $\begin{array}{l}\text {-ja(c)tar-se: jactarse } \\
\text {-ja(c)to: chorro }\end{array}$ & $\begin{array}{l}\text {-jornalístico: periodísti- } \\
\text { co } \\
\text {-joroba: 1. corcunda / } \\
\text { 2. (camelo) giba }\end{array}$ & \\
\hline $\begin{array}{l}\text {-jaculatoria: jaculató- } \\
\text { ria }\end{array}$ & -jaculatória: jaculatoria & -jorobado: corcunda & \\
\hline -jacuzzi: jacuzzi & -jacuzzi: jacuzzi & $\begin{array}{l}\text {-jorobar: 1. (molestar) } \\
\text { chatear / 2. (estropear) } \\
\text { lixar }\end{array}$ & \\
\hline -jade: jade & -jade: jade & & -jorrar: chorrear \\
\hline -jadeante: arquejante & & & -jorro: chorro \\
\hline -jadear: arquejar & & $\begin{array}{l}\text {-jota: 1. (letra) jota, jê / } \\
\text { 2. (danza) jota }\end{array}$ & $\begin{array}{l}\text {-jota: 1. (letra) jota / } \\
\text { 2. (dança) jota }\end{array}$ \\
\hline -jaguar: jaguar & -jaguar: jaguar & $\begin{array}{l}\text {-joven: 1. novo, jovem } \\
\text { / 2. (juvenil) jovem }\end{array}$ & -jovem: joven \\
\hline -jalar: tragar & & -jovial: jovial & -jovial: jovial \\
\hline -jalea: geleia & & -joya: joia & -joia: joya \\
\hline -jalear: aclamar & & -joyería: joalharia & -joalharia: joyería \\
\hline $\begin{array}{l}\text {-jaleo: 1. barullo / } 2 . \\
\text { (problema) sarilho }\end{array}$ & & -joyero: joalheiro & -joalheiro: joyero \\
\hline
\end{tabular}




\begin{tabular}{|c|c|c|c|}
\hline \multicolumn{2}{|l|}{$\begin{array}{l}\text {-jalón: baliza } \\
\text {-jalonar: balizar }\end{array}$} & $\begin{array}{l}\text {-juanete: joanete } \\
\text {-jubilación: reforma, } \\
\text { aposentação }\end{array}$ & -joanete: juanete \\
\hline -jamás: jamais & -jamais: jamás & & -juba: melena \\
\hline $\begin{array}{l}\text {-jamba: jamba } \\
\text {-jamelgo: pileca }\end{array}$ & -jamba: jamba & $\begin{array}{l}\text {-jubilado: reformado, } \\
\text { aposentado } \\
\text {-jubilar(se): reformar(- } \\
\text { se), aposentar(-se) }\end{array}$ & \\
\hline -jamón: presunto & -janeiro: enero & $\begin{array}{l}\text {-júbilo: júbilo } \\
\text {-jubón: gibão }\end{array}$ & -júbilo: júbilo \\
\hline & $\begin{array}{l}\text {-janela: ventana } \\
\text {-jangada: balsa } \\
\text {-jangadeiro: balsero }\end{array}$ & $\begin{array}{l}\text {-judaísmo: judaísmo } \\
\text {-judería: judiaria } \\
\text {-judía: (legumbre) } \\
\text { feijão }\end{array}$ & $\begin{array}{l}\text {-judaísmo: judaísmo } \\
\text {-judiaria: judería }\end{array}$ \\
\hline & $\begin{array}{l}\text {-jantar: 1. cenar / 2. m. } \\
\text { cena }\end{array}$ & -judicatura: judicatura & $\begin{array}{l}\text {-judicatura: judicatu- } \\
\text { ra }\end{array}$ \\
\hline & -jante: llanta & -judicial: judicial & -judicial: judicial \\
\hline -japonés: japonês & -japonês: japonés & -judío: judea, -dia & -judeu: judío \\
\hline -jaque: xeque & & -judo: judo & -judo: judo \\
\hline -jaqueca: enxaqueca & $\begin{array}{l}\text {-jaqueta: chaquetilla } \\
\text {-jarda: yarda }\end{array}$ & $\begin{array}{l}\text {-juego: 1. jogo / } 2 \text {. } \\
\text { (infantil) brincadeira }\end{array}$ & $\begin{array}{l}\text {-jogo: 1. juego / } \\
\text { 2. (futebol) partido } \\
\text {-jugo: yugo } \\
\text {-jugular: yugular }\end{array}$ \\
\hline -jara: esteva & & -juerga: farra, paródia & \\
\hline -jarabe: xarope & & -juerguista: pândego & \\
\hline -jarana: pândega & & -jueves: quinta-feira & \\
\hline -jarcia: enxárcia & & -juez: juiz & -juiz: juez \\
\hline -jardín: jardim & -jardim: jardín & -jugada: jogada & -jogada: jugada \\
\hline -jardinera: jardineira & -jardineira: jardinera & -jugador: jogador & -jogador: jugador \\
\hline -jardinero: jardineiro & -jardineiro: jardinero & $\begin{array}{l}\text {-jugar: 1. (con reglas) } \\
\text { jogar } / 2 \text {. (niños) brin- } \\
\text { car } / 3 \text {. (riesgo) pôr em } \\
\text { risco }\end{array}$ & $\begin{array}{r}\text {-jogar: (com regras) } \\
\text { jugar }\end{array}$ \\
\hline -jarra: jarra, caneca & -jarra: jarra & -jugarreta: partida & \\
\hline -jarro: jarro, caneca $f$. & -jarro: jarro & -juglar: jogral & -jogral: juglar \\
\hline -jarrón: jarrão & -jarrão: jarrón & $\begin{array}{l}\text {-jugo: 1. sumo / 2. (de } \\
\text { carne) suco }\end{array}$ & \\
\hline -jaspeado: jaspeado & -jaspeado: jaspeado & $\begin{array}{l}\text {-jugoso: sucoso, sucu- } \\
\text { lento }\end{array}$ & \\
\hline -jaula: gaiola & & -juguete: brinquedo & \\
\hline -jauría: matilha & & $\begin{array}{l}\text {-juguetería: loja de } \\
\text { brinquedos }\end{array}$ & \\
\hline -jazmín: jasmim & -jasmim: jazmín & -juguetón: brincalhão & \\
\hline
\end{tabular}




\begin{tabular}{|c|c|c|c|}
\hline & $\begin{array}{l}\text {-jazer: yacer } \\
\text {-jazida: yacimiento } \\
\text {-jazigo: yacimiento }\end{array}$ & $\begin{array}{l}\text {-juicio: 1. juízo / } 2 . \\
\text { (sentencia) julgamento } \\
\text {-juicioso: ajuizado } \\
\text {-julio: 1. julio / } 2 . \\
\text { (energía) joule }\end{array}$ & $\begin{array}{r}\text {-juízo: juicio } \\
\text {-julgamento: juicio } \\
\text {-joule: julio } \\
\text {-julho: julio }\end{array}$ \\
\hline -jazz: jazz & $\begin{array}{l}\text {-jazz: jazz } \\
\text {-jê: (letra) jota }\end{array}$ & -junco: junco & $\begin{array}{l}\text {-junco: junco } \\
\text {-jungir: uncir }\end{array}$ \\
\hline $\begin{array}{l}\text {-jefatura: 1. chefia / } \\
\text { 2. (organismo) re- } \\
\text { partição }\end{array}$ & & -jungla: selva & \\
\hline $\begin{array}{l}\text {-jefe: } 1 . \text { chefe / } 2 . \text { (de } \\
\text { organismo) dirigen- }\end{array}$ & & -junio: junho & -junho: junio \\
\hline & $\begin{array}{l}\text {-jeito: arte, mañaf. } \\
\text {-jeitoso: apañado }\end{array}$ & $\begin{array}{l}\text {-júnior: júnior } \\
\text {-junta: 1. junta / } 2 . \\
\text { (reunión) reunião }\end{array}$ & $\begin{array}{l}\text {-júnior: júnior } \\
\text {-junta: junta }\end{array}$ \\
\hline & -jejuar: ayunar & $\begin{array}{l}\text {-juntar(se): 1. jun- } \\
\operatorname{tar}(\text { se) / 2. (congregar) } \\
\text { reunir }\end{array}$ & $\begin{array}{l}\text {-juntar(-se): 1. juntar } \\
\text { / 2. (acrescentar) - } \\
\text { juntar, incorporar }\end{array}$ \\
\hline & -jejum: ayuno & -junto: junto & -junto: junto \\
\hline -jengibre: gengibre & -jejuno: yeyuno & $\begin{array}{l}\text {-juntura: juntura } \\
\text {-jura: } 1 \text {. (ato) tomada } \\
\text { de posse / } 2 \text {. juramen- } \\
\text { to } m \text {. }\end{array}$ & -juntura: juntura \\
\hline -jeque: xeque & & $\begin{array}{l}\text {-jurado: 1. juramenta- } \\
\text { do / 2. (tribunal) júri }\end{array}$ & $\begin{array}{r}\text {-juramentado: jurado } \\
\text {-júri: jurado }\end{array}$ \\
\hline $\begin{array}{l}\text {-jerarca: 1. (eclesiás- } \\
\text { tico) jerarca, hierar- } \\
\text { ca / 2. dirigente }\end{array}$ & -jerarca: jerarca & $\begin{array}{l}\text {-juramento: 1. jura- } \\
\text { mento / 2. (palabrota) } \\
\text { palavrão }\end{array}$ & \\
\hline -jerarquía: hierarquia & & $\begin{array}{l}\text {-jurar: 1. jurar / } 2 . \\
\text { (blasfemar) praguejar }\end{array}$ & -jurar: jurar \\
\hline $\begin{array}{l}\text {-jerarquizar: hierar- } \\
\text { quizar }\end{array}$ & & -jurásico: jurássico & -jurássico: jurásico \\
\hline -jerez: xerez & & -jurel: carapau & \\
\hline -jerga: gíria & & -jurídico: jurídico & -jurídico: jurídico \\
\hline -jergón: enxergão & & $\begin{array}{l}\text {-jurisdicción: jurisdi- } \\
\text { ção }\end{array}$ & $\begin{array}{l}\text {-jurisdição: jurisdic- } \\
\text { ción }\end{array}$ \\
\hline -jerigonza: gerigonça & & $\begin{array}{l}\text {-jurisprudencia: juris- } \\
\text { prudência }\end{array}$ & $\begin{array}{l}\text {-jurisprudência: } \\
\text { jurisprudencia }\end{array}$ \\
\hline -jeringa: seringa & & -jurista: jurista & -jurista: jurista \\
\hline -jeringuilla: seringa & & & -juro: interés, rédito \\
\hline $\begin{array}{l}\text {-jeroglífico: 1. adj. } \\
\text { hieroglífico / m. }\end{array}$ & & & -justapor: yuxtaponer \\
\hline
\end{tabular}




\begin{tabular}{|c|c|c|c|}
\hline \multirow{2}{*}{\multicolumn{2}{|c|}{$\begin{array}{l}\text { hieróglifo } \\
\text {-jersey: camisola }\end{array}$}} & \multirow[b]{3}{*}{-justicia: justiça } & \multirow{3}{*}{$\begin{array}{l}\text {-justaposição: yuxta- } \\
\text { posición } \\
\text {-justiça: justicia } \\
\text {-justiçar: ajusticiar }\end{array}$} \\
\hline & & & \\
\hline $\begin{array}{l}\text {-jesuita: jesuíta } \\
\text {-jeta: 1. cara / } 2 . \\
\text { (descaro) lata }\end{array}$ & -jesuíta: jesuita & & \\
\hline -jíbaro: índio & -jiboia: boa & $\begin{array}{l}\text {-justiciero: justiceiro } \\
\text {-justificación: justifi- } \\
\text { cação }\end{array}$ & $\begin{array}{l}\text {-justiceiro: justiciero } \\
\text {-justificação: justifi- } \\
\text { cación }\end{array}$ \\
\hline -jilguero: pintassilgo & & $\begin{array}{l}\text {-justificante: justifican- } \\
\text { te }\end{array}$ & $\begin{array}{l}\text {-justificante: justifi- } \\
\text { cante }\end{array}$ \\
\hline -jineta: gineta & & $\begin{array}{l}\text {-justificar(se): justificar } \\
\text { (-se) }\end{array}$ & $\begin{array}{l}\text {-justificar(-se): justi- } \\
\text { ficar(se) }\end{array}$ \\
\hline -jinete: ginete & & $\begin{array}{l}\text {-justo: } 1 . \text { justo / } 2 . \\
\text { (preciso) exato / } 3 . \\
\text { adv. mesmo }\end{array}$ & -justo: justo \\
\hline -jirafa: girafa & & -juvenil: juvenil & -juvenil: juvenil \\
\hline -jirón: farrapo & $\begin{array}{l}\text {-joaninha: (inseto) } \\
\text { mariquita }\end{array}$ & $\begin{array}{l}\text {-juventud: juventude } \\
\text {-juzgado: (lugar) tribu- } \\
\text { nal }\end{array}$ & -juventude: juventud \\
\hline -jocoso: jocoso & -jocoso: jocoso & -juzgar: julgar & $\begin{array}{l}\text {-julgar: 1. juzgar, } \\
\text { enjuiciar / 2. (opi- } \\
\text { nar) creer, juzgar }\end{array}$ \\
\hline $\begin{array}{l}\text {-joder: } 1 \text { foder / } 2 \text {. } \\
\text { (molestar) chatear / } \\
\text { 3. (estropear) lixar / } \\
\text { 4. adv. foda-se! }\end{array}$ & & & \\
\hline
\end{tabular}

Con todo, no se afirma en este texto que la lengua española sea más pobre léxicamente, nada más lejos. Se pretende, únicamente, demostrar que se utilizan menos palabras en el día a día pero con más significados, sobre todo, en los casos de dos contextos: es muy frecuente que el español tenga una sola voz de uso corriente y que corresponda a dos palabras diferentes en portugués. Nos recuerda Iriarte (2001: 43) que "Com um vocabulário e regras sintácticas muito semelhantes, tínhamos a convicção de que a diferença entre ambas [línguas] estava justamente na capacidade de combinatória lexical e no uso pragmático-contextual que se faz deste vocabulário comum".

En cifras totales, nuestro diccionario ofrece 18.265 lemas españoles. 2.534 de ellos presentan más de una acepción, cuya conformación es la siguiente: 1 lema (poner) con 13 acepciones, 1 lema (echar) con 11 acepciones, 1 lema (colgar) con 10 acepciones, 1 lema (arreglar) con 9 acepciones, 9 lemas (bajo, colar, enrollar, llevar, pasar, pinchar, plantar, quedar y tirar) con 7 acepciones, 12 lemas (a, dejar, enganchar, hacer, ir, liar, 
palo, pegar, picar, por, salir y taco) con 6 acepciones, 27 lemas con 5 acepciones, 106 lemas con 4 acepciones, 374 lemas con 3 acepciones y 2.002 lemas con 2 acepciones. El lemario portugués acoge 17.836 lemas de los cuales 1.289 presentan más de una acepción: 2 lemas (ficar y ligar) con 10 acepciones, 3 lemas ( $a$, buraco y passar) con 9 acepciones, 3 lemas (apanhar, arranjar y dar) con 8 acepciones, 5 lemas (bater, estar, lado, levantar y pôr) con 7 acepciones, 9 lemas (apertar, bem, encher, fixar, haver, lavar, mexer, servir y ter) con 6 acepciones, 14 lemas con 5 acepciones, 63 lemas con 4 acepciones, 170 lemas con 3 acepciones y 920 lemas con 2 acepciones.

Como se observa en el cómputo total, la lengua portuguesa presenta la mitad de casos frente al español en los que necesita desdoblar el lema para aportar el equivalente necesario según el contexto.

Los lemas con una gran cantidad de acepciones - los ejemplificados en cursivaindican la tendencia natural de cualquier lengua de servirse de la polisemia, sobre todo, en palabras muy comunes y de alta frecuencia de uso. El caso más interesante se produce cuando el español presenta una única voz usual con dos acepciones que genera en portugués dos voces diferentes, 2.002 casos, mientras que la lengua portuguesa solo recurre a esa táctica en la mitad de ocasiones, 920 .

Véanse unos ejemplos de la letra a:

\begin{tabular}{|c|c|c|c|}
\hline \multicolumn{2}{|c|}{ Español / Portugués } & \multicolumn{2}{|c|}{ Portugués / Español } \\
\hline abono & $\begin{array}{l}\text { 1. (estiércol) adubo, estru- } \\
\text { me. } \\
\text { 2. (lote de entradas) assi- } \\
\text { natura f. }\end{array}$ & aba & $\begin{array}{l}\text { 1. (da mesa, chapéu) ala. } \\
\text { 2. (da roupa) faldón } m \text {. }\end{array}$ \\
\hline abrigo & $\begin{array}{l}\text { 1. (prenda de vestir) casa- } \\
\text { co. } \\
\text { 2. (refugio) abrigo. }\end{array}$ & abertura & $\begin{array}{l}\text { 1. (começo) abertura, } \\
\text { apertura. } \\
\text { 2. (peça musical) obertu- } \\
\text { ra. }\end{array}$ \\
\hline actuar & $\begin{array}{l}\text { 1. (poner en acción) atuar. } \\
\text { 2. (obrar) agir. }\end{array}$ & abundante & $\begin{array}{l}\text { 1. (farto) abundante. } \\
\text { 2. (lucrativo) pingüe. }\end{array}$ \\
\hline afección & $\begin{array}{l}\text { 1. (dolencia) afeção. } \\
\text { 2. (afecto) afeição. }\end{array}$ & acalmar & $\begin{array}{l}\text { 1. (tranquilizar[-se]) } \\
\text { calmar[se]. } \\
\text { 2. (mitigar) acallar. }\end{array}$ \\
\hline ahondar & $\begin{array}{l}\text { 1. (hacer más hondo) } \\
\text { afundar. } \\
\text { 2. (escudriñar) aprofundar. }\end{array}$ & acessível & $\begin{array}{l}\text { 1. (com acesso) accesible. } \\
\text { 2. (atingível) asequible. }\end{array}$ \\
\hline aparición & $\begin{array}{l}\text { 1. (surgimiento) apareci- } \\
\text { mento } m \text {. } \\
\text { 2. (sobrenatural) aparição. }\end{array}$ & acreditar & $\begin{array}{l}\text { 1. (certificar) acreditar. } \\
\text { 2. (dar crédito }[a]) \text { creer } \\
\text { [en]. }\end{array}$ \\
\hline
\end{tabular}




\begin{tabular}{|c|c|c|c|}
\hline aportar & $\begin{array}{l}\text { 1. (añadir) contribuir } \\
\text { [para] } \\
\text { 2. (llegar a puerto) aportar. }\end{array}$ & adorar & $\begin{array}{l}\text { 1. (prestar culto) adorar. } \\
\text { 2. (gostar muito) encan- } \\
\text { tar, molar. }\end{array}$ \\
\hline arena & $\begin{array}{l}\text { 1. (partículas rocosas) } \\
\text { areia. } \\
\text { 2. (plaza de toros) arena. }\end{array}$ & agasalhar & $\begin{array}{l}\text { 1. (lisonjear) agasajar. } \\
\text { 2. (cobrir-se) abrigarse. }\end{array}$ \\
\hline arrugar & $\begin{array}{l}\text { 1. (hacer[se] arrugas) en- } \\
\text { rugar. } \\
\text { 2. (ejercer presión para } \\
\text { hacer arrugas) amarrotar. }\end{array}$ & alvo & $\begin{array}{l}\text { 1. (branco) albo. } \\
\text { 2. (objeto ao qual se tenta } \\
\text { acertar ao disparar uma } \\
\text { arma) diana } f \text {. }\end{array}$ \\
\hline asignación & $\begin{array}{l}\text { 1. (designación) atribuição. } \\
\text { 2. (dinero) subsídio } m \text {. }\end{array}$ & amabilidade & $\begin{array}{l}\text { 1. (afabilidade) amabili- } \\
\text { dad. } \\
\text { 2. (cortesia) detalle } m \text {. }\end{array}$ \\
\hline aventura & $\begin{array}{l}\text { 1. (suceso) aventura. } \\
\text { 2. (relación amorosa) caso } \\
m .\end{array}$ & aquecimento & $\begin{array}{l}\text { 1. (efeito de tornar quen- } \\
\text { te) calentamiento. } \\
\text { 2. (sistema para aquecer) } \\
\text { calefacción } f \text {. }\end{array}$ \\
\hline ayuntamiento & $\begin{array}{l}\text { 1. (consistorio) câmara } f \text {. } \\
\text { municipal. } \\
\text { 2. (reunión) ajuntamento. }\end{array}$ & assinar & $\begin{array}{l}\text { 1. (escrever nome e apeli- } \\
\text { dos) firmar. } \\
\text { 2. (subscrever) abo- } \\
\text { nar[se]. }\end{array}$ \\
\hline
\end{tabular}

Nos atreveríamos a decir que, mayoritariamente en estos casos, la diferencia (sea en una dirección, sea en la otra) es semánticamente sutil (casi siempre se refiere al mismo campo semántico con matizaciones o a campos semánticos afines).

Ahora bien, y retomando la sentencia de Richman ("Port. has more words than does Sp. to express the most common concepts"), ¿cómo se ha especificado y especifica esa tendencia en los diccionarios bilingües?, ¿cómo se establece en un diccionario esa especificación semántica atendiendo a criterios de frecuencia de uso?

Trascribimos en estas páginas un ejemplo representativo para, posteriormente entrar en la casuística más pormenorizada. Usaremos dos diccionarios actuales monolingües en los que buscamos la voz contestar, común a ambas lenguas. El Diccionario de la lengua española (2001, 21 ${ }^{\mathrm{a}}$ ed., Madrid) de la RAE dice:

contestar. (Del lat. contestäri). 1. tr. Responder a lo que se pregunta, se habla o se escribe. 2. tr. Responder a una llamada. 3. tr. Replicar, impugnar. 4. tr. desus. Declarar y atestiguar lo mismo que otros han dicho, conformándose en todo con ellos en su deposición o declaración. 5. tr. desus. Comprobar o confirmar.

La misma voz, viene definida como sigue en el Dicionário da língua portuguesa de la Porto Editora (2009, Oporto): 
contestar (Do lat. vulg. ${ }^{*}$ contestáre, do lat. cl. contestári, «contestar») verbo transitivo 1. sujeitar a discussão por não se estar de acordo; pôr em dúvida; contradizer; 2. negar; refutar; 3. recusar os direitos ou pretensões de; 4. impugnar; denegar; verbo intransitivo 1. discutir; 2. confirmar; 3. dizer a mesma coisa; 4. afirmar o contrário $[\ldots]$

Como se observa, las dos primeras acepciones españolas no se registran en portugués, siendo las acepciones tercera, cuarta y quinta las coincidentes con todas las portuguesas. Ello se debe a que en portugués, la voz utilizada para las acciones definidas en las dos primeras acepciones españolas es responder.

El aprendiz español debe aprender que contestar en portugués es una voz afín a protestar, polemizar (sentidos que también tiene el español pero que son poco usuales) y debe decir responder cuando quiere significar < dar una respuesta >; lo mismo le pasa al principiante portugués, debe centralizar su responder y contestar en una única palabra española, contestar, de mayor frecuencia que responder.

El caso arriba visto de contestar ${ }^{\mathrm{E}} /$ responder $^{\mathrm{P}}$ es uno de los pocos que desde los inicios de la lexicografía español-portugués se resuelve satisfactoriamente en los diccionarios. Esa situación, no obstante, no es la más frecuente.

Véanse esas entradas en el primer y último diccionarios publicados en el terreno que estamos describiendo:

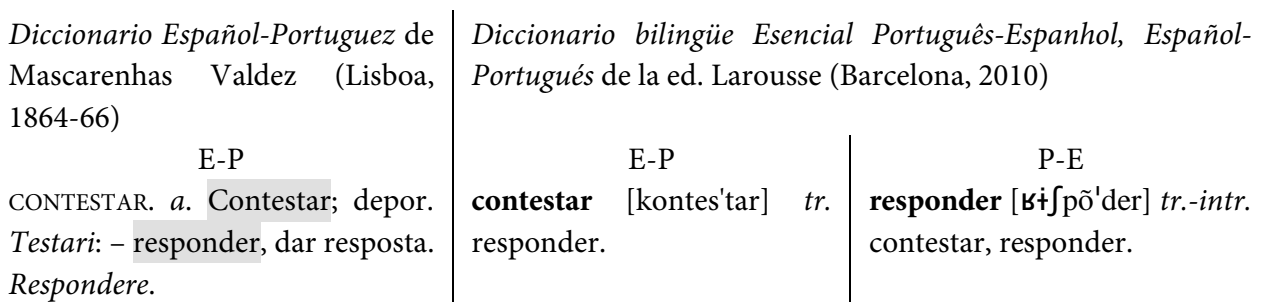

El verdadero problema se presenta en la inadecuada separación de los contextos y los equivalentes que se ofrecen en portugués para esos contextos. Iriarte (2001: 45) aclara que "É necessária uma actualização das acepções da língua de partida [español] e os equivalentes correspondentes na língua de chegada [portugués], por antiquados ou incompletos". En ocasiones, no se separan gráficamente y se dan los equivalentes portugueses de la voz española en sus diferentes acepciones separados por coma como si fuesen intercambiables en cualquier situación; en otros casos, aunque haya separación gráfica que delimite las acepciones, no se dan los equivalentes más utilizados o aparecen separados también por comas entre otros ya obsoletos. 
De ello se deriva que el elemento metalexicográfico que un diccionario debería usar para delimitar los contextos conforme a la frecuencia de uso y la especificidad de cada lengua es el discriminador de contexto.

\section{Los discriminadores de contexto y la frecuencia de uso}

Si la mayor neutralización de contextos en un solo vocablo se da en español y menos en portugués, como han mostrado las evidencias anteriores, privilegiaremos al lector español en esta exposición. Los ejemplos de responder y contestar nos han servido para ejemplificar la cuestión. Queremos, sin embargo, complicar el campo de acción con dos ejemplos muy usuales y penosamente tratados en la lexicografía bilingüe españolportugués hasta épocas recientes. Véanse las siguientes oraciones:

-un español cree en Dios, cree todo lo que le dicen, cree que la crisis va para largo y cree que llegará tarde. Un portugués crê em Deus, acredita em tudo o que lhe disserem, julga que a crise ainda vai durar y acha que chegará atrasado.

-un español coge un libro, coge el autobús, coge cerezas del árbol, coge al vecino por las solapas y se coge a la rama de una higuera. Un portugués pega num livro, apanha o autocarro, colhe cerejas da árvore, agarra o vizinho pela lapela y segura-se ao ramo de uma figueira ${ }^{6}$.

Como observará el lector, sea el alumno español, sea el portugués, debe aprender esas nuances en el uso de los verbos y uno de los utensilios que le servirá de ayuda es el diccionario. Con todo, estos deben ser consultados con muchas reservas ya que solo en los últimos años atienden a razones de frecuencia de uso y de contextualización; la lexicografía bilingüe español-portugués en su corta historia ha visto sus diccionarios confeccionados hasta épocas recientes utilizando criterios diacrónicos en el establecimiento de la información lexicográfica del artículo, así como atendiendo a un registro culto, casi literario de la lengua.

Retomando los ejemplos de creer y coger, utilizaremos los campos semánticos cotidianos de <creer, opinar, tener por verdadero, considerar $>$ y < coger, agarrar, tomar, asir $>$ para verificar lo que afirmamos a través de los diccionarios bilingües españolportugués.

\footnotetext{
${ }^{6}$ Evidentemente, un español también "piensa/opina que la crisis va para largo", también "ase un libro" y "toma el autobús". Un portugués también "pensa/acha que a crise ainda vai durar" y también "apanha cerejas da árvore", pero no son las expresiones más comunes, presentan una frecuencia de uso menor.
} 
Si tuviésemos que componer la entrada creer española con sus equivalentes portugueses, partiendo de la edición actual del DRAE $\left(2001,10^{a}\right)$, obtendríamos:

Español
creer. (Del lat. credĕre).
1. tr. Tener por cierto algo que el entendimiento
no alcanza o que no está comprobado o demos-
trado.

\section{Creer que los ovnis existen}

2. tr. Dar firme asenso a las verdades reveladas por Dios.

Creer la palabra de Dios

3. tr. Pensar, juzgar, sospechar algo o estar persuadido de ello.

Creyó ver luces en la casa

4. tr. Tener algo por verosímil o probable. U. t. c. prnl.

\section{Creo que va a llover}

Se lo cree todo

5. tr. Dar asenso, apoyo o confianza a alguien. ¿Nunca me habéis de creer? U. t. c. intr. Creemos EN él.

6. tr. creer en Dios.

No creo en lo que dices (uso intr.)

Yo creo (acto de tener fe religiosa)

7. prnl. tenerse por.

Se cree muy inteligente
Acreditar (+ usado) /Crer (- usado) que os óvnis existem

Crer/Acreditar na palavra de Deus (uso intr.)

Julgou (+ usado)/Pensou ter visto luzes em casa

Acho (+ usado)/Creio (- usado) que vai chover

Acredita em tudo (uso intr.)

Não acredito no que estás a dizer (uso intr.)

Eu creio

Acha-se/Julga-se (+ enfático) muito inteligente

Nos interesa particularmente la acepción cuarta, referida a la opinión: $\operatorname{creer}^{\mathrm{E}}=$ achar $^{\mathrm{P}}$ (creo que va a llover $=$ acho que vai chover) por ser muy cotidiana y de mucho uso en ambos idiomas. La acepción española se recoge ya en Autoridades (1726-39, Madrid):

CREER. v. a. Dar firme assenso à lo que el entendimiento no alcanza, ò no siente. [...]

CREER. Vale tambien convenir, dar crédito y assentir à algúna cosa por dificultosa que sea, ò por algun motivo, razón ò conjetúras [...]

CREER. Se toma tambien por pensar, juzgar, ò estar persuadido à algúna cosa [...]

La acepción portuguesa, desde el primer gran diccionario portugués, el Vocabulario Portuguez e Latino de Bluteau (1712, Coimbra):

ACHAR o que se busca. Aliquis invenire, ou reperire. 
Achar. Conhecer. Experimentar. Deprehendere. Depois de o ter bem examinado, achamos, que se contradizia nas suas respostas.

Achar. Julgar. Entender. Ser de parecer. Censere. Judicare. Acho, que bom será, que antes do Inverno te recolhas na tua casa. [...]

Cien años más tarde, en 1813 sigue apareciendo en el Diccionário da lingua portugueza de Morais Silva, publicado en Lisboa:

ACHAR, v. at. Encontrar, dar com alguma coisa buscando-se, ou acaso. $₫$ f. Vir no conhecimento, entender, julgar: v. g. "acho que tem razão" [...]

Casi un siglo después, nos dice el Novo Dicionário da Língua Portuguesa de Cândido de Figueiredo (1899, Lisboa):

Achar, v. t. descobrir; inventar; julgar.

Otra centuria después encontramos en el Dicionário da língua portuguesa contemporânea da Academia das Ciências de Lisboa (2001) la siguiente definición:

achar [efár]. $v$. I. Usa-se como verbo pleno, significando: 1. Descobrir ou encontrar por acaso ou porque se andava à procura; fazer um achado. $\neq$ PERDER. Acharam um tesouro no fundo do mar. 2. Descobrir ou encontrar através do raciocínio, da imaginação, da lógica... Já achaste um tema de trabalho? [...] II. Usa-se com valor modal, associado a outra predicação, indicando: 1. O ponto de vista do sujeito sobre a predicação a que está associado. Neste contexto, não tem regência própria $\mathrm{e}$ significa, ter como opinião. $\approx$ CONSIDERAR, ENTENDER, JULGAR, PENSAR, REPUTAR. Acho que o trabalho está bem feito. 2. O parecer do sujeito acerca da predicação a que está associado, regendo, neste contexto, uma oração completiva integrante $\mathrm{e}$ significando, admitir como provável; fazer uma suposição. ₹ ACREDITAR, PRESUMIR, TER A IMPRESSÃO. Os médicos achavam que ela podia salvar-se [...]

La acepción está consolidada desde inicios del siglo XVIII en la lexicografía monolingüe. Veamos su disposición en la bilingüe español-portugués. La obra que inaugura dicha lexicografía es el Diccionario Español-Portuguez de Mascarenhas Valdez, publicado en Lisboa entre 1864 y 1866 :

creer. a. Crer, acreditar, prestar fé. Credere: - crer; acreditar firmemente nas verdades reveladas por Deus, e propostas pela Igreja. Credere: - crer, pensar, imaginar. Conjicere: - crer; ter uma cousa por verosimil ou provavel. Credere, opinari.

No se consideran los verbos acreditar (creer en), ni julgar (formar concepto sobre algo para opinar) ni el más general achar (opinar). Ofrece solamente crer en la cuarta acepción, el mismo orden que establecen los diccionarios españoles. Y es que muchas de estas faltas se deben al origen propio de la obra, el señor Valdez utilizó como base primordial al confeccionar su diccionario el de la RAE en su edición $10^{a}$ de 1852 , así como 
el Diccionario enciclopédico de la lengua española de la Imprenta y Librería de Gaspar y Roig, publicado en Madrid entre 1853 y 1855. Adecuó muy bien la obra pero en algunas cuestiones fundamentales como la disposición de la microestructura parece una traducción del diccionario académico español.

Compárese la entrada de Valdez con los diccionarios españoles mencionados, coinciden incluso las etimologías:

$10^{\mathrm{a}}$ ed. DRAE (1852)

Gaspar y Roig (1853-55)

CREER. a. Dar asenso á una cosa teniéndola por cierta. Credere. I| Dar firme asenso á las verdades reveladas por Dios, y propuestas por la Iglesia. Credere. I| Pensar, juzgar, sospechar alguna cosa, ó estar persuadido de ella. Conjicere. II Tener una cosa por verosímil ó probable. Credere, opinari $[\ldots]$

Las obras siguientes ${ }^{7}$ hasta finales del siglo pasado siguen la ordenación de Valdez con modificaciones pero con una falta común en todas ellas: no se dispone la información de los equivalentes españoles especificando la contextualidad, los acotadores semánticos o discriminadores de contexto atendiendo a la frecuencia de uso, al uso real de las dos lenguas. He aquí un ejemplo de los años cincuenta del siglo pasado, el Diccionario español-português de Júlio Martínez Almoyna (Porto Editora, 1951) publicado en Oporto:

Creer, v. t. Crer, ter como verdadeiro, dar crédito a, acreditar. Crer, dar firme assentimento às verdades reveladas por Deus e propostas pela Igreja. Crer, pensar, julgar, ter para si, imaginar, suspeitar. Ter uma coisa por verosímil ou provável, supor, crer. [...]

Si se repara, la disposición de la información y las definiciones son las del diccionario académico español y por ende, de Valdez. No obstante, separa las acepciones con un simple punto y seguido, haciendo más difícil la consulta. Tampoco considera achar.

\footnotetext{
${ }^{7}$ Se sigue el estudio de Vázquez (2011) en el que se especifican todos los diccionarios de la lexicografía bilingüe español-portugués y viceversa. En este escrito solo se tratan los considerados principales de cada periodo.
} 
De 1966 es el Diccionario portugués-español, español-portugués de Júlio da Conceição Fernandes (Hymsa, Diccionarios Cuyás), publicado en Barcelona. Consultaremos también achar, dado que la obra es bidireccionals:

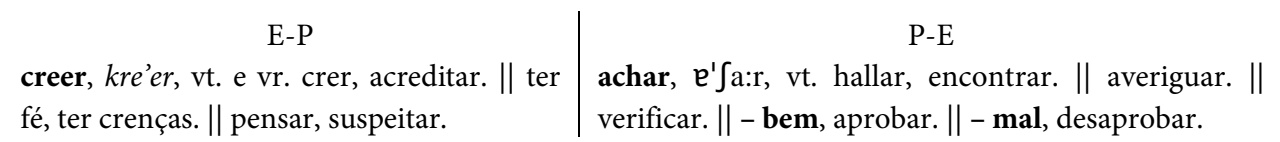

Ni en creer encontramos achar, ni en achar, creer. En ninguna acepción se especifica suficientemente el contexto, se dan pistas a través de los sinónimos en los equivalentes, y pensar y suspeitar no son intercambiables.

Veamos el Vértice: diccionario portugués-español, español-portugués de la editorial EVEREST (Madrid), en su edición de 1978 y en la renovada de 2002:

$$
\text { (1978) E-P }
$$

creer, $v$. $t$. crer; acreditar; imaginar; supor.

$$
\text { (2002) E-P }
$$

creer [kreér] $v$. tr. 1. acreditar; crer $[\mathrm{Ha}$ creído siempre que vencería. Sempre acreditou que venceria.] 2. (opinar) achar; crer [Creo que sí. Acho que sim.] || v. intr. 3. (tener fe, confianza) crer; acreditar [Creo en Dios. Creo en la justicia. Creio em Deus. Creio na justiça.] [...]

\section{P-E} achar, v. t. hallar, encontrar; inventar; suponer.

$$
\text { P-E }
$$

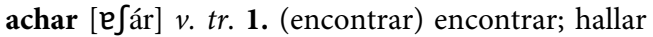
[Achou o dinheiro que procurava. Encontró el dinero que buscaba.] 2. (opinar) creer; suponer [Acho que sim. Creo que sí.] 3. (considerar) encontrar; juzgar [Acho-o muito chato. Le encuentro muy aburrido.] [...]

En 1978 continuaba la disposición clásica de las dos entradas pero ya en 2002 acoge las voces achar y creer en la microestructura. Los contextos de uso se delimitan bien y los ejemplos corresponden a la lengua viva.

Veamos el Dicionário Espanhol-Português 'Dicionários Editora' de la Porto Editora dirigido por Álvaro Iriarte y publicado en Oporto en 2008:

creer [kre'er, 'krer] v.tr., intr. e prnl. I v.tr. 1 Acreditar, crer (supor, julgar). 2 Achar, julgar (pensar [ser de opinião]). 3 Acreditar (julgar ser verdade). 4 Julgar (pensar, achar [considerar]). II v.intr. Crer, acreditar (ter fé). III creerse v.prnl. julgar-se [...]

\footnotetext{
${ }^{8}$ En 1897 se publicó el Novo diccionario hespanhol-portuguez e portuguez-hespanhol com a pronuncia figurada em ambas as linguas / Nuevo diccionario portugués-español y español-portugués con la pronunciación figurada en ambas lenguas del Vizconde de Wildik, donde se lee:

Achar [aschar] a. hallar, encontrar. || Descubrir, inventar. || Averiguar. || Notar, observar. || Pensar, ser de opinión. || Achar bem, aprobar. Achar máo, desaprobar.
}

Esta quinta definición tardará en volver a aparecer en los diccionarios. 
Se considera achar como el primer equivalente en la acepción [ser de opinião], se atiende al uso cotidiano y los marcadores de contexto son esenciales y están bien especificados. Y finalmente, el de la Larousse (2010):

\section{E-P}

creer [kre'er] 1 tr.-intr. (tener fe) crer (en, em). 2 tr. (suponer) achar, crer, pensar: creo que me equivoqué, acho que me enganei. $3 \mathrm{tr}$. (opinar) achar, pensar: creo que se fue a Londres de vacaciones, acho/penso que foi a Londres de férias. 4 tr. (dar crédito) acreditar (-, em): no me creo nada de eso, não acredito em nada disso. 5 prnl. julgar-se, achar-se: se cree un gran historiador, julga-se um grande historiador.

\section{P-E}

achar [ $\left.\mathrm{E}^{\prime} \int a r\right] 1$ tr. (opinar) creer, pensar, parecer intr., encontrar: acho que não, me parece que no. 2 tr.-prnl. (encontrar) hallar(se), encontrar(-se). 3 prnl. (considerar-se) creerse: acha-se o melhor de todos, se cree el mejor de todos.

Acontece lo mismo que en el caso anterior.

Se observa una separación entre la lexicografía monolingüe y la bilingüe debido al peso del diccionario académico español a través de Valdez y las obras siguientes hasta muy entrado el siglo XX.

El ejemplo siguiente es todavía más complicado, recordamos que se trata de la voz coger. Haremos la misma operación y partiremos de las acepciones dadas por el DRAE 2001:

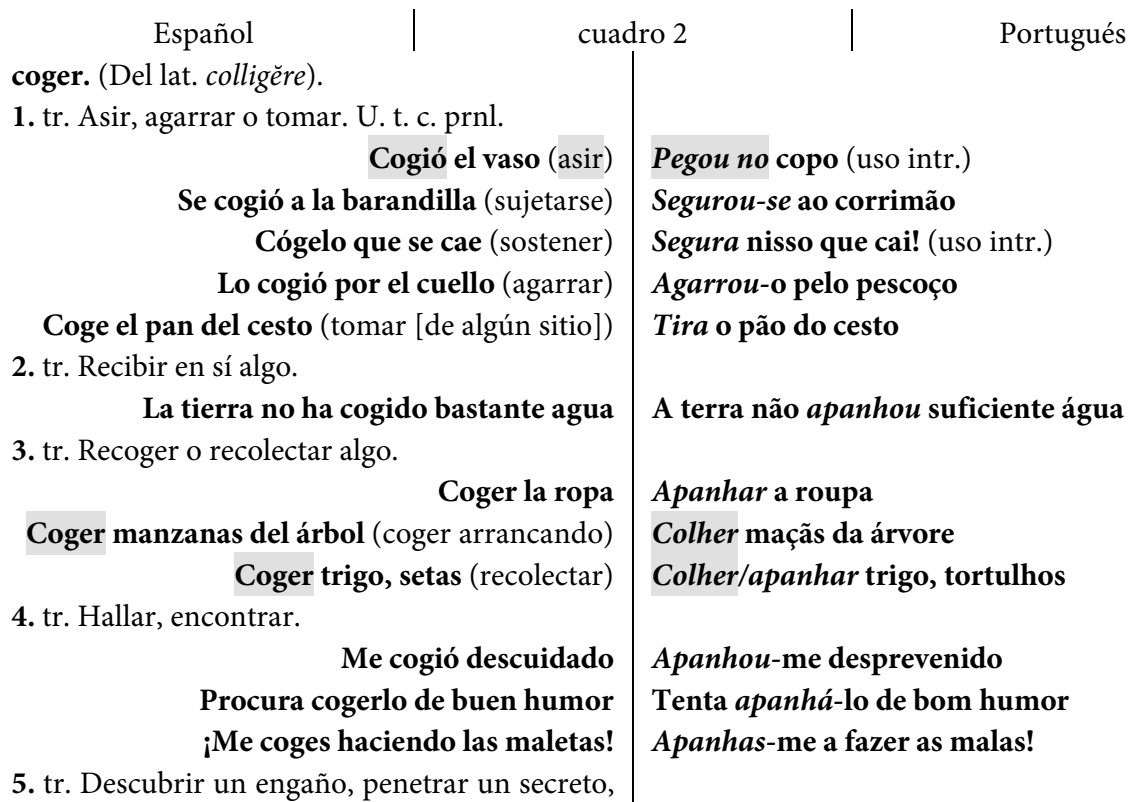


sorprender a alguien en un descuido.

Lo cogí en cuanto empezó a hablar

6. tr. Captar una emisión de radio o televisión.

No cojo 'Radio 3' con este transistor

7. tr. Tomar u ocupar un sitio u otra cosa.

Están las butacas cogidas

8. tr. Sobrevenir, sorprender.

Me cogió la hora, la noche, la tempestad

9. tr. Alcanzar a quien va delante.

¡A que no me coges!

10. tr. Tomar, prender, apresar.

Cogieron al ladrón con las manos en la masa

11. tr. Tomar, recibir o adquirir algo.

Coger velocidad (tomar)

Coger fuerzas (tomar)

Coger la costumbre (adquirir)

12. tr. Entender, comprender.

No he cogido la gracia del chiste

13. tr. Aprender algo.

Ha cogido enseguida el acento

14. tr. Escoger, elegir.

Cogió dos asignaturas nuevas

15. tr. Dicho de un vehículo: Atropellar a alguien.

Lo cogió un coche y lo mató

16. tr. Montarse en un vehículo.

Ha cogido el avión

17. tr. coloq. Ocupar cierto espacio.

La alfombra coge toda la sala

18. tr. coloq. Contratar o alquilar.

Me han cogido en ese trabajo

Cogimos un apartamento para el verano

19. tr. coloq. Contraer ciertas enfermedades o empezar a padecer ciertos estados físicos o anímicos.

Cogió una pulmonía (enfermedad)

Cogió una depresión (estado anímico)

20. intr. Dicho de una cosa: Encontrarse en determinada situación respecto a alguien.

Tu casa me coge de camino

Eso coge muy lejos

21. intr. Encaminarse, tomar una dirección.

Coge la línea amarilla del metro
Apanhei-o mal começou a falar

Não apanho 'Rádio 3' com este transístor

Estão os lugares ocupados

Apanhou-me a hora, a noite, a tempestade

Apanha-me se puderes!

Apanharam o ladrão com a boca na botija

Ganhar velocidade

Ganhar forças

Apanhar o vício

Não apanhei a piada

Apanhou rapidamente o sotaque

Escolheu duas cadeiras novas

Foi apanhado por um carro e matou-o

Apanhou o avião

O tapete apanha (tapa) toda a sala

Fui admitido nesse trabalho

Alugámos um apartamento para o verão

Apanhou uma pneumonia

Apanhou uma depressão

A tua casa fica-me de caminho

Isso fica muito longe

Apanha a linha amarela do metro 
22. intr. coloq. tomar (resolverse o determinarse).

23. intr. vulg. caber.

Cogió y se fue Agarrou e foi-se embora

Esto no coge aquí $\quad$ Isto não cabe aqui

Las 23 acepciones que presenta la Academia tienen como equivalentes los verbos portugueses segurar (1 acep.), tirar (1 acep.), ocupar (1 acep.), escolher (1 acepc.), caber (1 acep.), ficar (1 acep.), ganhar (1 acep.), admitir (1 acep.), alugar (1 acep.), agarrar (2 acep.), apanhar (16 acep.), colher (1 acep.) y pegar (1 acep.). Por frecuencia de uso, los más utilizados en portugués son pegar (asir; acción muy común en la vida cotidiana) y apanhar (en casi todos los demás contextos). Nos queremos detener en los tres últimos, pegar y apanhar por las razones aducidas y colher por el tratamiento dado en los diccionarios.

Tal y como hemos actuado en el caso de $\operatorname{creer}^{\mathrm{E}} /$ crer $^{\mathrm{P}}$-achar ${ }^{\mathrm{P}}$, vamos a verificar el verbo coger en castellano y los verbos colher, pegar y apanhar en portugués. La acepción que más nos interesa es la que se refiere al acto de <asir algo con la mano>. En Autoridades (1726-39), dicha acepción aparece en sexto lugar; en el primer DRAE de 1780 ya se coloca al principio:

Autoridades (1726-1739)

$1^{\text {a }}$ ed. DRAE 1780

COGER. v. a. Allegar, y juntar en uno lo que está esparcído, y dividído [...]

COGER. Se toma tambien por dar cobro ò recoger algúna cosa: como son los frutos de la tierra [...]

COGER. Vale tambien recibir en sí. La tierra no ha cogido bastante agua [...]

COGER. Se toma tambien por ocupar cierta porcion de distrito, ò extenderse en ella [...] COGER. Vale tambien colegir, inferir [...] COGER. Significa tambien asir ù agarrar algúna cosa. Lat. Apprehendere [...]

COGER. v. a. Asir, agarrar, ò tomar con la mano. Apprehendere, manu capere.

COGER. Recibir en sí alguna cosa, y así se dice: La tierra no ha cogido bastante agua [...] COGER. Recoger, ò juntar algunas cosas, lo que comunmente se dice de los frutos del campo $[\ldots]$

COGER. Tener capacidad $[\ldots]$

Veamos en los diccionarios portugueses los tres verbos anteriormente mencionados. El Vocabulario Portuguez e Latino de Bluteau (1712):

COLHER flores, frutos, folhas, ervas, \&c. Flores, fructus, folia, herbas carpere ou decerpere. Neste territorio
PEGAR huma cousa com outras, com alguma materia, que as una, como pez, grude, \&c.

Conglutinare aliquid cum Apanhar a vestidura, quando
APANHAR, Alcançar,\& prender pessoas, que fogem. Excipere fugientes. 
colhese muyto trigo. $\mathrm{O}$ mais tempo he bom para colher os frutos.

Colher alguem no tempo, em que faz alguma má acção. Colher um ladrão. Colher um malfeytor. aliquo. Cic. Conglutinare duas res inter se. Vitruv.

Pegar de alguem. Prender.

Pegar em alguem. Pôr as mãos em alguem. Aliquem manu prehendere. Pegar na penna. Stylum manu prehendere. Cic. [...] he muito solta. [...]

Apanhar, tomando huma cousa da mão de alguem. Aliquid arripere. Apanhar, empunhar. Apanhar. Colher a alguem improvisamente.

Ser apanhado em hum crime. Apanhar. Vid. Tomar.

El significado esencial de colher se refiere a la recolección; en pegar vemos dos sentidos muy diferenciados: a) encolar, colar <pegar $>$ y b) coger, asir <pegar em $>$ (ampliación a través de la metáfora en portugués); en apanhar vemos varios sentidos que se irán correspondiendo con la ampliación de contextos a los que se han llegado hoy como hemos visto en el [cuadro 2].

El Diccionário da lingua portugueza de Morais Silva, de 1813:

COLHÈR, v. at. Tirar donde nasce, e recolher para uso as flores, frutos, folhas, hervas: e no fig. colher doutrinas, trabalhos, infamia, \&c. $\$$ Apanhar alguem: v. g. colhi-o no furto. $[. .$.
PEgAR, v. at. Unir uma coisa á outra com massa, grude, \&c. $\$$ Pòr: v. g. pegar fogo ás casas. $₫$ Communicar; v. g. pegou-lhe as bexigas. $\$$ Segurar: pegar em alguma coisa. [...]
APANHAR, v. at. Colher: $v . g$ apanhar frutos, folha. \& Tomar na mão: $v . g$. apanhar conchinhas, oiro. \& Dar alcance: $v$. g. apanhar os que hiam diante. \& Apanhar os vestidos $[\ldots]$

Sigue la disposición semántica de Bluteau.

El Novo Dicionário da Língua Portuguesa de Cândido de Figueiredo (1899):

Colhêr, $v$. $t$. tirar das árvores ou das plantas; apanhar, recebêr; surpreender, encontrar; tomar; adquirir; attingir; amainar.
Pegar, v. t. unir; collar; segurar, agarrar; communicar; $v . \quad i$. collar-se; ficar adherente; lançar a mão; criar raízes [...]
Apanhar, v. t. colhêr; levantar do chão; dobrar; arregaçar; alcançar; obter; surprehendêr [...]

No se especifican los contextos con claridad.

El Dicionário da língua portuguesa contemporânea da Academia das Ciências de Lisboa (2001):

colher [ku/ér] $v$. 1. Separar da haste, do caule, uma flor, um vegetal, um fruto ou retirar da terra qualquer produto pegar [płłýr] v. 1. Fazer aderir ou aderir-se a um corpo, a uma superfície, por vezes com cola ou outro produto com apanhar [epenár] v. 1 Agarrar, levantando, o que se encontra no chão. = PEGAR EM. 2. Tirar alguma coisa de 
agrícola; fazer a colheita. 2 . Ter determinado cultivo ou plantação. 3. Obter um a um e reunir dados, objectos, informações... 4. Agarrar com as mãos, muitas vezes para impedir um movimento ou uma queda. $[\ldots]$ propriedades semelhantes = COLAR, FIXAR. 2. Pôr ou ficar junto. 3. Cul. Ficar um alimento agarrado. 4. Transmitir uma doença. (de 5. a 17. acepciones metafóricas relacionadas con unir, trans-mitir $=$ por colar $\mathrm{y}$ contagiar). 18. Agarrar, segurar, prender, sobretudo, com as mãos. = AGARRAR, SEgurar. Pegou na mala pela asa. Pega na chave e abre a porta. $[\ldots]$ algum lugar onde se encontrava. 3. Colher produtos da terra = COLHER. 4. Capturar. 6. Agarrar. 9. Surpreender. 11. Encontrar alguém em algum lugar em determinadas condições. 13. Chegar a um local e encontrá-lo em determinado estado = ENCONTRAR. 14. Entrar num meio de transporte para seguir um rumo $[\ldots]$

En colher sigue la idea básica de <recolectar $>$; en pegar, tras todas las acepciones relacionadas con <pegar, unir > aparece la acepción de <asir > y especificada - sobretudo, com as mãos- y apanhar recoge todas las acepciones restantes, estando bien delimitadas aquéllas más habituales en las que no entran en juego las manos (coger un transporte, una idea, un constipado... $)^{9}$.

Y ya el Diccionario Español-Portuguez de Mascarenhas Valdez (1864-66):

coger. $a$. V. Cojer.

cojer. a. Colher, recolher, apanhar; tomar com a mão. Colligere, capere: - colher, recolher: - colher; apanhar fructos: - [...]

En coger no se indica el equivalente pegar em que debería estar en primer lugar y se ofrece colher (relegado en portugués ya hace mucho tiempo a acciones agrícolas), así como tampoco se indica apanhar en su sentido de < contraer, tomar $>$. Compárese con la décima edición del DRAE de 1852 y con el diccionario de Gaspar y Roig, sus fuentes principales como ya hemos afirmado:

$10^{\mathrm{a}}$ ed. DRAE (1852)

COGER. a. Asir, agarrar, ó tomar con la mano. Apprehendere, manu capere. || Recibir en sí alguna cosa, y así se dice: La tierra no ha cogido bastante agua $[\ldots] \|$ Recoger ó juntar algunas cosas, lo que comunmente se dice de los frutos del

Gaspar y Roig (1853-55)

COJER: v. a.: asir, agarrar o tomar con la mano. Reunir en sí alguna cosa, y así se dice: la tierra no

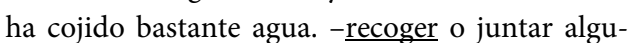
nas cosas, lo que comunmente se dice de los frutos del campo [...] -Tener capazidad [...] -

\footnotetext{
${ }^{9}$ De todas formas, merece una crítica, ya que en achar indica muy bien los dos campos semánticos y en pegar no (siendo una acción tan común e importante).
} 
campo [...] Colligere. || Tener capacidad [...] | Ocupar espacio [...]

El Diccionario español-português de Júlio Martínez Almoyna (Porto Editora, 1951):

Coger, v. t. agarrar, pegar ou tomar: coger de, ou por, la mano, apanhar. U. t. c. r. Colher, recolher ou juntar algumas coisas, como geralmente se diz dos frutos do campo: coger los granos, la uva, la aceituna. Ter capacidade para conter. Ocupar espaço: esta alfombra coge toda la sala. Achar, encontrar: procuré cogerle de buen humor. Descobrir um engano, penetrar um segredo, surpreender alguém num descuido: coger con el hurto. [...]

El Diccionario portugués-español, español-portugués de Júlio da Conceição Fernandes (Hymsa, Diccionarios Cuyás, 1966), también achar, dado que la obra es bidireccional:

\begin{tabular}{c|c} 
E-P & P-E \\
coger, ko'xer, vt. e vr. agarrar, pegar, & -colher, ku'Ke:r, vt. coger, agarrar. $\|$ cosechar. $\|$ sor-
\end{tabular} segurar, apanhar, colher. I| encontrar. I| prender.

descobrir um engano. || surpreender. || -pegar, pa'ga:r, vt. y vi. pegar, encolar, juntar, unir. \| recolher. || vi. caber. arraigar. || agarrar. || contagiar. || contender. -apanhar, epe'na:r, vt. apañar, coger. || sorprender. || recoger. || robar. || pescar. || entender con rapidez. || suspender.

El Vértice: diccionario portugués-español, español-portugués de la editorial Everest (Madrid), en su edición de 1978 y en la renovada de 2002:

(1978) E-P

coger, $v$. $t$. agarrar; pegar; tomar; alcanzar; colher; receber.

[No se contempla 'apanhar']

$$
\text { (2002) E-P }
$$

coger [koxér] v. tr. 1. (agarrar, sujetar) apanhar; pegar. 2. (autobús, resfriado) apanhar. 3. (frutas) apanhar. 4. (el sentido de algo) apanhar.

El Dicionário Espanhol-Português 'Dicionários Editora' de la Porto Editora dirigido por Álvaro Iriarte de 2008:

\section{P-E}

-colher $(\hat{\mathbf{e}}), v$. t. cosechar, coger; recolectar; agarrar; asir; tomar; obtener.

-pegar, v. t. e i. pegar; adherir; juntar; aceptar; agarrar.

[-apañar, $v$. $t$. apañar; coger; asir; recoger; pescar; guardar; interceptar; prender; agarrar.]

\section{P-E}

-colher [ku'Ker] v. tr. cosechar; recolectar.

-pegar [pi'gar] v. tr. 1. (segurar) coger. 2. (agarrar)

-apanhar [ере'nar] v. tr. 1. (tomar, agarrar) coger; agarrar. 2. (frutas) coger. 3. (autocarro, constipado) coger. 4. (uma coisa para alguém) alcanzar. [...] agarrar. 3. (colar) pegar. $\|[\ldots]$ 
coger [ko’xer] v.tr. e prnl. I v.tr. 1 Pegar em (agarrar com a mão). 6 Segurar (pegar com uma ou duas mãos). 12 Colher, apanhar [frutos, flores, etc.]. 14 Apanhar (tomar) [um meio de transporte] 17 Apanhar (prender, capturar) [...]

Y el Diccionario Vox Esencial Português-Espanhol/Español-Portugués de la ed. Larousse (Barcelona), de 2010:

\section{E-P}

coger [ko’xer] 1 tr. (asir) pegar intr. (-, em): cogió el libro, pegou no livro. $2 \mathrm{tr}$. (tomar, recibir, capturar, sorprender) apanhar: coger el metro, apanhar o metro; coger un resfriado, apanhar uma constipação; la policia cogió al ladrón, a polícia apanhou o ladrão; lo cogieron robando, foi apanhado a roubar. $3 \mathrm{tr}$. (con fuerza) agarrar. 4 tr. (recolectar) apanhar, colher: fueron a coger manzanas, foram colher/apanhar maçãs.
P-E

- colher [ku'Ker] tr. coger, cosechar, recolectar: foram colher maçãs, fueron a coger manzanas. -pegar [pi'gar] 1 intr. coger tr. (em, -): pegou no livro, cogió el libro. 2 intr. (um veículo) arrancar: o carro não pega, el coche no arranca. 3 tr.-intr. (colar) pegar, enganchar: pega um selo no envelope, pega un sello en el sobre. 4 tr. (contagiar) pegar: pegou-me a gripe, me pegó la gripe.

-apanhar [ере'^ar] 1 tr. (do chão) recoger: apanhei o livro que tinha caído, recogí el libro que se había caído. 2 tr. (no campo) recolectar: apanhar batatas, recolectar patatas. 3 tr. (pegar em; receber; surpreender) coger, agarrar, tomar, pillar (fam.): apanhou-me num mau momento e não soube o que dizer, me pilló en un mal momento y no supe qué decir. 4 tr. (uma doença) coger, pillar, agarrar: apanhou uma constipação, ha pillado / cogido un constipado. 6 tr. (um transporte) coger, tomar: apanhar o comboio, coger/tomar el tren. [...]

En todos los diccionarios observamos la misma casuística comentada en creer ${ }^{\mathrm{E}} /$ achar $^{\mathrm{P}}$. La situación vista anteriormente se repite en infinidad de entradas. Haga el lector la prueba, siga la historia de cada entrada en los diccionarios monolingües y bilingües y verá el resultado.

\section{Conclusiones}

En la dirección español-portugués, la que nos interesa desde el punto de vista de los equivalentes dados a los lemas españoles, se observa que existe continuidad desde el 
Diccionario Español-Portuguez de Valdez (1864) hasta la aparición de los diccionarios de la Porto Editora en la década de $1950^{10}$.

Los diccionarios siguientes hasta finales del siglo XX presentan claramente la estructura del DRAE simplificada ${ }^{11}$.

Los restantes diccionarios hasta la actualidad son formal y estructuralmente diferentes. Presentan una estructura informatizada e intentan observar (sin éxito, a veces) el criterio de la frecuencia de uso y la especificación semántica como base para la redacción de la obra. No obstante, la información del diccionario de la RAE está presente ${ }^{12}$.

Todas esas consideraciones, fruto de un estudio anterior (Vázquez, 2011), nos permiten afirmar que la suposición (muy divulgada) de la aparente proximidad entre español y portugués provoca falsos prejuicios. No existe el diccionario bilingüe ideal, todos los que hay en el mercado hasta los años 90 son claramente históricos: recogen el léxico conforme a la antigüedad en el idioma y no según su utilización; es más, los diccionarios español-portugués (hasta bien entrado el siglo XX) parten de los españoles hechos por la RAE - excepto contadas obras, son reticentes a mencionar las fuentes lexicográ-

\footnotetext{
${ }^{10}$ Pertenecen a este grupo el Diccionario hespanhol-portuguez e portuguez-hespanhol, de Jorge Cesar de Figaniere (1879-80, Oporto), el Novo diccionario hespanhol-portuguez e portuguez-hespanhol com a pronuncia figurada em ambas as linguas del Vizconde de Wildik (1897, París), el Novo diccionario hespanhol-portuguez (e portugués-hespanhol) contendo todos os vocabulos, phrases e locuções usados não só em Portugal, como no Brazil, colonias portuguezas da Africa e Asia, de Marques y Monsó (18971900, Lisboa) y el Nuevo diccionario portugués y español con la debida pronunciación de los vocablos de Frederico Duarte Coelho (1911, Lisboa).

${ }^{11}$ El Dicionário espanhol-português de la Colecção 'Dicionários Editora' (1951, Oporto). En la 2a edición de 1957 se ampliará siendo la base de los siguientes hasta casi el nuevo siglo. El Diccionario portugués-español y español-portugués de José Luis Pensado e Enriqueta Ruiz de Pensado (1960, Madrid), el primero publicado en España. El Diccionario español-portugués y portugués-español de J. Maria Viqueira Barreiro (1961, Madrid), el Diccionario portugués-español, español-portugués según las normas del acuerdo ortográfico lusobrasileño de 1945 e de la última edición de la Real Academia Española de la editorial Hymsa (autoría de Júlio da Conceição, 1966, Barcelona), el Diccionario portugués-español, español-português / Dicionário português-espanhol, españolportuguês de la editorial Sopena (autoría de David Ortega Cavero, 1966, Barcelona), el Vértice: diccionario portugués-español, español-portugués de la editorial Everest (1978, Madrid) y el Diccionario português-espanhol, español-portugués de Ángeles Martín y Weissman Waltraud (1995, Barcelona).

${ }^{12}$ En este grupo destacamos las siguientes obras: el Diccionario Collins gem español-portugués, portugués-español de la editorial Grijalbo-Mondadori (1998, Barcelona), el Gran Diccionario Espasa español-portugués/portugués-español de la editorial Espasa-Calpe (2001, Madrid), el Everest Vértice. Diccionario español-portugués/português-espanhol de la editorial Everest (2002, León), el Dicionário Espanhol-Português en los 'Dicionários Editora' de la Porto Editora (2008, Oporto, autoría de Iriarte Sanromán) y el Diccionario Vox Esencial Português-Espanhol/Español-Portugués de la editorial Larousse (2010, Barcelona).
} 
ficas-, por tanto, han sido casi traducciones literales a la lengua portuguesa sin adecuarlos. No marcan las sutilidades léxicas existentes en el uso entre español y portugués, detalles importantísimos en el par de lenguas que hemos tratado. Con todo, la tendencia empezó a cambiar a finales del siglo pasado y podemos decir que los más actuales se confeccionan atendiendo al uso cotidiano del léxico, sobre todo, los que llevan la etiqueta de usuales y/o esenciales.

Recibido: 23-I-2012

Aceptado: 12-III-2013

\section{Bibliografía}

\section{General}

Brown, Charles; Carr, Wesley y Shane, Milton (1945): A Graded Book of Brazilian Portuguese. New York, F.S. Crofts \& Co.

Buchanan, Milton (1927): A Graded Spanish Word Book. Toronto, Univ. of Toronto Press.

Carlinga, R (1997): “A distância da proximidade - a dificuldade de aprender uma língua fácil”, Intercâmbio, vol. VI, São Paulo, LAEL, págs. 653-671.

Iordan, I. (1964): Dos estudios de lingüística románica. Montevideo, Universidad de la República, Facultad de Humanidades y Ciencias, Departamento de Lingüística.

Iriarte Sanromán, Álvaro (2001): A Unidade Lexicográfica. Palavras, Colocações, Frasemas, Pragmatemas. Braga, Universidade do Minho, Centro de Estudos Humanísticos.

Mendes, Eliana Amarante de Mendonça (1998): "Ensino do léxico português para hispanofalantes". En Pinto e Júdice (coord.): Para acabar de vez com Tordesilhas. Lisboa, Colibri, págs. 101-117.

Montero, Hélder Julio Ferreira (2007): “«Nem tanto ao mar nem tanto à terra» o las desmesuras del vocabulario (una propuesta lexicográfica)". En Marcos de Dios, Ángel (ed.): Aula Ibérica. Salamanca, Ediciones Universidad, págs. 433-452.

Richman, Stephen (1965): A comparative study of Spanish and Portuguese. Department of Romance Languages, University of Pennsylvania.

Ulsh, Jack Lee (1971): From Spanish to Portuguese. Washington D. C., Foreign Service Institute, Department of State.

Vázquez, I. (2011): “Contribuição para a história da lexicografia bilingue entre as línguas espanhola e portuguesa". En Verdelho, T. e J. P. Silvestre (eds.): Lexicografia Bilingue. A tradição dicionarística Português - Línguas Modernas. Lisboa/Aveiro, 
Centro de Linguística da Universidade de Lisboa - Universidade de Aveiro, págs. $82-102$.

\section{Diccionarios nombrados}

Academia das Ciências de Lisboa (2001): Dicionário da língua portuguesa contemporânea da Academia das Ciências de Lisboa. Lisboa, Verbo.

Bluteau, Raphael (1712-21): Vocabulario Portuguez e Latino, Aulico... autorizado com exemplos dos melhores escritores portuguezes, e latinos. Coimbra, No Collegio das Artes da Companhia de Jesu.

[Gaspar y Roig ed.] Chao, Eduardo (coord.) (1853-55): Diccionario Enciclopédico de la Lengua Castellana. Madrid.

Figueiredo, António Cândido de (1899): Novo Dicionário da Língua Portuguesa. 2 volumes, Lisboa, Tavares Cardoso \& Irmão, Portugal-Brasil.

Morais Silva, António de (1813): Diccionário da lingua portugueza recopilado dos vocabulários impressos até agora. Lisboa, Typographia Lacerdina.

Porto Editora (2009): Dicionário da língua portuguesa. Oporto.

Real Academia Española (1726-39): Diccionario de Autoridades. 6 volúmenes, Madrid, Impres. Francisco del Hierro.

[DRAE] 10 $0^{\text {a }}$ edición (1852): Diccionario de la lengua castellana por la Real Academia Española. Madrid, Imprenta Nacional. // 21 a edición (2001): Diccionario de la lengua española. Madrid, Espasa-Calpe.

\section{Diccionarios bilingües español-portugués y viceversa}

Almoyna, Júlio Martínez (1951): Diccionario español-português. Contém todas as palavras de uso corrente e vulgar; vocabulario moderno e científico com todas as acepções possiveis das palavras. Porto, Porto Editora.

Coelho, Frederico Duarte (1911): Nuevo diccionario português-español. Lisboa, Typ. Annuario Commercial.

Espasa-Calpe ed. (2001): Gran diccionario español-portugués, portugués-español. Madrid.

Everest ed. (1978): Vértice: diccionario portugués-español, español-portugués. Madrid.

Everest ed. (2002): Diccionario español-portugués / Dicionário português-espanhol. León.

Figaniere, Jorge César de (1879-80): Diccionario español-portuguêz e portuguéshespanhol, com phrases e locuções usadas em España e na América hespanhola. Porto, Vianna, Empreza editora de obras classicas e illustradas. 
Grijalbo-Mondadori ed. (1998): Diccionario Collins gem español-portugués, portuguésespañol. Barcelona.

[Hymsa], Fernandes, Júlio da Conceição (1966): Diccionario portugués-español, según las normas del acuerdo ortográfico luso-brasileño de 1945 y de la última edición de la Real Academia Española. Barcelona, Hymsa, Diccionarios Cuyás.

Iriarte Sanromán, Álvaro (2008): Dicionário espanhol-português. Porto, Porto Editora.

Larousse ed. (I. Vázquez, coord.) (2010): Diccionario bilingüe Esencial PortuguêsEspanhol / Español-Portugués. Barcelona.

Marques, Henrique António, e Isidro Monsó (1897-1900): Novo dicionário hespanholportuguêz (e portuguêz-espanhol). Contendo todos os vocábulos, phrases e locuções usadas não só em Hespanha, mas ainda em toda a América hespanhola... Lisboa, Pereira.

Ortega Cavero, David (1966): Diccionario español-portugués y portugués-español. 2 vols, Barcelona, Ramón Sopena.

Pensado, José Luis, y Enriqueta Ruiz de Pensado (1960): Diccionario portugués-español y español-portugués. Madrid, [Blass], Mayfe.

Valdez, Manuel do Canto e Castro Mascarenhas (1864-66): Diccionario españolportugués el primero que se ha publicado con las voces, frases, refranes y locuciones usadas en España y Américas Españolas. Lisboa, Imprensa Nacional.

Viqueira Barreiro, J. Ma. (1961): Diccionario español-portugués y portugués-español. Madrid, Aguilar.

Wildik, Visconde de (1897): Novo diccionario hespanhol-portuguez e portuguezhespanhol com a pronuncia figurada. Paris, Garnier Hermanos. 


\title{
SOBRE LA FORMA MUNCHO
}

\author{
ENRIQUE PATO \\ Université de Montréal \\ Enrique.pato-maldonado@umontrel.ca
}

\begin{abstract}
Resumen
La presente nota aporta luz nueva sobre la historia y la evolución de muncho en español. En primer lugar, los ejemplos presentados confirman que estamos ante un fenómeno antiguo, documentado en el mismo latín, y característico del español clásico. Estudiamos la variación que ha mantenido con la forma estándar mucho a lo largo de la historia y, gracias a los datos del ALPI y del COSER, damos a conocer su extensión geográfica. La $-n-$ parasitaria se documenta también en otras lenguas y dialectos romances, como el asturiano y los dialectos septentrionales italianos, así como históricamente en francés. Por último, revisamos el origen latino (muntum) y presentamos varios ejemplos de su extensión a otras palabras en español moderno.
\end{abstract}

PALABRAS CLAVE: Dialectología, Historia de la lengua, Español, Adverbio mucho, muncho.

\section{Introducción}

El adverbio muncho ha sido descrito como forma propia del judeoespañol (Subak, 1906: 173; Zamora Vicente, 1967: 361; Quintana Rodríguez, 2006: 217-220), del murciano (Zamora Vicente, 1967: 341; García Soriano, 1980; Díez de Revenga, 1997: 158; Gómez Ortín, 2004: 18; García Mouton, 2007: 35; Hernández Campoy, 2008), del andaluz (cf., entre otros, Cuervo, 1886: XLVII, n.1; Alcalá Venceslada, 1951: 421; Montes Giraldo, 1995-1996), del español de México y de Estados Unidos (Canfield, 1934: 75;

\footnotetext{
${ }^{1}$ Esta investigación se ha llevado a cabo gracias al proyecto KNOW2 (TIN2009-14715-C04) del Ministerio Español de Ciencia e Innovación.
}

This note provides new light on the history and evolution of Spanish adverb muncho. First, the examples presented confirm that this characteristic of Classical Spanish. We study the variation that has remained with of COSER data, we present its geographical extension. The parasitic $-n-$ is also documented in other Romance languages and dialects, as in Asturian, northern Italian dialects and, historically, in French. Finally, we review the Latin origin (muntum) and present several examples of its extension to other modern Spanish words.

KEY WORDS: Dialectology, History of Language, Spanish, Adverb mucho, muncho is an old phenomenon, documented in Latin, 
Henríquez Ureña, 1938: 374; Marden, 1938: 156; Company y Melis, 2002: 579-580; French, 2003; Marcos Marín, 2005: 335 y 2007: 135; Lipski, 2008: 94 y 218; Bills y Vigil, 2008: 69 y 166, etc.). Hoffman (1886: 301), por ejemplo, señaló "how corrupted the Spanish language has become in the south-west portion of the United States", citando entre otros el uso de muncho en lugar de mucho. Para Espinosa (1909: 26), en cambio, se trataría de "a popular form in all Spanish countries and frequent in Old Spanish", y así aparece en el DRAE (vid. muncho), como adjetivo 'anticuado y usado como vulgar', esto es común al español vulgar.

A simple vista, la forma muncho no presenta gran interés para la gramática histórica y dialectal, pero la aparición de esa nasal nos lleva a preguntarnos por varias cuestiones. Aparte de los trabajos clásicos de Luria (1937) y Cross (1938), ningún autor se ha preocupado ni por el origen ni por su documentación histórica y actual; desconocemos hasta cuándo se empleó de manera habitual en los textos, y si existe algún patrón geográfico-dialectal en su uso. Tampoco se ha estudiado la variación que ha mantenido con la forma estándar mucho a lo largo de la historia, ni se ha descrito la extensión de la epéntesis nasal a otras palabras. En el presente trabajo intentaremos dar respuesta a estas cuestiones pendientes.

\section{Breve descripción de la forma muncho}

Según el DRAE, muncho es un término propio de México (cf. las ediciones del DRAE de 1925, 1927, 1936, 1939, 1947 y 1950). Como "forma antigua y hoy vulgar", aparece desde 1956 (cf. las ediciones de 1956, 1970, 1984, 1989 y 1992).

Desde el punto de vista gramatical, al igual que mucho, muncho puede ser: 1) adjetivo, y su significado es el de 'abundante'. Como tal presenta variación de género y número (muncho, muncha, munchos, munchas); 2) cuantificador indefinido antepuesto al nombre (En Europa hay mu(n)cha crisis); 3) pronombre (Estuvo llamando a los restaurantes que había en la ciudad. No eran $m u(n)$ chos, la verdad); 4) adverbio (cuantificador de grado), con el significado de 'abundantemente o intensamente', aparece en ocasiones antepuesto a mejor, peor, mayor, menor, más, menos, antes y después; 5) presenta lectura inespecífica (o cardinal), entonces el SN que le precede tiene alcance amplio: No vinieron $m u(n)$ chos niños ('Hay muchos niños que no vinieron'); y 6) adquiere lectura colectiva y distributiva, con SSNN plurales y nombres no contables y coordinados; en este caso, la predicación se refiere a un grupo de entidades y no a los componentes individuales (NGLE, 2009), como en Sobre su escritorio se acumulaba mu(n)chos papeles, donde el valor distributivo se aplica a cada una de las entidades individuales que componen el conjunto. 


\section{Documentación de muncho}

Tal y como quedó indicado en la Introducción, es posible documentar la forma muncho (adverbio/ cuantificador > adjetivo y pronombre) desde el español medieval, sola (cf. 1a, c-d) o en variación con la forma mucho (cf. 1b). Los siguientes ejemplos ofrecen una breve muestra de ello:

(1)

a. diz essa estoria de las prouincias que uiene muncho Açafran \& muy bueno \& de meior olor que otro \& mas amariello que oro (Alfonso X, General estoria II).

b. Pues que les este castigo ouo dado bendixo los \& dixo. yd agora benditos \& con salut \& con muncho bien ca uos tornaredes a uuestros lugares loado a dios con muncho oro \& mucha plata \& mucho cobre \& muncho fierro \& munchos pannos de precio (Alfonso X, General estoria II).

c. De aquestas viejas todas ésta es la mejor; / ruégal' que te non mienta, muéstral' buen amor, / que muncha mala bestia vende buen corredor, / e muncha mala ropa cubre buen cobertor (Juan Ruiz, Libro de Buen Amor).

d. Bien cred que vna de las cosas en que los omnes muncho yerran es por que non saben beuir derecha mente con su muger et con sus fijos (Don Juan Manuel, Libro enfenido).

También es común en español clásico (cf. 2a), en judeoespañol (cf. 2b), en español coloquial (cf. 2c, ejemplo de México) y en hablantes bilingües (cf. 2d):

a. es el dicho Hernando de Aguilar hombre tan bullicioso, y escandaloso, e acostumbrado a tener munchas rebueltas con la justicia, como es notorio en esta cidad (Doc. 1491, AGS, Consejo Real, C. 611-9E, 30 de diciembre de 1557, Écija, Sevilla).

b. Kavamente la Sra. Sara Pardo, guida de Turismo de munchos anios publiko un libro remarkable en Turko sovre la Komunidad Djudia de Izmir, profiti muncho de esta dokumentasion. Kero mensionar kon grande apresiasion a la Sra. Rachel SabaWolfe de la kuala me embezi muncho sovre las luchas sosialas en el seno de la comunidad ("La komunidad djudia de Izmir (Smyrna)", Selim Amado, 2007).

c. Hola, me da muncho gusto que munchas mujeres creamos en la virgen, ya que munchas lamentablemente no creamos [sic], pero tengan muncha fe y créanme que se les cunpliran [sic] sus deseos, munchos saludos a todas y a todos, su amiga Elena ("Caminata de la Virgen de la Encarnación", T-amo-Dios, México, 13/05/2010).

d. cuando salió el conejo "ya me voy", dice "orita voy y vengo", dice "Te voy a trai un queso pa que te la coma", dice, "pa que no me vas a comer a mí", dice. Entons "bueno, ps ándale", dice "pero te viene pronto". "Sí, vengo pronto". Se jué el conejo y duró muncho y no podía venir... (Cruz del Palmar, Guanajuato, México, H, 75, bilingüe español-otomí). 


\section{Nuevos datos históricos}

Una de las primeras documentaciones de muncho ha sido presentada por SánchezPrieto (2008: 245), quien registró la fórmula ni poco ni muncho en un documento de 1236 (cf., además, Pascual y Blecua, 2006). Los datos del Corpus del español y del CORDE nos ayudan a fechar con mayor precisión el uso de muncho a lo largo de la historia de la lengua y a conocer el tipo de texto en que aparece. En concreto, y según los datos del CORDE (cf. Tabla 1 infra), es interesante comprobar que el $71 \%$ de todos los casos registrados de muncho son de 1509-1527 (primera mitad del s. XVI). En cuanto al tipo de texto, el 64\% figura en textos de prosa histórica. La diferencia que encontramos en la tabla 1 entre ambos corpus radica en que los textos que incluye el Corpus del español donde se registra muncho son casi todos de finales del siglo XV, como Cura de la piedra (1498) de J. Gutiérrez de Toledo, Valerio de las historias escolásticas y de España (1487) de D. Rodríguez de Almela, Crónica de España (1482) de D. de Valera, Tratado médico (o Tratado de la patología general), Libro del Cuzari de Jehuda ha-Levi y De los oficios, trad. A. de Cartagena. En el CORDE, el Tratado médico es considerado como texto del siglo XVI (1500), por ejemplo. Este corpus incluye otras obras de autores como Fray Bartolomé de las Casas o Gonzalo Fernández de Oviedo (prosa histórica) donde la documentación de muncho es constante 2 .

En resumen, como podemos comprobar en la tabla 1 de distribución de las formas muncho y mucho, la diferencia entre los dos corpus seleccionados (Corpus del español s. XV y CORDE s. XVI) viene marcada por la inclusión-exclusión de ciertos textos, pero los datos de ambos corpus confirman que las dos formas son empleadas principalmente en el siglo XVI, con porcentajes muy similares.

\begin{tabular}{llllllllll}
\hline \multirow{4}{*}{ Corpus del español } & & XIII & XIV & XV & XVI & XVII & XVIII & XIX & XX \\
& muncho & $5 \%$ & $0.3 \%$ & $\mathbf{8 4 \%}$ & $9 \%$ & $0.4 \%$ & $1 \%$ & $0.2 \%$ & -- \\
& & & & & \\
CORDE & muncho & $3 \%$ & $4 \%$ & $21 \%$ & $\mathbf{7 1 \%}$ & $1 \%$ & --- & --- & --- \\
& mucho & $3 \%$ & $5 \%$ & $13 \%$ & $\mathbf{2 9} \%$ & $19 \%$ & $6 \%$ & $11 \%$ & $14 \%$ \\
\hline
\end{tabular}

Tabla 1. Distribución de muncho y mucho, por tipo de corpus, a lo largo de la historia de la lengua.

\footnotetext{
${ }^{2}$ Para una revisión más detallada de los textos y autores en donde es posible la documentación de la forma muncho, y los problemas de edición que conlleva (mũcho> muncho), cf. el trabajo de Pascual y Blecua (2006: 1363-1370).
} 
Por otro lado y como cabría esperar, muncho muestra un comportamiento similar al de mucho en cuanto a la documentación de sus formas (variación de género y número). En efecto, tanto la documentación de mucho (246.400 casos en el Corpus del español y 554.459 en el CORDE) como la de muncho (3.185 en el Corpus del español y 8.834 en el CORDE) ofrecen porcentajes de aparición que favorecen la forma del masculino singular, seguido de las formas de plural (cf. Pato, 2011).

\begin{tabular}{lrllllll}
\hline \multicolumn{3}{c}{ Corpus del español } & \multicolumn{4}{c}{ CORDE } \\
mucho & $\mathbf{4 1} \%$ & muncho & $\mathbf{4 0 \%}$ & mucho & $\mathbf{3 8} \%$ & muncho & $\mathbf{3 4} \%$ \\
mucha & $10 \%$ & muncha & $13 \%$ & mucha & $12 \%$ & muncha & $12 \%$ \\
muchos & $26 \%$ & munchos & $20 \%$ & muchos & $27 \%$ & munchos & $25 \%$ \\
muchas & $23 \%$ & munchas & $27 \%$ & muchas & $23 \%$ & munchas & $29 \%$ \\
\hline
\end{tabular}

Tabla 2. Distribución de mucho y muncho (variación de género y número), por tipo de corpus.

Como vemos en la tabla 2, en porcentajes totales mucho alcanza un $98.52 \%$ (800.859 casos) y muncho un $1.47 \%$ (12.019 casos). Datos que se asemejan a lo encontrado en el español de México por Company y Melis (2002: 579-580): mucho 95\% (692 casos) vs. muncho 5\% (38 casos).

En otros corpus lingüísticos, como el de Biblia Medieval, la forma muncho se documenta exclusivamente en las versiones romanceadas traducidas del canon hebreo de la primera mitad del siglo XV (71 casos). En efecto, se registra en la Biblia de Ajuda (14201430), el códice escurialense I.i.5 (1420-1445), la Biblia de Évora (1429, traducción que coincide con E5), el ms. 10.288 de la Biblioteca Nacional de Madrid (primera mitad del siglo XV), el ms. 87 de la Biblioteca de la Real Academia de la Historia (1450-1475) y la Biblia de Alba (1422-1430). Esta situación puede deberse a un condicionamiento cronológico, y no a la lengua subyacente del modelo o a la variedad romance de los traductores, ya que no aparece ni en la Fazienda ni en los manuscritos E6/E8 del siglo XIII. Aparece preferentemente como adverbio de cantidad, pero también como adjetivo.

Por último, en los vocabularios del XVI-XVII como el Vocabulario de las dos lenguas toscana y castellana de Cristóbal de las Casas (1576: 240) troppo se traduce como 'muncho', y en el Tesoro de las tres lenguas, española, francesa e italiana de Vittori (1644: 168) mont es el equivalente de 'moult, molto, mucho, muncho'.

\section{Extensión geográfica, histórica y actual}

Desde el punto de vista histórico, los datos del CODEA confirman la documentación de la forma muncho desde 1496 a 1625, especialmente en textos notariales de Écija (Sevilla), Granada y Calatayud. También aparece, aunque en menor proporción, en 
documentos notariales de Burgos, Toledo y Madrid. Los sustantivos a los que cuantifica son gente, personas, armas, rebueltas, beneficio y donaciones, aunque también figuran sustantivos coordinados del tipo escándalo e alboroto, daño y perjuizio.

Los datos que guarda el ALPI, datos ya histórico-dialectales, arrojan luz nueva sobre el fenómeno en estudio. Aunque algunas de las preguntas del cuestionario gramatical no fueron completadas en varios de los cuadernos, gracias a las preguntas Mucho (Cuaderno I, p. $8 \# 76)^{3}$ y Mucha cosecha (Cuaderno I, p. $\left.4 \# c h\right)^{4}$ podemos obtener una imagen precisa de su extensión geográfica en la península antes de la guerra civil; imagen que permite corroborar en parte la distribución de los datos de las descripciones previas.

El siguiente mapa, presentado por primera vez, muestra la extensión de muncho (y variantes) en el ALPI. Como podemos comprobar, la forma vernácula se registra en el centro y este de Asturias ${ }^{5}$, de manera esporádica en Aragón (sur de Zaragoza y Teruel) ${ }^{6}$ y Murcia ${ }^{7}$ y de manera general en Andalucía, en las provincias de Cádiz, Sevilla, Córdoba, Málaga, Granada y Jaén, así como en el sur de Ciudad Real.

\footnotetext{
${ }^{3} \mathrm{La}$ forma munchu se registra en los enclaves $311,312,313,315,316,317,318,319,320$, 321. La forma muntcho en 503, 505, 507, 508, 509, 512, 513, 514, 516. Los casos de muncho/ munsho en 314, 332, 480, $481,504,506,510,511,515,524,527,528,529,530,531,532,534,535,536,537,538,539,540,541$, $542,543,544,545,546,547,548,549,550,551,552,566,625,635,636,638$. Y por último muntu en 365.

${ }^{4}$ Las formas muncha (y muntcha) aparecen documentadas en los puntos de encuesta $315,320,321$, $332,480,481,625,635,638,504,505,506,507,508,509,510,511,512,513,514,515,516,524,527$, $529,530,532,534,535,536,537,538,539,540,541,542,543,544,545,546,547,548,549,550,551$, 552, 566. La forma munta en 365.

${ }^{5} \mathrm{La}$-n- epentética es habitual en asturiano (cf. García Arias, 2003: 250). Como es sabido, forma el adverbio de cantidad: trabaya muncho bien; son muncho bones (cf. ALlA, 2002: 45; ALlA, 2008: 156).

${ }^{6}$ Khun (2008: 111) registró en los años 30 casos 'espontáneos' de epéntesis consonántica en altoaragonés (Ansó, Hecho y Sallent), como henchizar ('hechizar') y henchicero ('hechicero').

${ }^{7}$ En este caso en particular, los datos del ALPI resultan un poco limitados, ya que la forma muncho constituye uno de los rasgos caracterizadores del murciano (cf., entre otros, Zamora Vicente, 1967: 341; García Mouton, 2007: 35; y desde el punto de vista histórico, Díez de Revenga, 1997: 158).
} 


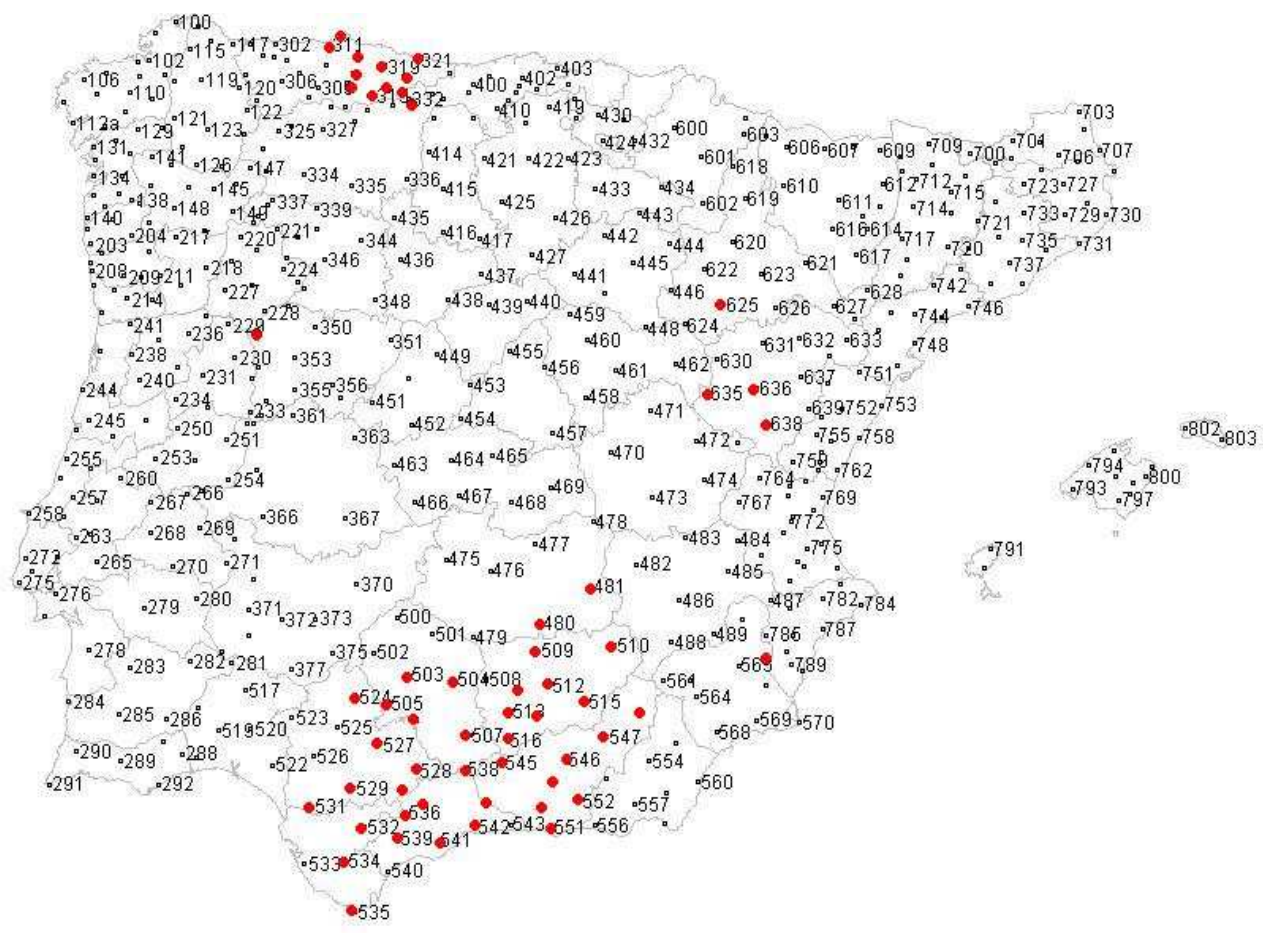

Mapa 1. Extensión de la forma muncho (y variantes), según los datos del ALPI.

Por último, los datos del COSER confirman, también, su uso pleno en Andalucía. La documentación sistemática de la forma muncho (en casi total ausencia de la estándar mucho) hace pensar en un proceso antiguo de lexicalización de un fenómeno fonético, que ha conducido a muncho a ser la forma aprendida y transmitida en el español rural de Andalucía, del mismo modo que ha ocurrido con otras palabras, especialmente adverbios, que en su proceso de fijación han añadido la nasal, tal es el caso de asín y ansí ('asi', cf. Rodríguez Molina, 2012), lenjos ('lejos', derivado de longe, cf. Zamora Vicente, 1967: 341) o mejón ('mejor', de origen andaluz, cf. Casares, 1992: 275, n. 1), entre otros.

\footnotetext{
${ }^{8}$ En su Diálogo de la lengua, Valdés hace referencia a este adverbio en estos términos: "MARCIO: Dos vocablos hallo de los quales vos, no sé por qué, quitáis una n, diziendo por invierno y lenxos, ivierno y lexos. ¿Hazéislo por industria o por descuido? VALDÉS: El descuido creo yo que está en los que ponen la $\mathrm{n}$ sin propósito ninguno. $\mathrm{Y}$ ésta es una de las letras que yo digo que por inadvertenzia se an mezclado en algunos vocablos".
} 
Los siguientes ejemplos, fruto de la campaña de encuesta realizada en septiembre de 2012, son solo una breve muestra de la rica documentación que guarda el COSER sobre el fenómeno:

(3)

a. A mí no, a mí me gusta que esté más, más cuajá [la morcilla]. Sí, pero... estaba estupenda. Sí. Yo he hecho muncha (Cañete de las Torres, Córdoba, COSER-1517).

b. ¿Con el trigo?, lo vendían; aquí había una fábrica de harina, lo cogían mayormente y se lo llevaban pa' fuera, ahí a los, a las comarcales, que decían "comarcal", y esas cosas, y na' luego lo cogían muncho, lo cogían y lo llevaban a una fábrica ahí pa' molerlo, pa' hacer pan (Sierra de Yeguas, Málaga, COSER-3015).

c. Eso estaba todo, cuando Marbella empezó... estaba todo de hoteles, y todo el mundo se fue allí. ¡Las muchachas ganaban muncho dinero! Mucho dinero han ganao... (Jubrique, Málaga, COSER-3009).

\section{Posible origen y fuente de analogía}

Según Menéndez Pidal (1968), la adición de la nasal podría explicarse por 'reflejo' de otra nasal que hay en la misma palabra ( $\underline{m} u c h o>$ muncho). Grandgent (cit. en Cross, 1938: 601) señaló el paso multu> muntu en el mismo latín (forma documentada también en el ALPI, si bien de manera esporádica, cf. las notas 3 y 4), y otros autores como Sommer (1914: 168) y Stolz-Schmalz (1928: 167) incluyeron el estudio de estas formas en sus trabajos. Para todos ellos la fuente de analogía (en latín) podría estar en los adjetivos de cantidad: tantum/ quantum/ multum $>$ muntum. De hecho, es posible documentar la adición de la - $n$ - en el Corpus Inscriptionum Latinarum (1863-1864: 1593) «SI VALES NON MVNTV CVRO», en el Appendix Probi «cultellum non cuntellum», así como en las pizarras visigodas «nontas» por notas (cf. Velázquez Soriano, 2004: 194).

Desde el punto de vista románico y tipológico, la nasalización del grupo -lt-> -nt(molto $>$ monto) se registra en algunos dialectos italianos (Parma y Génova, por ejemplo): monto bene, monto dificile; y en francés la $-n$ - 'parasita' ha aparecido en varias palabras ante consonante oclusiva, como langouste (LOCUSTA), concombre (fr.a. cocombre), jongleur (fr.a. jougleur 'malabarista'); o nasal, como tampon (fr.a. tapon), etc. (cf., entre otros, Nyrop, 1899: 375).

\footnotetext{
${ }^{9}$ Agradezco a Inés Fernández-Ordóñez (UAM/RAE) la consulta de los materiales del COSER, y a Carlota de Benito (UAM) la ayuda que me ofreció para localizar los ejemplos. La primera transcripción de los datos es mía.
} 
Por otro lado, el grupo - nch- ha sido muy productivo en español. Baste citar los casos de ancho (AMPLUS), concha (CONCHULA) o cincha (CINGULA), numerosos préstamos como lancha (port.), plancha (fr.) o poncho (¿quechua, mapudungun?), así como voces de origen incierto como gancho, pinche, etc. Además, aparece en palabras que etimológicamente no presentaban esa $-n$ - (ante consonante oclusiva de nuevo), como mancha (MACULA), mancilla (lat.vulg. MACELLA), ninguno ( $<$ NEC UNUS), manzana (mazana <MATTIANA), o en préstamos, como mensaje (prov. messatge). Tal y como han mostrado varios autores (cf., por ejemplo, Pharies 1994: 4), la nasal se registra a su vez en palabras derivadas como flaco $>$ flacuncho (Alvar, 1972: 31) o gordo> gordoncho (Alcalá Venceslada, 1951: 302). Aparece incluso con aumentativos (munchísimo, cf. 4a) y ha creado desde antiguo derivados del tipo munchedumbre ('muchedumbre', cf. 4b-c):

(4)

a. Hacía munchos, munchísimos años que en nuestro pueblo no era menester castigar a ningún malnacido por una falta como la tuya (Ramón Rubín, El canto de la grilla, 1952, México).

b. Et sobresto cuenta Josepho que Josue \& los de Jsrahel quando sopieron que tamanna era la munchedunbre destas yentes \& del guisamiento que trayen que dubdaron de yr a ellos (Alfonso X, General estoria II).

c. A los del linage de Joseph fazien se les poco las suertes delos heredamientos que auien. Et mostraron lo alli a Josue \& dixieron le assi / Por que nos diste por heredat tierra duna suerte \& duna medida; seyendo nos tamanna muchedunbre cuemo somos \& nos bendixo nuestro sennor \& nos acrescio assi. bendito sea ell (Alfonso X, General estoria II).

La extensión de la - $n$ - a otras palabras no ha recibido, que sepamos, atención por parte de ningún autor. La analogía con el grupo -nch- (concha, plancha, etc.) ha creado palabras como mancho ('macho', Sos muy mancho, chavón); manchete ('machete', Agarró a mi gata doméstica y le cortó el cuello con un manchete); mencha ('mecha'), menchero ('mechero'), menchones ('mechones'), monchila ('mochila'), munchachos ('muchachos'), cunchillo ('cuchillo'), chinchón ('chichón'), oncho ('ocho'), aprovenchar ('aprovechar'), anonchecer ('anochecer'), lunchar ('luchar'), henchizar ('hechizar'), nincho ('nicho'), etc. ${ }^{10}, y$ así se pueden registrar en varios corpus lingüísticos y en diversas fuentes en línea (cf. Pato, 2011). Aparece incluso con nombres propios, Manchín ('Machín',

\footnotetext{
${ }^{10} \mathrm{La}$-n- epentética se registra también en algunos enclaves de Alicante, como Villena, bolinche ('boliche'), calinche ('caliche'), moncho ('mocho'), etc., y en valenciano (ninxo, enxisar). Cf. Torreblanca (1976: 165) y Domene Verdú (2010: 227).
} 
Escucha las canciones de Antonio Manchín), Nancho ('Nacho'), y se extiende también al interior de palabras que ya presentan el grupo -nch-, como en zanfarrancho ('zafarrancho') (cf. Rodríguez Izquierdo, 1994: 46).

\section{Consideraciones finales}

Si bien Meyer-Lübke (1890: 519) adelantó una explicación sobre la asimilación nasal progresiva, por el que la $/ \mathrm{n} /$ nasaliza el comienzo plosivo del elemento africado (ch), la manera en que se produce la transmisión de los rasgos fónicos ha sido muy poco estudiada. Un trabajo fonológico sobre la adquisición de la lengua materna, y la lengua segunda, podría dar cuenta de este fenómeno.

Un trabajo piloto llevado a cabo en la Universidad de Montreal (cf. Pato, 2011) con 20 informantes (5 estudiantes nativos, 13 estudiantes francófonos de ELE y 2 personas sin competencia alguna en español) nos ha mostrado que la aparición de la nasal /n/ ayuda a los informantes en la pronunciación de la -ch-(hacha/ ancha; poncho/ pocho). Como es sabido, la pronunciación de las africadas exige una fase de obstrucción total y otra de fricción. En la primera etapa, el flujo del aire se interrumpe, y en la segunda, escapa forzadamente; es decir, el predorso de la lengua se separa gradualmente, creando una estrechez por donde escapa el aire produciendo así la fricación. Por tanto, y de forma natural, cuando se pronuncia la ch cuesta forzar el aire a que salga por la boca después de la fricción. En la pronunciación del grupo -nch-, en cambio, la lengua se eleva para hacer contacto con el paladar duro, y el predorso de la lengua se adhiere al prepaladar y los alvéolos, impidiendo la salida del aire por la boca, lo que facilita su pronunciación. Con todo, es posible considerar la aparición de la nasal (muncho vs. mucho) como elemento que ayuda en la emisión de la $\mathrm{ch}$, al menos para los informantes no nativos (90\% en alumnos de ELE y $100 \%$ en personas sin competencia en español) ${ }^{11}$.

La elaboración del presente trabajo nos ha permitido obtener una serie de resultados, hasta ahora desconocidos sobre el fenómeno en estudio, que aportan luz nueva sobre la historia y la evolución de muncho en español. En primer lugar, como hemos visto en los ejemplos presentados, estamos ante un fenómeno antiguo, documentado en el mismo latín, y característico del español clásico, en concreto del primer cuarto del siglo XVI (textos fechados entre 1509 y 1527). La -n- 'adventicia' se documenta tam-

\footnotetext{
${ }^{11}$ Habría que comprobar ahora en los datos del COSER si, allí donde la fricativización de la -ch- es más frecuente, como por ejemplo en las provincias de Sevilla y Cádiz (musho), los casos de -n(munsho) presentan un porcentaje de aparición menor.
} 
bién en otras lenguas y dialectos romances, como el asturiano y los dialectos septentrionales italianos, así como históricamente en francés. Gracias a los datos del ALPI y del COSER hemos conocido la extensión geográfica de muncho, que lo presentan como rasgo característico del andaluz. Por último, hemos revisado el posible origen (lat. muntum) y presentado varios ejemplos de la difusión de la $-n$ - a otras palabras en español moderno.

Recibido: 24-X-2012

Aceptado: 02-IV-2013

\section{Referencias bibliográficas}

Academia de la Llingua Asturiana. (2002): Informe sobre la Llingua Asturiana. Oviedo, Academia de la Llingua Asturiana.

Academia de la Llingua Asturiana. (2008): Gramática de la Llingua Asturiana. Oviedo, Academia de la Llingua Asturiana.

Alcalá Venceslada, A. (1951): Vocabulario andaluz. Madrid, Real Academia Española.

ALPI. Atlas Lingüistico de la Península Ibérica (en línea), Heap, D. (coord.), The University of Western Ontario: http://www.alpi.ca (20-04-2011).

Alvar, M. (1972): Cuestionario para el estudio coordinado de la norma lingüistica culta de las principales ciudades de Iberoamérica y de la Península Ibérica. Vol. 2: Morfosintaxis. Madrid, CSIC.

Biblia Medieval, Enrique-Arias, A. (dir.), Universidad de las Islas Baleares: http://www.bibliamedieval.com (20-04-2012).

Bills, G. D. y N. A. Vigil. (2008): The Spanish Language of New Mexico and Southern Colorado. A Linguistic Atlas. Nuevo México, The University of New Mexico Press.

Canfield, D. L. (1934): Spanish literature in Mexican languages as a source for the study of Spanish pronunciation. Nueva York, Instituto de las Españas en Estados Unidos.

Casares, J. (1992): Introducción a la lexicografía moderna. Madrid, CSIC.

CODEA. Corpus de Documentos Españoles anteriores a 1700. Universidad de Alcalá: http://demos.bitext.com/codea/codea_form.asp (22-03-2012).

Company, C. y C. Melis. (2002): Léxico histórico del español de México. Régimen, clases funcionales, usos sintácticos, frecuencias y variación gráfica. México, UNAM.

CORDE. Corpus diacrónico del español. Madrid, Real Academia Española: http://www.rae.es (28-10-2012).

Corpus del español, Davies, M. (dir.), Brigham Young University: http://www.corpusdelespanol.org (28-10-2012).

COSER. Corpus Oral y Sonoro del Español Rural, Fernández-Ordóñez, I. (dir.), Univer- 
sidad Autónoma de Madrid: http://www.coser.uam (28-10-2012).

CREA. Corpus de referencia del español actual. Madrid, Real Academia Española, www.rae.es (28-10-2012).

Cross, E. (1938): "On Spanish muncho, Portuguese muito", Modern Language Notes, $53 / 8$, págs. 600-602.

Cuervo, R. J. (1886): Diccionario de construcción y régimen de la lengua castellana. París, A Roger y F. Chernoviz.

De las Casas, C. (1576): Vocabulario de las dos lenguas toscana y castellana. Sevilla, Francisco de Aguilar.

Díez de Revenga Torres, P. (1997): "Observaciones filológicas sobre aspectos relativos al medio ambiente en la documentación notarial”, Epos, XIII, págs. 151-170.

Domene Verdú, J. F. (2010): "Caracterización lingüística del habla de Villena (Alicante)”, Archivo de Filología Aragonesa, 66, págs. 217-243.

Espinosa, A. M. (1909): Studies in New Mexican Spanish. Part I: Phonology. Chicago, The Chicago University Press.

French, W. E. (2003): “Te Amo Muncho: The Love Letters of Pedro and Enriqueta". En Pilcher, F. M. (ed.): The Human Tradition in Mexico. Wilmington (DE), Scholarly Resources, págs. 123-135.

García Arias, X. L. (2003): Gramática histórica de la lengua asturiana. Oviedo, Academia de la Llingua Asturiana.

García Mouton, P. (2007): Lenguas y dialectos de España. Madrid, Arco/ Libros.

García Soriano, J. (1980): Vocabulario del dialecto murciano. Murcia, Editoria Regional.

Gómez Ortín, F. (2004): "El dialecto murciano y sus variedades", Tonos digital, 8, págs. 7-27.

Henríquez Ureña, P. (1938): "Mutaciones articulatorias en el habla popular". En Henríquez Ureña, P. et alii. (eds.): El español en Méjico, los Estados Unidos y la América Central. Buenos Aires, Imprenta de la Universidad de Buenos Aires, págs. 329-379.

Hernández-Campoy, J. M. (2008): “Sociolinguistic aspects of Murcian Spanish”, International Journal of the Sociology of Language, 193/194, págs. 121-138.

Hoffman, W. J. (1886): "Remarks on Indian Tribal Names". En Proceedings of the American Philosophical Society. Philadelphia, M'Calla \& Stavely, págs. 294-303.

Khun, A. (2008): El Dialecto Altoaragonés. Zaragoza, Xordica-Prensas Universitarias de Zaragoza.

Lispki, J. M. (2008): Varieties of Spanish in the United States. Washington, Georgetown University Press.

Luria, M. A. (1937): "Old and Dialectical Spanish muncho, Portuguese muito", Language, 13/4, págs. 317-318. 
Marcos Marín, F. (2005): "Pluralidad del español en los Estados Unidos de América". En El Español en el Mundo. Anuario del Instituto Cervantes 2005. Barcelona, Plaza \& Janés/ Círculo de Lectores, págs, 283-357.

Marcos Marín, F. (2007): "Tres líneas léxicas del español en los Estados Unidos de América". En Actas del I Congreso Internacional de Léxico Español Actual. Venecia, Librería Editrice Cafoscarina, págs. 127-141.

Marden, C. C. (1938): "La fonología del español en la ciudad de Méjico". En Henríquez Ureña, P. et alii. (eds.): El español en Méjico, los Estados Unidos y la América Central. Buenos Aires, Imprenta de la Universidad de Buenos Aires, págs. 87-187.

Menéndez Pidal, R. (1968): Manual de Gramática Histórica Española. Madrid, EspasaCalpe.

Meyer-Lübke, W. (1890): Grammatik der romanischen Sprachen. Leipzig, Fues's Verlag.

Montes Giraldo, J. J. (1995-1996): "La bipartición dialectal del español”, Boletín de Filología de la Universidad de Chile, 35, págs. 317-331.

Nyrop, K. (1899): Grammaire historique de la langue française. París, A. Picard \& fills.

Pascual, J. A. y J. M. Blecua. (2006): "De los munchos tipos de $n$ adventicia del español". En Filología y Lingüística. Estudios ofrecidos a Antonio Quilis. Madrid, CSIC/UNED, vol. II, págs. 1361-1384.

Pato, E. (2011): "La historia de mucho/ muncho en español", ponencia presentada en el 64th Annual Kentucky Foreign Language Conference. Lexington, University of Kentucky (14-16 de abril de 2011).

Pharies, D. (1994): “Origin of the Spanish -nch- Suffixes”, Iberoromania, 40, págs. 1-43.

Quintana Rodríguez, A. (2006): Geografía lingüística del judeoespañol. Estudio sincrónico y diacrónico. Bern, Peter Lang.

Real Academia Española. (2009): Nueva gramática de la lengua española. Madrid, Espasa/ Real Academia Española.

Rodríguez Izquierdo, F. (1994): "Voces con eco nasal", $A B C$ (Sevilla), 5 de diciembre de 1994, pág. 46.

Rodríguez Molina, J. (2012): “El adverbio así en español medieval: variantes morfológicas", ponencia presentada en el IX Congreso Internacional de Historia de la Lengua Española. Cádiz, Universidad de Cádiz (10-14 de septiembre de 2012).

Sánchez-Prieto Borja, P. (2008): "La variación lingüística en los documentos de la catedral de Toledo". En Elvira, J. et alii. (eds.): Lenguas, reinos y dialectos en la Edad Media Ibérica: la construcción de la identidad. Homenaje a Juan Ramón Lodares. Madrid/ Frankfurt, Iberoamericana/ Vervuert, págs, 233-256.

Sommer, F. (1914): Handbuch der lateinischen Laut- und Formenlehre. Heidelberg, C. Winter.

Stolz, F. y J. H. Schmalz. (1928): Lateinische Grammatik. Laut-und Formenlehre, Syntax 
und Stilistik. Munich, C. H. Beck.

Subak, J. (1906): “Zum Jüdenspanischen”, Zeitschrift für Romanische Philologie, XXX, págs. 129-185.

Torreblanca, M. (1976): Estudio del habla de Villena y su comarca. Alicante, Instituto de Estudios Alicantinos.

Velázquez Soriano, I. (2004): Las pizarras visigodas. Burgos, Instituto Castellano y Leonés de la Lengua/ Real Academia Española.

Vittori, G. (1644): Tesoro de las tres lenguas, española, francesa e italiana. Ginebra, Jaques Crespin.

Zamora Vicente, A. (1967): Dialectología española. Madrid, Gredos. 


\section{RESEÑAS}

GARCÍA GODOY, M. ${ }^{a}$ Teresa (ed.), El español en el siglo XVIII. Cambios diacrónicos en el primer español moderno. Bern, Peter Lang [Fondo Hispánico de Lingüística y Filología], 2012, 335 págs. ISBN: 9783034310581.

La evolución del español durante el siglo XVIII sigue estando insuficientemente estudiada en la actualidad. Durante años se ha difundido la idea de que aquel siglo era parco en cambios lingüísticos y que su inicio constituye un periodo de estabilidad gramatical, muy distinto, por tanto, de lo que sucede durante los siglos precedentes, en los que tienen lugar alteraciones significativas del sistema gramatical. Así, hace ya más de dos décadas Cano Aguilar (1988: 255) escribía: "Con el siglo XVIII puede decirse que concluyen los grandes procesos históricos constitutivos de la lengua española. A partir de entonces, no sólo estamos ante el "español moderno", sino, sobre todo, ante una lengua que ha alcanzado su estabilidad [...], las grandes líneas de la estructura idiomática no han variado: ni en el plano fónico ni en el morfosintáctico puede señalarse en este periodo ninguna alteración fundamental, y el vocabulario básico sigue siendo, en general, el mismo". Al respecto, resulta significativo que Lapesa (1981: 418-434 y 454-456) tan solo dedicara en torno a veinte páginas al español dieciochesco en su Historia de la lengua española. Podría decirse que la idea de inmutabilidad llega casi hasta nuestros días. Es lo que sugiere, por ejemplo, la Historia de la lengua española coordinada por Cano Aguilar (2004), que reúne trabajos estimables sobre la morfosintaxis medieval y de los siglos XV, XVI-XVII e incluso del siglo XX, pero no presta atención, salvo en lo que atañe al léxico (Álvarez de Miranda, 2004), al español de los siglos XVIII y XIX. Aquella idea es, por tanto, una de las causas fundamentales que han podido motivar el relativo abandono que han sufrido los estudios de historia de la lengua durante el siglo XVIII (Brumme, 1995; Octavio de Toledo, 2007: 421, nn. 1 y 2).

Sin embargo, en los últimos años, y partiendo de la concepción de que el idioma está en permanente cambio, están viendo la luz distintas investigaciones (aún escasas desde luego) que atienden a ciertos procesos evolutivos que tuvieron lugar en dicho siglo (entre otros, Girón Alconchel, 2002; Company, 2002; Melis, Flores y Bogard, 2003; Octavio de Toledo, 2007 y 2008). Además, algunas obras de gran aliento, como sucede con la Sintaxis histórica de la lengua española dirigida por Company (2006 y 2009), han in- 
cluido decididamente en sus corpus textos del siglo XVIII, que estudian desde perspectivas tanto sincrónicas y como diacrónicas.

Partiendo, pues, del postulado de que la historia del español moderno no ha sido investigada suficientemente y que su estudio aún ha de dar frutos a la luz de la exploración de nuevos corpus documentales, García-Godoy ha reunido en El español del siglo XVIII. Cambios diacrónicos en el primer español moderno diez trabajos que pretenden contribuir al mayor conocimiento de los procesos evolutivos de nuestra lengua durante el Siglo Ilustrado aportando nuevos datos sobre el español dieciochesco y su pretendida inmutabilidad. Con estos estudios se quiere demostrar que esta centuria es fundamental en la historia del español y, concretamente, en la de sus variedades dialectales. Además de la introducción de la editora ("El siglo XVIII en la Edad Moderna de la lengua española"), en la que presenta su trabajo y lo justifica, y el útil "Índice de materias" que figura al final, el volumen se organiza en cuatro secciones. La primera de ellas, con un trabajo, se dedica al problema de la periodización; la segunda, al léxico (también con un trabajo). Las dos últimas secciones, formadas por cuatro trabajos cada una, atienden a cuestiones morfosintácticas y a las variedades diatópicas del español.

Encabeza el libro el trabajo de Carlos Sánchez Lancis "Periodización y cambio gramatical: el siglo XVIII, ¿frontera temporal del español?”. En primer lugar, se hace un repaso de las periodizaciones propuestas hasta la fecha en distintas gramáticas históricas o en manuales de historia de la lengua, y se indica que son en muchos casos coincidentes en acotar los periodos: los orígenes del castellano (ss. IX-XI), el castellano medieval (ss. XII-XIV), el español preclásico (1474-1525), el español clásico (ss. XVI-XVII) y el español moderno (s. XVIII hasta la actualidad). Se insiste, como en otros trabajos del autor, en que los criterios que han prevalecido para establecer tales etapas no han sido puramente lingüísticos, sino que en no pocas ocasiones se han adoptado criterios externos a la propia lengua, teniendo en cuenta aspectos históricos, literarios o sociales, como por ejemplo para la diferenciación entre el español medieval y el clásico. Como se viene haciendo desde hace ya varias décadas (entre otros, Eberenz, 1992; Marcos Marín, 1992 y 1995), el autor reclama la necesidad de atender fundamentalmente a los aspectos internos del español para el establecimiento de sus etapas históricas.

Antes de abordar el caso del español del Siglo Ilustrado, alude al español preclásico y pone de manifiesto que, en efecto, en esta etapa, que supone la transición del español medieval al clásico, confluyen diversos cambios (morfológicos, sintácticos o morfosintácticos) que produjeron un reajuste o una modificación gramatical de la lengua, lo que permite constatar la existencia de "fronteras" entre diversas épocas y, así, caracterizar el español preclásico como un periodo en el que tienen lugar numerosos cambios en el 
sistema. El autor se plantea, entonces, si algo parecido sucede en el paso del español clásico al moderno.

Al margen de los factores externos normalmente aducidos por los investigadores para justificar el inicio del español moderno, como la fundación de la Real Academia Española y el proceso de normativización, Sánchez Lancis se pregunta si en el inicio del siglo XVIII tienen lugar cambios lingüísticos relevantes, y concluye que, a tenor del panorama actual, en el que no abundan los estudios dedicados a la historia interna del español de este periodo, ni el número de cambios lingüísticos ni su naturaleza permiten considerar el Setecientos una frontera temporal en la historia del español. Sí cabe hablar, no obstante, de un rasgo caracterizador del español de este periodo: su estabilidad; se trata, en palabras del autor, de un siglo que "viene a ser simplemente, desde el punto de vista interno, la continuación del anterior y el preámbulo del siguiente" (pág. 47). Hemos de considerar, por tanto, que este primer trabajo, cuyas conclusiones contravienen los supuestos con que se concibió el volumen, en cierto modo pretende animar al estudio de la centuria en cuestión para su mayor conocimiento.

En "El vocabulario médico de los novatores en el siglo XVIII" Josefa Gómez de Enterría se ocupa de una parcela del léxico técnico, la del vocabulario de la Medicina, en la transición del siglo XVII al XVIII, periodo en el que se produce en España una gran renovación científica auspiciada por los novatores, quienes asimilan y difunden, con una orientación ecléctica, las corrientes europeas de la ciencia experimental y de la filosofía antiaristotélica. La autora basa su trabajo en un corpus formado por las obras de tres importantes médicos de este periodo: Carta philosóphica médico-chymica (1687), de Juan de Cabriada, Anatomía galénico-moderna (1716), de Manuel de Porras, y Anatomía completa del hombre (1728) y Cirugía moderna (1747), de Martín Martínez.

A partir de dicho corpus se constata que, en las primeras décadas del siglo XVIII, son diversos los procedimientos empleados para renovar la terminología del lenguaje de la Medicina, como la revitalización de términos especializados (adiposo), la formación de derivados (p. ej., en -oso: arterioso, lacticinoso, tendinoso y vasculoso; o en -ante: coagulante, corroborante, evacuante e indicante/contraindicante) o el recurso a la cantera grecolatina (bíceps, cóccix, laringe o tríceps). Un trabajo fundamental para observar este hecho es el de Cabriada, que, en palabras de López Piñero (1969: 102), quien rescató la figura de este novator, supone "el auténtico manifiesto de la renovación en nuestro país de la medicina y de los saberes químicos y biológicos con ella relacionados". Si bien encontramos en la Carta una tendencia claramente latinista, no ha de pasarse por alto que también se observa en su autor la adopción de "los neologismos que le imponen las nuevas corrientes científicas imperantes en Europa" (pág. 62). En el trabajo de Gómez 
de Enterría se trata de mostrar, en fin, el "activo proceso lexicogenético" que experimenta el vocabulario de la Medicina en el periodo tratado.

Encabeza la tercera sección, la dedicada a la morfosintaxis, el trabajo de Rosa María Espinosa Elorza "Novedades del siglo XVIII en aspectos relacionados con los cambios gramaticales", en el que se ofrece un primer acercamiento al estudio de una serie de fenómenos morfosintácticos, en su mayoría de gramaticalización, tomando como referencia el corpus académico CORDE. Se inicia el estudio de la evolución de formas autóctonas (p. ej., vaya, desde luego o para nada), algunos cambios en los que quizá haya habido alguna influencia del francés (p. ej., a más de o aparte de), un préstamo del italiano ( $a$ dúo) y un par de expresiones que posiblemente encuentren su explicación en el inglés ( $a$ decir verdad y tan pronto como). No obstante, es preciso indicar que existe cierta desproporción en el análisis de los fenómenos tratados; mientras que en general se presenta apenas un esbozo de ellos, en el caso de la locución con valor sumativo $a$ más y la aditiva aparte nos encontramos con un desarrollo de cinco páginas (págs. 9599). De ello es consciente la autora, quien, en efecto, confiesa al inicio del estudio, y repite a su término, que se trata de "un sí es no es de proyecto de estudio de algunas innovaciones de la época" (pág. 85). Además, no ha de perderse de vista que, aunque varios de los cambios lingüísticos tratados se documentan en el siglo XVIII, otros comienzan a tomar carta de naturaleza en el español durante el siglo XVII, e incluso antes.

Dentro de la misma sección, los restantes tres estudios analizan algunos aspectos atinentes al sistema de tratamientos del español. En el trabajo "El tratamiento de merced en el español del siglo XVIII" M. a Teresa García-Godoy aporta nuevos datos, concretamente referidos a la etapa dieciochesca, en torno a la gramaticalización y el desgaste fonético que llevan al tratamiento vuestra merced a convertirse en usted. La autora maneja dos corpus. El fundamental lo constituyen textos no literarios, obtenidos principalmente de documentación de archivo (cartas y declaraciones de testigos, insertas en pleitos o averiguaciones). A este se suma un corpus adicional que se compone de cinco tratados sobre correspondencia y tres de obras de autores andaluces de la llamada por algunos "literatura menor" de ámbito dialectal. En cada caso se justifica la elección del corpus y su idoneidad para el propósito que se persigue.

Antes de presentar un completo balance sobre los estudios previos (en el que se señala que hasta la fecha se han tratado principalmente seis aspectos del "cambio vuestra merced > usted", pero se ha olvidado casi por completo su faceta dieciochesca), la investigadora, consciente de que la representación gráfica del tratamiento de merced en los textos del siglo XVIII es un problema espinoso al manifestarse casi siempre de forma abreviada $(v m d$.), considera necesario, de manera muy oportuna, abordarlo, $\mathrm{y}$, avalada por los datos que al respecto muestra el análisis del corpus base, concluye: "en este tra- 
bajo adoptamos el criterio de que la variación $v m(d) / V(d)$, en las abreviaturas, se corresponde con la de vuesa merced / usted, en las formas plenas" (pág. 125).

En el apartado que se dedica al análisis se muestra, pormenorizada y exhaustivamente, que en la etapa estudiada los tratamientos vuestra merced y usted coexistieron con valores semánticos y funcionales diferentes. Además, se postula que durante el siglo XVIII hay diferencias significativas entre la forma singular del pronombre usted y la forma plural. García-Godoy termina su estudio proclamando la relevancia del siglo XVIII para la formación de los nuevos pronombres: "el cambio vuestra merced > usted - afirma - no acaba en el siglo XVII, sino que, en esa centuria, se inicia una fase evolutiva, hasta ahora inexplorada, en la que conviven el tratamiento nominal y el pronominal" (pág. 147).

Son dos los motivos que llevan a Elisabeth Fernández Martín a realizar su trabajo ("Vosotros/ustedes. Estudios del tratamiento plural en el español dieciochesco"): la inexistencia de investigaciones en torno a la segunda persona del plural en el español del siglo XVIII y el hecho de que dicho periodo es - según la autora- "clave en la configuración de los paradigmas de tratamiento del español actual” (pág. 154). El corpus utilizado, perteneciente en su mayoría a la variedad del español peninsular, se compone de tres bloques: lengua codificada (diálogos de enseñanza gramatical del español a extranjeros), lengua literaria (sainetes) y documentación archivística (correspondencia privada y declaraciones de testigos en juicios).

El detallado análisis de los datos que ofrecen los documentos seleccionados permite a la autora confirmar que durante la centuria estudiada los pronombres ustedes y vosotros aún no habían establecido los valores semánticos que presentan en la actualidad. Concretamente, se esgrime, de una parte, que ustedes es el tratamiento que predomina claramente en las relaciones sociales de entonces, lo que anuncia el empleo que tendrá, como forma de trato informal, en el español de América; y de otra, que vosotros se reserva, en cambio, para usos específicos, como son el trato a inferiores (señor-criados), el trato que se dispensan inferiores entre sí (criados), el trato en situaciones en las que existe algún tipo de emotividad o afectividad por parte del emisor (enfado o acusación) o el trato en determinados discursos, como el religioso.

El último trabajo de esta sección también se interesa por los tratamientos del español. El estudio de Francisca Medina Morales ("Los títulos de tratamiento en la España del siglo XVIII: la preceptiva de los tratados de cartas ilustrados"), basado en siete tratados epistolares publicados en España en el siglo ilustrado, se propone, por un lado, identificar los títulos protocolarios que figuran en dichos tratados (entre muchos otros, V. Reverencia, Muy Sr. Mío, Mi Excmo. Sr., V. E. El Cardenal, Ilmo. Padre y Amado Dueño) y, por otro, mostrar "el peso extraordinario que tiene a la hora de determinar el 
título una variable no estrictamente social como es el género textual o la tradición discursiva" (pág. 196).

El trabajo de Medina Morales manifiesta una gran capacidad de síntesis y análisis; además de ordenar y resumir con claridad los datos que le ofrece el corpus elegido, comenta cada caso con detalle y ofrece unas explicaciones muy oportunas. Se llega a la conclusión de que los tratados estudiados no solo reflejan una notable simplificación de los tratamientos protocolarios heredados de la tradición epistolar de los dos siglos precedentes, sino que además los tratamientos comienzan a perder paulatinamente frecuencia de uso, si bien no se constata la desaparición de ninguno de ellos. Asimismo, se demuestra que, en relación con lo anterior, el empleo de las fórmulas de cortesía se limita cada vez más a ciertas partes de la carta (el sobrescrito y el encabezamiento) y, simultáneamente, aquellas sufren un proceso de abreviación o las ya abreviadas se acortan aún más. A la autora no se le escapa que los límites temporales marcados para su trabajo impiden conocer la suerte que corrieron esos tratamientos en la centuria siguiente o la evolución que tuvieron en otros tipos textuales semejantes, como los documentos oficiales o los discursos cortesanos, de manera que, finalmente, se nos anuncia un interesante trabajo complementario.

La cuarta y última sección, dedicada a las variedades diatópicas, se inicia con el trabajo de Miguel Calderón Campos "Variaciones gráficas y fonéticas del español del siglo XVIII en tres corpus hispánicos". Partiendo de documentación de archivo perteneciente a México (Documentos lingüísticos de la Nueva España. Altiplano Central, 1994, compilados por C. Company), Venezuela (Documentos para la historia del español de Venezuela, 2006, compilados por L. de Stefano y M. J. Tejera) y al Reino de Granada, en la actualidad aproximadamente Málaga, Granada y Almería ("Corpus Diacrónico del Español del Reino de Granada (1492-1833)”/CORDEREGRA; Calderón Campos y García Godoy, 2009), en este estudio se analizan los siguientes cinco rasgos fonéticos delimitadores de las variedades dialectales de los territorios mencionados: el yeísmo, la relajación de -s implosiva, la confusión de los fonemas /r/ y /l/, el comportamiento de la - $d$ intervocálica y - $d$ final y la inestabilidad de las consonantes agrupadas de los cultismos.

Tras el análisis de los datos que el corpus le ofrece, Calderón Campos confirma que ya en el siglo XVIII las tres modalidades del español estudiadas "en lo esencial, habían adquirido sus principales rasgos fonéticos identificadores y se habían diferenciado, por tanto, como modalidades dialectales con características fonéticas definidas, de carácter innovador el Reino de Granada y, en menor medida, Venezuela y de tendencia conservadora el español mexicano" (pág. 248). Importa destacar el corolario que se obtiene de la lectura de este trabajo (y que el autor remacha con sus palabras finales): es de suma importancia, como se viene insistiendo desde hace un tiempo, la producción de corpus 
lingüísticos, no solo con el objeto de que capaciten a los investigadores para confirmar o mejorar los conocimientos actuales sobre la historia de la lengua general, sino también para conocer con mayor precisión, tal y como se hace en este trabajo, la evolución de las distintas modalidades del español.

Continuando con las variedades dialectales del español, Concepción Company Company se encarga de la mexicana ("El español del siglo XVIII. Un parteaguas lingüístico entre México y España"). La investigadora inicia su trabajo con una introducción que trasciende el tema que posteriormente la ocupará. Esta introducción no solo lo es de su estudio, sino que en ella se habla del "olvido y (re)surgimiento del siglo XVIII" para los estudios de historia del español (págs. 255-258). Con este trabajo, que sin duda es uno de los más minuciosos y exhaustivos del presente volumen, se demuestra a partir de los nuevos datos que arroja el corpus manejado (textos procedentes en su mayoría de archivos y fondos documentales), cuya selección se justifica por menudo, que el siglo XVIII, el último novohispano, supone una centuria fundamental en la configuración de la identidad lingüística del español de México, en tanto que este comienza a distanciarse desde el punto de vista lingǘstico del español peninsular.

Para respaldar la hipótesis de que parte la investigación, además de mencionar a modo de antecedentes ocho identificadores lingüísticos que distancian la variedad del español de México de la de España, se analizan cinco fenómenos pertenecientes a tres niveles de lengua: morfológico-léxico (la generalización de la forma de tratamiento ustedes y la selección de -ito como sufijo empleado casi en exclusividad para la derivación apreciativa), léxico (la gran incorporación de indigenismos y sus distintos tipos de glosas) y sintáctico (la duplicación del objeto indirecto y su relación con la desmarcación y generalización de ustedes con valor de vosotros, y la marcación prepositiva del objeto directo).

En "Una aportación a la historia de la lengua española en Nicaragua: algunos datos sobre el siglo XVIII", de José Luis Ramírez Luengo, se acomete el estudio de, según el autor, la variedad del español que mayor abandono ha sufrido en los estudios de historia de la lengua. A partir del análisis de un corpus compuesto por veintidós documentos nicaragüenses de la primera mitad del siglo XVIII, con su trabajo Ramírez Luengo pretende dar a conocer algunos datos del español dieciochesco de este territorio y descubrir, como hace Company en suyo, si en esa época cabe hablar de un dialecto del español propiamente nicaragüense.

Con respecto a los rasgos fónicos que observa en dicha documentación, el investigador concluye que en esa centuria el español de Nicaragua es muy semejante a esa misma variedad en la actualidad, a excepción del yeísmo, del que no dan cuenta los textos analizados; lo que parece indicar que se trataría de un fenómeno que tiene lugar con poste- 
rioridad. Sin embargo, en lo que se refiere a los elementos morfosintácticos analizados, estos parecen indicar que el español de Nicaragua de la primera mitad del Siglo Ilustrado no presenta rasgos diferenciadores respecto del español del siglo XVII, es decir, esta centuria "pertenece al español clásico, y no tanto a la etapa moderna de la lengua" (pág. 309). Otra conclusión a la que se llega, esta de carácter más general, es que, a tenor de la semejanzas fónicas y morfosintácticas observables entre el español de Nicaragua y el de las diferentes regiones centroamericanas, se podría hablar, como han hecho otros autores (p. ej., Lipski), de una sola área dialectal. No obstante, cabe señalar que la naturaleza de los textos que componen el corpus, pertenecientes al ámbito notarial (en los que, por tanto, se adopta un "registro relativamente elevado", pág. 296), lastra y condiciona en cierta medida el análisis realizado, puesto que impide constatar diversos fenómenos lingüísticos propios del habla espontánea y menos estandarizada que la lengua escrita. De este hecho es consciente el autor, que presenta este estudio como "un primer acercamiento" a la espera de que se disponga de nuevas investigaciones basadas en corpus más amplios y, ante todo, más representativos de la lengua oral.

M. ${ }^{a}$ Esther Vivancos Mulero, en el último trabajo de la sección destinada al estudio de las variedades diatópicas ("El sufijo -ico/-iquio como caracterizador dialectal del español murciano (siglo XVIII)"), estudia la presencia del sufijo -ico y su alomorfo iquio en tres textos de la "literatura menor" murciana cuyos autores "comparten el objetivo de representar rasgos dialectales del español hablado en Murcia en el siglo XVIII" (pág. 315): la tonadilla Dos limeras y un murciano (1763), la zarzuela Las labradoras de Murcia (1769) y las Letras de los villancicos que se han de cantar en los Solemnes Maytines del Sagrado Nacimiento de Nuestro Señor Jesuchristo... (1797).

Al igual que Abad Merino (2003), quien ofreció un testimonio de la prensa local de Murcia de fines del Setecientos en el que muestra que los rasgos dialectales murcianos ya eran reconocibles entonces, Vivancos Mulero pretende mostrar mediante el caso del sufijo -ico, uno de los rasgos más idiosincrásicos de la variedad en cuestión, que aquel siglo es "crucial en la formación del geolecto murciano" (pág. 330). Uno de los aspectos más interesantes de este trabajo es el que atañe al alomorfo -iquio. Con los datos extraídos del corpus no solo se constata que estamos ante una variante singular del sufijo -ico adscribible a un grupo social concreto, el de los habitantes de la huerta murciana de estrato humilde, sino que además se retrodata el fenómeno en cuestión, hasta ahora atestiguado, según la autora, en la obra de Fuentes y Ponte Murcia que se fue (1872).

No empece la oportunidad de este trabajo la desproporción entre la sección II, con un único trabajo, y las secciones III y IV, con cuatro estudios cada una. No se nos escapa que la historia del léxico para el siglo XVIII ha recibido una mayor atención que 
otros ámbitos de estudio, pues, en efecto, disponemos de trabajos como los de Álvarez de Miranda (1992, 2004, 2006 y 2009), Gómez de Enterría (1996) o Lapesa (1996). Con todo, pensamos que una obra como la que reseñamos podría haber dado cabida en aquella sección a uno o, acaso, dos trabajos más, no solo en beneficio del equilibrio de contenidos entre las partes fundamentales del volumen (lo que es menos importante), sino también con el objeto de mostrar procesos evolutivos de nuestra lengua que, precisamente, se producen en el nivel léxico, de modo que se hubiera apuntalado aún más la idea que inspira la reunión de los presentes estudios, la de que el siglo XVIII constituye un periodo clave en la historia del español.

Si bien también podría señalarse cierto desequilibrio en la tercera sección, en la que se otorga un mayor peso a las formas de tratamiento frente a otros fenómenos morfosintácticos (tres de los cuatro trabajos se dedican a los tratamientos), comprendemos que la editora del volumen haya decidido que esto sea así, entre otras razones, por el hecho de que, mientras que tradicionalmente se había establecido como límite cronológico el siglo XVII, en los últimos años se ha demostrado que los siglos XVIII y XIX resultan de especial relevancia para la difusión y generalización de la forma usted y el establecimiento de las diferencias entre España y América en lo que atañe al paradigma de las formas de tratamiento.

Un aspecto que, dada su importancia, es necesario justipreciar es que la mayoría de los trabajos recogidos se nutren de los datos extraídos de corpus que arrojan información novedosa y de primera mano para la centuria estudiada. En este sentido, estimamos que ha de ponerse de relieve lo que se esconde detrás de algunos de los estudios del presente volumen: la encomiable tarea de rescatar textos del siglo XVIII que hasta ahora habían permanecido relegados a fondos documentales archivísticos. Entre muchos otros (véase Enrique-Arias, 2009), podemos mencionar aquí el trabajo de investigadores como Bertolotti, Coll y Polakof (2010) o Ramírez Luengo (2011). Es muy de agradecer la labor de compilación de corpus emprendida en los últimos años por parte de la comunidad científica, especialmente la de textos no literarios, pues, como ha quedado dicho más arriba, aquellos nos permiten mejorar cualitativamente el conocimiento de la lengua pretérita.

Uno de los presupuestos que motivaron la elaboración de El español del siglo XVIII. Cambios diacrónicos en el primer español moderno fue la escasez de trabajos de corte diacrónico sobre el español del Siglo de la Ilustración. Sin duda alguna, su publicación ha venido a paliar en parte el panorama que esbozábamos brevemente al comienzo de estas líneas. Al tiempo, con este libro se está reclamando una mayor atención a la historia del español de un siglo cuya exploración lingüística podría depararnos nuevos y reveladores datos e incluso cambiar la concepción heredada tradicionalmente de que se 
trata de un siglo en el que el español ya ha experimentado, en el anterior fundamentalmente, los procesos evolutivos que nos lo presentan casi semejante a la lengua de hoy, un siglo, en fin, de estancamiento gramatical. Lejos de que esto sea cierto, los diez trabajos que se recogen en este volumen pretenden mostrar, unos de una manera más decidida que otros, que la evolución del español no se detuvo en el siglo XVII, sino que continuó en el español dieciochesco. Por todo lo expuesto, para terminar estas líneas, hemos de aplaudir el mérito de la presente obra en tanto que sin duda supone una contribución destacable para avanzar en el conocimiento de la historia de nuestra lengua en un siglo que, aunque llamado de las luces, sigue siendo especialmente oscuro en cuestiones gramaticales.

Referencias bibliográficas

Abad Merino, M. (2003): "Realidad dialectal y recreación lingüística en el murciano: el Vía Crucis lorquino de 1785”. En Girón Alconchel, J. L. y J. J. de Bustos Tovar (eds.): Actas del VI Congreso Internacional de Historia de la Lengua Española. Madrid, Arco/Libros, vol. III, págs. 2403-2414.

Álvarez de Miranda, P. (1992): Palabras e ideas: el léxico de la Ilustración temprana en España (1680-1760). Madrid, Real Academia Española.

Álvarez de Miranda, P. (2004): "El léxico español, desde el siglo XVIII hasta hoy". En Cano Aguilar, R. (coord.): Historia de la lengua española. Barcelona, Ariel, págs. 1037-1064.

Álvarez de Miranda, P. (2006): "La estela linguîstica del Quijote”. En Giménez, E. (ed.): El Quijote en el Siglo de las Luces. Alicante, Universidad de Alicante, págs. 43-77.

Álvarez de Miranda, P. (2009): "Sobre los italianismos en el español del siglo XVIII". En 30 años de Dieciocho / Dieciocho at 30, Charlottesville, University of Virginia [Anejo 4 de Dieciocho], págs. 19-47.

Bertolotti, V., M. Coll y A. C. Polakof (2010): Documentos para la historia del español en el Uruguay, vol. I. Cartas personales y documentos oficiales y privados del siglo XVIII. Montevideo, Universidad de la República.

Brumme, J. (1995): "El español moderno y el siglo XIX, en especial, como objeto de estudio en la historia de la lengua (balance, lagunas y tareas)". En Estudis de lingüística i filologia oferts a Antoni M. Badia i Margarit. Barcelona, Universitat de Barcelona/Publicacions de l'Abadia de Montserrat, vol. I, págs. 131-140.

Calderón Campos, M. y M. ${ }^{a}$ T. García Godoy (2009): "El Corpus diacrónico del español del Reino de Granada (CORDEREGRA)". En A. Enrique-Arias (ed.): Diacronía de las lenguas iberorrománicas. Nuevas aportaciones desde la lingüística de corpus. Madrid/Frankfurt, Iberoamericana/Vervuert, págs. 229-250. 
Cano Aguilar, R. (1988): El español a través de los tiempos. Madrid, Arco/Libros.

Cano Aguilar, R. (coord.) (2004): Historia de la lengua española. Barcelona, Ariel.

Company Company, C. (2002): "Gramaticalización y dialectología comparada. Una isoglosa sintáctico-semántica del español”, Dicenda. Cuadernos de Filología Hispánica, 20, págs. 39-71.

Company Company, C. (dir.) (2006): Sintaxis histórica de la lengua española. Primera parte: La frase verbal. 2 vols., México, Universidad Nacional Autónoma de México/Fondo de Cultura Económica.

Company Company, C. (dir.) (2009): Sintaxis histórica de la lengua española. Segunda parte: La frase nominal. 2 vols., México, Universidad Nacional Autónoma de México/Fondo de Cultura Económica.

Eberenz, R. (1991): "Castellano antiguo y español moderno: reflexiones sobre la periodización en la historia de la lengua”, Revista de Filología Española, 71, págs. 79-106.

Enrique-Arias, A. (ed.) (2009): Diacronía de las lenguas iberorrománicas. Nuevas aportaciones desde la lingüística de corpus. Madrid/Frankfurt, Iberoamericana/Vervuert.

Girón Alconchel, J. L. (2002): "Procesos de gramaticalización del español clásico al moderno”. En Echenique, M. ${ }^{a}$ T. y J. Sánchez Méndez (eds.): Actas del V Congreso Internacional de Historia de la Lengua Española. Madrid, Gredos, vol. I, págs. 103121.

Gómez de Enterría, J. (1996): Voces de la economía y el comercio en el español del siglo XVIII. Alcalá de Henares, Universidad de Alcalá.

Lapesa, R. (1981): Historia de la lengua española. 9. ${ }^{a}$ ed., Madrid, Gredos.

Lapesa, R. (1996): El español moderno y contemporáneo. Estudios lingüísticos. Barcelona, Crítica.

López Piñero, J. M. (1969): La introducción de la ciencia moderna en España. Barcelona, Ariel.

Marcos Marín, F. (1992): “Spanisch: Periodisierung. Periodización”. En Holtus, G., M. Metzeltin y C. Schmitt (eds.): Lexikon der Romanistischen Linguistik. Tübingen, Max Niemeyer, vol. VI, 1, págs. 602-607.

Marcos Marín, F. (1995): “La periodización”. En Martín Zorraquino, M. a A. y T. Blesa (coords.): Homenaje a Félix Monge. Estudios de lingüistica hispánica. Madrid, Gredos, págs. 325-334.

Melis, Chantal, Marcela Flores y Sergio Bogard (2003): "La historia del español. Propuesta de un tercer periodo evolutivo", Nueva Revista de Filología Hispánica, 51, 1, págs. 1-56.

Octavio de Toledo y Huerta, Á. S. (2007): "Un rasgo sintáctico del primer español moderno (ca. 1675-1825): las relaciones interoracionales con interin (que)". En 
Fernández Alcaide, M. y A. López Serena (eds.): Cuatrocientos años de la lengua del Quijote. Estudios de historiografía e historia de la lengua española. Actas del V Congreso Nacional de la Asociación de Jóvenes Investigadores de Historia e Historiografía de la Lengua Española. Sevilla, Universidad de Sevilla, págs. 421-442.

Octavio de Toledo y Huerta, Á. S. (2008): "Un nuevo esquema adversativo en el primer español moderno (h. 1675-1825): la historia del nexo sino es". En Company Company, C. y J. G. Moreno de Alba (eds.): Actas del VII Congreso Internacional de Historia de la Lengua Española. Madrid, Arco/Libros, vol. II, págs. 877-907.

Ramírez Luengo, J. L. (2011): "Un corpus para la historia del español en Nicaragua: edición de documentos oficiales del siglo XVIII (1704-1756)", Moenia. Revista lucense de Lingüística \& Literatura, 17, págs. 333-366.

DAVID PRIETO GARCÍA-SECO

Universidad de Murcia

KIESLING, Scott, F., Linguistic Variation and Change. Edinburgh, Edinburgh University Press, 2011, 200 págs. ISBN: 9780748637621.

The subject of this book - linguistic variation and change - has occupied a very important place in the landscape of sociolinguistics since 1952. Indeed, these were the questions which have puzzled the scholars for decades.

This book is conceived as a source of information for students and researchers from other study areas: "Students and (teachers) are encouraged to follow the literature cited for topics that they want to pursue further." (XIII).

Dr. Scott Kiesling organized this research in four parts: first, he puts the reader in touch with a very sketchy survey of questions with respect to language variation; secondly, the author presents a view of the variation and the social relationships; the third part is a more detailed description of linguistic variation and change; and the last one can be seen as the culmination part of the research.

Chapter 1 introduces the development of sociolinguistics from a historical point of view. This section presents an overview to some general characteristics of Labovian linguistics. Kiesling considers that variation language is tied to the imbrications of linguistic, social and cognitive structures. These follow naturally from the claim of heterogeneity language: "All three of the major constraints (structural, social and cognitive) 
act on language simultaneously, and it is the tension among them that ends up driving and determining the direction of changes" (12).

Before going into methods of analysis, the linguist comments briefly (chapter 2) on the way in which the linguistic variable was defined since it was used by Labov in 1963. This is not the only point in which Dr. Kiesling shifts his focus. The linguist emphasizes that during the discussions on the linguistic variable, scholars like Cedergren and Sankoff (1974) or Guy (1980) had intended to elaborate new methods for the analysis of the variables. Finally, the author concludes that the relationship among the linguistic variables in a community can be interpreted as an independent one; although they are part of our need to translate our ideas, sometimes they can interact.

The third chapter "Discovering and describing patterns of variation and change" focuses on scope and concerns methods approaching to language variation, with special attention to data gathering and the informants profile. Dr. Kiesling also argues that the manner in which the surveyed speakers evaluate the language of the other people needs to be incorporated within the methodology.

Interestingly, the speech community is another factor which places tight constraints on the variation language and change. However, some scholars dispense with this concept. Penelope Eckert, for example, stressed the need of the speech community to be seen as a community of practice which goes hand in hand with the activities that the individuals realize.

The rest of this chapter deals with data sample, the interview and the statistic analyses. Unquestionably, it explains the ways in which they can be generated and their role for sociolinguistics.

The second part "Variation and social relationships" synthesizes the social patterns from which variationist linguistics has developed. It begins with the fourth chapter "Social patterns I: Interspeaker variation", which takes as a foundation the major findings of the social constraints on the linguistic variation.

The findings which Scott Kiesling reports are meant to broaden and enrich the readers' knowledge by bringing new observation. Therefore, the linguist thinks it is more important to focus on taking into account all the groups that can be relevant for a speech community in order to use the social patterns that were used in others researches: "[...] urban language surveys have designed the social categories of age, sex, social class, and ethnicity in order to ensure that the sample includes all types of relevant people in a speech community. The real problem comes in using these categories in the interpretation of results". (89) 
The central fact of the fifth chapter "Social pattern II: intraspeaker variation" is that people are not programmed to use the same way of speaking in various situations. Factors like power or solidarity drive them towards the speech pattern they perceive as the most valid in that situation. This cannot be confined to the conversations give and take. When these are occurring, normally speakers pay attention to what happens in that situation.

In chapter 6, Dr. Kiesling looks more closely at the relation between meaning and social patterns. Following Labov (1972), Silverstein (2003), Johnstone et al. (2006), the author makes a distinction between three types of indexical meanings of variants, in order to explain under better circumstances the linguistic change.

The social structure and cultural values of the speech community have been invoked as an explanation for the different meanings of a variant.

The way in which children acquire language is introduced in the following chapter. If we scrutinize the examples which the scholar highlights, we observe that a child first becomes acquainted with a general variation pattern; then more differentiating features are acquired creating new ways of speaking in their peer groups.

Chapter 8 traces three phonological processes (the shifts, the mergers and splits) and some morphological variables (the morphophonemic and the morphological alternation). The shift changes to be considered here involve chain and drag shifts.

The second phenomenon, the development of mergers, depends on the collapse of two vowels, while the splits produced depend on the phonetic effects on segments.

As far as the phonological factors are concerned, grammatical category, semantics, frequency and preceding realizations involve the pivotal points in morphophonemic variables that largely determine changes.

The following chapter "Structural patterns II: syntax, lexical variables, and suprasegmentals" deals with the syntactic and pragmatic variation.

A set of syntactic variation principles might be attributed to the grammaticalization, although there are few studies that approach such inferences.

In its most general sense, pragmatic variation denotes any form of linguistic use in a syntactic construction.

The study of the lexical change called by some researches related to the intensifiers and address term.

Finally, the suprasegmental variables are further explored in this chapter. Here, the author reviews the general problems that might appear when the scholars study this kind of change. 
Chapter 10, the last one, sums up some general conclusions that are moulded to the language variation and change. This is a summary about the problems that have puzzled and continue baffling this field: "In most cases once a change begins it tends to keep going unless arrested by an unusually strong social influence or very large-scaled demographic reasons. To expand the metaphor even further, the path does not end; varieties only pause at different points" (176).

In this research, which constitutes a detailed and meaningful approach of general and abstract problems of language variation, Dr. Kiesling has attempted to explain and improve our understanding of linguistic variation and change by paying close attention to various studies.

This book enables us to identify these phenomena, to illuminate long-standing problems of Labovian sociolinguistics. In fact, the analyses and observations are meant to map us out through this language variation.

All in all, this volume covers a wide range of core issues, unveiling new perspectives by challenging us to develop thoughtful reflections and insights on the field.

\section{Reference}

Cedergren, H. and Sankoff, D. (1974): "Variable rules: performance as a statistical reflection of competence", Language, 50, 333-55.

Guy, G. (1980): "Variation in the group and the individual: the case of final stop deletion". In Labov, W. (ed.), Locating Language in Time and Space (pp. 1-36). New York: Academic Press.

Johnstone, B., Andrus, J. and Danielson, A. E. (2006): "Mobility, indexicality, and the enregisterment of Pittsburghese", Journal of English Linguistics, 34 (2), 77-104.

Kiesling, Scott F. (2011): Linguistic Variation and Change. Edinburgh: Edinburgh University Press.

Labov, W. (1963): "The social motivation of a sound change", Word, 19, 273-309.

Labov, W. (1972): Sociolinguistic Patterns. Philadelphia: University of Pennsylvania Press.

Silverstein, M. (2003): "Indexical order and the dialectics of sociolinguistic life", Language and communication, 23, 193.-229. 
LITOSSELITI, Lia, Research Methods in Linguistics. London: Continuum International Publishing Group, 2010, 240 págs.

En este libro, la profesora e investigadora en temas de Análisis del Discurso Lia Litosseliti, de la Universidad de la Ciudad de Londres, Inglaterra, nos presenta la edición de un documento en el que se compila información sobre los métodos cualitativos y cuantitativos que se usan actualmente en la lingüística.

El texto se divide en 5 partes: la primera está dedicada a los aspectos preliminares al desarrollo de los contenidos principales del libro, la segunda presenta una reflexión general sobre las preguntas de investigación y la conveniencia o no de combinar métodos cualitativos con métodos cuantitativos, la tercera nos informa sobre los desarrollos que han tenido estos últimos métodos en los últimos 30 años, la cuarta nos reporta sobre los métodos cualitativos que se están empleado en la investigación lingüística y la quinta nos expone un índice temático y de autores citados en todo el documento.

La primera parte, de 19 páginas, está conformada de una tabla de contenidos, información sobre los autores que escribieron los capítulos de las partes 2,3 y 4 , y una introducción escrita por la editora del libro. Es de resaltar la reflexión a la cual nos quiere invitar la profesora Litosseliti sobre los tipos de lector a los cuales dirige este documento:

The newcomer to the field will appreciate the clear introductions to key concepts, a plethora of illustrative examples, and carefully drawn links between theory and practice. The experienced researcher and teacher of linguistics will find authoritative and critical engagement with current debates in this diverse field (especially in the later chapters). Both types of readers will hopefully find the book a useful resource for the supervision of research projects and theses (p. 1)

La segunda parte, de 39 páginas, abarca dos capítulos:

En el primero de ellos, la investigadora Jane Sunderland, de la Universidad de Lancaster, Inglaterra, nos presenta una interesante reflexión acerca del papel que juega la elección de la(s) pregunta(s) de investigación en la decisión de emplear uno o varios métodos de investigación. También, expone las diferencias entre plantear hipótesis y preguntas de investigación, así como la necesidad de definir claramente el tipo de pregunta de investigación según el propósito que se tiene, esto es, nos aclara que se debe formular una pregunta distinta si lo que se pretende es describir un fenómeno o explicar las causas por las que ello ocurre.

En el segundo capítulo, la investigadora Jo Angouri, de la Universidad del Occidente de Inglaterra, nos expone una reflexión acerca de la necesidad de combinar métodos 
cualitativos y métodos cuantitativos para poder hacer investigaciones cuyos resultados sean más exactos y confiables.

La tercera parte, de 67 páginas, abarca tres capítulos:

En el tercer capítulo, el profesor Sebastian M. Rasinger, de la Universidad de Anglia Ruskin, Inglaterra, nos expone una comparación acerca de las diferencias que existen entre los métodos cualitativos y los métodos cuantitativos, así como los conceptos que se deben tener presentes cuando se van a realizar investigaciones con métodos cuantitativos tales como: variable, confiabilidad y validez de los datos, estudios longitudinales, diseños de investigación experimentales, etc.

En el cuarto capítulo, el profesor Erez Levon, de la Universidad Queen Mary de Londres, Inglaterra, nos presenta los principales métodos cuantitativos que se están empleando en lingüística tales como las pruebas de $\mathrm{X}$-al cuadrado (el cual se aplica sobre datos crudos y permite corroborar o descartar hipótesis derivadas de preguntas de alguna investigación, así como analizar estadísticamente variables categóricas) o el método-t (que permite realizar estudios estadísticos sobre variables continuas y permite identificar probabilidades de realización de un fenómeno muy particular). Además, se nos presenta una pequeña reflexión sobre la necesidad de determinar, antes del desarrollo de los métodos cuantitativos, qué porcentaje o proporción de los resultados deben arrojarnos los análisis para considerar sus conclusiones como significativas o no para la investigación.

En el quinto capítulo, el profesor Paul Baker, de la Universidad de Lancaster, nos informa acerca de los puntos a favor y en contra que tiene usar los métodos de la Lingüística de Corpus. Allí queda claro que la más significativa ventaja reside en que podemos desarrollar estudios tipológicos, sociolingüísticos e, incluso, diacrónicos con estadísticas bastante sólidas porque los corpus suelen ser extensos (agrupan miles de muestras de palabras, frases u oraciones), son susceptibles de ser analizados sistemáticamente por grupos de edad, género, estrato social, variante dialectal o lengua, y se constituyen con base en información que fue producida en contextos cotidianos, esto es, sin recurrir a encuestas diseñadas en un laboratorio. El punto débil que tiene reside en el hecho de que construir un corpus toma muchísimo tiempo y aun no hay un formato estándar único para organizar todos los datos, por lo que se hace difícil comparar la información de un corpus elaborado recientemente con uno que fue hecho una década atrás.

La cuarta parte, de 102 páginas, abarca cinco capítulos:

En el sexto capítulo, la profesora Judith Baxter, de la Universidad Aston de Inglaterra, nos enseña el papel significativo que han tenido cuatro métodos y modelos de análisis del discurso en la comprensión del papel significativo de la actuación lingüística en 
el funcionamiento de la competencia comunicativa, a saber: el Análisis de la Conversación, el cual, de manera local, nos ayuda a entender el papel de los participantes y el contexto de situación en el uso de determinados enunciados que son expresados en un diálogo; el Análisis del Discurso, con el cual aprendemos que la interacción de rasgos lingüísticos estilísticos con el contexto de situación y las estructuras léxicas, gramaticales y textuales generales contribuye a construir las realidades sociales que nos rodean; el Análisis Crítico de Discurso, por el cual hemos logrado considerar al discurso como el tejido lingüístico por el cual se expresan (o se esconden) los diferentes problemas sociales, muchos de ellos asociados a discriminación y rechazo; y el Análisis Feminista y Post-estructuralista del Discurso, en el que se toma información local de un texto (oral o escrito), se compara con datos generales de textos del mismo tipo y los contextos circunstanciales que los rodean, y se llega a conclusiones que se acercan a explicaciones universales de la actuación lingüística como fuente de origen y variación del lenguaje humano.

En el séptimo capítulo, la profesora Angela Creese, de la Universidad de Birmingham, Inglaterra, nos presenta los avances que ha tenido la etnografía lingüística en los últimos 40 años. La autora del capítulo recomienda que estos estudios sean realizados por un equipo de trabajo, con distintos instrumentos de registro de datos distintos al diario de campo y sin enfocarse solo en el habla y los actos de una sola persona.

En el octavo capítulo, el profesor Nigel Edley, de la Universidad Nottingham Trent, y la profesora Lia Litosseliti, de la Universidad de la Ciudad de Londres, Inglaterra, enseñan una reflexión sobre el papel que cumplen los métodos de entrevista individual $\mathrm{y}$ con grupos de foco en los primeros acercamientos que un investigador realiza con una comunidad (contribuye a la generación y el fortalecimiento de las relaciones humanas) y en etapas posteriores de una investigación, en las que el lingüista necesita corroborar o descartar algunas hipótesis (esto es posible porque permite que el entrevistado tenga un papel de participante activo). También, los autores de este capítulo nos presentan como limitación principal que es un grupo de métodos que, por sí solo, no ofrece respuestas plenas a la investigación que los use, en ellos se corre el riesgo de obtener información falsa o poco cercana a los datos que se registrarían, por ejemplo, en una conversación espontánea.

En el noveno capítulo, los investigadores Jeff Bezemer y Carey Jewitt, de la Universidad de Londres, nos presentan cómo funciona el diseño metodológico multimodal en lingüística. Para ello, nos informan de los modos que se han de registrar en una conversación (la señal sonora, los gestos de la cara, la postura corporal de la persona, el lugar y los objetos que rodean a la persona, etc.), los instrumentos que usan (grabaciones en audio y en video), los tipos de notaciones y herramientas que se usan para sistematizar 
los datos recogidos (notas de campo, computadores, sistemas de transcripción fonética, fonológica, morfológica, sintáctica, de Análisis de la Conversación, etc.). Las limitaciones de este tipo de métodos radican en lo individualizados que se usan, dado que solo se aplican a interacciones muy específicas (e.g. profesor-estudiante, mamá-hijo, violinistadirector de orquesta, etc.) y, al igual que lo que ocurre con la Lingüística del Corpus, lo lentos y dispendiosos que pueden llegar a ponerse en ejecución.

En el último capítulo, el profesor Julio C. Giménez, de la Universidad de Nottingham, Inglaterra, nos expone el papel que tiene la recolección de narrativas orales en la descripción de la expresión lingüística de hechos sociales problemáticos como la discriminación de género o la censura, así como en la construcción de aspectos culturales como los tabús. También, profundiza en la interacción de métodos y modelos como el Análisis Crítico del Discurso y el enfoque Composicionalista de Análisis Narrativo propuesto por sociolingüistas como William Labov y JoshuaWaletzky. Al final, propone un método de 14 pasos y 4 etapas en el cual se integran una colección significativa de narrativas, las cuales son revisadas una y otra vez, de tal manera que sean susceptibles de interpretaciones lingüísticas, sociológicas y antropológicas en cualquier momento.

La última parte, de 13 páginas, presenta un índice ordenado alfabéticamente que nos informa solamente en qué página se encuentran los temas tratados, los autores citados y los datos de las diferentes lenguas del mundo presentados en el libro.

Las contribuciones que hace este texto editado por la profesora Lia Litosseliti son enormes. No es fácil integrar en un solo libro métodos cualitativos y cuantitativos, y sostener con firmeza la tesis de que estos dos tipos de métodos se pueden usar juntos en un mismo proyecto de investigación. Semejante capacidad argumentativa y claridad discursiva son difíciles de encontrar en nuestros días. Por eso es un libro recomendado para todo aquel que desea realizar investigaciones en lingüística.

CAMILO ENRIQUE DÍAZ ROMERO

Universidad Nacional de Colombia

PLACENCIA, María Elena y GARCÍA, Carmen (eds.), Pragmática y comunicación intercultural en el mundo hispanohablante. Amsterdan - Nueva York: Editions Rodopi B.V., Foro Hispánico, 2012, 330 págs. ISBN: 9789042036048.

Este volumen recoge diversas contribuciones de investigadores de prestigio sobre aspectos de pragmática intercultural en la comunicación entre hispanohablantes o, de 
manera contrastiva, en un contexto multicultural en que el español (en alguna de sus variedades) es una de las lenguas en uso. Esta publicación se estructura en tres bloques, organizados en 13 capítulos, cuyos autores amplían el estado de la cuestión de los estudios interculturales. Todos los capítulos parten de un corpus que permite sustentar los presupuestos teóricos que postulan, esto es, no se basan en intuiciones o ideas previas, sino que sus resultados son fruto de una investigación minuciosa con un material real.

El interés de este trabajo reside en múltiples aspectos: tanto por ese carácter empírico, que avala la validez de sus contenidos y resultados, como por el hecho de centrarse en aspectos concretos de la comunicación intercultural, no únicamente planteamientos teóricos generales, que se incluyen, eso sí, como base metodológica en que enmarcar la investigación particular de los autores. Sin duda, es una obra de consulta preferente tanto para los investigadores del tema, como para quienes intervienen en los contextos o situaciones comunicativas que constituyen su objeto de estudio: los profesionales de la mediación y los intérpretes que, según propone F. Raga, en el primer capítulo, tienen mucho en común y se beneficiarían del trabajo mutuo; los empleados de multinacionales con una plantilla multicultural (caps. 2 y 12); los pacientes afásicos y sus familiares, así como quienes participan en su tratamiento terapéutico (en el capítulo 3); traductores (caps. 6 y, en general, el segundo bloque), profesores de segundas lenguas (L2) (cap. 5 y último bloque, concretamente, de aquellas que se incluyen en los trabajos aquí recopilados); así como funcionarios del cuerpo diplomático o empresarios y asesores de empresas multinacionales; en definitiva, quienes necesitan interactuar satisfactoriamente con profesionales de otra cultura y necesitan garantizar el éxito de su comunicación.

En efecto, la comunicación efectiva parece ser el fin último de todo contacto intercultural, para lo que es preciso desarrollar una competencia específica que permita aplicar las estrategias oportunas según la situación comunicativa en que se encuentre un hablante. Así, trabajos particulares como estos contribuyen a mejorar la comprensión de las dificultades y el desarrollo de las comunicaciones interculturales. Estas constituyen un campo de estudio complejo porque en él confluyen múltiples factores que afectan a todos los aspectos de la comunicación: participantes (aspectos socioculturales: edad, procedencia, nivel sociocultural...; aspectos biológicos o fisiológicos: alteraciones del lenguaje, tipo afasias u otras), código (lenguaje figurativo, fraseología), contexto (ironía, humor, petición de disculpas, marcas de cotilleo). Todos estos factores quedan representados en este libro.

El primer capítulo reflexiona sobre la competencia intercultural en servicios públicos (en concreto, sanitarios) con la presencia de profesionales (mediadores), a quienes se dirige, especialmente, la investigación del grupo CRIT (Comunicación y Relaciones Interculturales y Transculturales) al que el autor pertenece. La figura del mediador in- 
tercultural se separa de la del intérprete tanto por su formación (más heterogénea), como por su tarea (no solo traduce sino que interviene para resolver posibles conflictos, realiza tareas facilitadoras, es decir, se hace más visible); sin embargo, F. Raga se centra en sus puntos en común y aboga por la cooperación mutua. Ambos son conscientes del modelo de interacción (más próximo o más distante) de las culturas que entran en contacto y, por ello, pueden favorecer la adecuación de un modelo a otro para conducir sin conflictos la interacción médico-paciente.

El ámbito del segundo capítulo (empresarial) puede llegar a ser también conflictivo, por lo que se requiere igualmente de una competencia intercultural. Para L. Dam y Ó. García Agustín, esta implica una categorización del encuentro comunicativo en que cada hablante se posiciona frente al Otro para comprender su propio comportamiento, de ahí que adopten un enfoque cognitivo. En su análisis, emplean entrevistas semiestructuradas realizadas a empleados hispanohablantes de una empresa danesa de alcance internacional. Los participantes se sitúan en una determinada posición según su competencia profesional e intercultural, compuesta, esta última, por tres aspectos: su representación del lugar de trabajo (en este caso, se trata de una empresa no discriminatoria aunque no llega a ser multicultural, pues no desarrolla estrategias específicas en ese sentido), la categorización de la cultura danesa (tanto su carácter, como su política) y, por último, las distintas posiciones que asume el sujeto según el grupo al que se adscribe (en función del tema, la situación o el contexto, si se encuentra en su país de origen o en otro). La conclusión a la que llegan los autores es que la competencia intercultural no solo se aprende individualmente sino que debe fomentarse desde cada organización que aspira a ser multicultural.

En el tercer capítulo, C. Hernández Sacristán analiza el papel de la pragmática clínica para la negociación de la imagen cultural en contextos o eventos comunicativos donde interviene un sujeto afectado por una patología del lenguaje y, más concretamente, una afasia. El autor aporta sendos ejemplos (extraídos del corpus PerLA: Percepción, Lenguaje y Afasia) de varones con afasia, fluente y no fluente, para mostrar que, en cada caso, la imagen social forma parte de su sintomatología, pues el déficit lingüístico condiciona esa imagen social, esto es, los 'errores pragmáticos' que cometen implican un déficit simbólico que altera su identidad social, la distorsiona. El paciente, al tomar conciencia de ello, adopta estrategias para preservar su imagen. Asimismo, destaca el papel de los interlocutores próximos en las interacciones, que intentan minimizar el efecto literalizador de la patología (el prejuicio de asociar simbólicamente la calidad del habla con la del pensamiento), así como el interés en tener en cuenta esta negociación de la imagen cultural, mediante el uso de un código pragmático-cultural concreto. 
Este primer bloque de pragmática intercultural lo completa la propuesta de C. Valero Garcés (capítulo 4) sobre la interacción intercultural médico-paciente. En concreto, analiza las estrategias interrelacionales (rapport management, Spencer-Oatey 2008; Spencer-Oatey y Franklin 2009) en 75 interacciones en centros de salud de Madrid y Castilla la Mancha, en las que intervienen bien un paciente español o bien uno extranjero que habla español, como lengua materna o L2 (descarta aquellas en que el paciente no habla español e interviene un acompañante como intérprete). Aunque en ambos casos se intenta mantener la estructura de la consulta y hay una tendencia a 'coloquializar' la interacción, el doctor suele alargar sus turnos con los pacientes extranjeros; estos emplean más el tuteo en situaciones donde un nativo mantiene el 'usted' y, en general, emplean ciertas convenciones sociales con el deseo de gestionar de forma positiva las relaciones interpersonales en estos encuentros interculturales.

El segundo bloque del libro demuestra la importancia de la pragmática contrastiva en los estudios interculturales, precisamente porque compara las realizaciones de dos lenguas o culturas.

Un campo de estudio donde resulta más necesario, si cabe, el conocimiento sociocultural e intercultural es el que presentan X. A. Padilla y E. Gironzetti en el capítulo 5: las investigaciones sobre humor e ironía. En concreto, los autores del capítulo analizan pragmáticamente 100 viñetas cómicas publicadas en la prensa española e italiana y llevan a cabo 60 cuestionarios que exploran el grado de comprensión del humor de los lectores de viñetas cómicas, usando como punto de partida para su estudio las teorías de Raskin (1985) y Attardo (1994, 2001), especialmente los conceptos de script y comunicación non bona-fide; las implicaturas conversacionales de Levinson (2000) y la teoría de los esquemas (para la comprensión de textos) de Rumelhart (1980) y Carrel (1983).

Los resultados del análisis determinan que los lectores de viñetas cómicas interpretan las mismas partiendo de unos determinados índices de lectura y que estos índices permiten activar o no una serie de supuestos socioculturales. Esto tiene como consecuencia que no todos los lectores alcancen el mismo nivel de interpretación de la ironía y el humor o de resolución de la incongruencia planteada en la viñeta analizada. Los autores constatan igualmente que humor e ironía pueden o no combinarse en el mensaje trasmitido por una determinada viñeta, esto es, que los dos fenómenos examinados no se exigen mutuamente o no están presentes simultáneamente en todos los casos. El capítulo, por último, sirve de introducción general para quienes deseen iniciarse en la investigación de la ironía y el humor, así como en la propuesta del grupo GRIALE de la Universidad de Alicante, al que pertenecen los autores del artículo.

El concepto de incongruencia se analiza, de nuevo, en el capítulo 6, aplicado aquí por B. Núñez-Perucha a la comprensión de expresiones idiomáticas en contextos inter- 
culturales, cuyo equivalente funcional no siempre coincide con la traducción que ofrecen los diccionarios generales, ni siquiera los de fraseología. El contraste se establece entre las formas españolas estar en las nubes / en la higuera / en Babia y las inglesas to have one's head in the clouds y to be up in clouds, que los diccionarios bilingües consultados ofrecen como equivalentes. Parte de un corpus de ejemplos que se nutre de tres fuentes: el CREA (Corpus de Referencia del Español Actual), el BNC (British National Corpus) y el COCA (Corpus of Contemporary American English). Además de la función evaluativa que todas transmiten, pueden desempeñar otras funciones discursivas (como la informativa o la elaborativa, menos frecuente) y funciones pragmáticas (tanto fática para llamar la atención del oyente, como eufemística) en situaciones de mayor informalidad. En definitiva, expresiones idiomáticas como estas, por su multifuncionalidad, generalmente dependiente del contexto, provocan una incongruencia o 'disonancia' (Zamborlin, 2007) semántica o pragmática en situaciones multiculturales, de ahí que sea relevante considerar estos valores pragmáticos tanto en la traducción (reflejarlos en los diccionarios) como en la adquisición de L2.

El valor de los trabajos contrastivos de este segundo bloque es incuestionable, tanto para los marcos teóricos en que se encuadran, como para los estudios sobre las lenguas que analizan. En el caso del capítulo 7, M. Bernal, partiendo del marco de la cortesía lingüística, se centra en interacciones telemáticas entre internautas y personajes conocidos. En esas ciberentrevistas, analiza muestras de cortesía valorizante (realce de la imagen) y de críticas (menoscabo de la imagen, que podrían considerarse ejemplos de descortesía, entendida no como uso intencional sino justificada a partir del efecto que causa en el receptor y su reacción). El corpus seleccionado destaca por su homogeneidad, tanto en la selección de los medios de comunicación como en los participantes escogidos, por lo que los resultados son coherentes y corroboran estudios anteriores sobre las diferencias en el manejo de la imagen entre españoles y suecos, bien conocidas para la autora. Este estudio, asimismo, contribuye a las investigaciones sobre comunicación mediada por ordenador, donde la imagen social se ve alterada por la particular gestión de la identidad en el espacio virtual.

El capítulo 8 es, sin duda, el más novedoso en cuanto al contraste de los grupos escogidos. Por una parte, G. Taylor plantea una situación conflictiva a nivel intercultural (la expresión de una disculpa) y, por otra, contrasta dos culturas - la china y la colombiana- alejadas en su concepción de las relaciones sociales (más o menos colectivistas), pero cada vez más próximas por intereses empresariales o económicos. Compara las estrategias orientadas al hablante (expresión explícita de la disculpa, uso de intensificadores) y al oyente (aceptación o negación de la responsabilidad, oferta de reparación o de no repetir la ofensa) en diferentes situaciones: con un jefe, con desconocidos y con 
familiares o amigos. Los resultados muestran que, en general, predominan las estrategias de cortesía negativa. En cuanto al método, el uso de los juegos de rol para crear situaciones conflictivas y la mediación de hablantes nativos para garantizar la corrección de las traducciones son el medio para llevar a cabo esta investigación, que llena un vacío en los estudios interculturales y abre la puerta a nuevas investigaciones.

La aportación de A. M. Jørgensen en el octavo capítulo no destaca solo por su interés contrastivo intralingüístico, sino porque se centra en un aspecto pragmático al que se sigue prestando gran atención por su complejidad: los marcadores del discurso. En concreto, analiza las funciones pragmáticas de como en el habla de jóvenes de Madrid y Santiago de Chile (corpus COLAm y COLAs), cuando funciona como marcador. La investigación demuestra su carácter multifuncional, pues puede presentar distintos valores, incluso simultáneamente: contribuye a la fluidez y a mantener el turno de habla, señala que existe un parecido no idéntico con lo dicho, es introductor de estilo directo no literal, se convierte en enfocador de información nueva por lo que la realza o enfatiza, y, por el contrario, también es mitigador o marca de atenuación, precisamente por esa vaguedad que transmite.

El análisis se completa con dos apuntes interesantes: por una parte, un comentario sobre la posición del marcador y su relación con las funciones que desempeña (generalmente en posición inicial o media) y, por otra, la descripción de la variación sociolingüística según las variables sexo y nivel sociocultural, que determinan un mayor uso en chicas y clases altas en Madrid y en chicos y en la clase media en Santiago de Chile.

El capítulo 10, de C. Maíz-Arévalo y J. Arús-Hita, trata sobre el contraste de la expresión inglesa apparently, que suele emplearse como marca de cotilleo, y su traducción en español, que puede equivaler a dos formas que no siempre funcionan como sinónimos: por lo visto y aparentemente. La noción de evidencial y la posición son las que permiten discriminar los valores de cada expresión.

Desde el punto de vista pragmático, este estudio interesa, por un lado, por el intento de sistematizar marcas lingüísticas que permitan reconocer un acto de cotilleo, así como su estructura y su función pragmática para favorecer solidaridad de grupo y, por otro, su relación con la cortesía. A su vez, también es un trabajo de corpus y no una descripción solo teórica, meramente lexicográfica. En concreto, utilizan el CREA y el BNC, cuya validez y representatividad están sobradamente demostradas. Finalmente, reclaman la necesidad de más análisis contrastivos como este, sin duda imprescindibles para la competencia lingüística e intercultural de los hablantes.

El apartado contrastivo se completa con la propuesta de $\mathrm{M}^{\mathrm{a}}$. de la $\mathrm{O}$ Hernández López sobre la gestión de la imagen en la interacción médico-paciente en el ámbito espa- 
ñol y británico. Para ello, parte de los episodios de comunicación fática (CF) hallados en 80 interacciones y analiza si la imagen que se intenta gestionar es la individual, la interaccional o la social, tipología tomada de Spencer-Oatey (2008: 13), según el grado de personalismo que se perciba en la relación (concepto aplicado ya por Placencia a la CF en 2004 y 2005). La comparación se realiza no solo entre ambas culturas -española y británica- sino también según el participante (gestión de la imagen del médico y del paciente) y según la orientación de la estrategia (hacia uno mismo o hacia el otro), para tratar de establecer los tipos de CF. En el corpus examinado no se han encontrado amenazas o pérdida de la imagen, sino, en general, su búsqueda y mantenimiento, más orientada hacia sí mismos en el caso de los pacientes españoles y con mayor preocupación hacia el doctor, y orientada en ambos sentidos en el caso británico y en los doctores de ambos grupos. Estos resultados muestran las tendencias en la gestión de la imagen mediante la $\mathrm{CF}$ en un tipo de interacción en la que lo transaccional propiamente dicho no puede desligarse de lo interpersonal.

El último bloque de este volumen, dedicado a la relación entre los aspectos de interlenguaje y la enseñanza de ELE, consta de dos capítulos interesados en el desarrollo de la competencia intercultural, bien por el dominio de estrategias lingüístico-pragmáticas, bien a partir de la literatura, respectivamente. Así, en el capítulo 12, L. Fant, F. Forsberg y C. Olave Roco analizan la competencia sociocultural de usuarios de L2 en situaciones asimétricas (jefe chileno-empleado sueco aprendiz avanzado de español) partiendo del concepto de Aculturación de Schumann (1978). El método escogido es el juego de rol y la interacción entraña un acto problemático, pues consiste en una llamada telefónica cuyo objetivo es pedir un permiso. Las intervenciones de los no nativos están condicionadas en tres planos: la identidad colectiva, la relación de proximidad/distancia y el reconocimiento jerárquico del Otro. Los autores comparan todas las fases en dos de los quince diálogos recogidos: uno endolingüe y otro exolingüe: saludo y despedida, apertura, acto de petición, referencia a motivos afectivos, negociación y acuerdo, y la presencia de incrementos. Observan que los no-nativos muestran una mayor distancia hacia el jefe y cierta inseguridad al elegir las estrategias para la petición y la argumentación. Por otra parte, la extensión es mayor en los exolingües, por la necesidad de reparar las disonancias comunicativas o afectivas que se producen. Lo que plantea este estudio es, en definitiva, hasta qué punto es posible una aculturación completa del no nativo, pero esa cuestión requiere de un planteamiento más desarrollado.

El capítulo final reflexiona sobre los diferentes métodos empleados en el aprendizaje de la competencia intercultural en las aulas de ELE y propone como fuente enciclopédica las crónicas del peruano Alfredo Bryce Echenique. La propuesta se realiza con estudiantes de empresariales, en su mayoría belgas, cuya motivación (una de las tres etapas, 
junto a la de conocimiento y a las actitudes que, según Shadid, 1998, articulan el aprendizaje de esta competencia) es el éxito en los negocios internacionales. Ciertas obras literarias familiarizan a los aprendices con diversos aspectos de la sociedad, la historia o los valores de la cultura meta: la distancia frente al poder, individualismo-colectivismo, feminidad-masculinidad y el rechazo de la incertidumbre (Hofstede, 1991). Las diferencias entre la cultura de América Latina en general, y peruana en particular, y la española son, entre otras, la frecuencia de diminutivos o de eufemismos como estrategia atenuante, relacionada con un trasfondo cultural colectivista. Reflexiones como estas ayudan a los aprendices de español a conducirse en sus relaciones interculturales mediante las estrategias adecuadas a cada cultura con la que interactúen.

En síntesis, es destacable la especial atención que ocupan dos tipos de interacciones interculturales asimétricas, una más privada y otra más pública: la primera se refiere a las comunicaciones médico-paciente, que por su carácter cotidiano y de especial interés para el individuo captan el interés de los investigadores (caps. 1, 4 y 11 y, en parte, el 3); la segunda se refiere a las relaciones laborales de tipo internacional (jefe-empleado), que es uno de los ámbitos donde más relevantes son estas investigaciones (caps. 2 y 12 y, en parte, el 8). En ambos casos, se trata de interacciones asimétricas desde el punto de vista de la relación de poder o jerarquía, por lo que la necesidad de mantener con éxito la comunicación y, en especial, de preservar la imagen de ambos interlocutores resulta más fuerte y, más aún, cuando la situación de asimetría cae del lado del no nativo, esto es, cuando el rol de poder lo ostenta el hablante nativo y es el aprendiz quien debe desarrollar más estrategias para amoldarse o adaptarse a los patrones culturales de la lengua meta. En general, las aportaciones que aquí se recogen a este respecto muestran notables diferencias en las interacciones asimétricas cuando intervienen hablantes nativos respecto de aquellas en que hay una relación intercultural, pues, en estos casos, los no nativos suelen hacer un mayor esfuerzo para gestionar la propia imagen y la del interlocutor y una voluntad de ser comprendidos.

Los aspectos pragmáticos y didácticos presentes en los otros capítulos resultan especialmente relevantes en la comunicación intercultural, puesto que se desarrollan en interacciones donde pueden provocar incongruencias o disonancias que afecten a la comunicación: la comprensión del humor y la ironía (cap. 5), aspectos de fraseología o expresiones idiomáticas (caps. 6 y 10), cortesía (cap. 7), marcadores del discurso (cap. 9) y enseñanza de ELE (caps. 12 y 13). En todos los casos, se analizan situaciones que requieren de una alta competencia y de un nivel avanzado del idioma, más allá de los conocimientos lingüísticos básicos, incluso en algunos casos parecen señalar los límites en la adquisición de una segunda lengua. 
Finalmente, cabe señalar que las contribuciones que aquí se incluyen ahondan en la problemática de las relaciones interculturales, pues el contacto de lenguas genera conflictos que pueden hacer peligrar la comunicación. Los aspectos tratados en los artículos son una buena muestra de diversas situaciones y tipos de conflicto, y sirven de base para estudios posteriores que, sin estos, no avanzarían con tanta firmeza en la investigación de los contactos interculturales.

Marta Pilar MONTAÑEZ Mesas

Universitat de València

GRÜMPEL, Claudia, La adquisición del alemán en un contexto universitario por adultos hispanohablantes. Granada: Editorial Comares, 2009, 158 págs. ISBN: 9788498364996.

La obra reseñada se centra en un estudio sobre la adquisición del orden de palabras del alemán por hablantes que poseen como lengua materna la española. Partiendo de las investigaciones sintácticas que se realizan dentro del marco que se conoce como Programa Minimalista (Chomsky 1993, 1995; Zwart, 1993, 1997) y de trabajos paralelos (Kayne 1994), en este trabajo se intenta dar respuesta a una serie de preguntas sobre las características del alemán no nativo de hispanohablantes que adquieren esta lengua en un contexto institucional. Los datos de los que se sirven los investigadores se obtuvieron a partir de experimentos dirigidos a contestar una serie de preguntas diseñadas específicamente para comprobar la validez de las hipótesis que se formulan a partir de dicho marco teórico.

El estudio se compone de seis capítulos, además de la bibliografía final.

El primer capítulo es una amplia introducción mediante la cual queda determinado tanto el objeto de estudio del trabajo como la metodología que se sigue para llevar a cabo el análisis pretendido.

En el segundo capítulo se presenta el marco teórico en que se basa el análisis realizado y que se aplica en los capítulos siguientes. En el planteamiento teórico se siguen fundamentalmente las ideas de Zwart (1993, 1997), que parte de la hipótesis de que las lenguas germánicas con asimetría (SVO en las oraciones simples y SOV en las oraciones subordinadas) pertenecen al grupo tipológico de lenguas de núcleo inicial. Dado que también el español es una lengua de núcleo inicial, se adopta el planteamiento de Kayne (1994), que postula que el orden universal de todas las lenguas es SVC. También en el 
capítulo dos se expone una descripción comparada de las estructuras del alemán y del español, poniendo de relieve tanto las diferencias como las similitudes en relación con los rasgos sintácticos y con los órdenes superficiales a los que dan lugar.

En el tercer capítulo se realiza una revisión de los estudios de la adquisición de lenguas segundas para así poder comparar los resultados de estos investigadores con los resultados de estudios anteriores que se realizaron dentro del marco teórico de Principios y Parámetros. De este modo se repasa la adquisición del orden de palabras en alemán por hablantes de otras lenguas y se plantean las hipótesis de trabajo.

El capítulo cuarto está dedicado a la metodología del estudio empírico, que constituye la parte central del estudio, y a la discusión de los datos. Así pues, en este apartado se comentan los sujetos y las pruebas realizadas con el fin de conseguir un corpus de datos que sirva como base empírica para probar las hipótesis planteadas. Los sujetos son aprendices de alemán que reciben una instrucción formal, ya que se produce en un marco institucional. Se contrastan dos tipos de aprendices: los que no salen de España, divididos en dos grupos en función de las horas lectivas de instrucción, y los que han realizado una estancia de inmersión en Alemania tras haber recibido instrucción durante un año académico.

En el quinto capítulo se describen y evalúan los resultados de la prueba de juicios de gramaticalidad y de la prueba de traducción llevados a cabo por los tres grupos experimentados de hispanohablantes; también se hace referencia a los resultados de las mismas pruebas realizadas por el grupo de control de hablantes nativos de alemán. Es decir, en este apartado se estudian las intuiciones no nativas para compararlas con las intuiciones nativas del grupo de control.

En el capítulo sexto se resumen los hallazgos de la investigación y se comentan las conclusiones obtenidas para comprobar la validez de las hipótesis. En este sentido, siguiendo determinados planteamientos teóricos, concretamente en el Programa Minimalista, se parte del supuesto de que en la adquisición de la L1 los rasgos funcionales y las propiedades morfológicas no son independientes y se desarrollan como un sistema, esto es, se relacionan los unos con los otros. En el caso de la L2, por el contrario, los dos sistemas (morfología y sintaxis) se desarrollarían de forma independiente y no se procesarían como una unidad. Así pues, los responsables de este estudio formulan un total de cinco hipótesis respecto a la adquisición del orden de palabras en alemán por parte de hispanohablantes, a las que dan respuesta en este capítulo. En consecuencia, y como se desprende de los datos empíricos de esta tesis, en la adquisición de la L2 el adulto puede alcanzar niveles muy altos de competencia, pero sus juicios de gramaticalidad se basan en el análisis metalingüístico y no en la intuición propia del hablante nativo del alemán. 
En síntesis, el estudio recogido en esta obra se basa en el proceso de adquisición del alemán como lengua no nativa, concretamente en el orden de palabras bajo el modelo de la gramática generativa chomskiana, el Programa Minimalista. Este modelo permite detectar las diferencias entre los órdenes de palabras del alemán nativo (el hablante ideal) y del alemán no nativo. A pesar de ello, este estudio solo presenta una parte de la problemática de la IL del alemán por parte de aprendices adultos que se enfrentan a una lengua segunda, principalmente en un contexto institucional.

\section{Referencias bibliográficas}

Chomsky, N. (1993): “A Minimalist Program for Linguistic Theory”. En Hale, K. y Keyser, S.J. (eds.), The view from building 20: Essays in Linguistics in Honor of Sylvain Bromberger. Cambridge, MIT Press, 1-52.

Chomsky, N. (1995): The Minimalist Program. Cambridge, MIT Press.

KAYNE, R.S. (1994): The Antisymmetry of Syntax. Cambridge, MIT Press.

ZWART, J.W. (1993): Dutch Syntax. A Minimalist Approach. Tesis Doctoral, Universidad de Groningen.

ZWART, J.W. (1997): Dutch Syntax: A Minimalist Approach. Dordrecht, Kluwer.

NURIA MERCHÁN ARAVID

Universidad de Alicante 

. 


\section{Colaboraciones}

Artículos:

M.Agüero Guerra, 7

Alicia Avellana, 31

Claudia Borzi, 61

L. Camargo Fernández y B. Méndez Guerrero, 89

A. Grau Sempere, 121

Abeer Hussein Abid, 145

A. López Samaniego, 167

F. Polanco Martínez, 199

Leonor Ruiz Gurillo, 251

María José Serrano, 275

Ignacio Vázquez Diéguez, 301

Notas

Enrique Pato, 329

Reseñas

Dpto. Filología Española, Lingüística General

y Teoría de la Literatura
2013 